*ak RMIS View/Frint Document Cover Sheet tow

This document was retrieved from the Documentation and Records Manaqement (DRM) ISEARCH System. It is intended for Information only and may not be the most recent or updated version. Contact a Document Service Center (see Hanford Info for locations) if you need additional retrieval information.

Accession \#: D195067219

Document \#: SD-W378-ES-002

Title/Desc:

FACILITY DESIGN PHILOSOPHY TWRS PROCESS SUPPORT \& INFRASTRUCTURE DEFINITION [SEC 1 OF 4]

Pages: 151 
THIS DOCUMENT WAS TOO LARGE TO SCAN AS A SINGLE

DOCUMENT. IT REQUIRED BREAKING INTO SMALLER SECTIONS.

DOCUMENT NUMBER: SD $111378-89-002$

SECTION: 1 OF 4

TITLE: facility Dusign Philonophy gan w Wante

Permadiation syotem Proves sespont \& Infrastrusture

Definition

AUTHOR: keash, galleraith

RECIPIENT:

DATE: $12 / 11 / 95$

KEYWORDS:

REFERENCES: $80 T-618)|6|$ 


\section{DEC 111995 Sth. 211 is

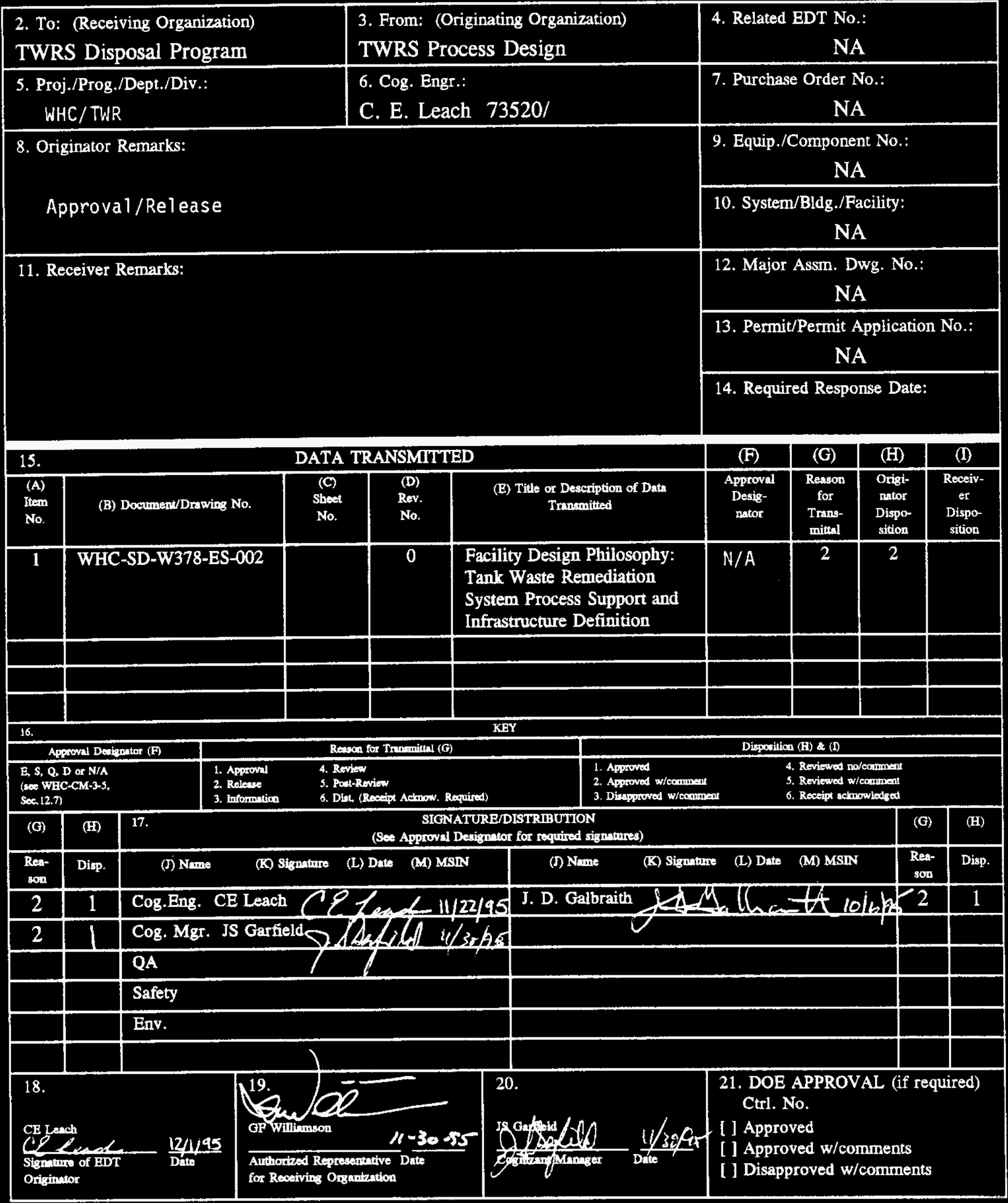




\title{
Facility Design Philosophy: Tank Waste Remediation System Process Support and Infrastructure Definition
}

\author{
C. E. Leach and J. D. Galbraith
}

Westinghouse Hanford Company, Richland, WA 99352

U.S. Department of Energy Contract DE-AC06-87RL10930

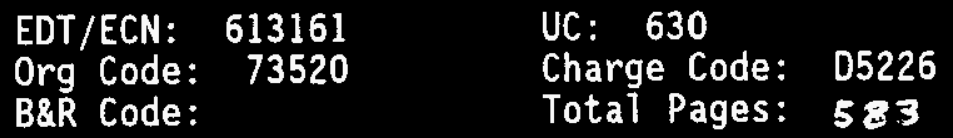

Key Words: Functions, Infrastructure

Abstract: This report documents the current facility design philosophy for the Tank Waste Remediation System (TWRS) process support and infrastructure definition. The Tank Waste Remediation System Facility Configuration Study (FCS) (Boomer et al. 1994) initially documented the identification and definition of support functions and infrastructure essential to the TWRS processing mission. Since the issuance of the FCS, the Westinghouse Hanford Company (WHC) has proceeded to develop information and requirements essential for the technical definition of the TWRS treatment processing programs.

TRADEMARK DISCLAIMER. Reference herein to any specific commercial product, process, or service by trade nane, tradenark, manufacturer, or otherwise, does not necessarily constitute or imply its endorsement, recommendation, or favoring by the United States Government or any agency thereof or its contractors or subcontractors.

Printed in the United States of Anerica. To obtain copies of this document, contact: WHC/BCS Document Control Services, P.0. Box 1970, Mai lstop H6-08, Richland HA 99352. Phone (509) 372-2420; Fax (509) 376-4989.
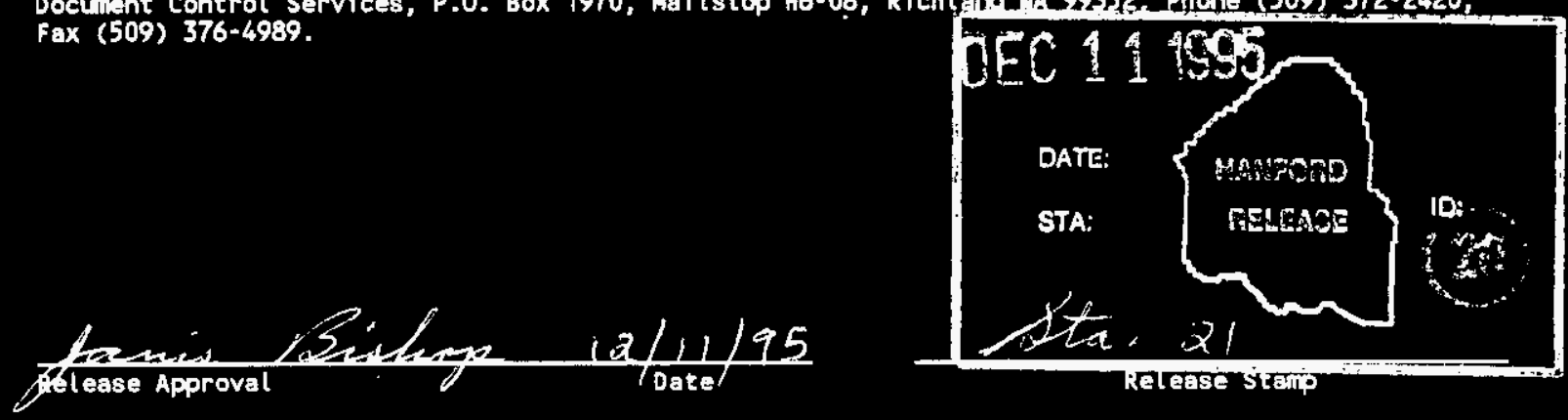

Approved for Public Release 


\title{
FACILITY DESIGN PHILOSOPHY: TANK WASTE REMEDIATION SYSTEM PROCESS SUPPORT AND INFRASTRUCTURE DEFINITION
}

November 1995

\author{
Prepared by: \\ C. E. Leach \\ J. D. Galbraith \\ Westinghouse Hanford Company \\ Richland, Washington \\ and \\ P. R. Grant \\ D. J. Francuz \\ P. J. Schroeder \\ Fluor Daniel, Inc. \\ Richland, Washington \\ Prepared for: \\ U.S. Department of Energy \\ Richland, Washington
}




\section{WHC-SD-W378-ES-002 \\ Revision 0 \\ ACKNOWLEDGEMENTS}

Study Sponsors

John S. Garfield/Kayle D. Boomer

Westinghouse Hanford Company

Lead Engineer

Carole E. Leach/John D. Galbraith . . . . . . . Westinghouse Hanford Company

Document Coordinator

Patrick R. Grant . . . . . . . . . . . . . Fluor Daniel, Inc.

Document Authors

Patrick R. Grant $\ldots \ldots \ldots \ldots \ldots \ldots \ldots$ Fluor Daniel, Inc.

David J. Francuz $\ldots \ldots \ldots \ldots \ldots \ldots \ldots$ Fluor Daniel, Inc.

Paul J. Schroeder $\ldots \ldots \ldots \ldots \ldots \ldots \ldots$ Fluor Daniel, Inc.

Carole E. Leach . . . . . . . . . . . . . Westinghouse Hanford Company

$\underline{\text { Technical Consultants }}$

Paul C. Andrews $\ldots \ldots \ldots \ldots \ldots \ldots \ldots$ Fluor Daniel, Inc.

Robert D. Bromm . . . . . . . . . . . . . F Fluor Daniel, Inc.

Jack F. Donnelly $\ldots \ldots \ldots \ldots \ldots \ldots \ldots \ldots$ Fluor Daniel, Inc.

Patricia I. Earley $\ldots \ldots \ldots \ldots \ldots \ldots \ldots \ldots \ldots$ Fluor Daniel, Inc.

Ali A. Farsadi . . . . . . . . . . . . . . F Fluor Daniel, Inc.

John D. Galbraith . . . . . . . . . . . . . . Westinghouse Hanford Company

John J. Harrington $\ldots \ldots \ldots \ldots \ldots \ldots \ldots$ Fluor Daniel, Inc.

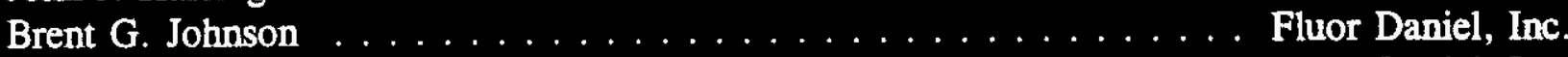

Ted J. Koppenaal $\ldots \ldots \ldots \ldots \ldots \ldots \ldots \ldots \ldots$ Fluor Daniel, Inc.

Leon 0. Lago $\ldots \ldots \ldots \ldots \ldots \ldots \ldots \ldots$ Fluor Daniel, Inc.

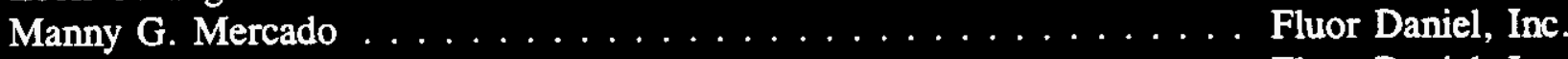

Kenneth A. Owrey $\ldots \ldots \ldots \ldots \ldots \ldots \ldots \ldots \ldots$ Fluor Daniel, Inc.

Jay B. Thompson $\ldots \ldots \ldots \ldots \ldots \ldots \ldots$ Fluor Daniel, Inc.

Alvin K. Yee $\ldots \ldots \ldots \ldots \ldots \ldots \ldots \ldots \ldots \ldots \ldots$ Fluor Daniel, Inc.

Tony $\mathrm{L}$. Waldo $\ldots \ldots \ldots \ldots \ldots \ldots \ldots \ldots$ ICF Kaiser Hanford Company 
WHC-SD-W378-ES-002

Revision 0

CONTENTS

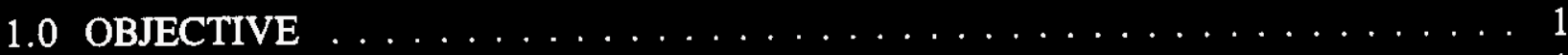

1.1 PURPOSE AND NEED $\ldots \ldots \ldots \ldots \ldots \ldots \ldots \ldots$

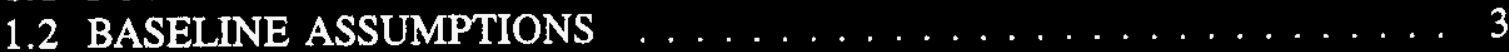

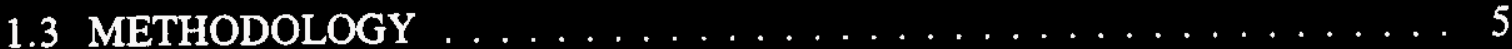

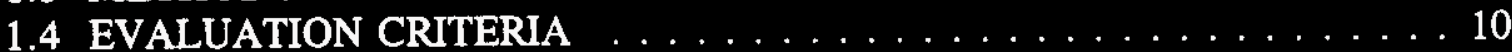

1.4 .1 Operability and Maintainability . . . . . . . . . . . 10

1.4 .2 Cost Effectiveness . . . . . . . . . . . . . . . . 11

1.4 .3 Radiological Protection . . . . . . . . . . . . . . 11

1.4 .4 Safety . . . . . . . . . . . . . . . . . 12

1.4.5 Environmental Regulatory Compliance . . . . . . . . . . . 12

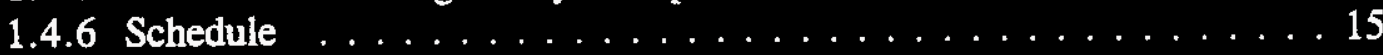

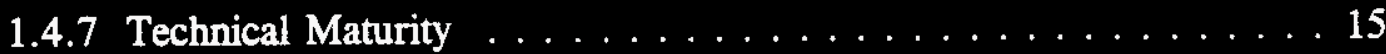

1.4 .8 Design Impact $\ldots \ldots \ldots \ldots \ldots \ldots$

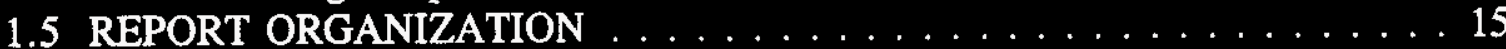

2.0 SUMMARY OF TECHNICAL FINDINGS $\ldots \ldots \ldots \ldots \ldots \ldots$

3.0 DESCRIPTION AND EVALUATION OF SUPPORT FUNCTIONS $\ldots \ldots$. . . . 39

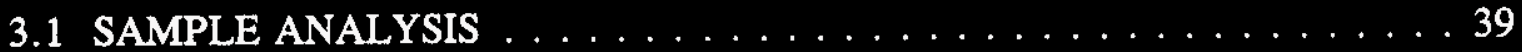

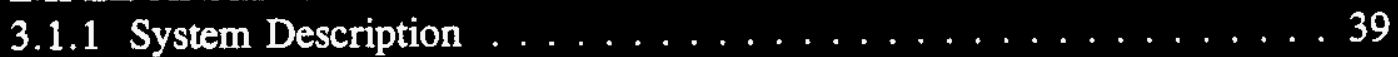

3.1 .2 Findings .......................... 40

3.1.3 Functional Configuration Considerations and Rationale . . . . . . . 40

3.2 COLLECT AND HANDLE SOLID WASTE SYSTEM $\ldots \ldots$. . . . . . . 42

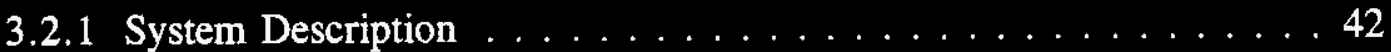

3.2 .2 Findings ......................... 43

3.2.3 Functional Configuration Considerations and Rationale . . . . . . 43

3.3 COLLECT AND HANDLE LIQUID WASTE . . . . . . . . . . . . . . . 44

3.3.1 Collect and Handle Potentially Radioactive Liquid Waste System . . 44

3.3.2 Collect and Handle Nonradioactive Liquid Waste System . . . . . . . 46

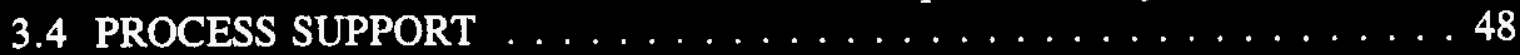

3.4 .1 Oxygen System $\ldots \ldots \ldots \ldots \ldots$

3.4 .2 Cold Chemical Supply System . . . . . . . . . . . . . 51

3.4.3 Cold Chemical Feed System ... . . . . . . . . . . 55

3.4 .4 Cold Chemical Vent System $\ldots \ldots \ldots \ldots$. . . . . . . 57

3.4 .5 Process Facility Vent System . . . . . . . . . . . . . . . . 59

3.4.6 Process Steam and Condensate System . . . . . . . . . . . . 62

3.4 .7 Process Cooling Water System . . . . . . . . . . . . . 65

3.4 .8 Melter Cooling Water System $\ldots \ldots \ldots$. . . . . . . 67

3.4 .9 Process Chilled Water System . . . . . . . . . . . . . . . 69

3.4 .10 Utility Steam System $\ldots \ldots \ldots \ldots \ldots$. . . . . . . . . . . . . . .

3.4 .11 Compressed Air System . . . . . . . . . . . . 73 
3.4.12 Process Water System $\ldots \ldots \ldots \ldots \ldots \ldots \ldots \ldots \ldots$

3.4.13 Demineralized Water System . . . . . . . . . . . . 78

3.4.14 Sanitary Water System . . . . . . . . . . . . 80

3.4 .15 Raw Water System . . . . . . . . . . . . . . . . . 82

3.4.16 Tank Waste Remediation System Treatment Complex Site

Fire Water System . . . . . . . . . . . . . . . . . . . 83

3.4.17 Process Facility Fire Water System . . . . . . . . . . . . . 86

3.4.18 Waste Condensate Collection System $\ldots \ldots \ldots \ldots$. . . . 88

3.4 .19 Cooling Tower Water System . . . . . . . . . . . . 89

3.4 .20 Telecommunications System . . . . . . . . . . . . . . . 92

3.4.21 Sanitary Sewer System $\ldots \ldots \ldots \ldots \ldots$

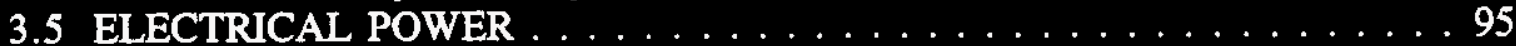

3.5.1 Normal AC Power . . . . . . . . . . . . . 95

3.5.2 Emergency Power System . . . . . . . . . . . . . . 97

3.5.3 Uninterruptible Power Supply System . . . . . . . . . . . . . 99

3.6 FACILITY MANAGEMENT AND SUPPORT $\ldots \ldots \ldots \ldots \ldots \ldots$

3.6.1 Treatment Complex Management and Support System . . . . . . . 100

3.6.2 Regulated Tank Waste Remediation System Treatment Complex Entry System . . . . . . . . . . . . . . . . . . . . 101

3.6.3 Regulated Facility Entry System . . . . . . . . . . . . 103

3.6.4 Personnel Protection System . . . . . . . . . . . . . . . . 104

3.6.5 Employee Support System . . . . . . . . . . . . . . . 105

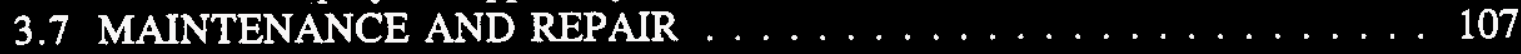

3.7.1 Shipping and Receiving System $\ldots \ldots \ldots \ldots \ldots \ldots$

3.7.2 Warehousing and Storage System $\ldots \ldots \ldots \ldots \ldots \ldots$

3.7.3 Storage and Service Yard . . . . . . . . . . . . . 109

3.7 .4 Major Equipment Assembly . . . . . . . . . . . . . . 111

3.7.5 Spare Parts Fabrication $\ldots \ldots \ldots \ldots \ldots \ldots \ldots$

3.7.6 Maintenance and Repair System . . . . . . . . . . . . . . 114

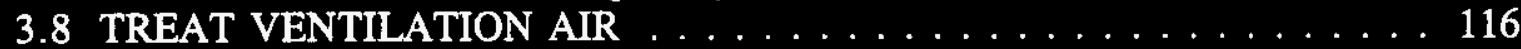

3.8.1 Supply Air Treatment System . . . . . . . . . . . 116

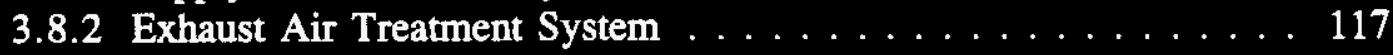

3.8.3 HVAC Chilled Water $\ldots \ldots \ldots \ldots \ldots \ldots \ldots \ldots$

3.9 MONITOR AND CONTROL THE PROCESS $\ldots \ldots \ldots \ldots \ldots \ldots \ldots 121$

3.9.1 Process Facility Operational Control System . . . . . . . . . . . 121

3.9.2 Health Protection System Vacuum System . . . . . . . . . . 123

4.0 DISCUSSION AND EVALUATION OF SUPPORT FACILITIES $\ldots \ldots \ldots \ldots$

4.1 REGULATED TANK WASTE REMEDIATION SYSTEM COMPLEX

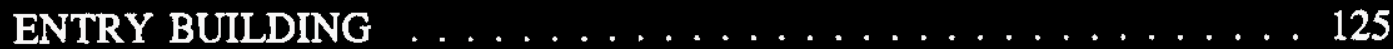

4.2 OPERATIONS SUPPORT BUILDING $\ldots \ldots \ldots \ldots \ldots \ldots \ldots$

4.3 EMERGENCY RESPONSE CENTER . . . . . . . . . . . . . . 127

4.4 BULK COLD CHEMICAL BUILDING/BULK HANDLING AREA $\ldots \ldots 128$

4.5 MECHANICAL UTILITIES BUILDING $\ldots \ldots \ldots \ldots \ldots \ldots \ldots \ldots$

4.6 WATER PUMPHOUSE . . . . . . . . . . . . . . . . . . . . 129 
WHC-SD-W378-ES-002

Revision 0

4.7 ANALYTICAL FACILITY $\ldots \ldots \ldots \ldots \ldots \ldots \ldots$

4.8 SWITCHGEAR BUILDING $\ldots \ldots \ldots \ldots \ldots \ldots \ldots \ldots \ldots$

4.9 WAREHOUSES/SHIPPING AND RECEIVING BUILDING $\ldots \ldots \ldots \ldots 131$

4.10 FABRICATION AND ASSEMBLY SHOP $\ldots \ldots \ldots \ldots \ldots \ldots \ldots 131$

4.11 EMERGENCY GENERATOR BUILDING $\ldots \ldots \ldots \ldots \ldots \ldots \ldots$

4.12 SITE INFRASTRUCTURE $\ldots \ldots \ldots \ldots \ldots \ldots \ldots \ldots \ldots \ldots$

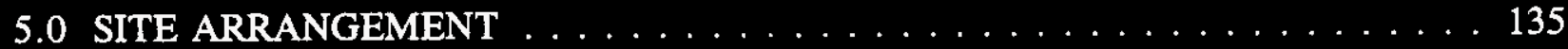

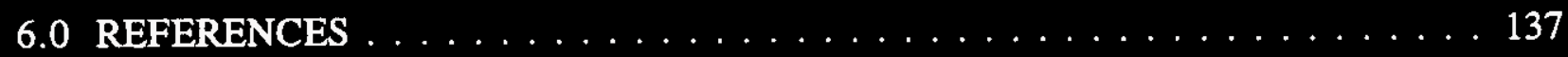


WHC-SD-W378-ES-002

Revision 0

APPENDIXES

A BLOCK FLOW DIAGRAMS $\ldots \ldots \ldots \ldots \ldots \ldots \ldots \ldots$ A-1

B UTILITY FLOW DIAGRAMS $\ldots \ldots \ldots \ldots \ldots \ldots \ldots$ B-1

C UTILITY CONSUMPTION TABLES AND ELECTRICAL LOAD LIST $\ldots$. C-1

D COLD CHEMICAL CONSUMPTION TABLES $\ldots \ldots \ldots \ldots$ D-1

E1 SUPPORT FACILITY EQUIPMENT LIST . . . . . . . . . . . . . E1-1

E2 HIGH-LEVEL WASTE STANDALONE SUPPORT FACILITY EQUIPMENT LIST $\ldots \ldots \ldots \ldots \ldots \ldots \ldots \ldots \ldots \ldots \ldots \ldots \ldots$ E2-1

E3 SEPARATIONS/LOW-LEVEL WASTE STANDALONE SUPPORT FACILITY EQUIPMENT LIST $\ldots \ldots \ldots \ldots \ldots \ldots \ldots \ldots \ldots$. . . . . E3-1

F SUPPORT FACILITY LAYOUTS $\ldots \ldots \ldots \ldots \ldots \ldots \ldots \ldots$ F-1

G1 BASE CASE SUPPORT FACILITY CONFIGURATION COST BASIS . . . . G1-1

G2 ALTERNATE CASE SUPPORT FACILITY CONFIGURATION COST BASIS . . . . . . . . . . . . . . . . . . . . . G2-1

G3 TANK WASTE REMEDIATION SYSTEM FACILITY CONFIGURATION STUDY FACILITY COST COMPARISON $\ldots \ldots \ldots \ldots \ldots \ldots$. . . . . . . .

H1 SEPARATIONS/LOW-LEVEL WASTE ANALYTICAL FUNCTION STUDY H1-1 H2 HIGH-LEVEL WASTE ANALYTICAL FUNCTION STUDY $\ldots \ldots \ldots$ H2-1 
WHC-SD-W378-ES-002

Revision 0

LIST OF FIGURES

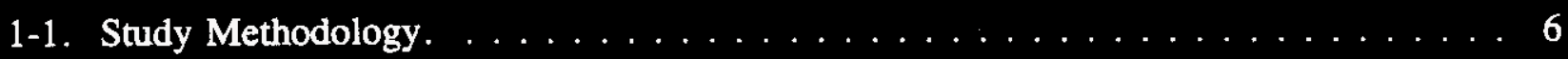

1-2. Tank Waste Remediation System Functional Block Diagram . . . . . . . . . 7

2-1. Tank Waste Remediation System Treatment Complex Site Plan . . . . . . . . . . 37

\section{LIST OF TABLES}

2-1. Summary of Tank Waste Remediation System Treatment Complex Peak Annual

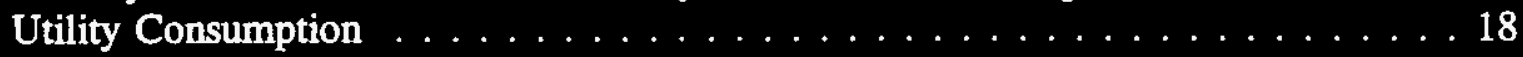

2-2. Factors Influencing Function Configuration $\ldots \ldots \ldots \ldots \ldots$

2-3. Support Function Definition $\ldots \ldots \ldots \ldots \ldots \ldots \ldots \ldots \ldots \ldots \ldots \ldots$

2-4. Impacts to Function Configuration Due to Resolution of Outstanding Issues . . . . 28

2-5. Support Facility Capital Cost Basis $\ldots \ldots \ldots \ldots \ldots \ldots \ldots \ldots \ldots \ldots$

2-6. Alternate Support Facility Capital Cost Differential $\ldots \ldots \ldots . \ldots . \ldots . \ldots$

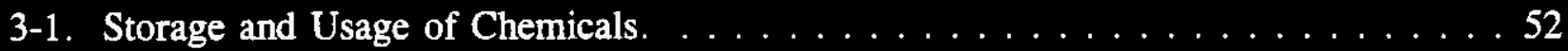

3-2. Tanks That Vent to Bulk Cold Chemical Building Exhaust Stack. . . . . . . . . 57

3-3. Tanks That Vent to Process Facility Exhaust Stack. . . . . . . . . . . . 60 
WHC-SD-W378-ES-002

Revision 0

\section{LIST OF TERMS}

\begin{tabular}{ll} 
AF & Analytical Facility \\
ALARA & As low as reasonably achievable \\
BCCB & Bulk Cold Chemical Building \\
BHA & Bulk Cold Chemical Handling Area \\
DOE & U.S. Department of Energy \\
CPD & Cyclopentadiene \\
DCPD & Di-cyclopentadiene \\
DTU & Distributed Treatment Unit \\
DWPF & Defense Waste Processing Facility \\
EGB & Emergency Generator Building \\
FCS & Tank Waste Remediation System Facility Configuration Study \\
HEPA & High-efficiency particulate air \\
HLW & High-level waste \\
HPS & Health Protection System \\
HVAC & Heating, ventilating, and air conditioning \\
HWVP & Hanford Waste Vitrification Plant \\
IEEE & Institute of Electrical and Electronics Engineers \\
ILLW & Immobilized low-level waste \\
INEL & Idaho National Engineering Laboratory \\
LETF & Liquid Effluent Treatment Facility \\
LFCM & Liquid Fed Combustion Melter \\
LLW & Low-level waste \\
MSM & Master-slave manipulator \\
MUB & Mechanical Utilities Building \\
PUREX & Plutonium Uranium Extraction Facility \\
RAL & Remote Analytical Laboratory \\
RCRA & Resource Conservation and Recovery Act of 1976 \\
RMW & Radioactive Mixed Waste \\
TEC & Total Estimated Cost \\
TEDF & Treated Effluent Disposal Facility \\
TRU & Transuranic \\
TSD & Treatment, storage, and disposal \\
TWRS & Tank Waste Remediation System \\
UFD & Utility Flow Diagram \\
UPS & Uninterruptible Power Supply \\
WHC & Westinghouse Hanford Company \\
WPH & Water pumphouse \\
& \\
\hline
\end{tabular}


WHC-SD-W378-ES-002

Revision 0

\section{FACILITY DESIGN PHILOSOPHY: TANK WASTE REMEDIATION SYSTEM PROCESS SUPPORT AND INFRASTRUCTURE DEFINITION}

\subsection{OBJECTIVE}

This report documents the current facility design philosophy for the Tank Waste Remediation System (TWRS) process support and infrastructure definition. The Tank Waste Remediation System Facility Configuration Study (FCS) (Boomer et al. 1994) initially documented the identification and definition of support functions and infrastructure essential to the TWRS processing mission. The FCS provided the following types of information for consideration in the facility configuration decision (i.e., the decision to house the separations, low-level waste [LLW], and high-level waste [HLW] processing functions in one, two, or three facilities):

- Initial identification and discussion of the utilities, support buildings, and infrastructure required to support the TWRS Treatment Complex

- Initial identification of alternatives for siting the TWRS Treatment facilities and discussion of factors involved in the assessment of alternative sites

- Provision of site layout drawings and cost estimates for alternative sites and facility configurations.

Since the issuance of the FCS, the Westinghouse Hanford Company (WHC) has proceeded to develop information and requirements essential for the technical definition of the TWRS treatment processing programs.

\subsection{PURPOSE AND NEED}

The need for this work is identified under the TWRS Systems Engineering Architecture titled "Support Immobilize Low-Level Waste (ILLW) Process" (Function 4.2.2.4.4). This report was developed in parallel with other engineering studies called for by the TWRS Systems Engineering process. As such, it has advanced the level of detail originally provided in Appendix $\mathbf{K}$ of the FCS and it will aid in developing process support and infrastructure definitions. The principal purposes of this effort are as follows:

- Completely identify the functions necessary to support the Separations, LLW, and HLW processes. 
- Identify which of the support functions can be shared between the process facilities and which must be dedicated to each of the process facilities.

- Provide an initial placement of the support and infrastructure functions within the preferred TWRS Treatment Complex site.

- Arrive at an initial identification of facilities and structures that provide support and infrastructure functions and identify which functions are potential candidates for being provided from existing Hanford Site facilities. No effort is being made to identify specific facilities that could be used to provide any of the functions identified herein.

- Provide a cost estimate for the facilities required to provide support and infrastructure functions and compare with FCS cost basis for the same facilities.

The development of process support and infrastructure function definitions allows WHC and the U.S. Department of Energy (DOE) to better understand factors that may affect key decisions. In particular, early cost estimates and identification of the support facilities required for each processing facility needs to be considered when scheduling and defining individual project scopes. Detailed and defensible cost estimates also provide a better understanding of the role of support function cost in assessing the potential merits of Distributed Treatment Units (DTUs) over a large single centralized processing facility. Lastly, the consideration of all necessary support functions in one study is an acknowledgement that there is only one continuous process flowsheet, regardless of the number of facilities that may house segments of the process and regardless of the business and project arrangements that may be used to implement the construction and operation of the TWRS Treatment facilities.

There are a considerable number of options for how the support functions are configured and delivered. This report endeavors to narrow the options on the basis of the following critical evaluation criteria:

- Operability and Maintainability

- Cost Effectiveness

- Radiological Protection (ALARA)

- Safety

- Environmental Regulatory Compliance

- Schedule

- Technical Maturity

- Design Impact. 
The intent of the report is to provide a sound basis for project definition that can evolve with the processing facility design efforts. As such, the results presented in this study are preliminary and are expected to change as the design matures and the functions and requirements are finalized.

\subsection{BASELINE ASSUMPTIONS}

As indicated in the TWRS FCS, the process support and infrastructure functions are essential to the processing mission and represent a significant capital expenditure. There is no question that the configuration of the facilities and structures that provide the support utilities and services will be dependent on specific characteristics of the main processing facilities. Until the processing facility designs are finalized, or nearly so, requirements associated with the support functions could be subject to change. This is true of any major process facility and must not be used as a rationale for delaying the development of a definition for the support functions as early in the TWRS Treatment projects as possible.

The present progress in the identification and definition of support functions is based on the FCS and subsequent engineering trade studies. As parallel engineering and design efforts continue, the validity of the assumptions and their impact on the support function requirements will have to be continuously reevaluated. Despite the probability of adjustment to these baseline assumptions, the findings documented in this report will provide essential initial project definition and a reasonable basis for project planning. Key assumptions to this report include the following:

Melter Technology. This report did not select or discriminate against any of the various melter types being evaluated for LLW or HLW. In particular, any mention of the combustion melter concept in the context of HLW processing is not in any way an endorsement or promotion of that particular melter concept. Melter technology selection is a specific activity in the systems engineering approach to design; this report in no way addresses melter technology selection for either LLW or HLW processing. The task of this study is to define what site infrastructure would be required regardless of the melter type for LLW and HLW. From an infrastructure standpoint, the report uses the "worst case" scenario for each type of melter. Electrical loads for joule-heated melters in conjunction with oxygen and kerosene requirements for combustion melters have been addressed in this study. Each requirement is defined as a possible site function dependent upon the melter type chosen for each of the vitrification facilities.

LLW Glass Form and Disposal Configuration. Consistent with the current TWRS Treatment process flowsheet, glass cullet in a polymer-sulfur cement matrix is assumed. A separate trade study is evaluating a range of engineering alternatives to forming the matrix and transporting it to the onsite LLW storage vaults. As of this writing, the preferred alternative is to combine the cullet and polymer-sulfur cement 
in $2 \mathrm{~m} \mathrm{X} 2 \mathrm{~m} \mathrm{X} 8 \mathrm{~m}$ casks and transport them through an underground tunnel to the LLW storage vaults.

Staffing Estimates. The size of the support facilities takes into account staffing estimates for each job category or trade that will be required to operate and maintain the TWRS Treatment Complex. Staffing estimates and profiles were initially compiled as part of the FCS and have been further refined for use in this study. The types of facilities, the number of facilities and their placement on the site takes into account the practical aspects of maintenance, operations and movement of personnel. Section 4.1, Regulated TWRS Complex Entry Building, contains a complete breakdown of the staffing profile used in this study.

Facility Configuration. This study assumes the process facility configuration recommended by the WHC TWRS management decision process. Specifically, it is assumed that the Separations process is combined with the LLW process in a common facility (building). The HLW process is assumed to be housed in a separate facility (building). This report includes an indication of whether any of the study conclusions or findings are subject to change if an alternative process facility configuration is implemented. This includes the option to incorporate the HLW processing into the combined Separations/LLW facility. The melter line conversion concept considered briefly in this report (i.e., completion of the LLW processing mission in a combined separations/vitrification facility followed by conversion of the LLW melter line for HLW processing) is fully defined in the draft of the Tank Waste Remediation System Reduced Cost Strategy, WHC-SD-WM-TI-694 (WHC 1995).

Dispersed Processing Functions. Consistent with the conclusions reached in the FCS, this study does not consider the possibility of dividing any of the main processing functions (Separations, LLW, and HLW) into multiple DTUs. The FCS concluded that such an approach is not cost effective and poses a scheduling risk. One of the key factors detracting from the cost effectiveness of DTUs is the provision of support functions and services. The cost estimates and layouts provided in this report can be used to make the cost comparison that would validate the FCS conclusion.

Waste Staging and Sampling. The feed sampling and queuing functions for the Separations/LLW facility and the HLW facility are assumed to be provided from infacility tanks. Therefore, the external $378.5-\mathrm{m}^{3}$ (100,000-gal) tanks ("six-packs") shown in the FCS are no longer external support facilities and have been eliminated from the site layout.

Siting. This study has assumed that the TWRS Treatment Complex will be located east of Baltimore Street, north and/or south of 4th Street and west of the Plutonium-Uranium Extraction Facility (PUREX) in an area of approximately 220 acres. While results of the study are not dependent on exact siting, it is assumed that any alternative site will be comparable in size, terrain, and viability for excavation 
and construction. It is also assumed that the site can accommodate the collocation of all of the processing facilities and support functions; although, provision of support functions and services from locations outside of the complex fence is still an option.

Standalone. The term "standalone" indicates that a particular facility is fully independent and is not functionally integrated with any other facility.

Detached. A detached facility indicates that the facility is not physically attached to any other facility, but is functionally integrated with other facilities.

It must be remembered that this is a first pass effort to evaluate the process support functions and infrastructure to develop configuration definitions. The goal is to determine and address major concerns. Other concerns that may impact the final configuration definition may occur as the design matures. Sufficient effort has been expended to provide a high degree of confidence that the findings documented in this report can be used to develop an actual design for the TWRS Treatment Complex process support facilities and infrastructure.

\subsection{METHODOLOGY}

The findings presented in this report were developed using the logic process shown in Figure 1-1, Study Methodology.

Each step of the process and definitions of pertinent terms follow:

Step 1. All of the support functions necessary for the operation and maintenance of the main processing functions are identified. See Figure 1-2, TWRS Functional Block Diagram. These functions span the provision of utilities to the provision of radiation protection services.

Step 2. The support functions are divided between those that must remain dedicated to the main processing function or facility it supports and those that may be shared between processing functions. The criteria used to select one choice over another are described in Section 1.4, Evaluation Criteria. This study assumes the following definitions:

Dedicated - A support function that is not shared between the Separations/LLW facility and the HLW facility. If needed by both facilities, the function is provided to each facility separately.

Shared - A support function that is needed by both the Separations/LLW facility and the HLW facility, and which is provided by a common facility or area. 
WHC-SD-W378-ES-002

Revision 0

Figure 1-1. Study Methodology.

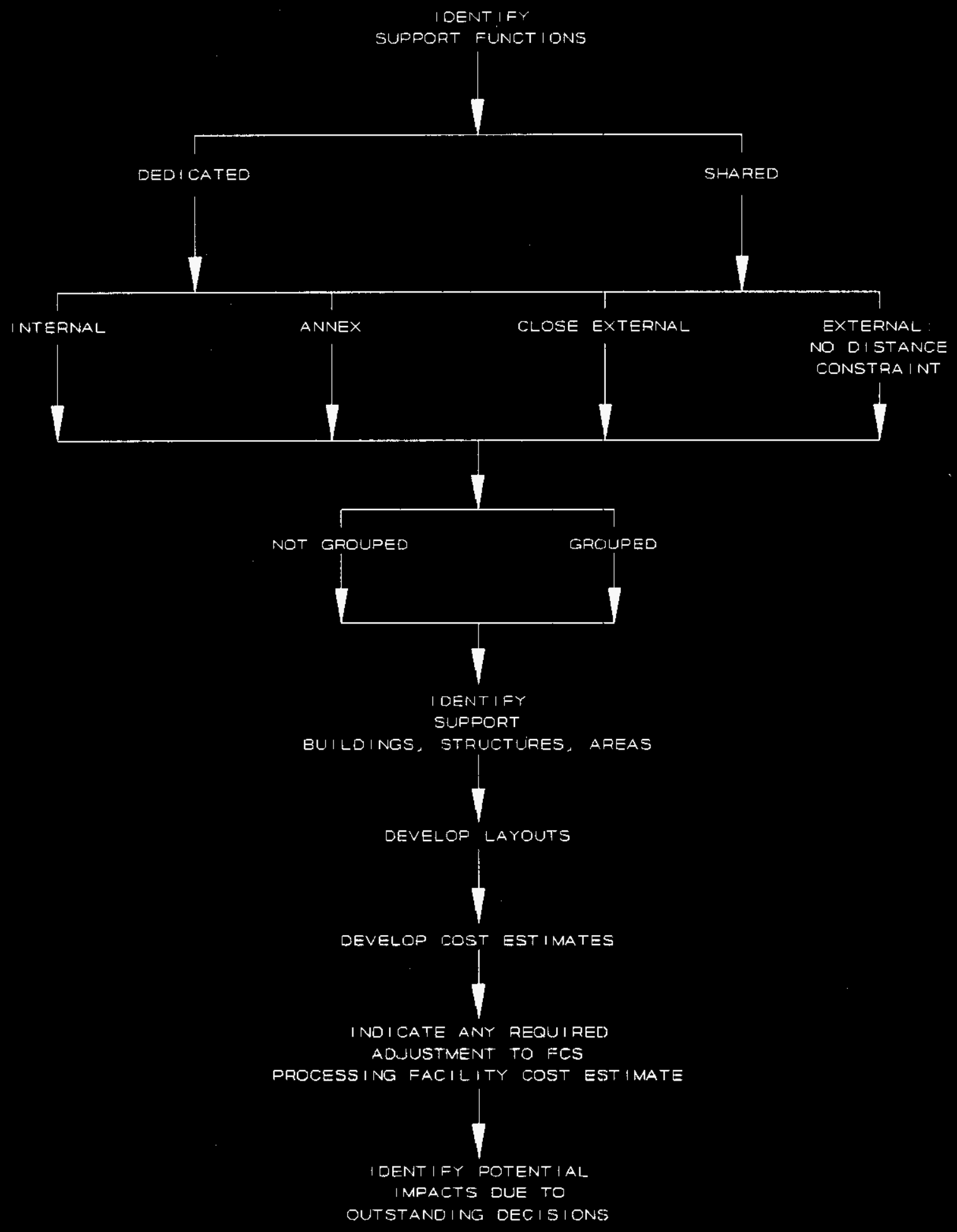




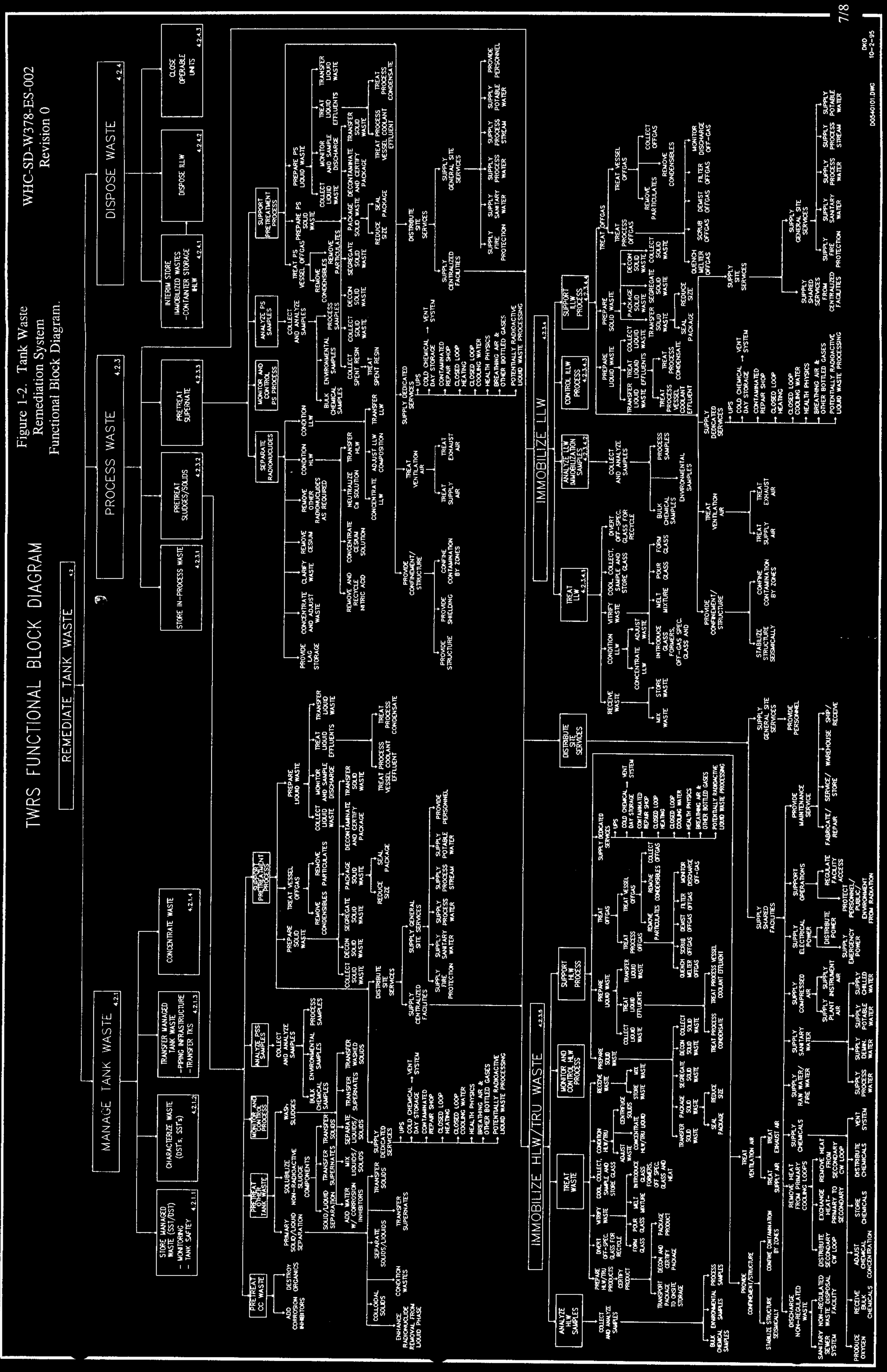


Step 3. Determine the physical relationship (distance) between each function and the process facilities. Each function will be classified as one of the following:

Internal - The support function is physically located inside a processing facility.

Annex - The support function is separated from the processing function it supports but is located in a structure immediately adjacent to the outside walls of the processing facility (within approximately $30 \mathrm{~m}$ ).

Close External - The support function is physically detached from, but needs to be located fairly close to (within $1,000 \mathrm{~m}$ ), the processing facility(ies) that it serves.

External: No Distance Constraint - The support function is physically detached from the processing facility(ies) that it serves. There is no particular constraint on how close by or far away the support function can be located from the processing facility(ies).

Step 4. Each shared and dedicated support function in its chosen location is examined to determine whether or not it is a candidate for "grouping". "Grouping" considers the possibility that there may be an advantage to collocating similar functions in a common facility or area.

Step 5. Based on the findings developed in Steps 1 through 4, develop definitions for each support facility or area.

Step 6. Develop layouts for the support function facilities and areas based on the support facility or area definitions.

Step 7. Cost estimates are developed for the support facility buildings, areas and equipment.

Step 8. Indicate any adjustments required to update the Rev 0 FCS cost estimates.

Step 9. Because a DOE decision on processing facility configuration remains outstanding and because there are parallel engineering studies whose outcomes appear particularly relevant to this study, Step 9 evaluates the following four issues with regards to the results of Steps 1 through 8. 
i. Would the choice of an alternative processing facility configuration (i.e., anything other than a combined Separations/LLW and a detached HLW) change the results of any of the Steps 1 through 8 ?

ii. Would the strategy to phase in HLW via LLW melter line conversion change the results of any of the Steps 1 through 8 ?

iii. Would the strategy to phase in HLW via staged addition to the Separations/LLW facility change the results of any of the Steps 1 through 8 ?

iv. Would the results of any of the Steps 1 through 8 change if alternative melter technologies were implemented?

Step 9 does not include a detailed assessment of the nature of any changes to the results of Steps 1 through 8 . Step 9 is provided only as an indication of how sensitive the report findings may be to key decisions that have not been finalized. It also serves as a flag for what support functions need to be revisited once final decisions are made.

\subsection{EVALUATION CRITERIA}

The evaluation criteria discussed here are common to all of the engineering trade studies currently being performed for the TWRS processing programs. Adjustments on emphasis and detail are tailored, as appropriate, for this study.

\subsubsection{Operability and Maintainability}

Assessment of operability is a qualitative measure of the inherent complexity of a system with respect to four key factors: (1) physical complexity, (2) the nature of the operator interface and (3) the responsiveness of the system, (4) practicality of design. Physical complexity is influenced by the number of unit operations or equipment pieces involved, the number of control points required (including process samples) and the quantity and type of consumables involved in the operation. Operator interface is influenced by factors such as the level of training required and the degree, type and frequency of operator interaction with the system. System responsiveness is related to the ability of the system to respond to fluctuations or variability in the process flowsheet and to off-normal conditions. Practicality of design refers to a "fit for purpose" design configuration that will efficiently perform its intended function.

The maintainability of a system can be assessed by evaluating the complexity, reliability and repairability of the associated equipment. Complexity is influenced by factors such as the level of training required to perform maintenance on the equipment, the need for 
special or unique tools, design qualities such as the ability of the equipment to be repaired, the availability of standardized parts and provisions for troubleshooting. Reliability can be directly measured through failure rate/mean time to failure data, but also is associated with qualitative factors such as the frequency of test, calibration and preventative maintenance procedures. Another key measure of reliability is the impact of failures on the process including recovery or downtime following a failure. Repairability is influenced by work space factors (interferences, confined spaces, etc.), location of the equipment, means of component repair or replacement (remote or contact maintenance), number and type of personnel required to support repairs, pre-maintenance preparation requirements and postmaintenance impacts such as quantities and types of wastes produced and functional test requirements.

\subsubsection{Cost Effectiveness}

Generally, factors considered in the use of cost effectiveness as a decision making discriminator could include: technical development costs; engineering costs; capital equipment, facility and construction costs; operating costs that include staff loading, consumables and utilities; and spending profile. This study provides quantitative information related to costs for: capital equipment, facilities and construction, and engineering. Operating costs are not explicitly tabulated. Instead, estimated quantities of consumables and utilities are provided. Similarly, while support function provisions and layouts are based in part on anticipated staffing levels, no staff loadings are included in cost estimates. If operating costs are a discriminator, a qualitative rationale is documented under other evaluation criteria such as operability and maintainability. Development costs are related to technical maturity, which was not found to be a discriminator among options for the provision and arrangement of support functions. Therefore, no development costs are provided.

Cost estimates provided in this study are based on layouts and equipment lists developed under a "fit for purpose" philosophy. Specifically, an attempt was made to provide costs for a configuration that is suitable to perform the expected functions using commonly available technology and does not reflect higher costs associated with "state of the art" technology.

\subsubsection{Radiological Protection}

The radiological protection evaluation criterion is a subset of the safety criterion. It is called out separately because of its prominence as a discriminator or key factor in recommending a configuration for the support functions. The radiological protection criterion refers strictly to maintaining worker dose to "As Low As Reasonably Achievable" (ALARA). Considerations related to accidental releases and exposures are part of the "safety" criterion. With regards to the development of support function configuration definition, the radiological protection criterion considers the minimization of worker contact 
with contamination or exposure to shine. It considers strategies to avoid spread of contamination and to simplify operations and maintenance.

\subsubsection{Safety}

The safety criterion considers hazards (other than occupational radiation exposure) and implications for onsite/offsite safety, in-facility worker safety, and mission and property protection. The configuration chosen to deliver support functions needs to be based on consideration of the potential to introduce or create hazards. If a potential hazard related to the support functions cannot be eliminated by reasonable design measures, the choice of a support function configuration needs to be that which offers the greatest potential for hazard prevention and mitigation.

With regard to the safety of the public and onsite workers, the safety criterion considers several factors. First, impacts on the specification of Safety Class are considered. A scheme that minimizes the need for high Safety Class specification of systems, structures and components is generally preferable. In the same way, a scheme that justifies less stringent Performance Categories or seismic design criteria is generally preferable. These are largely qualitative judgements for this study. Further, this study assumes that all support functions can be designed to comply with the quantitative risk acceptance criteria documented in WHC Safety Analysis Procedures (WHC-CM-4-46). Therefore discriminators between alternatives for support function configuration are captured in the qualitative assessment of ease of hazard prevention and mitigation.

In-facility worker safety considers such factors as minimizing worker exposure to potentially harmful materials and environments. The in-facility worker safety criterion overlaps the operability, maintainability and radiation protection criteria. Nevertheless, it is called out separately to emphasize the importance of process and industrial safety to the overall safety risk profile of the TWRS processing complex.

"Mission and property protection" is included with the safety criterion because a key source for major interruption of mission or damage to property is assumed to be related to accidents. Hence, threats to the health and safety of the public and onsite workers also are threats to the processing mission and capital property. This aspect of the safety criterion considers the potential for accident propagation and implications for recovery from any accidents expected to possibly occur during the lifetime of the facilities or mission.

\subsubsection{Environmental Regulatory Compliance}

The environmental regulatory impacts of a support function configuration is assessed by evaluating: (1) regulated liquid effluent generation, (2) regulated gaseous effluent generation, (3) secondary dangerous waste generation, and (4) permitting requirements. 
Regulated liquid effluent generation is defined as the volume of regulated liquid effluents generated and discharged to the Liquid Effluent Treatment Facility (LETF) and/or the Treated Effluent Disposal Facility (TEDF). Ideally, the volume of liquid effluents should be minimized. The degree of treatment required before discharge to LETF/TEDF is also a factor that is examined, as appropriate, in comparing support facility configuration options.

Regulated gaseous effluent generation is defined as the rate of emission of regulated pollutants, both radioactive and nonradioactive. Ideally, emission rates should be kept ALARA. The degree of treatment required to meet airborne effluent discharge limits is also a factor that is examined, as appropriate, in comparing support facility configuration options.

Secondary dangerous waste generation is defined as the quantity of wastes (including mixed wastes) generated as a result of the primary processing operation. Secondary dangerous waste generation should be minimized as much as possible. The extent of in-plant secondary waste treatment and dangerous waste packaging and storage and accumulation areas are considered, as appropriate, when comparing support function configurations.

Permitting requirements should be evaluated based on the following factors: (1) number of permits required, (2) complexity of required permitting documentation, (3) potentially required permits or approvals that are unique to the system being examined, (4) regulatory obstacles (e.g., applying for an exemption or seeking a different ruling on a regulation, and (5) impacts of permitting activities on the project schedule.

The specific regulatory requirements examined in the evaluation of this criterion for the support function configuration are indicated below. While the regulations are grouped by category, several overlap into one or more categories. In addition, some regulations apply to NRC licensed facilities (e.g., 10 CFR 61 and 10 CFR 71) but may become important to DOE facilities in the future. These were considered but did not mandate design decisions.

\subsubsection{Hazardous Wastes.}

40 CFR 264, Standards for Owners and Operators of Hazardous Waste Treatment, Storage, and Disposal Facilities

WAC 173-303, Dangerous Waste Regulations

WAC 173-360, Underground Storage Tank Regulations.

\subsubsection{Mixed Wastes.}

DOE 5820.2A, Radioactive Waste Management (exemption applied for).

\subsubsection{Radioactive Wastes.}

10 CFR 61, Licensing Requirements for Land Disposal of Radioactive Wastes 
10 CFR 71, Packaging and Transportation of Radioactive Material

DOE 5480.3, Safety Requirements for the Packaging and Transportation of Hazardous Materials, Hazardous Substances and Hazardous Wastes

RLID 5820.2A, Radioactive Waste Management (exemption applied for)

WAC 173-325, Low-Level Radioactive Waste Disposal.

\subsubsection{Air Quality.}

40 CFR 61(H), National Emission Standards for Hazardous Air Pollutants

DOE 5400.1, General Environmental Protection Program

WAC 173-400, General Regulations for Air Pollution Sources

WAC 173-401, Operating Permit Regulation

WAC 173-460, Controls for New Sources of Toxic Air Pollutants

WAC 173-480, Ambient Air Quality Standards and Emission Limits for Radionuclides

WAC 246-247, Radiation Protection - Air Emissions.

\subsubsection{Confinement Systems.}

DOE 6430.1A, General Design Criteria.

\subsubsection{Radiation Protection.}

DOE 5400.5, Radiation Protection of the Public and Environment

DOE 5480.11, Radiation Protection for Occupational Workers

DOE/EH-0256T, Rev 1, Radiological Control Manual.

\subsubsection{Environmental, Safety and Health.}

DOE 5480.1B, Environmental, Safety and Health Program for Department of Energy Operations

RLIP 5480.4C, Environmental Protection, Safety, and Health Protection Standards for $R \mathbf{R}$. 


\subsubsection{Miscellaneous.}

RLIP 5820.2A, Radioactive Waste Management

WAC 173-216, State Waste Discharge Permit Program

WAC 246-272, Onsite Sewage System.

\subsubsection{Schedule}

The schedule criterion considers any impact or special needs that a configuration choice may have on design, construction and start-up schedule. As the support functions are not anticipated to be the limiting factor in meeting pre-determined project milestones, schedule does not serve to eliminate any configuration options. At this stage in the engineering studies, important relative advantages of one option over another on the basis of schedule have not been identified.

\subsubsection{Technical Maturity}

The technical maturity criterion considers whether any aspect of a support function configuration is beyond the state of the art, requires development, is undemonstrated technology, or is not readily available in terms of supply. In general, configurations employing demonstrated and readily supplied technology are preferred. To the level of detail they are provided in this report, layouts, equipment lists and cost estimates for a recommended support function configuration are based on proven, commercially available technology.

\subsubsection{Design Impact}

The design impact criterion considers the possibility that the choice of support function configuration may impact: (1) the process flowsheet, (2) special requirements or restrictions for siting, and (3) constructibility.

\subsection{REPORT ORGANIRATION}

The report sections following this introduction are organized as follows:

Section 2.0, Summary of Technical Findings and Conclusions, provides the key findings of the study in convenient tabular format. The remaining sections of the report and the appendices may be viewed as detailed back-up information for that provided in these tables. 
Section 3.0, Description and Evaluation of Support Functions, provides a brief description of each of the identified support functions, a summary of the findings for each function, and a brief discussion of the considerations and rationale upon which the findings were based.

Section 4.0, Description of Support Facilities, describes the facilities or areas that house or contain each of the support functions.

Section 5.0, Description of Site Layout and Infrastructure, provides an initial attempt to place the support functions and areas within a 200-acre TWRS Treatment Complex site. This site is being recommended in the Tank Waste Remediation System Complex Site Evaluation Report (WHC-SD-WM-SE-021 Rev 0A draft 1995) as the preferred location for the TWRS Treatment Complex. While there may be many ways to arrange the facilities on the prescribed site, this exercise helps to validate the findings documented herein with regard to support function and infrastructure configuration.

Section 6.0, References, lists the documents referenced by this report.

The following appendices contain material used in the evaluation of various support functions and development of the support facility definition:
A Block Flow Diagrams
B Utility Flow Diagrams
C Utility Consumption Tables and Electrical Load List
D Cold Chemical Consumption Tables
E1 Support Facility Equipment List
E2 High-Level Waste Standalone Support Facility Equipment List
E3 Separations/Low-Level Waste Standalone Support Facility Equipment List
F Facility Layouts
G1 Base Case Support Facility Configuration Cost Basis
G2 Alternate Case Support Facility Configuration Cost Basis
G3 Tank Waste Remediation System Facility Configuration Study
Facilities Cost Comparison
H1 Separations/Low-Level Waste Analytical Function Study
H2 High-Level Waste Analytical Function Study. 
WHC-SD-W378-ES-002

Revision 0

\subsection{SUMMARY OF TECHNICAL FINDINGS}

The TWRS Functional Block Diagram, was reviewed to identify the separations and process support functions. Each support function was evaluated to determine the overall annual utility consumption requirements. Table 2-1, Summary of TWRS Treatment Complex Peak Annual Utility Consumption, summarizes the peak annual utility consumption for each process function. Appendix C, Utility Consumption Tables and Electrical Load List, provides a detailed breakdown of the estimated annual utility consumption requirements and the electrical load requirements.

Each support function was evaluated against the Evaluation Criteria identified in Section 1.4 and a rationale developed to define its configuration. Table 2-2, Factors Influencing Function Configuration, indicates which of the criteria factored most prominently in defining the proposed configuration. Table 2-3, Support Function Definition, defines the proposed configuration for each function. It identifies the function, the facility from where the function is provided, whether it is shared between the process facilities or dedicated to each, if it is grouped with other similar functions, and the physical relationship to the process facilities it serves. It also indicates if the function is a candidate for being provided from an existing Hanford facility.

Also of interest is the impact of resolution of outstanding issues on the proposed configuration. Table 2-4, Impacts to Function Configuration Definition Due to Resolution of Outstanding Issues, indicates which aspects of the configuration definition would be affected by these issues. The issues addressed are the implementation of staged HLW construction, LLW-HLW melter conversion, detached Separations, LLW, and HLW, or an alternate melter technology. It is inherent that these process facility variations would have impacts not only to individual process and process support facility layouts but also to the overall site layout. It was assumed that these process facility variations would not impact the grouping of functions within the process support facilities.

Table 2-5, Support Facility Capital Cost Basis, provides an estimated cost for the TWRS Treatment Complex process support facilities and infrastructure defined in this report. The Total Estimated Cost (TEC) for the facilities and infrastructure required to provide these functions is $\$ 524,842,000$. This compares with an estimated value of $\$ 521,836,000$ reported in the FCS for support facilities. Appendix G3 contains a detailed comparison between the TWRS Treatment Complex support facility and infrastructure costs and the FCS costs.

When Cost Effectiveness was indicated to have had an influence on a function's configuration, an attempt was made to determine the cost advantage of the chosen configuration. Alternate support facilities are defined in the study as the alternative to the proposed configuration, shared or combined support facilities (a standalone support facility constructed for each of the processing facilities). Table 2-6, Alternate Support Facility Capital Cost Differential, summarizes the overall cost advantage of the proposed configuration over the alternate. The total cost advantage is $\$ 90,211,000$. 


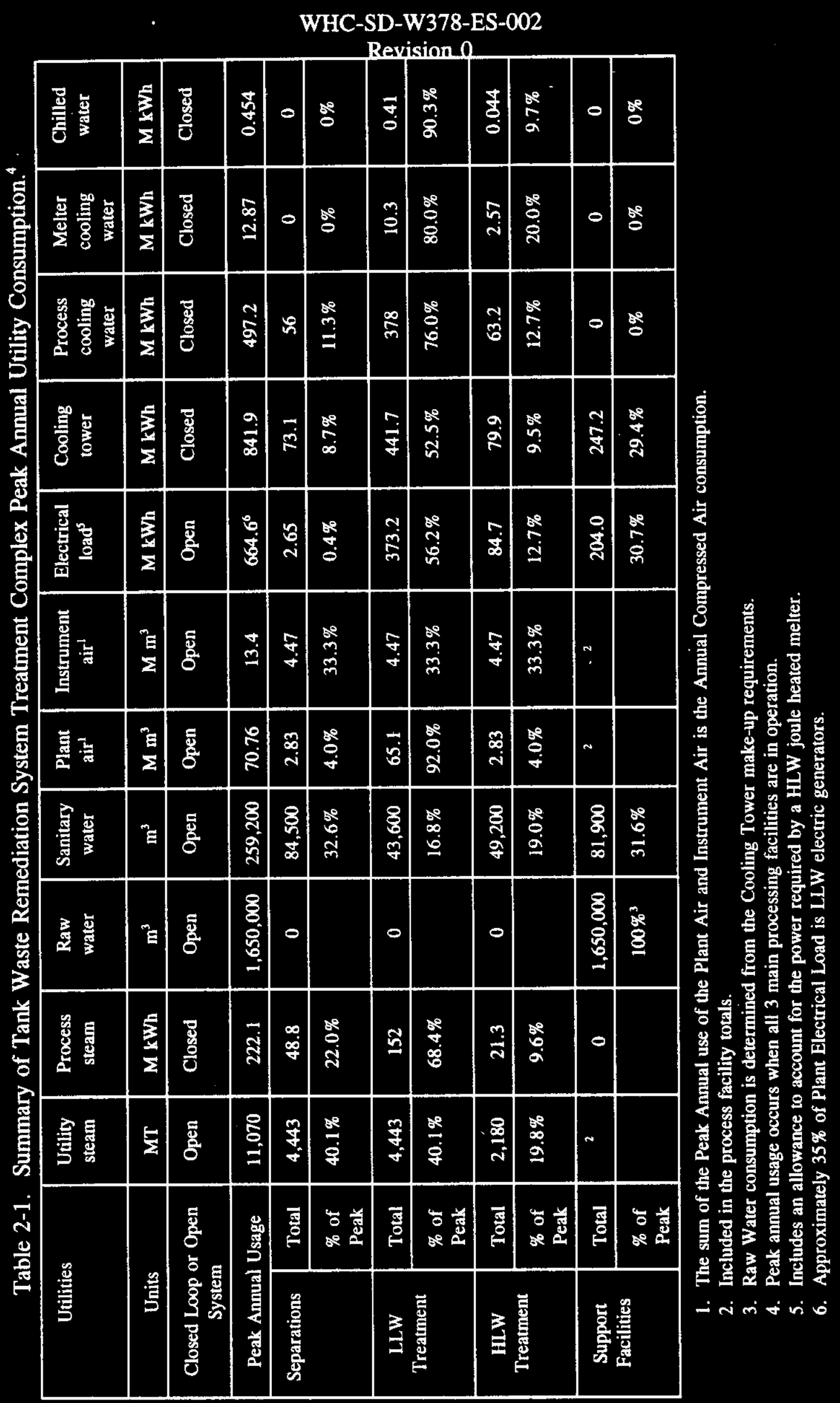


Table 2-2. Factors Influencing Function Configuration. (5 sheets)

\begin{tabular}{|c|c|c|c|c|c|c|c|c|c|}
\hline $\begin{array}{l}\text { Section } \\
\text { no. }\end{array}$ & $\begin{array}{l}\text { Function } \\
\text { description }\end{array}$ & $\begin{array}{l}\text { Operability/ } \\
\text { Maintain- } \\
\text { ability }\end{array}$ & $\begin{array}{c}\text { Cost } \\
\text { effectiveness }\end{array}$ & $\begin{array}{l}\text { Radiological } \\
\text { protection } \\
\text { (ALARA) }\end{array}$ & Safety & $\begin{array}{l}\text { Environmental } \\
\text { regulatory } \\
\text { compliance }\end{array}$ & Schedule & $\begin{array}{l}\text { Technical } \\
\text { maturity }\end{array}$ & $\begin{array}{l}\text { Design } \\
\text { impact }\end{array}$ \\
\hline 3.1 & Sample Analysis & $\mathbf{x}$ & $\mathbf{X}$ & & & & & & \\
\hline 3.2 & $\begin{array}{l}\text { Collect and Handle } \\
\text { Solid Waste System }\end{array}$ & & $\mathbf{X}$ & $\mathrm{X}$ & $\mathbf{X}$ & & & & \\
\hline 3.3 .1 & $\begin{array}{l}\text { Collect and Handle } \\
\text { Potentially Radioactive } \\
\text { Liquid Waste System }\end{array}$ & & & $\mathbf{x}$ & & & & & \\
\hline 3.3 .2 & $\begin{array}{l}\text { Collect and Handle } \\
\text { Nonradioactive Liquid } \\
\text { Waste System }\end{array}$ & & $\mathbf{X}$ & & & & & & \\
\hline 3.4 .1 & Oxygen System & & $\mathbf{x}$ & & $\mathbf{X}$ & & & $\mathbf{x}$ & \\
\hline 3.4 .2 & $\begin{array}{c}\text { Cold Chemical Supply } \\
\text { System }\end{array}$ & $\mathbf{x}$ & $\mathbf{X}$ & & $\mathbf{X}$ & & & & \\
\hline 3.4 .3 & $\begin{array}{c}\text { Cold Chemical Feed } \\
\text { System }\end{array}$ & & & $\mathbf{x}$ & & & & & \\
\hline 3.4 .4 & $\begin{array}{c}\text { Cold Chemical Vent } \\
\text { System }\end{array}$ & $\mathbf{X}$ & & & & & & & \\
\hline 3.4 .5 & $\begin{array}{c}\text { Process Facility Vent } \\
\text { System }\end{array}$ & & & $\mathbf{X}$ & & & & & \\
\hline 3.4 .6 & $\begin{array}{l}\text { Process Steam and } \\
\text { Condensate System }\end{array}$ & $\mathbf{X}$ & $\mathbf{X}$ & $\mathbf{X}$ & $\mathrm{x}$ & & & & \\
\hline 3.4 .7 & $\begin{array}{c}\text { Process Cooling Water } \\
\text { System }\end{array}$ & & & $\mathrm{X}$ & & & & & \\
\hline
\end{tabular}


Table 2-2. Factors Influencing Function Configuration. (5 sheets)

\begin{tabular}{|c|c|c|c|c|c|c|c|c|c|}
\hline $\begin{array}{l}\text { Section } \\
\text { no. }\end{array}$ & $\begin{array}{l}\text { Function } \\
\text { description }\end{array}$ & $\begin{array}{l}\text { Operability/ } \\
\text { Maintain- } \\
\text { ability }\end{array}$ & $\begin{array}{c}\text { Cost } \\
\text { effectiveness }\end{array}$ & $\begin{array}{l}\text { Radiological } \\
\text { protection } \\
\text { (ALARA) }\end{array}$ & Safety & $\begin{array}{l}\text { Environmental } \\
\text { regulatory } \\
\text { compliance }\end{array}$ & Schedule & $\begin{array}{l}\text { Technical } \\
\text { maturity }\end{array}$ & $\begin{array}{l}\text { Design } \\
\text { impact }\end{array}$ \\
\hline 3.4 .8 & $\begin{array}{l}\text { Melter Cooling Water } \\
\text { System }\end{array}$ & & & $\mathrm{x}$ & & & & & \\
\hline 3.4 .9 & $\begin{array}{l}\text { Process Chilled Water } \\
\text { System }\end{array}$ & & & $\mathrm{x}$ & & & & & \\
\hline 3.4 .10 & Utility Steam System & & $\mathrm{x}$ & & & & & & \\
\hline 3.4 .11 & $\begin{array}{l}\text { Compressed Air } \\
\text { System }\end{array}$ & & $\mathrm{X}$ & & & & & & \\
\hline 3.4 .12 & Process Water System & & $\mathrm{X}$ & & & & & & \\
\hline 3.4 .13 & $\begin{array}{c}\text { Demineralized Water } \\
\text { System }\end{array}$ & $\mathrm{x}$ & $x$ & & & & & & \\
\hline 3.4 .14 & Sanitary Water System & $\mathbf{x}$ & & & & & & & \\
\hline 3.4 .15 & Raw Water System & $\mathbf{x}$ & & & & & & & \\
\hline 3.4 .16 & $\begin{array}{l}\text { TWRS Treatment Com- } \\
\text { plex Stite Fire Water } \\
\text { System }\end{array}$ & $\mathbf{x}$ & & & & & & & \\
\hline 3.4 .17 & $\begin{array}{l}\text { Process Facility Fire } \\
\text { Water System }\end{array}$ & $\mathrm{x}$ & & & $\mathbf{x}$ & & & & \\
\hline 3.4 .18 & $\begin{array}{l}\text { Waste Condensate Col- } \\
\text { lection System }\end{array}$ & & & & & & & & $\mathbf{X}$ \\
\hline 3.4 .19 & $\begin{array}{c}\text { Cooling Tower Water } \\
\text { System }\end{array}$ & & $\mathrm{X}$ & & & & & & \\
\hline
\end{tabular}




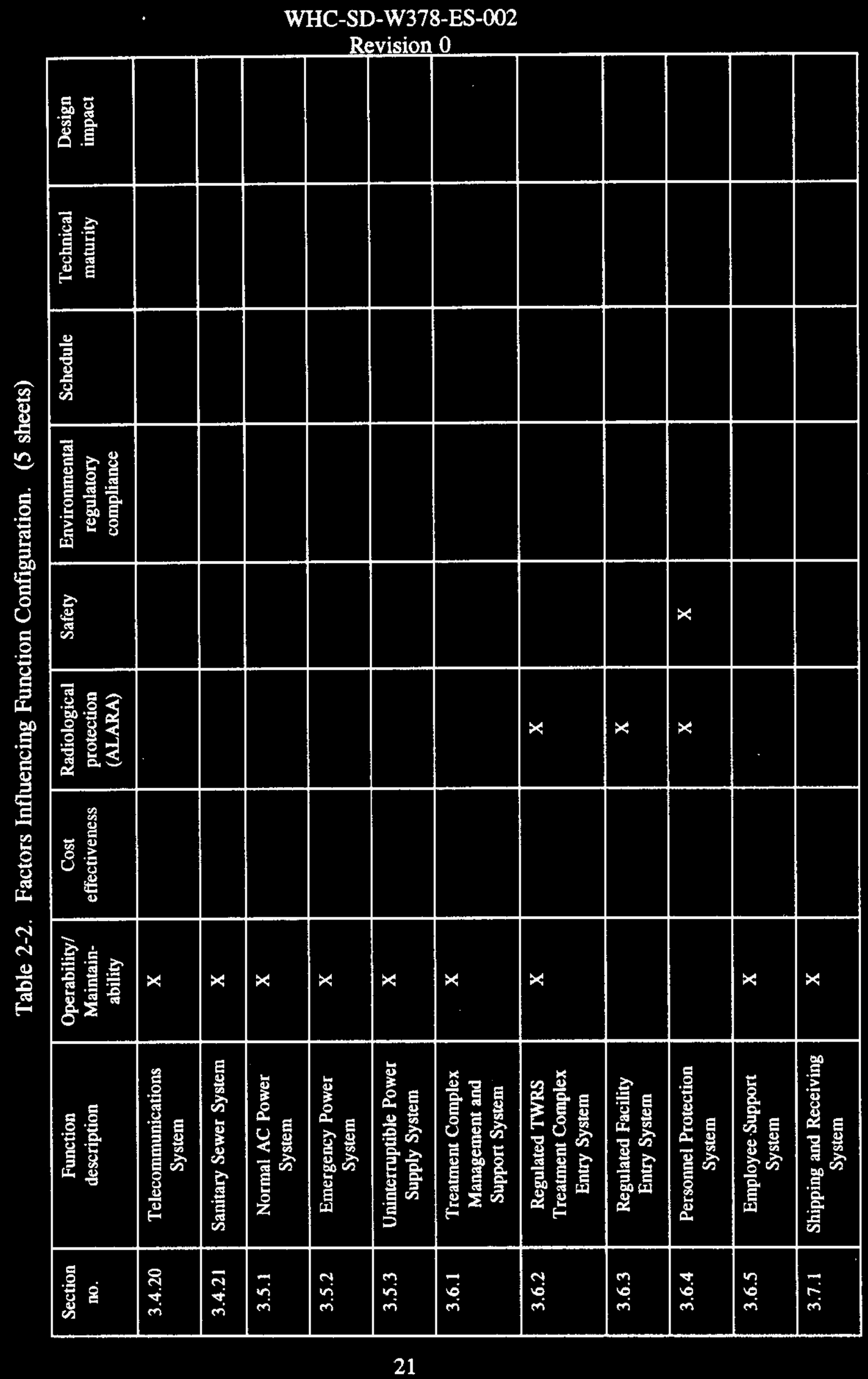


Table 2-2. Factors Influencing Function Configuration. (5 sheets)

\begin{tabular}{|c|c|c|c|c|c|c|c|c|c|}
\hline $\begin{array}{l}\text { Section } \\
\text { no. }\end{array}$ & $\begin{array}{l}\text { Function } \\
\text { description }\end{array}$ & $\begin{array}{l}\text { Operability/ } \\
\text { Maintain- } \\
\text { ability }\end{array}$ & $\begin{array}{c}\text { Cost } \\
\text { effectiveness }\end{array}$ & $\begin{array}{l}\text { Radiological } \\
\text { protection } \\
\text { (ALARA) }\end{array}$ & Safety & $\begin{array}{l}\text { Environmental } \\
\text { regulatory } \\
\text { compliance }\end{array}$ & Schedule & $\begin{array}{l}\text { Technical } \\
\text { maturity }\end{array}$ & $\begin{array}{l}\text { Design } \\
\text { impact }\end{array}$ \\
\hline 3.7 .2 & $\begin{array}{l}\text { Warehousing and } \\
\text { Storage System }\end{array}$ & $\mathbf{X}$ & & & & & & & \\
\hline 3.7 .3 & $\begin{array}{c}\text { Storage and Service } \\
\text { Yard }\end{array}$ & $\mathbf{x}$ & & & & & & & \\
\hline 3.7 .4 & Major Equip Assembly & $\mathbf{x}$ & & & & & & & \\
\hline 3.7 .5 & Spare Parts Fabrication & $\mathbf{X}$ & & & & & & & \\
\hline 3.7 .6 & $\begin{array}{l}\text { Maintenance and } \\
\text { Repair System } \\
\text { (MSM and other) }\end{array}$ & $\mathbf{x}$ & & $\mathrm{x}$ & & & & & \\
\hline 3.8 .1 & $\begin{array}{l}\text { Supply Air Treatment } \\
\text { System }\end{array}$ & $\mathbf{X}$ & & & & & & & \\
\hline 3.8 .2 & $\begin{array}{c}\text { Exhaust Air Treatment } \\
\text { System }\end{array}$ & $\mathbf{x}$ & & & $\mathbf{X}$ & & & & \\
\hline 3.8 .3 & $\begin{array}{l}\text { HVAC Chilled Water } \\
\text { System }\end{array}$ & $\mathbf{x}$ & $\mathbf{X}$ & & & & & & \\
\hline 3.9 .1 & $\begin{array}{l}\text { Process Facility Oper } \\
\text { Control System }\end{array}$ & $\mathbf{x}$ & & & $\mathbf{X}$ & & & & \\
\hline 3.9 .2 & $\begin{array}{c}\text { Health Protection } \\
\text { System Vacuum System }\end{array}$ & & & $\mathbf{X}$ & & & & & \\
\hline
\end{tabular}

*Dedicated to the Bulk Cold Chemical Building. 
Table 2-3. Support Function Definition. (5 sheets)

\begin{tabular}{|c|c|c|c|c|c|c|c|c|c|}
\hline $\begin{array}{l}\text { Section } \\
\text { no. }\end{array}$ & $\begin{array}{c}\text { Function } \\
\text { description }\end{array}$ & Location & $\begin{array}{c}\text { Shared versus } \\
\text { dedicated }\end{array}$ & Grouped & Internal & Annex & $\begin{array}{c}\text { Close } \\
\text { External }\end{array}$ & $\begin{array}{c}\text { No Distance } \\
\text { Constraint }\end{array}$ & $\begin{array}{c}\text { Potential to } \\
\text { use an } \\
\text { Existing } \\
\text { Facility }\end{array}$ \\
\hline$\overline{3.1}$ & Sample Analysis & Analytical Facility & Dedicated & $\mathbf{x}$ & & & $\mathbf{X}$ & & \\
\hline 3.4 .1 & Oxygen System & BHA & Shared & & & & & $\mathbf{x}$ & $\mathbf{X}$ \\
\hline 3.3 .2 & $\begin{array}{l}\text { Collect and Handle } \\
\text { Nonradioactive Liquid } \\
\text { Waste System }\end{array}$ & $\begin{array}{l}\text { Bulk Cold Chem } \\
\text { Bldg/MUB }\end{array}$ & Shared & $\mathrm{x}$ & & & $\mathbf{X}$ & & \\
\hline 3.4 .2 & $\begin{array}{l}\text { Cold Chemical Supply } \\
\text { System }\end{array}$ & $\begin{array}{l}\text { Bulk Cold Chem } \\
\text { Bldg }\end{array}$ & Shared & $\mathbf{x}$ & & & $\mathrm{x}$ & & \\
\hline 3.4 .4 & $\begin{array}{l}\text { Cold Chemical Vent } \\
\text { System }\end{array}$ & $\begin{array}{l}\text { Bulk Cold Chem } \\
\text { Bldg }\end{array}$ & Dedicated* & $\mathrm{X}$ & & & $\mathbf{X}$ & & \\
\hline 3.4 .19 & $\begin{array}{c}\text { Cooling Tower Water } \\
\text { System }\end{array}$ & Cooling Tower & Shared & & & & & $\mathbf{x}$ & $\mathbf{x}$ \\
\hline 3.4 .20 & $\begin{array}{c}\text { Telecommunications } \\
\text { System }\end{array}$ & $\begin{array}{c}\text { Emerg Response } \\
\text { Ctr }\end{array}$ & Shared & $\mathbf{x}$ & & & $\mathbf{x}$ & & \\
\hline 3.5 .2 & $\begin{array}{l}\text { Emergency Power } \\
\text { System }\end{array}$ & $\begin{array}{l}\text { Emerg Generator } \\
\text { Bldg }\end{array}$ & Dedicated & & & & $\mathbf{x}$ & & \\
\hline 3.7 .4 & $\begin{array}{l}\text { Major Equip } \\
\text { Assembly }\end{array}$ & $\begin{array}{c}\text { Fabrica- } \\
\text { tion/Assembly Shop }\end{array}$ & Shared & $\mathbf{x}$ & & & & $\mathbf{x}$ & $\mathbf{x}$ \\
\hline 3.7 .5 & $\begin{array}{l}\text { Spare Parts } \\
\text { Fabrication }\end{array}$ & $\begin{array}{c}\text { Fabrica- } \\
\text { tion/Assembly Shop }\end{array}$ & Shared & $\mathbf{x}$ & & & & $\mathbf{x}$ & $\mathrm{x}$ \\
\hline 3.4 .10 & Utility Steam System & Mech Utilities Bldg & Shared & $\mathbf{x}$ & & & $\mathrm{X}$ & & \\
\hline
\end{tabular}




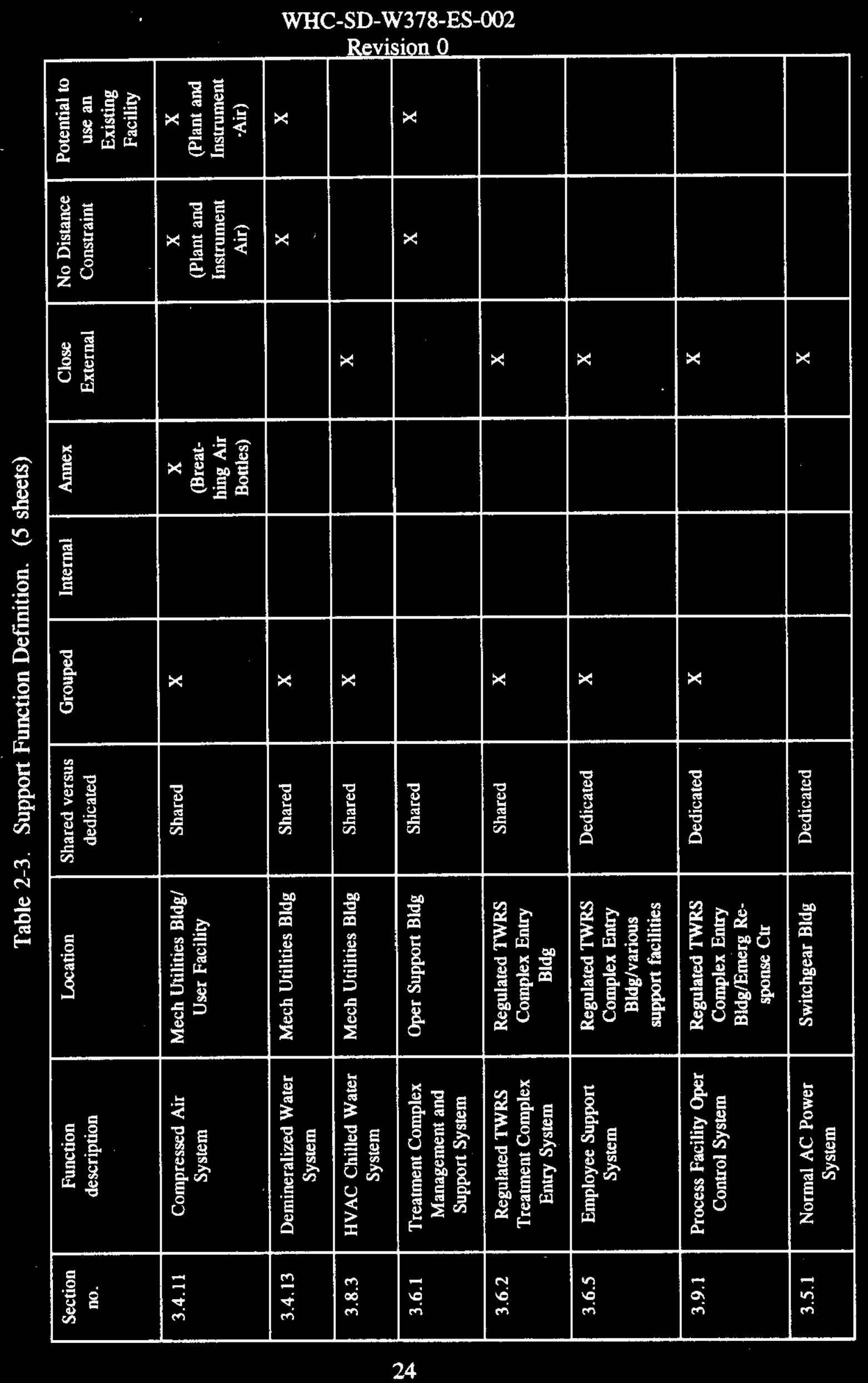




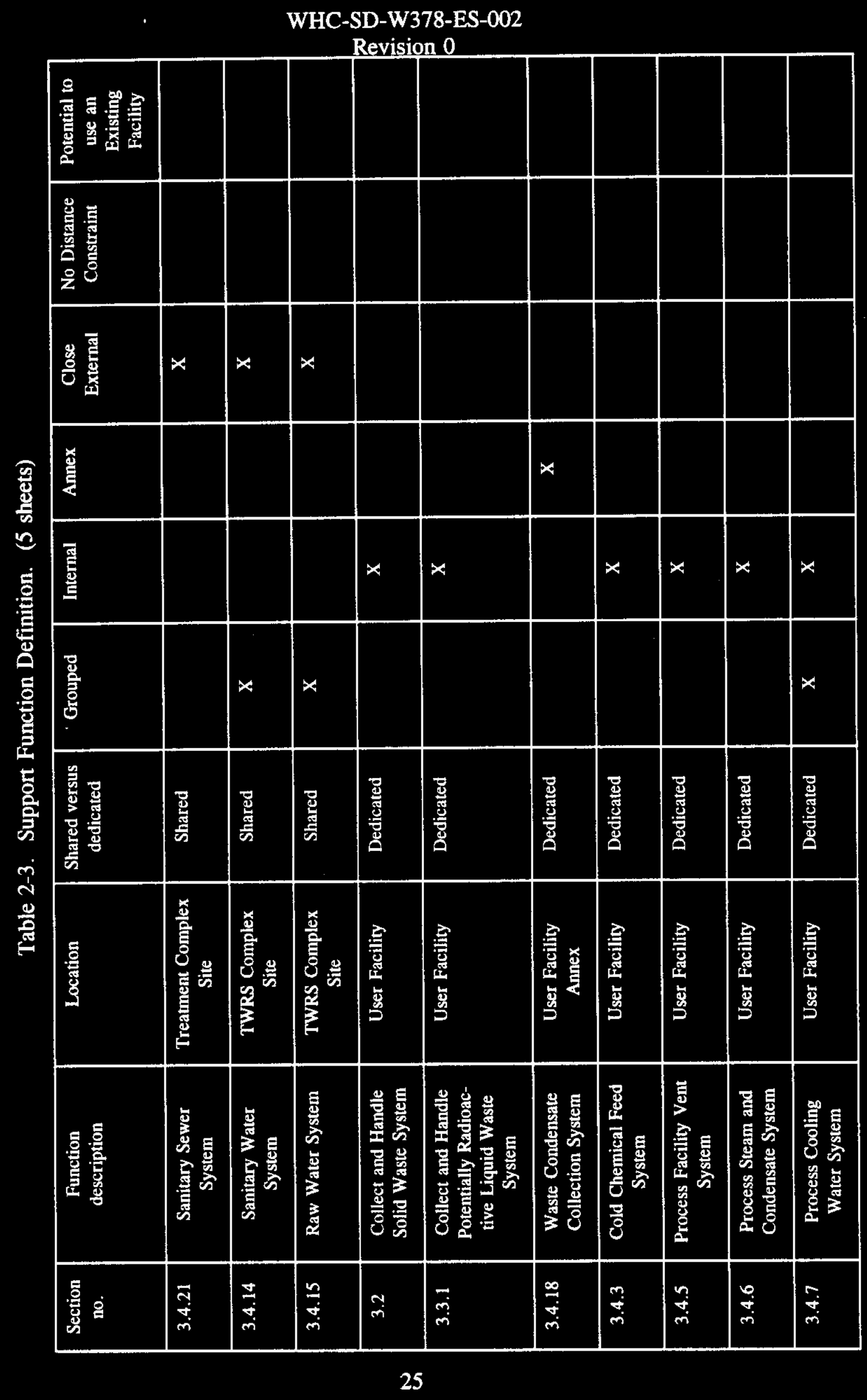


Table 2-3. Support Function Definition. (5 sheets)

\begin{tabular}{|c|c|c|c|c|c|c|c|c|c|}
\hline $\begin{array}{l}\text { Section } \\
\text { no. }\end{array}$ & $\begin{array}{l}\text { Function } \\
\text { description }\end{array}$ & Location & $\begin{array}{l}\text { Shared versus } \\
\text { dedicated }\end{array}$ & Grouped & Internal & Annex & $\begin{array}{l}\text { Close } \\
\text { External }\end{array}$ & $\begin{array}{l}\text { No Distance } \\
\text { Constraint }\end{array}$ & $\begin{array}{l}\text { Potential to } \\
\text { use an } \\
\text { Existing } \\
\text { Facility }\end{array}$ \\
\hline 3.4 .8 & $\begin{array}{l}\text { Melter Cooling Water } \\
\text { System }\end{array}$ & User Facility & Dedicated & $\mathbf{X}$ & $\mathbf{X}$ & & & & \\
\hline 3.4 .9 & $\begin{array}{c}\text { Process Chilled Water } \\
\text { System }\end{array}$ & User Facility & Dedicated & $\mathbf{x}$ & $\mathbf{X}$ & & & & \\
\hline 3.5 .3 & $\begin{array}{l}\text { Uninterruptible Power } \\
\text { Supply System }\end{array}$ & User Facility & Dedicated & & $\mathbf{X}$ & & & & \\
\hline 3.6 .3 & $\begin{array}{l}\text { Regulated Facility } \\
\text { Entry System }\end{array}$ & User Facility & Dedicated & & & $\mathrm{X}$ & & & \\
\hline 3.6 .4 & $\begin{array}{l}\text { Personnel Protection } \\
\text { System }\end{array}$ & User Facility & Dedicated & & $\mathrm{X}$ & & & & \\
\hline 3.7 .6 & $\begin{array}{l}\text { Maintenance and } \\
\text { Repair System } \\
\text { (MSM and other) }\end{array}$ & User Facility & Dedicated & & $\mathbf{x}$ & & & & \\
\hline 3.8 .1 & $\begin{array}{l}\text { Supply Air Treatment } \\
\text { System }\end{array}$ & $\begin{array}{c}\text { User Facility } \\
\text { (Proc Bldg Roof) }\end{array}$ & Dedicated & $\mathbf{x}$ & & $\mathbf{X}$ & & & \\
\hline 3.8 .2 & $\begin{array}{c}\text { Exhaust Air } \\
\text { Treatment System }\end{array}$ & $\begin{array}{l}\text { User Facility } \\
\text { (Fan/Filter Annex } \\
\text { and Proc Bldg } \\
\text { Roof) }\end{array}$ & Dedicated & $\begin{array}{c}\mathrm{X} \\
\text { (Zone II and } \\
\text { III Systems) }\end{array}$ & & $\mathbf{X}$ & & & \\
\hline 3.9 .2 & $\begin{array}{l}\text { Health Protection } \\
\text { System Vacuum } \\
\text { System }\end{array}$ & User Facility & Dedicated & & $\mathbf{X}$ & & & & \\
\hline
\end{tabular}


Table 2-3. Support Function Definition. (5 sheets)

\begin{tabular}{|c|c|c|c|c|c|c|c|c|c|}
\hline $\begin{array}{l}\text { Section } \\
\text { no. }\end{array}$ & $\begin{array}{l}\text { Function } \\
\text { description }\end{array}$ & Location & $\begin{array}{l}\text { Shared versus } \\
\text { dedicated }\end{array}$ & Grouped & Internal & Annex & $\begin{array}{l}\text { Close } \\
\text { External }\end{array}$ & $\begin{array}{c}\text { No Distance } \\
\text { Constraint }\end{array}$ & $\begin{array}{l}\text { Potential to } \\
\text { use an } \\
\text { Existing } \\
\text { Facility }\end{array}$ \\
\hline 3.7 .1 & $\begin{array}{l}\text { Shipping and } \\
\text { Receiving System }\end{array}$ & Warehouse & Shared & $\mathbf{x}$ & & & & $\mathrm{X}$ & $\mathbf{x}$ \\
\hline 3.7 .2 & $\begin{array}{l}\text { Warehousing and } \\
\text { Storage System }\end{array}$ & Warehouse & Shared & $\mathrm{x}$ & & & & $\mathrm{x}$ & $\mathbf{x}$ \\
\hline 3.7 .3 & $\begin{array}{c}\text { Storage and Service } \\
\text { Yard }\end{array}$ & Warehouse & Shared & $\mathbf{x}$ & & & & $\mathbf{X}$ & $\mathbf{X}$ \\
\hline 3.4 .12 & Process Water System & Water Pumphouse & Shared & $\mathrm{X}$ & & & & $\mathbf{x}$ & $\mathbf{x}$ \\
\hline 3.4 .16 & $\begin{array}{l}\text { TWRS Treatment } \\
\text { Complex Site Fire } \\
\text { Water System }\end{array}$ & $\begin{array}{c}\text { Water Pumphouse/ } \\
\text { TWRS Complex } \\
\text { Site }\end{array}$ & Shared & $\mathbf{X}$ & & & $\begin{array}{c}\text { X } \\
\text { (Under- } \\
\text { ground } \\
\text { Piping) }\end{array}$ & $\begin{array}{c}\text { X } \\
\text { (Pumps and } \\
\text { Stor Tank) }\end{array}$ & $\begin{array}{c}\text { X } \\
\text { (Pumps and } \\
\text { Stor Tank) }\end{array}$ \\
\hline 3.4 .17 & $\begin{array}{l}\text { Process Facility Fire } \\
\text { Water System }\end{array}$ & $\begin{array}{c}\text { Water Pumphouse } \\
\text { TWRS Complex } \\
\text { Site }\end{array}$ & Dedicated & $\mathbf{X}$ & & & $\begin{array}{c}\text { X } \\
\text { (Under- } \\
\text { ground } \\
\text { Piping) }\end{array}$ & $\begin{array}{c}\mathrm{X} \\
\text { (Pumps and } \\
\text { Stor Tank) }\end{array}$ & $\begin{array}{c}\text { X } \\
\text { (Pumps and } \\
\text { Stor Tank) }\end{array}$ \\
\hline
\end{tabular}

*Dedicated to the Bulk Cold Chemical Building. 
Table 2-4. Impacts to Function Configuration Due to Resolution of Outstanding Issues. (5 sheets)

Legend: S/D - Shared versus Dedicated It is understood that these variations would have impacts to both facility and site layouts, but not impact
G - Grouped/Not Grouped
the grouping of functions within facilities

C $\mathbf{t}$ - Capital Cost $U_{p}$

C $\downarrow$ - Capital Cost Down

\begin{tabular}{|c|c|c|c|c|c|c|}
\hline \multirow{2}{*}{$\begin{array}{c}\text { Sect. } \\
\text { no }\end{array}$} & \multirow{2}{*}{$\begin{array}{l}\text { Function } \\
\text { description }\end{array}$} & \multirow{2}{*}{$\begin{array}{c}\text { Type of func- } \\
\text { tion }\end{array}$} & \multicolumn{4}{|c|}{ Perturbations Considered } \\
\hline & & & Staged construction & Melter conversion & $\begin{array}{c}\text { Three separate process } \\
\text { facilities }\end{array}$ & Melter technology \\
\hline 3.1 & Sample Analysis & Dedicated & & $\begin{array}{c}\text { C } t \text {, substitution of a } \\
\text { HLW melter train for } \\
\text { a LLW melter train } \\
\text { will reduce the number } \\
\text { of process trains being } \\
\text { sampled }\end{array}$ & - & $\begin{array}{l}C+\text {, may impact the } \\
\text { number and types of } \\
\text { samples required }\end{array}$ \\
\hline 3.2 & $\begin{array}{c}\text { Collect and Handle Solid } \\
\text { Waste System }\end{array}$ & Dedicated & $\begin{array}{c}\text { S/D, C } \downarrow \text {, will share } \\
\text { solid waste handling } \\
\text { facilities }\end{array}$ & $\begin{array}{c}\text { S/D, C } \downarrow \text {, will share } \\
\text { solid waste handling } \\
\text { facilities }\end{array}$ & $\begin{array}{c}\text { C } 1 \text {, will require an } \\
\text { additional solid waste } \\
\text { handling facility }\end{array}$ & $\begin{array}{c}\mathrm{C} \uparrow \text {, will impact size } \\
\text { of solid waste handling } \\
\text { facilities }\end{array}$ \\
\hline 3.3 .1 & $\begin{array}{l}\text { Collect and Handle Poten- } \\
\text { tially Radioactive Liquid } \\
\text { Waste System }\end{array}$ & Dedicated & & & & \\
\hline 3.3 .2 & $\begin{array}{c}\text { Collect and Handle } \\
\text { Nonradioactive Liquid } \\
\text { Waste System }\end{array}$ & Shared & & & & \\
\hline 3.4 .4 & Cold Chemical Vent System & $\begin{array}{l}\text { Dedicated to } \\
\text { the Bulk } \\
\text { Cold } \\
\text { Chemical } \\
\text { Building }\end{array}$ & & & & \\
\hline 3.4 .5 & $\begin{array}{c}\text { Process Facility Vent } \\
\text { System }\end{array}$ & Dedicated & & & & \\
\hline
\end{tabular}


Table 2-4. Impacts to Function Configuration Due to Resolution of Outstanding Issues. (5 sheets)

Legend: S/D - Shared versus Dedicated It is understood that these variations would have impacts to both facility and site layouts, but not impact G - Grouped/Not Grouped the grouping of functions within facilities

C $\uparrow$ - Capital Cost Up

C $\downarrow$ - Capital Cost Down

\begin{tabular}{|c|c|c|c|c|c|c|}
\hline \multirow{2}{*}{$\begin{array}{c}\text { Sect. } \\
\text { no }\end{array}$} & \multirow{2}{*}{$\begin{array}{l}\text { Function } \\
\text { description }\end{array}$} & \multirow{2}{*}{$\begin{array}{l}\text { Type of func- } \\
\text { tion }\end{array}$} & \multicolumn{4}{|c|}{ Perturbations Considered } \\
\hline & & & Staged construction & Melter conversion & $\begin{array}{l}\text { Three separate process } \\
\text { facilities }\end{array}$ & Melter technology \\
\hline 3.4 .2 & $\begin{array}{l}\text { Cold Chemical Supply } \\
\text { System }\end{array}$ & Shared & & & & $\begin{array}{l}\mathrm{C} \uparrow \text {, will increase } \\
\text { types and quantities of } \\
\text { chemicals required }\end{array}$ \\
\hline 3.4 .3 & Cold Chemical Feed System & Dedicated & & & & $\begin{array}{l}C \uparrow, \text { will increase } \\
\text { types and quantities of } \\
\text { chemical required }\end{array}$ \\
\hline 3.4 .1 & Oxygen System & $\begin{array}{c}\text { Shared } \\
.\end{array}$ & & & & $\begin{array}{c}C \downarrow \text {, will decrease the } \\
\text { amount of oxygen } \\
\text { required }\end{array}$ \\
\hline 3.4 .6 & $\begin{array}{l}\text { Process Steam and } \\
\text { Condensate System }\end{array}$ & Dedicated & & $\begin{array}{c}\text { S/D, } C \downarrow, \text { will share } \\
\text { system }\end{array}$ & $\begin{array}{l}\mathrm{C} \uparrow \text {, will require an } \\
\text { additional system }\end{array}$ & $\begin{array}{c}C \downarrow, \text { will reduce size } \\
\text { of system }\end{array}$ \\
\hline 3.4 .10 & Utility Steam System & Shared & & $C \downarrow$, will share system & $\begin{array}{c}\mathrm{C} \uparrow \text {, will increase the size } \\
\text { of the system }\end{array}$ & \\
\hline 3.4 .12 & Process Water System & Shared & & $C \downarrow$, will share system & & \\
\hline 3.4.13 & $\begin{array}{c}\text { Demineralized Water } \\
\text { System }\end{array}$ & Shared & & $C \downarrow$, will share system & & \\
\hline 3.4.14 & Sanitary Water System & Shared & & & & \\
\hline 3.4 .15 & Raw Water System & Shared & & & & \\
\hline 3.4.16 & $\begin{array}{l}\text { TWRS Treatment Complex } \\
\text { Fire Water System }\end{array}$ & Shared & & & & \\
\hline
\end{tabular}




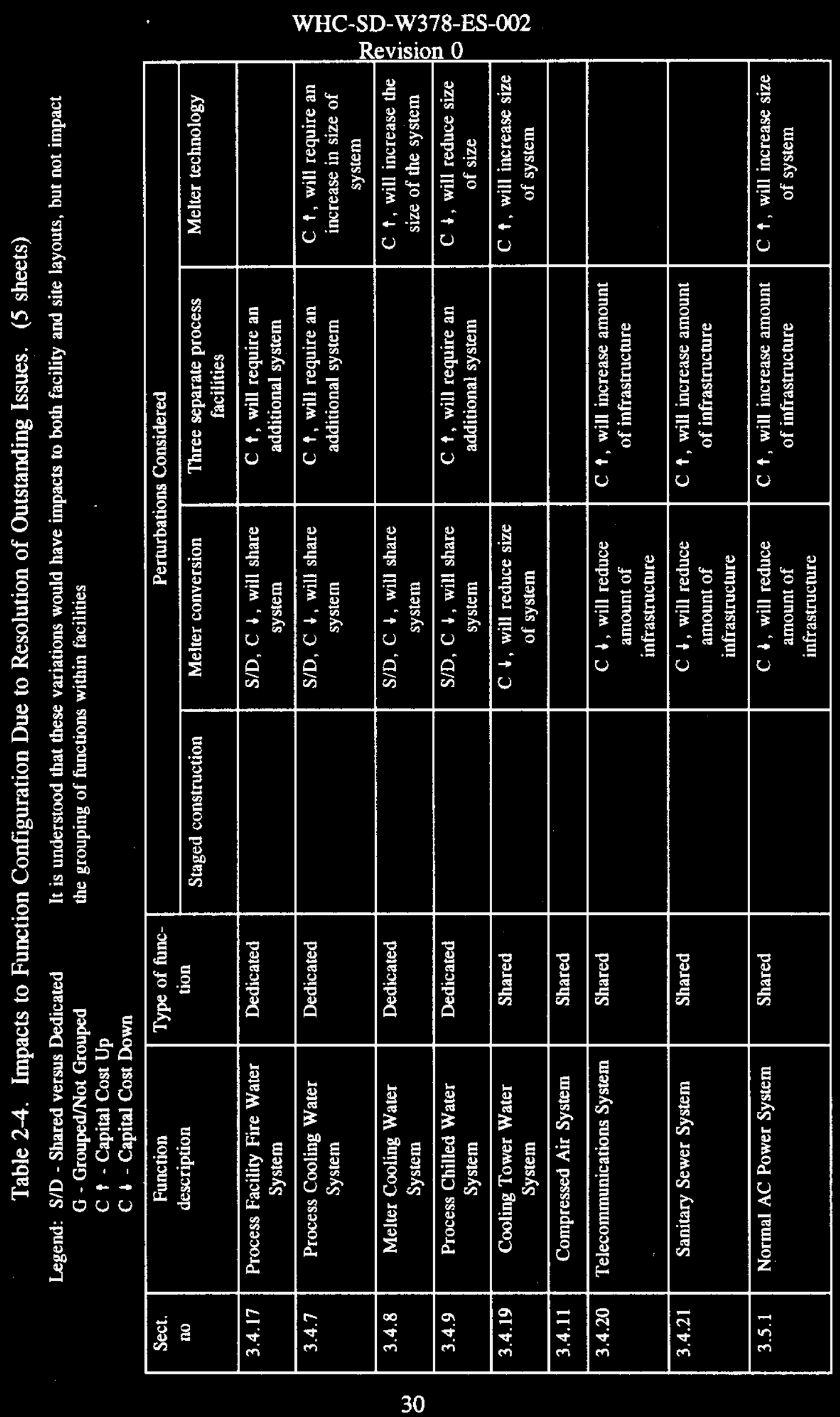




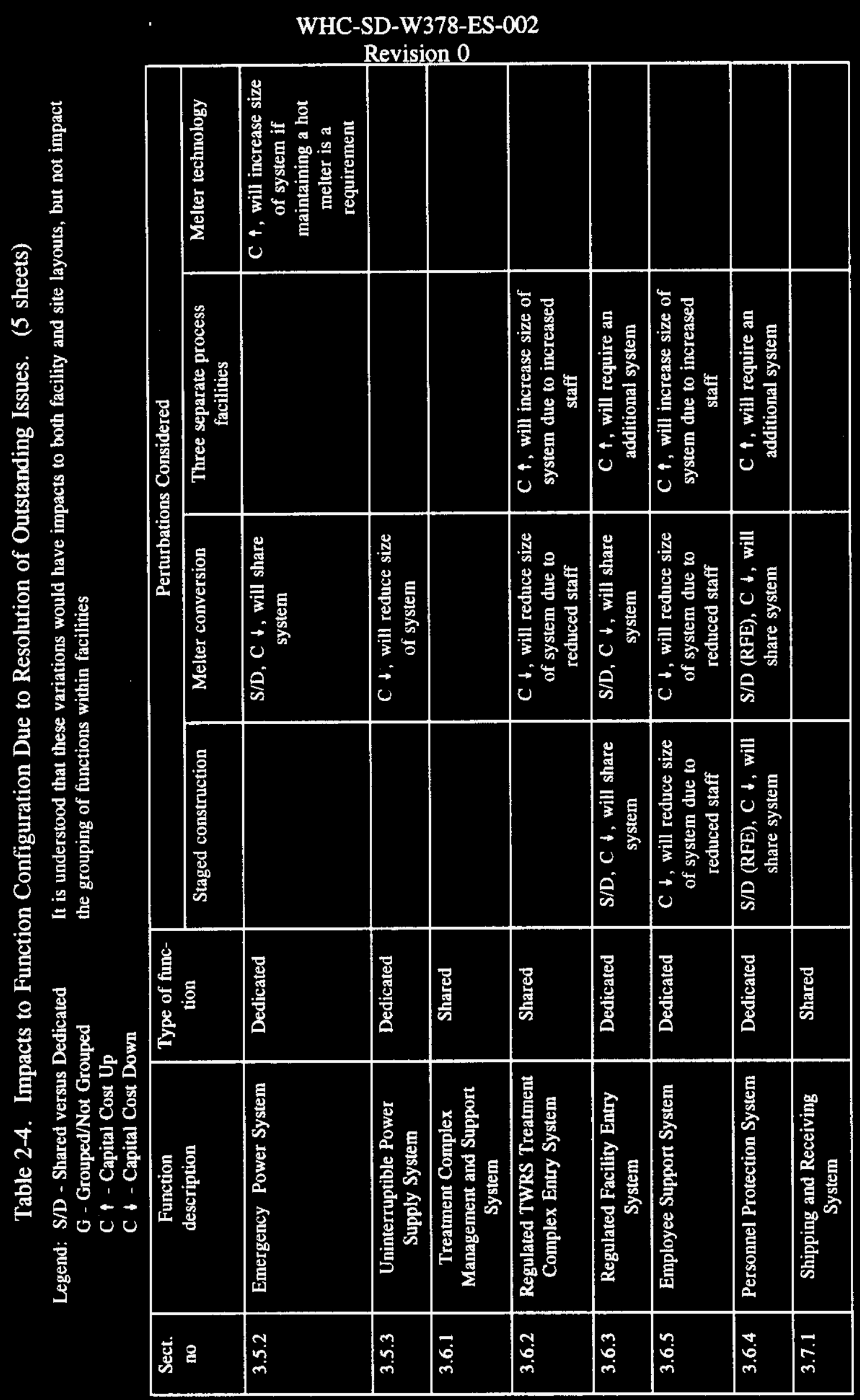


Table 2-4. Impacts to Function Configuration Due to Resolution of Outstanding Issues. (5 sheets)

Legend: S/D - Shared versus Dedicated G - Grouped/Not Grouped C $\mathbf{\uparrow}$ - Capital Cost Up

C $\downarrow$ - Capital Cost Down
It is understood that these variations would have impacts to both facility and site layouts, but not impact the grouping of functions within facilities

\begin{tabular}{|c|c|c|c|c|c|c|}
\hline \multirow{2}{*}{$\begin{array}{l}\text { Sect. } \\
\text { no }\end{array}$} & \multirow{2}{*}{$\begin{array}{l}\text { Function } \\
\text { description }\end{array}$} & \multirow{2}{*}{$\begin{array}{c}\text { Type of func- } \\
\text { tion }\end{array}$} & \multicolumn{4}{|c|}{ Perturbations Considered } \\
\hline & & & Staged construction & Melter conversion & $\begin{array}{l}\text { Three separate process } \\
\text { facilities }\end{array}$ & Melter technology \\
\hline 3.7 .2 & $\begin{array}{l}\text { Warehousing and Storage } \\
\text { System }\end{array}$ & Shared & & & & \\
\hline 3.7 .3 & Storage and Service Yard & Shared & & & & \\
\hline 3.7 .4 & Major Equip Assembly & Shared & & & & \\
\hline 3.7 .5 & Spare Parts Fabrication & Shared & & & & \\
\hline 3.7 .6 & $\begin{array}{c}\text { Maintenance and Repair } \\
\text { System }\end{array}$ & Dedicated & $\begin{array}{c}\text { S/D, C } \downarrow, \text { will share } \\
\text { system }\end{array}$ & $\begin{array}{c}\text { S/D, C } \downarrow, \text { will share } \\
\text { system }\end{array}$ & $\begin{array}{l}\mathrm{C} \uparrow \text {, will require an } \\
\text { additional system }\end{array}$ & \\
\hline 3.8 .1 & $\begin{array}{l}\text { Supply Air Treatment } \\
\text { System }\end{array}$ & Dedicated & & $\begin{array}{c}\text { S/D, C } \downarrow, \text { will share } \\
\text { sysțem }\end{array}$ & $\begin{array}{l}\mathrm{C} \uparrow \text {, will require an } \\
\text { additional system }\end{array}$ & \\
\hline 3.8 .2 & $\begin{array}{c}\text { Exhaust Air Treatment } \\
\text { System }\end{array}$ & Dedicated & $\begin{array}{c}\mathrm{C} \downarrow \text { will share } \\
\text { system }\end{array}$ & $\begin{array}{c}\text { S/D, C } \downarrow \text {, will share } \\
\text { system }\end{array}$ & $\begin{array}{l}\mathrm{C} \uparrow \text {, will require an } \\
\text { additional system }\end{array}$ & \\
\hline 3.8 .3 & $\begin{array}{c}\text { HVAC Chilled Water } \\
\text { System }\end{array}$ & Shared & & $\begin{array}{l}\mathrm{C} \downarrow \text {, will reduce size } \\
\text { of system }\end{array}$ & $\begin{array}{c}\mathrm{C} \uparrow, \text { will increase size of } \\
\text { system }\end{array}$ & \\
\hline 3.4 .18 & $\begin{array}{l}\text { Waste Condensate } \\
\text { Collection System }\end{array}$ & Dedicated & & & $\begin{array}{l}\mathrm{C} \uparrow \text {, will require an } \\
\text { additional system }\end{array}$ & \\
\hline 3.9 .1 & $\begin{array}{l}\text { Process Facility Oper } \\
\text { Control System }\end{array}$ & Dedicated & & $\begin{array}{l}C \downarrow, \text { will reduce size } \\
\text { of system }\end{array}$ & $\begin{array}{c}\mathrm{C} \uparrow, \text { will increase size of } \\
\text { system }\end{array}$ & \\
\hline 3.9 .2 & $\begin{array}{c}\text { Health Protection System } \\
\text { Vacuum System }\end{array}$ & Dedicated & & C $\downarrow$, will share system & $\begin{array}{c}\mathbf{C} \mathfrak{\uparrow} \text {, will increase size of } \\
\text { system }\end{array}$ & \\
\hline
\end{tabular}


Table 2-5. Support Facility Capital Cost Basis. (2 sheets)

\begin{tabular}{|c|c|c|c|c|c|c|c|}
\hline Facility/building & Area $\left(m^{2}\right)$ & $\begin{array}{c}\text { Volume } \\
\left(\mathrm{m}^{3}\right)\end{array}$ & $\begin{array}{l}\text { Direct cost } \\
(\$ \mathbf{M})\end{array}$ & $\begin{array}{c}\text { Eng/PM/CM } \\
(\$ M)\end{array}$ & $\begin{array}{l}\text { Subtotal } \\
\text { (\$ M) }\end{array}$ & $\begin{array}{l}\text { Contingency } \\
\text { total }^{4}(\$ \mathrm{M})\end{array}$ & $\begin{array}{l}\text { TEC total } \\
\quad(\$ M)\end{array}$ \\
\hline Regulated TWRS Complex Entry (Structure) & 5,580 & 28,400 & $9,613.0$ & $6,248.5$ & 15,862 & 6,345 & 22,207 \\
\hline Regulated TWRS Complex Entry (Other) & $\mathbf{N} / \mathbf{A}$ & N/A & $1,532.0$ & 995.8 & 2,528 & 1,011 & 3,539 \\
\hline Operation Support Bldg (Structure) & 6,510 & 30,800 & $9,929.0$ & $6,453.9$ & 16,383 & 6,553 & 22,936 \\
\hline Operation Support Bldg (Other) & N/A & N/A & 53.0 & 34.5 & 88 & 35 & 123 \\
\hline Emergency Response Center (Structure) & 1,880 & 11,340 & $4,467.0$ & $2,903.6$ & 7,371 & 2,948 & 10,319 \\
\hline Emergency Response Center (Other) & N/A & N/A & $1,802.0$ & $1,171.3$ & 2,973 & 1,189 & 4,162 \\
\hline Bulk Cold Chemical Bldg (Structure) & 1,680 & 22,350 & $3,111.0$ & $2,021.5$ & 5,133 & 2,053 & 7,186 \\
\hline Bulk Cold Chemical Bldg (Other) & N/A & N/A & $8,713.0$ & $5,663.5$ & 14,377 & 5,751 & 20,128 \\
\hline Bulk Handling Area (Pad and Berms) & N/A & N/A & 459.0 & 298.4 & 757 & 303 & 1,060 \\
\hline Bulk Handling Area (Other) & $\mathbf{N} / \mathbf{A}$ & N/A & $9,922.0$ & $6,453.9$ & $\begin{array}{r}16,371 . \\
3\end{array}$ & $\begin{array}{r}6,548 \\
5\end{array}$ & $\begin{array}{r}22,919 . \\
8\end{array}$ \\
\hline Mechanical Utilities Bldg (Structure) & 3,000 & 23,730 & $3,822.0$ & $2,484.3$ & 6,306 & 2,522 & 8,828 \\
\hline Mechanical Utilities Bldg (Other) & N/A & N/A & $11,261.0$ & $7,319.7$ & 18,581 & 7,432 & 26,013 \\
\hline Water Pumphouse (Structure) & 760 & 4,670 & $1,032.0$ & 670.8 & 1,703 & 681 & 2,384 \\
\hline Water Pumphouse (Other) & N/A & $\mathbf{N} / \mathbf{A}$ & $4,787.0$ & $3,111.6$ & 7,899 & 3,160 & 11,059 \\
\hline Analytical Facility (Structure) & 7,160 & 31,750 & $18,318.0$ & $11,906.7$ & 30,225 & 12,090 & 42,315 \\
\hline Analytical Facility (Other) & N/A & N/A & $59,401.0$ & $38,610.7$ & 98,012 & 39,205 & 137,217 \\
\hline Switchgear Bldg (Structure) & 1,080 & 7,000 & $1,668.0$ & $1,084.2$ & 2,752 & 1,101 & 3,853 \\
\hline Switchgear Bldg (Other) & N/A & N/A & $7,702.0$ & $5,006.3$ & 12,708 & 5,083 & 17,791 \\
\hline
\end{tabular}




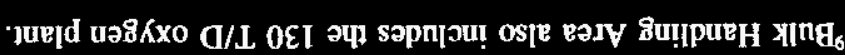

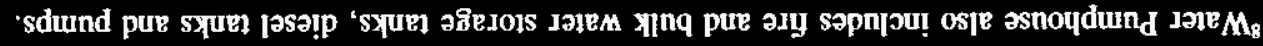

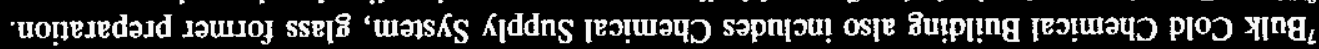

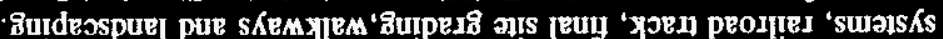

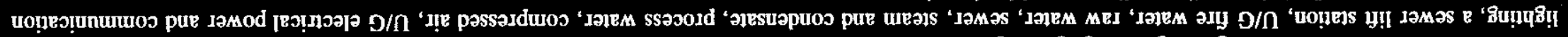

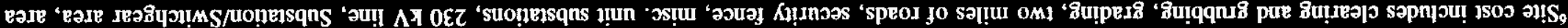

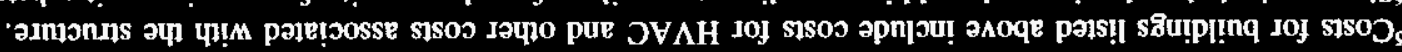

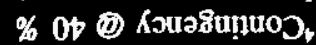

WD + 8ug +1500 10อI! jo \%0I (Wd)

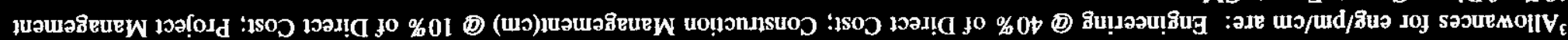
papniara st sptonues iselord on totiejeasg,

suefop b66I u! passejdxe are saj! $\mathbf{d}_{1}$

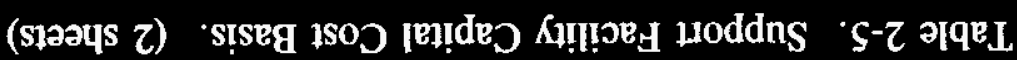


Table 2-6. Alternate Support Facility Capital Cost Differential.

\begin{tabular}{|c|c|c|c|c|c|c|c|}
\hline Facility/building & $\begin{array}{l}\text { Base case } \\
\text { direct cost } \\
(\$ \mathrm{M})\end{array}$ & $\begin{array}{l}\text { Alt case } \\
\text { direct cost } \\
(\$ M)\end{array}$ & $\begin{array}{l}\text { Direct cost } \\
\text { differential } \\
(\$ \mathrm{M})\end{array}$ & $\begin{array}{c}\text { Eng/PM/CM }{ }^{3} \\
(\$ \mathrm{M})\end{array}$ & $\begin{array}{c}\text { Subtotal } \\
(\$ M)\end{array}$ & $\begin{array}{c}\text { Contingency } \\
\text { total }^{4} \\
(\$ \mathrm{M})\end{array}$ & $\begin{array}{c}\text { TEC delta cost } \\
\text { total } \\
(\$ \mathrm{M})\end{array}$ \\
\hline $\begin{array}{l}\text { Bulk Cold Chemical Bldg } \\
\text { (Structure and Equip) }\end{array}$ & $11,823.0$ & $17,832.0$ & 6,009 & 3,906 & 9,915 & 3,966 & 13,881 \\
\hline Bulk Handling Area & $10,381.0$ & $12,328.8$ & 1,948 & 1,266 & 3,214 & 1,286 & 4,500 \\
\hline Mechanical Utilities Bldg & $15,083.0$ & $24,609.0$ & 9,526 & 6,192 & 15,718 & 6,287 & 22,005 \\
\hline Analytical Facility & $77,719.0$ & $82,193.0$ & 4,474 & 2,908 & 7,382 & 2,953 & 10,335 \\
\hline Cooling Tower & $5,381.0$ & $6,549.0$ & 1,168 & 759 & 1,927 & 771 & 2,698 \\
\hline Total Support Facility Costs & 120,387 & 143,512 & 23,125 & 15,031 & 38,156 & 15,263 & 53,419 \\
\hline \multicolumn{8}{|c|}{ Base case capital costs included in process facility costs; however, alternate facility costs would impact overall facility costs. } \\
\hline \multirow{4}{*}{ 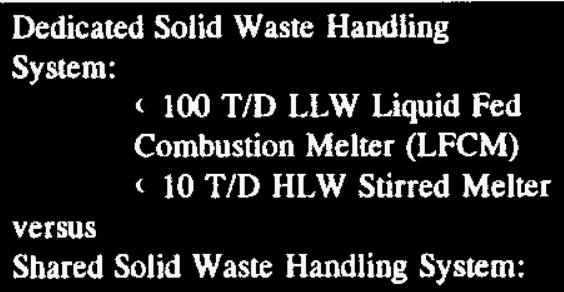 } & & & & & & & \\
\hline & $9,768.0$ & & & & & & \\
\hline & $4,829.0$ & & & & & & \\
\hline & & $30,524.0$ & & & & & \\
\hline Total Solid Waste Facility Costs & 14,597 & 30,524 & 15,927 & 10,353 & 26,280 & 10,512 & 36,792 \\
\hline Total & 134,984 & 174,036 & 39,052 & 25,384 & 64,436 & 25,775 & 90,211 \\
\hline
\end{tabular}

1. Prices are expressed in 1994 dollars.

2. Escalation to project centroids is excluded.

3. Allowances for ENG/PM/CM are: Engineering @ $40 \%$ of Direct Cost; Construction Management(cm)@ 10\% of Direct Cost; Project Management (PM) 10 10\% of Direct Cost + Eng + CM.

4. Contingency@ $40 \%$. 


\section{WHC-SD-W378-ES-002}

Revision 0

Figure 2-1, TWRS Treatment Complex Site Plan, depicts the configuration of the overall site incorporating the findings and conclusions of this report. 


\subsection{DESCRIPTION AND EVALUATION OF SUPPORT FUNCTIONS}

This section addresses each function required to support the TWRS Treatment Complex process mission. A narrative discussion is provided for each identified support function. This discussion will provide a brief description of the system providing the function, a summary of the findings, and a brief discussion of the considerations and rationale used to define the system.

The System Description will describe the system, identify who it serves, and where it is located. The Findings portion provides a definition for the system's configuration, identifies the primary considerations that drove the configuration, identifies if the system is grouped with other systems, identifies which systems it is grouped with, and identifies if it is a candidate for being provided from an existing Hanford facility. The Function Configuration Considerations and Rationale address the impact of the Evaluation Criteria identified in Section 1.4 on the configuration of the system. The primary drivers are identified and discussed as well as any other considerations or rationale that was used to develop the definition of the configuration.

\subsection{SAMPLE ANALYSIS}

\subsubsection{System Description}

The Sample Analysis function analyzes all of the solid, liquid and gas samples collected within the Separations, LLW, HLW, and support functions. The sample and analytical lab equipment for each mission is considered to be dedicated. Support elements for sample and analytical systems, where practical, are considered to be shared. The following Sample Analysis functions occur within the Analytical Facility (AF):

- Process control, including process diagnosis and history

- Waste form qualification

- Process gas, waste, wastewater, and environmental sample analysis

- Examination of smear test samples.

The samples are taken in the Separations/LLW process facility and the HLW process facility. The samples are transferred to the AF with a pneumatic rabbit system. A sample tracking system records the analytical requirements and results for each sample. The $\mathbf{A F}$ contains analytical cells where undiluted, high radiological activity samples are remotely handled. Sample preparation, dilution, and limited sample analysis occurs in analytical cells. Diluted and/or low radiological activity samples are analyzed in analytical laboratories. Analyzers within the laboratories are located in hoods to contain radioactivity. Other rooms within the AF include service rooms, receiving rooms, counting rooms, equipment and stock 
rooms, solid waste handling areas, and analytical instrument rooms. Radiological liquid wastes are collected in catch tanks located in the AF basement.

The sample analysis function is required to provide waste form qualification. The waste form qualification for the Separations/LLW facility is assumed to be product qualification. Product qualification requires statistically significant sampling and analysis of the product glass. Any glass that does not meet requirements is recycled. Process qualification with limited product qualification is the assumed basis for HLW waste form qualification. Process qualification requires sampling and analyzing the melter feed and comparing the results to reference compositions that were previously identified. Feed characterization, melter feed envelop determination, equipment qualification and process parameter control are also required for process qualification.

Development of the requirements for the Sample Analysis function has substantially profited from the design of the Hanford Waste Vitrification Plant (HWVP) analytical function. As such, it incorporates the many lessons learned at the Defense Waste Process Facilities (DWPF).

Other Sample Analysis functions occur outside of the AF. On-line stream analysis occurs within the Separations/LLW and HLW facilities to obtain accurate analysis. Radiological protection (ALARA) is an equal concern. Finally, the Bulk Cold Chemical Building (BCCB) contains a dedicated area for bulk cold chemical quality assurance. Analysis of bulk cold chemical samples does not require radiological protection.

See Appendices $\mathrm{H} 1$ and $\mathrm{H} 2$ for further definition of the AF Sample Analysis function and sample schedules.

\subsubsection{Findings}

The Sample Analysis function is a dedicated, close-external function. Operability (practicality of design) is the prime consideration for the configuration of the Sample Analysis function. Master-Slave Manipulator (MSM) repair that is dedicated to the Sample Analysis function is also located in the AF. The Sample Analysis function is not a candidate for location in existing Hanford Site facilities.

\subsubsection{Functional Configuration Considerations and Rationale}

Operability (practicality of design) is the prime consideration for the Sample Analysis function configuration. Due to the number of samples scheduled for analysis and the time constraints for continuous operation, each process facility requires its own dedicated set of analytical equipment. Dedicated analytical equipment for the Separations function, the LLW treatment function, and the HLW treatment function affords independent operation of the process facilities. Therefore, due to operability (practicality of design) this function is 
dedicated. The possibility for some of the analytical equipment to be shared has not been determined yet. Further time-motion studies are required to make this determination.

The Sample Analysis function is close-coupled to the Separations/LLW and HLW process facilities. The AF is physically located near the process facilities inside a common complex. The AF is 200 feet (at the closest point) from the Separations/LLW process facility and 600 feet (at the closest point) from the HLW process facility. The sample analysis functions support operating facilities under a common management. The Remote Analytical Laboratory (RAL) at the Idaho Chemical Processing Plant is an example of combining facilities to better utilize staffing equipment and space. The pneumatic rabbit system is proven technology for fast, accurate sample transport. A pneumatic rabbit system at the Idaho National Engineering Lab (INEL) Chemical Processing Plant successfully connects three facilities, which are the 601 Building reprocessing plant, the New Waste Calcine Facility, and the Fluorinel and Storage Facility, to the Remote Analytical Lab. Pneumatic rabbit systems have also been used successfully at other nuclear facilities (e.g., Pamela and Sellafield).

The use of existing Hanford site laboratories, such as $222-\mathrm{S}$ or 325 labs, has been considered. Neither of these labs would be close-coupled to the Separations/LLW or HLW process facilities. Sample transport via truck would be slow. Finally, analytical samples from these facilities would probably not receive the priority required to meet facility TOE objectives.

Even though the Sample Analysis function is defined as dedicated, it is collocated in the AF. Cost and operability are the prime considerations for collocating this equipment in the AF. Collocation of the Sample Analysis function in the AF allows the AF to contain all of the functions required of an analytical facility. This is discussed in further detail in the AF section.

Other considerations that were evaluated and found not to be contributors to the function configuration are noted below:

Radiological Protection (ALARA). This study has not identified any radiological protection (ALARA) issues that are unique to the configurations considered for this system. Therefore, radiological protection (ALARA) is not a consideration that was used to determine the configuration of this system.

Safety. This study has not identified any safety issues that are unique to any single configuration considered for this system. Therefore, safety is not a consideration that was used to determine the configuration of this system.

Environmental Regulatory Compliance. This study has not identified any environmental regulatory compliance issues that are unique to any single configuration considered for this system. Therefore, environmental regulatory compliance is not a consideration that was used to determine the configuration of this system. This 
analysis has not taken into account the possibility that each facility will require a permit, however, this will not impact our conclusions at this time.

Schedule. The configuration of this system does not impact the schedule for the design, construction, or startup of the TWRS Treatment Complex.

Technical Maturity. Commercially demonstrated technology is used in the design of this system. Therefore, Technology issues were not a consideration for the configuration of this system.

Design Impact. This study has not identified any design impact issues that are unique to any single configuration considered for this system. Therefore, design impact is not a consideration that was used to determine the configuration of this system.

Note: Technical disagreement with these conclusions surfaced in the peer review process. One dissenting position is that the LLW processing function would be penalized by the attempt to integrate HLW requirements in the design of the Analytical Facility due to diverse needs and schedules. In addition, this same source of dissention contends that the present equipment and layout for LLW processing analytical functions are overly designed, causing the implied savings for a combined function to be overstated.

\subsection{COLLECT AND HANDLE SOLID WASTE SYSTEM}

\subsubsection{System Description}

The Collect and Handle Solid Waste System collects, surveys, segregates, decontaminates and packages solid waste (failed, used, or spent equipment and materials) generated from within the TWRS Treatment Complex process facilities. This system consists of the facilities and equipment required to collect, survey, segregate, decontaminate, package, assay, and temporarily store solid wastes. This system is located within the TWRS process facilities and provides for temporary storage for eight weeks worth of solid wastes.

Solid wastes are segregated into radioactive and nonradioactive wastes. Radioactive wastes will be further segregated into the following ten categories as defined in Hanford Site Solid Waste Acceptance Criteria, WHC-EP-0063:

- $\quad$ High-Level Waste (HLW)

, Transuranic Waste (TRU)

, Low-Level Waste, Category 1 (LLW) 
WHC-SD-W378-ES-002

Revision 0

- Low-Level Waste, Category 3

- Low-Level Waste, Greater than Category 3

- Radioactive Mixed Waste Components (RMW) of each of the above five categories.

Solid wastes will be disassembled and packaged in accordance with WHC-EP-0063. Packaged wastes will be decontaminated and assayed to determine the isotope content before shipment to the Treatment, Storage, and Disposal (TSD) facility. The overall system will be designed to prevent the spread of contamination and maintain the waste handling operator's station as a Radiation Zone 1 area.

It is assumed that this system will package solid wastes into $200-\mathrm{L}$ (55-gal) drums and must be able to handle and safely dispose of a failed melter full of glass. The system will be able to accommodate larger packages required for certain wastes (such as the melter), which cannot be cut-up to fit within the $200-\mathrm{L}$ drums.

\subsubsection{Findings}

The Collect and Handle Solid Waste System is a dedicated internal system. Cost efficiency, Radiological Protection (ALARA), and Safety are the prime considerations used to define this system.

\subsubsection{Functional Configuration Considerations and Rationale}

Cost Efficiency, Radiological Protection (ALARA), and Safety are the prime considerations for defining the Collect and Handle Solid Waste System. Solid wastes are potentially radiologically contaminated. Therefore appropriate measures must be taken to provide radiological protection for personnel involved in the cut-up, decon, and packaging of solid wastes. With respect to Safety, accidents occurring during the transportation of radiologically contaminated solid wastes to a shared facility, outside the process facilities, could cause the spread of contamination to other areas on the site. Therefore locating dedicated systems within each process facility provides radiological protection for the operators and limits the risk for spread of contamination.

With an appropriate design the radiological and safety considerations associated with an independent, shared, solid waste handling facility can be overcome. However, it would not seem cost effective to do so. To validate this assumption an estimate of the cost for a single shared facility verses two dedicated internal systems including facility cost was developed. The results indicate that the TEC of a single shared facility is $\$ 70,510,000$ and the TEC of two dedicated internal facilities is $\$ 33,719,000$, thereby providing a $\$ 36,791,000$ cost advantage. 
Other considerations that were evaluated and found not to be contributors to the function configuration are noted below:

Operability and Maintainability. This study has not identified any Operability or Maintainability issues that are unique to any single configuration considered for this system. Therefore, Operability and Maintainability are not considerations that were used to determine the configuration of this system.

Environmental Regulatory Compliance. Assuming that RCRA type dangerous wastes regulated by WAC 173-303 will be collected and handled by this system, each facility will require permitting under this regulation. This is not considered to be a significant issue, therefore, Environmental Regulatory Compliance is not a consideration that was used to determine the configuration of this system.

Schedule. The configuration of this system does not impact the schedule for the design, construction, or startup of the TWRS Treatment Complex.

Technical Maturity. Commercially demonstrated technology is used in the design of this system. Therefore, Technology issues were not a consideration for the configuration of this system.

Design Impact. This study has not identified any Design Impact issues that are unique to any single configuration considered for this system. Therefore, Design Impact is not a consideration that was used to determine the configuration of this system.

\subsection{COLLECT AND HANDLE LIQUID WASTE}

\subsubsection{Collect and Handle Potentially Radioactive Liquid Waste System}

3.3.1.1 System Description. The Collect and Handle Potentially Radioactive Liquid Waste System collects and accumulates liquid waste from potentially contaminated areas in both the HLW facility and the Separations/LLW facility. This liquid waste is generated as a part of normal facility operations. Under normal/desirable circumstances the liquid waste is not contaminated. However, due to the fact that the liquid waste is collected from process support areas within the process facility, contamination is possible.

The drain catch tanks and collection headers are designed to segregate incompatible chemical solutions for subsequent treatment and disposal. The Floor Drain Catch Tank and Regulated Drains Catch Tank collect waste water from regulated areas (areas where the entrance and exit are regulated). Liquid wastes from floor and area washdown of regulated areas are collected in floor drains and sent to the Floor Drain Catch Tank. Personnel decontamination wash water and regulated floor drain effluent from the Regulated Facility 
Entrance is sent to the Regulated Drains Catch Tank. The liquid waste from these tanks is pumped into the Floor Drain Sampling Tank for analysis. A separate tank is used for analysis to eliminate the possibility of contamination during the analysis period. If the analyses show the tank contents to be radioactive, the liquid waste is transferred to a radioactive process waste collection tank for processing. Otherwise, the liquid waste is transferred to the nonradioactive waste collection tanks for treatment and disposal.

The Organic Acid Drain Catch Tank and Acid Drain Catch Tank collect waste water from nonregulated areas. Liquid wastes that have low $\mathrm{pH}$ are collected by the acid drains and sent to the Acid Drain Catch Tank. Organic acids and organic liquid wastes are collected by the organic acid drains and sent to the Organic Acid Drain Catch Tank. The liquid waste stored in these tanks is analyzed for radioactivity. If the analyses show the tank contents to be radioactive, the liquid waste is transferred to a radioactive process waste collection tank for processing. Otherwise, the liquid waste is transferred to the nonradioactive waste collection tanks for treatment and disposal.

This system is designed for collection and analysis only. No treatment of waste is performed.

The system includes drain catch tanks, sumps, transfer pumps, collection headers and piping. Liquid wastes from floor washdown drains, tank overflow piping, tank drain lines, closed-loop cooling water blowdown and personnel decontamination drains are collected by gravity flow into the drain catch tanks located on the tunnel level of each of the process facilities. The HLW facility and the Separations/LLW facility each have their own, dedicated systems to collect and process potentially contaminated liquid wastes.

See page A-2 of Appendix A for the Block Flow Diagram of this system. Drawing UFD-4-01 is a Utility Flow Diagram (see Appendix B) for the Collect and Handle Potentially Radioactive Liquid Wastes System.

3.3.1.2 Findings. The Collect and Handle Potentially Radioactive Liquid Waste System is a dedicated internal system. Radiological Protection (ALARA) is the prime configuration consideration for this system. This function is located in each of the process facilities for radiological protection.

3.3.1.3 Function Configuration Considerations and Rationale. Radiological Protection (ALARA) is the prime consideration for the Collect and Handle Potentially Radioactive Liquid Wastes System configuration. This is a dedicated, internal system. This system provides intermediate holding and analysis of liquid waste generated in potentially contaminated areas. The system may contain radiological materials and, therefore, radiological protection must be provided. This system must be located as close as possible to where the wastes originate. Since the main process facilities also provide radiological protection, they can provide the shielding required for this system. A dedicated system allows the liquid waste from the individual facilities to be sampled and characterized before it is transferred to the treatment facility. 
Other considerations that were evaluated and found not to be contributors to the function configuration are noted below:

Operability and Maintainability. This study has not identified any Operability or Maintainability issues that are unique to any single configuration considered for this system. Therefore, Operability and Maintainability are not considerations that were used to determine the configuration of this system.

Cost Effectiveness. This study has not identified any cost drivers that would override the technical considerations used to define the configuration of this system.

Therefore, Cost Effectiveness is not a consideration that was used to determine the configuration of this system.

Safety. This study has not identified any Safety issues that are unique to any single configuration considered for this system. Therefore, Safety is not a consideration that was used to determine the configuration of this system.

Environmental Regulatory Compliance. This system is designed to handle RCRA type dangerous wastes regulated by WAC 173-303, and each facility within this system will be permitted under this regulation. This is not considered to be a significant issue; therefore, Environmental Regulatory Compliance is not a consideration that was used to determine the configuration of this system.

Schedule. The configuration of this system does not impact the schedule for the design, construction, or startup of the TWRS Treatment Complex.

Technical Maturity. Commercially demonstrated technology is used in the design of this system. Therefore, Technology issues were not a consideration for the configuration of this system.

Design Impact. This study has not identified any Design Impact issues that are unique to any single configuration considered for this system. Therefore, Design Impact is not a consideration that was used to determine the configuration of this system.

\subsubsection{Collect and Handle Nonradioactive Liquid Waste System}

3.3.2.1 System Description. The Collect and Handle Nonradioactive Liquid Waste System collects, receives, stores, neutralizes, and disposes of all nonradioactive liquid waste from sources outside of the process facilities and from the Collect and Handle Potentially Radioactive Liquid Waste System within the process facilities in a safe and environmentally acceptable manner. This system, which is located in the BCCB, includes hold tanks, neutralization tanks, sumps and pumps. The Effluent Discharge Collection Sump, located in 
the MUB, and the Water Pumphouse (WPH) Sump, located in the WPH, also are part of this system.

Chemically contaminated liquid wastes are collected and neutralized. Incompatible chemicals are collected separately, to prevent them from mixing. Cooling Tower blowdown and waste water from the Mechanical Utilities Building (MUB) and the WPH are collected in the Effluent Discharge Collection Sump that is located in the MUB. The Effluent Discharge Collection Sump's contents do not require any treatment. All nonradioactive liquid wastes are transferred to the 200 Area TEDF.

The caustic waste and acid waste collection and neutralization tanks are located in the BCCB. These tanks collect area washdown water and chemical spills from the Process Facilities and the BCCB. The liquid waste from the process facilities is routed through the Collect and Handle Potentially Radioactive Liquid Wastes System. The liquid waste is analyzed and ascertained to be nonradioactive before transfer to this system. From here it is transferred directly to the 200 Area TEDF.

See page A-3 of Appendix A for the Block Flow Diagram of this system. Drawing UFD-4-02 is a Utility Flow Diagram (see Appendix B) for the Collect and Handle Nonradioactive Liquid Wastes System.

3.3.1.2 Findings. The Collect and Handle Nonradioactive Liquid Waste System is a shared, close-external system. Cost effectiveness is the prime consideration for the configuration of this system. The hold tanks, neutralization tanks, sumps, and pumps are shared, to take advantage of the economies of scale. This system, except for the WPH Sump and the Effluent Discharge Collection Sump, is grouped with the Cold Chemical Supply System in the BCCB.

3.3.1.3 Function Configuration Considerations and Rationale. Cost Effectiveness is the prime consideration for the Collect and Handle Nonradioactive Liquid Wastes System configuration. The shared facility would consist of a single set of equipment for this system housed in a single facility (with the exception of the Effluent Discharge Sump and the WPH Sump that are located in the MUB and WPH). Because this equipment is common to all of the facilities, the space required for the equipment, and the equipment costs, are also reduced. Two, separate, dedicated systems would require two facilities and two sets of equipment, thereby losing the advantage of the economies of scale. The total engineered cost of a shared Collect and Handle Nonradioactive Liquid Wastes System would be $\$ 3,287,000$.

The total engineered cost of two dedicated systems for the Separations/LLW and HLW facilities would be $\$ 4,274,000$. The shared configuration, which has a single set of equipment, would cost less than dedicated systems with duplicate equipment.

Costs given here represent the mechanical equipment costs and specifically exclude the costs of the building to house the equipment. 


\section{Revision 0}

Other considerations that were evaluated and found not to be contributors to the function configuration are noted below:

Operability and Maintainability. This study has not identified any Operability or Maintainability issues that are unique to any single configuration considered for this system. Therefore, Operability and Maintainability are not considerations that were used to determine the configuration of this system.

Radiological Protection (ALARA). This study has not identified any Radiological Protection (ALARA) issues that are unique to any single configuration considered for this system. Therefore, Radiological Protection (ALARA) is not a consideration that was used to determine the configuration of this system.

Safety. This study has not identified any Safety issues that are unique to any single configuration considered for this system. Therefore, Safety is not a consideration that was used to determine the configuration of this system.

Environmental Regulatory Compliance. This system is designed to handle RCRA type dangerous wastes regulated by WAC 173-303, and each facility within this system will be permitted under this regulation. This is not considered to be a significant issue, therefore, Environmental Regulatory Compliance is not a consideration that was used to determine the configuration of this system.

Schedule. The configuration of this system does not impact the schedule for the design, construction, or startup of the TWRS Treatment Complex.

Technical Maturity. Commercially demonstrated technology is used in the design of this system. Therefore, Technology issues were not a consideration for the configuration of this system.

Design Impact. This study has not identified any Design Impact issues that are unique to any single configuration considered for this system. Therefore, Design Impact is not a consideration that was used to determine the configuration of this system.

\subsection{PROCESS SUPPORT}

\subsubsection{Oxygen System}

3.4.1.1 System Description. The function of the Oxygen System is to provide gaseous oxygen (95 to 100 percent pure) to the HLW combustion melter, LLW combustion melters, and Melter Offgas systems in the Process Facilities. 
Oxygen is produced by the liquefaction and rectification of air. The Oxygen System includes a vendor supplied cryogenic unit that produces $118 \mathrm{MT} /$ day of 95 to 100 percent pure oxygen, an oxygen storage tank and its associated piping. Oxygen from the storage tank is vaporized (by vendor supplied equipment) and piped as a gas to the process facilities.

The equipment listed below receives gaseous oxygen. The annual consumption of oxygen for each facility is shown on the Summary of Annual Utility and Chemical Consumption table (Appendix C).

Equipment that Receives Oxygen

\begin{tabular}{|l|l|}
\hline Description & Equipment No. \\
\hline HLW Melter & EM-323 \\
\hline LLW Melter & EM-412 A \\
\hline LLW Melter & EM-412 B \\
\hline Melter offgas heat exchanger inlet lines & $\begin{array}{l}\text { EC-628-3B, } \\
\text { EC-628-4 (inlets) }\end{array}$ \\
\hline
\end{tabular}

See page A-4 of Appendix A for the Block Flow Diagram of the Oxygen System. Drawing UFD-4-03 is a Utility Flow Diagram (see Appendix B) of the Oxygen System.

3.4.1.2 Findings. The Oxygen System is a shared, no distance constrained, system. Technical Maturity is the prime consideration for the configuration of the Oxygen System. This function could be provided from almost anywhere and is a candidate for being furnished from an existing oxygen plant. For the purposes of this effort the oxygen supply unit is located in the Bulk Handling Area.

3.4.1.3 Functional Configuration Considerations and Rationale. Technical Maturity, in terms of commercially available equipment, is the prime consideration for the Oxygen System configuration. A single cryogenic oxygen plant is selected for the onsite production of oxygen.

The majority of the oxygen consumed onsite is used in the LLW facility. Oxygen plants capable of producing pure oxygen are not available for production rates in the range needed for the HLW facility. The technology required to produce high purity oxygen is well known and has long been available commercially. However, the smallest units available for the production of high purity oxygen are in the 20 to 30 tons per day range. The HLW facility requires only 14 tons per day of pure oxygen for a $20 \mathrm{MT}$ per day glass production rate. Selecting a dedicated unit that may be 40 to 100 percent oversized for the HLW facility is not reasonable as it will increase capital and operating costs. The amount of oxygen needed for the HLW facility is about 10 percent of the total peak requirement for both the HLW and LLW facilities (refer to Appendix D, Cold Chemical Consumption 
Tables, for the peak annual consumption of oxygen). Therefore, due to the lack of availability of small commercial units, a shared oxygen plant is selected to serve both the HLW and LLW facilities.

The hazards associated with the production of oxygen (supports combustion, can be explosive) dictate that the oxygen plant be located outdoors, outside of any process or support facilities. A cryogenic plant produces liquid oxygen that is very cold and significantly increases in volume when it vaporizes. Hence, safety demands that any enclosed volume, where liquid could be trapped, must be provided with adequate ventilation or pressure-relief. For this reason, the oxygen plant is located outdoors in the Bulk Handling Area.

The oxygen demand for the HLW combustion melter is about 10 percent of the total oxygen demand. Therefore, potential conversion to a joule heated melter would not have a significant impact to the Oxygen Supply System design.

There is no specific need for this system to be located in close proximity to the process operations. Therefore, this system is defined as not being distance constrained.

Other considerations that were evaluated and found not to be contributors to the function configuration are noted below:

Operability and Maintainability. This study has not identified any Operability or Maintainability issues that are unique to any single configuration considered for this system. Therefore, Operability and Maintainability are not considerations that were used to determine the configuration of this system.

Radiological Protection (ALARA). This study has not identified any Radiological Protection (ALARA) issues that are unique to any single configuration considered for this system. Therefore, Radiological Protection (ALARA) is not a consideration that was used to determine the configuration of this system.

Environmental Regulatory Compliance. This study has not identified any Environmental Regulatory Compliance issues that are unique to any single configuration considered for this system. Therefore, Environmental Regulatory Compliance is not a consideration that was used to determine the configuration of this system.

Schedule. The configuration of this system does not impact the schedule for the design, construction, or startup of the TWRS Treatment Complex.

Design Impact. This study has not identified any Design Impact issues that are unique to any single configuration considered for this system. Therefore, Design Impact is not a consideration that was used to determine the configuration of this system. 
WHC-SD-W378-ES-002

Revision 0

\subsubsection{Cold Chemical Supply System}

3.4.2.1 System Description. The Cold Chemical Supply System provides the cold chemical receipt, storage, preparation, and distribution functions for the Separations, LLW, and HLW process and support functions. This system is sized to provide a minimum 30 day supply of cold chemicals, except for the storage bins that are located in the Bulk Handling Area. The size of the bulk storage bins is based on the size of the delivery rail car or 16 days of storage, whichever is larger.

The Cold Chemicals Supply System includes all equipment required to receive, store, prepare, and distribute cold (nonradioactive) chemicals. This system serves the process, neutralization, and decontamination functions that are located in various process and support facilities. This system includes the bulk storage tanks, bulk storage bins, chemical make-up tanks, sumps, decontamination solution tanks, and associated transfer pumps and piping. The bulk storage and make-up tanks are located in the BCCB, on a pad adjacent to the BCCB, or in the Bulk Cold Chemical Handling Area (BHA). Table 3-1 shows where each chemical is stored and used.

The cold chemical solutions and decontamination solutions are prepared in make-up tanks that are located inside the BCCB. Except for bulk caustic and nitric acid, which are stored in tanks within the BCCB, the bulk chemicals that are used in large quantities are stored in bins or tanks that are located on the BCCB pad, which is adjacent to the BCCB. Glass former formulations are prepared in mixers in the BCCB, and are subsequently pneumatically conveyed to the process facilities. Automated conveying and mixing of other chemicals, not currently defined, may be needed, depending on the melter technology selected. Cold chemicals that are delivered to the site in bags or drums are stored within the BCCB. The prepared chemical solutions are transferred from the make-up tanks in the BCCB to the cold chemical feed tanks in the Separations/LLW facility and the HLW facility.

See pages A-5 and A-6 of Appendix A for the Block Flow Diagrams for this system. Drawing UFD-4-04 is a Utility Flow Diagram (see Appendix B) for the Cold Chemical System. The annual consumption of cold chemicals is in Appendix C, Utility Consumption Tables and Electrical Load List.

3.4.2.2 Findings. The Cold Chemical Supply System is a shared, close-external system. Cost Effectiveness, Operability and Maintainability, and Safety are considerations for the configuration of Cold Chemical Supply System. This system is grouped with the Collect and Handle Nonradioactive Liquid Waste System in the BCCB. 
Table 3-1. Storage and Usage of Chemicals. (2 sheets)

\begin{tabular}{|c|c|c|c|}
\hline \multirow{2}{*}{$\begin{array}{l}\text { Chemical description } \\
\text { Glass formers }\end{array}$} & \multicolumn{2}{|c|}{ Storage location } & \multirow[t]{2}{*}{ Usage } \\
\hline & & & \\
\hline $\mathrm{SiO}_{2}$ & Bin, B-1901-C & BCCB pad & Glass former used with the combustion melters (HLW and LLW facilities) \\
\hline $\mathrm{B}_{2} \mathrm{O}_{3}$ & Bin, B-1904-C & BCCB pad & Glass former used with the combustion melters (HLW and LLW facilities) \\
\hline $\mathrm{Li}_{2} \mathrm{O}$ & Bin, B-1905-C & BCCB pad & Glass former used with the combustion melters (HLW and LLW facilities) \\
\hline $\mathrm{CaO}$ & Bin, B-1906-C & BCCB pad & Glass former used with the combustion melters (HLW and LLW facilities) \\
\hline $\mathrm{MgO}$ & Bin, B-1907-C & BCCB pad & Glass former used with the combustion melters (HLW and LLW facilities) \\
\hline Bulk frit & Bags & BCCB & Filter media (separations facility) \\
\hline $50 \%$ nitric acid & Tank, TK-1014-C & $\mathrm{BCCB}$ & $\begin{array}{l}\text { Equipment decontamination (all facilities) } \\
\text { ion exchange (separations) }\end{array}$ \\
\hline $50 \%$ caustic & Tank, TK-1013-C & BCCB & $\begin{array}{l}\text { Equipment decontamination, (all facilities) chemical adjustment of process liquid } \\
\text { waste (decontaminated condensate), (all facilities) regeneration of ion exchange } \\
\text { columns (separations facility) }\end{array}$ \\
\hline Ion exchange resin & Drums & $\begin{array}{l}\text { LLW vit bldg } \\
\text { shipping and } \\
\text { receiving }\end{array}$ & Ion exchange (separations) \\
\hline Dry KMnO4 & Drums & $\mathrm{BCCB}$ & Equipment decontamination (all facilities) \\
\hline Dry sodium nitrite & Bin, B-1920-C & BCCB pad & $\begin{array}{l}\text { Adjustment of decontaminated process liquid waste before discharge, to reduce } \\
\text { corrosiveness of process streams sent to tankage (all facilities) }\end{array}$ \\
\hline Dry offgas treatment chemical & Bags or drums & BCCB & Treatment of offgas (all facilities) \\
\hline Dry oxalic acid & Drums & $\mathrm{BCCB}$ & Equipment decontamination (all facilities) \\
\hline Dry TSP & Bin, B-1921-C & BCCB pad & $\begin{array}{l}\text { General equipment and area decontamination, all-purpose cleaning agent (all } \\
\text { facilities) }\end{array}$ \\
\hline Antifoam solution & Drums & $\mathrm{BCCB}$ & In-cell process tanks, possibly melter offgas system (HLW and LLW facilities) \\
\hline
\end{tabular}


Table 3-1. Storage and Usage of Chemicals. (2 sheets)

\begin{tabular}{|c|c|c|c|}
\hline Chemical description & \multicolumn{2}{|c|}{ Storage location } & Usage \\
\hline Glycolic acid ${ }^{1}$ & Bin & BCCB pad & Feed preparation - adjustment of process feed upstream of the melter \\
\hline Cold chemical no. 1 & Bags or drums & $\mathrm{BCCB}$ & $\begin{array}{l}\text { Usage presently not defined. Space for a make-up tank in the BCCB and a feed } \\
\text { tank in the facility have been reserved. }\end{array}$ \\
\hline Cold chemical no. 2 & Bags or drums & BCCB & $\begin{array}{l}\text { Usage presently not defined. Space for a make-up tank in the BCCB and a feed } \\
\text { tank in the facility have been reserved. }\end{array}$ \\
\hline Cold chemical no. 3 & Bags or drums & BCCB & $\begin{array}{l}\text { Usage presently not defined. Space for a make-up tank in the BCCB and a feed } \\
\text { tank in the facility have been reserved. }\end{array}$ \\
\hline Cold chemical no. 4 & Bags or drums & BCCB & $\begin{array}{l}\text { Usage presently not defined. Space for a make-up tank in the BCCB and a feed } \\
\text { tank in the facility have been reserved. }\end{array}$ \\
\hline Anhydrous ammonia & Tank, TK-1015-C & BHA & Offgas - NOx abatement (HLW and LLW facilities) \\
\hline Kerosene $^{2}$ & Tank, TK-1022-C & BHA & Fuel for combustion melter and claus plant (HLW and LLW facilities) \\
\hline Oxygen ${ }^{2}$ & Unit w/tank & Outside $^{3}$ & Combustion of fuel in melter (HLW and LLW facilities) \\
\hline \multicolumn{4}{|l|}{ Bulk sulfur cement } \\
\hline Sulfur & Tank, 1007-C & BHA & Disposal matrix for LLW cullet (LLW storage vaults) \\
\hline DCPD & Tank, 1008-C & BCCB & Sulfur modifier (LLW storage vaults) \\
\hline CPD oligomer & Tank, 1009-C & ВСCВ & Sulfur modifier (LLW storage vaults) \\
\hline
\end{tabular}

BCCB $=$ Bulk Cold Chemical Building

BHA $=$ Bulk Cold Chemical Handling Area

HLW $=$ High-level waste

LLW $=$ Low-level waste

'Indicated glycolic acid consumption based on joule-heated and induction heated melter systems (HLW vitrification: stirred, liquid fed ceramic-lined, cold crucible; LLW vitrification: stirred, liquid fed ceramic-lined.

${ }^{2}$ Kerosene and oxygen are used only by the base case combustion melter, and not by the alternate melters.

${ }^{3}$ The oxygen plant is skid mounted and located near the BCCB. 
3.4.2.3 Function Configuration Considerations and Rationale. Cost effectiveness is the prime consideration for defining this system. A majority of the cold chemicals are used in both the Separations/LLW or the HLW facilities. Two dedicated systems could be supplied, but, a majority of the equipment would be duplicated. The total engineered cost of a shared Cold Chemical Supply System would be $\$ 38,203,000$. The total engineered cost of two such sets of dedicated cold chemical supply equipment (one dedicated to the Separations/LLW facility and the other dedicated to the HLW facility) would be $\$ 46,870,000$. Installing or providing space for a separate future HLW Cold Chemical Supply System is more costly than installing a single Cold Chemical Supply System sized to serve both the Separations/LLW and HLW facilities. Therefore, this system is designated a shared function.

Costs given here represent the mechanical equipment costs and specifically exclude the costs of the building to house the equipment.

The following cold chemicals need to be stored in close proximity to the process facilities where they are consumed:

Ammonia (Toxic and highly flammable, minimize transfer line leaks)

Molten Sulfur (Piping requires heating and insulation)

Bulk Glass Formers (Requires costly conveying/handling equipment)

Glass Frit (Pumped as a high erosion slurry).

The length of solids transport lines from the BCCB to the users in the process facilities should be minimized, to avoid the problems inherent with solids transport, such as line pluggage and erosion. Therefore, the solid chemical storage bins and solids transport equipment are located in the storage area adjacent to the $\mathrm{BCCB}$, as close as possible to the Separations/LLW facility, which is the main cold chemical user.

Operability and Maintainability are also considerations in determining the configuration for this system. Sharing of the bulk cold chemical storage and make-up functions reduces operator attention requirements. It also provides a common unloading point for the chemicals. The operator can make up solutions for both facilities at the same time, instead of repeatedly making the same solution for each process facility.

There are some maintenance advantages to a shared facility due to the reduced amount of machinery, such as pumps, exhaust blowers, and conveyors, to maintain.

Safety dictates that the Cold Chemical Supply System be located outside of the main processing facilities. Kerosene and ammonia are both highly flammable (and ammonia is toxic as well). These storage vessels should be located far enough away from the process and support facilities to mitigate any possible safety concerns that are based on minor leaks. However, reliability and maintainability dictate that this system be located in close proximity to the end users. 
WHC-SD-W378-ES-002

Revision 0

Spilling liquid chemicals due to a pipe leak, tank failure or other accidents could potentially release toxic vapors into the atmosphere. Inadvertent mixing of liquid chemicals due to an accident would increase the amount of toxic vapors released. Measures can be taken to contain spills and prevent accidental mixing of liquid chemicals and minimize the amount of toxic vapors released. Although those are concerns, they are not considered obstacles to being able to develop the configuration as defined above.

Other considerations that were evaluated and found not to be contributors to the function configuration are noted below:

Radiological Protection (ALARA). This study has not identified any Radiological Protection issues that are unique to any single configuration considered for this system. Therefore, Radiological Protection (ALARA) is not a consideration that was used to determine the configuration of this system.

Environmental Regulatory Compliance. This study has not identified any Environmental Regulatory Compliance issues that are unique to any single configuration considered for this system. Therefore, Environmental Regulatory Compliance is not a consideration that was used to determine the configuration of this system.

Schedule. The configuration of this system does not impact the schedule for the design, construction, or startup of the TWRS Treatment Complex.

Technical Maturity. Commercially demonstrated technology is used in the design of this system. Therefore, Technology issues were not a consideration for the configuration of this system.

Design Impact. This study has not identified any Design Impact issues that are unique to any single configuration considered for this system. Therefore, Design Impact is not a consideration that was used to determine the configuration of this system.

\subsubsection{Cold Chemical Feed System}

3.4.3.1 System Description. There are two dedicated Cold Chemical Feed subsystems. One subsystem is located within the Separations/LLW facility, and the other is located within the HLW process facility. These systems consists of Cold Chemical Feed Tanks and Decontamination Solution Tanks. These systems provide intermediate storage for the chemicals needed to support the in-cell process equipment and decontamination facilities. These systems also provide backflow protection for the cold chemicals within the process facilities. 
See page A-7 of Appendix A for the Block Flow Diagram of this system. Drawing UFD-4-04 is a Utility Flow Diagram (see Appendix B) for the Cold Chemical System.

3.4.3.2 Findings. The Cold Chemical Feed System is a dedicated internal system. Radiological Protection (ALARA) is the prime configuration consideration for the Cold Chemical Feed Tank System. This function is located in the process facilities for radiological protection.

3.4.3.3 Function Configuration Considerations and Rationale. Radiological Protection (ALARA) is the prime consideration for defining this system. This is a dedicated, internal system. Located in the process facilities, high enough above in-cell equipment to prevent siphoning, the feed tanks act as break tanks. This is an intrinsically safe method for the prevention of radiological waste leaving the facility through the chemical supply system.

Other considerations that were evaluated and found not to be contributors to the function configuration are noted below:

Operability and Maintainability. This study has not identified any Operability or Maintainability issues that are unique to any single configuration considered for this system. Therefore, Operability and Maintainability are not considerations that were used to determine the configuration of this system.

Cost Effectiveness. This study has not identified any cost drivers that would override the technical considerations used to define the configuration of this system.

Therefore, Cost Effectiveness is not a consideration that was used to determine the configuration of this system.

Safety. This study has not identified any Safety issues that are unique to any single configuration considered for this system. Therefore, Safety is not a consideration that was used to determine the configuration of this system.

Environmental Regulatory Compliance. This study has not identified any Environmental Regulatory Compliance issues that are unique to any single configuration considered for this system. Therefore, Environmental Regulatory Compliance is not a consideration that was used to determine the configuration of this system.

Schedule. The configuration of this system does not impact the schedule for the design, construction, or startur of the TWRS Treatment Complex.

Technical Maturity. Commercially demonstrated technology is used in the design of this system. Therefore, Technology issues were not a consideration for the configuration of this system. 


\section{WHC-SD-W378-ES-002}

\section{Revision 0}

Design Impact. This study has not identified any Design Impact issues that are unique to any single configuration considered for this system. Therefore, Design Impact is not a consideration that was used to determine the configuration of this system.

\subsubsection{Cold Chemical Vent System}

3.4.4.1 System Description. The primary function of the Cold Chemical Vent System is to provide vapor control on the cold chemicals storage and make-up tanks in the BCCB. The system discharges the cold chemical tanks' vent gases to the BCCB Exhaust Stack that releases to an uncontrolled area. An additional function of the Cold Chemical Vent System is to prevent the out-migration of the cold chemicals storage and make-up tanks' vent gases into the BCCB.

The Cold Chemical Vent System includes piping and blowers venting all the bulk cold chemical storage and make-up tanks. Two 100 percent flow capacity, motor driven, vent blowers (one operating and one spare) pull a vacuum on the vent header and exhaust to the BCCB exhaust. A condensate knockout drum is also provided upstream of the vent blowers. The tanks listed in Table 3-2 vent to the Cold Chemical Vent System.

Table 3-2. Tanks That Vent to Bulk Cold Chemical Building Exhaust Stack.

\begin{tabular}{|r|l|c|}
\hline \multicolumn{1}{|c|}{ Description } & Equipment identification \\
\hline 1. & Bulk caustic storage tank & TK-1013 \\
\hline 2. & Bulk nitric acid storage tank & TK-1014 \\
\hline 3. & Caustic waste hold tank & TK-1658 \\
\hline 4. & Acid waste hold tank & TK-1660 \\
\hline 5. & Organic acid waste hold tank & TK-1661 \\
\hline 6. & Caustic waste neutralization tank & TK-1662 \\
\hline 7. & Organic waste neutralization tank & TK-1663 \\
\hline 8. & Cold chemicals no. 1 make-up tank & TK-1716 \\
\hline 9. & Offgas treatment chemicals make-up tank & TK-1717 \\
\hline 10. & Cold chemicals no. 2 make-up tank & TK-1718 \\
\hline 11. & Nitric acid decon make-up tank & TK-1719 \\
\hline 12. & Decon solution make-up tank & TK-1720 \\
\hline 13. & MSM decon solution make-up tank & TK-1721 \\
\hline
\end{tabular}


Table 3-2. Tanks That Vent to Bulk Cold Chemical Building Exhaust Stack.

\begin{tabular}{|r|l|l|}
\hline & \multicolumn{1}{|c|}{ Description } & Equipment identification \\
\hline 14. & Oxalic acid decon make-up tank & TK-1722 \\
\hline 15. & Potassium Permanganate make-up tank & TK-1723 \\
\hline 16. & Cold chemicals no. 3 make-up tank & TK-1724 \\
\hline 17. & Cold chemicals no. 4 make-up tank & TK-1725 \\
\hline 18. & Frit slurry make-up tank & TK-1775 \\
\hline
\end{tabular}

See page A-8 of Appendix A for the Block Flow Diagram of this system. Drawing UFD-4-05 is a Utility Flow Diagram (see Appendix B) of the Cold Chemical Vent System.

3.4.1.2 Findings. The Cold Chemical Vent System is a dedicated close-external system grouped together with the Cold Chemical Storage Tanks in the BCCB.

Operability is the prime consideration for the configuration of the Cold Chemical Vent System. The system is dedicated to serve only the tanks located in the BCCB.

3.4.1.3 Function Configuration Considerations and Rationale. Operability is the prime consideration for design of this system. The Cold Chemical Vent System is operationally integral to the Cold Chemical Supply System. The tanks in this system require a vent system for the control of vapors and particulates. This vent system is tied to, and operates in conjunction with, the cold chemical supply system. Therefore, this system is dedicated to the cold chemical tanks within the BCCB.

Because of the low operating pressure (the system operates at a slight vacuum), the vapors vented by the system have a relatively high volume. The piping distances should be minimized, to limit the size of the piping and blowers required. Therefore, the vent system blower should be located in close-proximity to the tanks it serves.

Other considerations that were evaluated and found not to be contributors to the function configuration are noted below:

Cost Effectiveness. This study has not identified any cost drivers that would override the technical considerations used to define the configuration of this system.

Therefore, Cost Effectiveness is not a consideration that was used to determine the configuration of this system. 
Radiological Protection (ALARA). This study has not identified any Radiological Protection (ALARA) issues that are unique to any single configuration considered for this system. Therefore, Radiological Protection (ALARA) is not a consideration that was used to determine the configuration of this system.

Safety. This study has not identified any Safety issues that are unique to any single configuration considered for this system. Therefore, Safety is not a consideration that was used to determine the configuration of this system.

Environmental Regulatory Compliance. This system is designed to vent waste vapors regulated by WAC 173-303, WAC 173-400, WAC 173-401 and WAC 173-460 and each facility within this system will be permitted under these regulations. This is not considered to be a significant issue, therefore, Environmental Regulatory Compliance is not a consideration that was used to determine the configuration of this system.

Schedule. The configuration of this system does not impact the schedule for the design, construction, or startup of the TWRS Treatment Complex.

Technical Maturity. Commercially demonstrated technology is used in the design of this system. Therefore, Technology issues were not a consideration for the configuration of this system.

Design Impact. This study has not identified any Design Impact issues that are unique to any single configuration considered for this system. Therefore, Design Impact is not a consideration that was used to determine the configuration of this system.

\subsubsection{Process Facility Vent System}

3.4.5.1 System Description. The primary function of the Process Facility Vent System is to provide vapor control in the overhead vent lines from the cold chemical feed tanks, drain catch tanks, and other potentially radioactive sources in the HLW and the Separations/LLW facilities. The detached HLW and combination Separations/LLW facility each have their own separate vent system. Each system discharges the vent gases through HEPA filters to the dedicated HVAC Zone II and III exhaust stack, which releases the gases to the atmosphere. An additional function of the Process Facility Vent System is to prevent the out-migration of the cold chemical feed tanks' vent gases into the operating areas.

The Process Facility Vent System includes piping, HEPA filters, and blowers that vent all the process facilities' cold chemical feed tanks. All tanks connected to this vent system header have overflow piping with a water seal leg so that normally no atmospheric air is pulled into the tanks on a continuous basis. Two, 100 percent flow capacity, motor driven, vent blowers (one operating and one spare) pull a vacuum on the vent header through 
two HEPA filters (one operating and one spare). These blowers exhaust to the Process Facility Exhaust Stack for each facility. The HEPA filter removes submicron particulates from the gas stream. A condensate knockout drum is also provided upstream of the vent blowers.

If the loop-seal water is blown out or missing, the vent system would pull atmospheric air through the overflow lines. The vent blower can handle the air flow of several open overflow lines. The tanks listed in Table 3-3 vent to the Process Facility Vent System.

Table 3-3. Tanks That Vent to Process Facility Exhaust Stack.

\begin{tabular}{|c|c|c|}
\hline & Description & Equipment identification \\
\hline 1. & Cesium regen. nitric acid tank & TK-205-4 \\
\hline 2. & Startup nitric acid tank & TK-208-4 \\
\hline 3. & $\mathrm{NaOH}$ regeneration tank & TK-211-4 \\
\hline 4. & $\mathrm{NaOH}$ regeneration tank & TK-212-4 \\
\hline 5. & $\mathrm{NaOH}$ neutralizing solution tank & TK-213-4 \\
\hline 6. & Head Bin & B-319-3B \\
\hline 7. & Weigh feeder & $M F-321-3 B$ \\
\hline 8. & Head Bin & B-408A-4 \\
\hline 9. & Head Bin & B-408B-4 \\
\hline 10. & Weigh feeder & $\mathrm{MF}-410 \mathrm{~A}-4$ \\
\hline 11. & Weigh feeder & $\mathrm{MF}-410 \mathrm{~B}-4$ \\
\hline 12. & Scrub solution make-up tank & TK-619-3B/4 \\
\hline 13. & Acid drain catch tank & TK-1197-3B/4 \\
\hline 14. & Organic acid drain catch tank & TK-1198-3B/4 \\
\hline 15. & Floor drain sampling tank & TK-1199-3B/4 \\
\hline 16. & Cold chemicals No. 1 feed tank & TK-1200-3B/4 \\
\hline 17. & Cold chemicals No. 4 feed tank & TK-1201-3B/4 \\
\hline 18. & Cold chemicals No.2 feed tank & TK-1202-3B/4 \\
\hline 19. & Cold chemicals No.3 feed tank & TK-1203-3B/4 \\
\hline 20. & $50 \%$ nitric acid feed tank & TK-1205-3B/4 \\
\hline
\end{tabular}


WHC-SD-W378-ES-002

Revision 0

Table 3-3. Tanks That Vent to Process Facility Exhaust Stack.

\begin{tabular}{|c|l|c|}
\hline & \multicolumn{1}{|c|}{ Description } & Equipment identification \\
\hline 21. & Nitric acid decon feed tank & TK-1206-3B/4 \\
\hline 22. & Oxalic acid decon feed tank & TK-1207-3B/4 \\
\hline 23. & Potassium Permanganate feed tank & TK-1208-3B/4 \\
\hline 24. & $50 \%$ caustic feed tank & TK-1209-3B/4 \\
\hline 25. & Offgas treatment chemical feed tank & TK-1211-3B/4 \\
\hline
\end{tabular}

See page A-9 of Appendix A for the Block Flow Diagram of this system. Drawing UFD-4-06 is a Utility Flow Diagram (see Appendix B) of the Process Facility Vent System.

3.4.5.2 Findings. The Process Facility Vent System is dedicated and is located in the process facilities for radiological protection. Radiological Protection (ALARA) is the prime configuration consideration for the Process Facility Vent System.

3.4.5.3 Function Configuration Considerations and Rationale. Radiological Protection (ALARA) is the prime consideration for the design of this system. The Process Facility Vent System is operationally integrated with the tanks it serves. In addition to the cold chemical day tanks inside the process facility, the system provides vapor control for the Floor Drain Catch Tank, the Regulated Drains Catch Tank, the Process Condensate Collection Tank, the Process Cooling Water Expansion Tank, and the Melter Cooling Water Expansion Tank. These tanks are all dedicated because they require radiological protection. Therefore, the Process Facility Vent System also requires radiological protection, and, this vent system is a dedicated system.

The radiological considerations that dictate that the tanks be dedicated also apply to the vent system. See the following sections for discussions related to the tanks served by this system:

- Collect and Handle Potentially Radioactive Liquid Wastes System

- Cold Chemical Supply System

- Process Steam and Condensate System

- Melter Cooling Water System

- Process Chilled Water System.

Other considerations that were evaluated and found not to be contributors to the function configuration are noted below: 
Operability and Maintainability. This study has not identified any Operability or Maintainability issues that are unique to any single configuration considered for this system. Therefore, Operability and Maintainability are not considerations that were used to determine the configuration of this system.

Cost Effectiveness. This study has not identified any cost drivers that would override the technical considerations used to define the configuration of this system.

Therefore, Cost Effectiveness is not a consideration that was used to determine the configuration of this system.

Safety. This study has not identified any Safety issues that are unique to any single configuration considered for this system. Therefore, Safety is not a consideration that was used to determine the configuration of this system.

Environmental Regulatory Compliance. This system is designed to vent waste vapors regulated by WAC 173-303, WAC 173-400, WAC 173-401 and WAC 173-460 and each facility within this system will be permitted under these regulations. This is not considered to be a significant issue, therefore, Environmental Regulatory Compliance is not a consideration that was used to determine the configuration of this system.

Schedule. The configuration of this system does not impact the schedule for the design, construction, or startup of the TWRS Treatment Complex.

Technical Maturity. Commercially demonstrated technology is used in the design of this system. Therefore, technology issues were not a consideration for the configuration of this system.

Design Impact. This study has not identified any Design Impact issues that are unique to any single configuration considered for this system. Therefore, Design Impact is not a consideration that was used to determine the configuration of this system.

\subsubsection{Process Steam and Condensate System}

3.4.6.1 System Description. The Process Steam and Condensate System supplies steam to various process users in the Separations/LLW facility and the HLW facility. Saturated steam is generated at $1,136 \mathrm{kPa}$ (150 psig) in electric steam generators that are located within a contact maintained shielded area inside each process facility.

The Process Steam and Condensate System consists of two subsystems. One is dedicated to the Separations/LLW facility and the other is dedicated to the HLW facility. Each subsystem consists of electric steam generators and their associated equipment, and the condensate collection equipment that returns the condensate to the steam generators. Each 
subsystem is designed as a closed, primary steam distribution loop. The steam generators supply steam directly to in-cell feed evaporators. The process steam condensate from the evaporators is routed to the steam condenser/cooler, accumulated in the collection tank, from where it is pumped back to the steam generator as make-up water.

A total of five steam generators $(7.76 \mathrm{MW}$ each) is required for the Separations/LLW facility. Four steam generators are required to meet the maximum demand. One unit is a spare. The HLW facility contains two steam generators (7.76 MW each). One steam generator is required to meet the maximum load, and the other is a spare.

See page A-10 of Appendix A for the Block Flow Diagram of the Process Steam and Condensate System. Drawing UFD-4-07 is a Utility Flow Diagram for the Process Steam and Condensate System (see Appendix B). Refer to Appendix C, Utility Consumption Tables and Electrical Load List, for a listing of the annual Process Steam Consumption.

3.4.6.2 Findings. The Process Steam and Condensate System is a dedicated system and is located within the process facilities. Radiological Protection (ALARA), Cost Effectiveness, Operation and Maintenance, and Safety are configuration considerations for the Process Steam and Condensate System.

3.4.6.3 Functional Configuration Considerations and Rationale. Radiological Protection (ALARA) is the prime consideration for the design of this system. This is a dedicated system with one set of steam generators and condensate return equipment serving the Separations/LLW facility and one serving the HLW process facility. The steam generators and associated equipment are located entirely within the process facilities they serve.

There are three possible alternatives to the selected configuration. They are as follows:

1. Locate the Process Steam Generators in the MUB or an accessible Steam Generator building outside of the process facilities. These shared steam generators would serve both process facilities.

2. Dedicate one set of steam generators to the Separations process and one set to the LLW process, with both sets inside an annex to the Separations/LLW facility. The HLW facility would have its own steam generators.

3. Locate sufficient steam generator capacity inside the Separations/LLW facility to serve the Separations/LLW processes and the HLW process.

Maintenance considerations favor Alternative 1, where the steam generators would be accessible in the MUB. However, Radiological Protection is the prime configuration consideration that eliminates both alternatives 1 and 3. All steam and condensate that has come into direct contact with the HLW or the Separations/LLW processes may become 
contaminated with radioactive process fluid and, therefore, must remain within the associated facility.

Secondary steam loops and other backflow prevention measures can be designed into the process to mitigate the backflow of radioactive material from the process cells and from the process facilities. However, it is inherently safer to contain the steam generation subsystems in the facility where the steam is used.

Operational considerations favor having a dedicated Process Steam and Condensate System for the LLW process and another dedicated system for the Separations process, as in Alternative 2. However, cost considerations have a negative impact on Alternative 2. Each process steam and condensate subsystem would require its own steam generators, both operating and spare. This would increase the number of steam generators and the cost over the selected configuration. Alternatives 1 and 3 may also have cost advantages over the selected process steam and condensate configuration. However, the radiological protection consideration once again takes precedence.

Due to a reduction in redundant equipment and the economies of scale there is a cost advantage in combining the Process Steam and Condensate Systems as much as possible. However, radiological protection considerations dictate that a dedicated system be provided for the Separations/LLW facility and a dedicated system be provided for the HLW facility.

The Process Steam and Condensate System is a significant energy source. The amount of steam produced by a dedicated system is much smaller than the amount of steam that would be produced by a shared system. Thus, the amount of energy released by a steam excursion/explosion will be less for a dedicated facility. Therefore, safety considerations favor a dedicated Process Steam and Condensate System.

Other considerations that were evaluated and found not to be contributors to the function configuration are noted below:

Operability and Maintainability. This study has not identified any Operability or Maintainability issues that are unique to any single configuration considered for this system. Therefore, Operability and Maintainability are not considerations that were used to determine the configuration of this system.

Environmental Regulatory Compliance. This study has not identified any Environmental Regulatory Compliance issues that are unique to any single configuration considered for this system. Therefore, Environmental Regulatory Compliance is not a consideration that was used to determine the configuration of this system.

Schedule. The configuration of this system does not impact the schedule for the design, construction, or startup of the TWRS Treatment Complex. 


\section{WHC-SD-W378-ES-002 \\ Revision 0}

Technical Maturity. Commercially demonstrated technology is used in the design of this system. Therefore, Technology issues were not a consideration for the configuration of this system.

Design Impact. This study has not identified any Design Impact issues that are unique to any single configuration considered for this system. Therefore, Design Impact is not a consideration that was used to determine the configuration of this system.

\subsubsection{Process Cooling Water System}

3.4.7.1 System Description. The Process Cooling Water System removes heat from the process equipment during normal operation. The process cooling water equipment is located inside the Separations/LLW facility and the HLW facility. The system is capable of maintaining the process tanks at $50^{\circ} \mathrm{C}\left(122{ }^{\circ} \mathrm{F}\right)$ or less during normal process operations, idle, or shutdown periods. The system is designed to remove both decay heat from the process stream and frictional heat from agitators. Also, the system provides cooling for the offgas.

The Process Cooling Water System is a closed, recirculating cooling water loop that cools in-cell radioactive and potentially radioactive streams. The heated process cooling water is routed to the Process Cooling Water Cooler where the heat is removed by cooling tower water.

The Process Cooling Water System consists of two complete process cooling water subsystems, one for the Separations/LLW facility and another for the HLW facility.

Each subsystem consists of a process cooling water cooler, an expansion tank, circulation pumps, HEPA filters, a chemical addition tank, and distribution piping. Each subsystem is entirely contained within the facility it serves. Demineralized water is used both as fill and make-up water.

See page A-11 of Appendix A for the Block Flow Diagram of the Process Cooling Water System. Drawings UFD-4-08 (sheet 1 through 3) are the Utility Flow Diagrams (see Appendix B) of the Process Cooling Water System. The annual duty of the Process Cooling Water System is provided in Appendix C, Utility Consumption Tables and Electrical Load List.

3.4.7.2 Findings. The Process Cooling Water System is dedicated and located with in the process facilities for radiological protection. This system is grouped with the Melter Cooling Water System and the Process Chilled Water system. Radiological Protection (ALARA) is the prime consideration for defining the configuration of the Process Cooling Water System. 
WHC-SD-W378-ES-002

Revision 0

3.4.7.3 Functional Configuration Considerations and Rationale. Radiological Protection (ALARA) is the prime consideration for the design of this system. The Process Cooling Water System is designed as a dedicated system with one set of process cooling water equipment serving the Separations/LLW facility, and another set of process cooling water equipment serving the HLW process facility. Each subsystem is located entirely within the process facility it serves. follows:

There are three possible alternatives to the selected configuration. They are as

1. Locate the Process Cooling Water System equipment in the MUB or an accessible building outside of the process facilities. This single, shared cooling system would serve both process facilities.

2. Dedicate one set of process cooling water equipment to the Separations process and one set to the LLW process, with both sets inside the Separations/LLW facility. The HLW facility would have its own process cooling water equipment.

3. Locate sufficient process cooling capacity inside the Separations/LLW facility to serve the Separations/LLW processes, and the HLW process.

Radiological protection is the prime configuration consideration for the Process Cooling Water System and this eliminates Alternatives 1 and 3. All cooling water that has come into direct contact with the vitrification and separations processes may become contaminated with radioactive process fluids and, therefore, must remain within the respective vitrification or separations facility.

Secondary cooling loops and other backflow prevention measures can be designed into the process to mitigate the backflow of radioactive material from the process cells and from the process facilities. However, it is inherently safer to contain the process cooling subsystems in the facility where the cooling is needed.

The process cooling water equipment requires relatively low maintenance. However, maintenance considerations favor Alternative 1 where the process cooling equipment would be accessible in the MUB. Radiological safety considerations are the primary reason for the elimination of Alternatives 1 and 3.

Operational considerations may favor having dedicated process cooling equipment for the LLW process and dedicated process cooling equipment for the Separations process, as in Alternative 2. However, cost considerations have a negative impact on Alternative 2. Each cooling water subsystem would require its own coolers, both operating and spare. This would lead to four total process cooling water coolers for the Separations/LLW facility as opposed to two for a combined Process Cooling Water System. Alternatives 1 and 3 may 
also have cost advantages over the selected process cooling water configuration. However, the radiological protection consideration once again takes precedence.

Other considerations that were evaluated and found not to be contributors to the function configuration are noted below:

Operability and Maintainability. This study has not identified any Operability or Maintainability issues that are unique to any single configuration considered for this system. Therefore, Operability and Maintainability are not considerations that were used to determine the configuration of this system.

Safety. This study has not identified any Safety issues that are unique to any single configuration considered for this system. Therefore, Safety is not a consideration that was used to determine the configuration of this system.

Environmental Regulatory Compliance. This study has not identified any Environmental Regulatory Compliance issues that are unique to any single configuration considered for this system. Therefore, Environmental Regulatory Compliance is not a consideration that was used to determine the configuration of this system.

Schedule. The configuration of this system does not impact the schedule for the design, construction, or startup of the TWRS Treatment Complex.

Technical Maturity. Commercially demonstrated technology is used in the design of this system. Therefore, Technology issues were not a consideration for the configuration of this system.

Design Impact. This study has not identified any Design Impact issues that are unique to any single configuration considered for this system. Therefore, Design Impact is not a consideration that was used to determine the configuration of this system.

\subsubsection{Melter Cooling Water System}

3.4.8.1 System Description. The Melter Cooling Water System removes heat from the Melters during normal process operation. The LLW Melters and the HLW Melter have separate cooling subsystems. Each subsystem is designed with a primary and a secondary cooling loop. The primary melter cooling water loop is a closed system that is designed to cool the various melter components by continuously circulating cooling water in a loop from the melter to the Melter Cooling Water Cooler. The primary loop includes heat exchangers, recirculation pumps, distribution piping, an expansion tank with HEPA filters on the tank vent, and a chemical addition tank. 
The secondary cooling water loop is an open system. The secondary cooling water loop uses cooling tower water to remove the heat from the melter cooling water (via the exchanger) and expel it to the atmosphere (through the cooling tower). (Refer to the Cooling Tower Water System section for a system description.)

See page A-12 of Appendix A for the Block Flow Diagram of the Melter Cooling Water System. Drawing UFD-4-09 is a Utility Flow Diagram (see Appendix B) of the Melter Cooling Water System. The annual duty of the Melter Cooling Water System is provided in Appendix C, Utility Consumption Tables and Electrical Load List.

3.4.8.2 Findings. The Melter Cooling Water System is a dedicated system located within the process facilities. This system is grouped with the Process Cooling Water System and the Process Chilled Water System. Radiological Protection (ALARA) is the prime configuration consideration for the Melter Cooling Water System.

3.4.8.3 Functional Configuration Considerations and Rationale. Radiological Protection (ALARA) is the prime consideration for the design of this system. The primary loop of the Melter Cooling Water System is designed as a dedicated utility system, located within the detached and combination process facilities.

There are two possible alternatives to the selected configuration for the Melter Cooling Water System:

1. Locate a single Melter Cooling Water System inside the MUB. This shared cooling system would serve both the LLW and the HLW facilities.

2. Locate a single Melter Cooling Water System inside the Separations/LLW facility with enough capacity to serve both the LLW and the HLW facilities.

Radiological protection, which is the prime configuration consideration here, eliminates both alternatives 1 and 2 . All cooling water that has come into direct contact with the process may become contaminated with radioactive process fluids and, therefore, must remain within the facilities.

Secondary cooling loops and other backflow prevention measures can be designed into the process to mitigate the backflow of radioactive material from the cells and from the process facilities. However, it is inherently safer to contain the melter cooling subsystems in the facilities where the cooling is needed.

Other considerations that were evaluated and found not to be contributors to the function configuration are noted below: 
Operability and Maintainability. This study has not identified any Operability or Maintainability issues that are unique to any single configuration considered for this system. Therefore, Operability and Maintainability are not considerations that were used to determine the configuration of this system.

Cost Effectiveness. This study has not identified any cost drivers that would override the technical considerations used to define the configuration of this system.

Therefore, Cost Effectiveness is not a consideration that was used to determine the configuration of this system.

Safety. This study has not identified any Safety issues that are unique to any single configuration considered for this system. Therefore, Safety is not a consideration that was used to determine the configuration of this system.

Environmental Regulatory Compliance. This study has not identified any Environmental Regulatory Compliance issues that are unique to any single configuration considered for this system. Therefore, Environmental Regulatory Compliance is not a consideration that was used to determine the configuration of this system.

Schedule. The configuration of this system does not impact the schedule for the design, construction, or startup of the TWRS Treatment Complex.

Technical Maturity. Commercially demonstrated technology is used in the design of this system. Therefore, Technology issues were not a consideration for the configuration of this system.

Design Impact. This study has not identified any Design Impact issues that are unique to any single configuration considered for this system. Therefore, Design Impact is not a consideration that was used to determine the configuration of this system.

\subsubsection{Process Chilled Water System}

3.4.9.1 System Description. The Process Chilled Water System removes heat from the melter offgas during normal operation. The LLW melter offgas system and the HLW melter offgas system have separate chilled water subsystems. Each subsystem is designed with a primary and a secondary cooling loop. The primary chilled water loop is a closed system that is designed to cool the melter offgas by continuously circulating chilled water in a loop from the process water chiller to the melter offgas chiller. The primary loop includes the process water chiller unit that includes: the water chiller, circulation pump, expansion tank, vent HEPA filter, and distribution piping. 


\section{WHC-SD-W378-ES-002 \\ Revision 0}

The secondary cooling water loop is an open system. The secondary cooling water loop uses cooling tower water to remove the heat from the process chilled water and expel it to the atmosphere (through the cooling tower - Refer to the Cooling Tower Water System).

See page A-13 of Appendix A for the Block Flow Diagram of the Process Chilled Water System. Drawing UFD-4-09 is a Utility Flow Diagram (see Appendix B) of the Process Chilled Water System. The annual duty for the Process Chilled Water System is provided in Appendix C, Utility Consumption Tables and Electrical Load List.

3.4.9.2 Findings. The Process Chilled Water System is a dedicated system, located within the process facilities. This system is grouped with the Process Cooling Water System and the Melter Cooling Water System. Radiological Protection is the prime configuration consideration for the Process Chilled Water System.

3.4.9.3 Functional Configuration Considerations and Rationale. Radiological Protection (ALARA) is the prime consideration for the design of this system. Because radiological protection is required, the primary loop of the Process Chilled Water System is designed as a dedicated utility system that is located within the detached or combination process facility.

There are two possible alternatives to the selected configuration for the Process Chilled Water System:

1. Locate a single Process Chilled Water System inside the MUB. This shared chilled water system would serve both the LLW and the HLW facilities.

2. Locate a single Process Chilled Water System inside the Separations/LLW facility with enough capacity to serve both the LLW and the HLW facilities.

Radiological protection considerations eliminate both alternatives 1 and 2. All cooling water that has come into direct contact with the offgas process may become contaminated with radioactive process fluids and, therefore, must remain within the Process facilities.

Secondary cooling loops and other backflow prevention measures would be designed into the process to mitigate the backflow of radioactive material from the process cells and from the process facilities. However, it is inherently safer to contain the Process Chilled Water Subsystems in the facilities where the cooling is needed.

Other considerations that were evaluated and found not to be contributors to the function configuration are noted below:

Operability and Maintainability. This study has not identified any Operability or Maintainability issues that are unique to any single configuration considered for this system. Therefore, Operability and Maintainability are not considerations that were used to determine the configuration of this system. 
Cost Effectiveness. This study has not identified any cost drivers that would override the technical considerations used to define the configuration of this system.

Therefore, Cost Effectiveness is not a consideration that was used to determine the configuration of this system.

Safety. This study has not identified any Safety issues that are unique to any single configuration considered for this system. Therefore, Safety is not a consideration that was used to determine the configuration of this system.

Environmental Regulatory Compliance. This study has not identified any Environmental Regulatory Compliance issues that are unique to any single configuration considered for this system. Therefore, Environmental Regulatory Compliance is not a consideration that was used to determine the configuration of this system.

Schedule. The configuration of this system does not impact the schedule for the design, construction, or startup of the TWRS Treatment Complex.

Technical Maturity. Commercially demonstrated technology is used in the design of this system. Therefore, Technology issues were not a consideration for the configuration of this system.

Design Impact. This study has not identified any Design Impact issues that are unique to any single configuration considered for this system. Therefore, Design Impact is not a consideration that was used to determine the configuration of this system.

\subsubsection{Utility Steam System}

3.4.10.1 System Description. The Utility Steam System produces and distributes steam to various TWRS facility users. Saturated steam is generated at $1,136 \mathrm{kPa}$ (150 psig) in electric steam generators.

The Utility Steam System consists of two shared electric Utility Steam Generators and their associated equipment, the condensate collection system (for condensate trapped from steam distribution piping), and the steam distribution piping. This equipment is located in the MUB.

The system consists of two equally sized steam generators (7.76 MW each). The steam required for continuous users in both process facilities along with the steam required for 60 percent of all intermittent users operating simultaneously, can be supplied by one steam generator. Therefore, the second steam generator is a spare. 
The utility steam is supplied to various steam jet pumps in the process system, the process equipment decontamination cell, the radioactive waste treatment sump jet pumps, as well as utility stations in various facilities. The utility steam generators receive make-up water from the demineralized water system.

See page A-14 of Appendix A for the Block Flow Diagram of this system. UFD-4-10 is a Utility Flow Diagram (see Appendix B) for the Utility Steam System. The annual consumption of utility steam is shown on the Configuration 4 Summary of Annual Utility Consumption in Appendix C.

3.4.10.2 Findings. The Utility Steam System is a shared, close-external, system. Cost Effectiveness is the prime consideration for the configuration of the Utility Steam System. The steam produced by the Utility Steam System is shared by the process facilities to take advantage of the economies of scale. This system is grouped with the Compressed Air System, the Demineralized Water System, and the HVAC Chillers in the MUB.

3.4.10.3 Function Configuration Considerations and Rationale. Cost Effectiveness is the prime consideration for the design of this system. The majority of the utility steam users are in the Separations/LLW facilities. The amount of utility steam needed for the HLW facilities is about one-forth of the total steam demand. The steam generators selected for the Separations/LLW facilities are nearly the same size as the steam generators selected for the entire load, including the HLW facility area. There is no cost savings realized by installing a smaller, dedicated Utility Steam System for the Separations/LLW because an additional dedicated system would need to be installed for the future HLW facility. Installing a single Utility Steam System sized to serve the entire treatment complex is the most cost effective configuration. The total engineered cost of a single Utility Steam System sized to serve the entire facility would be $\$ 6,279,000$. The total engineered cost of two individual systems (one sized to serve the Separations/LLW facility and the other sized to serve the HLW facility) would be $\$ 8,286,000$. It is clearly more cost effective to install a single Utility Steam System sized to serve all facilities.

Costs given here represent the mechanical equipment costs and specifically exclude the costs of the building to house the equipment.

Due to the heat loss involved with long lengths of piping, the Utility Steam Generators and their associated equipment need to be located on site, close to the process facilities. A remote location for the steam generators would require steam superheating at the steam generator, line tracing, and additional insulation. These features would increase the capital and operating costs.

Other considerations that were evaluated and found not to be contributors to the function configuration are noted below: 
Operability and Maintainability. This study has not identified any Operability or Maintainability issues that are unique to any single configuration considered for this system. Therefore, Operability and Maintainability are not considerations that were used to determine the configuration of this system.

Radiological Protection (ALARA). This study has not identified any Radiological Protection (ALARA) issues that are unique to any single configuration considered for this system. Therefore, Radiological Protection (ALARA) is not a consideration that was used to determine the configuration of this system.

Safety. This study has not identified any Safety issues that are unique to any single configuration considered for this system. Therefore, Safety is not a consideration that was used to determine the configuration of this system.

Environmental Regulatory Compliance. This study has not identified any Environmental Regulatory Compliance issues that are unique to any single configuration considered for this system. Therefore, Environmental Regulatory Compliance is not a consideration that was used to determine the configuration of this system.

Schedule. The configuration of this system does not impact the schedule for the design, construction, or startup of the TWRS Treatment Complex.

Technical Maturity. Commercially demonstrated technology is used in the design of this system. Therefore, Technology issues were not a consideration for the configuration of this system.

Design Impact. This study has not identified any Design Impact issues that are unique to any single configuration considered for this system. Therefore, Design Impact is not a consideration that was used to determine the configuration of this system.

\subsubsection{Compressed Air System}

3.4.11.1 System Description. The Compressed Air System provides instrument air for pneumatically controlled components; plant air for spargers, jets, and general maintenance use; and breathing air. The air compressors provide a continuous supply of plant and instrument air at varying flow rates for users throughout the site. Breathing air is supplied from dedicated bottles, as needed.

The Compressed Air System is divided into three subsystems - plant air, instrument air, and breathing air. The plant air subsystem includes compressors, filters, and an air receiver. The instrument air subsystem includes compressors, filters, air dryers, and an air 
receiver. The breathing air subsystem includes bottled breathing quality air, filters, manifolds, and carts.

One set of compressors provides both the instrument air and the plant air. Bottled breathing air is purchased from an approved supplier. The compressed air equipment is located in the MUB and the breathing air bottles are located in the breathing air bottle storage area. A set of three 50 percent capacity compressors (two operating and one spare) serves the needs of the Separations/LLW facility, the HLW facility, and the other process support facilities.

See pages A-15 of Appendix A for the Block Flow Diagrams for this system. Drawing UFD-4-11 is a Utility Flow Diagram (see Appendix B) for the Compressed Air System. The annual consumption of compressed air is shown on the Summary of Annual Utility and Chemical Consumption table in Appendix C.

3.4.11.2 Finding. The Compressed Air System is a shared, no distance constrained (with the exception of the breathing air subsystem), system. Cost Effectiveness is the prime consideration for the configuration of the Compressed Air System. The air compressors, plant air filters, plant and instrument air receivers, and instrument air dryers are shared by the process facilities to take advantage of the economies of scale. This system is grouped with the Utility Steam System, the HVAC Chillers, and the Demineralized Water System in the MUB. With the exception of the breathing air subsystem, which must be close-linked and located in a process facility annex, these functions could be provided from almost anywhere and are candidates for being furnished from existing facilities.

3.4.11.3 Function Configuration Considerations and Rationale. Cost Effectiveness is the prime consideration for the Compressed Air System configuration. The majority of the compressed air is used in the Separations/LLW facility and the HLW facility consumes only about one-twelfth of the total air consumed on site. The number and size of the compressors selected for the Separations/LLW facility will have sufficient capacity to serve both the Separations/LLW and the HLW facilities. No additional compressors are needed for the future HLW facility. Therefore, adding future HLW compressors to the system adds extra, unnecessary cost.

Other components of the Compressed Air System, such as the receiver vessels, may be marginally reduced in size if a dedicated system for the HLW facility were installed. However, the duplication of equipment for dedicated systems would more than offset this minimal cost savings. A shared Compressed Air System would have a total engineered cost of $\$ 7,325,000$. Two separate, dedicated Compressed Air Systems would have a total engineered cost of $\$ 9,316,000$.

Costs given here represent the mechanical equipment costs and specifically exclude the costs of the building to house the equipment. 
There is no specific need for this system to be located in close proximity to the process operations. This system is defined as not being distance constrained.

Other considerations that were evaluated and found not to be contributors to the function configuration are noted below:

Operability and Maintainability. This study has not identified any Operability or Maintainability issues that are unique to any single configuration considered for this system. Therefore, Operability and Maintainability are not considerations that were used to determine the configuration of this system.

Radiological Protection (ALARA) This study has not identified any Radiological Protection (ALARA) issues that are unique to any single configuration considered for this system. Therefore, Radiological Protection (ALARA) is not a consideration that was used to determine the configuration of this system.

Safety. This study has not identified any Safety issues that are unique to any single configuration considered for this system. Therefore, Safety is not a consideration that was used to determine the configuration of this system.

Environmental Regulatory Compliance. This study has not identified any Environmental Regulatory Compliance issues that are unique to any single configuration considered for this system. Therefore, Environmental Regulatory Compliance is not a consideration that was used to determine the configuration of this system.

Schedule. The configuration of this system does not impact the schedule for the design, construction, or startup of the TWRS Treatment Complex.

Technical Maturity. Commercially demonstrated technology is used in the design of this system. Therefore, Technology issues were not a consideration for the configuration of this system.

Design Impact. This study has not identified any Design Impact issues that are unique to any single configuration considered for this system. Therefore, Design Impact is not a consideration that was used to determine the configuration of this system.

\subsubsection{Process Water System}

3.4.12.1 System Description. The Process Water System supplies process water to various users around the facility. The Sanitary Water System is the source of the Process Water. The Process Water System in turn is the source of demineralized water. 
The Process Water System consists of the Bulk Water Storage Tank, the Bulk Water Supply Pumps, and the water distribution piping.

Process water is primarily used for feed water to the demineralizer, cold chemical make-up, pump priming and equipment flushing.

The process water is received from the Sanitary Water System. It is stored in the Bulk Water Storage Tank, which is collocated with the fire water tanks outside the WPH. From this storage tank, the process water is distributed on demand to the demineralizer, various cold chemical make-up tanks, and the chemically contaminated liquid waste tanks in the BCCB. The process water is also supplied on demand to various in-cell process tanks, cold chemical feed tanks, the potentially radioactive liquid waste catch tanks (seal legs), the $\mathrm{AF}$, and the Fan/Filter Annexes. All of these process water users are once-through, and the water is consumed in the process.

See pages A-16 and A-17 of Appendix A for the Block Flow Diagrams for the Process Water System. Drawing UFD-4-12 is a Utility Flow Diagram (see Appendix B) for the Process Water System and Demineralized Water System. The annual consumption of process water is in Appendix C, Utility Consumption Tables Electrical Loads List.

3.4.12.2 Findings. The Process Water System is a shared system with no distance constraints. Cost Effectiveness is the prime consideration for the configuration of the Process Water System. The Process Water Tank and pumps are shared by the process facilities to take advantage of the economies of scale. The Process Water Pumps are grouped with the Fire Water Pumps in the WPH. The Process Water Tank is grouped with the Fire Water Tanks that are located near the WPH. The Process Water System functions could be provided from almost anywhere and are candidates for being furnished from existing Hanford facilities.

3.4.12.3 Function Configuration Considerations and Rationale. Cost Effectiveness is the prime function discriminator for the Process Water System. The process water requirement for the HLW facility is about 23 percent of the TWRS site process water usage. The shared Process Water System consists of a single Bulk Water Storage Tank and a set of pumps that are sized to serve the entire TWRS facility. Alternatively, dedicated Process Water Systems would consist of a tank and set of pumps dedicated to serve the Separations/LLW facility and an additional tank and set of pumps dedicated to serve the HLW facility. The total engineered cost of a single process water tank and a set of pumps that are sized to serve the entire facility would be $\$ 349,000$. The total engineered cost for two dedicated process water tanks and their associated pumps (one tank with pumps dedicated to the Separations/LLW facility and one tank with pumps dedicated to the HLW facility) would be $\$ 441,000$. Sizing a single tank, set of pumps, and header to serve the entire site, with a tie-in for the future HLW facility, is less costly than running a separate line from a separate tank to the HLW facility. 
The process water costs given here represent the mechanical equipment costs and specifically exclude the costs of the building to house the equipment.

There are no technical requirements for the close-proximity of the water tanks or WPH to the process or process support facilities. This system is defined as not being distance constrained.

Other considerations that were evaluated and found not to be contributors to the function configuration are noted below:

Operability and Maintainability. This study has not identified any Operability or Maintainability issues that are unique to any single configuration considered for this system. Therefore, Operability and Maintainability are not considerations that were used to determine the configuration of this system.

Radiological Protection (ALARA). This study has not identified any Radiological Protection (ALARA) issues that are unique to any single configuration considered for this system. Therefore, Radiological Protection (ALARA) is not a consideration that was used to determine the configuration of this system.

Safety. This study has not identified any Safety issues that are unique to any single configuration considered for this system. Therefore, Safety is not a consideration that was used to determine the configuration of this system.

Environmental Regulatory Compliance. This study has not identified any Environmental Regulatory Compliance issues that are unique to any single configuration considered for this system. Therefore, Environmental Regulatory Compliance is not a consideration that was used to determine the configuration of this system.

Schedule. The configuration of this system does not impact the schedule for the design, construction, or startup of the TWRS Treatment Complex.

Technical Maturity. Commercially demonstrated technology is used in the design of this system. Therefore, Technology issues were not a consideration for the configuration of this system.

Design Impact. This study has not identified any Design Impact issues that are unique to any single configuration considered for this system. Therefore, Design Impact is not a consideration that was used to determine the configuration of this system. 
WHC-SD-W378-ES-002

Revision 0

\subsubsection{Demineralized Water System}

3.4.13.1 System Description. The Demineralized Water System supplies demineralized water to various users around the facility. The Process Water System supplies water to the demineralizer.

The Demineralized Water System consists of the Demineralizer, the Demineralized Water Storage Tank, the Demineralized Water Supply Pumps and the water distribution piping.

The largest continuous user of demineralized water is the Utility Steam System, which uses the demineralized water as make-up water. Demineralized water is also used for noncontinuous uses, such as fill and make-up of the closed loop water systems - the Process Steam System, the Process Cooling Water System, the Melter Cooling Water System, and the Chilled Water System. Process water is converted to Demineralized Water by the Demineralizer in the MUB, and is stored in the Demineralized Water Storage Tank. The Demineralized Water is distributed on demand to the users listed above.

See page A-18 of Appendix A for the Block Flow Diagram for the Demineralized Water System. Drawing UFD-4-12 is a Utility Flow Diagram (see Appendix B) for the Process Water System and Demineralized Water System. The annual consumption of process water is in Appendix C, Utility Consumption Tables Electrical Loads List.

3.4.13.2 Findings. The Demineralized Water System is a shared system with no distance constraints. Cost Effectiveness and operability are considerations for the configuration of the Demineralized Water System. The Demineralizer, Demineralized Water Storage Tank, and pumps are shared by the process facilities to take advantage of the economies of scale. The Demineralizer, Demineralized Water Storage Tank, and Demineralized Water Pumps are grouped with the Utility Steam System, the HVAC chillers, and the Compressed Air System in the MUB. However, the Demineralized Water System functions could be provided from álmost anywhere and are candidates for being furnished from existing Hanford facilities.

3.4.13.2 Function Configuration Considerations and Rationale. Cost Effectiveness is the prime function discriminator for the Demineralized Water System. The demineralized water requirement for the HLW facility is about 17 percent of the total demineralized water usage. Sizing a single, shared Demineralized Water System to serve the entire site, with a tie-in for the future HLW facility, is less costly than reserving space in the MUB and installing a future dedicated Demineralized Water System for the HLW facility. A shared Demineralized Water System would have a total engineered cost $\$ 975,000$. The total engineered cost of two, separate, dedicated Demineralized Water Systems would be $\$ 1,268,000$.

The demineralized water costs given here represent the mechanical equipment costs and specifically exclude the costs of the building to house the equipment. 
Operability is also a consideration for the Demineralized Water System. The Demineralized Water System is operationally integrated with the Utility Steam System. The Utility Steam System requires a continuous supply of demineralized water to make steam. The Utility Steam System is also the largest consumer of demineralized water. The Demineralized Water System can be considered to be an integral part of the Utility Steam System. Therefore, it is logical to make the configuration of the Demineralized Water System match the configuration of the Utility Steam System. A set of dedicated demineralized water units would be mismatched with the shared steam generators. Therefore, a shared Demineralized Water System, grouped with the Utility Steam System, is favored for the operability of the shared Utility Steam System.

There are no technical requirements for the close-proximity of the Demineralizer, Demineralized Water Storage Tank, and pumps to the process or process support facilities. Higher head pumps would need to be provided for this system if a remote location is selected. This system is defined as not being distance constrained.

Other considerations that were evaluated and found not to be contributors to the function configuration are noted below:

Radiological Protection (ALARA). This study has not identified any Radiological Protection (ALARA) issues that are unique to any single configuration considered for this system. Therefore, Radiological Protection (ALARA) is not a consideration that was used to determine the configuration of this system.

Safety. This study has not identified any Safety issues that are unique to any single configuration considered for this system. Therefore, Safety is not a consideration that was used to determine the configuration of this system.

Environmental Regulatory Compliance. This study has not identified any Environmental Regulatory Compliance issues that are unique to any single configuration considered for this system. Therefore, Environmental Regulatory Compliance is not a consideration that was used to determine the configuration of this system.

Schedule. The configuration of this system does not impact the schedule for the design, construction, or startup of the TWRS Treatment Complex.

Technical Maturity. Commercially demonstrated technology is used in the design of this system. Therefore, Technology issues were not a consideration for the configuration of this system.

Design Impact. This study has not identified any Design Impact issues that are unique to any single configuration considered for this system. Therefore, Design Impact is not a consideration that was used to determine the configuration of this system. 


\subsubsection{Sanitary Water System}

3.4.14.1 System Description. The Sanitary Water System supplies water for potable water and utility users, and for HVAC humidifiers. It is also the source for the Process Water System, the TWRS Treatment Complex Site Fire Water Tank, and the Process Facility Fire Water Tanks. All safety showers and eye washes are supplied by the Sanitary Water System. The Sanitary Water System consists of distribution piping installed in a loop around the site. The sanitary water is available at 100 psig from the sanitary water header north of 4th Street.

See page A-19 of Appendix A for the Block Flow Diagrams for this system. Drawing UFD-4-13 is a Utility Flow Diagram (see Appendix B) for the Sanitary Water System. The annual consumption of sanitary water is provided in Appendix C, Utility Consumption Tables and Electrical Load List.

3.4.14.2 Findings. The Sanitary Water System is a shared, close-external system. Operability and Maintainability are the prime considerations for the configuration of the Sanitary Water System. The sanitary water inlet manifold is grouped with the raw water inlet manifold in the WPH. The most significant portion of this system is the underground distribution piping. By definition this must be close external to the facilities being served and runs throughout the complex site.

3.4.14.3 Function Configuration Considerations and Rationale. Operability (practicality of design) and Maintainability are the prime considerations for the configuration of the Sanitary Water System. The sanitary water is supplied to the facility from a single source, and is distributed to the users through underground piping. The sanitary water must be provided (by a piping distribution system) to each building where it is required. Therefore, the piping distribution loop must be by nature close-external. This system is also, by its nature, a shared facility. Dedicated sanitary water systems would require two piping loop systems. These two piping loops would unnecessarily increase the complexity of the system. Therefore, a single shared system is provided.

Tie-in points to the future HLW facility, or any process support facilities that are dedicated to the HLW facility, would be provided in the distribution loop.

Maintainability is also a configuration design consideration for the Sanitary Water System. The main sanitary supply header is designed as a continuous loop around the site. This loop design allows the water to flow in either direction through the header. Sections of the header can be isolated and taken out of service for maintenance without interrupting the supply of sanitary water to the other users. Therefore, a complete loop should be installed to serve the Separations/LLW facilities. The loop should have a "blinded" tie-in point for the line to the deferred HLW facility. 
WHC-SD-W378-ES-002

Revision 0

There is no distance constraint on the location of the inlet manifold as long as the pressure and flow requirements are met. However, the distribution loop portion of the Sanitary Water System must be located in close-proximity to the process and process support facilities. This system is defined as being close-external.

Other considerations that were evaluated and found not to be contributors to the function configuration are noted below:

Cost Effectiveness. This study has not identified any cost drivers that would override the technical considerations used to define the configuration of this system. Therefore, Cost Effectiveness is not a consideration that was used to determine the configuration of this system.

Radiological Protection (ALARA). This study has not identified any Radiological Protection (ALARA) issues that are unique to any single configuration considered for this system. Therefore, Radiological Protection (ALARA) is not a consideration that was used to determine the configuration of this system.

Safety. This study has not identified any Safety issues that are unique to any single configuration considered for this system. Therefore, Safety is not a consideration that was used to determine the configuration of this system.

Environmental Regulatory Compliance. This study has not identified any Environmental Regulatory Compliance issues that are unique to any single configuration considered for this system. Therefore, Environmental Regulatory Compliance is not a consideration that was used to determine the configuration of this system.

Schedule. The configuration of this system does not impact the schedule for the design, construction, or startup of the TWRS Treatment Complex.

Technical Maturity. Commercially demonstrated technology is used in the design of this system. Therefore, Technology issues were not a consideration for the configuration of this system.

Design Impact. This study has not identified any Design Impact issues that are unique to any single configuration considered for this system. Therefore, Design Impact is not a consideration that was used to determine the configuration of this system. 


\subsubsection{Raw Water System}

3.4.15.1 System Description. The Raw Water System supplies make-up water for the cooling tower and fire water for the TWRS Treatment Complex site fire water header. The raw water is available at 100 psig from the 200 East Area raw water header north of 4th Street. The Raw Water System consists exclusively of piping (which includes items like flow meters, pressure gages, and temperature gages).

See page A-20 of Appendix A for the Block Flow Diagram of the Raw Water System. Drawing UFD-4-14 is a Utility Flow Diagram (see Appendix B) for the Raw Water and Fire Water System. Refer to the Utility Consumption Tables, Appendix C, for the annual consumption of Raw Water.

3.4.15.2 Findings. The Raw Water System is a shared, close-external system. Operability is the prime consideration for the configuration of the Raw Water System. The Raw Water inlet manifold is grouped with the Sanitary Water manifold in the WPH.

3.4.15.3 Function Configuration Considerations and Rationale. Operability (practicality of design) is the prime consideration for the configuration of the Raw Water System. The raw water is supplied to the facility from a single source and distributed to the users through underground piping. The Raw Water System provides fire water for the site fire water loop, and make-up water for the Cooling Tower. Both of these users are designated as shared functions. This system is, then, by its nature a shared facility. The most significant portion of this system is the underground distribution piping. By definition this must be close external to the facilities being served and runs throughout the complex site.

Tie-in points to any future HLW facility users, or any future process support facilities that are dedicated to the HLW facility, would be provided in the distribution loop.

There is no distance constraint on the location of the inlet manifold as long as the pressure and flow requirements are met. This system is defined as not being distance constrained.

Other considerations that were evaluated and found not to be contributors to the function configuration are noted below:

Cost Effectiveness. This study has not identified any cost drivers that would override the technical considerations used to define the configuration of this system. Therefore, Cost Effectiveness is not a consideration that was used to determine the configuration of this system.

Radiological Protection (ALARA). This study has not identified any Radiological Protection (ALARA) issues that are unique to any single configuration considered for this system. Therefore, Radiological Protection (ALARA) is not a consideration that was used to determine the configuration of this system. 
WHC-SD-W378-ES-002

Revision 0

Safety. This study has not identified any Safety issues that are unique to any single configuration considered for this system. Therefore, Safety is not a consideration that was used to determine the configuration of this system.

Environmental Regulatory Compliance. This study has not identified any Environmental Regulatory Compliance issues that are unique to any single configuration considered for this system. Therefore, Environmental Regulatory Compliance is not a consideration that was used to determine the configuration of this system.

Schedule. The configuration of this system does not impact the schedule for the design, construction, or startup of the TWRS Treatment Complex.

Technical Maturity. Commercially demonstrated technology is used in the design of this system. Therefore, Technology issues were not a consideration for the configuration of this system.

Design Impact. This study has not identified any Design Impact issues that are unique to any single configuration considered for this system. Therefore, Design Impact is not a consideration that was used to determine the configuration of this system.

\subsubsection{Tank Waste Remediation System Treatment Complex Site Fire Water System}

3.4.16.1 System Description. The TWRS Treatment Complex Site Fire Water System provides water to fire hydrants located throughout the site, and risers and sprinklers in support building facilities. The main fire water header forms a continuous loop around the site. Sectionalizing valves are provided on the main fire water loop. In the event of a leak or line break, a section of the main header can be isolated without interrupting service to the rest of the header.

The TWRS Treatment Complex Site Fire Water System has two independent sources of water, Raw Water and Sanitary Water. Raw water is used to pressurize the main fire water loop. Sanitary water is used to fill the Site Fire Water Storage Tank TK-1612.

An independent source of water from the fire water storage tank increases the reliability of the system to fight fire. The jockey pumps ensure that the fire water headers are pressurized. The fire water pumps supplement the fire water supply when the raw water supply from the 200 East Area cannot meet the demand. The diesel generator supplies power to the fire water pumps when there is a power failure.

The TWRS Treatment Complex Site Fire Water System includes storage tanks, pumps, electric heaters, headers, and distribution piping. Diesel driven fire water pumps are 
WHC-SD-W378-ES-002

Revision 0

provided as a backup to the main electric motor driven pumps. The electric heaters and circulation pumps provide freeze protection by heating the water in the outdoor storage tanks.

See page A-20 of Appendix A for the Block Flow Diagram of the TWRS Treatment Complex Site Fire Water System. Drawing UFD-4-14 is a Utility Flow Diagram (see Appendix B) for the Raw Water and TWRS Treatment Complex Site Fire Water System.

3.4.16.2 Findings. The TWRS Treatment Complex Site Fire Water System, with the exception of the underground piping, is a shared, no distance constrained system. The underground piping is considered to be a shared close-external system. Operability and Maintainability are considerations for the configuration of the TWRS Treatment Complex Site Fire Water System. The TWRS Treatment Complex Site Fire Water System is shared by all facilities onsite except the process facilities, which have dedicated fire water systems.

The Fire Water Storage Tank is grouped with the Process Facility Fire Water Tanks and the Process Water Tank in an area adjacent to the WPH. The jockey pumps are grouped with the Process Facility Fire Water Pumps and the Process Water Pumps in the WPH. The underground piping is routed throughout the complex site and is considered close-external to the process facilities.

The TWRS Treatment Complex Site Fire Water storage and pumping functions could be provided from almost anywhere and are candidates for being furnished from existing facilities.

3.4.16.3 Function Configuration Considerations and Rationale. Operability (practicality of design) is the prime consideration for the TWRS Treatment Complex Site Fire Water System configuration. The TWRS Treatment Complex Site Fire Water Systems is designed as a shared system. The site fire water header is looped around the buildings on site and is designed to serve both the Separations/LLW facility support buildings and the future HLW facility support buildings. A "blinded" tie-in point is added in to the fire water loop for the future HLW process support facilities. Two dedicated site fire water systems would require an additional piping loop and pumps. This would unnecessarily increase the physical complexity of the system. Therefore, a single shared system is specified here.

For ease of operation and maintenance, a single pumphouse is used to house all of the fire water pumps and the Process Water Pumps, and to shelter the off-site water supply manifolds. Also, the loop design of the fire water header allows sections of the fire water loop to be isolated for maintenance without impairing the fire protection capability of the system.

Due to the design requirements of the TWRS Treatment Complex Fire Water System, the site fire water tank and loop will be sized the same regardless of whether or not the HLW facility is in place. 
This storage and pumping portion of this system is defined as not being distance constrained. Therefore, there are no distance constraints on the location of the Site Fire Water Tank or the WPH. The distribution loop portion of the TWRS Treatment Complex Site Fire Water System must be located in close-proximity to the process and process support facilities that it serves.

Other considerations that were evaluated and found not to be contributors to the function configuration are noted below:

Cost Effectiveness. This study has not identified any cost drivers that would override the technical considerations used to define the configuration of this system.

Therefore, Cost Effectiveness is not a consideration that was used to determine the configuration of this system.

Radiological Protection (ALARA). This study has not identified any Radiological Protection (ALARA) issues that are unique to any single configuration considered for this system. Therefore, Radiological Protection (ALARA) is not a consideration that was used to determine the configuration of this system.

Safety. This study has not identified any Safety issues that are unique to any single configuration considered for this system. Therefore, Safety is not a consideration that was used to determine the configuration of this system.

Environmental Regulatory Compliance. This study has not identified any Environmental Regulatory Compliance issues that are unique to any single configuration considered for this system. Therefore, Environmental Regulatory Compliance is not a consideration that was used to determine the configuration of this system.

Schedule. The configuration of this system does not impact the schedule for the design, construction, or startup of the TWRS Treatment Complex.

Technical Maturity. Commercially demonstrated technology is used in the design of this system. Therefore, Technology issues were not a consideration for the configuration of this system.

Design Impact. This study has not identified any Design Impact issues that are unique to any single configuration considered for this system. Therefore, Design Impact is not a consideration that was used to determine the configuration of this system. 
WHC-SD-W378-ES-002

Revision 0

\subsubsection{Process Facility Fire Water System}

3.4.17.1 System Description. The Process Facility Fire Water System provides water for fire suppression for each process facility.

The fire water storage tanks TK-1613 A and B provide fire water to the process facilities through dedicated distribution loops. These tanks are sized to limit the amount of fire water entering each process facility. In cases of mis-operation, the volume of the TWRS Treatment Complex Site Fire Water Tank would potentially flood the process buildings. One tank is dedicated to the sprinkler system within the HLW facility and the other tank is dedicated to the sprinkler system within the Separations/LLW facility. Sanitary Water is used to fill the Process Facility Fire Water Storage Tanks TK-1613 A and B.

Each Process Facility Fire Water System includes a storage tank, pumps, electric heaters, headers and distribution piping. Diesel driven fire water pumps are provided as a backup to the main electric motor driven pumps. The electric heaters and circulation pumps provide freeze protection by heating the water in the outdoor storage tanks.

See page A-21 of Appendix A for the Block Flow Diagram of the Process Facility Fire Water System. Drawing UFD-4-14 is a Utility Flow Diagram (see Appendix B) for the Process Facility Fire Water System.

3.4.17.2 Findings. The Process Facilities Fire Water System with the exception of the underground piping, is a dedicated, no distance constrained system. The underground piping system is considered to be a shared close-external system. Safety and Operability and Maintainability considerations for the configuration of the Process Facilities Fire Water System. To prevent flooding of the process facilities, each process facility has its own, dedicated fire water system. The Process Facilities Fire Water Tanks and Pumps are grouped with the TWRS Treatment Complex Site Fire Water Tank and Pumps. The fire water storage and pumping functions could be provided from almost anywhere and are candidates for being furnished from existing Hanford facilities. However, it must be noted that there is a maximum size limitation for these tanks to prevent flooding. The underground piping is routed through the TWRS Treatment Complex and is considered close-external to the process facilities.

3.4.17.3 Functional Configuration Considerations and Rationale. Safety is the prime consideration for the Process Facilities Fire Water System configuration. The fire water pumps activate automatically, but require an operator to stop them. Therefore, it is possible to empty the entire contents of a fire water tank into a process facility. The dedicated Fire Water Tanks are sized to limit the amount of fire water that can enter a process facility to prevent flooding of the building and the potential damage that flooding can cause. Therefore, the Process Facility Fire Water System is a dedicated system. 
Operability and maintainability are also considerations for the Process Facility Fire Water System. For ease of operation a single pumphouse is used to house the all of the Fire Water Pumps and the Process Water Pumps, and to shelter the off-site water supply manifolds. The fire water pumps are automated to deliver water to the required services. The fire water pumps are switched on when the pressure in the fire water line falls below the desired set-point. The pumps, however, do not have an automatic shut-off. An operator is required to shut down the pumps.

Two dedicated fire water piping loops serve the Separations/LLW and HLW Process Buildings only. These loops allow the water to flow in either direction through the headers. Sections of the fire water loop can be isolated for maintenance without impairing the fire protection capability of the system.

The construction of the HLW fire water tank and pumps could be deferred until the HLW facility is constructed. However, plot space onsite for the Fire Water Tank and inside the WPH for the fire water pumps needs to be reserved.

There is no specific need for this system to be located in close-proximity to the process operations. However, higher head pumps would be needed if a remote location is selected. This system is defined as not being distance constrained.

Other considerations that were evaluated and found not to be contributors to the function configuration are noted below:

Cost Effectiveness. - This study has not identified any cost drivers that would override the technical considerations used to define the configuration of this system. Therefore, Cost Effectiveness is not a consideration that was used to determine the configuration of this system.

Radiological Protection (ALARA). This study has not identified any Radiological Protection (ALARA) issues that are unique to any single configuration considered for this system. Therefore, Radiological Protection (ALARA) is not a consideration that was used to determine the configuration of this system.

Environmental Regulatory Compliance. This study has not identified any Environmental Regulatory Compliance issues that are unique to any single configuration considered for this system. Therefore, Environmental Regulatory Compliance is not a consideration that was used to determine the configuration of this system.

Schedule. The configuration of this system does not impact the schedule for the design, construction, or startup of the TWRS Treatment Complex. 
Technical Maturity. Commercially demonstrated technology is used in the design of this system. Therefore, Technology issues were not a consideration for the configuration of this system.

Design Impact. This study has not identified any Design Impact issues that are unique to any single configuration considered for this system. Therefore, Design Impact is not a consideration that was used to determine the configuration of this system.

\subsubsection{Waste Condensate Collection System}

3.4.18.1 System Description. The Waste Condensate Collection Systems for the HLW facility and the Separations/LLW facility have essentially the same function. Both systems are located in annexes outside, but adjacent to, the process buildings.

In the HLW process, condensate drains from in-cell evaporators to any one of three condensate collection tanks, where chemical adjustments are made before pumping the condensate to a single $\mathrm{pH}$ Adjustment tank, and from there, to the condensate retention basin. Off-spec condensate can be returned to the in-cell feed evaporator tanks for reprocessing.

The function of the condensate collection system for the LLW process is the same as described above for the HLW process with the exception that part of the condensate is recycled for use in the Separations process. The balance of the condensate is pumped to the condensate retention basin.

3.4.18.2 Findings. The Waste Condensate Collection System is a dedicated system located in an annex adjacent to the process facility it serves. Design impact is the prime configuration consideration for the Waste Condensate Collection System.

3.4.18.3 Facility Configuration Considerations and Rationale. Design Impact is the prime consideration for the Waste Condensate Collection System configuration. The condensate collection functions are to be dedicated to the process facilities they serve, i.e., the Separations/LLW and the HLW facilities. Condensate is generated within the processing facilities as a result of evaporating water from the process feeds and then condensing the water from the vapors leaving the evaporators. The condensed water must flow by gravity to the condensate collection tanks. Sloping requirements and the associated depth of excavation is minimized by installing collection tanks dedicated to the building they serve, located at minimum distance from that building.

The process operating conditions and location of the condensate tanks for each facility should be optimized for each facility. Keeping the condensate collection system for the High Level Waste process divorced from the Separations/LLW processes maximizes flow sheet and facility layout design flexibility. 
A shared condensate collection system would provide a cost savings associated with economies of scale and consolidation of support functions. For the overall function and associated facility, these cost savings would be at least partially and probably totally offset by the greater depth of excavation required for locating the shared facility at a greater distance from the process facilities. Any cost advantage is outweighed by process flow sheet requirements and flexibility considerations.

Other considerations that were evaluated and found not to be contributors to the function configuration are noted below:

Operability and Maintainability. This study has not identified any Operability or Maintainability issues that are unique to any single configuration considered for this system. Therefore, Operability and Maintainability are not considerations that were used to determine the configuration of this system.

Radiological Protection (ALARA). This study has not identified any Radiological Protection (ALARA) issues that are unique to any single configuration considered for this system. Therefore, Radiological Protection (ALARA) is not a consideration that was used to determine the configuration of this system.

Safety. This study has not identified any Safety issues that are unique to any single configuration considered for this system. Therefore, Safety is not a consideration that was used to determine the configuration of this system.

Environmental Regulatory Compliance. This system is designed to handle RCRA type dangerous wastes regulated by WAC 173-303, and each facility within this system will be permitted under this regulation. This is not considered to be a significant issue, therefore, Environmental Regulatory Compliance is not a consideration that was used to determine the configuration of this system.

Schedule. The configuration of this system does not impact the schedule for the design, construction, or startup of the TWRS Treatment Complex.

Technical Maturity. Commercially demonstrated technology is used in the design of this system. Therefore, Technology issues were not a consideration for the configuration of this system.

\subsubsection{Cooling Tower Water System}

3.4.19.1 System Description. The Cooling Tower Water System removes heat from normal processing operations and from the various cooling water systems in the process and support facilities, and then rejects that heat via evaporative cooling. The Cooling Tower Water System includes the Cooling Tower, Cooling Tower Water Circulation Pumps, Inhibitor Addition Pump, and distribution piping for the various users. Raw water is used 
for cooling tower make-up. The bleedoff from the cooling tower is routed to the 200 Area TEDF.

The Cooling Tower Water System has a recirculating cooling water loop that provides cooling water to out-of-cell equipment including the closed loop Process Cooling Water System and the closed loop Melter Cooling Water System. It consists of three cooling water pumps (two operating and one spare). An electric heater is provided in the basin to prevent the water temperature from falling below $4.4{ }^{\circ} \mathrm{C}\left(40^{\circ} \mathrm{F}\right)$.

The Cooling Tower is constructed of multiple cooling cells. Each cell has a fixed cooling capacity. The individual cells can be put into service or removed from service to match the cooling load.

The cooling water is lost from the system on a continuous basis due to evaporation, drift, and bleedoff. Raw water is used as make-up and is regulated by the level control of the cooling tower basin. A corrosion inhibitor is pumped directly from a storage drum to the cooling tower water return header by a metering pump.

See page A-22 of Appendix A for the Block Flow Diagram of this system. Drawing UFD-4-15 is the Utility Flow Diagram (see Appendix B) of the Cooling Tower Water System. The annual duty for the cooling tower is provided in Appendix C, Utility Consumption Tables and Electrical Load List.

3.4.19.2 Findings. The Cooling Tower Water system is a shared, no distance constrained, system. Cost Effectiveness is the prime configuration consideration for the Cooling Water System. The Cooling Tower and Cooling Tower Water Circulation Pumps are shared by the process and support facilities to take advantage of the economies of scale. The Cooling Tower function could be provided from almost anywhere and is a candidate for being furnished from the existing Hanford facilities.

3.4.19.3 Function Configuration Considerations and Rationale. Cost Effectiveness is the prime consideration for the Cooling Tower Water System configuration. Installing a tower, basin, and associated equipment to serve the HLW facility is not warranted. The HLW facility cooling water requirement is about 10 percent of the total cooling water requirement for the site. There is no cost savings realized by installing a marginally smaller Cooling Tower Water System dedicated to the Separations/LLW facility because an additional dedicated system would have to be installed for the future HLW facility. Installing a Cooling Tower Water System sized to serve the entire treatment complex is the most cost effective design.

A shared Cooling Tower Water System that serves various facilities has a single set of equipment. Taking advantage of the economies of scale, this shared configuration costs less than individual dedicated systems with duplicate equipment. The total engineered cost of a shared Cooling Tower Water System would be $\$ 8,011,000$. The total engineered cost of two separate, dedicated Cooling Tower Water Systems would be $\$ 9,912,000$. Therefore, it is 
more cost effective to build a single Cooling Tower Water System designed for the entire site than to build a dedicated Separations/LLW cooling tower and a future HLW cooling tower.

Consideration should be given to the prevailing wind direction when determining the location of the cooling tower. The prevailing wind is from the northwest. The tower should be to the southeast of the TWRS Treatment Complex. Drift from the cooling tower should not be allowed to travel across construction areas, operational facilities, parking lots or operational areas. Condensate plumes should not be allowed to "fog" or obscure visibility along facility road systems.

There is no specific need for this system to be located in close-proximity to the process operations. However, a higher head pump and longer piping would be required if a remote location is selected. This system is defined as being not distance constrained.

Other considerations that were evaluated and found not to be contributors to the function configuration are noted below:

Operability and Maintainability. This study has not identified any Operability or Maintainability issues that are unique to any single configuration considered for this system. Therefore, Operability and Maintainability are not considerations that were used to determine the configuration of this system.

Radiological Protection (ALARA). This study has not identified any Radiological Protection (ALARA) issues that are unique to any single configuration considered for this system. Therefore, Radiological Protection (ALARA) is not a consideration that was used to determine the configuration of this system.

Safety. This study has not identified any Safety issues that are unique to any single configuration considered for this system. Therefore, Safety is not a consideration that was used to determine the configuration of this system.

Environmental Regulatory Compliance. All sources of air emission, including cooling towers will be permitted for air emissions. Each cooling tower, if more than one were provided would require a permit. However, the cooling tower would be included under the permit for the process facilities. This is not considered a significant issue, therefore, Environmental Regulatory Compliance is not a consideration that was used to determine the configuration of this system.

Schedule. The configuration of this system does not impact the schedule for the design, construction, or startup of the TWRS Treatment Complex.

Technical Maturity. Commercially demonstrated technology is used in the design of this system. Therefore, Technology issues were not a consideration for the configuration of this system. 
Design Impact. This study has not identified any Design Impact issues that are unique to any single configuration considered for this system. Therefore, Design Impact is not a consideration that was used to determine the configuration of this system.

\subsubsection{Telecommunications System}

3.4.20.1 System Description. The Telecommunications System consists of all equipment required to provide internal and external communications functions for the TWRS Treatment Complex. The external telecommunications system will provide for telephone, emergency response and data transfer into and out of the TWRS Treatment Complex, while the internal telecommunications system will provide for communications within the complex. This system includes voice, video, spectrum-dependent communications and data communications required to support facility operations, maintenance, management, and emergency response.

Land based trunk lines will enter the Treatment Complex at a single location and be routed to the telecommunications room in the Emergency Response Center. Distribution equipment will then route both hard wired and wireless communications to the various facilities within the complex.

3.4.20.2 Findings. The Telecommunications System is a shared, close-external system. This system is grouped within the Emergency Response Center with the Safety Class 1 safe shutdown portion of the Process Operational Control System.

Operability and Maintainability is the prime consideration used to define the configuration for this system. Centralizing the telecommunications distribution equipment in a one location provides a single point of contact between the TWRS Treatment Complex and the outside world. It also provides an efficient system to route and transfer communications and information within the complex. Additionally, maintenance and repair of the system will be greatly simplified with all the components in a single location.

3.4.20.3 Functional Considerations and Rationale. Operability and Maintainability is the prime consideration for defining the Telecommunications System configuration. Locating the telecommunications distribution equipment in a single location provides for a single point of contact for external communications and provides for fast and efficient internal voice and data transfer. Maintenance and repair will be easier since all the equipment is grouped in a single location. To minimize the length of internal lines of communication this system is located within the TWRS Complex but away from the main process areas. Therefore this system is defined to be a shared, close-external system.

Other considerations that were evaluated and found not to be contributors to the function configuration are noted below: 
Cost Effectiveness. This study has not identified any cost drivers that would override the technical considerations used to define the configuration of this system.

Therefore, Cost Effectiveness is not a consideration that was used to determine the configuration for this system.

Radiological Protection (ALARA). This study has not identified any Radiological Protection issues that are unique to any single configuration considered for this system. Therefore, Radiological Protection is not a consideration that was used to determine the configuration for this system.

Safety. This study has not identified any Safety issues that are unique to any single configuration considered for this system. Therefore, Safety is not a consideration that was used to determine the configuration for this system.

Environmental Regulatory Compliance. This study has not identified any Environmental Regulatory Compliance issues that are unique to any single configuration considered for this system. Therefore, Environmental Regulatory Compliance is not a consideration that was used to determine the configuration for this system.

Schedule. The configuration of this system does not impact the schedule for the design, construction, or startup of the TWRS Treatment Complex.

Technical Maturity. Commercially demonstrated technology is used in the design of this system. Therefore, Technology issues were not a consideration for the configuration of this system.

Design Impact. This study has not identified any Design Impact issues that are unique to any single configuration considered for this system. Therefore, Design Impact is not a consideration that was used to determine the configuration of this system.

\subsubsection{Sanitary Sewer System}

3.4.21.1. System Description. The Sanitary Sewer System is designed to convey the domestic sewage from facilities containing restrooms, showers, or sanitary sinks, to a domestic waste water facility for further processing and disposal. The system is comprised of sewer collection mains and a sewage lift station. The system discharges the domestic sewage to the 200 Area Sanitary Sewer System.

The sewer system is provided for disposal of domestic waste only. The sewer collection system will serve a multi-building complex that has a maximum shift population of 779 persons (708 shift plus 10 percent transient personnel). The sanitary sewer collection 


\section{Revision 0}

system runs throughout the unregulated areas of the facility. Manholes will be located at all places where there are changes in the pipe alignment both horizontal and vertical.

It is assumed that a lift station is required to drain the sewage from all the facilities within the complex. However, whenever possible, the sewage collection system would drain individual building's sewage by gravity, thereby bypassing the lift station. The table below lists the facilities that discharge domestic sewage to the sewer collection main. The sewer collection main drains into the sewage lift station tank that discharges the sewage to the 200 Area Sanitary Sewer System. The following buildings are connected with sewage discharge main:

1. Fabrication and Assembly Shop

2. Warehouses

3. Operations Support Building

4. Regulated TWRS Complex Entry Building

5. Regulated Facility Entry Annex (Separations/LLW facility)

6. Regulated Facility Entry Annex (HLW facility)

7. MUB

8. AF.

See page A-23 of Appendix A for the Block Flow Diagram of this system. Drawing UFD-4-16 is a Utility Flow Diagram (see Appendix B) of the Sanitary Sewer System.

3.4.21.2 Findings. The Sanitary Sewer system is a shared, close-external system. The most significant portion of this system is the underground distribution piping. By definition this must be close external to the facilities being served and is routed throughout the TWRS Treatment Complex.

Operability is the prime consideration for the configuration of the Sanitary Sewer System. Due to the nature of the service provided, the Sanitary Sewer System is shared by all of the office buildings and other nonregulated users that it serves.

3.4.21.3 Function Configuration Considerations and Rationale. Operability (practicality of design) is the prime consideration for the design of this system. The Sanitary Sewer System is system is designed to handle the sanitary sewage from the office buildings and buildings with nonregulated sanitary facilities. These buildings have been designated as shared facilities and will be installed as shared facilities from the outset. The sanitary sewer operates by gravity an must be in close-proximity to the facilities that it serves. Therefore, the sanitary sewer system that serves these facilities must be a shared, close-external system.

If, for any reason, a building becomes dedicated to the HLW facility, a tie-in point for a future sewer line would be provided.

Other considerations that were evaluated and found not to be contributors to the function configuration are noted below: 
Cost Effectiveness. This study has not identified any cost drivers that would override the technical considerations used to define the configuration of this system. Therefore, Cost Effectiveness is not a consideration that was used to determine the configuration of this system.

Radiological Protection (ALARA). This study has not identified any Radiological Protection (ALARA) issues that are unique to any single configuration considered for this system. Therefore, Radiological Protection (ALARA) is not a consideration that was used to determine the configuration of this system.

Safety. This study has not identified any Safety issues that are unique to any single configuration considered for this system. Therefore, Safety is not a consideration that was used to determine the configuration of this system.

Environmental Regulatory Compliance. This system will require permitting under either WAC 173-216 or WAC 246-272 depending upon system capacity. The system would tie into a single line connecting to the 200 Area Sanitary Sewer System. Assuming that the initial permits for the 200 Area Sanitary Sewer System includes the capacity to handle the TWRS Treatment Complex, no further permitting is anticipated. These issues are not considered to be significant, therefore, Environmental Regulatory Compliance is not a consideration that was used to determine the configuration of this system.

Schedule. The configuration of this system does not impact the schedule for the design, construction, or startup of the TWRS Treatment Complex.

Technical Maturity. Commercially demonstrated technology is used in the design of this system. Therefore, Technology issues were not a consideration for the configuration of this system.

Design Impact. This study has not identified any Design Impact issues that are unique to any single configuration considered for this system. Therefore, Design Impact is not a consideration that was used to determine the configuration of this system.

\subsection{ELECTRICAL POWER}

\subsubsection{Normal AC Power System}

3.5.1.1 System Description. The Normal AC Power System provides AC power to the TWRS Treatment Complex. It originates from the existing Hanford $230 \mathrm{kV}$ power system. The $230 \mathrm{kV}$ distribution loop, provides the site with power from two independent substations, and giving the normal power a high availability. It is delivered, via overhead 
lines, to a Substation/Switchgear Area where it is stepped down to $34.5 \mathrm{kV}$. The $34.5 \mathrm{kV}$ power is converted to $13.8 \mathrm{kV}$ at the Switchgear Building located within the TWRS Treatment Complex. $13.8 \mathrm{kV}$ power is distributed to individual facilities where unit substations transform it to $4.16 \mathrm{kV}$ or $480 \mathrm{~V}$ to meet the specific requirements of each facility.

3.5.1.2 Findings. The Normal AC Power System is a dedicated, close-external system. Operability and Maintainability is the prime consideration used to define the configuration for this system. Transformers for converting the incoming $34.5 \mathrm{kV}$ power to $13.8 \mathrm{kV}$ and switchgear for distributing the power to the process and process support facilities are grouped together at the Switchgear Building. The transformers are located outside of the building.

3.5.1.3 Function Configuration Considerations and Rationale. Operability and Maintainability is the prime consideration for the Normal AC Power System configuration. Providing dedicated $13.8 \mathrm{kV}$ power distribution for each process facility allows each to operate independently. A failure in a shared system could shut down both process facilities. Providing dedicated transformers and distribution allows for continuous operation of one facility while the second is shut down due to a system failure.

There are no technical consideration governing the location of the Substation/Switchyard Area other than it be between the power supply and the TWRS Treatment Complex. Therefore it is not distance constrained. To limit voltage losses and reduce distribution costs the Switchgear Building is located so as to provide easy access from the incoming line and be in close proximity to the process facilities.

Other considerations that were evaluated and found not to be contributors to the function configuration are noted below:

Cost Effectiveness. This study has not identified any cost drivers that would override the technical considerations used to define the configuration of this system. Therefore, Cost Effectiveness is not a consideration that was used to determine the configuration for this system.

Radiological Protection (ALARA). This study has not identified any Radiological Protection issues that are unique to any single configuration considered for this system. Therefore, Radiological Protection (ALARA) is not a consideration that was used to determine the configuration of this system.

Safety. This study has not identified any Safety issues that are unique to any single configuration considered for this system. Therefore, Safety is not a consideration that was used to determine the configuration of this system.

Environmental Regulatory Compliance. This study has not identified any Environmental Regulatory Compliance issues that are unique to any single configuration considered for this system. Therefore, Environmental Regulatory 
Compliance is not a consideration that was used to determine the configuration of this system.

Schedule. The configuration of this system does not impact the schedule for the design, construction, or startup of the TWRS Treatment Complex.

Technical Maturity. Commercially demonstrated technology is used in the design of this system. Therefore, Technology issues were not a consideration for the configuration of this system.

Design Impact. This study has not identified any Design Impact issues that are unique to any single configuration considered for this system. Therefore, Design Impact is not a consideration that was used to determine the configuration of this system.

\subsubsection{Emergency Power System}

3.5.2.1 System Description. The Emergency Power System will provide emergency power for the TWRS Treatment Complex. This system provides emergency power to safety class loads required to maintain confinement in the event of a loss of normal $\mathrm{AC}$ power. The Emergency Power System will provide $480 \mathrm{~V}$ power from redundant Class $1 \mathrm{E}$ diesel generators, switchgear, motor control centers, batteries, and Uninterruptible Power Supplies designed to meet Institute of Electrical and Electronics Engineers (IEEE) requirements. The generators are located in dedicated Emergency Generator Bldgs. Switchgear, motor control centers, batteries, and Uninterruptible Power Supplies (UPSs) will be located as required throughout the complex.

3.5.2.2 Findings. The Emergency Power System is a dedicated close-external system. Operability and Maintainability is the prime consideration used to define the configuration for this system. Emergency power is supplied from dedicated redundant 1-E generators located in close proximity to the facility they serve. UPSs adjacent to the equipment they support offers operational and maintenance advantages over a shared facility. Emergency DC power is limited to station batteries supplying emergency switchgear.

\subsubsection{Function Configuration Considerations and Rationale. Operability and} Maintainability is the prime consideration for defining the Emergency Power System configuration. Use of dedicated 1-E power generator sets has the advantage that when one of the process facilities experiences a loss of power, only that portion of the system dedicated to that facility is activated. Supplying power from a generator sized to supply the entire complex places unnecessary wear and tear on the system increases the complexity of the distribution system. Thus dedicated generator sets are a better operational solution to safety requirements. 


\section{Revision 0}

The Emergency Power System is a Safety Class 1 system. As such, it must be protected from damage and requires periodic inspection and/or testing to verify that its operability has not deteriorated. Therefore the distance between the Emergency Power System and its major users should be kept to a minimum. The major users are the HVAC Zone 1 exhaust fans. This drives the configuration to a close-external system located as close as physically possible to the Fan/Filter Annexes.

Other considerations that were evaluated and found not to be contributors to the function configuration are noted below:

Cost Effectiveness. This study has not identified any cost drivers that would override the technical considerations used to define the configuration of this system.

Therefore, Cost Effectiveness is not a consideration that was used to determine the configuration for this system.

Radiological Protection (ALARA). This study has not identified any Radiological Protection issues that are unique to any single configuration considered for this system. Therefore, Radiological Protection (ALARA) is not a consideration that was used to determine the configuration of this system.

Safety. This study has not identified any Safety issues that are unique to any single configuration considered for this system. Therefore, Safety is not a consideration that was used to determine the configuration of this system.

Environmental Regulatory Compliance. This study has not identified any Environmental Regulatory Compliance issues that are unique to any single configuration considered for this system. Therefore, Environmental Regulatory Compliance is not a consideration that was used to determine the configuration of this system.

Schedule. The configuration of this system does not impact the schedule for the design, construction, or startup of the TWRS Treatment Complex.

Technical Maturity. Commercially demonstrated technology is used in the design of this system. Therefore, Technology issues were not a consideration for the configuration of this system.

Design Impact. This study has not identified any Design Impact issues that are unique to any single configuration considered for this system. Therefore, Design Impact is not a consideration that was used to determine the configuration of this system. 
WHC-SD-W378-ES-002

Revision 0

\subsubsection{Uninterruptible Power Supply System}

3.5.3.1 System Description. The Uninterruptible Power Supply System provides continuous power to monitoring and control equipment, excluding Life Support Systems, that requires continuous power during short duration power outages. The system consists of rectifiers/battery chargers, inverters, switching components, and batteries.

3.5.3.2 Findings. The Uninterruptible Power Supply (UPS) System is a dedicated internal system. Operability and Maintainability is the prime consideration used to define the configuration for this system. UPSs should be as close to the equipment items they support. The further they are apart the larger the voltage drop, thus increasing the size of the UPS distribution system and the possibility of having the power interrupted due to damage to the connecting wiring.

3.5.3.3 Function Configuration Considerations and Rationale. Operability and maintainability is the prime consideration for the Uninterruptible Power Supply System configuration. The majority of the loads operate at $120 \mathrm{~V}$, which limits the distance between the UPS and the item supported. Combining loads would require distribution at a higher voltage and the use of transformers to break the supply back down to $120 \mathrm{~V}$. Failure in this system would affect larger portions of the facility thereby affecting reliability. Therefore, this system is defined to be a dedicated internal system.

Other considerations that were evaluated and found not to be contributors to the function configuration are noted below:

Cost Effectiveness. This study has not identified any cost drivers that would override the technical considerations used to define the configuration of this system. Therefore, Cost Effectiveness is not a consideration that was used to determine the configuration for this system.

Radiological Protection (ALARA). This study has not identified any Radiological Protection issues that are unique to any single configuration considered for this system. Therefore, Radiological Protection (ALARA) is not a consideration that was used to determine the configuration of this system.

Safety. This study has not identified any Safety issues that are unique to any single configuration considered for this system. Therefore, Safety is not a consideration that was used to determine the configuration of this system.

Environmental Regulatory Compliance. This study has not identified any Environmental Regulatory Compliance issues that are unique to any single configuration considered for this system. Therefore, Environmental Regulatory Compliance is not a consideration that was used to determine the configuration of this system. 
Schedule. The configuration of this system does not impact the schedule for the design, construction, or startup of the TWRS Treatment Complex.

Technical Maturity. Commercially demonstrated technology is used in the design of this system. Therefore, Technology issues were not a consideration for the configuration of this system.

Design Impact. This study has not identified any Design Impact issues that are unique to any single configuration considered for this system. Therefore, Design Impact is not a consideration that was used to determine the configuration of this system.

\subsection{FACILITY MANAGEMENT AND SUPPORT}

\subsubsection{Treatment Complex Management and Support System}

3.6.1.1 System Description. The Treatment Complex Management and Support System provides facilities for the management and support of the TWRS Treatment Complex operations. This system provides office space for management and support personnel as well as facilities postal services, plant records retention, reprographics, training, and public outreach displays. These facilities are located in the Operations Support Building.

3.6.1.2 Findings. The Treatment Complex Management and Support System is a shared, no distance constrained system. Operability and Maintainability is the prime consideration used to define this system. A shared management and support system provides for better management control of the TWRS Treatment Complex. These management and support functions can be provided from almost anywhere and are candidates for being provided from existing Hanford facilities.

\subsubsection{Function Configuration Considerations and Rationale. Operability and} Maintainability is the prime consideration for defining the Treatment Complex Management and Support System. A shared system allows for centralized management and direction of the complex. It also provides for more efficient use of support facilities and eliminates potential duplication of facilities and personnel required to provide required facility support services.

Other considerations that were evaluated and found not to be contributors to the function configuration are noted below:

Cost Effectiveness. This study has not identified any cost drivers that would override the technical considerations used to define the configuration of this system.

Therefore, Cost Effectiveness is not a consideration that was used to determine the configuration for this system. 
Radiological Protection (ALARA). This study has not identified any Radiological Protection issues that are unique to any single configuration considered for this system. Therefore, Radiological Protection (ALARA) is not a consideration that was used to determine the configuration of this system.

Safety. This study has not identified any Safety issues that are unique to any single configuration considered for this system. Therefore, Safety is not a consideration that was used to determine the configuration of this system.

Environmental Regulatory Compliance. This study has not identified any Environmental Regulatory Compliance issues that are unique to any single configuration considered for this system. Therefore, Environmental Regulatory Compliance is not a consideration that was used to determine the configuration of this system.

Schedule. The configuration of this system does not impact the schedule for the design, construction, or startup of the TWRS Treatment Complex.

Technical Maturity. Commercially demonstrated technology is used in the design of this system. Therefore, Technology issues were not a consideration for the configuration of this system.

Design Impact. This study has not identified any Design Impact issues that are unique to any single configuration considered for this system. Therefore, Design Impact is not a consideration that was used to determine the configuration of this system.

\subsubsection{Regulated Tank Waste Remediation System Treatment Complex Entry System}

3.6.2.1 System Description. The Regulated TWRS Treatment Complex Entry System controls the entry to and exit from the TWRS Treatment Complex. Personnel requiring entry to the complex must first change from their street clothes to a "blues" uniform. Upon exiting, they must remove their blues uniform, shower, change into their street clothes and exit through portal monitors. This system is composed of unregulated change areas, lockers, showers, and radiation monitors. It is located in the Regulated TWRS Complex Entry Building.

3.6.2.2 Findings. The Regulated TWRS Treatment Complex Entry System is a shared close-external system. This system is grouped together with the Employee Support System and the Process Operational Control System in the Regulated TWRS Complex Entry Building.

Operability and Maintainability as well as Radiological Protection are the prime considerations used to define this system. A shared system provides for a single point of 
departure for personnel entering or exiting the complex. It also assures that all personnel are screened for radiological contamination before exiting the TWRS Treatment Complex and rejoining the general population. To efficiently provide these functions this system must be located on the edge of the site boundary.

3.6.2.3 Function Configuration Considerations and Rationale. Operability and Maintainability as well as Radiological Protection are the prime considerations for defining the Regulated TWRS Treatment Complex Entry System. A shared system forces all personnel entering and exiting the complex to pass through a central control point. Thus assuring control of all personnel within the complex and that everyone entering the complex complies with the radiological detection and control procedures before exiting.

Other considerations that were evaluated and found not to be contributors to the function configuration are noted below:

Cost Effectiveness. This study has not identified any cost drivers that would override the technical considerations used to define the configuration of this system. Therefore, Cost Effectiveness is not a consideration that was used to determine the configuration for this system.

Safety. This study has not identified any Safety issues that are unique to any single configuration considered for this system. Therefore, Safety is not a consideration that was used to determine the configuration of this system.

Environmental Regulatory Compliance. This study has not identified any Environmental Regulatory Compliance issues that are unique to any single configuration considered for this system. Therefore, Environmental Regulatory Compliance is not a consideration that was used to determine the configuration of this system.

Schedule. The configuration of this system does not impact the schedule for the design, construction, or startup of the TWRS Treatment Complex.

Technical Maturity. Commercially demonstrated technology is used in the design of this system. Therefore, Technology issues were not a consideration for the configuration of this system.

Design Impact. This study has not identified any Design Impact issues that are unique to any single configuration considered for this system. Therefore, Design Impact is not a consideration that was used to determine the configuration of this system. 


\subsubsection{Regulated Facility Entry System}

3.6.3.1 System Description. The Regulated Facility Entry System controls the entry to and exit from facilities that pose a threat of radiological contamination to the worker population. Personnel requiring entry to or exit from these facilities must first pass through this system. This system is composed of step off pads, regulated change areas, lockers, hand sinks and showers, full body monitors, hand and foot monitors, and portal monitors.

Personnel that need to visit "blues" areas within the facility are allowed to enter those areas through a controlled entrance. Upon exiting these areas they will be checked by hand and foot monitors and pass through portal monitors before being allowed to exit the facility. Personnel visiting "whites" areas will change to whites before entering those areas through a separate controlled entrance. Upon exiting they will be routed to a step off pad area to remove their potentially contaminated clothing, required to wash or shower, change back into blues, be checked for contamination with hand and foot monitors, and pass through a portal monitor before being allowed to exit the facility. Facilities identified as requiring a regulated entry system are the main process facilities, the Fan/Filter Annexes, and the AF.

3.6.3.2 Findings. The Regulated Facility Entry System is a dedicated annexed system. Radiological Protection is the prime consideration for defining this system. This system is grouped with personnel protection equipment in areas close-linked (annexed) to the facility whose entry they are regulating.

3.6.3.3 Function Configuration Considerations and Rationale. Radiological Protection is the prime consideration for defining the Regulated Facility Entry System. A dedicated system forces all personnel entering and exiting facilities where they can potentially be contaminated to pass through a central control point. Thus assuring control of personnel into and out of each facility and that radiological detection and control procedures to detect and limit the spread of contamination are complied with.

Other considerations that were evaluated and found not to be contributors to the function configuration are noted below:

Operability and Maintainability. This study has not identified any Operability or Maintainability issues that are unique to any single configuration considered for this system. Therefore, Operability and Maintainability are not considerations that were used to determine the configuration of this system.

Cost Effectiveness. This study has not identified any cost drivers that would override the technical considerations used to define the configuration of this system.

Therefore, Cost Effectiveness is not a consideration that was used to determine the configuration for this system. 


\section{Revision 0}

Safety. This study has not identified any Safety issues that are unique to any single configuration considered for this system. Therefore, Safety is not a consideration that was used to determine the configuration of this system.

Environmental Regulatory Compliance. This study has not identified any Environmental Regulatory Compliance issues that are unique to any single configuration considered for this system. Therefore, Environmental Regulatory Compliance is not a consideration that was used to determine the configuration of this system.

Schedule. The configuration of this system does not impact the schedule for the design, construction, or startup of the TWRS Treatment Complex.

Technical Maturity. Commercially demonstrated technology is used in the design of this system. Therefore, Technology issues were not a consideration for the configuration of this system.

Design Impact. This study has not identified any Design Impact issues that are unique to any single configuration considered for this system. Therefore, Design Impact is not a consideration that was used to determine the configuration of this system.

\subsubsection{Personnel Protection System}

3.6.4.1 Systems Description. The Personnel Protection System provides for worker safety within the TWRS Treatment Complex. This system includes emergency exits, fire walls, shield walls, air locks, change areas, step off pads, alarms, radiation monitors, air samplers, and other items required to assure work safety. This system is distributed to all areas within the complex that may pose a threat to the worker population.

3.6.4.2 Findings. The Personnel Protection System is a dedicated internal system. Radiological Protection and Safety are the prime considerations used to define this system. It is distributed throughout each process and process support facility to assure worker safety within the complex.

3.6.4.3 Function Configuration Considerations and Rationale. Radiological Protection (ALARA) and Safety are the prime considerations for defining the Personnel Protection System. The system provides for worker safety within the TWRS Treatment Complex and as such is distributed throughout each facility within the complex.

Other considerations that were evaluated and found not to be contributors to the function configuration are noted below: 
Operability and Maintainability. This study has not identified any Operability or Maintainability issues that are unique to any single configuration considered for this system. Therefore, Operability and Maintainability are not considerations that were used to determine the configuration of this system.

Cost Effectiveness. This study has not identified any cost drivers that would override the technical considerations used to define the configuration of this system. Therefore, Cost Effectiveness is not a consideration that was used to determine the configuration for this system.

Radiological Protection (ALARA). This study has not identified any Radiological Protection issues that are unique to any single configuration considered for this system. Therefore, Radiological Protection (ALARA) is not a consideration that was used to determine the configuration of this system.

Environmental Regulatory Compliance. This study has not identified any Environmental Regulatory Compliance issues that are unique to any single configuration considered for this system. Therefore, Environmental Regulatory Compliance is not a consideration that was used to determine the configuration of this system.

Schedule. The configuration of this system does not impact the schedule for the design, construction, or startup of the TWRS Treatment Complex.

Technical Maturity. Commercially demonstrated technology is used in the design of this system. Therefore, Technology issues were not a consideration for the configuration of this system.

Design Impact. This study has not identified any Design Impact issues that are unique to any single configuration considered for this system. Therefore, Design Impact is not a consideration that was used to determine the configuration of this system.

\subsubsection{Employee Support System}

3.6.5.1 System Description. The Employee Support System provides for amenities required to enhance worker comfort and moral. This system consists of lunch rooms, vending machines, toilet facilities, and any other item aimed at enhancing the work environment.

3.6.5.2 Findings. The Employee Support System is a dedicated close external system. Operability and Maintainability is the prime consideration used to define this system. Distributing this system throughout the TWRS Treatment Complex places amenities near to the actual work areas thereby making them readily available to the facility population. 
WHC-SD-W378-ES-002

Revision 0

3.6.5.3 Function Configuration Considerations and Rationale. Operability and Maintainability is the prime consideration for defining the Employee Support System.

Distributing this system to the various support facilities in proportion to the permanent staff assigned to each makes this system readily available to the facility population.

Other considerations that were evaluated and found not to be contributors to the function configuration are noted below:

Cost Effectiveness. This study has not identified any cost drivers that would override the technical considerations used to define the configuration of this system.

Therefore, Cost Effectiveness is not a consideration that was used to determine the configuration for this system.

Radiological Protection (ALARA). This study has not identified any Radiological Protection issues that are unique to any single configuration considered for this system. Therefore, Radiological Protection (ALARA) is not a consideration that was used to determine the configuration of this system.

Safety. This study has not identified any Safety issues that are unique to any single configuration considered for this system. Therefore, Safety is not a consideration that was used to determine the configuration of this system.

Environmental Regulatory Compliance. This study has not identified any Environmental Regulatory Compliance issues that are unique to any single configuration considered for this system. Therefore, Environmental Regulatory Compliance is not a consideration that was used to determine the configuration of this system.

Schedule. The configuration of this system does not impact the schedule for the design, construction, or startup of the TWRS Treatment Complex.

Technical Maturity. Commercially demonstrated technology is used in the design of this system. Therefore, Technology issues were not a consideration for the configuration of this system.

Design Impact. This study has not identified any Design Impact issues that are unique to any single configuration considered for this system. Therefore, Design Impact is not a consideration that was used to determine the configuration of this system. 


\subsection{MANTENANCE AND REPAIR}

\subsubsection{Shipping and Receiving System}

3.7.1.1 System Description. The Shipping and Receiving System provides for the receipt, inspection, and inventory control of equipment, spare parts, and miscellaneous goods being delivered to the TWRS Treatment Complex. It also provides for the packaging and distribution of these items to the various process and process support facilities within the TWRS Treatment Complex.

3.7.1.2 Findings. The Shipping and Receiving System is a shared not distance constrained system. Operability and Maintainability is the prime consideration used for defining this system. This system is grouped together with the Warehousing and Storage System and the Storage and Service Yard.

A shared system provides for a single point of delivery to the TWRS Treatment Complex. The only consideration for the location of this system is that it be readily accessible by rail and motor vehicle. Therefore this system is a candidate for being located in an existing Hanford facility.

3.7.1.3 Function Configuration Considerations and Rationale. Operability and Maintainability is the prime consideration for defining this system. A shared system provides for a single point of delivery and distribution for material required to operate and maintain the TWRS Treatment Complex. It also eliminates duplication of equipment and personnel required to operate two dedicated systems. There is no specific need for this system to be located in close proximity to the process operations. Therefore this system is defined as not being distance constrained.

Other considerations that were evaluated and found not to be contributors to the function configuration are noted below:

Cost Effectiveness. This study has not identified any cost drivers that would override the technical considerations used to define the configuration of this system.

Therefore, Cost Effectiveness is not a consideration that was used to determine the configuration for this system.

Radiological Protection (ALARA). This study has not identified any Radiological Protection issues that are unique to any single configuration considered for this system. Therefore, Radiological Protection (ALARA) is not a consideration that was used to determine the configuration of this system.

Safety. This study has not identified any Safety issues that are unique to any single configuration considered for this system. Therefore, Safety is not a consideration that was used to determine the configuration of this system. 
Environmental Regulatory Compliance. This study has not identified any Environmental Regulatory Compliance issues that are unique to any single configuration considered for this system. Therefore, Environmental Regulatory Compliance is not a consideration that was used to determine the configuration of this system.

Schedule. The configuration of this system does not impact the schedule for the design, construction, or startup of the TWRS Treatment Complex.

Technical Maturity. Commercially demonstrated technology is used in the design of this system. Therefore, Technology issues were not a consideration for the configuration of this system.

Design Impact. This study has not identified any Design Impact issues that are unique to any single configuration considered for this system. Therefore, Design Impact is not a consideration that was used to determine the configuration of this system.

\subsubsection{Warehousing and Storage System}

3.7.2.1 System Description. The Warehousing and Storage System provides for the environmental protection and storage of equipment, spare parts, and miscellaneous goods required to operate and maintain the TWRS Treatment Complex.

3.7.2.2 Findings. The Warehousing and Storage System is a shared not distance constrained system. Operability and Maintainability is the prime consideration used for defining this system. This system is grouped together with the Shipping and Receiving System and the Storage and Service Yard.

A shared system provides for a single environmentally protected storage area for material required for the operation and maintenance of the TWRS Treatment Complex. The only consideration for the location of this system is that it be readily accessible by rail and motor vehicle. Therefore this system is a candidate for being located in an existing Hanford facility.

3.7.2.3 Function Configuration Considerations and Rationale. Operability and Maintainability is the prime consideration for defining this system. A shared system provides for a single environmentally protected storage area for material required to operate and maintain the TWRS Treatment Complex. It also eliminates duplication of equipment and personnel required to operate two dedicated systems. There is no specific need for this system to be located in close proximity to the process operations. Therefore this system is defined as not being distance constrained. 


\section{Revision 0}

Other considerations that were evaluated and found not to be contributors to the function configuration are noted below:

Cost Effectiveness. - This study has not identified any cost drivers that would override the technical considerations used to define the configuration of this system. Therefore, Cost Effectiveness is not a consideration that was used to determine the configuration for this system.

Radiological Protection (ALARA). This study has not identified any Radiological Protection issues that are unique to any single configuration considered for this system. Therefore, Radiological Protection (ALARA) is not a consideration that was used to determine the configuration of this system.

Safety. This study has not identified any Safety issues that are unique to any single configuration considered for this system. Therefore, Safety is not a consideration that was used to determine the configuration of this system.

Environmental Regulatory Compliance. This study has not identified any Environmental Regulatory Compliance issues that are unique to any single configuration considered for this system. Therefore, Environmental Regulatory Compliance is not a consideration that was used to determine the configuration of this system.

Schedule. The configuration of this system does not impact the schedule for the design, construction, or startup of the TWRS Treatment Complex.

Technical Maturity. Commercially demonstrated technology is used in the design of this system. Therefore, Technology issues were not a consideration for the configuration of this system.

Design Impact. This study has not identified any Design Impact issues that are unique to any single configuration considered for this system. Therefore, Design Impact is not a consideration that was used to determine the configuration of this system.

\subsubsection{Storage and Service Yard}

3.7.3.1 System Description. The Storage and Service Yard provides for the storage of equipment, vehicles, and materials required to operate and maintain the TWRS Treatment Complex that do not require environmental protection. It also provides for outside maintenance and repair of vehicles and large equipment items. 
3.7.3.2 Findings. The Storage and Service Yard is a shared not distance constrained facility. Operability and Maintainability is the prime consideration used for defining this function. This function is grouped together with the Shipping and Receiving System and Warehousing and Storage System.

A shared function provides for a single storage area for vehicles equipment and materials not requiring environmental protection used for the operation and maintenance of the TWRS Treatment Complex. The only consideration for the location of this function is that it be readily accessible by rail and motor vehicle. Therefore this function is a candidate for being located in an existing Hanford facility.

3.7.3.3 Function Configuration Considerations and Rationale. Operability and Maintainability is the prime consideration for defining this function. A shared function provides for a single outdoor storage area for vehicles, equipment, and materials required to operate and maintain the TWRS Treatment Complex and do not require environmental protection. It also eliminates duplication of equipment and personnel required to operate two dedicated functions. There is no specific need for this function to be located in close proximity to the process operations. Therefore this function is defined as not being distance constrained.

Other considerations that were evaluated and found not to be contributors to the function configuration are noted below:

Cost Effectiveness. This study has not identified any cost drivers that would override the technical considerations used to define the configuration of this function.

Therefore, Cost Effectiveness is not a consideration that was used to determine the configuration for this function.

Radiological Protection (ALARA). This study has not identified any Radiological Protection issues that are unique to any single configuration considered for this function. Therefore, Radiological Protection (ALARA) is not a consideration that was used to determine the configuration of this function.

Safety. This study has not identified any Safety issues that are unique to any single configuration considered for this function. Therefore, Safety is not a consideration that was used to determine the configuration of this function.

Environmental Regulatory Compliance. This study has not identified any Environmental Regulatory Compliance issues that are unique to any single configuration considered for this function. Therefore, Environmental Regulatory Compliance is not a consideration that was used to determine the configuration of this function.

Schedule. The configuration of this function does not impact the schedule for the design, construction, or startup of the TWRS Treatment Complex. 


\section{Revision 0}

Technical Maturity. Commercially demonstrated technology is used in the design of this function. Therefore, Technology issues were not a consideration for the configuration of this function.

Design Impact. This study has not identified any Design Impact issues that are unique to any single configuration considered for this function. Therefore, Design Impact is not a consideration that was used to determine the configuration of this function.

\subsubsection{Major Equipment Assembly}

3.7.4.1 System Description. The Major Equipment Assembly Function provides for the assembly of new in-cell equipment before installation in the process facilities. It consists of an enclosed assembly area, bridge crane and other items and equipment required to assemble new in-cell equipment.

3.7.4.2 Findings. The Major Equipment Assembly Function is a shared not distance constrained function. Operability and Maintainability is the prime consideration used for defining this function. This function is grouped together with the Spare Parts Fabrication Function in the Fabrication and Assembly Shop.

A shared function provides for a single new in-cell equipment assembly area. The only consideration for the location of this function is that it be readily accessible by rail and motor vehicle. Therefore this function is a candidate for being located in an existing Hanford facility.

3.7.4.3 Function Configuration Considerations and Rationale. Operability and Maintainability is the prime consideration for defining this function. A shared function provides for a single new in-cell equipment assembly area. It also eliminates duplication of equipment and personnel required to operate two dedicated functions. There is no specific need for this function to be located in close proximity to the process operations. Therefore this function is defined as not being distance constrained.

Other considerations that were evaluated and found not to be contributors to the function configuration are noted below:

Cost Effectiveness. This study has not identified any cost drivers that would override the technical considerations used to define the configuration of this function. Therefore, Cost Effectiveness is not a consideration that was used to determine the configuration for this function. 
Radiological Protection (ALARA). This study has not identified any Radiological Protection issues that are unique to any single configuration considered for this function. Therefore, Radiological Protection (ALARA) is not a consideration that was used to determine the configuration of this function.

Safety. This study has not identified any Safety issues that are unique to any single configuration considered for this function. Therefore, Safety is not a consideration that was used to determine the configuration of this function.

Environmental Regulatory Compliance. This study has not identified any Environmental Regulatory Compliance issues that are unique to any single configuration considered for this function. Therefore, Environmental Regulatory Compliance is not a consideration that was used to determine the configuration of this function.

Schedule. The configuration of this function does not impact the schedule for the design, construction, or startup of the TWRS Treatment Complex.

Technical Maturity. Commercially demonstrated technology is used in the design of this function. Therefore, Technology issues were not a consideration for the configuration of this function.

Design Impact. This study has not identified any Design Impact issues that are unique to any single configuration considered for this function. Therefore, Design Impact is not a consideration that was used to determine the configuration of this function.

\subsubsection{Spare Parts Fabrication}

3.7.5.1 System Description. The Spare Parts Fabrication Function provides for the manufacturing and assembling of small equipment items and spare parts required for the operation and maintenance of the TWRS Treatment Complex. It consists of an enclosed area, work benches, tool crib and other items required to assemble or manufacture small equipment items and spare parts.

3.7.5.2 Findings. The Spare Parts Fabrication Function is a shared not distance constrained function. Operability and Maintainability is the prime consideration used to define this system. This function is grouped together with the Major Equipment Assembly function in the Fabrication and Assembly Shop.

A shared function provides for a single small equipment and spare parts manufacturing and assembly area. The only consideration for the location of this function is that it be readily accessible by rail and motor vehicle. Therefore this function is a candidate for being located in an existing Hanford Site facility. 
3.7.5.3 Function Configuration Considerations and Rationale. Operability and Maintainability is the prime consideration for defining the Spare Parts Fabrication Function. A shared function provides for a common area in which to manufacture and/or assemble small equipment items and spare parts required for the operation and maintenance of the TWRS Treatment Complex. The only consideration for the location of this function is that it be readily accessible by rail and motor vehicle. Therefore this function is a candidate for being located in an existing Hanford Site facility.

Other considerations that were evaluated and found not to be contributors to the function configuration are noted below:

Cost Effectiveness. This study has not identified any cost drivers that would override the technical considerations used to define the configuration of this system.

Therefore, Cost Effectiveness is not a consideration that was used to determine the configuration for this system.

Radiological Protection (ALARA). This study has not identified any Radiological Protection issues that are unique to any single configuration considered for this system. Therefore, Radiological Protection (ALARA) is not a consideration that was used to determine the configuration of this system.

Safety. This study has not identified any Safety issues that are unique to any single configuration considered for this system. Therefore, Safety is not a consideration that was used to determine the configuration of this system.

Environmental Regulatory Compliance. This study has not identified any Environmental Regulatory Compliance issues that are unique to any single configuration considered for this system. Therefore, Environmental Regulatory Compliance is not a consideration that was used to determine the configuration of this system.

Schedule. The configuration of this system does not impact the schedule for the design, construction, or startup of the TWRS Treatment Complex.

Technical Maturity. Commercially demonstrated technology is used in the design of this system. Therefore, Technology issues were not a consideration for the configuration of this system.

Design Impact. This study has not identified any Design Impact issues that are unique to any single configuration considered for this system. Therefore, Design Impact is not a consideration that was used to determine the configuration of this system. 


\subsubsection{Maintenance and Repair System}

3.7.6.1 System Description. The Maintenance and Repair System provides for the maintenance and repair of failed noncontaminated equipment, failed contaminated equipment, and failed Master-Slave Manipulators (MSMs). This system consists of washdown and decon areas, repair areas, and tools and equipment required to remove, maintain and repair failed equipment and MSMs.

Failed noncontaminated equipment is defined as failed equipment located in areas that will not be radioactively contaminated and will not require decontamination before it can be contact maintained and/or repaired. This equipment includes large items that can be maintained or repaired in place, or smaller items that can be removed and placed in a shop for bench work. It is assumed that equipment which requires major overhauling will be removed and shipped offsite to a refurbishing contractor. Therefore, there will not be any maintenance and repair facilities to perform this function onsite.

Failed contaminated equipment is defined as failed equipment located in areas that can become contaminated and must be remotely maintained and/or repaired in place, remotely removed and remotely maintained and/or repaired, or be remotely removed, decontaminated and contact maintained and/repaired. Contaminated equipment that must be remotely maintained and/or repaired includes but is not limited to centrifuges, venturi scrubbers, metal HEPA filters, cyclone separators, and cullet roll crushers. Contact maintained contaminated equipment includes but is not limited to in-cell pumps and agitators.

Master-Slave Manipulators (MSMs) are of a three piece construction where the hot or "contaminated" portion will be removed from the hot side. This portion of the MSM must be removed from its installed position and moved to an area where it can be decontaminated before it is moved to a failed contaminated equipment repair shop within the facility. The MSM cold portion and wall piece would require similar handling, with the exception of decontamination. These pieces can be sent to a failed noncontaminated equipment repair shop within the site.

It is noted that the AF has a dedicated MSM repair shop for contaminated and noncontaminated MSMs. It is assumed that the AF will be the prime onsite user of MSMs. Separations/LLW and the HLW facility are assumed not to require MSMs, but will have the potential to service them in the site failed noncontaminated equipment repair shop and within each of the Separations/LLW and HLW facility's contaminated equipment repair shop.

3.7.6.2 Findings. The Maintenance and Repair System is a dedicated internal system. Radiological Protection and Operability and Maintainability are the prime considerations used to define this system. Failed contaminated equipment and the contaminated portion of the MSMs, even after external decontamination, have the potential to spread contamination. There are operational advantages in repairing failed equipment in or near the facility where they are used. 
3.7.6.3 Function Configuration Considerations and Rationale. Radiological Protection and Operability and Maintainability are the prime considerations for defining the Maintenance and Repair System. Any item that has been contaminated has the potential to spread contamination to otherwise clean areas. These items would need to be decontaminated, packaged, and inspected to assure the that the operators are not exposed and that contamination will not be spread to other areas of the complex. Performing maintenance and repair of failed contaminated and noncontaminated equipment within the facility in that they are used would minimize overall down time and increase efficiency.

Other considerations that were evaluated and found not to be contributors to the function configuration are noted below:

Cost Effectiveness. This study has not identified any cost drivers that would override the technical considerations used to define the configuration of this system. Therefore, Cost Effectiveness is not a consideration that was used to determine the configuration for this system.

Safety. This study has not identified any Safety issues that are unique to any single configuration considered for this system. Therefore, Safety is not a consideration that was used to determine the configuration of this system.

Environmental Regulatory Compliance. This study has not identified any Environmental Regulatory Compliance issues that are unique to any single configuration considered for this system. Therefore, Environmental Regulatory Compliance is not a consideration that was used to determine the configuration of this system.

Schedule. The configuration of this system does not impact the schedule for the design, construction, or startup of the TWRS Treatment Complex.

Technical Maturity. Commercially demonstrated technology is used in the design of this system. Therefore, Technology issues were not a consideration for the configuration of this system.

Design Impact. This study has not identified any Design Impact issues that are unique to any single configuration considered for this system. Therefore, Design Impact is not a consideration that was used to determine the configuration of this system. 


\subsection{TREAT VENTILATION AIR}

\subsubsection{Supply Air Treatment System}

3.8.1.1 System Description. The Supply Air Treatment System provides incoming ventilation air for the TWRS Treatment Complex process facilities. Incoming air is first filtered then conditioned before being distributed throughout each process facility.

The Supply Air Treatment System is broken down into two subsystems; a Zone I system and a Zone II and III system. The Zone I system is a once through system and the Zone II and III system is a cascading system. The Supply Air Treatment System is comprised of the following major components:

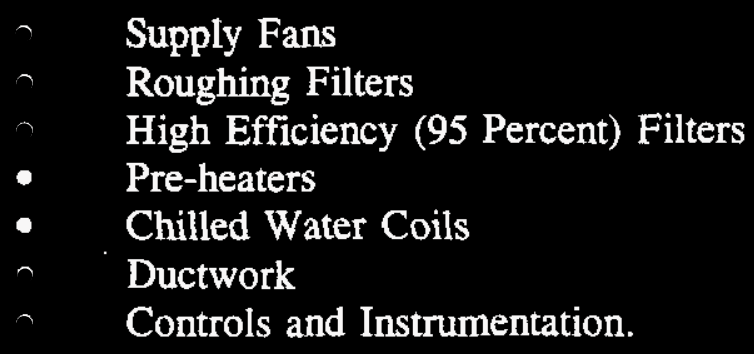

The supply air fans are located on the roof of the process facility they serve while the controls are distributed throughout the facility.

3.8.1.2 Findings. The Supply Air Treatment System is a dedicated annexed system. This system is grouped with the HVAC Zone II and III Exhaust Air Treatment system on the roof of the process facilities.

Operability and Maintainability is the prime consideration used to define this system. A dedicated supply air treatment system close coupled to each facility allows for better operational control and increases the overall reliability of the system.

3.8.1.3 Function Configuration Considerations and Rationale. Operability and Maintainability is the prime consideration for defining the Supply Air Treatment System configuration. Dedicated systems annexed (placed on the roof) to each process facility allows each facility to operate independently without relying on an independent facility to provide treated air. A failure in a shared system would shutdown both process facilities while a dedicated system would allow continuous operation one facility while the second could be shutdown due to a failure. Locating the supply air treatment equipment on the roof each facility minimizes the pressure drop and reduces the risk of damage to the supply air treatment ductwork due to an accident.

Other considerations that were evaluated and found not to be contributors to the function configuration are noted below: 
Cost Effectiveness. This study has not identified any cost drivers that would override the technical considerations used to define the configuration of this system.

Therefore, Cost Effectiveness is not a consideration that was used to determine the configuration for this system.

Radiological Protection (ALARA). This study has not identified any Radiological Protection issues that are unique to any single configuration considered for this system. Therefore, Radiological Protection (ALARA) is not a consideration that was used to determine the configuration of this system.

Safety. This study has not identified any Safety issues that are unique to any single configuration considered for this system. Therefore, Safety is not a consideration that was used to determine the configuration of this system.

Environmental Regulatory Compliance. This study has not identified any Environmental Regulatory Compliance issues that are unique to any single configuration considered for this system. Therefore, Environmental Regulatory Compliance is not a consideration that was used to determine the configuration of this system.

Schedule. The configuration of this system does not impact the schedule for the design, construction, or startup of the TWRS Treatment Complex.

Technical Maturity. Commercially demonstrated technology is used in the design of this system. Therefore, Technology issues were not a consideration for the configuration of this system.

Design Impact. This study has not identified any Design Impact issues that are unique to any single configuration considered for this system. Therefore, Design Impact is not a consideration that was used to determine the configuration of this system.

\subsubsection{Exhaust Air Treatment System}

3.8.2.1 System Description. The Exhaust Air Treatment System filters, samples and monitors the air exhausted from the TWRS Treatment Complex process facilities. The Exhaust Air Treatment System is broken down into two subsystems; a Zone I system and a Zone II and III system.

Ventilation air is drawn through the facility then through a double filtration system by means of a negative pressure supplied by the exhaust fans. The filtered air is then exhausted to the atmosphere through an exhaust stack. The main components of the Zone I exhaust system are as follows: 


\section{Revision 0}

- High Eff. Metal Fiber filters

- HEPA Filters

- Exhaust Fans

- Exhaust Stack.

The main components of the Zone II and III exhaust system are as follows:

- High Eff.(95 Percent) Filters

- 2 Stages of HEPA Filters

- Exhaust Fans

- Exhaust Stack.

The Zone I exhaust filters and fans are located in the Fan/Filter Annexes close coupled (annexed) to each process facility. The exhaust stack is located adjacent to the Fan/ Filter building. The Zone II and Zone III exhaust filters and fans are located on the roof of each process facility.

3.8.2.2 Findings. The Exhaust Air Treatment System is a dedicated annexed system. Operability and Maintainability as well as Safety are the prime considerations used to define this system. A dedicated exhaust air treatment system close coupled to each process facility allows for better operational control and increases overall reliability of the system. Close coupling is require to conform to DOE Order $6430.1 \mathrm{~A}$ requirements that the filtration system be as close as possible to the source of contamination and minimizes the risk of loss of confinement due to a breach in the ductwork connecting the exhaust air treatment equipment and the process facilities.

3.8.2.3 Function Configuration Considerations and Rationale. Operability and Maintainability as well as Safety are the prime considerations for defining this system. Dedicated systems close coupled (annexed) to each process facility allows each facility to operate independently. A failure in a shared system would shutdown both facilities while a dedicated system would allow continuous operation of one facility while the second is shutdown due to a failure or accident.

DOE Order 6430.1A, Section 1550-99.0.2 states that "air filtration units shall be installed as close as possible to the source of contaminants to minimize the contamination of the ventilation system ductwork". This requirement is aimed at minimizing final decontamination and decommissioning costs, but it also results in minimizing the length of ductwork that would need to be protected from damage due to an accident. Any break in the ductwork would threaten the ability of the HVAC system to maintain confinement and therefore could result in an unacceptable release of contaminants.

It must be noted the one disadvantage to dedicated Exhaust Air Treatment Systems would be that multiple air exhaust permits would be required. This is viewed as a administrative consideration and not a technical issue. Other considerations that were evaluated and found not to be contributors to the function configuration are noted below: 
Cost Effectiveness. This study has not identified any cost drivers that would override the technical considerations used to define the configuration of this system.

Therefore, Cost Effectiveness is not a consideration that was used to determine the configuration for this system.

Radiological Protection (ALARA). This study has not identified any Radiological Protection issues that are unique to any single configuration considered for this system. Therefore, Radiological Protection(ALARA) is not a consideration that was used to determine the configuration of this system.

Environmental Regulatory Compliance. This system is regulated by air emission regulations WAC 173-401, WAC 173-403, and WAC $173-460$ and each facility within this system will require permitting under these regulations. This is not considered to be a significant issue, therefore, Environmental Regulatory Compliance is not a consideration that was used to determine the configuration of this system.

Schedule. The configuration of this system does not impact the schedule for the design, construction, or startup of the TWRS Treatment Complex.

Technical Maturity. Commercially demonstrated technology is used in the design of this system. Therefore, Technology issues were not a consideration for the configuration of this system.

Design Impact. This study has not identified any Design Impact issues that are unique to any single configuration considered for this system. Therefore, Design Impact is not a consideration that was used to determine the configuration of this system.

\subsubsection{HVAC Chilled Water}

3.8.3.1 System Description. The HVAC Chilled Water System provides chilled water for the process facility Supply Air Treatment System and certain other process support facilities (Regulated Complex Entry Building, BCCB, AF, and MUB). The HVAC Chilled Water System consists of the compressors, evaporators, condensers, pumps, and insulated piping required to provide chilled water to the TWRS Treatment Complex.

The HVAC Chilled Water System is a closed loop system. Circulating water is cooled by the chilled water equipment in the MUB. From there it is routed to the cooling coils in the air handling units at the user facilities. The coils cool and dehumidify the filtered supply air before being introduced into the ventilation air distribution system. Captured heat is then expelled through the condensers in the mechanical Utilities Building to the Cooling Tower System where it is released to the environment. 
3.8.3.2 Findings. The HVAC Chilled Water System is a shared close-external system. This system is grouped together with portions of the Nonradioactive Liquid Waste Handling System, Utility Steam System, Process Water and Demineralized Water System and the Compressed Air System in the MUB.

Operability and Maintainability as well as Cost Effectiveness. are the prime considerations used to define this system. Locating this system in a shared close-external facility provides for easier operating and maintenance access and allows the system to take advantage of economies of scale and eliminate duplication of equipment.

\subsubsection{Function Configuration Considerations and Rationale. Operability and} Maintainability as well as Cost Effectiveness are the prime considerations for defining the HVAC Chilled Water System. A shared system located in a common, close-external facility provides for easier access for operations and maintenance personnel thus reducing the effort required to operate and maintain the system. A shared system allows the use of larger more efficient units and eliminates duplication of equipment.

As noted above the HVAC Chilled Water System should be located (for ease of access) outside of the process facilities. However, it should be located in close proximity to the facilities it serves. This is to keep down the amount of heat gained during transport to each facility. Therefore, this system is located as close as possible to the process facilities but out of the main process areas.

Other considerations that were evaluated and found not to be contributors to the function configuration are noted below:

Radiological Protection (ALARA). This study has not identified any Radiological Protection issues that are unique to any single configuration considered for this system. Therefore, Radiological Protection (ALARA) is not a consideration that was used to determine the configuration of this system.

Safety. This study has not identified any Safety issues that are unique to any single configuration considered for this system. Therefore, Safety is not a consideration that was used to determine the configuration of this system.

Environmental Regulatory Compliance. This system is regulated by air emission regulations WAC 173-401, WAC 173-403, and WAC 173-460 and each facility within this system will require permitting under these regulations. This is not considered to be a significant issue, therefore, Environmental Regulatory Compliance is not a consideration that was used to determine the configuration of this system.

Schedule. The configuration of this system does not impact the schedule for the design, construction, or startup of the TWRS Treatment Complex. 


\section{WHC-SD-W378-ES-002 \\ Revision 0}

Technical Maturity. Commercially demonstrated technology is used in the design of this system. Therefore, Technology issues were not a consideration for the configuration of this system.

Design Impact. This study has not identified any Design Impact issues that are unique to any single configuration considered for this system. Therefore, Design Impact is not a consideration that was used to determine the configuration of this system.

\subsection{MONITOR AND CONTROL THE PROCESS}

\subsubsection{Process Facility Operational Control System}

3.9.1.1 System Description. The Process Facility Operational Control System provides operational control of the TWRS Treatment Complex process facilities. This system monitors and controls remote operations (cranes, etc), process operations, melter operation, and canister handling activities. This system also provides for emergency shutdown of the process facilities in the event of an accident and the ability to shutdown the process with the process control system is impaired. This system is composed of control consoles, instruments, connective wiring, transmitters, and other items required to provide monitor and control the process facilities. The safe shutdown portion of the system is considered to be redundant and Safety Class 1.

The operational controls, except for the Safety Class 1 safe shutdown portion of the system, are located in the Control Room in the Regulated TWRS Complex Entry Building. The Safety Class 1 safe shutdown portion of the system is located in the Emergency Response Control Building.

3.9.1.2 Findings. The Process Operational Control System is a dedicated close-external system. The process control equipment for each process facility, with the exception of the safe shutdown equipment, are grouped together with other administrative control functions in the Regulated TWRS Complex Entry Building. The safe shutdown equipment is grouped together with the telecommunications equipment in the Emergency Response Center.

Operability and Maintainability as well as Safety are the prime considerations used to define this system. A shared system provides for better coordination and control of the TWRS Treatment Complex as well improving the maintainability of the system. Locating the process controls and more importantly the Safety Class 1 Safe Shutdown controls outside the main process facilities insures that an accident within a facility will not threaten the operators and the ability to monitor and control the process. 
3.9.1.3 Function Configuration Considerations and Rationale. Operability and Maintainability as well as Safety are the prime considerations for defining the Process Operational Control System. Locating all the control equipment together in a single facility improves the communication and coordination between the individual process facility operators and thereby provide better operational control of the complex. This configuration will also provide for easier scheduling and coordination of the maintenance activities associated with this system.

Placing these controls in a facility apart from the main process facilities we achieve additional safety for the operators and protects them from threats originating from within the process facilities. This will assure continued monitoring and control of the process during and after an accident. Placing the safe shutdown controls in a separate Safety Class 1 rated structure assures that these controls are readily accessible and can be used to bring the process operations into a safe shutdown condition after a Design Basis Accident.

Other considerations that were evaluated and found not to be contributors to the function configuration are noted below:

Cost Effectiveness. This study has not identified any cost drivers that would override the technical considerations used to define the configuration of this system. Therefore, Cost Effectiveness is not a consideration that was used to determine the configuration for this system.

Radiological Protection (ALARA). This study has not identified any Radiological Protection issues that are unique to any single configuration considered for this system. Therefore, Radiological Protection (ALARA) is not a consideration that was used to determine the configuration of this system.

Environmental Regulatory Compliance. This study has not identified any Environmental Regulatory Compliance issues that are unique to any single configuration considered for this system. Therefore, Environmental Regulatory Compliance is not a consideration that was used to determine the configuration of this system.

Schedule. The configuration of this system does not impact the schedule for the design, construction, or startup of the TWRS Treatment Complex.

Technical Maturity. Commercially demonstrated technology is used in the design of this system. Therefore, Technology issues were not a consideration for the configuration of this system.

Design Impact. This study has not identified any Design Impact issues that are unique to any single configuration considered for this system. Therefore, Design Impact is not a consideration that was used to determine the configuration of this system. 


\subsubsection{Health Protection System Vacuum System}

3.9.2.1 System Description. The Health Protection System (HPS) Vacuum System provides a continuous vacuum for the continuous air monitors and samplers at various locations in the Separations/LLW facility and the HLW facility, the Canister/Cask Handling Annex, and the Fan/Filter Annexes. The system discharges to the HVAC Exhaust Plenum. The samples are used to determine the quality (radioactivity) of air that any personnel within the monitored area will breathe.

The HPS Vacuum System includes piping, HEPA filters, and blowers. This blower system provides vacuum for $\alpha-\beta$ continuous air monitors, $B$ continuous air monitors, and record air samplers. Two, 100 percent flow capacity, motor driven vacuum blowers (one operating and one spare) are provided for each system. The blowers pull a vacuum on the system header through a HEPA filter(s) and send the exhaust to the HVAC Exhaust. The HEPA filter(s) removes submicron particulate from the gas stream. subsystems.

The HPS Vacuum System consists of the following five dedicated central vacuum

1. An HPS Vacuum System for the HLW facility and Regulated Facility Entry Annex.

2. An HPS Vacuum System for the Separations/LLW facility and Regulated Facility Entry Annex.

3. An HPS Vacuum System for the Canister/Cask Handling Annex.

4. An HPS Vacuum System for the HLW Fan/Filter Annex.

5. An HPS Vacuum System for the Separations/LLW Fan/Filter Annex.

Each system performs in a similar manner, and includes air monitor vacuum piping, HEPA filters, and vacuum blowers to provide continuous monitoring at all required locations. The HPS is designed so that no undetected single point failure results in the loss of the monitoring function.

See page A-24 of Appendix A for the Block Flow Diagram of the HPS Vacuum System. Drawings UFD-4-17 (sheets 1 through 8 ) are the Utility Flow Diagrams (see Appendix B) of the HPS Vacuum System.

3.9.2.2 Findings. The HPS Vacuum System is a dedicated system and is located inside the process facilities. Radiological Protection (ALARA) is the prime configuration consideration for the HPS Vacuum System. 


\section{Revision 0}

3.9.2.3 Functional Configuration Considerations and Rationale. Radiological Protection (ALARA) is the prime consideration for the HPS Vacuum System configuration. The HPS Vacuum System interfaces with monitors and samplers located in potentially contaminated areas. To ensure complete radiological protection the required HPS Vacuum System equipment is located entirely within each facility that it serves. The air monitors and samplers are designed to keep radioactive particles from entering the vacuum lines. Should accidental contamination of the vacuum headers occur, the HEPA filters provide an addition barrier to prevent radioactive particulate from leaving the facility. Therefore, Radiological Protection (ALARA) is an overriding concern in the determination of a shared or dedicated system and the HPS Vacuum System is designated as a dedicated system.

Other considerations that were evaluated and found not to be contributors to the function configuration are noted below:

Operability and Maintainability. This study has not identified any Operability or Maintainability issues that are unique to any single configuration considered for this system. Therefore, Operability and Maintainability are not considerations that were used to determine the configuration of this system.

Cost Effectiveness. This study has not identified any cost drivers that would override the technical considerations used to define the configuration of this system.

Therefore, Cost Effectiveness is not a consideration that was used to determine the configuration of this system.

Safety. This study has not identified any Safety issues that are unique to any single configuration considered for this system. Therefore, Safety is not a consideration that was used to determine the configuration of this system.

Environmental Regulatory Compliance. This study has not identified any Environmental Regulatory Compliance issues that are unique to any single configuration considered for this system. Therefore, Environmental Regulatory Compliance is not a consideration that was used to determine the configuration of this system.

Schedule. The configuration of this system does not impact the schedule for the design, construction, or startup of the TWRS Treatment Complex.

Technical Maturity. Commercially demonstrated technology is used in the design of this system. Therefore, Technology issues were not a consideration for the configuration of this system.

Design Impact. This study has not identified any Design Impact issues that are unique to any single configuration considered for this system. Therefore, Design Impact is not a consideration that was used to determine the configuration of this system. 
WHC-SD-W378-ES-002

Revision 0

\subsection{DISCUSSION AND EVALUATION OF SUPPORT FACILITIES}

This section describes the support facilities required to provide the close-external and no distance constrained functions identified in Section 2.0. A narrative is provided for each support facility identifying the size of the facility, type of construction, and functions provided. The narrative addresses the benefits of the particular grouping of functions within each facility and identifies any considerations that will impact where each facility is to be located with regard to the other process and process support facilities.

\subsection{REGULATED TANK WASTE REMEDIATION SYSTEM COMPLEX ENTRY BUILDING}

The Regulated TWRS Complex Entry Building is a $45.7 \mathrm{~m}$ by $61 \mathrm{~m}$ two story steel frame structure. It provides office and office support facilities for 66 people, facilities to regulate and control the flow of up to 620 people who may need to enter and exit the TWRS Treatment Complex on any given day, and facilities for the control of remote operations of the TWRS Treatment Complex process facilities. These functions (Regulated TWRS Treatment Complex Entry and Process Operational Control) are grouped together to enhance the overall operation of the TWRS Treatment Complex and minimize the amount of effort required to maintain the facilities providing these functions. In addition Employee Support facilities in the form of changerooms, lunchrooms, etc., are located in this building.

The population flowing through this facility is based on the following:

\begin{tabular}{|l|c|}
\hline Day Shift & 348 \\
\hline A Shift & 72 \\
\hline Training & 72 \\
\hline Back Shift & 72 \\
\hline Sub-Total & 564 \\
\hline Potential transient personnel & $\times 10 \%$ \\
\hline Total capacity & 620 \\
\hline
\end{tabular}


It is assumed that this worker population will be 65 percent male and 35 percent female. A breakdown of the allocated space is provided below:

\begin{tabular}{|l|c|}
\hline Offices & $514 \mathrm{~m}^{2}$ \\
\hline Toilet Facilities & $39 \mathrm{~m}^{2}$ \\
\hline Unregulated change rooms & $236 \mathrm{~m}^{2}$ \\
\hline Unregulated toilet facilities & $110 \mathrm{~m}^{2}$ \\
\hline Unregulated shower areas & $257 \mathrm{~m}^{2}$ \\
\hline Lunch/Staging areas & $710 \mathrm{~m}^{2}$ \\
\hline $\begin{array}{l}\text { Health Protection areas, corridors, } \\
\text { stairways, and other common areas }\end{array}$ & $1,846 \mathrm{~m}^{2}$ \\
\hline HVAC/Elect equipment room & $916 \mathrm{~m}^{2}$ \\
\hline Control Room & $307 \mathrm{~m}^{2}$ \\
\hline
\end{tabular}

All personnel entering and exiting the TWRS Treatment Complex must pass through this facility. It is preferred that the walking distance between the parking areas and this building and between this building and the processing facilities be minimized. Therefore this building is located near the automobile and bus parking areas and as close as possible to the process facilities.

\subsection{OPERATIONS SUPPORT BUILDING}

The Operations Support Building is a 45.7 meter by 61 meter two story steel frame structure with a mechanical penthouse for its dedicated HVAC and electrical distribution systems. It houses the TWRS Treatment Complex Management and Support System. Office space is provided for up to 216 people. In addition, space is provided for postal services, record retention, reprographics, training, and public outreach displays. A breakdown of the allocated space is provided below: 
WHC-SD-W378-ES-002

Revision 0

\begin{tabular}{|l|c|}
\hline Offices & $1834 \mathrm{~m}^{2}$ \\
\hline Record retention and reprographics & $116 \mathrm{~m}^{2}$ \\
\hline Display and conference areas & $116 \mathrm{~m}^{2}$ \\
\hline Computer maintenance & $30 \mathrm{~m}^{2}$ \\
\hline Training areas & $558 \mathrm{~m}^{2}$ \\
\hline Postal services & $70 \mathrm{~m}^{2}$ \\
\hline Lunch rooms and toilet facilities & $581 \mathrm{~m}^{2}$ \\
\hline $\begin{array}{l}\text { stairways, corridors, storage, loading } \\
\text { dock, and other common areas }\end{array}$ & $2,269 \mathrm{~m}^{2}$ \\
\hline HVAC/Elect equipment penthouse & $929 \mathrm{~m}^{2}$ \\
\hline
\end{tabular}

There are no technical consideration governing the location of this facility. The function provided by this facility can be provided from almost anywhere, including existing Hanford facilities. For the purposes of this study the Operations Support Building is located adjacent to the parking areas.

\subsection{EMIERGENCY RESPONSE CENTER}

The Emergency Response Center is a $27.43 \mathrm{~m}$ by $38.1 \mathrm{~m}$ single story structure with a mechanical penthouse for its dedicated HVAC system. The outer walls are cast-in-place concrete while the roof and interior columns are fabricated from structural steel.

The Telecommunications Center and the safe shutdown portion of the Process Facility Operational Control System for each process facility are grouped together in this structure. The safe shutdown portion of the Process Facility Operational Control System provides redundant controls to bring each process facility into a safe shutdown condition in the event of an Design Basis Accident. In addition it provides for the monitoring of the shutdown process to assure that the shutdown is actually occurring. The Telecommunications Center is collocated with these systems to assure that the personnel involved with shutting down the process facilities can communicate with emergency personnel located elsewhere on or off the Hanford site.

The personnel assigned to staff the Emergency Response Center normally work in the Regulated TWRS Complex Entry Building. Therefore the Emergency Response Center is located adjacent to the Regulated TWRS Complex Entry Building but far enough away not to be impacted by a structural failure of the Regulated TWRS Treatment Complex Entry Building. 
NOTE: During the peer review process, a concern surfaced that the remote configuration of the ERC presented in this study could be difficult to implement due to the rigor of Safety Class 1 instrumentation and control requirements.

\subsection{BULK COLD CHEMICAL BUILDING/BULK HANDLING AREA}

The BCCB is a one story, steel frame structure $37.8 \mathrm{~m}$ wide by $43.3 \mathrm{~m}$ long. The Bulk Handling Area is an area located adjacent to the BCCB used to unload bulk chemicals and provide storage for those that do not require environmental protection. The BCCB/Bulk Handling Area houses the Cold Chemical Supply System, the Cold Chemical Vent System, and the Collect and Handle Nonradioactive Liquid Waste System.

Storing all the cold chemicals in a single facility will provide for a single delivery point for the receipt of these consumables, and will simplify the logistics of scheduling shipments on and off the site.

Collocating the storage facilities with the mixing facilities will reduce the problems (mainly plugging and erosion) associated with transporting the solids from storage to the mixing tanks. Also, the length of the solids transport lines to reduce the potential for plugging and erosion and the length of the liquid transport lines must be minimized to reduce the potential for leakage of toxic chemicals from the liquid transport lines. Therefore, the BCCB should be located in close proximity to both of the process facilities and preferably closest to the primary user, the Separations/LLW process facility.

\subsection{MECHANICAL UTILITIES BUILDING}

The MUB is a one story, steel frame structure $45.1 \mathrm{~m}$ wide by $52.7 \mathrm{~m}$ long. It houses the Compressed Air, Utility Steam, and the HVAC Chilled Water Systems and the Demineralized Water Subsystem. It also provides space for electrical and mechanical repair shops for noncontaminated, support facility equipment located in this building as well as conference rooms, office, and restrooms for the operation and maintenance staff.

The machinery associated with the utilities systems housed in the MUB has a relatively high noise and heat output. Failure of air and refrigeration compressors, as well as low pressure steam generators, poses a threat of internally generated missiles (such as failed equipment parts, fan belts, etc.). Therefore, the air, steam, demineralized water, and chiller systems are located together in one building, where operators will have limited exposure to these threats. This shared facility reduces the need for operator entry for routine checkout and panel readings, provides an operational advantage, and enhances operator safety.

These utility systems located in the MUB are defined as shared, close-external functions and, from a process standpoint, would be desirable to locate it as close as possible 


\section{Revision 0}

to the main process facilities. Therefore, the MUB should be located in close proximity to both of the process facilities.

\subsection{WATER PUMPHOUSE}

The WPH is a one story, steel frame structure $15.2 \mathrm{~m}$ wide by $45.9 \mathrm{~m}$ long. It houses pumps for the TWRS Treatment Complex Site Fire Water System, the Process Facilities Fire Water System, and the Process Water Subsystem. It also provides space for a maintenance room and a field operating station.

The WPH provides a single point for the inlet and distribution of all of the water used on site. The water systems have several interfaces and contain common types of equipment, i.e., water pumps. Therefore, there is an operational and maintenance advantage to collocate these functions.

The water systems have been defined as shared and grouped, no distance constraints functions. Therefore, the WPH is a candidate for being provided from an existing Hanford Site facility.

\subsection{ANALYTICAL FACLITY}

The AF is a two story structure with a partial basement for waste catch tanks. It has steel frame structure except for the analytical cells and MSM decontamination and repair, which have concrete walls, floors, beams, and columns for shielding.

The AF houses the following functions:

- Analytical cells for remote sample preparation, dilution, and analysis of radioactive samples from the Separations/LLW and HLW process facilities.

- Analytical laboratories for contact sample analysis.

- Lag storage for contaminated MSMs.

- Areas for decontaminating MSMs.

- Lag storage for decontaminated MSMs.

- Repair Shop for MSMs.

- $\quad$ Lag storage of repaired MSMs.

- Offices for an MSM repair shop, labs and health physics. 
WHC-SD-W378-ES-002

Revision 0

- Storage areas for an MSM repair shop and labs.

- HVAC and electrical equipment.

- Regulated and unregulated change rooms.

Waste collection tanks.

Even though the Sample Analysis function is defined as dedicated, the function is collocated in the AF. Cost and operability are the prime considerations for collocating this equipment in the AF. Collocation of the Sample Analysis function in the AF allows the AF to contain all of the functions required of an analytical facility. For example, the AF contains all of the service rooms, receiving rooms, counting rooms, equipment and stock rooms, analytical instrument rooms, solid and liquid waste handling, a nd MSM repair required to fully support the function in a single facility. Collocation of functions in the AF also allows for a sharing of personnel, which may also improve productivity.

The initial layouts are based on performing remote analysis in the AF analytical cells. Further analysis may indicate that some remote analysis can be performed in the process facilities.

Radiological protection (ALARA) is not a consideration in collocating the Sample Analysis function in the AF. Failure of an analytical cell shield window does not significantly impact the AF operating efficiency. The alpha shield located inside the shield window provides an air flow barrier to control contamination spread. Materials with a high source term would be removed from the analytical cell during window replacement. Radioactive shine would probably prevent operation of that cell plus one cell on either side for the day required to replace the shield window.

A shared analytical and MSM repair facility serving the Separations/LLW and HLW facilities allows consolidation of support functions (electrical, HVAC, decontamination equipment, etc.) and support rooms (regulated entrance, offices, etc.). Therefore, a shared facility has a smaller footprint than two facilities. Taking advantage of the economies of scale, and the elimination of the duplication of equipment and rooms, provides a cost advantage for a shared AF over separate dedicated facilities.

Maintainability and radiological protection are the key reasons for collocating the analytical laboratories with the MSM decontamination and repair operations. The majority, if not all, of the MSMs on the TWRS Treatment site are used for the analytical hot cells. Collocating the MSM decontamination and repair facilities with the AF will enhance the logistics of maintenance and repair operations. This collocation will also eliminate the need to transport MSMs between facilities, and therefore, eliminate the radiological protection problems that would be associated with the transport. 


\section{Revision 0}

The total engineered cost of a shared AF with analytical equipment and support equipment is $\$ 179,531,000$. The total engineered cost of two dedicated facilities including equipment is $\$ 189,865,800$.

Reports that provide the basis for the sizing of the AF, including sample schedules, are provided in Appendix $\mathrm{H} 1$ and $\mathrm{H} 2$.

\subsection{SWITCHGEAR BULDING}

The Switchgear Building is a $15.24 \mathrm{~m}$ by $45.72 \mathrm{~m}$ single story steel frame structure with an $8.84 \mathrm{~m}$ by $39.17 \mathrm{~m}$ by $3.96 \mathrm{~m}$ deep underground cable vautt. It houses cables and other equipment required to transform the $34.5 \mathrm{kV}$ incoming feed to $13.8 \mathrm{kV}$ power for the Separations/LLW process facility, the HLW process facility, and the process support facilities. The transformers are located outside, adjacent to the building.

Redundant $34.5 \mathrm{kV}$ power enters the Switchgear Building where it is broken down into dedicated $13.8 \mathrm{kV}$ power supply for the process and process support facilities. Locating all the switchgear in a single location simplifies the maintenance of the Normal AC Power System. To reduce the amount of and complexity of the underground electrical distribution system, this facility is located in an area that affords easy access to the incoming $34.5 \mathrm{kV}$ line and is in close proximity to both process facilities.

\subsection{WAREHOUSES/SHIPPING AND RECEIVING BUILDING}

The Warehouses and Shipping and Receiving Building are single story steel framed structures. Together they provide approximately $8,030 \mathrm{~m}^{2}$ of storage area and $1,600 \mathrm{~m}^{2}$ of receiving, packaging, and inventory control area. These facilities provide single point of control for small equipment, spare parts, and consumables required to operate and maintain the TWRS Treatment Complex.

There are no technical considerations governing the location of these facilities and as such are not distance constrained. Existing Hanford facilities could be used to provide these functions. It should be kept in mind that these facilities could be used to support construction activities and in that case should be located in an area designated for construction support.

\subsection{FABRICATION AND ASSEMBLY SHOP}

The Fabrication and Assembly Shop is a $45.72 \mathrm{~m}$ by $87.78 \mathrm{~m}$ single story steel frame structure with a $15.24 \mathrm{~m}$ wide by $22.9 \mathrm{~m}$ high center bay. The center high bay is equipped with a bridge crane used in assembling the larger heavier components such as a melter. 


\section{Revision 0}

The spare parts fabrication and major equipment assembly functions are grouped together in this facility. Also provided are office areas, tool cribs, shipping/receiving areas, lunch/conference areas, and toilet facilities. There are no technical considerations governing the location of this facility and as such is not distance constrained. Existing Hanford facilities could be used to provide these functions. It should be kept in mind that this facility could be used to support construction activities and in that case should be located in an area designated for construction support.

\subsection{EMERGENCY GENERATOR BUILDINGS}

The dedicated Emergency Generator Buildings are $30.5 \mathrm{~m}$ by $38.1 \mathrm{~m}$ single story steel frame structures with mechanical penthouses for their dedicated HVAC systems. They house redundant dedicated Emergency Power Systems for each of the TWRS Treatment Complex process systems. Housed are emergency generators, transformers, batteries, and any other equipment required to supply emergency power in the event of a loss of power.

The primary load for the Emergency Power Systems are the HVAC Zone I exhaust fans located in the Fan/Filter Annexes for each process facility. Therefore these buildings are located as close as possible to the Fan/Filter Annex they support. The cost for the EGB and equipment is reflected in the separations and vitrification facilities.

\subsection{STTE INFRASTRUCTURE}

The TWRS Treatment Complex site infrastructure consists of the following:

- Earthwork and Grading

- $\quad$ Site Roads $(3.3 \mathrm{~km})$

- $\quad$ Rail Line $(2.7 \mathrm{~km})$

- Security Fencing

- Area Lighting

- U/G Fire Water Piping

- U/G Raw Water Piping

- $\quad \mathrm{A} / \mathrm{G}$ Steam and Condensate Piping

- U/G Process Water Piping

- $\quad$ A/G Compressed Air Piping

- U/G Electrical Ductbanks

- U/G Telecommunications Cable

- U/G Sanitary Sewer System (includes Lift Station)

- Unit Substations

- $230 \mathrm{kV}$ Pole Line $(3 \mathrm{~km})$ and Substation

- 4 Feed Transfer Lines (1.12 km each). 
These items represent the above ground and below ground infrastructure required to operate the TWRS Treatment Complex. The cost basis for some of these items (roads, rail line, pole line etc.) are based on estimated quantities while others are based on a factored cost per hectare.

The factored cost for earthwork and grading was applied to an 80 hectare site while the factored costs for the underground mechanical utilities was based on a 60 hectare site. This acknowledges the fact that the process and process support functions do not occupy the entire site but leaves approximately 20 hectares for construction support and laydown as well as allows future expansion.

It should be noted that although the interconnecting process piping, $230 \mathrm{kV}$ pole line, $230 \mathrm{kV}$ Substation and sewage lift station has been considered as part of the site infrastructure, the feed transfer lines have not. It has been identified as a separate cost item in Table 2-5.

The utility interface points are assumed to be as follows:

1. Raw Water

2. Sanitary Water

3. Electrical Power

4. Feed Transfer lines

5. Sewer system
At the existing raw water line at 4 th Street.

At the existing sanitary water line at 4 th Street.

Bonneville Power Administration (Existing $230 \mathrm{kV}$ power loop), located north of the $200 \mathrm{E}$ Area.

Tie into Project W-058, Cross-Site Transfer System, Diversion Box 3.

No tie in point identified. Assumed that to be connected at site boundary to the proposed 200 Area Sanitary Sewer System (L-116). 
WHC-SD-W378-ES-002

Revision 0

This page intentionally left blank. 
WHC-SD-W378-ES-002

Revision 0

\subsection{STTE ARRANGEMENT}

The TWRS Treatment Complex occupies approximately 81 hectares. It is situated north of Route 4 South and between Baltimore Ave and the PUREX Plant. There is rail access from an existing rail line and vehicle access from the existing Hanford road system.

A site arrangement (Figure 2-1) has been developed that shows the arrangement and location of the TWRS Treatment Complex process facilities, process support facilities, permanent and interim product storage facilities, and infrastructure on the site. The Arrangement clusters the Separations/LLW facility and its associated annexes together in one location and the HLW facility and its annexes in another. The support facilities, storage areas, and infrastructure are arranged so as to provide optimal support of the process mission.

The overall arrangement provides for a phased construction effort. That is, construction of the Separations/LLW facility would begin several years before the construction of the HLW facility. This is in concert with the specified Hanford Federal Facility and Consent Order (Tri-Party Agreement) (Ecology et al. 1994) start up dates for these facilities.

It is assumed that the tie-ins to the Hanford power grid would be from the east side of the site and that most of the utility water and steam tie-ins would be at the existing lines located at the west side of the site, near 4th Street. The process feed would originate from a diversion box placed at the new cross-site transfer line (W-058) on the north side of the site.

The process and utility supply facilities are arranged to facilitate the connection between these tie-in points and the treatment complex. The Separations/LLW and HLW facilities are located on the north end of the site to be near the cross-site transfer lines and the existing rail line. The Switchgear Building is on the east side to be near the electrical supply system and the WPH is on the west side to be near the utility tie-in points.

The Emergency Generator Buildings provide dedicated emergency power to the HVAC Zone I exhaust fans. To minimize the length of Safety Class 1 ductbank and the potential for damage due to an accident these buildings are located adjacent to the Fan/Filter Annexes they serve. The AF, MUB, BCCB, BHA, Regulated TWRS Complex Entry Building, and the Emergency Response Center are all shared, close-external facilities. Therefore they have been positioned in locations that are central to both the main process facilities. The LLW storage vaults and the HLW cask pads are located in an area that is easily accessible from their associated process facility.

The remaining support facilities (Warehouses, Shipping and Receiving Bldg, Storage and Service Yard, Fabrication and Assembly Shop, Cooling Tower and the Operations Support Building) are shared, no distance constraint facilities. That is, there are no overwhelming considerations that drive the location of these facilities. 
The Operations Support Building houses management personnel so it is located away from the operations areas but near to the parking area. The Cooling Tower gives off moisture into the atmosphere and is located downwind from the rest of the complex. The Warehouses, Shipping and Receiving Building, Storage and Service Yard, and the Fabrication and Assembly Shop are located away from the operations area but within easy road and rail access. Space has been left between the buildings to provide for plant roads and utility corridors within the complex. Space for construction laydown, spoils, and potential expansion of the storage areas has been provided on southern portion of the site.

It is noted that the High Level Condensate Collection Facility and the Low Level Condensate Collection Facility, although shown as separate facilities, are considered to be annexes to their respective process facilities and are included in the discussion of the arrangement of the process facilities. 


\section{WHC-SD-W378-ES-002 \\ Revision 0}

\subsection{REFERENCES}

Boomer, K. D., J. M. Colby, T. W. Crawford, J. S. Garfield, J. D. Galbraith, C. E. Golberg, C. E. Leach, D. E. Mitchell, F. D. Nankani, E. J. Slaathaug, L. M. Swanson, T. L. Waldo, and C. M. Winkler, 1994, Tank Waste Remediation System Facility Configuration Study, WHC-ED-WM-ES-295, Rev 0, Westinghouse Hanford Company, Richland, Washington.

Ecology, EPA, and DOE, 1994, Hanford Federal Facility Agreement and Consent Order, as amended, Washington State Department of Ecology, U.S. Environmental Protection Agency, and the U.S. Department of Energy, Olympia, Washington.

Resource Conservation and Recovery Act of 1976, 42 USC 6901 et seq.

Shord, A. L., 1995, Tank Waste Remediation System Complex Site Evaluation Report, WHC-SD-WM-SE-021, Rev 0, Westinghouse Hanford Company, Richland, Washington.

WHC, 1995, Tank Waste Remediation System Reduced Cost Strategy, WHC-SD-WM-TI-694, Draft, Westinghouse Hanford Company, Richland, Washington.

Willis, N. P., 1993, Hanford Site Solid Waste Acceptance Criteria, WHC-EP-0063, Westinghouse Hanford Company, Richland, Washington. 
WHC-SD-W378-ES-002

Revision 0

This page intentionally left blank. 
WHC-SD-W378-ES-002

Revision 0

\section{APPENDIX A}

\section{BLOCK FLOW DIAGRAMS}


WHC-SD-W378-ES-002

Revision 0

This page intentionally left blank. 


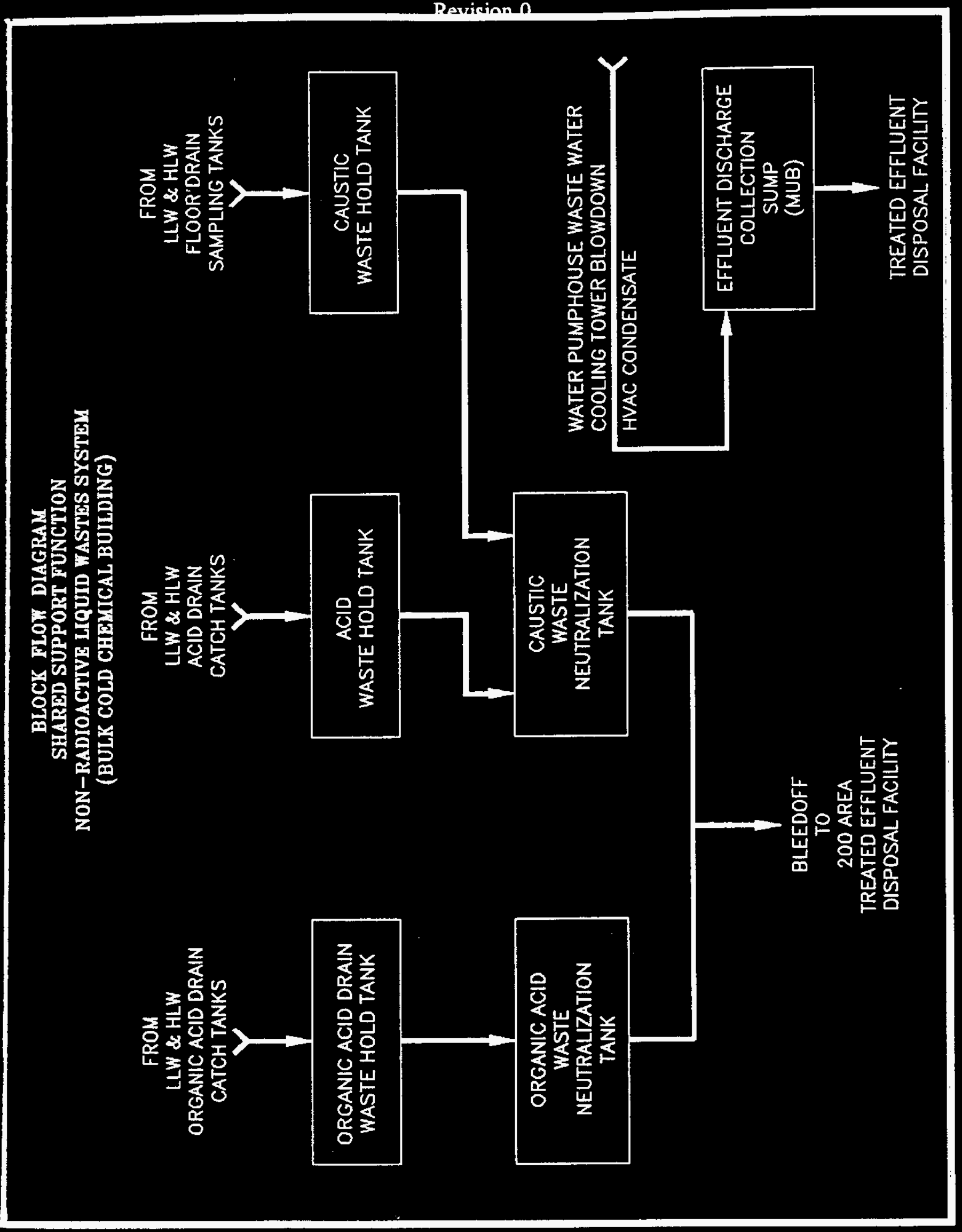




\section{*alls View/Frint Document Cover Sheet tow}

This document was retrieved from the Documentation and Records Manaqement (DRM) ISEARCH System. It is intended for Information only and may not be the most recent or updated version. Contact a Document Service Center (see Hanford Info for locations) if you need additional retrieval information.

Accession \#: D195067260

Document \#: SD-W378-ES-002

Title/Desc:

FACILITY DESIGN PHILOSOPHY TWRS PROCESS SUPPORT \& INFRASTRUCTURE DEFINITION [SEC 2 OF 4]

Pages: 151 
THIS DOCUMENT WAS TOO LARGE TO SCAN AS A SINGLE

DOCUMENT. IT REQUIRED BREAKING INTO SMALLER SECTIONS.

DOCUMENT NUMBER: SD-11378- \&S-002

SECTION: $\quad 2$ OF 4

TITLE: facility Duigno Philonophy janb, Waste

Pemediation syotem Proceses seppoost \& Infractructure

Definition

AUTHOR: Beach, galleraith

RECIPIENT:

DATE: $12 / 11 / 95$

KEYWORDS:

REFERENCES: $8 D T-(0 \mid 3)|h|$ 
BLOCX FLON DIAGRM SEARED SUPPORT FUNCTION OXYGEN SYSTEM

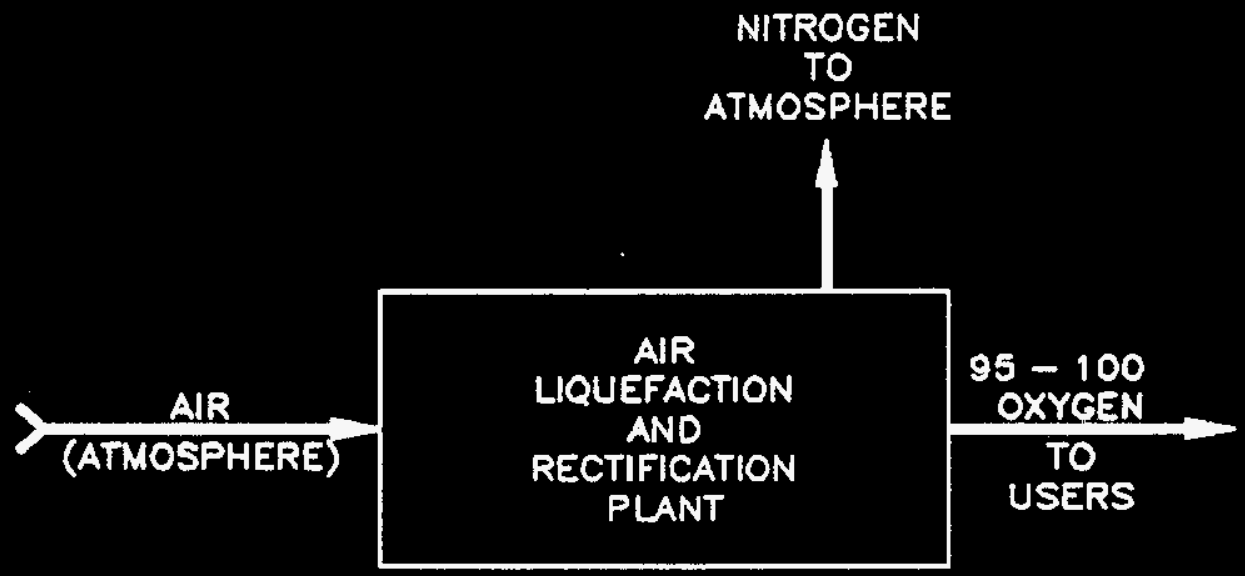


BLOG DHI DHERM

SENAT SUPPOET FUNCION

COLD CHATCA, DUL STOPLAE

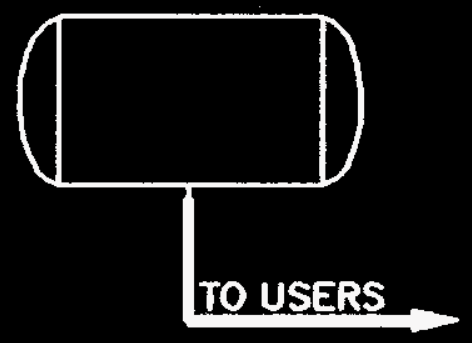

BULK ANHYDROUS $\mathrm{NH}_{3}$ STORAGE

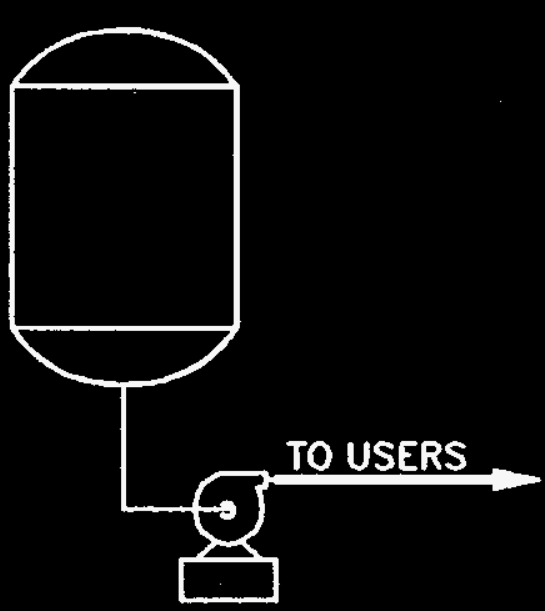

TYPICAL FOR:

BULK KEROSENE BULK $\mathrm{HNO}_{3}$

STORAGE

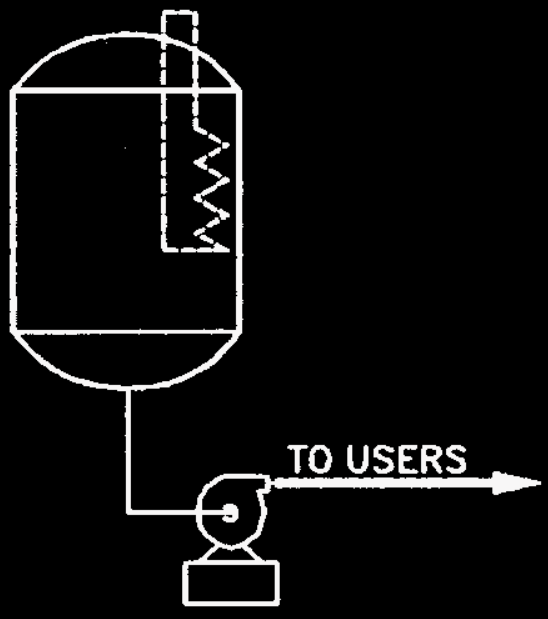

TYPICAL FOR:

BULK NaOH

STORAGE 


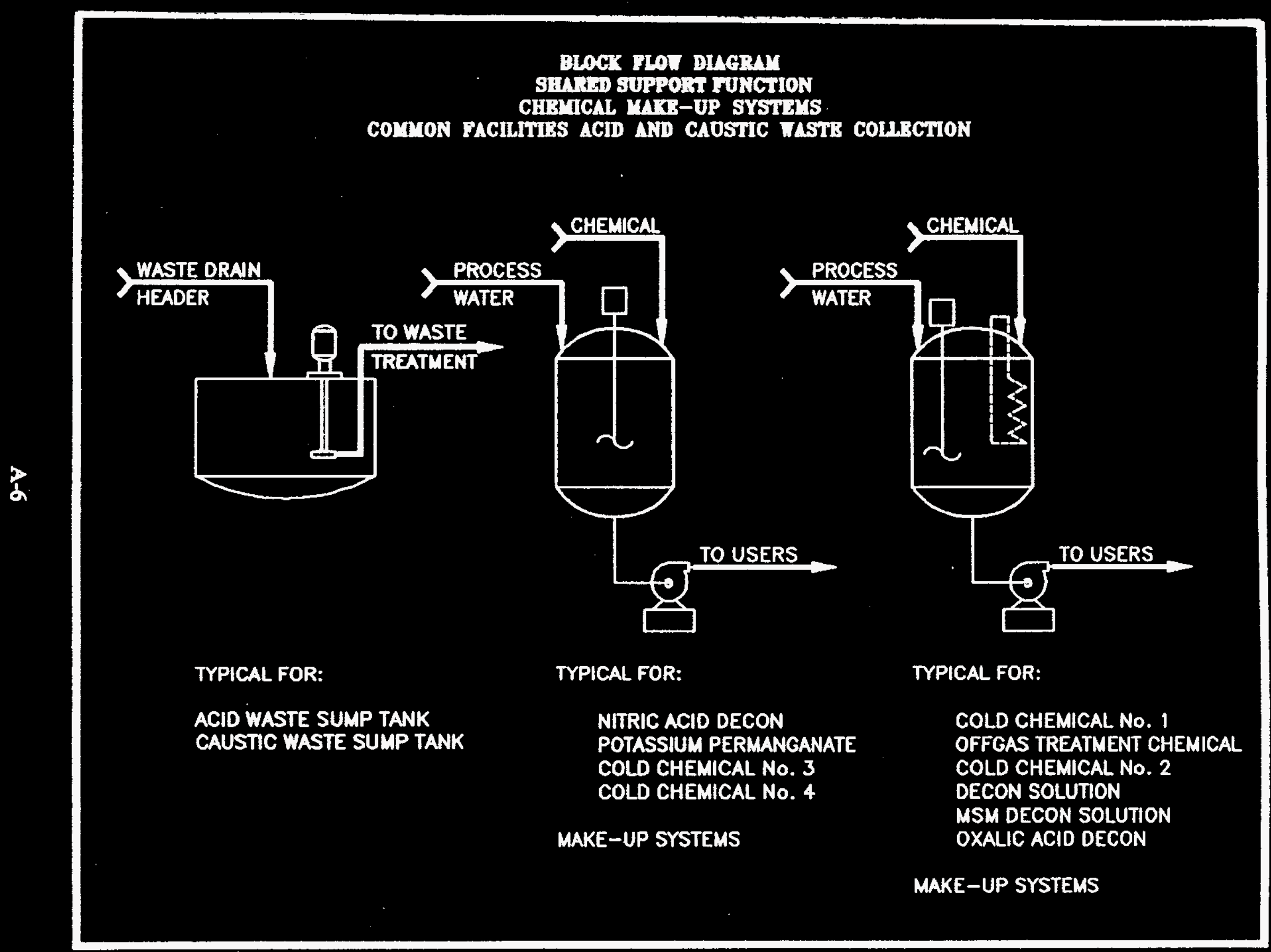




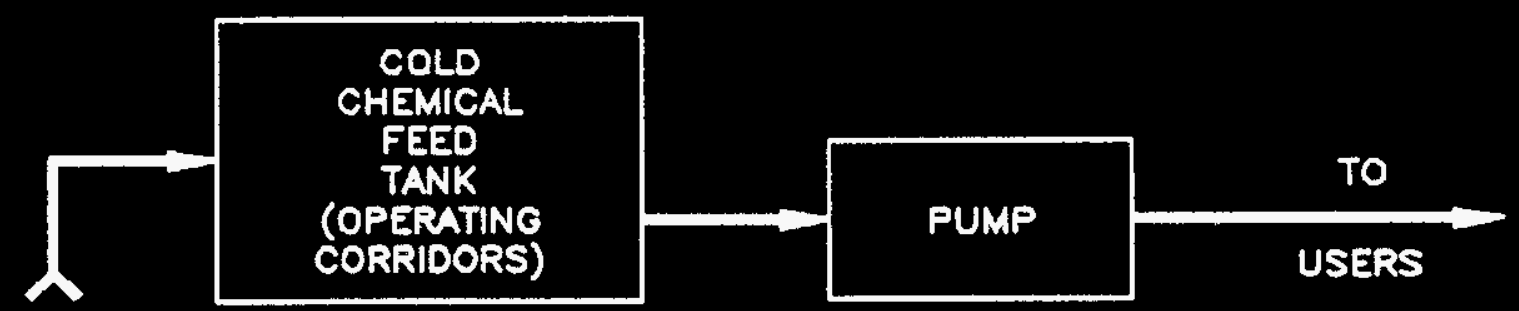

FROM

STORAGE (EULK COLD TYPICAL OF ALL COLD CHEMICAL FEEDS CHEM. BLDG)

TYPICAL FOR:

SEPARATIONS/LOW LEVEL WASTE,

DETACHED HIGH LEVEL WASTE VITRIFICATION BUILOING 
BLOCK FLOW DIAGRAM

COLD CIINICAL VINT SYSTEM

(DEDTCATEA JUNCTION)

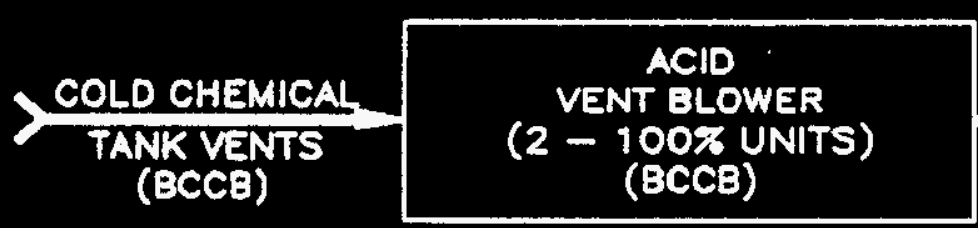

\begin{tabular}{l} 
TO \\
ATMOSPHERE \\
THRU \\
\hline BCCB \\
EXHAUST \\
STACK
\end{tabular}


BLOCX FLOT DIAGRAM

CONPIGURATOK 4 (STP/LHT, DETACEBD ELT)

PROCLSS pacturt VINT STSTMM

(DEDICLTHO FUTCTION)

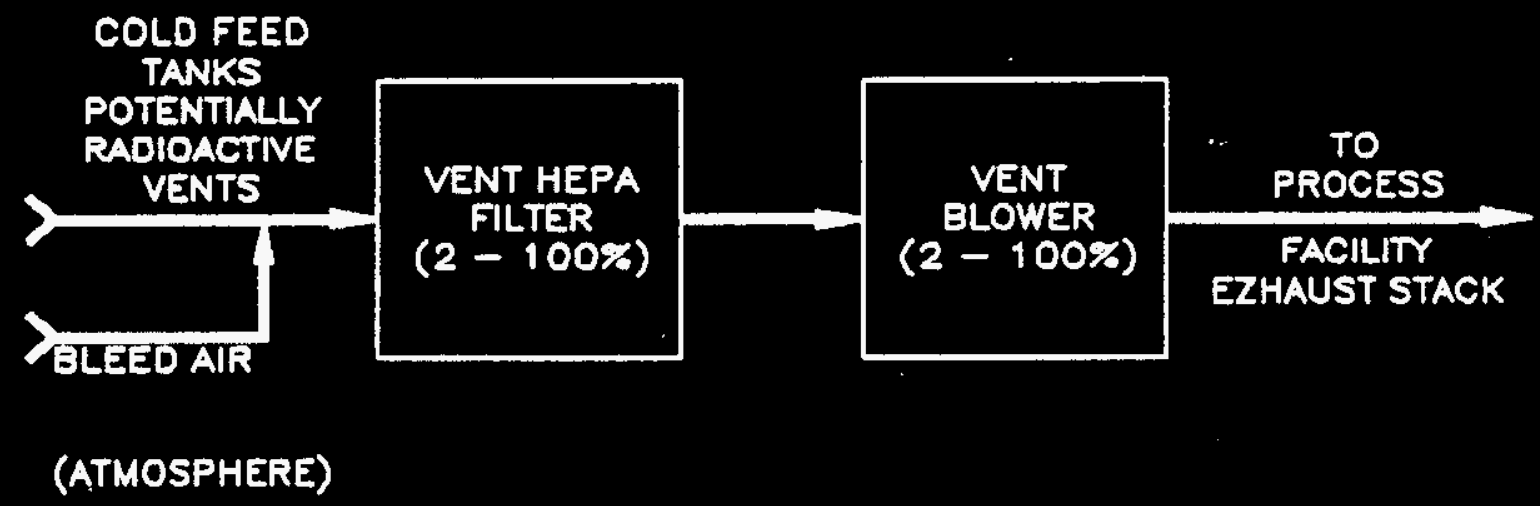

TYPICAL FOR:

SEPARATIONS/LOW LEVEL WASTE.

DETACHED HIGH LEVEL WASTE VITRIFICATION BUILDINGS 

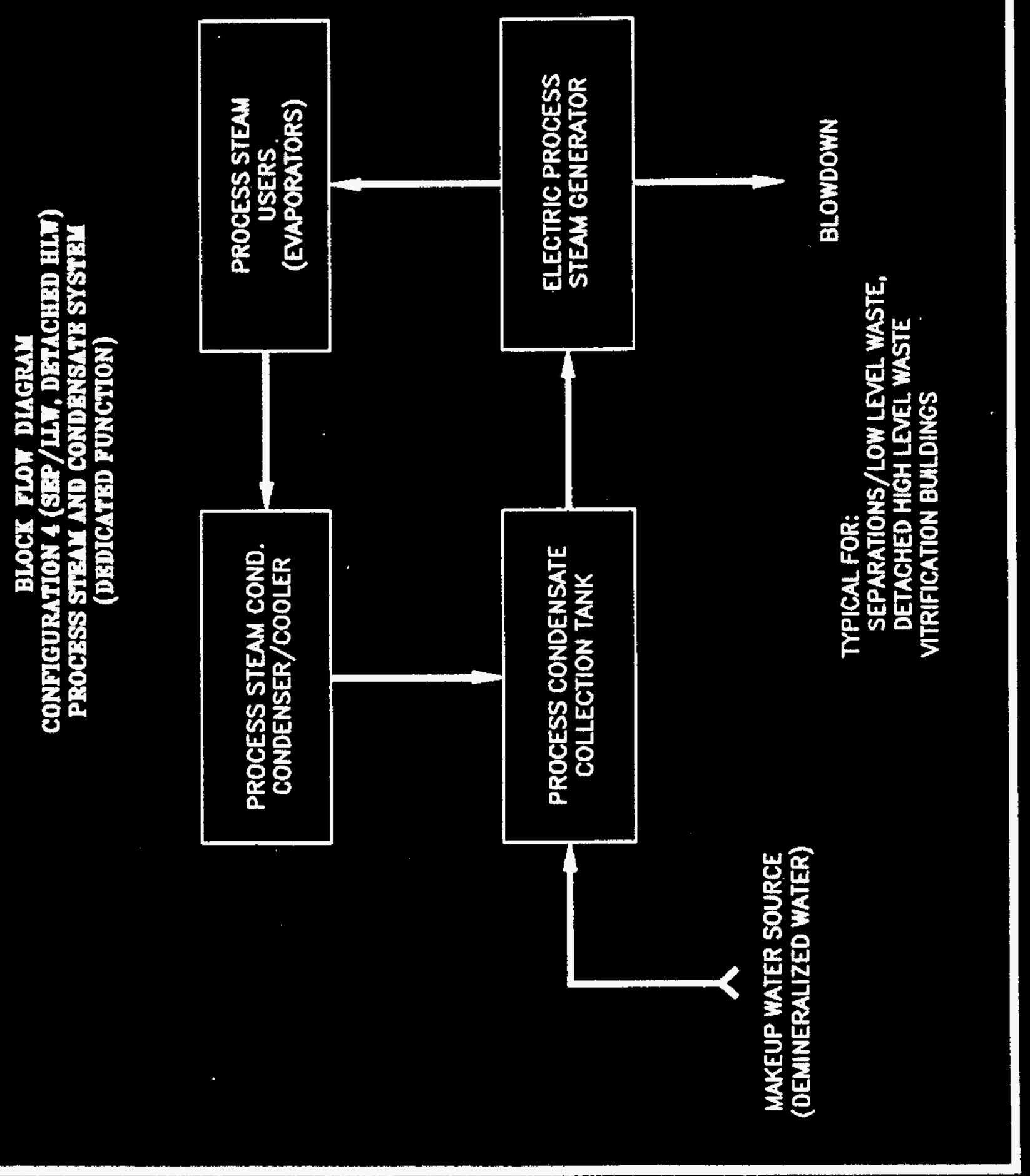


\section{BLOCK FLOT DTAGRAM \\ CONFIGUBATION 4 (SHP/LLT, DEMACHID HIT) \\ PROCBAS coOUME WLTHR SYSTEY \\ (DEDTCATHD FUNCTION)}

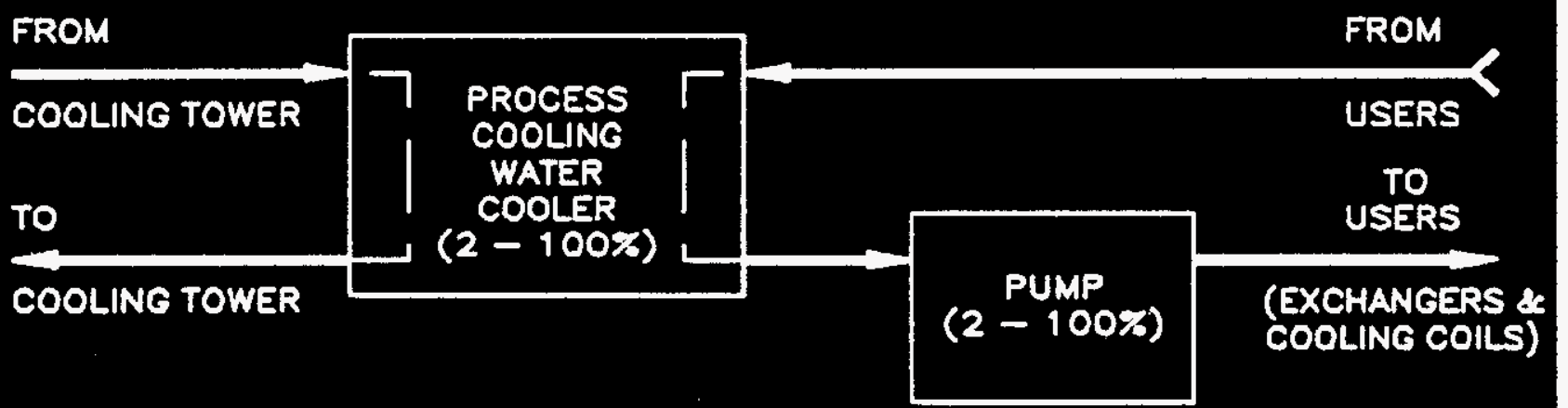

TYPICAL FOR:

SEPARATIONS/LOW LEVEL WASTE;

DETACHED HIGH LQVEL WASTE

VITRIFICATION BUILDINGS 
BLOCX FWT DIAGRAK

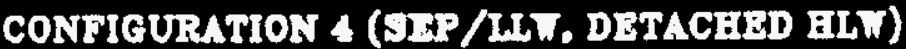

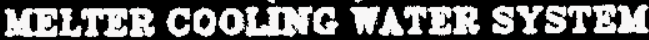

(DADICatid UTHEYT)

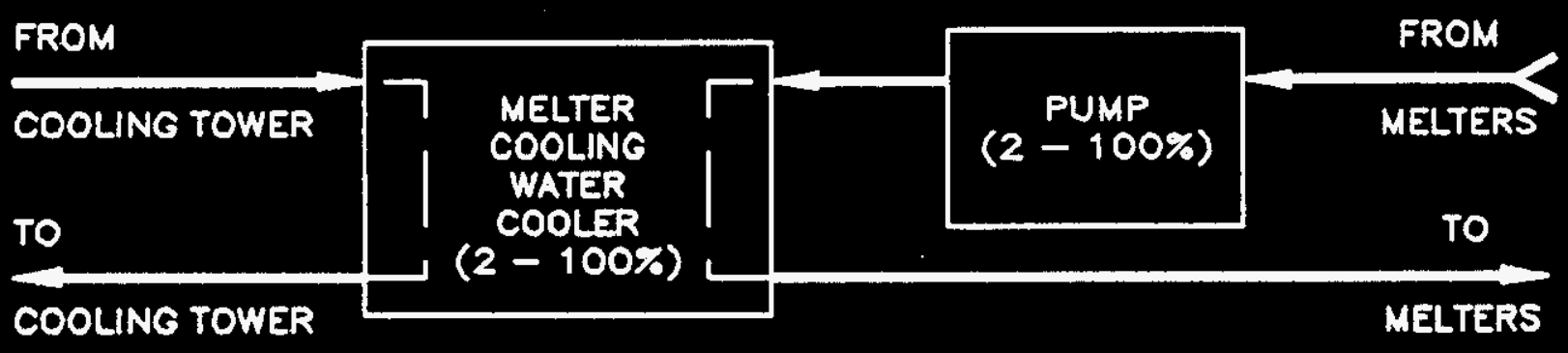

MPICAL FOR:

SEPARATKONS/LOW LEVEL WASTE.

DETACHED HIGH LEVEL WASTE

VITRIFICATION BULLOINGS 
BLOCK FLOW DIAGRAM

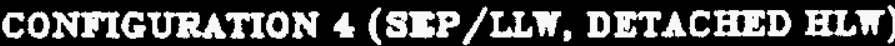

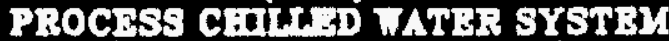

(DIDICATED PUNCTION)

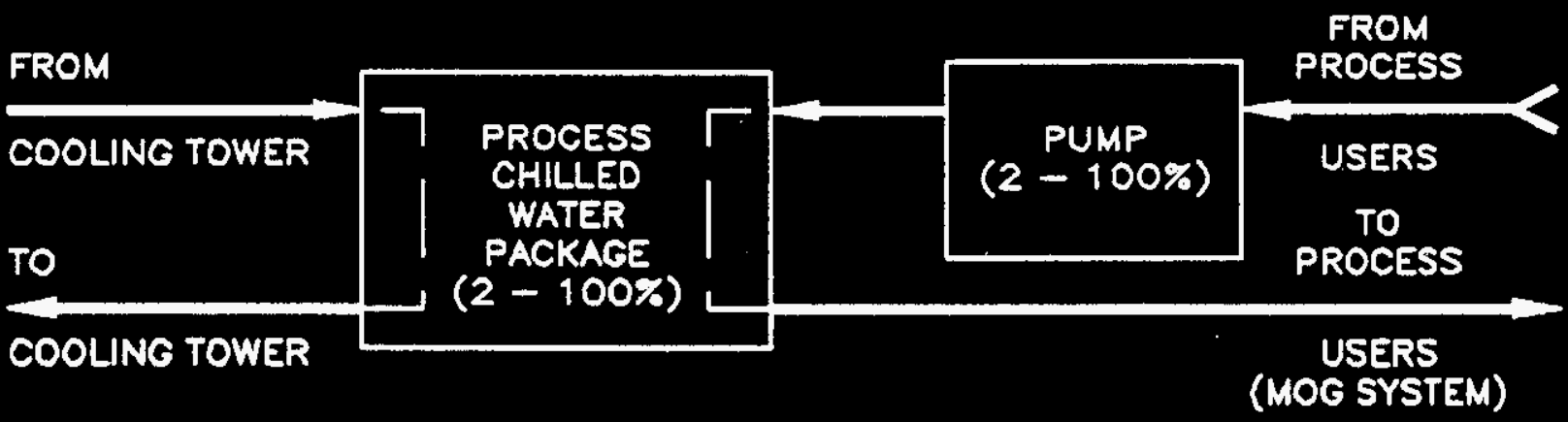

TYPICAL FOR:

SEPARATIONS/LOW LEVEL WASTE,

DETACHED HIOH LEVEL WASTE VIRIFICATION BUILOING 

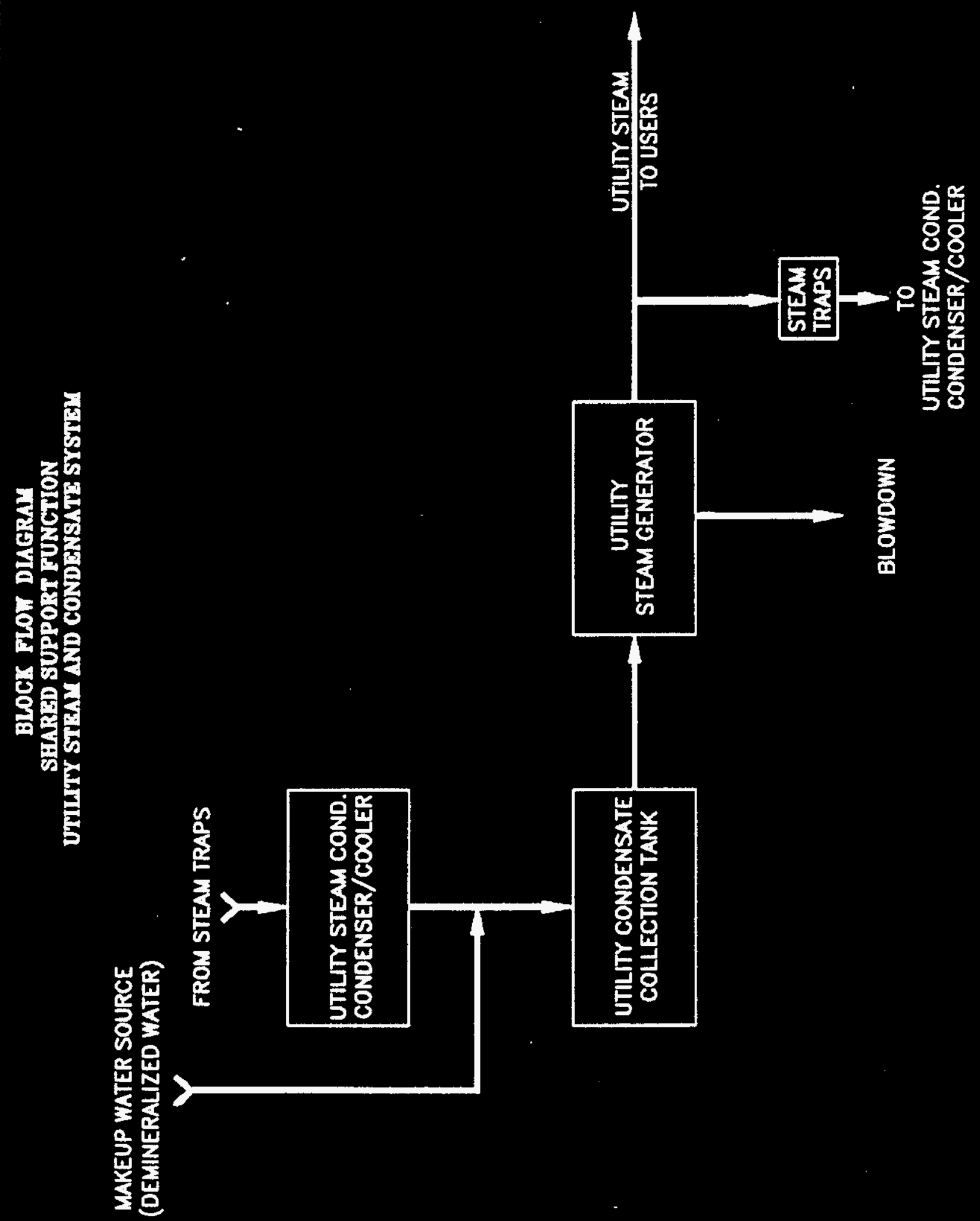


\section{BLOCX FLOT DIAGRAM \\ SIUATD SUPPORT FUNCTION \\ COLPRESSID AR SYSTHY}

PLANT AND INETRUYGNT AIR SUBSYSTEMS

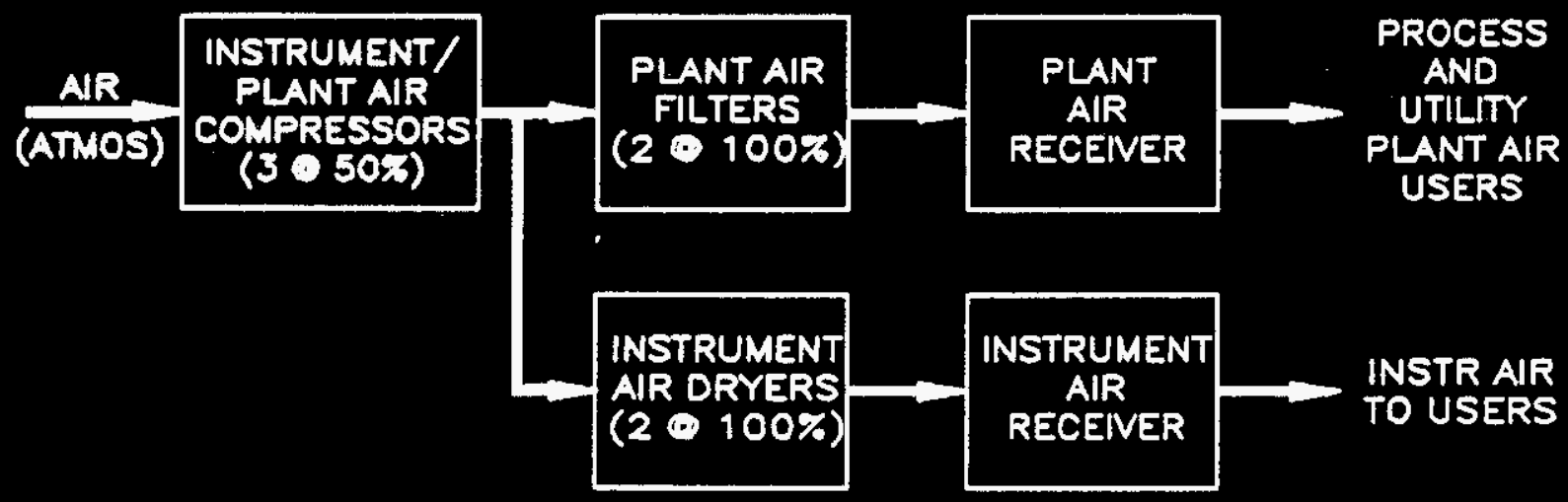


WHC-SD-W378-ES-002

Revision 0

\section{BLOCK FLOW DIAGRAM} SENRTD SUPPORT FUNCTION

PROCRAS W ATHR SYSTEY

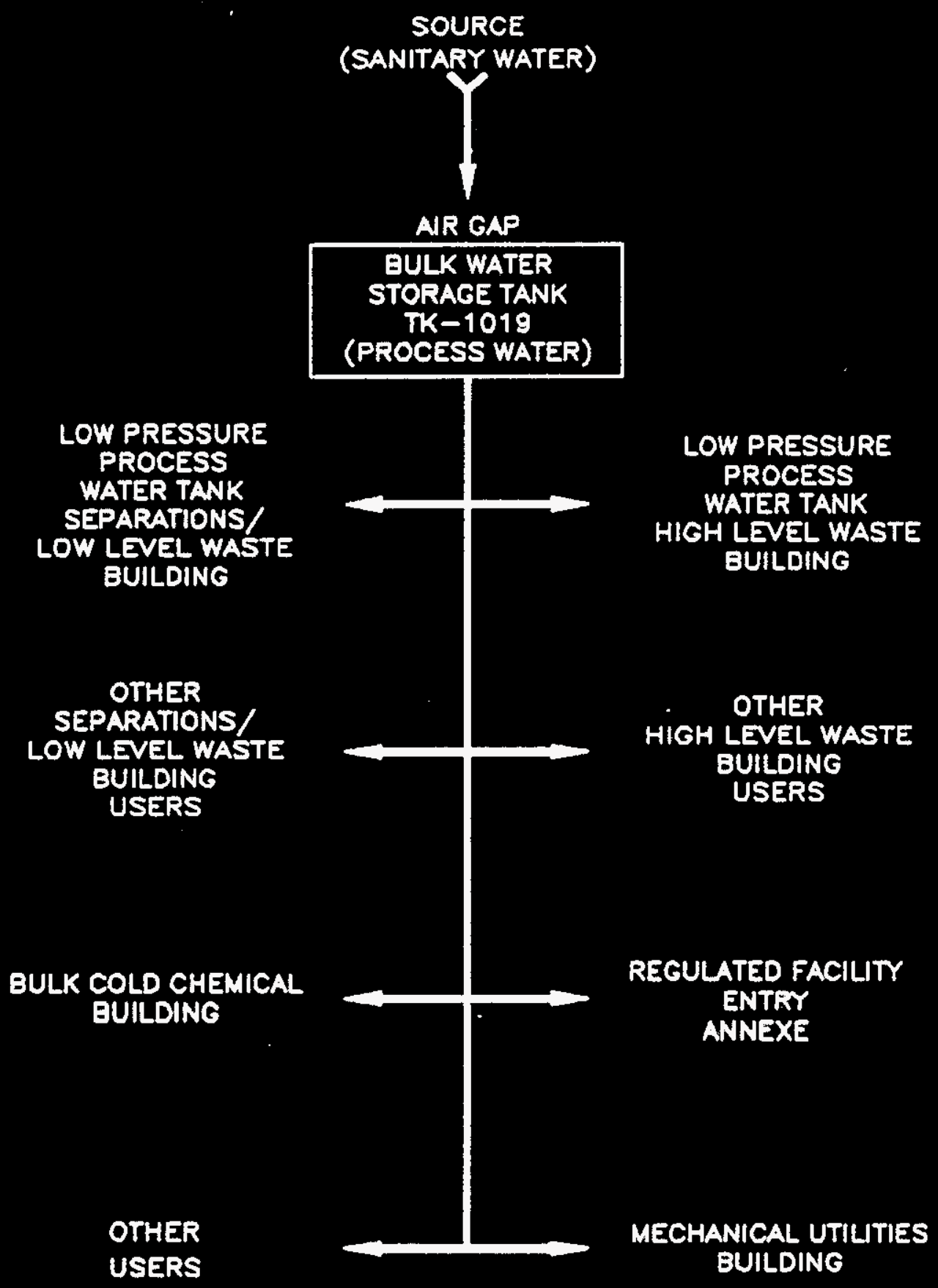




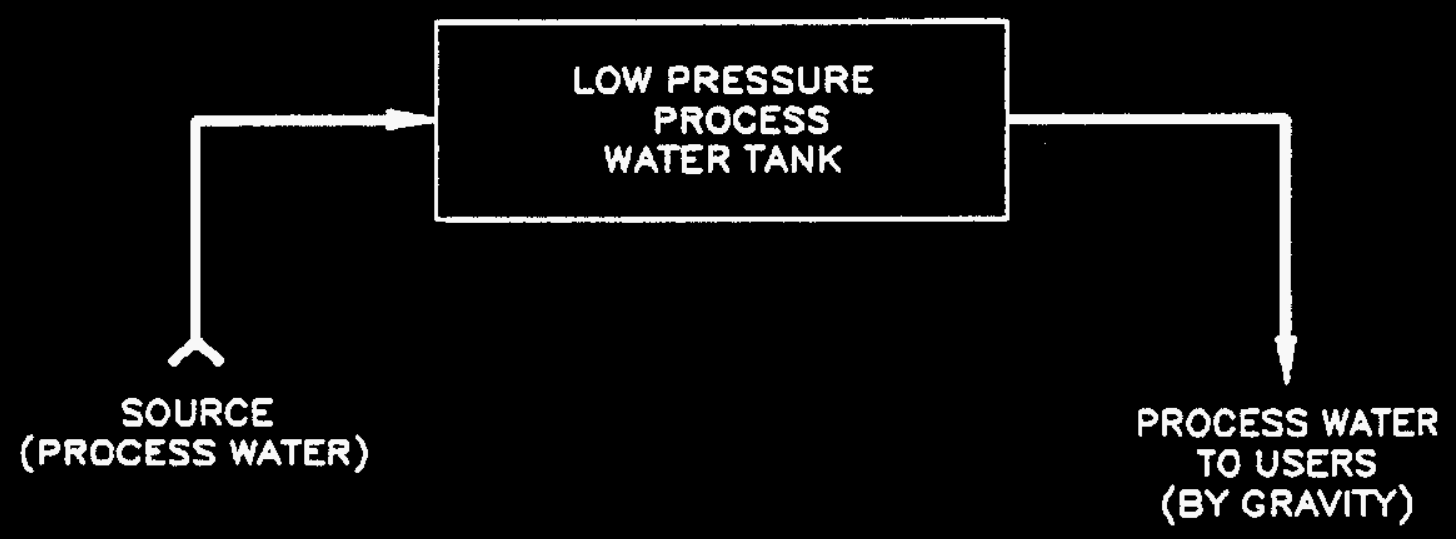

TYPICAL FOR:

SEPARATIONS/LOW LEVEL WASTE,

DETACHED HIGH LEVEL WASTE

VITRIFICATION BUILDINGS 


\section{BLOCK FLON DIAGRAM}

SEARED SUPPORT FUNCTION

DEMTERATVED VATER SYSTEY

SOURCE

(PROCESS WATER)

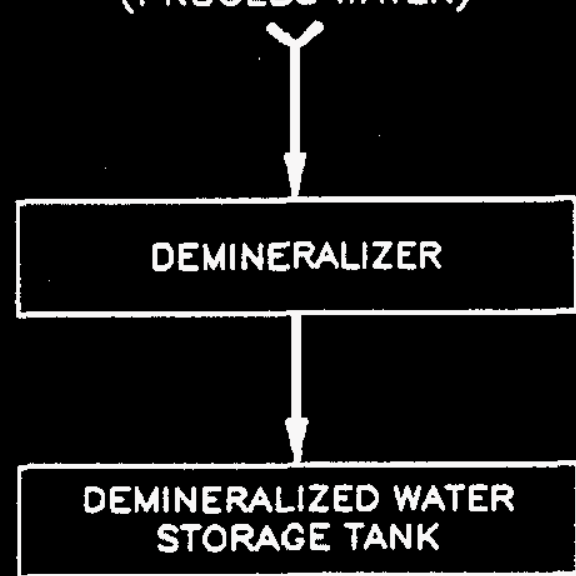

PROCESS

COOLINE WATER

EXPANSION TANK

LOW LEVEL WASTE

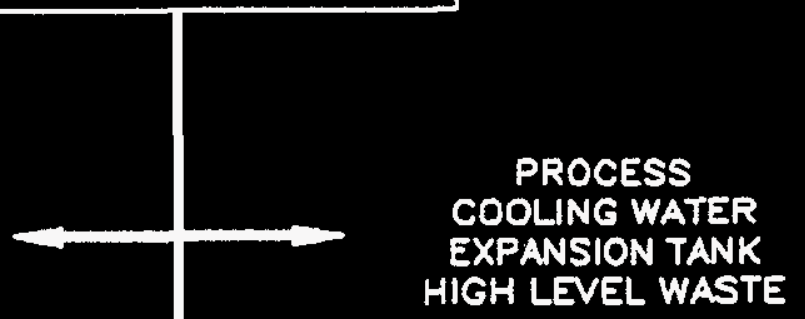

MELTER COOLING WATER EXPANSION TANK LOW LEVEL WASTE

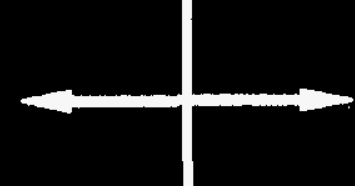

MELTER

COOLING WATER

EXPANSION TANK

HIGH LEVEL WASTE

PROCESS STEAM

AND

CONDENSATE SYSTEM

LOW LEVEL WASTE

PROCESS STEAM AND

CONDENSATE SYSTEM HIGH LEVEL WASTE 
BLOCK FLON DHGRAY

SENRED SUPPORT FUNCTIO

SANIYARY WATHR STETHY

PRETREAT/

LOW LEVEL WASTE BUILDING

USERS

BULK COLD CHEMICAL BUILDING

\section{SANITARY WATER}

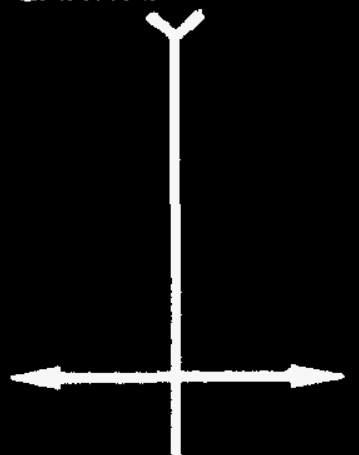

HIGH LEVEL WASTE BUILDING USERS

OTHER

USERS

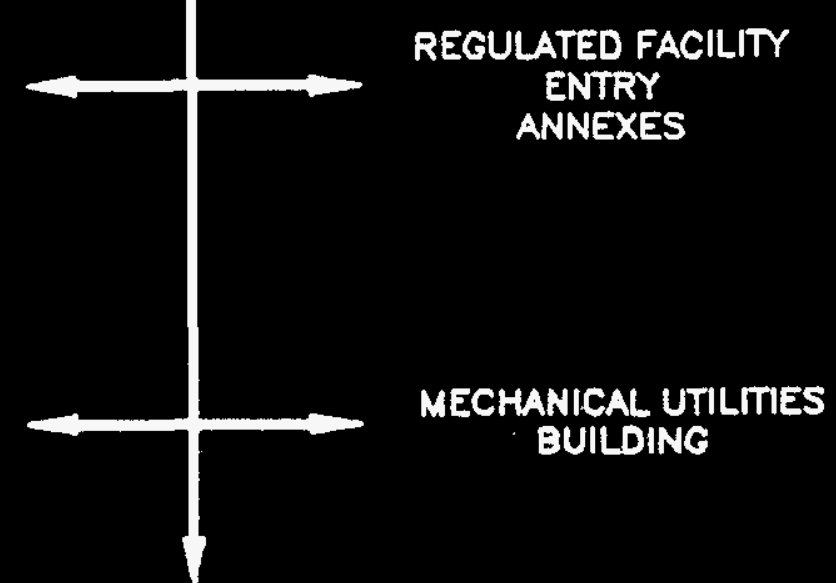

AIR GAP

BULK WATER

STORAGE TANK

TK-1019

(PROCESS WATER) 


\section{BLOCK FLOT DLGRAM \\ SENAED SUPPORT FUNCTION \\ BAW TATAR SYSTHY \\ TWRS TRMATMFNT COMPLX SITB FIRE WATER SYSTEM}

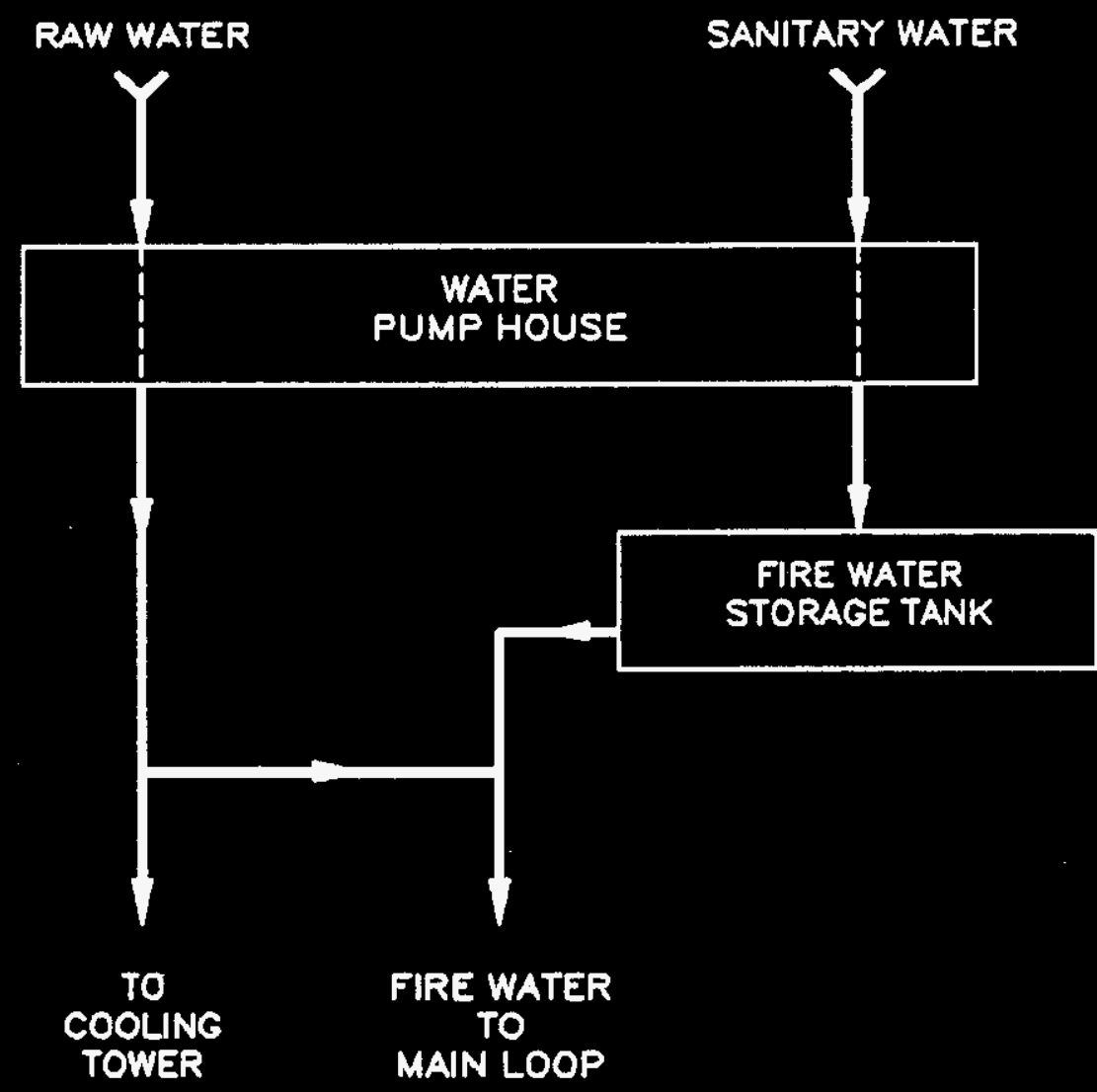


BLOCK FLOW DLAGRAM SELABD SUPPOAT FUNCTION

PROCJSS FLCILFY TIRE WATHR SYSTEM

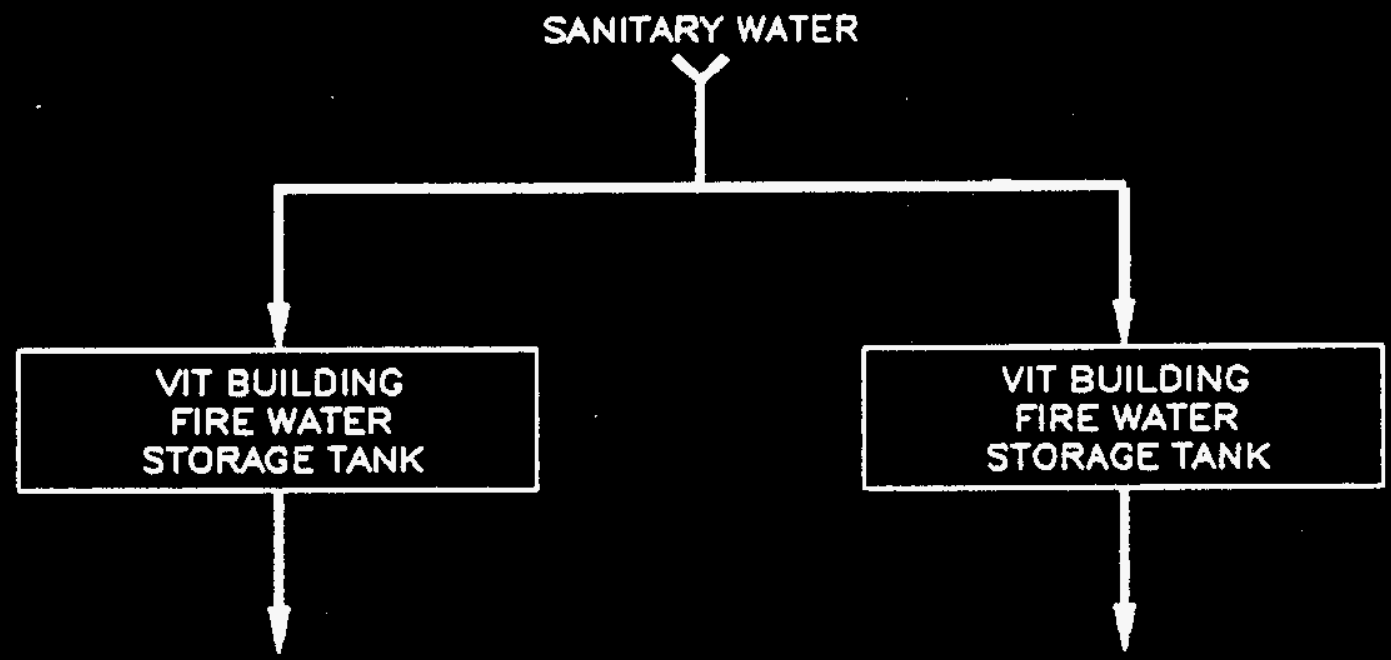

FIRE WATER LOOP SEPARATIONS/

LOW LEVEL WASTE

FIRE WATER LOOP

HIGH LEVEL WASTE

BUILDING

BUILDING 
WHC-SD-W378-ES-002

Revision 0

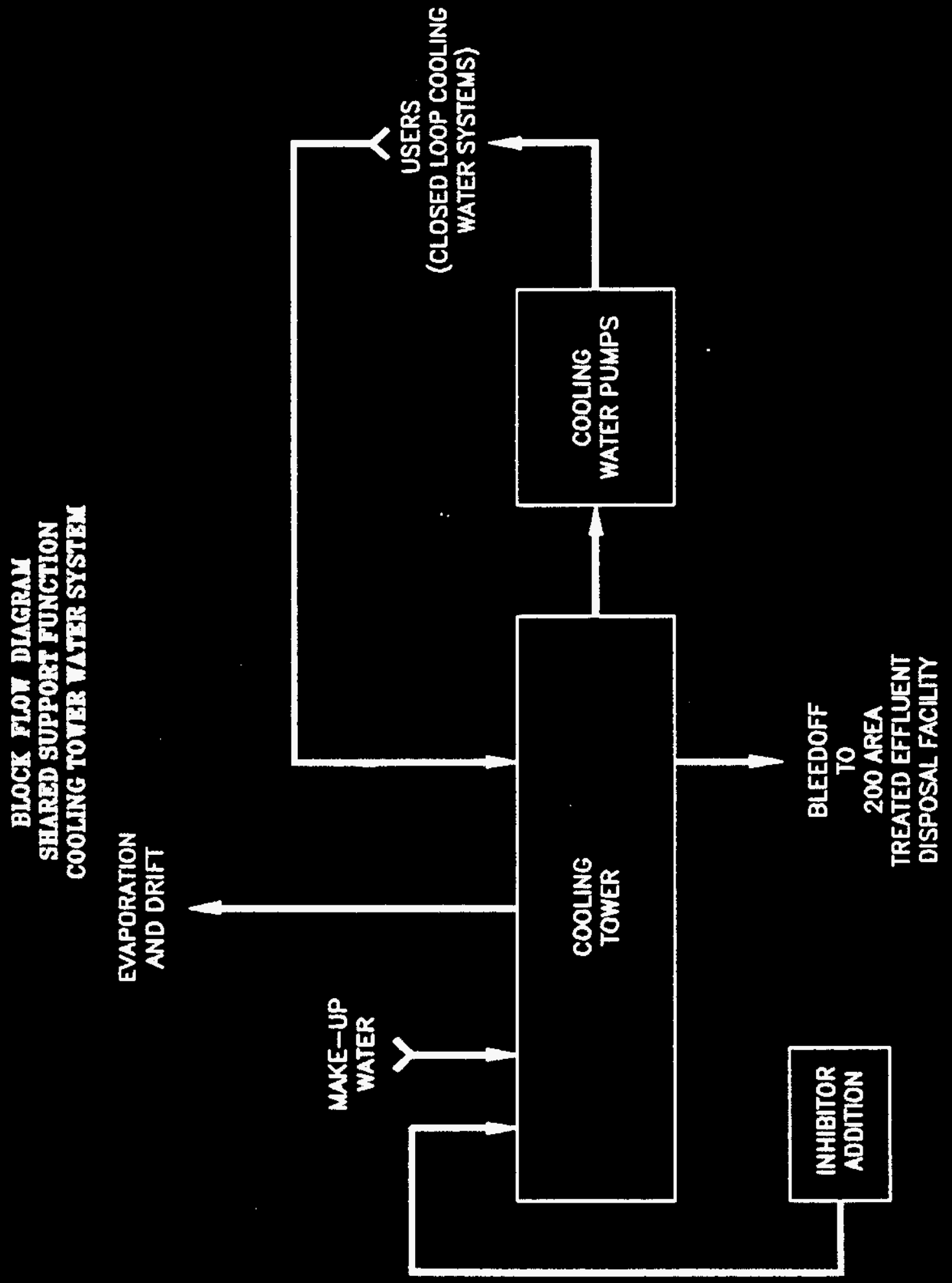


BLOCX FLOT DUGRAY SEARED SUPPORT FUNCTION

SANITABY STWHR SYSTEM

\section{FROM}

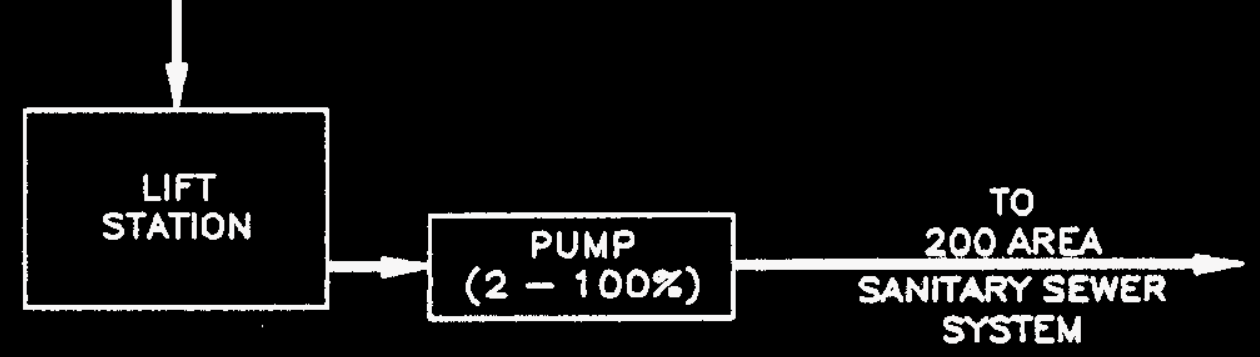




\section{BLOCX FLON DLAGRAM \\ CONFGURATON 4 (STP/LLT, DJTACHBD FLT) \\ FPS VACUUM STSTHM \\ (DEDICATED FUNCTION)}

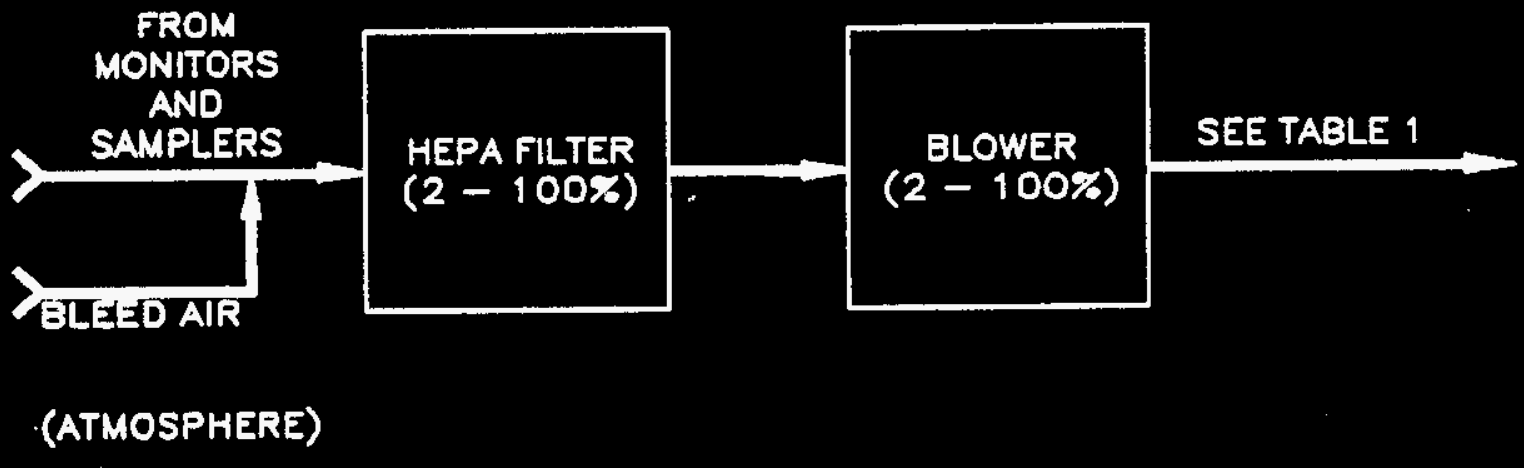

TABLE 1

SOINRCE

SEPARATIONS/LOW LEVEL WASTE BUILOING

HIGH LEVEL WASTE BUILDING

CONTANER STAGING ANNEX

CANISTER/CASK HANDLING ANNEX

FAN/FILTER ANNEXES
EXHAUST

PROCESS FACILITY EXHAUST STACK

PROCESS FACILITY EXHAUST STACK

CONTAINER STAGING ANNEX EXHAUST STACK

CANISTER/CASK HANDLING ANNEX EXHAUST STACK

FAN/FILTER ANNEXES HVAC EXHAUST STACKS 


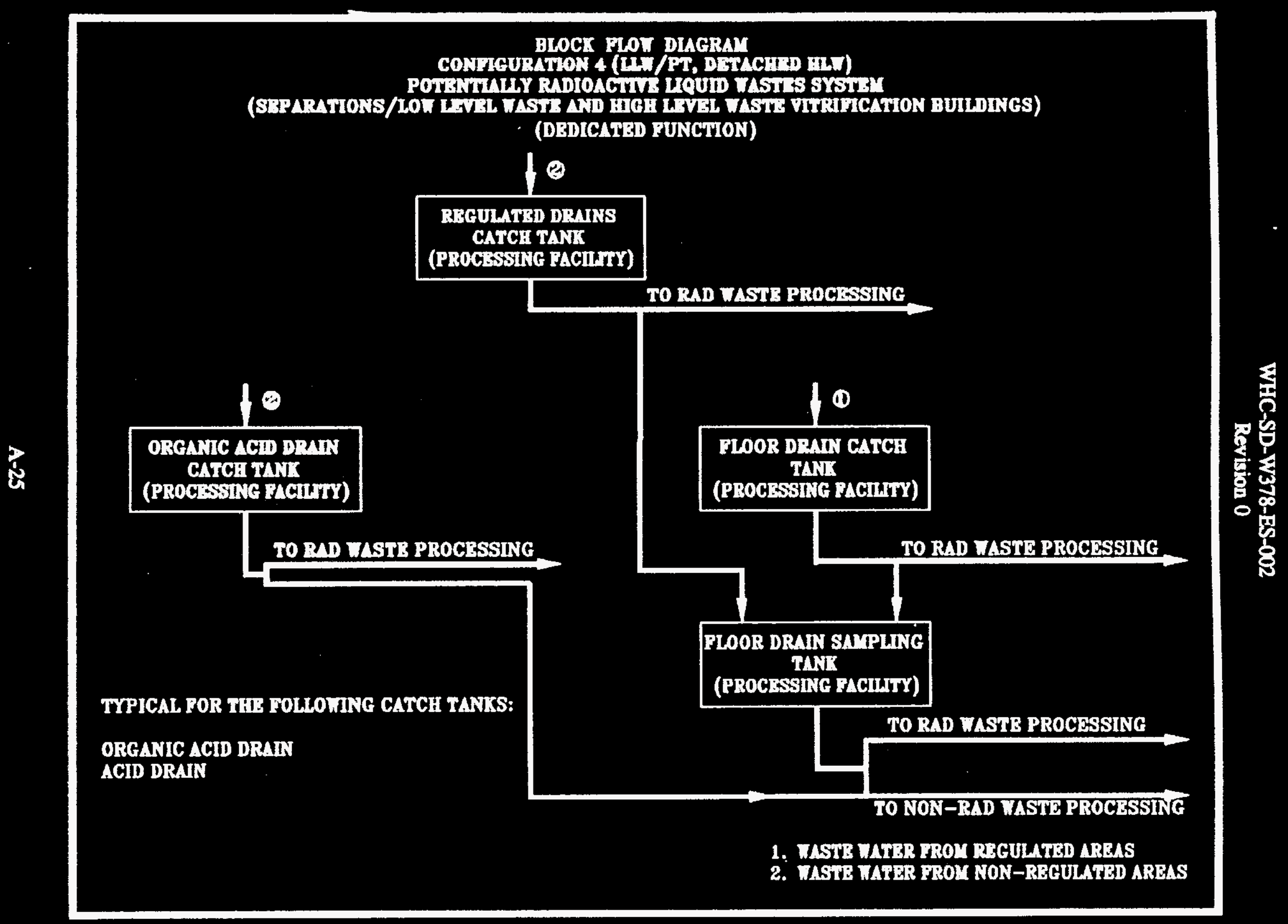




\section{WHC-SD-W378-ES-002}

Revision 0

This page intentionally left blank. 
WHC-SD-W378-ES-002

Revision 0

APPENDEX B

UTILITY FLOW DIAGRAMS

B-1 


\section{WHC-SD-W378-ES-002}

Revision 0

This page intentionally left blank. 


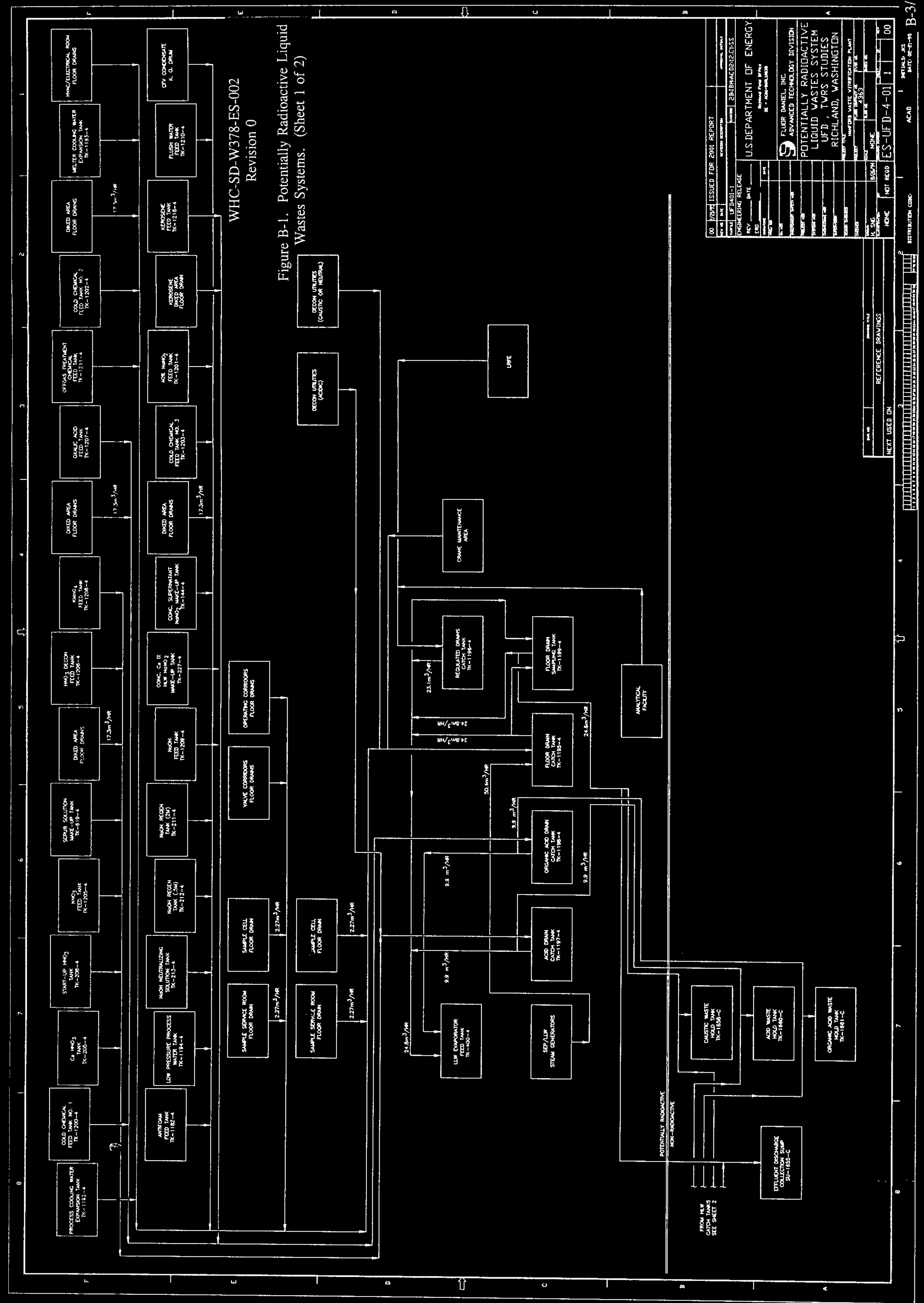




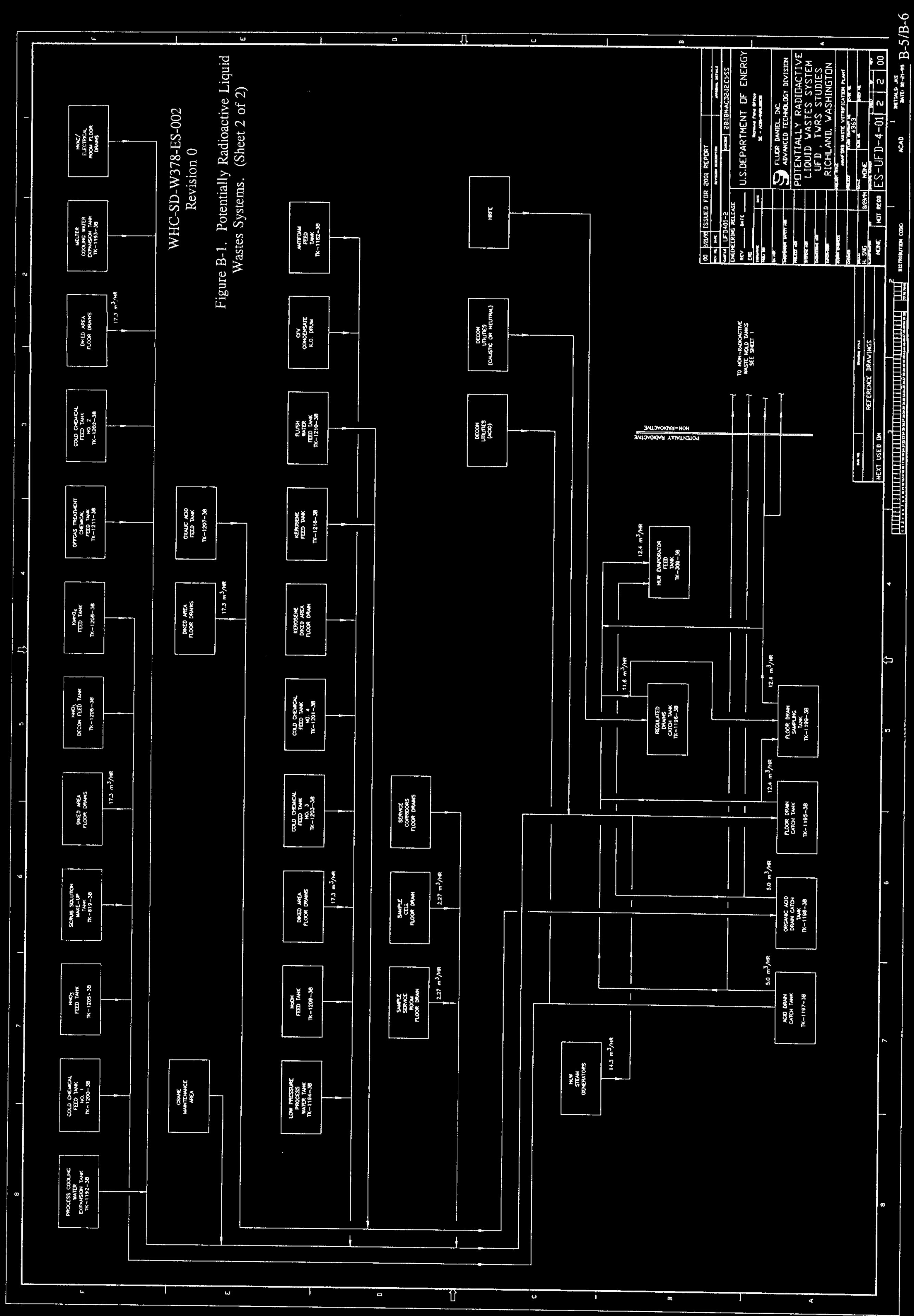




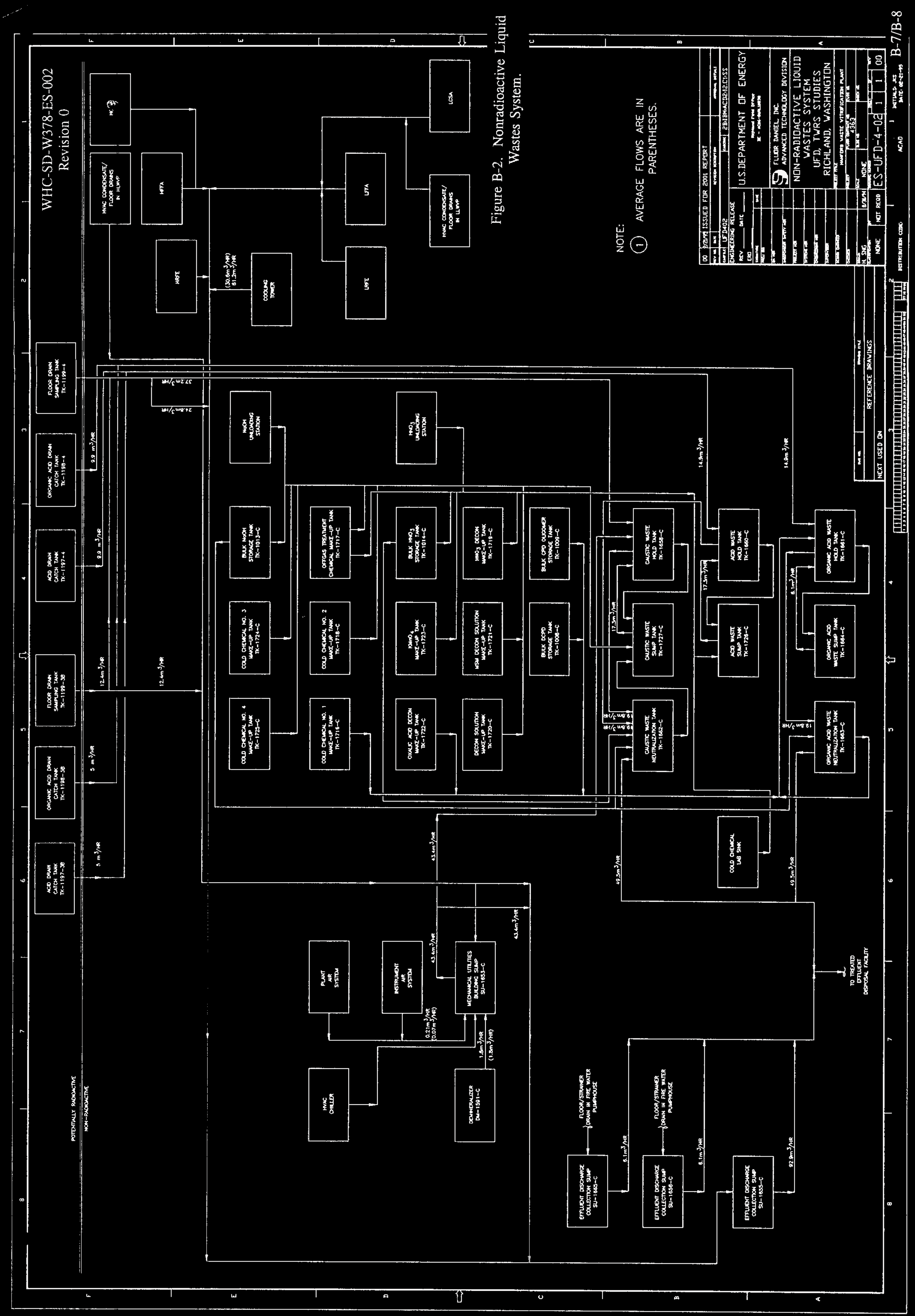




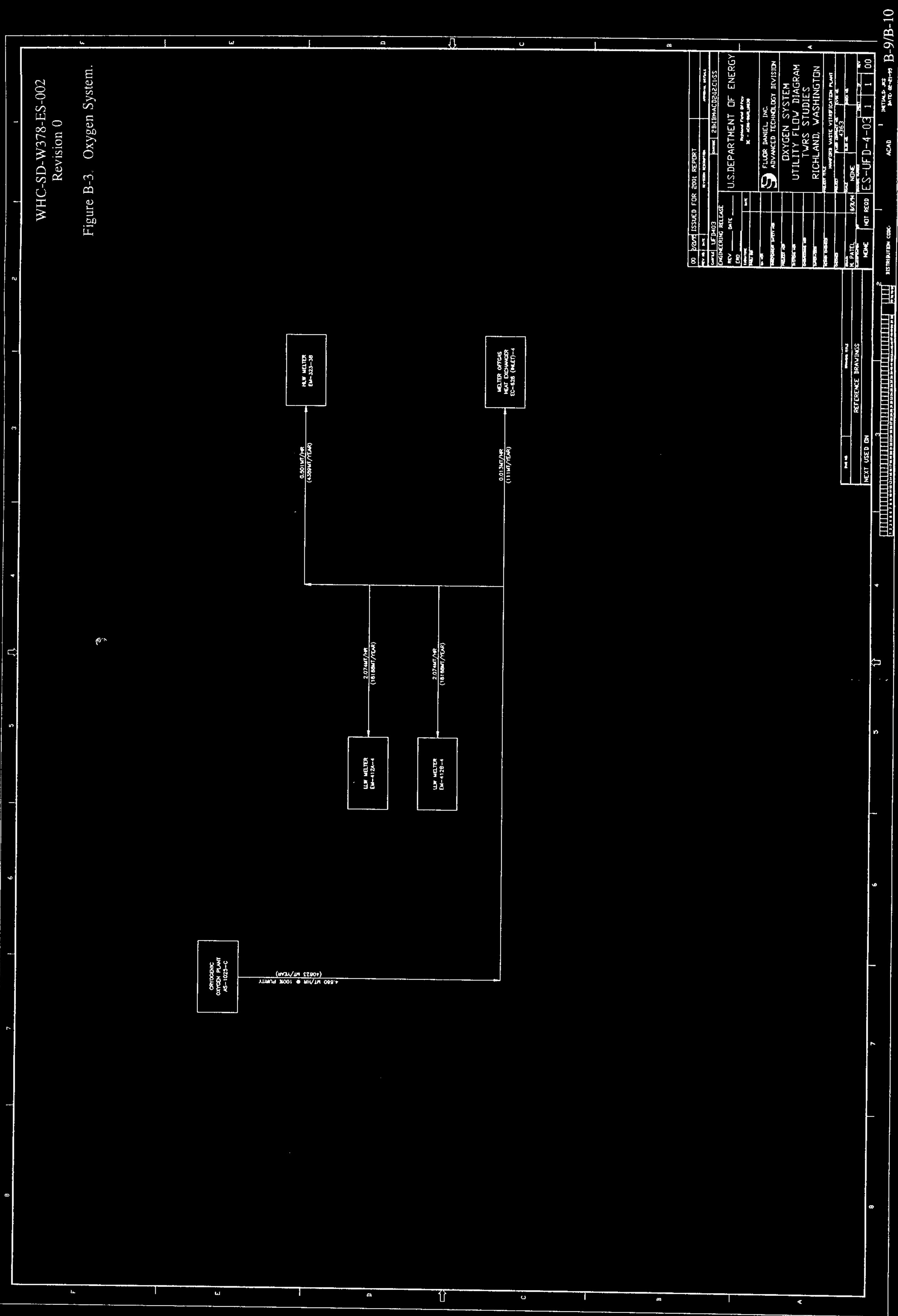




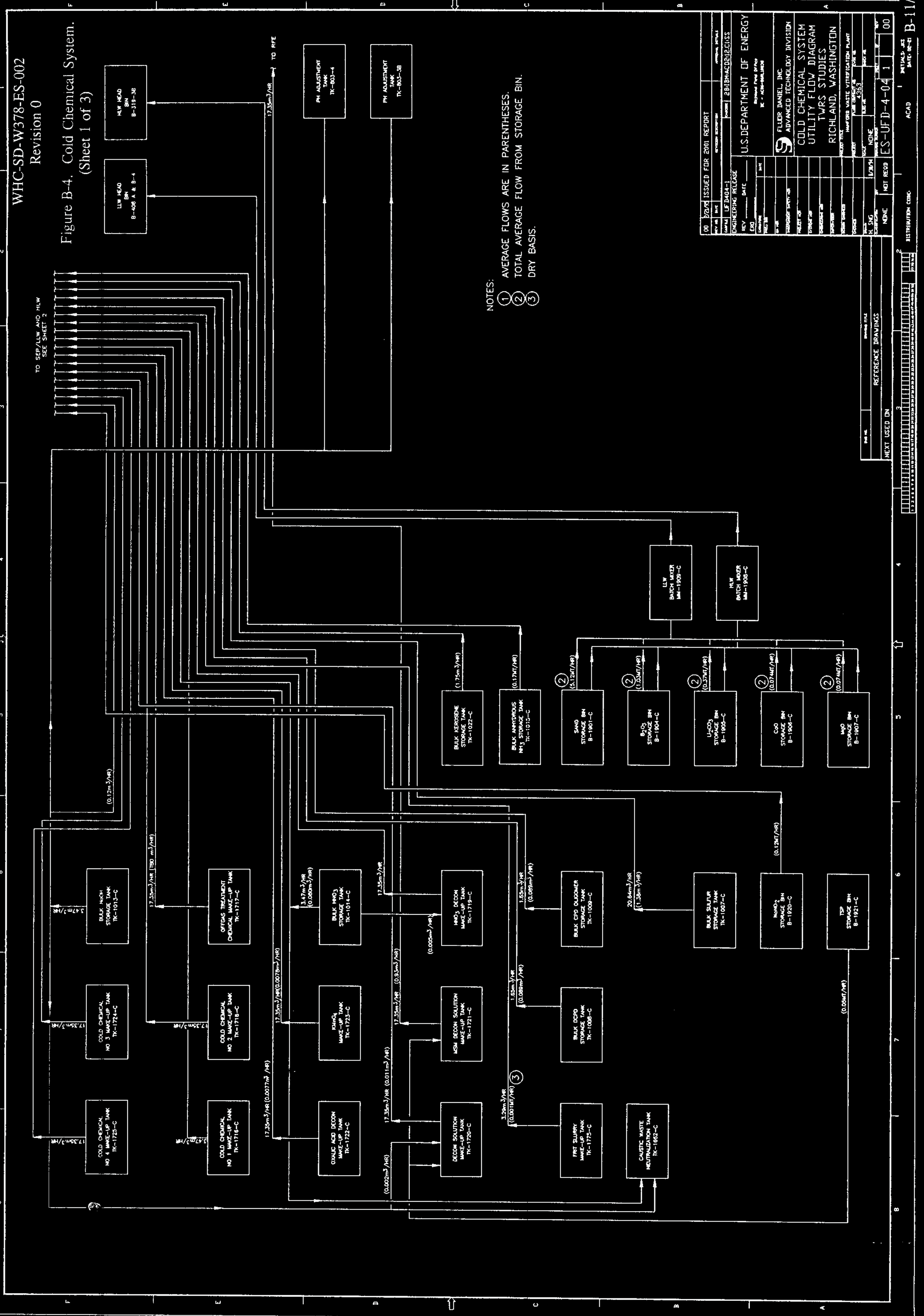




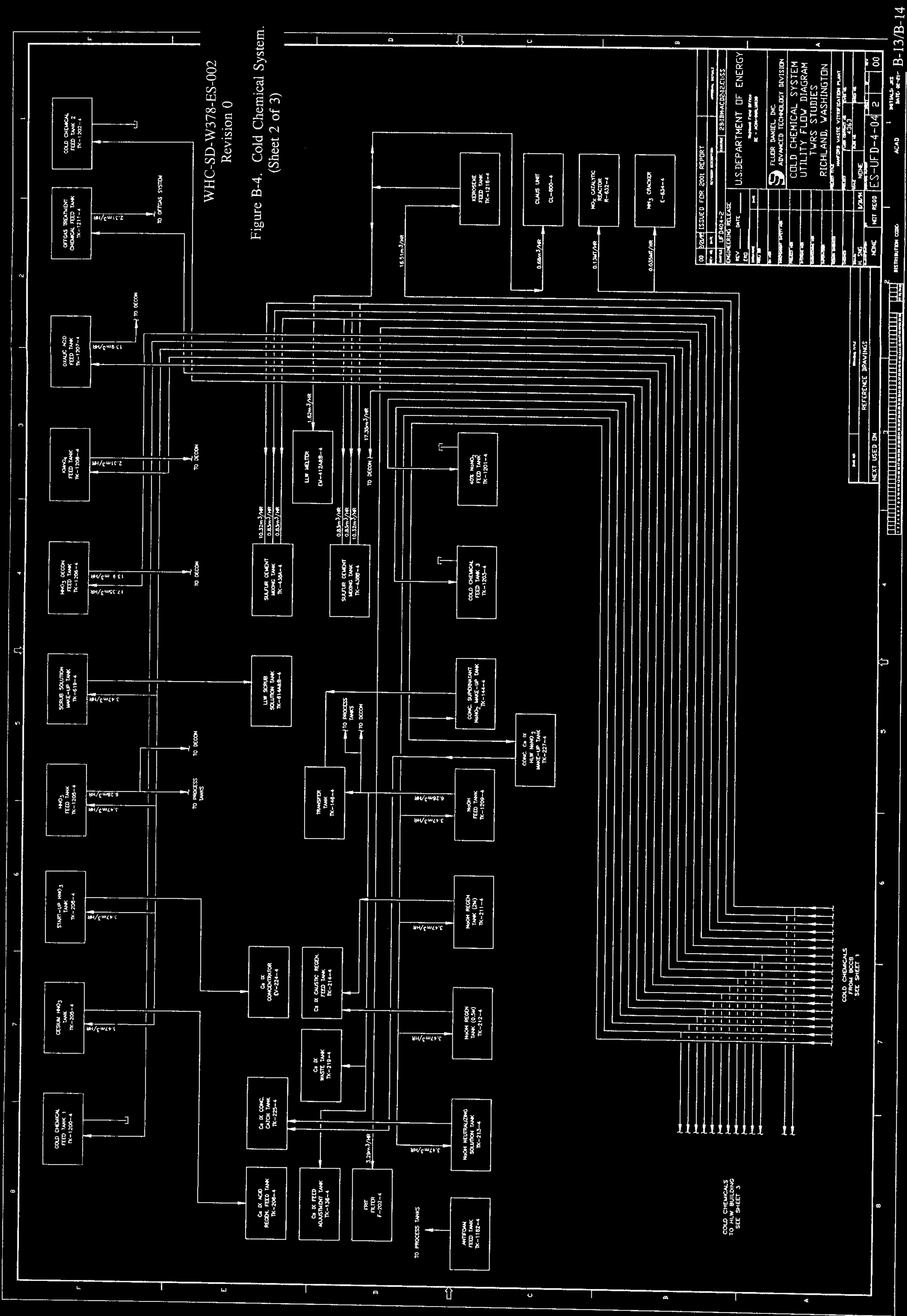




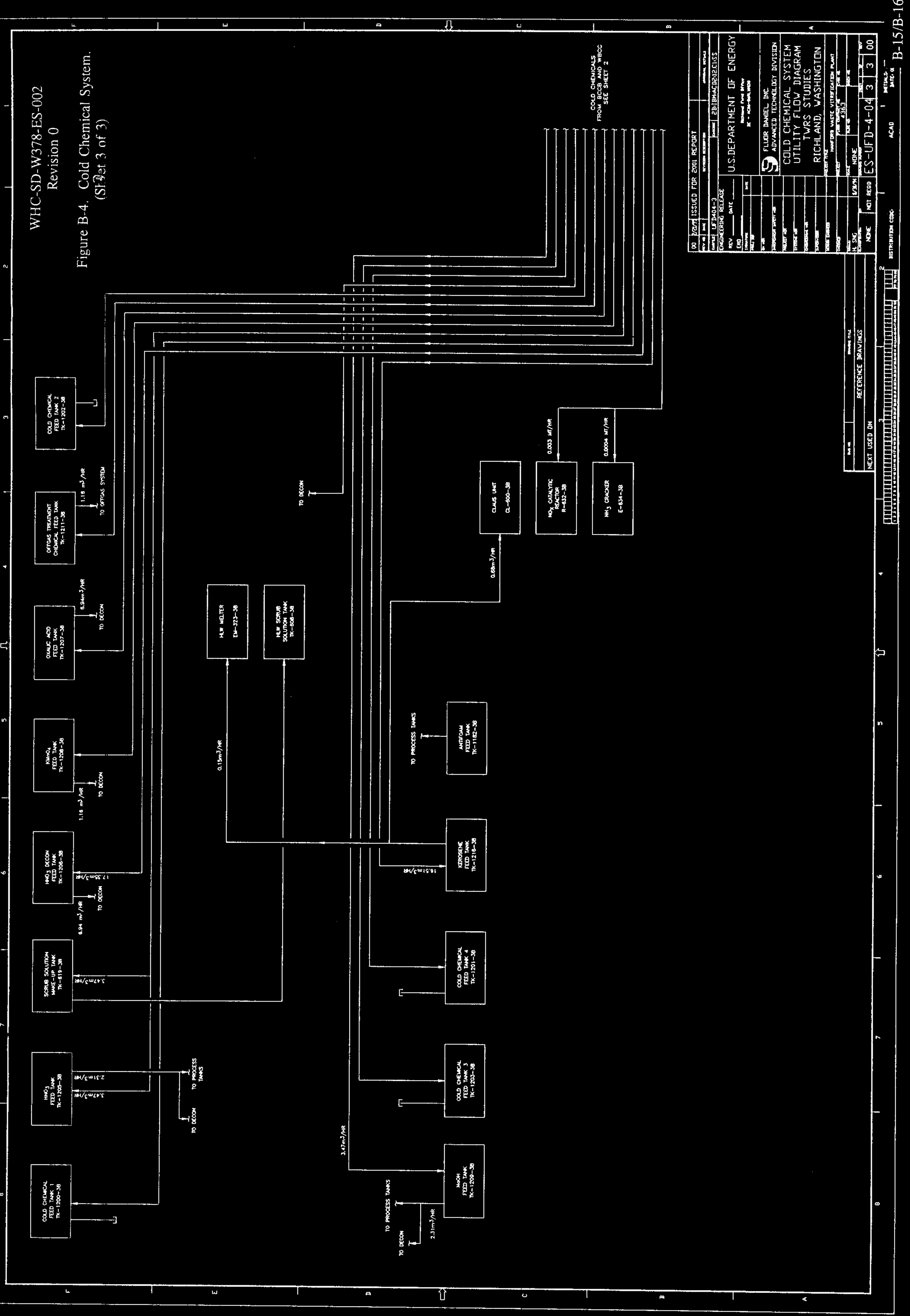




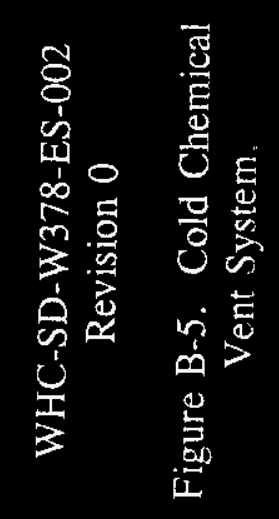

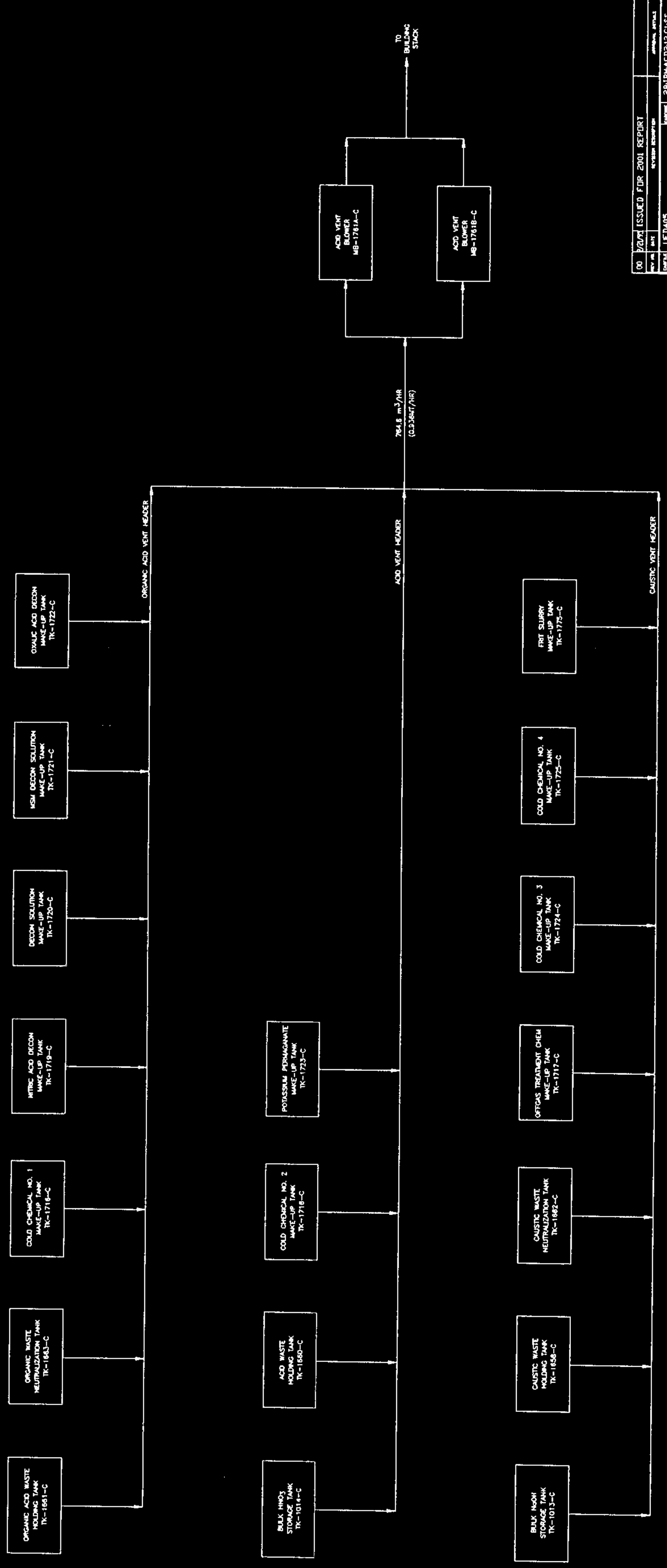

$\infty$ 


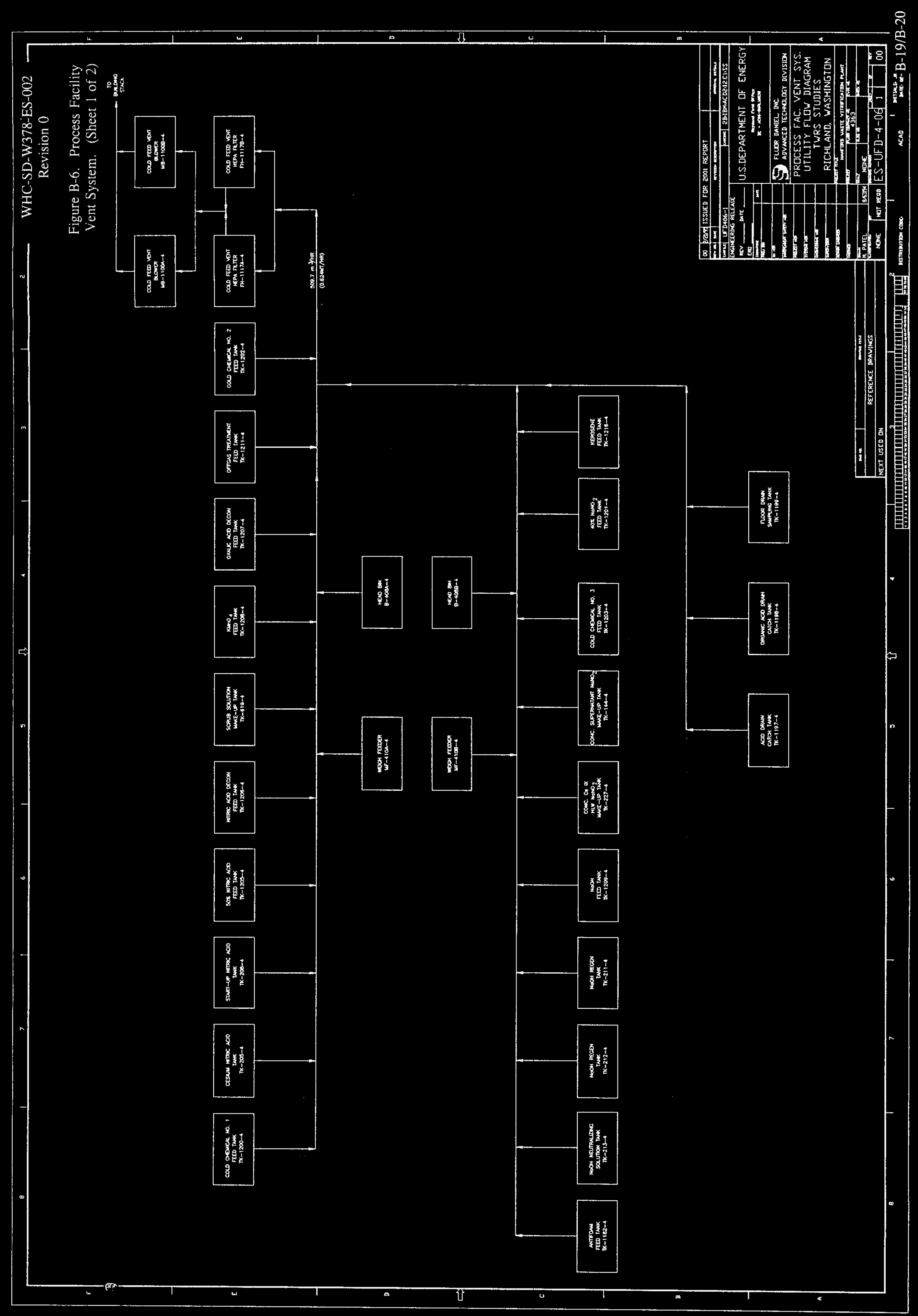




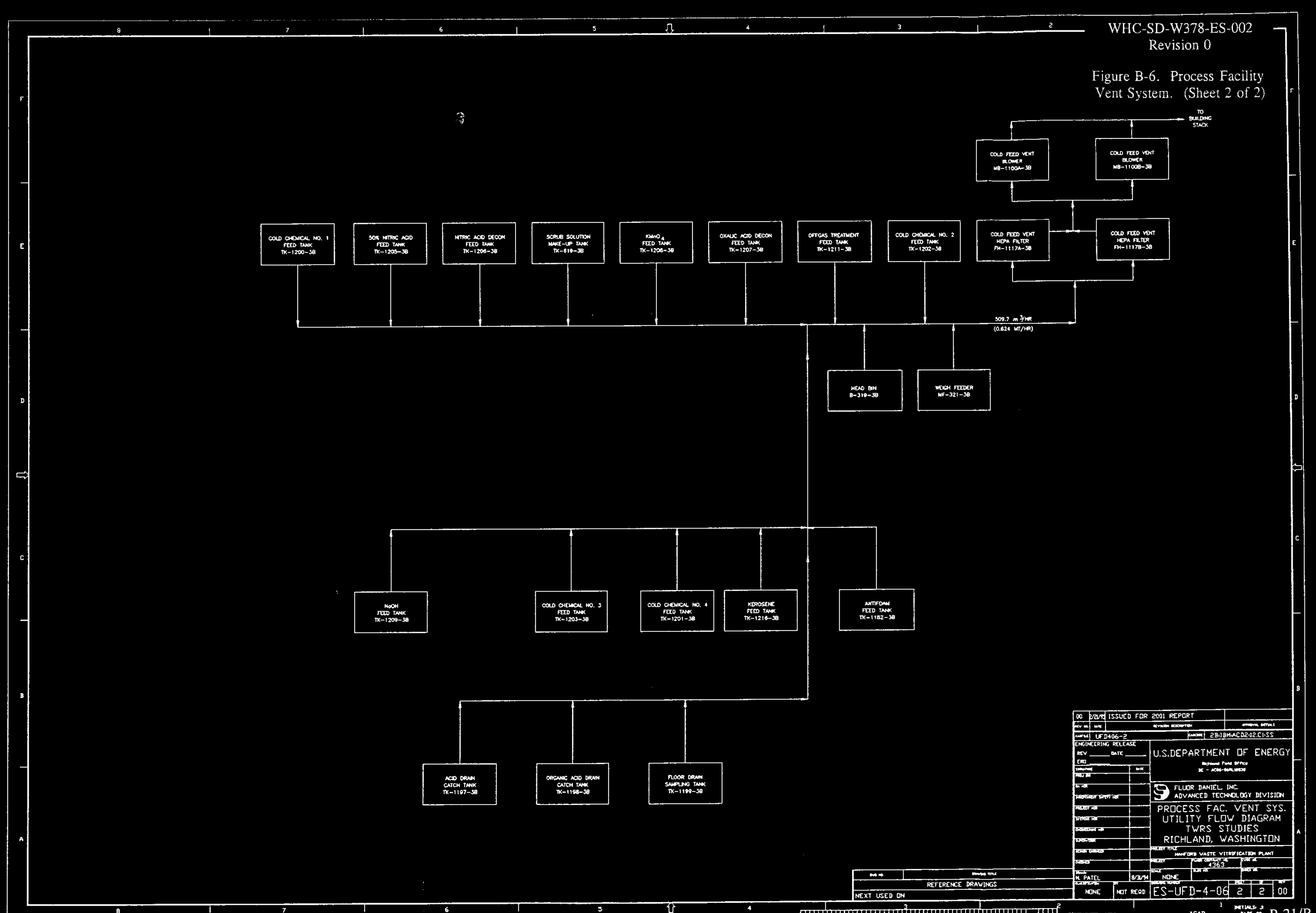




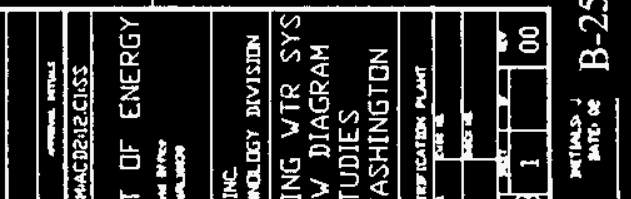

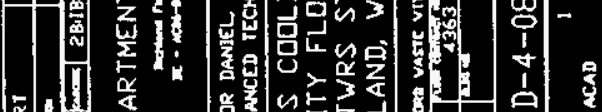

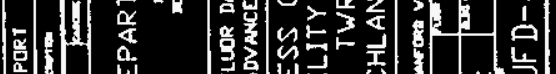
离 解
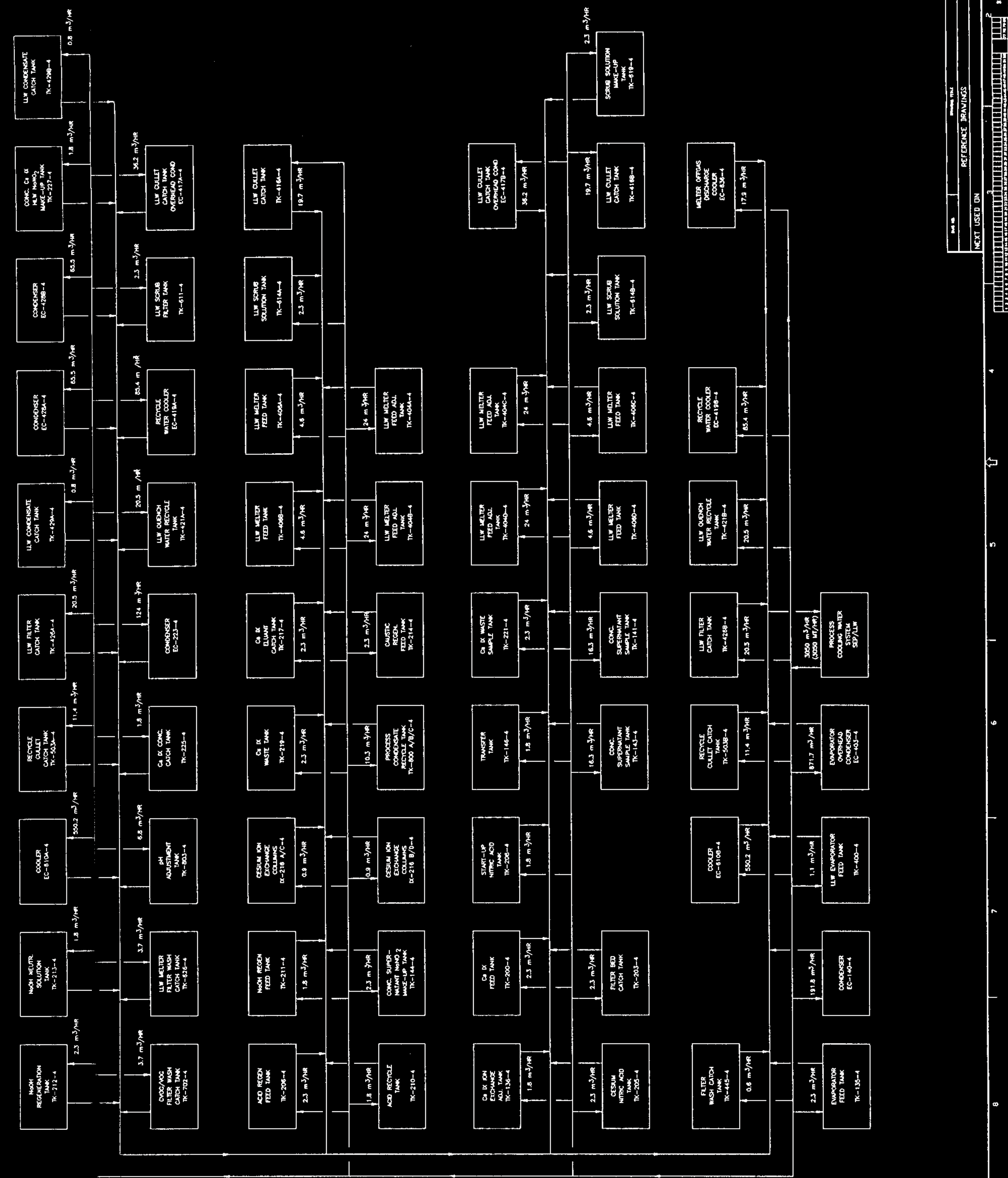


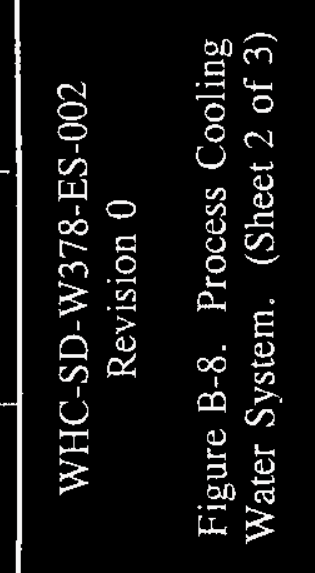
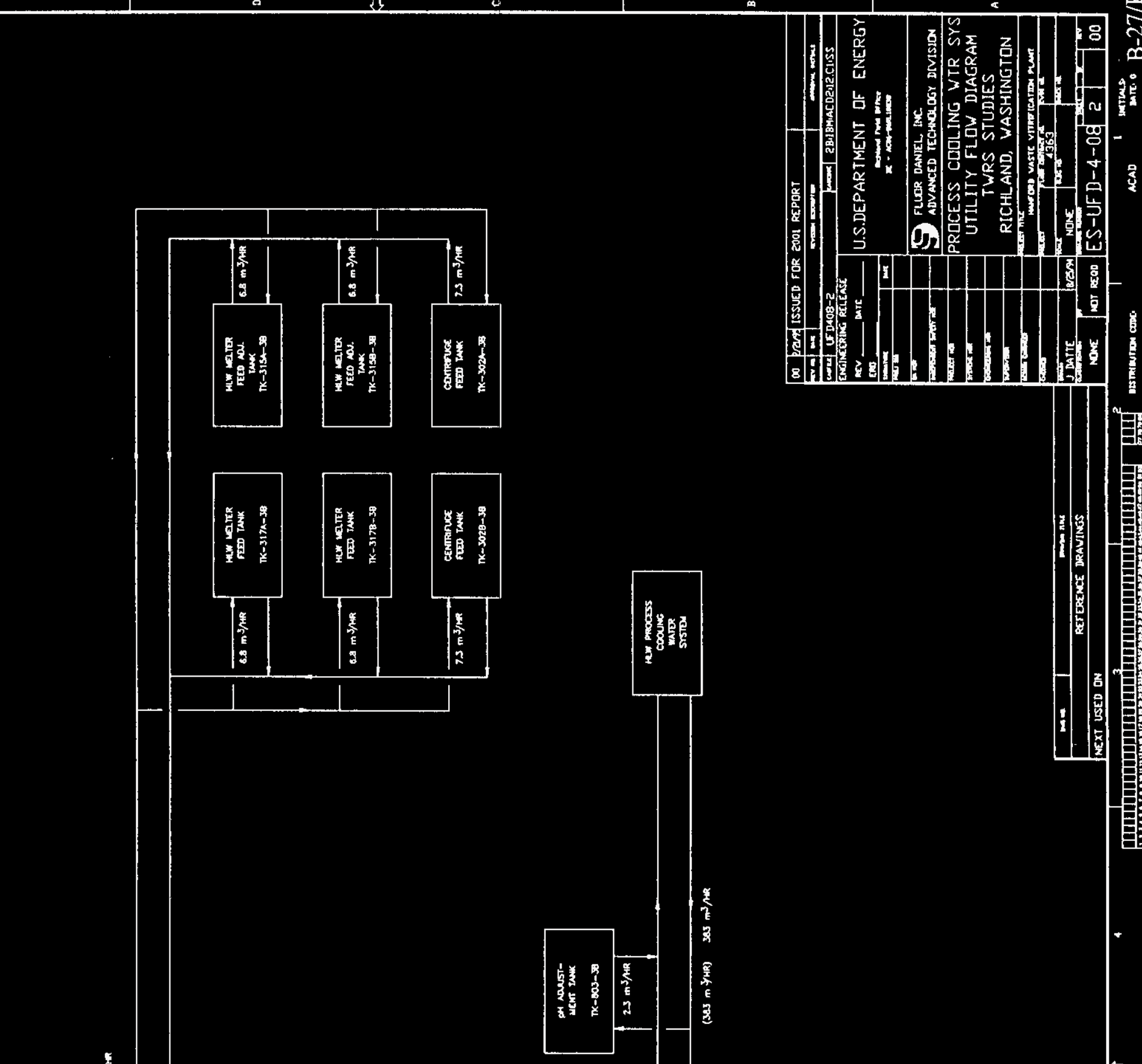

明
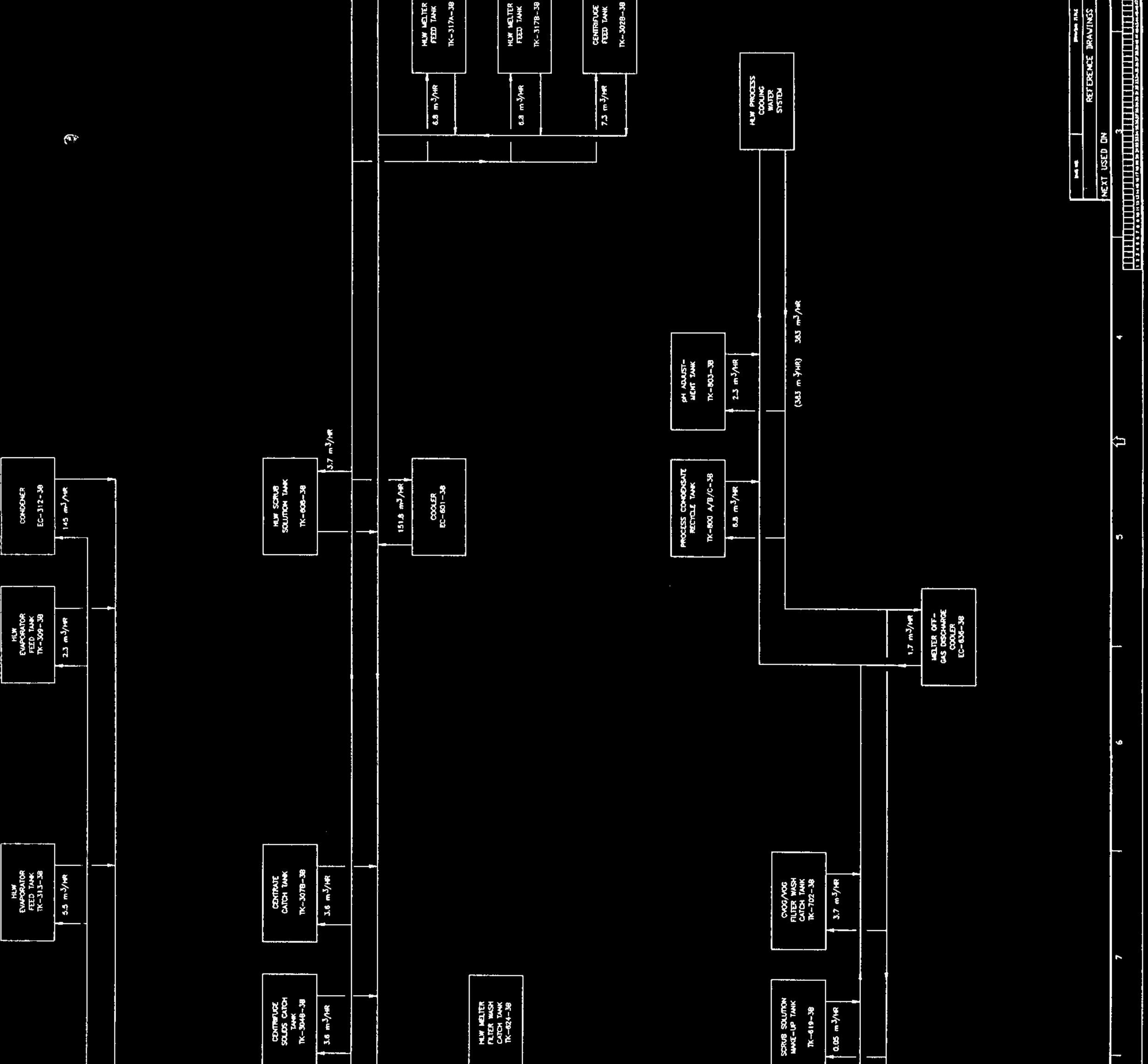

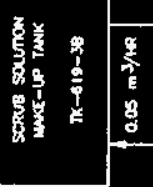

缃

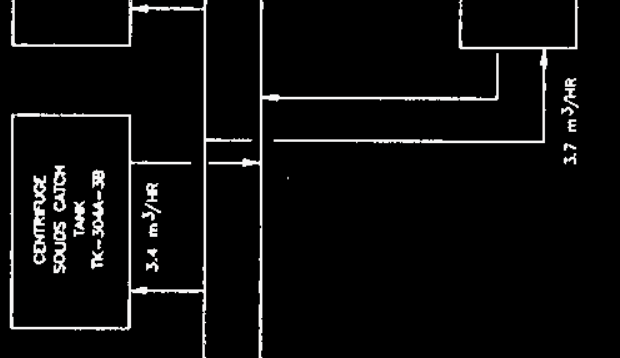




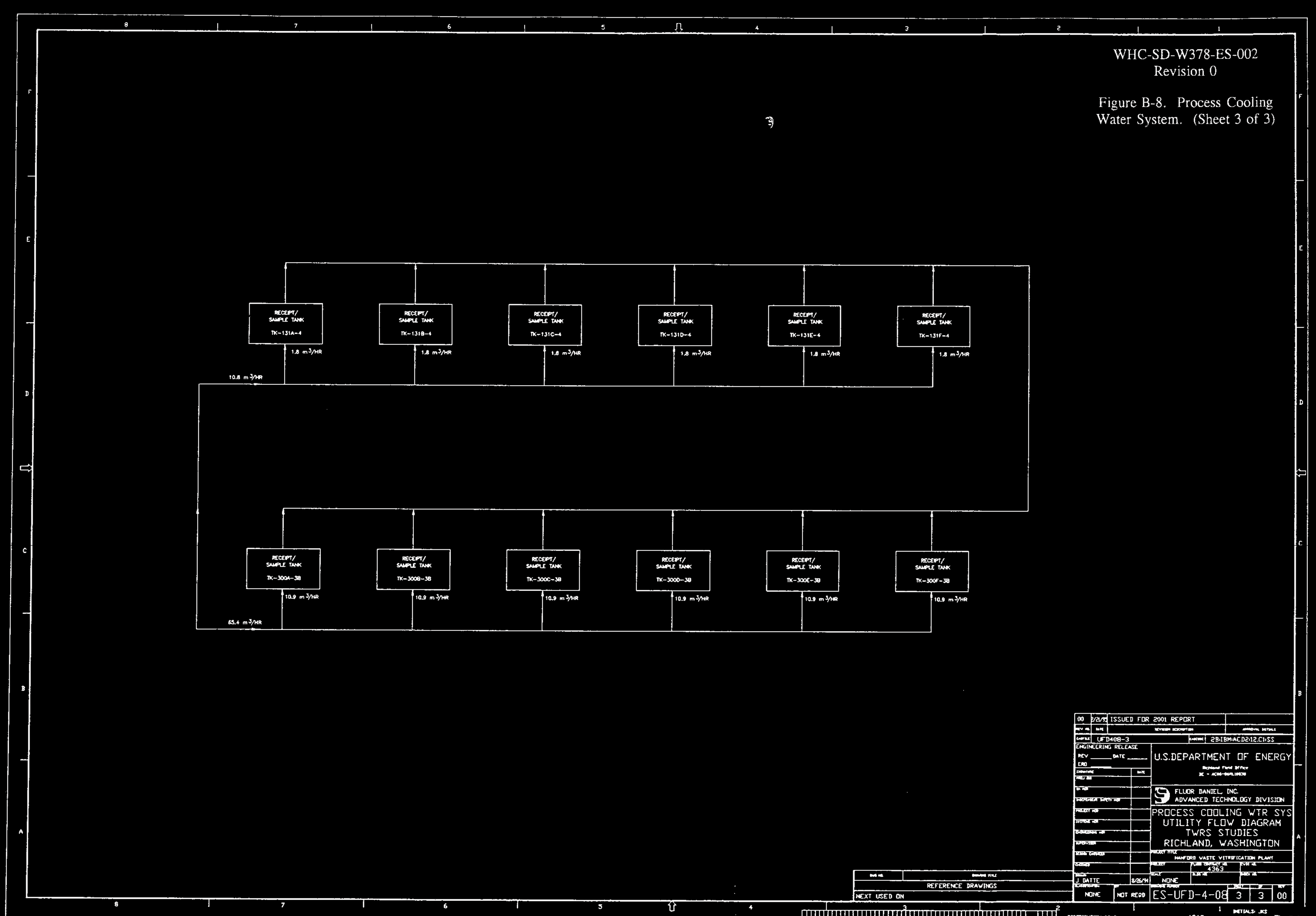

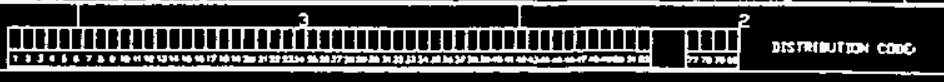
san 


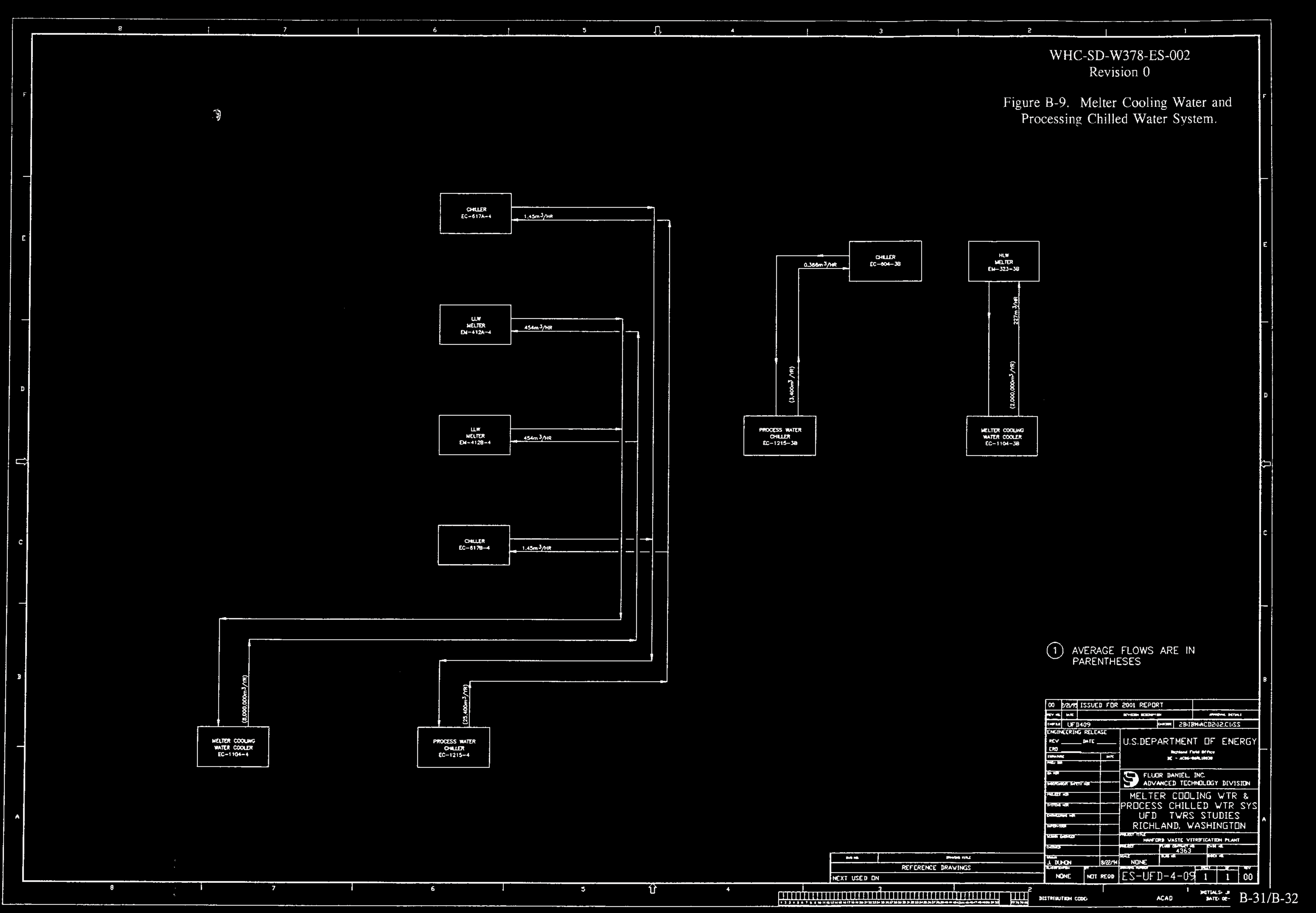




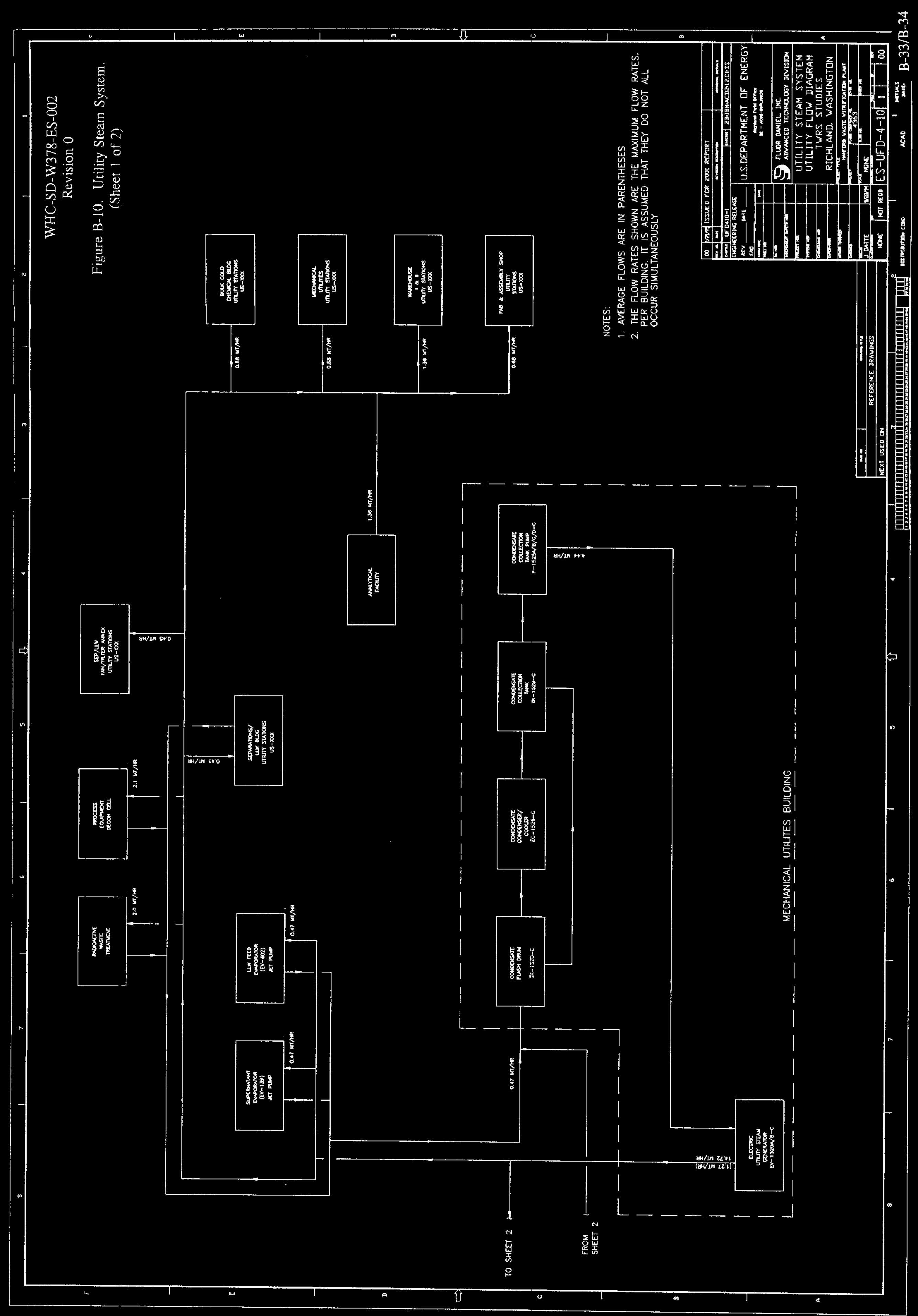




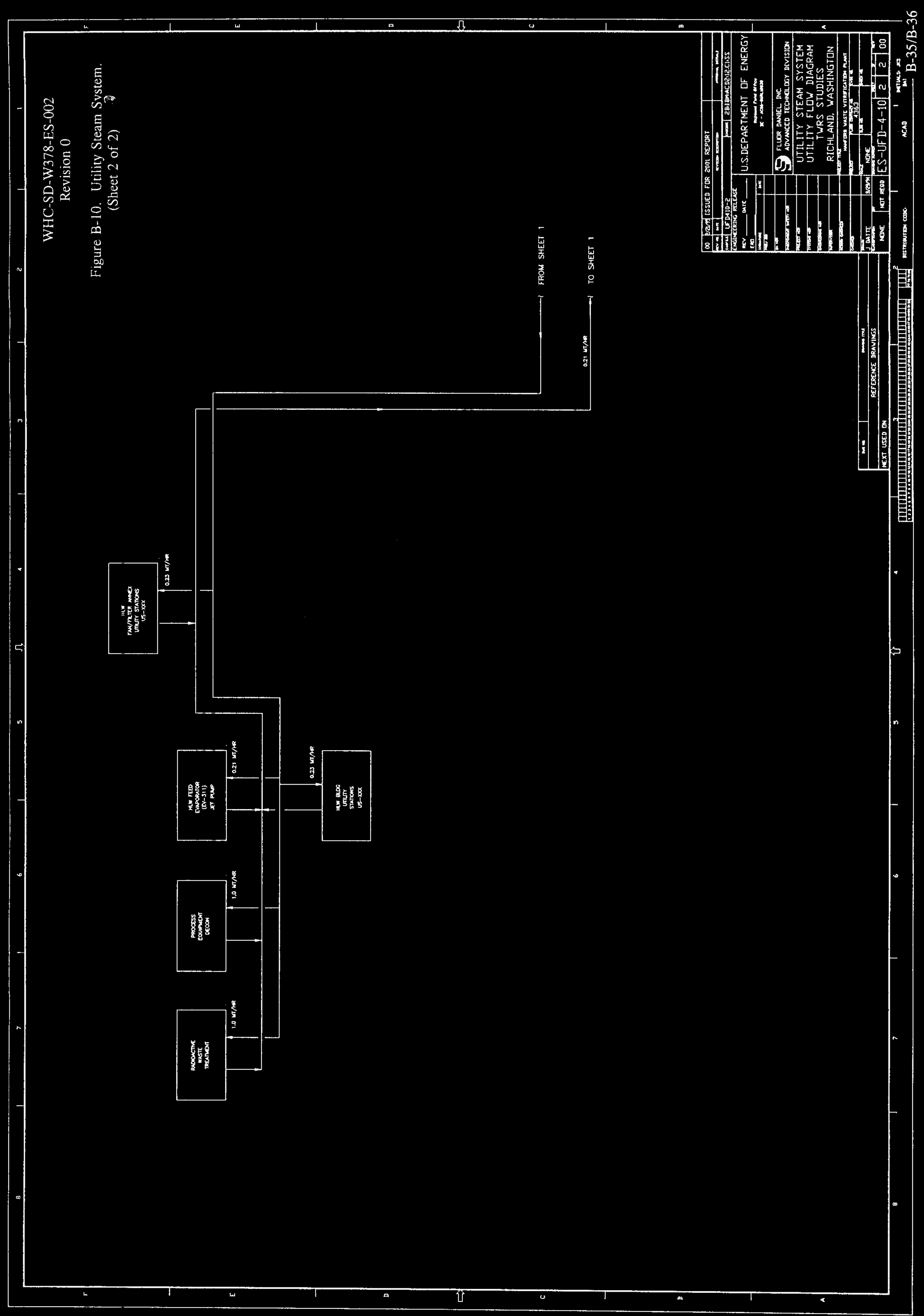




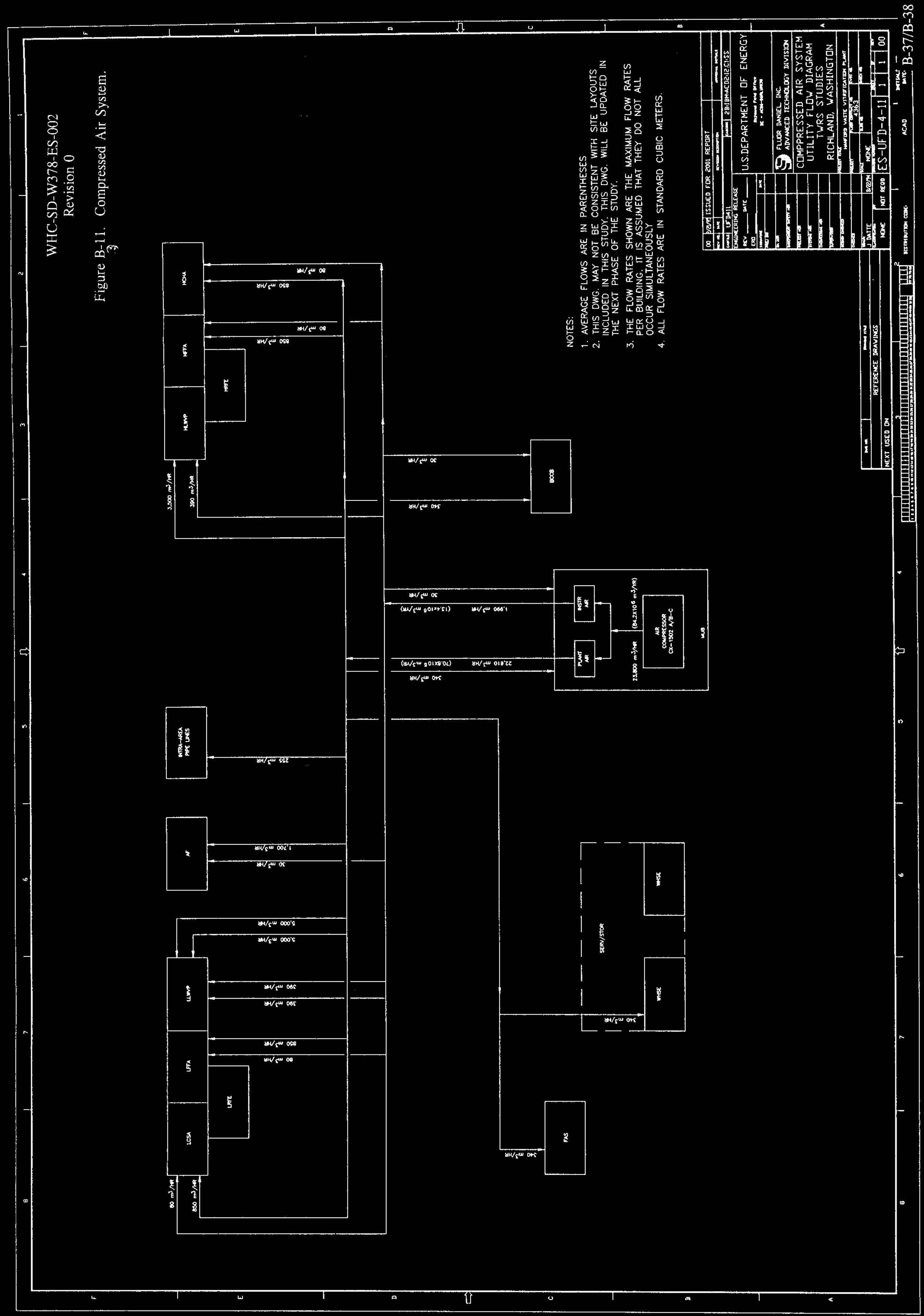




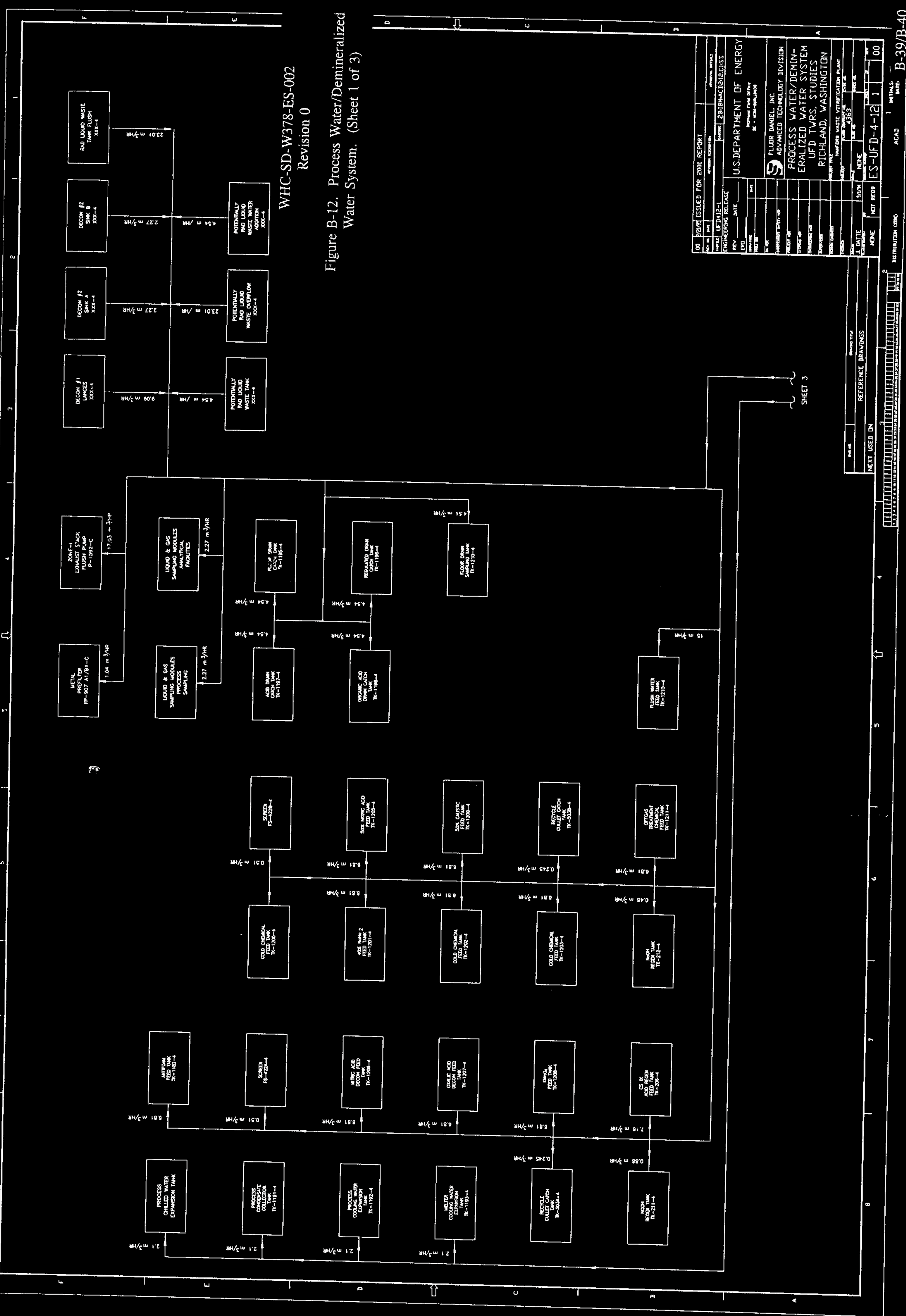


$\tau t-q /[t-q)$

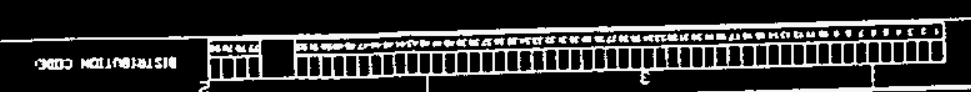

$\Omega$

.

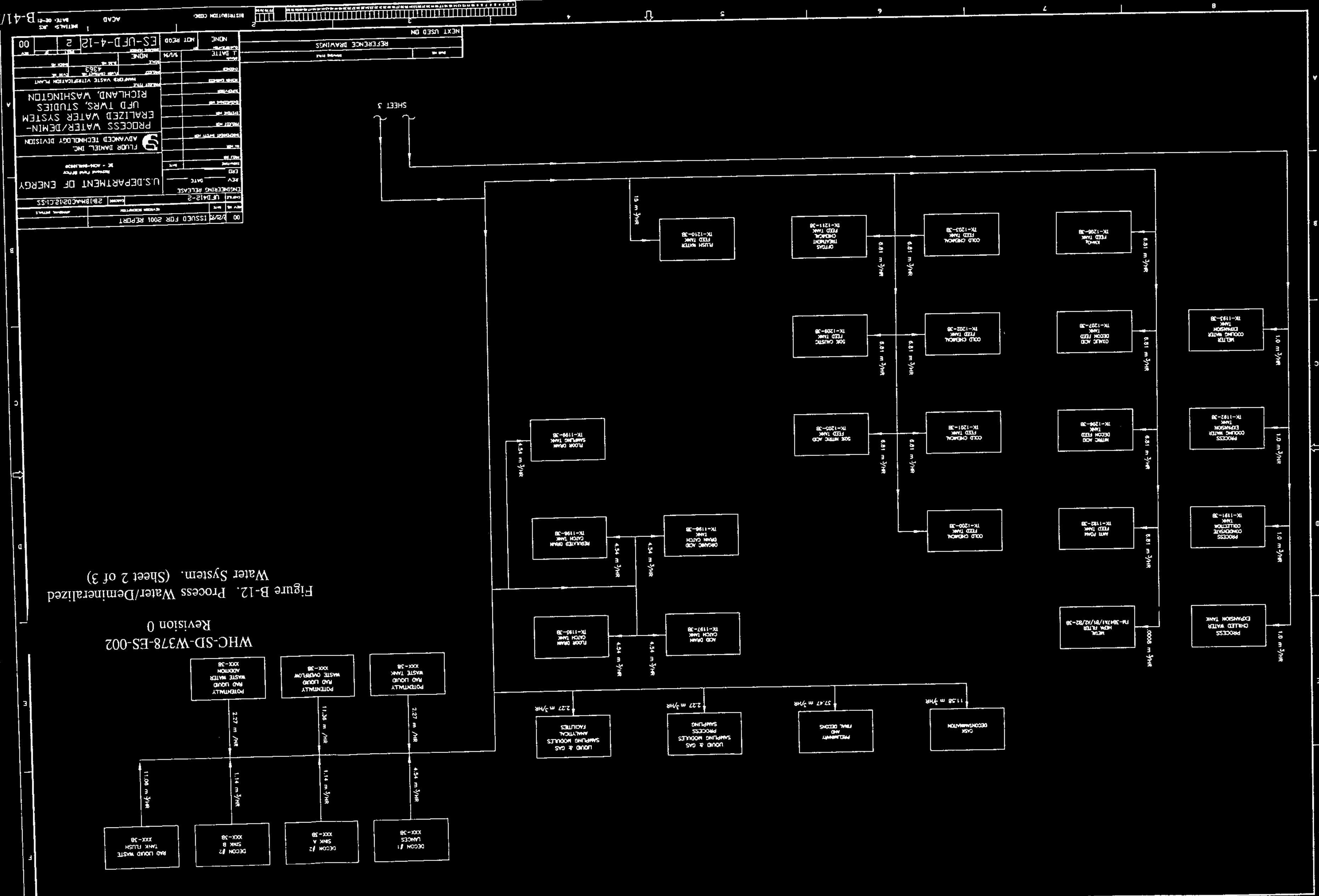

20-SA-8LEM-GS-JHM

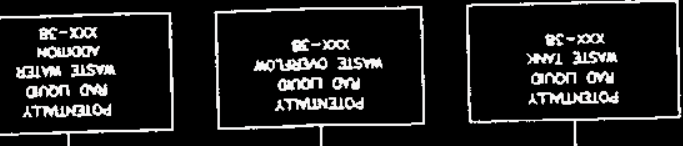

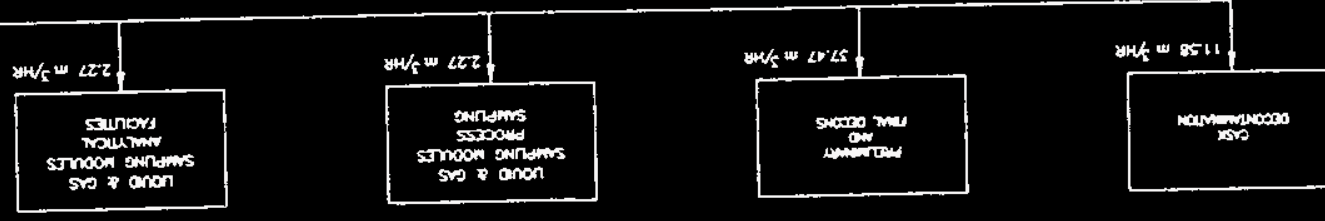




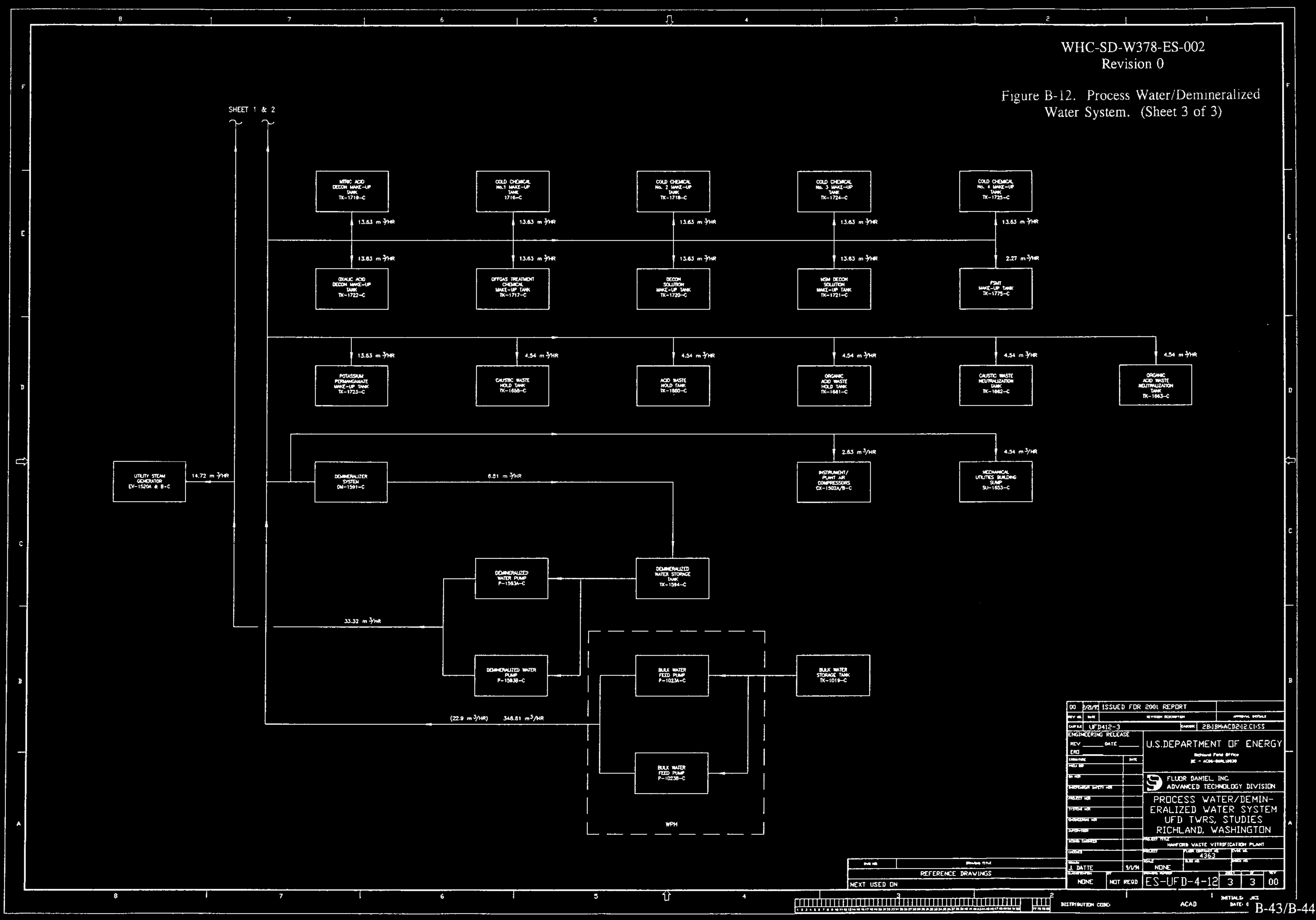




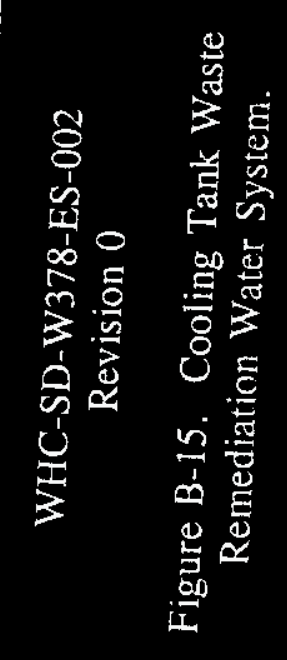
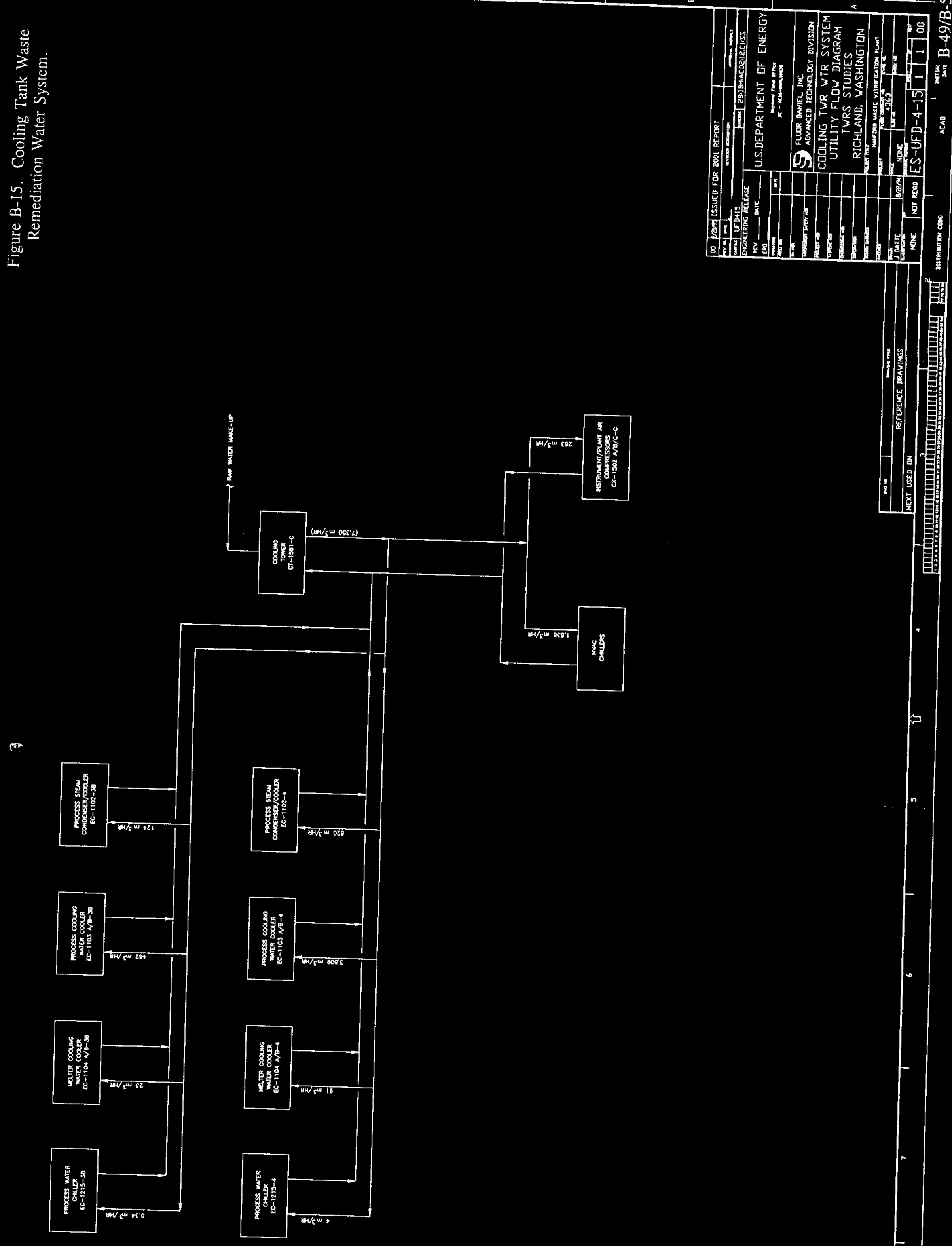

: 


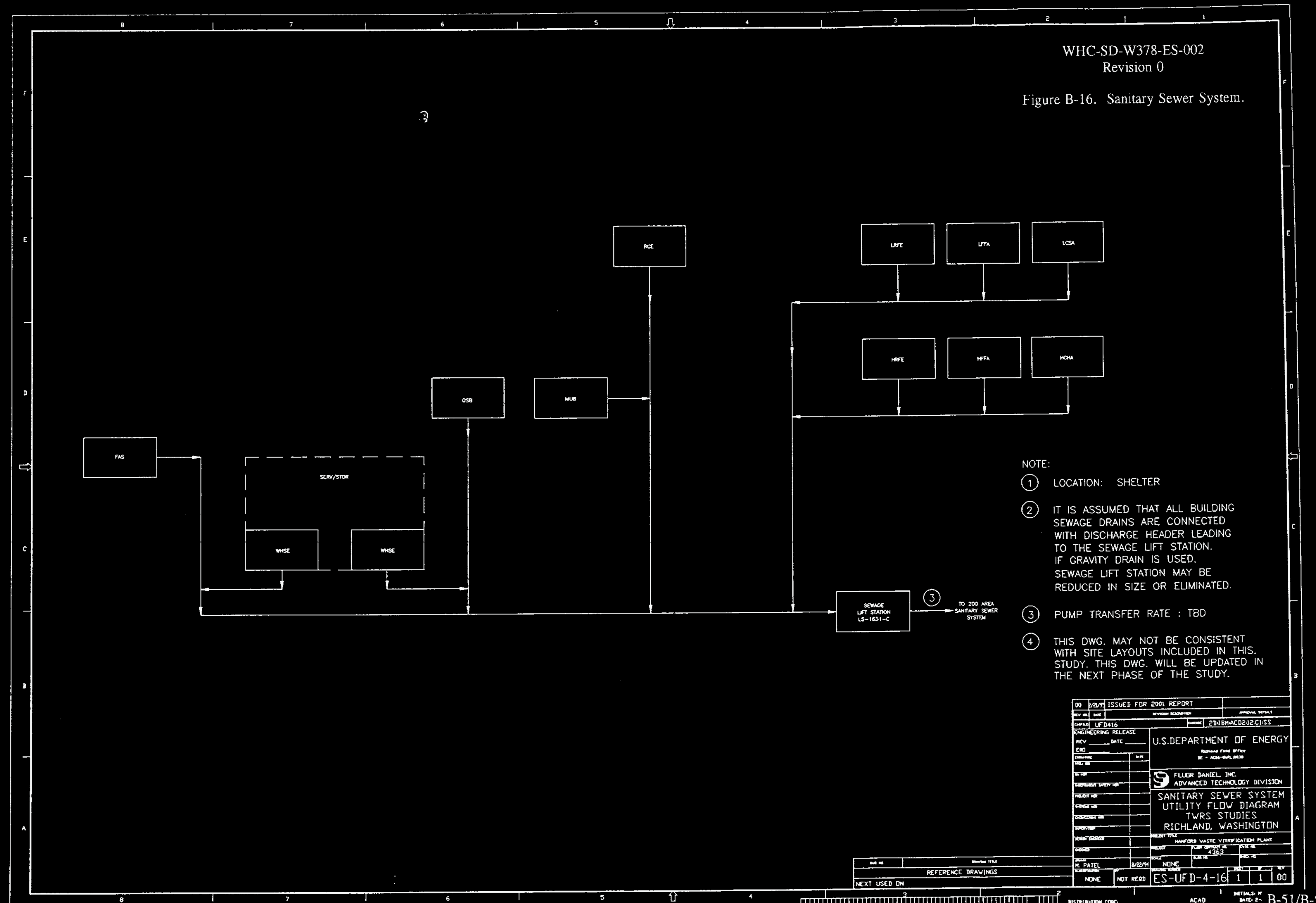




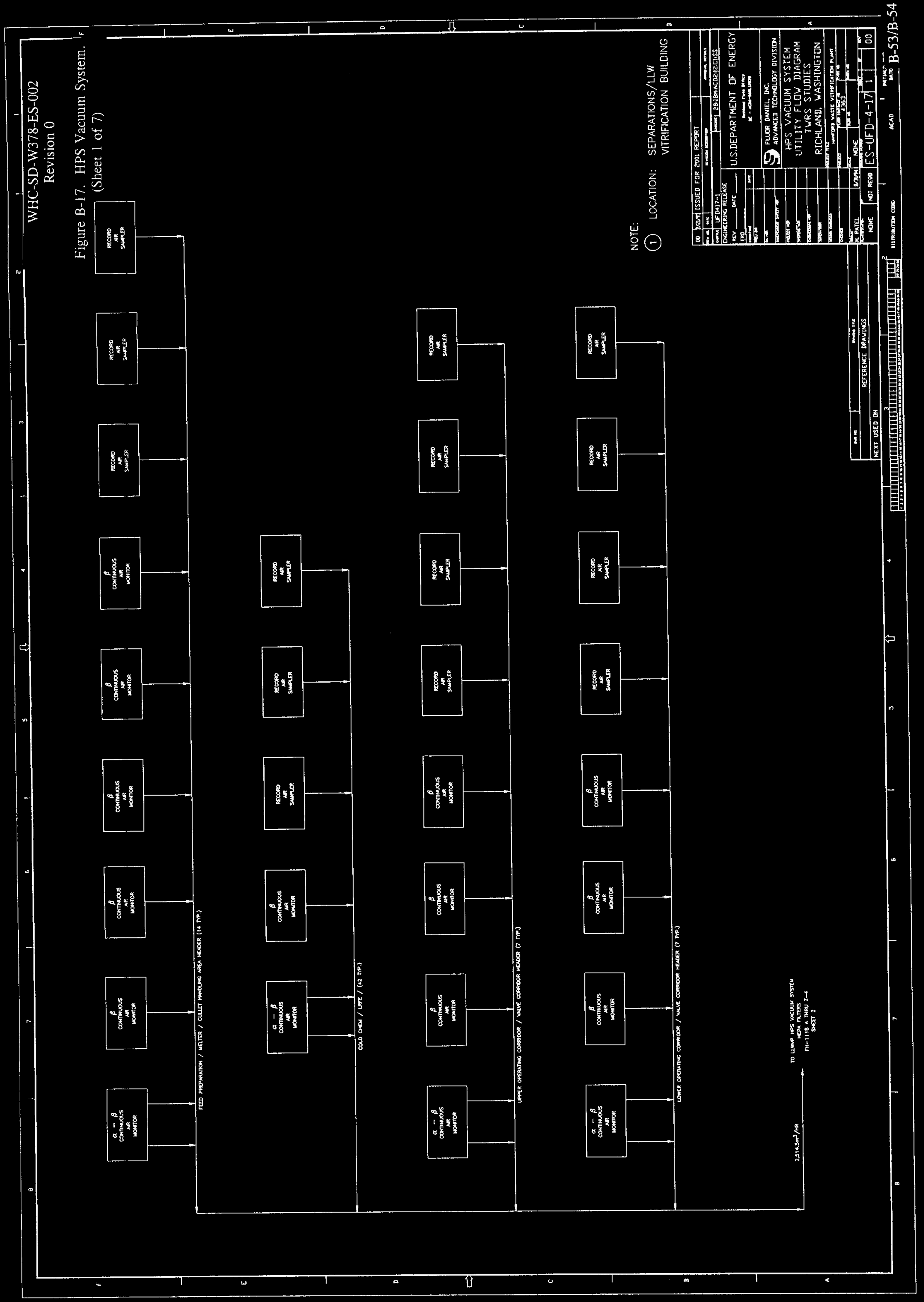




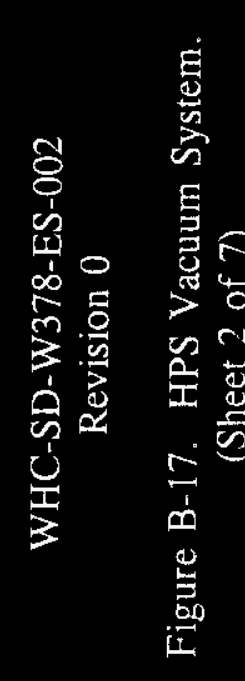
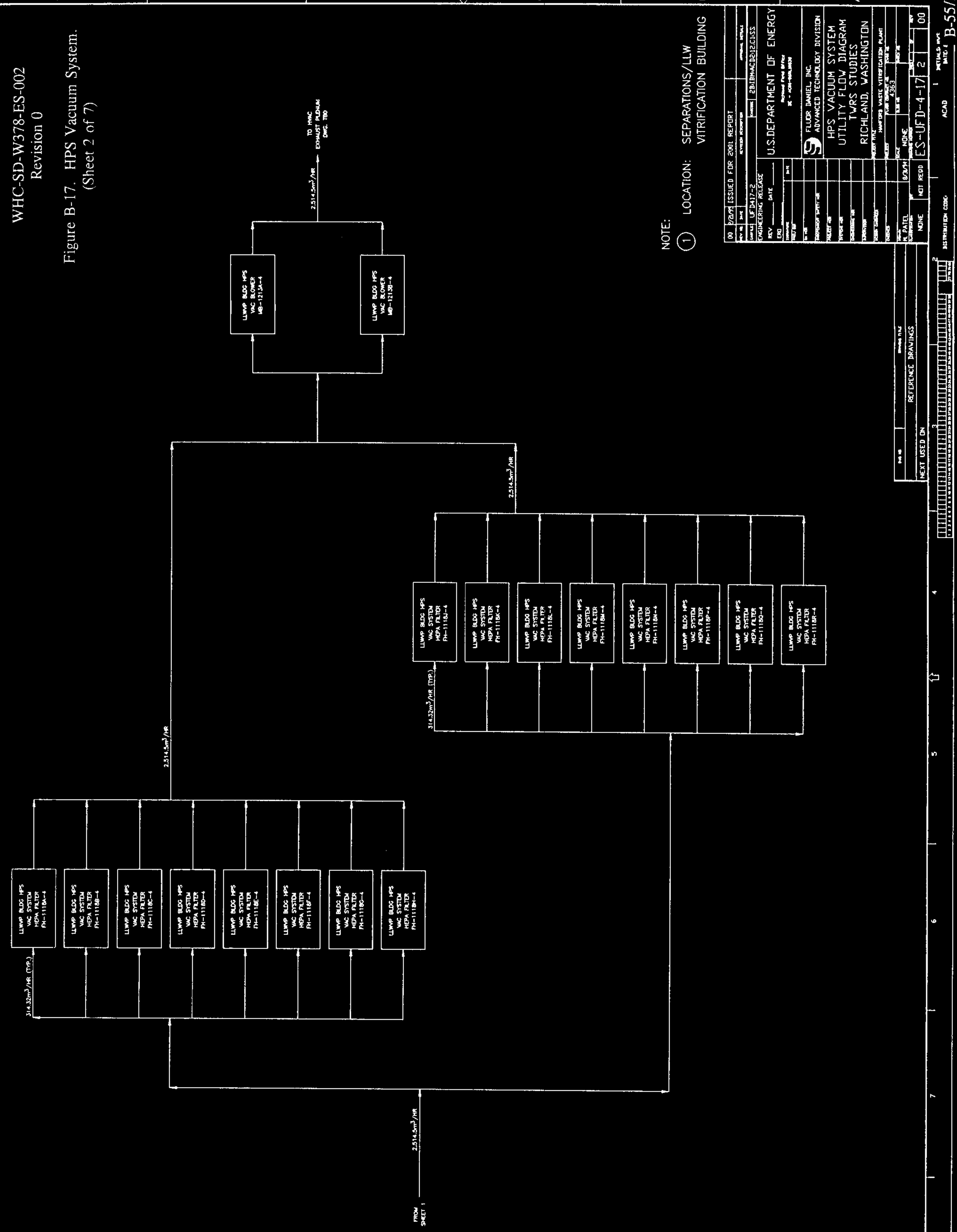


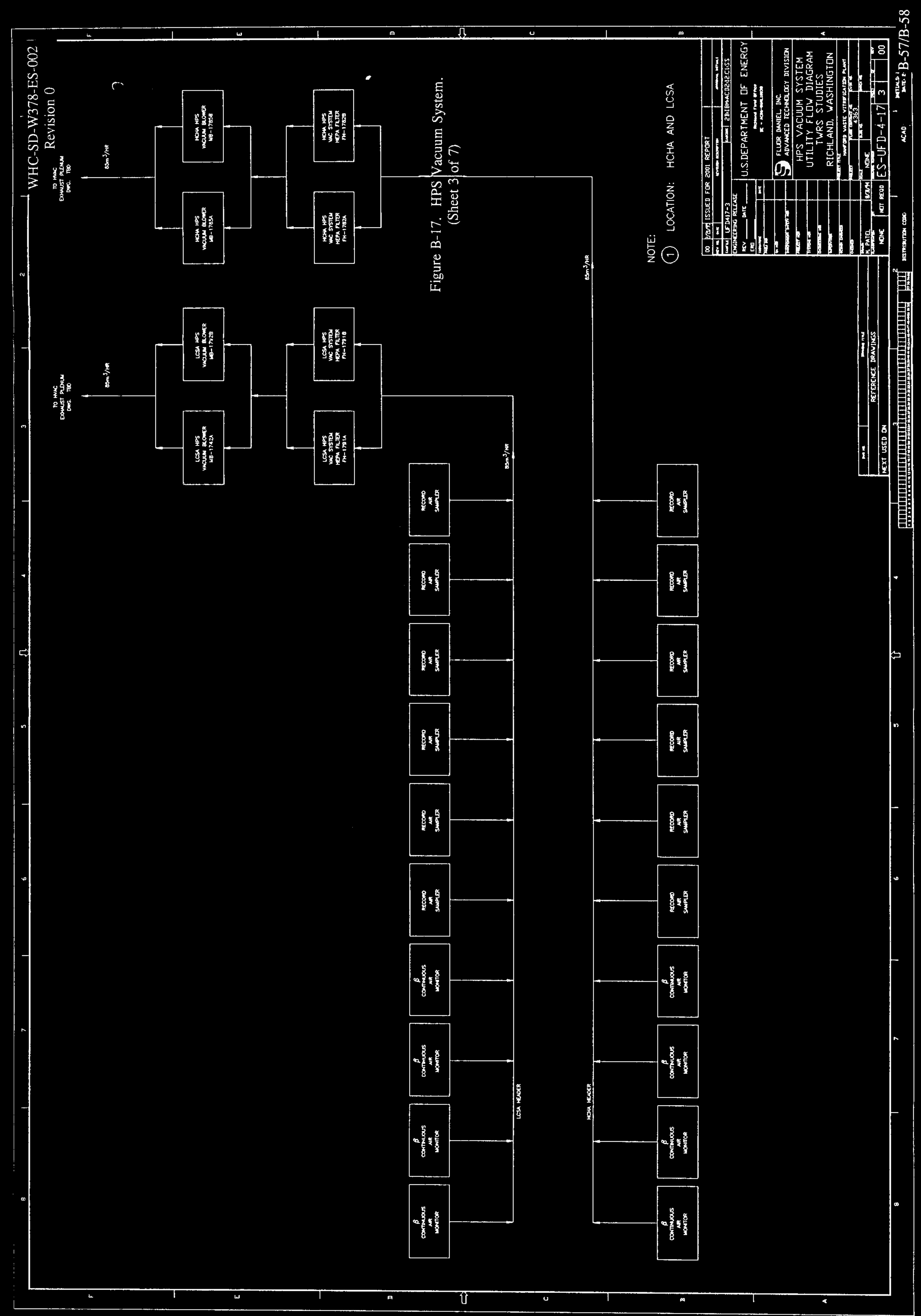




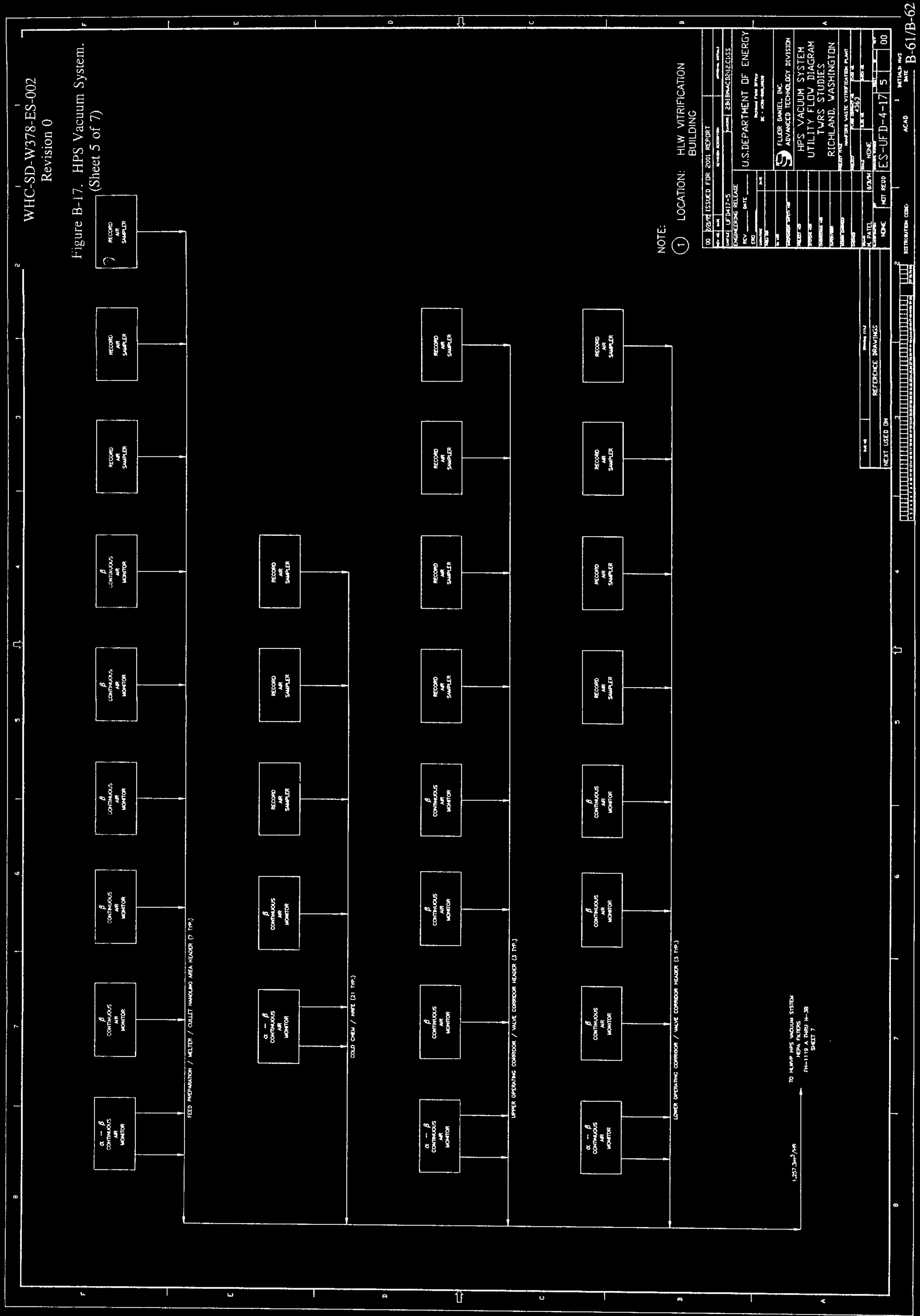




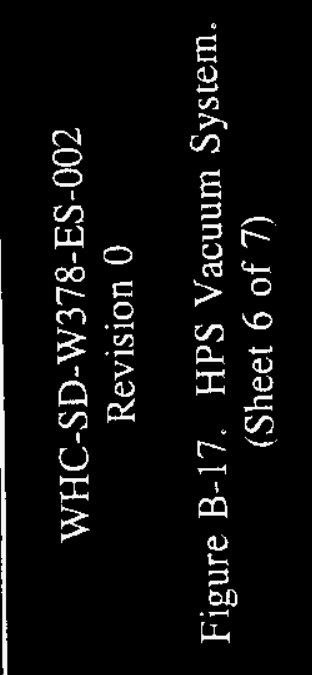
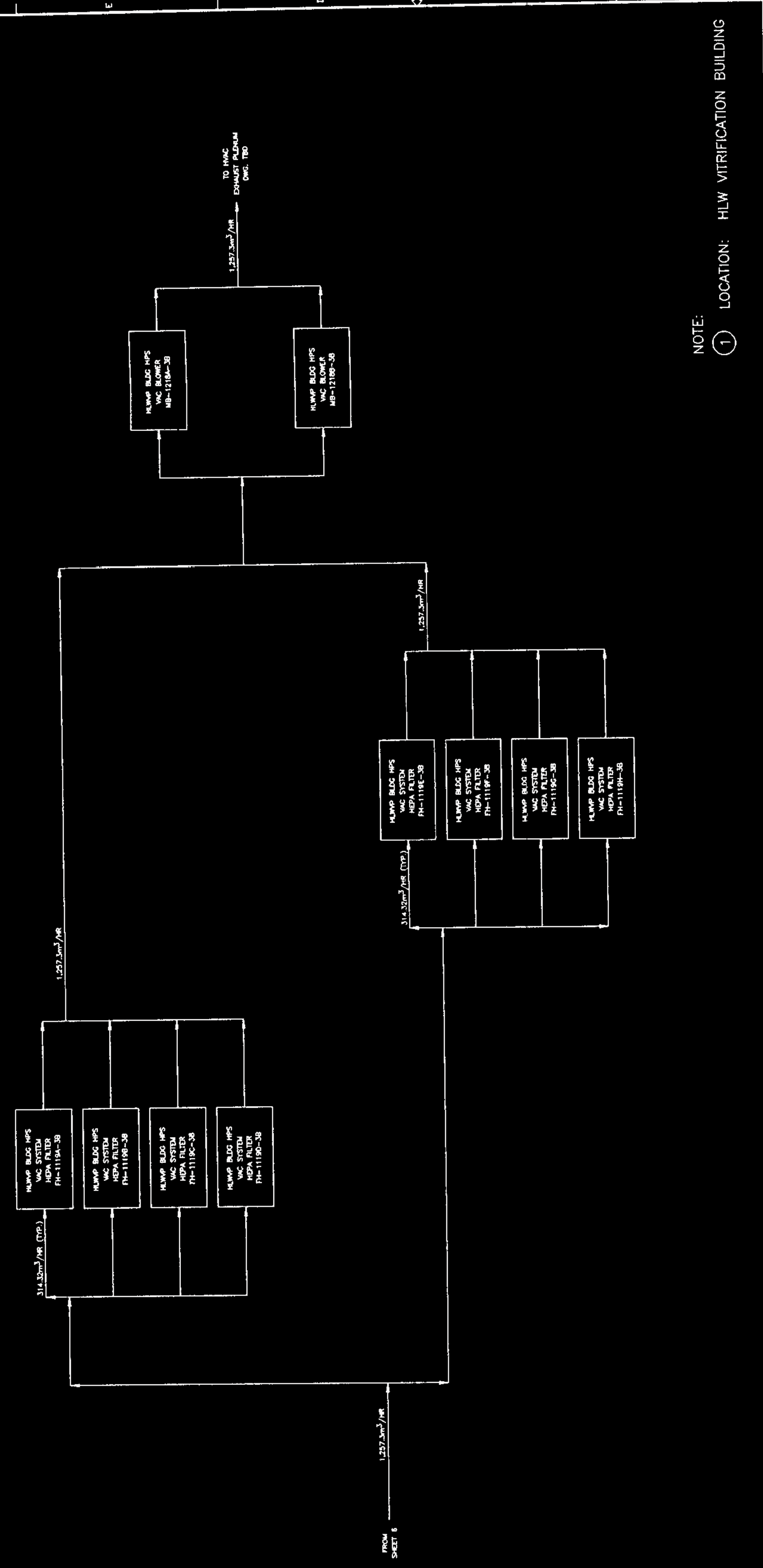

8 (ֶ)

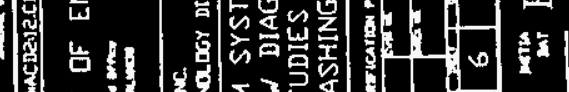

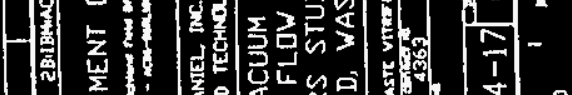

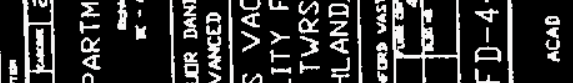

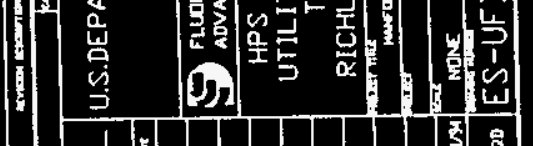

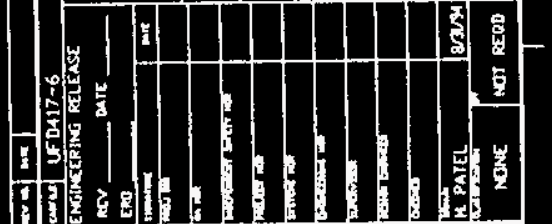

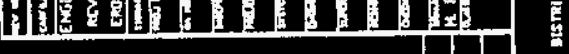

岁 $\odot$

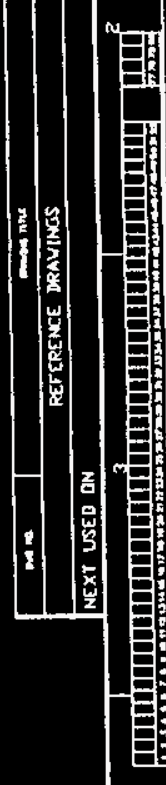




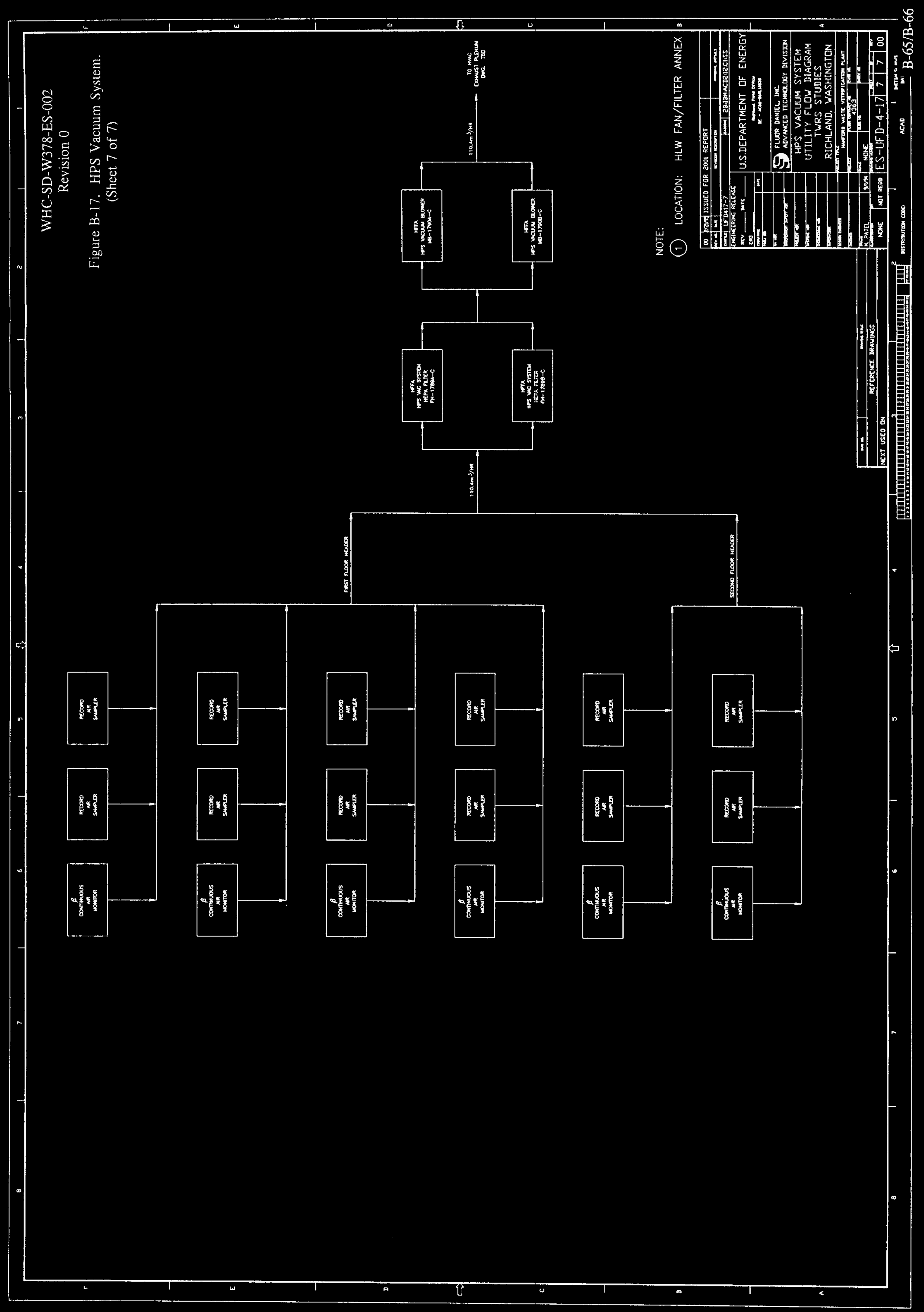


WHC-SD-W378-ES-002

Revision 0

APPENDIX C

\section{UTILITY CONSUMPTION TABLES AND ELECTRICAL LOAD LIST}

C-1 


\section{WHC-SD-W378-ES-002}

Revision 0

This page intentionally left blank.

C-2 


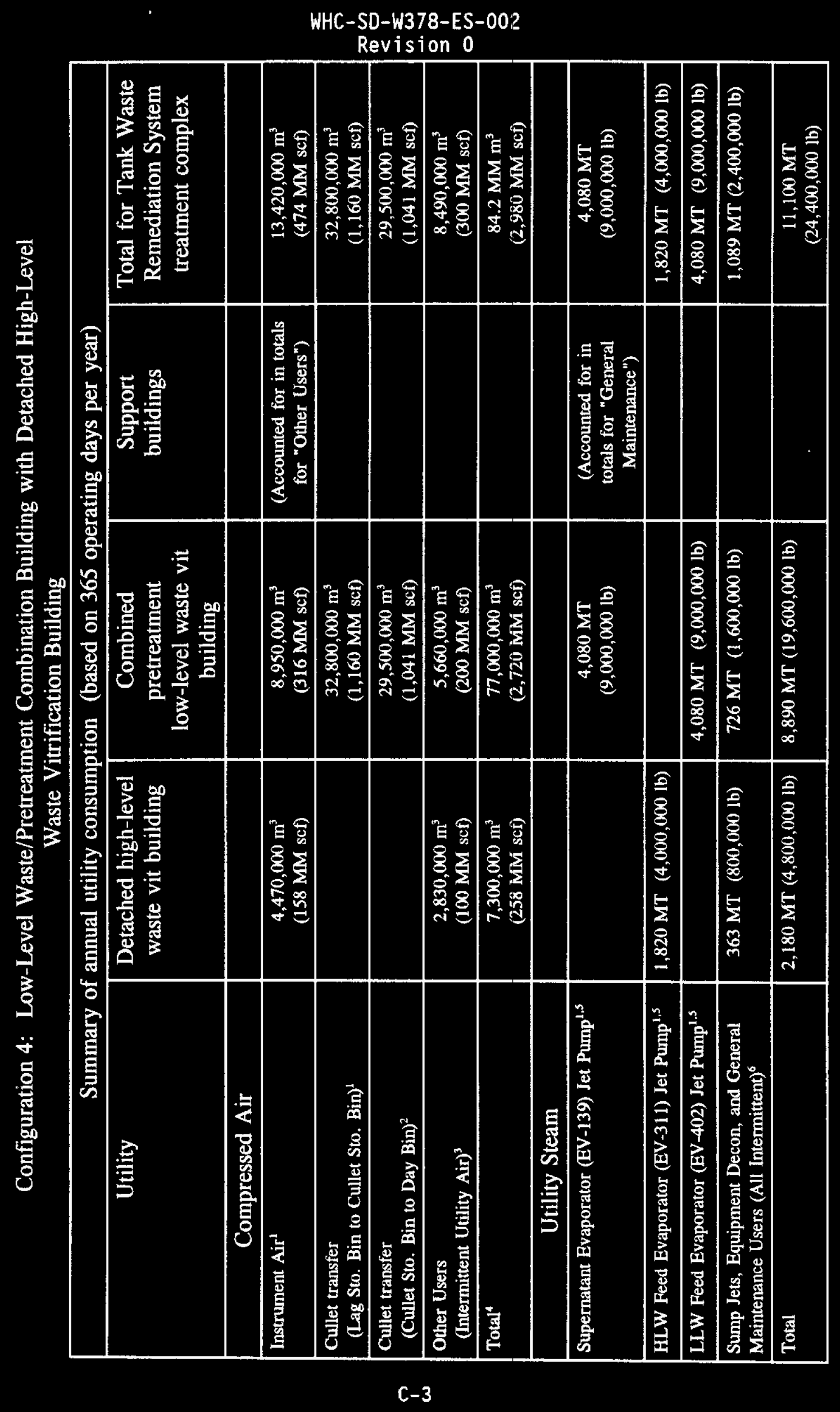


Revision 0

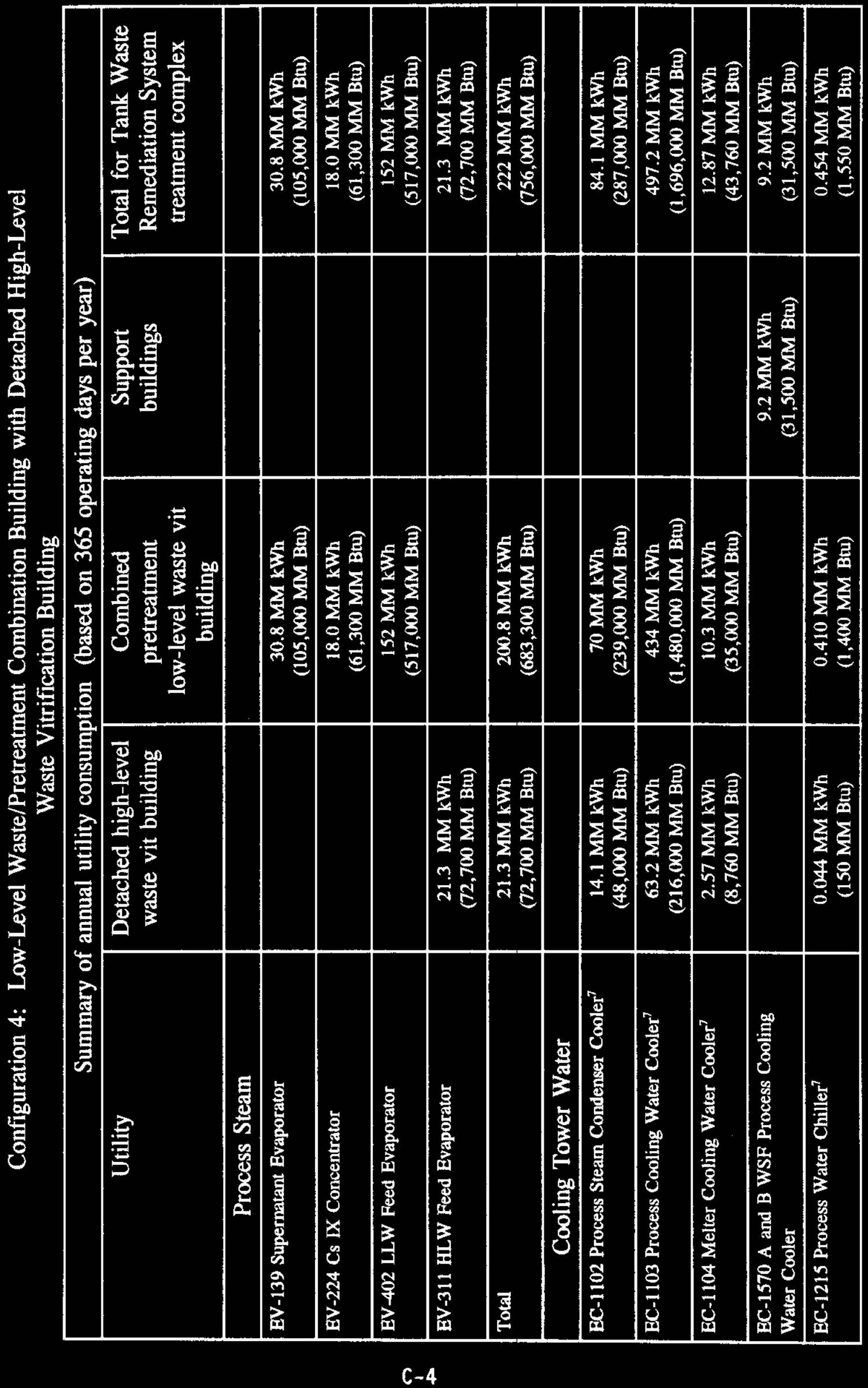


Configuration 4: Low-Level Waste/Pretreatment Combination Building with Detached High-Level

Waste Vitrification Building

\begin{tabular}{|c|c|c|c|c|}
\hline \multicolumn{5}{|c|}{ Summary of annual utility consumption (based on 365 operating days per year) } \\
\hline Utility & $\begin{array}{c}\text { Detached high-level } \\
\text { waste vit building }\end{array}$ & $\begin{array}{c}\text { Combined } \\
\text { pretreatment } \\
\text { low-level waste vit } \\
\text { building }\end{array}$ & $\begin{array}{c}\text { Support } \\
\text { buildings }\end{array}$ & $\begin{array}{l}\text { Total for Tank Waste } \\
\text { Remediation System } \\
\text { treatment complex }\end{array}$ \\
\hline Other Users ${ }^{8}$ & & & $\begin{array}{c}238 \mathrm{MM} \mathrm{kWh} \\
(813,000 \mathrm{MM} \mathrm{Btu})\end{array}$ & $\begin{array}{c}238 \mathrm{MM} \mathrm{kWh} \\
(813,000 \mathrm{MM} \mathrm{Btu})\end{array}$ \\
\hline Total & $\begin{array}{c}79.9 \mathrm{MM} \mathrm{kWh} \\
(273,000 \mathrm{MM} \mathrm{Btu})\end{array}$ & $\begin{array}{c}514.7 \mathrm{MM} \mathrm{kWh} \\
(1,755,000 \mathrm{MM} \text { Btu) }\end{array}$ & $\begin{array}{c}247 \text { MM kWh } \\
(844,500 \text { MM Btu) }\end{array}$ & $\begin{array}{c}841.8 \mathrm{MM} \text { kWh } \\
(2,873,000 \mathrm{MM} \mathrm{Btu})\end{array}$ \\
\hline \multicolumn{5}{|l|}{ Process Cooling Water } \\
\hline EC-140 Condenser & & $\begin{array}{c}27.2 \mathrm{MM} \mathrm{kWh} \\
(92,700 \mathrm{MM} \mathrm{Btu})\end{array}$ & & $\begin{array}{c}27.2 \mathrm{MM} \mathrm{kWh} \\
(92,700 \mathrm{MM} \text { Btu) }\end{array}$ \\
\hline EC-223 Condenser & & $\begin{array}{c}17.5 \mathrm{MM} \mathrm{kWh} \\
(59,800 \mathrm{MM} \mathrm{Btu})\end{array}$ & & $\begin{array}{c}17.5 \mathrm{MM} \mathrm{kWh} \\
(59,800 \mathrm{MM} \mathrm{Btu})\end{array}$ \\
\hline EC-312 Condenser & $\begin{array}{c}20.5 \mathrm{MM} \mathrm{kWh} \\
(70,100 \mathrm{MM} \mathrm{Btu})\end{array}$ & & & $\begin{array}{c}20.5 \text { MM kWh } \\
(70,100 \mathrm{MM} \mathrm{Btu})\end{array}$ \\
\hline EC-403 Evaporator Overhead Condenser & & $\begin{array}{c}123 \mathrm{MM} \mathrm{kWh} \\
(420,000 \mathrm{MM} \mathrm{Btu})\end{array}$ & & $\begin{array}{c}123 \mathrm{MM} \mathrm{kWh} \\
(420,000 \mathrm{MM} \mathrm{Btu})\end{array}$ \\
\hline EC-417 A and B Condenser & & $\begin{array}{c}10.2 \mathrm{MM} \mathrm{kWh} \\
(34,900 \mathrm{MM} \mathrm{Btu})\end{array}$ & & $\begin{array}{c}10.2 \mathrm{MM} \mathrm{kWh} \\
(34,900 \mathrm{MM} \mathrm{Btu})\end{array}$ \\
\hline EC-419 A and B LLW Recycle Water Cooler & & $\begin{array}{c}24.1 \mathrm{MM} \mathrm{kWh} \\
(82,300 \mathrm{MM} \mathrm{Btu})\end{array}$ & & $\begin{array}{c}24.1 \mathrm{MM} \mathrm{kWh} \\
(82,300 \mathrm{MM} \mathrm{Btu})\end{array}$ \\
\hline EC-428 A and B Condenser & & $\begin{array}{c}18.5 \mathrm{MM} \mathrm{kWh} \\
(63,200 \mathrm{MM} \mathrm{Btu})\end{array}$ & & $\begin{array}{c}18.5 \mathrm{MM} \mathrm{kWh} \\
(63,200 \mathrm{MM} \mathrm{Btu})\end{array}$ \\
\hline EC-601 Cooler & $\begin{array}{c}21.4 \mathrm{MM} \mathrm{kWh} \\
(73,200 \mathrm{MM} \mathrm{Btu})\end{array}$ & & & $\begin{array}{c}21.4 \mathrm{MM} \mathrm{kWh} \\
(73,200 \mathrm{MM} \mathrm{Btu})\end{array}$ \\
\hline EC-610 A and B Cooler & & $\begin{array}{c}156 \mathrm{MM} \mathrm{kWh} \\
(531,000 \mathrm{MM} \mathrm{Btu})\end{array}$ & & $\begin{array}{c}156 \mathrm{MM} \mathrm{kWh} \\
(531,000 \mathrm{MM} \mathrm{Btu})\end{array}$ \\
\hline
\end{tabular}




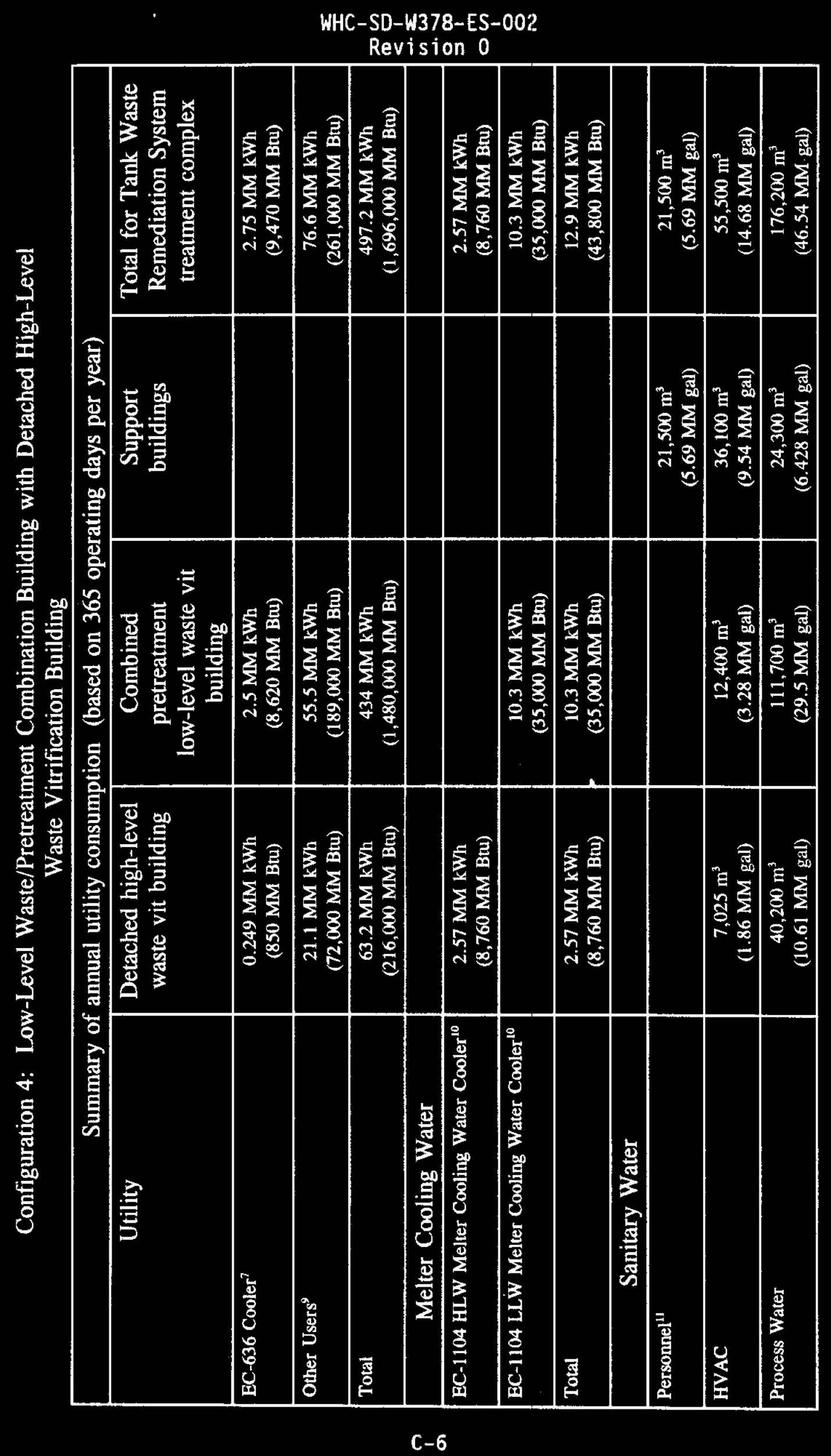




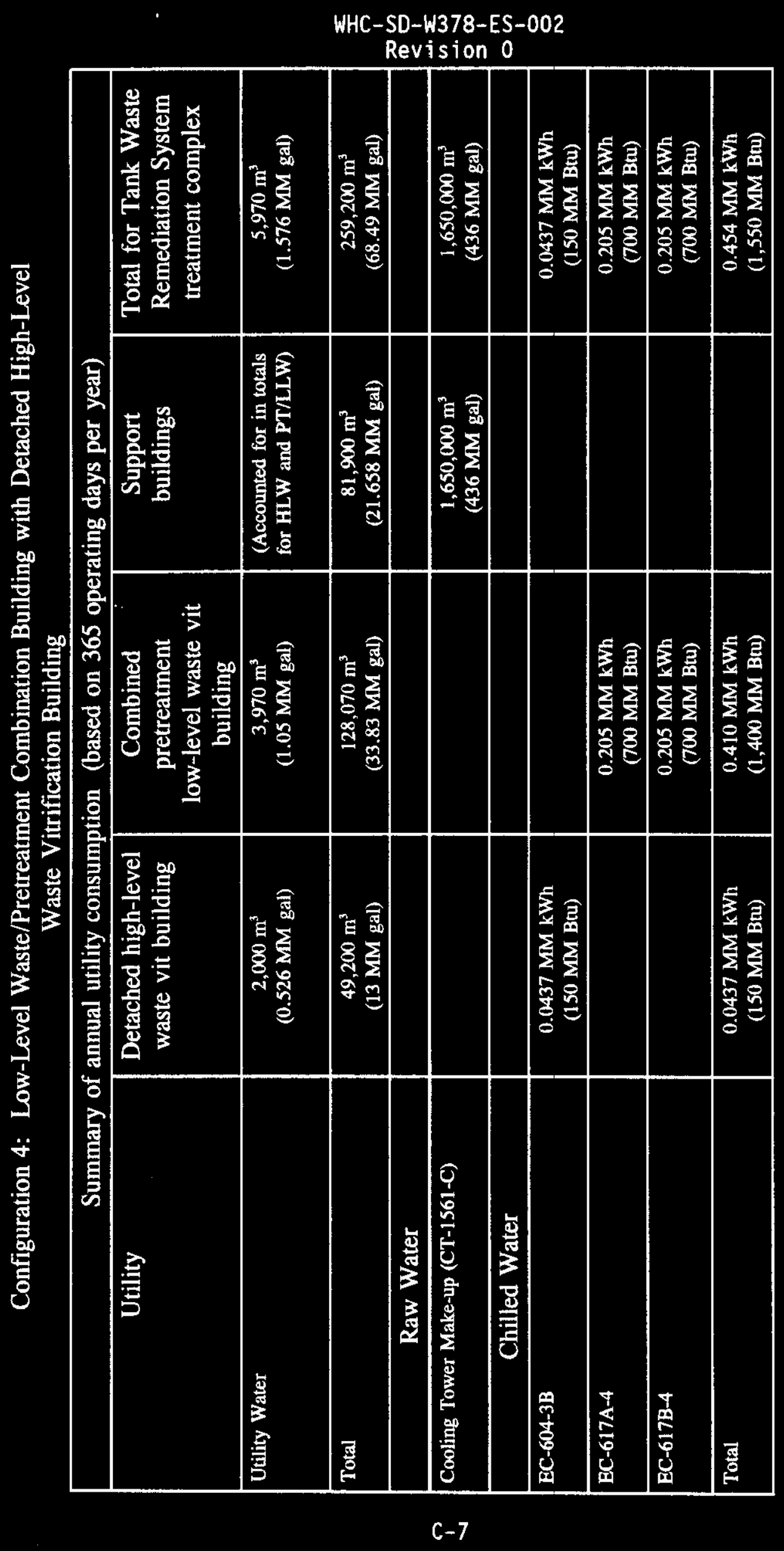


Configuration 4: Low-Level Waste/Pretreatment Combination Building with Detached High-Level Waste Vitrification Building

\begin{tabular}{|l|c|c|c|c|}
\hline \multicolumn{5}{|c|}{ Summary of annual utility consumption (based on 365 operating days per year) } \\
\hline Utility & $\begin{array}{c}\text { Detached high-level } \\
\text { waste vit building }\end{array}$ & $\begin{array}{c}\text { Combined } \\
\text { pretreatment } \\
\text { low-level waste vit } \\
\text { building }\end{array}$ & $\begin{array}{c}\text { Support } \\
\text { buildings }\end{array}$ & $\begin{array}{c}\text { Total for Tank Waste } \\
\text { Remediation System } \\
\text { treatment complex }\end{array}$ \\
\hline
\end{tabular}

1. The annual consumption values listed are based on 100 percent of the maximum flow rate for this item occurring on a continuous basis.

2. The annual consumption is based on the maximum flow rate occurring for 60 percent of the time.

3. The annual consumption of intermittent utility air is assumed to be 10 percent of the total air consumers being in operation, with one third consumed in the HLW Facility and two-thirds consumed in the PT/LLW Facility.

4. This total is an average annul rate. It does not reflect the maximum simultaneous flow or the additional 30 percent margin that is used to size the compressors.

5. Fluor Daniel, Inc., determined that a steam jet or purnp is required to transfer the liquid from the evaporators to the downstream tanks. For this study, a steam jet was chosen for this service. The choice of a steam jet will be confirmed in a later trade study.

6. The annual consumption of intermittent utility steam is assumed to be 10 percent of the total steam consumers being in operation, with one third consumed in the HLW Facility and two-thirds consumed in the PT/LLW Facility.

7. There âte two equipment items associated with the equipment number listed, une in the Preireatnent/LLW Builuing and one in the HLW Vitrification Building.

8. The other users are HVAC chillers, air compressors and miscellaneous equipment.

9. Cooling coils in the process tanks.

10. The melter cooling duties are estimates that may need future refinement.

11. Based on a Facility population of 708 people. 


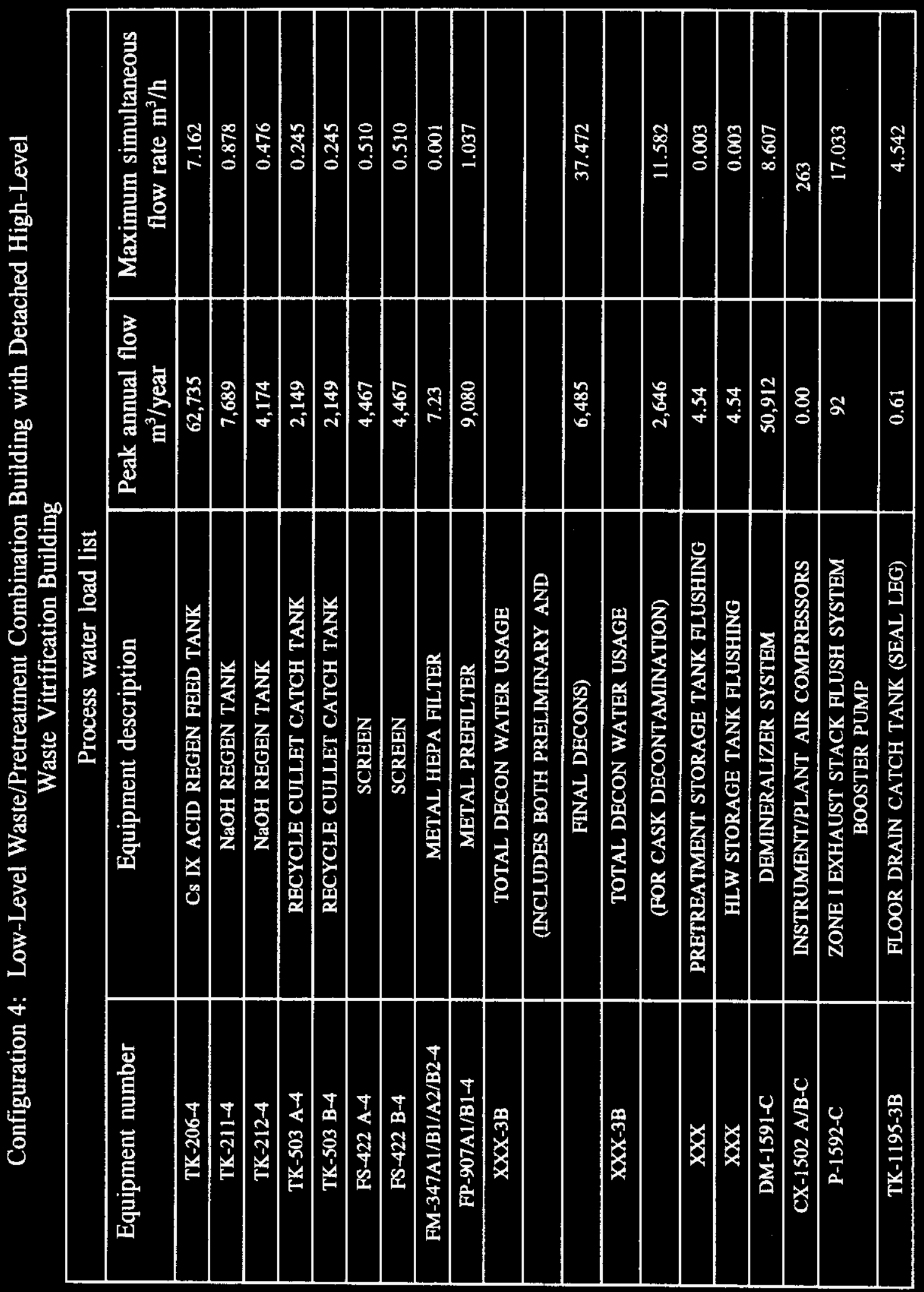




\begin{tabular}{|c|c|c|c|}
\hline$\varepsilon 18.9$ & $5 t^{\circ} \mathrm{I}$ & XNVI व日EA TVOIKAHว व7Oว & gE-E0ZI-XIL \\
\hline$\varepsilon 18 \cdot 9$ & $Z \varepsilon^{\prime} I$ & XNVL GAgH TVDIWAHว वTOว & 8E-Z0ZI-XIL \\
\hline$\varepsilon 18.9$ & St. I & XNVl agat TVOIK日Hว a70ว & ge-10ZI-XIL \\
\hline$\varepsilon 18 * 9$ & $\tau E^{\prime} I$ & XNVL GAEA TVDIWEHS QTOS & gE-00ZI-Х̃L \\
\hline$z t S^{\prime} t$ & $00 \%$ & 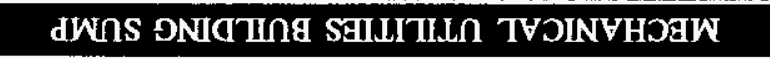 & s-esgt-ns \\
\hline $2 t s^{\prime} t$ & I0 $0^{\prime} \varepsilon \mathrm{I}$ & $\begin{array}{c}\text { XNVL } \\
\text { NOILVZITVXLINAN GLSVM AIJV JINVO\&O }\end{array}$ & ว-દ99I-XXL \\
\hline $2 t S^{\prime} t$ & IL.9 & XNVL, NOLLVZITVALIAN GLSVM JLLSกVD & $9-299 \mathrm{I}-\mathrm{XI}$ \\
\hline $2 t s^{*} t$ & I0' $\varepsilon I$ & XNYL GTOH BLSVM GIJV JINYD\&O & 5-I99I-XL \\
\hline $2+S^{\prime} t$ & $8 b^{\circ} 6$ & XNVL GTOH GLSVM GIJV & כ-099I-X.L \\
\hline $2 t s^{\circ} t$ & $8 t^{\circ}+2$ & XNNVL GTOH GLSVM OILSOVJ & T-8S9I-XXI \\
\hline $2 t s^{*} t$ & $I Z \cdot I$ & (OAT TVBS) XNVI פNIdKYS NIVAG \&OOTH & t-66II-XL \\
\hline $2 t S^{\prime} t$ & $I Z \cdot I$ & $\begin{array}{c}\text { (OAT } \\
\text { TVas) XNVL HOLVO NIVya đIJ JINVDYo }\end{array}$ & $\downarrow-86 I I-X I L$ \\
\hline $\operatorname{cts} s^{\prime} t$ & $I Z \cdot I$ & (פGT TVGS) XNVL HOJVD NIVXd GIJV & $t L 6 I 1-X L$ \\
\hline $2 t S^{\circ} t$ & $I Z \cdot I$ & (OAT TVGS) XNVL HOLVD NIV\&d GaLVTnDA8 & $t-96 \mathrm{II}-\mathrm{XL}$ \\
\hline $2 t s^{\prime} t$ & $\mathbf{I} \cdot \mathbf{I}$ & (OAT TVAS) XNVL HOLVD NIVAd \&OOTH & $\checkmark-S 6 I I-X I L$ \\
\hline $2 t 5 \cdot t$ & I9:0 & (0BT TVES) XNVL ONITdWVS NIVAd צOOTA & gع-66II-XL \\
\hline $2 t s^{\prime} t$ & $19 \cdot 0$ & $\begin{array}{c}\text { (OAT } \\
\text { TVas) XNVL HOLV NIVyd GDV DINVO\&O }\end{array}$ & gย-86I I-XL \\
\hline $2 t S^{\prime} t$ & $19 \%$ & (OGT TVGS) X्XNVL HOLVO NIVYA GIJV & 8E-L6I I-XXL \\
\hline $2 t S^{\circ} t$ & $19 \cdot 0$ & (DAT TVES) XNVL HOLVD NIV\&d GALVTnOAd & gE-96 II-XXL \\
\hline 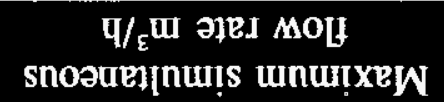 & 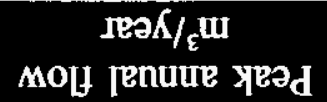 & uo!̣d!̣əsəp quəurd!nbg & Jəqunu juəud!nbg \\
\hline \multicolumn{4}{|c|}{ ISII PROI JәIEM SSOOOId } \\
\hline
\end{tabular}

8u!p!!ng uo!̣eo!y!n! $\Lambda$ әłse $M$

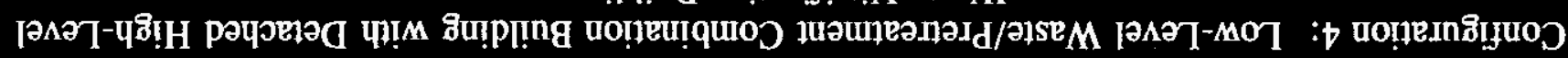


Configuration 4: Low-Level Waste/Pretreatment Combination Building with Detached High-Level Waste Vitrification Building

\begin{tabular}{|c|c|c|c|}
\hline \multicolumn{4}{|c|}{ Process water load list } \\
\hline Equipment number & Equipment description & $\begin{array}{c}\text { Peak annual flow } \\
\mathrm{m}^{3} / \text { year }\end{array}$ & $\begin{array}{l}\text { Maximum simultaneous } \\
\text { flow rate } \mathrm{m}^{3} / \mathrm{h}\end{array}$ \\
\hline TK-1205-3B & $50 \%$ NITRIC ACID FEED TANK & 1.45 & 6.813 \\
\hline TK-1206-3B & NITRIC ACID DECON FEED TANK & 2.63 & 6.813 \\
\hline TK-1207-3B & OXALIC ACID DECON FEED TANK & 1.32 & 6.813 \\
\hline TK-1208-3B & POTASSIUM PERMANGANATE FEED TANK & 1.45 & 6.813 \\
\hline TK-1209-3B & 50\% CAUSTIC FEED TANK & 1.32 & 6.813 \\
\hline TK-1210-3B & FLUSH WATER FEED TANK & 27.25 & 14.989 \\
\hline TK-1211-3B & OFFGAS TREATMENT CHEMICAL FEED TANK & 1.32 & 6.813 \\
\hline TK-1200-4 & COLD CHEMICAL FEED TANK & 2.89 & 6.813 \\
\hline TK-1201-4 & COLD CHEMICAL FEED TANK & 2.89 & 6.813 \\
\hline TK-1202-4 & COLD CHEMICAL FEED TANK & 2.63 & 6.813 \\
\hline TK-1203-4 & COLD CHEMICAL FEED TANK & 2.89 & 6.813 \\
\hline TK-1205-4 & 50\% NITRIC ACID FEED TANK & 2.89 & 6.813 \\
\hline TK-1206-4 & NITRIC ACID DECON FEED TANK & 5.27 & 6.813 \\
\hline TK-1207-4 & OXALIC ACID DECON FEED TANK & 2.63 & 6.813 \\
\hline TK-1208-4 & POTASSIUM PERMANGANATE FEED TANK & 2.89 & 6.813 \\
\hline TK-1209-4 & $50 \%$ CAUSTIC FEED TANK & 2.63 & 6.813 \\
\hline TK-1210-4 & FLUSH WATER FEED TANK & 54.50 & 14.989 \\
\hline TK-1211-4 & OFFGAS TREATMENT CHEMICAL FEED TANK & 2.63 & 6.813 \\
\hline TK-1716-C & COLD CHEMICAL No. 1 MAKEUP TANK & 500 & 13.626 \\
\hline TK-1717-C & $\begin{array}{l}\text { OFFGAS TREATMENT CHEMICAL MAKEUP } \\
\text { TANK }\end{array}$ & 174 & 13.626 \\
\hline TK-1718-C & COLD CHEMICAL No. 2 MAKEUP TANK & 500 & 13.626 \\
\hline
\end{tabular}




\begin{tabular}{|c|c|c|c|}
\hline & & (МОТЖУААО НSกТА) & \\
\hline$\varepsilon 18 \cdot 9$ & $00^{\circ} 0$ & ELSVM बIกOIT बVd & \\
\hline $590^{\circ} \downarrow \varepsilon$ & $00^{\circ} 0$ & HSกTE X्रNVL GLSVM बIIOIT avd & $\mathbf{g} \varepsilon-\mathrm{XXX}$ \\
\hline$\angle 0 t^{\prime} \mathcal{E}$ & ZEl & Q XNIS Z\# NOOGa & \\
\hline$\angle 0 b^{`} \varepsilon$ & $z \varepsilon I$ & $\checkmark$ XNIS Z\# NOOEd & \\
\hline $9 Z 9^{\circ} \varepsilon I$ & 9zS & SGONVT I\# NOJAd & $\mathbf{g \varepsilon - X X X}$ \\
\hline$I \angle \tau^{\prime} \tau$ & $8 \$ 9^{4} \mathrm{I}$ & 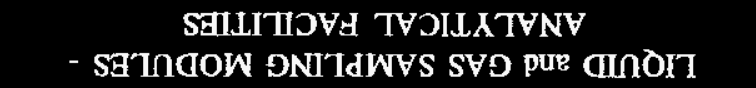 & $\mathbf{t}-\mathbf{X X X}$ \\
\hline$I \angle Z \tau$ & $859^{\circ} \mathrm{I}$ & $\begin{array}{c}\text { DNITdWVS SSAOOYd } \\
\text { - saTndOW ONITdWVS SVO puE GInOIT }\end{array}$ & $\mathbf{t}-\mathbf{X X X}$ \\
\hline $\mathrm{I} \angle \tau^{\prime} \tau$ & 628 & $\begin{array}{c}\text { SEILITIJVA TVOILATVNV } \\
\text { - sGTIAOW ONITdWVS SVD puE GInOIT }\end{array}$ & $\mathbf{g E}-\mathbf{X X X}$ \\
\hline$I \angle Z \cdot \tau$ & 628 & 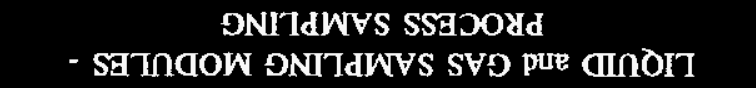 & $\mathbf{g} \varepsilon-\mathbf{X X X}$ \\
\hline$I \angle \tau \cdot \tau$ & SEZ & XNVI dกGYXVW LWSA & כ-SLLI-XIL \\
\hline $9 Z 9^{\circ} \varepsilon 1$ & 005 & 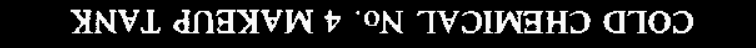 & כ-SZLI-XXI \\
\hline $9 z 9 \cdot \varepsilon I$ & 005 & XNVL dกAXVW $\varepsilon$ 'oN TVOIWAH वTOS & כ-†ZLI-XIL \\
\hline $9 Z 9^{\circ} \varepsilon I$ & $L Z b$ & XNVL dกAXVW GLVNVONVWXEd NOISSVLOd & כ-EZLI-XXL \\
\hline $9 Z 9^{\circ} \varepsilon \mathrm{I}$ & $80 t$ & XNVL dnEXXVW NODGA GIJV ITTXO & כ-ZZLI-XIL \\
\hline $9 z 9^{\circ} \varepsilon \mathrm{I}$ & $\angle 9 L^{\prime} L$ & XNVL dngXVW NOILnTOS NOJga WSW & $3-I Z L I-X L$ \\
\hline $9 Z 9^{\circ} \varepsilon I$ & LSZ & XNVL dกAXVW NOILnTOS NOJEA & כ-0ZLI-XI \\
\hline $9 Z 9^{\circ} \varepsilon \mathrm{I}$ & 982 & 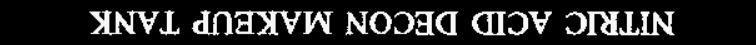 & $5-6 \mathrm{I} L \mathrm{~L}-\mathrm{XI}$ \\
\hline 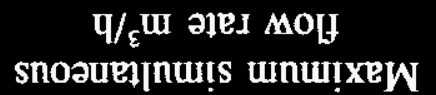 & 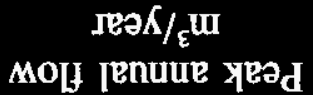 & uọ̣d!Josəp quəudinbg & sequnu quəudinbg \\
\hline \multicolumn{4}{|c|}{ 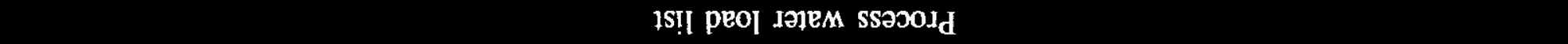 } \\
\hline
\end{tabular}

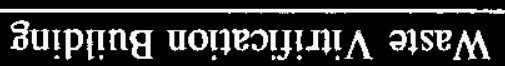

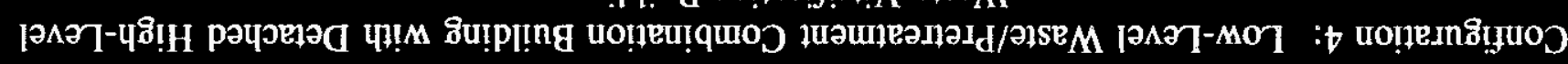




\begin{tabular}{|c|c|c|c|}
\hline I8. $86 \varepsilon$ & $\angle S I^{\prime} 9 L I$ & ANVWEO \&ALVM SSEOO\&d TVLOL & \\
\hline & & (MотеУв & \\
\hline \multirow[t]{2}{*}{$\$ 90 \triangleright \varepsilon$} & $00^{\circ} 0$ & ALSVM AInOIT GVA LOd & $t-X X X$ \\
\hline & & (NolliadV у日JVM) & \\
\hline \multirow[t]{2}{*}{$\varepsilon 18.9$} & $00 \%$ & GLSVM aInOIT avd LOd & $t \mathbf{X X X}$ \\
\hline & & 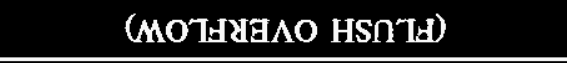 & \\
\hline$\varepsilon 18.9$ & $00 \%$ & aLSVM GIกOIT GFd & \\
\hline$\varsigma 90^{\circ} \downarrow \varepsilon$ & $00 \%$ & HSกTE XNVL aLSVM aInOIT avd & $\checkmark \mathrm{XXX}$ \\
\hline$\angle 0 t^{\circ} \varepsilon$ & $\varepsilon 92$ & g XNIS Z\# NODaG & \\
\hline$\angle 0 t^{\circ} \varepsilon$ & $\varepsilon 92$ & $\checkmark$ XNIS Z\# NOOEd & \\
\hline \multirow[t]{2}{*}{$9 Z 9^{\cdot} \mathcal{E I}$} & $\varepsilon S 0^{\circ} \mathrm{I}$ & SEONVT I\# NOSEd & $\mathbf{t}-\mathbf{X X X}$ \\
\hline & & (МотнувАО НSกт) & \\
\hline \multirow[t]{2}{*}{$\$ 90^{\circ} \downarrow \varepsilon$} & $00^{\circ} 0$ & GLSVM GinOIT avd LOd & gq-XXX \\
\hline & & (NOLHAaV yaLVM) & \\
\hline$\varepsilon 18 \cdot 9$ & 000 & aLSVM बInOI7 aVd LOd & gE-XXX \\
\hline 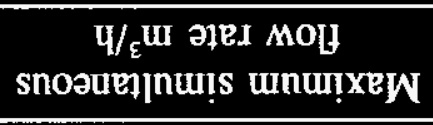 & 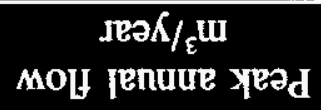 & 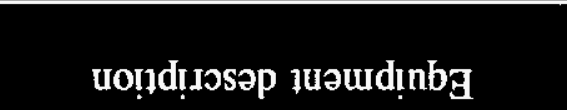 & Jəquinu łuəud!̣bg \\
\hline & & हO| JәIEM SSəכOId & \\
\hline
\end{tabular}

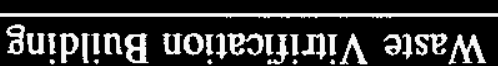

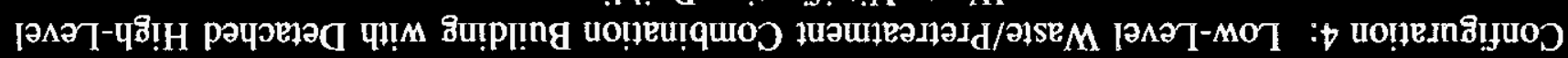




\section{Normal Electrical Load List}

This electrical load list was developed for the proposed combined Separations/LowLevel Waste Treatment plant, High-Level Waste Treatment plant and all the required support facilities described in this study. The process loads for the and Common Utilities were derived from equipment lists provided by Process. The HVAC loads for the main process facilities are factored from HWVP by the HVAC group. The HVAC for the support facilities are based on watts/ft2 values derived from similar buildings on the HWVP. Mechanical loads are an allowance to account for non-process loads such as cranes,elevators, etc. and are not broken out by facility. Electrical loads are based on watts $/ \mathrm{ft}^{2}$ values derived from HWVP for the process and support facilities. An allowance was made for control loads served from UPS's.

It was assumed that the joule heated melter adds 3 MVA to the process load. No allowance was made for spare or future loads. All loads were rounded off to the nearest $100 \mathrm{kVA}$.

Normal Electrical Load Summary Table

\begin{tabular}{|l|c|c|c|c|c|c|}
\hline \multicolumn{2}{|c|}{} & \multicolumn{3}{c|}{ Joule Heated High Level Melter } \\
\hline & \multicolumn{2}{|c|}{ Main Process Facilities } & Support Facilities & \multicolumn{3}{c|}{ Total } \\
\hline & $\begin{array}{c}\text { Oper } \\
(\mathrm{kVA})\end{array}$ & $\begin{array}{c}\text { Conn } \\
(\mathrm{kVA})\end{array}$ & $\begin{array}{c}\text { Oper } \\
(\mathrm{kVA})\end{array}$ & $\begin{array}{c}\text { Conn } \\
(\mathrm{kVA})\end{array}$ & $\begin{array}{c}\text { Oper } \\
(\mathrm{kVA})\end{array}$ & $\begin{array}{c}\text { Conn } \\
(\mathrm{kVA})\end{array}$ \\
\hline Process Equipment & 55591 & 74770 & 23289 & 30716 & 78880 & 105486 \\
\hline HVAC Equipment & 4430 & 5538 & 3464 & 4330 & 7894 & 9868 \\
\hline Mechanical Equipment & 0 & 2000 & 800 & 1000 & 800 & 3000 \\
\hline Electrical Equipment & 1063 & 1329 & 2115 & 2644 & 3178 & 3973 \\
\hline Total & 61085 & 83637 & 29668 & 38690 & 90800 & 122300 \\
\hline
\end{tabular}

A breakout of the HVAC and Electrical equipment loads per facility is provided on the next page. 
WHC-SD-W378-ES-002

\section{Revision 0}

HVAC and Electrical Equipment Normal Loads

\begin{tabular}{|c|c|c|c|c|c|c|}
\hline Facility & $\begin{array}{c}\text { Case } \\
3 \mathrm{~B}+4 \mathrm{C}\end{array}$ & Sq FT & $\begin{array}{l}\text { HVAC } \\
\text { W/Ft }\end{array}$ & $\begin{array}{c}\text { HVAC } \\
\text { Equip } \\
\text { Load(kVA) }\end{array}$ & $\begin{array}{l}\text { Elect } \\
\text { W/Ft }\end{array}$ & $\begin{array}{c}\text { Elect } \\
\text { Equip } \\
\text { Load(kVA) }\end{array}$ \\
\hline Warehouse \#2 & 1 & 43,200 & 2 & 86.4 & 0.5 & 21.6 \\
\hline Warehouse \#1 & 1 & 43,200 & 2 & 86.4 & 0.5 & 21.6 \\
\hline Regulated Entrance Building & 1 & 60,000 & 5 & 300 & 2 & 120 \\
\hline Operation Support & 1 & 70,000 & 5 & 350 & 2.5 & 175 \\
\hline Mock-up Shop & 1 & 43,200 & 5 & 216 & 2.5 & 108 \\
\hline Fab Shop & 1 & 43,200 & 5 & 216 & 2.5 & 108 \\
\hline Emergency Generator & 1 & 12,500 & 1 & 12.5 & 1 & 12.5 \\
\hline Mech Utilities & 1 & 26,250 & 2 & 52.5 & 0.5 & 13.125 \\
\hline Switchgear & 1 & 7,500 & 2 & 15 & 0.5 & 3.75 \\
\hline Analytical Facility & 1 & 243,600 & 4.5 & 1096.2 & 3 & 730.8 \\
\hline Operations Cont & 1 & 22,500 & 5 & 112.5 & 3 & 67.5 \\
\hline Load/Unload & 1. & 160,000 & 0 & 0 & 0.5 & 80 \\
\hline Bulk Cold Chem & 1 & 18,750 & 5 & 93.75 & 1 & 18.75 \\
\hline Chem Handling & 1 & 25,200 & 0 & 0 & 1 & 25.2 \\
\hline Parking Lot & 1 & 600,000 & 0 & 0 & 0.5 & 300 \\
\hline Fire Water Pumphouse & 1 & 7,500 & 1 & 7.5 & 1 & 7.5 \\
\hline Low Level Grout Vaults & 1 & 324,000 & $\underline{0}$ & 0 & 0.5 & 162 \\
\hline Receiving and Storage & 1 & 15,500 & 0 & 0 & 0.5 & 7.75 \\
\hline WSSF 12 pack & 1 & 92,500 & 2 & 185 & 1 & 92.5 \\
\hline Fan Filter Bldg HLW & 1 & 80,000 & 3 & 240 & 1 & 80 \\
\hline Fan Filter Bldg $L L W$ & 1 & 80,000 & 3 & 240 & 1 & 80 \\
\hline Vit Regulated Entrance & 1 & 50,000 & 5 & 250 & 2 & 100 \\
\hline Vit Requlated Entrance & 1 & 57,000 & 5 & 285 & 2 & 114 \\
\hline Canister Staging & 1 & 97,000 & 5 & 485 & 2 & 194 \\
\hline Total Conn (Support Fac) & & & & $4,329.75$ & & $2,643.575$ \\
\hline Total Oper (Support Fac) & & & & $3,463.8$ & & $2,114.86$ \\
\hline Sep/Low-Level Waste Treat & 1 & 180,000 & 12.5 & 2,250 & 3 & 540 \\
\hline High-Level Waste Treat & 1 & 263,000 & 12.5 & $3,287.5$ & 3 & 789 \\
\hline Total Connected & & & & 5.537 .5 & & 1,329 \\
\hline Total Operating & & & & 4,430 & & $1,063.2$ \\
\hline
\end{tabular}


WHC-SD-W378-ES-002

Revision 0

This page intentionally left blank. 
WHC-SD-W378-ES-002

Revision 0

\section{APPENDIX D}

\section{COLD CHEMICAL CONSUMPTION TABLES}




\section{WHC-SD-W378-ES-002}

Revision 0

This page intentionally left blank.

D-2 
WHC-SD-W378-ES-002

Revision 0

Summary of Annual Utility and Chemical Consuption for

Collocated Configuration 4 [Case 3B (Detached High-Level Waste),

Case 4C (Pretreatment/Low-Level Waste)] Support Facilities

\begin{tabular}{|c|c|c|c|c|}
\hline Utility/chemical description & $\begin{array}{l}\text { HLW vit building } \\
\text { (Case 3B) }\end{array}$ & $\begin{array}{c}\text { Pretreatment/LLW vit } \\
\text { building (Case 4C) }\end{array}$ & Support buildings & Total \\
\hline Sanitary water ${ }^{2}$ & $\begin{array}{c}49,200 \mathrm{~m}^{3} \\
(13,000,000 \mathrm{gal})\end{array}$ & $\begin{array}{c}128,070 \mathrm{~m}^{3} \\
(33,800,000 \mathrm{gal})\end{array}$ & $\begin{array}{c}81,900 \mathrm{~m}^{3} \\
(21,658,000 \text { gal })\end{array}$ & $\begin{array}{c}259,200 \mathrm{~m}^{3} \\
(68,490,000 \text { gal })\end{array}$ \\
\hline Raw water ${ }^{3}$ & & & $\begin{array}{c}1,650,000 \mathrm{~m}^{3} \\
(436,000,000 \mathrm{gal})\end{array}$ & $\begin{array}{c}1,650,000 \mathrm{~m}^{3} \\
(436,000,000 \mathrm{gal})\end{array}$ \\
\hline Sanitary sewer & & & $\begin{array}{c}21,500 \mathrm{~m}^{3} \\
(5,690,000 \mathrm{gal})\end{array}$ & $\begin{array}{c}21,500 \mathrm{~m}^{3} \\
(5,690,000 \mathrm{gal})\end{array}$ \\
\hline \multicolumn{5}{|l|}{ Glass formers } \\
\hline $\mathrm{SiO}_{2}$ & $\begin{array}{c}4,268 \mathrm{MT} \\
(9,410,000 \mathrm{lb})\end{array}$ & $\begin{array}{c}40,550 \mathrm{MT} \\
(89,400,000 \mathrm{lb})\end{array}$ & & $\begin{array}{c}44,818 \mathrm{MT} \\
(98,810,000 \mathrm{lb})\end{array}$ \\
\hline $\mathrm{B}_{2} \mathrm{O}_{3}$ & $\begin{array}{c}862 \text { MT }(1,900,000 \\
\text { lb) }\end{array}$ & $\begin{array}{c}8,165 \mathrm{MT} \\
(18,000,000 \mathrm{lb})\end{array}$ & & $\begin{array}{c}9,027 \mathrm{MT} \\
(19,900,000 \mathrm{lb})\end{array}$ \\
\hline $\mathrm{Li}_{2} \mathrm{O}$ & 305 MT $(672,000 \mathrm{lb})$ & $\begin{array}{c}2,903 \mathrm{MT} \\
(6,400,000 \mathrm{lb})\end{array}$ & & $\begin{array}{c}3,208 \mathrm{MT} \\
(7,072,000 \mathrm{lb})\end{array}$ \\
\hline $\mathrm{CaO}$ & $61 \mathrm{MT}(135,000 \mathrm{lb})$ & $\begin{array}{c}590 \mathrm{MT} \\
(1,300,000 \mathrm{lb})\end{array}$ & & $\begin{array}{c}651 \mathrm{MT}(1,435,000 \\
\mathrm{lb})\end{array}$ \\
\hline $\mathrm{MgO}$ & $61 \mathrm{MT}(135,000 \mathrm{lb})$ & $\begin{array}{c}590 \mathrm{MT} \\
(1,300,000 \mathrm{lb}) \\
\end{array}$ & & $\begin{array}{c}651 \mathrm{MT} \\
(1,435,000 \mathrm{lb}) \\
\end{array}$ \\
\hline Bulk frit & & $10 \mathrm{MT}(22,000 \mathrm{lb})$ & & $10 \mathrm{lb}(22,000 \mathrm{lb})$ \\
\hline Ion exchange resin & & $16 \mathrm{~m}^{3}\left(565 \mathrm{ft}^{3}\right)$ & & $16 \mathrm{~m}^{3}\left(565 \mathrm{ft}^{3}\right)$ \\
\hline 50 percent nitric acid & $45.4 \mathrm{~m}^{3}(12,000 \mathrm{gal})$ & $\begin{array}{c}700 \mathrm{~m}^{3} \\
(185,000 \text { gal }) \\
\end{array}$ & & $\begin{array}{c}745.4 \mathrm{~m}^{3} \\
(197,000 \mathrm{gal})\end{array}$ \\
\hline 50 percent caustic & $19 \mathrm{~m}^{3}(5,000 \mathrm{gal})$ & $\begin{array}{c}1,022 \mathrm{~m}^{3} \\
(270,000 \mathrm{gal})\end{array}$ & & $\begin{array}{c}1,041 \mathrm{~m}^{3} \\
(275,000 \mathrm{gal})\end{array}$ \\
\hline Dry $\mathrm{KMnO}_{4}$ & $1.2 \mathrm{MT}(2,600 \mathrm{lb})$ & $2.4 \mathrm{MT}(5,200 \mathrm{lb})$ & & $3.6 \mathrm{MT}(7,800 \mathrm{lb})$ \\
\hline Dry sodium nitrite & Not Defined & $\begin{array}{c}1,043 \mathrm{MT} \\
(2,307,000 \mathrm{lb})^{4}\end{array}$ & & $\begin{array}{c}1,043 \mathrm{MT} \\
(2,307,000 \mathrm{lb})\end{array}$ \\
\hline Dry offgas treatment chemical & Not Defined & Not Defined & Not Defined & Not Defined \\
\hline Dry oxalic acid & $2.3 \mathrm{MT}(5,100 \mathrm{lb})$ & 4.6 MT $(10,200 \mathrm{lb})$ & & $6.9 \mathrm{MT}(15,300 \mathrm{lb})$ \\
\hline Dry TSP & 136 MT $(300,000 \mathrm{lb})$ & $\begin{array}{c}273 \mathrm{MT} \\
(601,000 \mathrm{lb}) \\
\end{array}$ & & $\begin{array}{c}409 \mathrm{MT} \\
(901,000 \mathrm{lb})\end{array}$ \\
\hline Antifoam solution & Not Defined & Not Defined & Not Defined & Not Defined \\
\hline Anhydrous ammonia & $76 \mathrm{~m}^{3}(20,000 \mathrm{gal})$ & $\begin{array}{c}2,771 \mathrm{~m}^{3} \\
(732,000 \mathrm{gal})\end{array}$ & & $\begin{array}{c}2,847 \mathrm{~m}^{3} \\
(752,000 \mathrm{gal})\end{array}$ \\
\hline
\end{tabular}


WHC-SD-W378-ES-002

\section{Revision 0}

Summary of Annual Utility and Chemical Consuption for

Collocated Configuration 4 [Case 3B (Detached High-Level Waste),

Case 4C (Pretreatment/Low-Level Waste)] Support Facilities

\begin{tabular}{|c|c|c|c|c|}
\hline Utility/chemical description & $\begin{array}{l}\text { HLW vit building } \\
\text { (Case 3B) }\end{array}$ & $\begin{array}{c}\text { Pretreatment/LLW vit } \\
\text { building (Case } 4 C \text { ) }\end{array}$ & Support buildings & Total \\
\hline Sanitary water ${ }^{2}$ & $\begin{array}{c}49,200 \mathrm{~m}^{3} \\
(13,000,000 \mathrm{gal})\end{array}$ & $\begin{array}{c}128,070 \mathrm{~m}^{3} \\
(33,800,000 \mathrm{gal})\end{array}$ & $\begin{array}{c}81,900 \mathrm{~m}^{3} \\
(21,658,000 \mathrm{gal})\end{array}$ & $\begin{array}{c}259,200 \mathrm{~m}^{3} \\
(68,490,000 \mathrm{gal})\end{array}$ \\
\hline Raw water ${ }^{3}$ & & & $\begin{array}{c}1,650,000 \mathrm{~m}^{3} \\
(436,000,000 \mathrm{gal})\end{array}$ & $\begin{array}{c}1,650,000 \mathrm{~m}^{3} \\
(436,000,000 \mathrm{gal})\end{array}$ \\
\hline Kerosene $^{5}$ & $\begin{array}{c}1,670 \mathrm{~m}^{3} \\
(440,000 \mathrm{gal})\end{array}$ & $\begin{array}{c}13,630 \mathrm{~m}^{3} \\
(3,600,000 \mathrm{gal})\end{array}$ & & $\begin{array}{c}15,300 \mathrm{~m}^{3} \\
(4,070,000 \mathrm{gal})\end{array}$ \\
\hline Oxygen ${ }^{5}$ & $\begin{array}{c}4,400 \mathrm{MT} \\
(9,700,000 \mathrm{lb})\end{array}$ & $\begin{array}{c}36,450 \mathrm{MT} \\
(80,400,000 \mathrm{lb})\end{array}$ & & $\begin{array}{c}40,850 \mathrm{MT} \\
(90,100,000 \mathrm{lb})\end{array}$ \\
\hline \multicolumn{5}{|l|}{ Bulk sulfur cement } \\
\hline Sulfur & & $\begin{array}{c}24,040 \mathrm{MT} \\
(53,000,000 \mathrm{lb})\end{array}$ & & $\begin{array}{c}24,040 \mathrm{MT} \\
(53,000,000 \mathrm{lb})\end{array}$ \\
\hline DCPD & & $\begin{array}{c}640 \mathrm{MT} \\
(1,410,000 \mathrm{lb})\end{array}$ & & $\begin{array}{c}640 \mathrm{MT} \\
(1,410,000 \mathrm{lb})\end{array}$ \\
\hline CPD Oligomer & & $\begin{array}{c}640 \mathrm{MT} \\
(1,410,000 \mathrm{lb})\end{array}$ & & $\begin{array}{c}640 \mathrm{MT} \\
(1,410,000 \mathrm{lb})\end{array}$ \\
\hline
\end{tabular}

$\mathrm{m}^{3} \quad$ Cubic meters

MT Metric tons

N/A Not applicable

1 The anmual consumptions are based on 365 operating days per year.

2 The major sanitary water consumers are process and utility, HVAC, and site personnel users.

3 The raw water consumption listed is cooling tower makeup.

$4 \quad$ The sodium nitrite usage is based on whe material balance information.

$5 \quad$ Kerosene and oxygen are used only by the base case combustion melter, and not by the altermate melters. 
WHC-SD-W378-ES-002

Revision 0

\section{APPENDIX E1}

\section{SUPPORT FACILITY EQUIPMENT LIST}


WHC-SD-W378-ES-002

Revision 0

This page intentionally left blank.

E1-2 
ABBREVIATIONS

EQUIPMENT IDENTIFICATION CODE
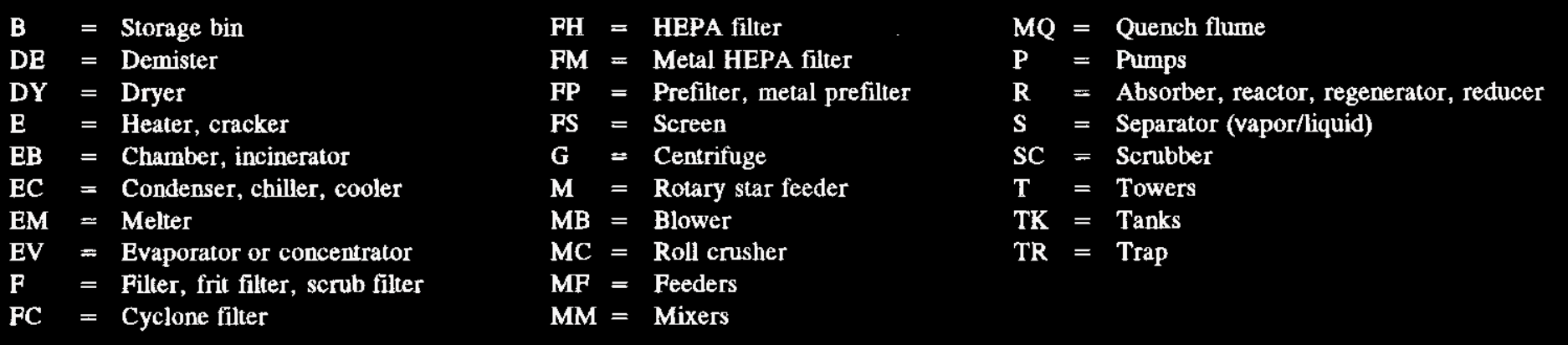

\begin{tabular}{lcccc} 
EQUIPMENT & EQUIPMENT & CAPACITY/ & PHYSICAL & MATERIAL \\
DESCRIPTION & ID & FLOWRATE & SIZE & COMMENTS \\
\hline \hline
\end{tabular}

w ONE LOT MACHINE SHOP

EQUIPMENT SMALL

MONORAILS and JBB CRANES

REPAIR SHOP EQUIPMENT 1 LOT

(WELDER, - BAND SAW GRINDER,

ETC. NO LARGE MACHINE TOOLS)

$\begin{array}{lc}\text { BULK SULPUR STORAGE TANK } & \text { TK-1007 } \\ \text { BULK DCPD STORAGE TANK } & \text { TK-1008 } \\ & \\ \text { BUILDING: } \\ \text { BCCB = BULK COLD CHEMICAL BUILDING } \\ \text { MUB = MECHANICAL UTILITIES BUILDING } \\ \text { WPH = WATER PUMP HOUSE } \\ \text { DB4:NEWEQLST:CASE4C:CONF4:CONP4 }\end{array}$

$1,000 \mathrm{~m}^{3} \quad 10 \mathrm{~m}$ ID X $13 \mathrm{~m} \mathrm{H}$

CARBON STEEL

ADJACENT TO

$\mathrm{BCCB}$

DB4:NEWEQLST:CASE4C:CONF4:CONP4 


\section{WHC-SD-W378-ES-002 \\ Revision 0}

Equipment list

Configuration 4 Revision 13, Issued on 02/16/95

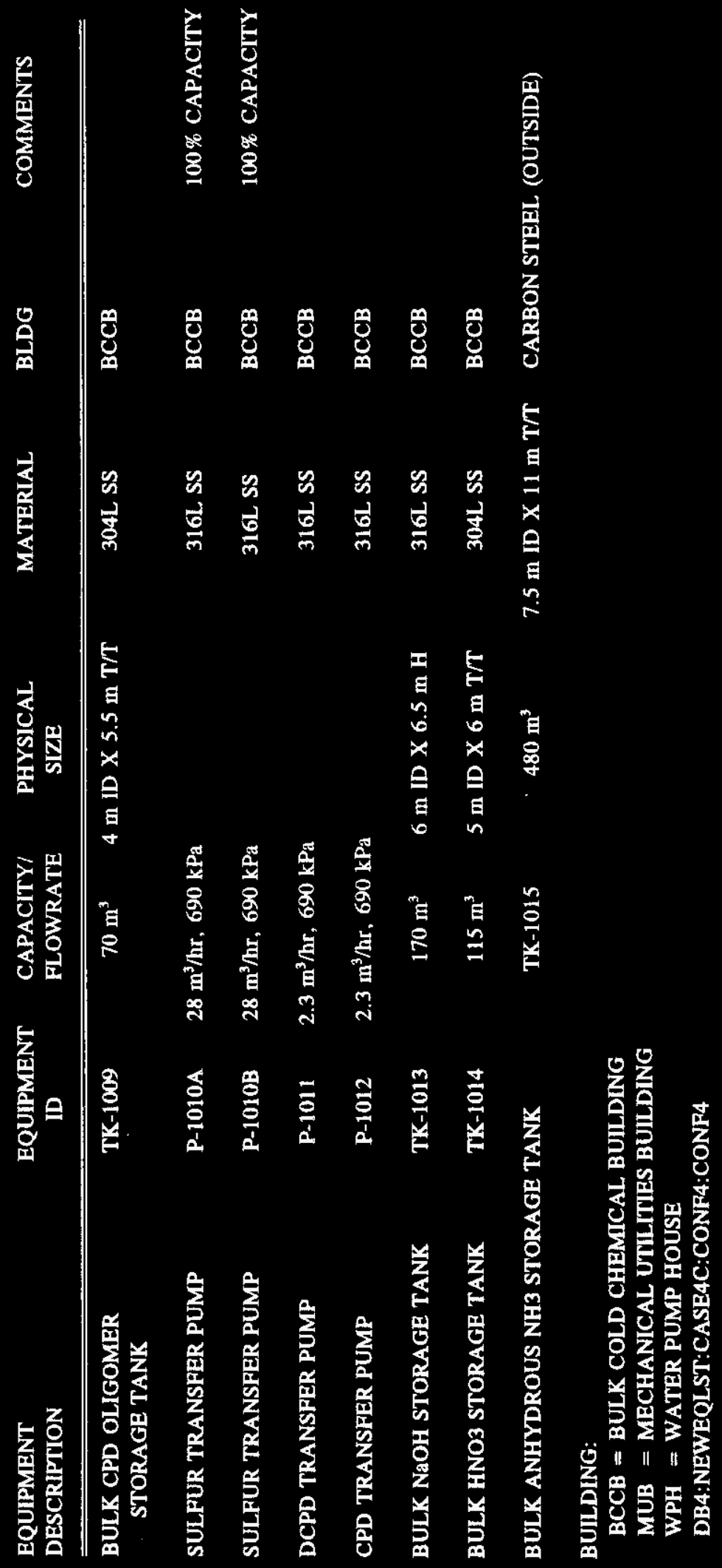




\begin{tabular}{|c|c|c|c|c|c|c|}
\hline $\begin{array}{l}\text { EQUIPMENT } \\
\text { DESCRIPTION }\end{array}$ & $\begin{array}{l}\text { EQUIPMENT } \\
\text { ID }\end{array}$ & $\begin{array}{l}\text { CAPACITY/ } \\
\text { FLOWRATE }\end{array}$ & $\begin{array}{l}\text { PHYSICAL } \\
\text { SIZE }\end{array}$ & MATERIAL & BLDG & COMMENTS \\
\hline NaOH TRANSFER PUMP & P-1016 & $4.8 \mathrm{~m}^{3} / \mathrm{hr}, 214 \mathrm{kPa}$ & & $316 \mathrm{LSS}$ & ВССВ & \\
\hline NaOH TRANSFER PUMP & P-1017 & $4.8 \mathrm{~m}^{3} / \mathrm{hr}, 110 \mathrm{kPa}$ & & 304L SS & BCCB & \\
\hline BULK WATER STORAGE TANK & TK-1019 & $340 \mathrm{~m}^{3}$ & $9 \mathrm{~m} \mathrm{ID} \mathrm{X} 6 \mathrm{~m} \mathrm{H}$ & CARBON STEEL & (OUTSIDE) & \\
\hline BULK KEROSENE STORAGE TANK & TK-1022 & $2,025 \mathrm{~m}^{3}$ & $15.5 \mathrm{~m} \mathrm{X} 11 \mathrm{~m} \mathrm{H}$ & CARBON STEEL & (OUTSIDE) & \\
\hline KEROSENE TRANSFER PUMP & P-1022A & $23 \mathrm{~m}^{3} / \mathrm{hr}, 690 \mathrm{kPa}$ & & $316 \mathrm{~L} \mathrm{SS}$ & (OUTSIDE) & $100 \%$ CAPACITY \\
\hline KEROSENE TRANSFER PUMP & P-1022B & $23 \mathrm{~m}^{3} / \mathrm{hr}, 690 \mathrm{kPa}$ & & $316 \mathrm{~L} \mathrm{SS}$ & (OUTSIDE) & $100 \%$ CAPACITY \\
\hline BULK WATER FEED PUMP & P-1023A & $340 \mathrm{~m}^{3} / \mathrm{hr}, 690 \mathrm{kPa}$ & & CARBON STEEL & WPH & $100 \%$ CAPACITY \\
\hline BULK WATER FEED PUMP & P-1023B & $340 \mathrm{~m}^{3} \mathrm{hr}, 690 \mathrm{kPa}$ & & CARBON STEEL & WPH & $100 \%$ CAPACITY \\
\hline $\begin{array}{l}\text { BUILDING: } \\
\text { BCCB }=\text { BULK COLD CHEMICAL } \\
\text { MUB }=\text { MECHANICAL UTILITIE } \\
\text { WPH }=\text { WATER PUMP HOUSE } \\
\text { DB4:NEWEQLST:CASE4C:CONF4: }\end{array}$ & $\begin{array}{l}\text { BUILDING } \\
\text { BUILDING } \\
\text { CONF4 }\end{array}$ & & & & & \\
\hline
\end{tabular}




\section{WHC-SD-W378-ES-002}

Revision 0

Equipment list

Configuration 4 Revision 13, Issued on 02/16/95

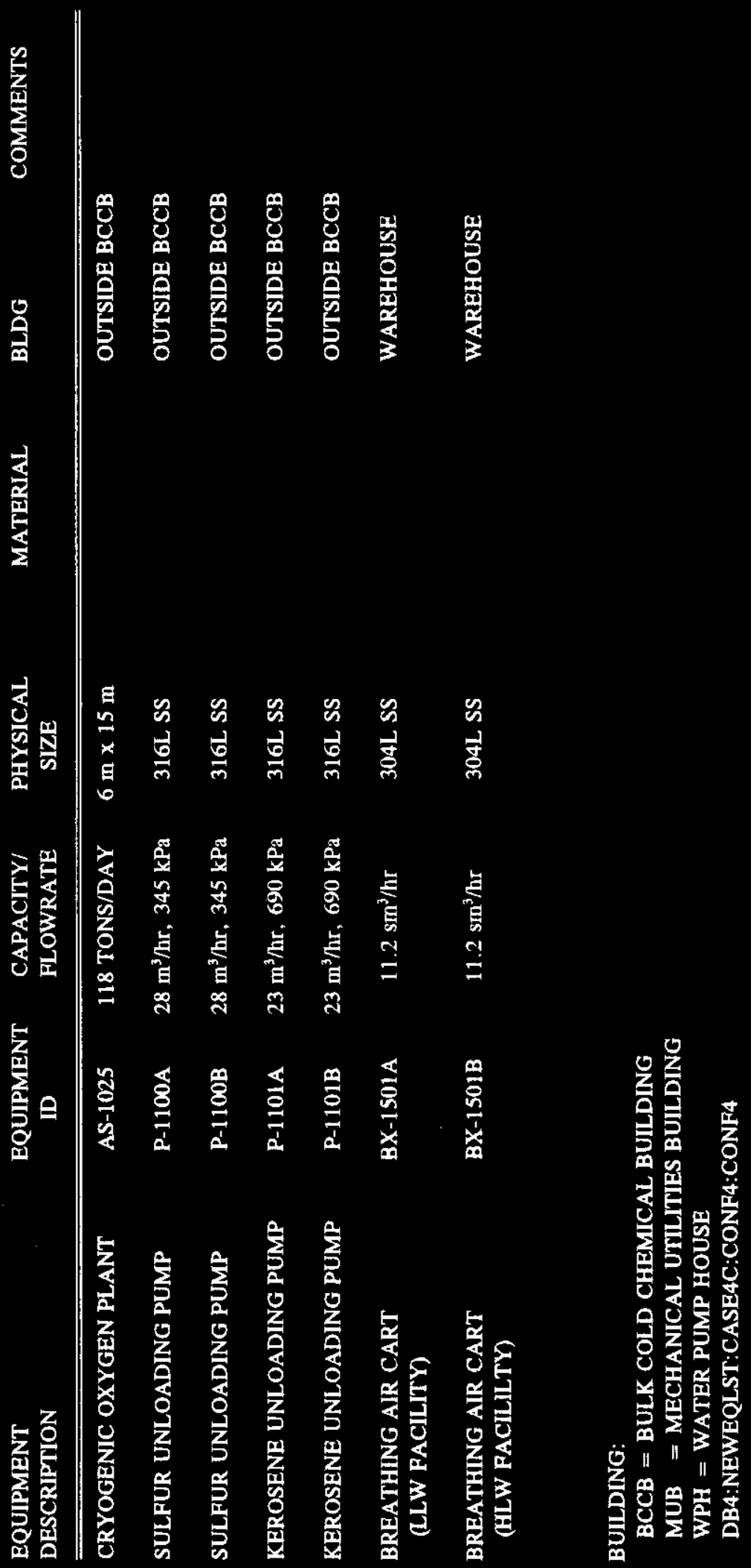




\section{WHC-SD-W378-ES-002 \\ Revision 0}

Equipment list

Configuration 4 Revision 13, Issued on 02/16/95

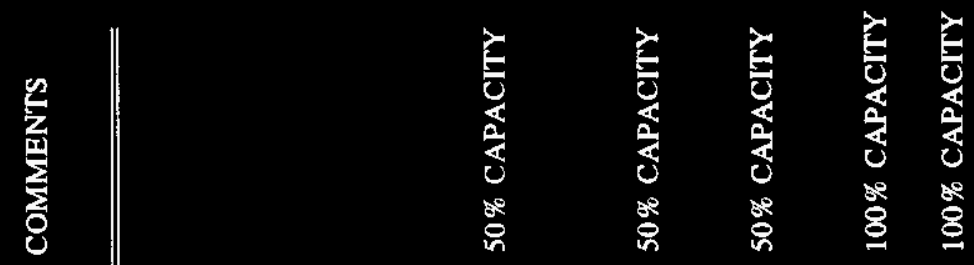

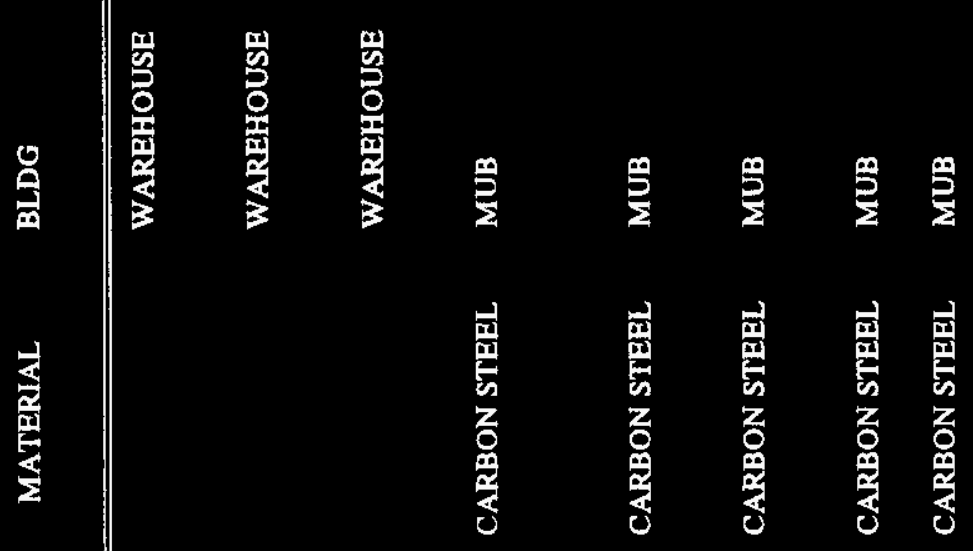

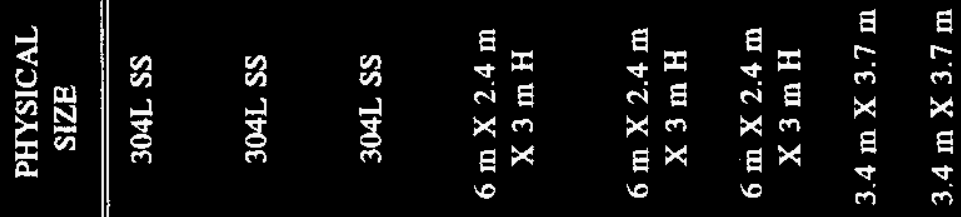

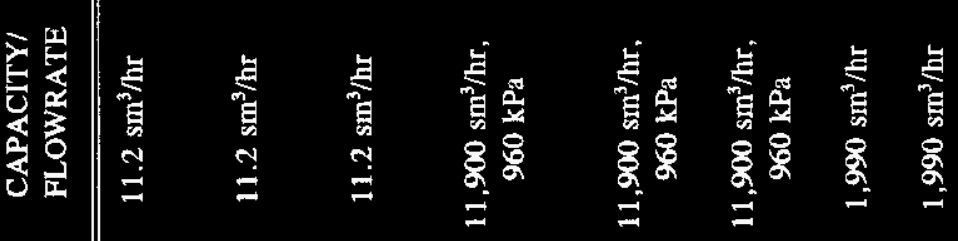

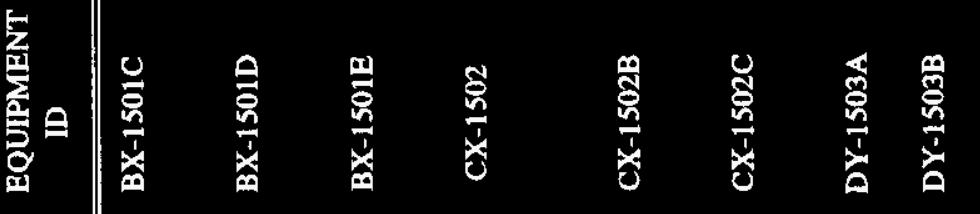

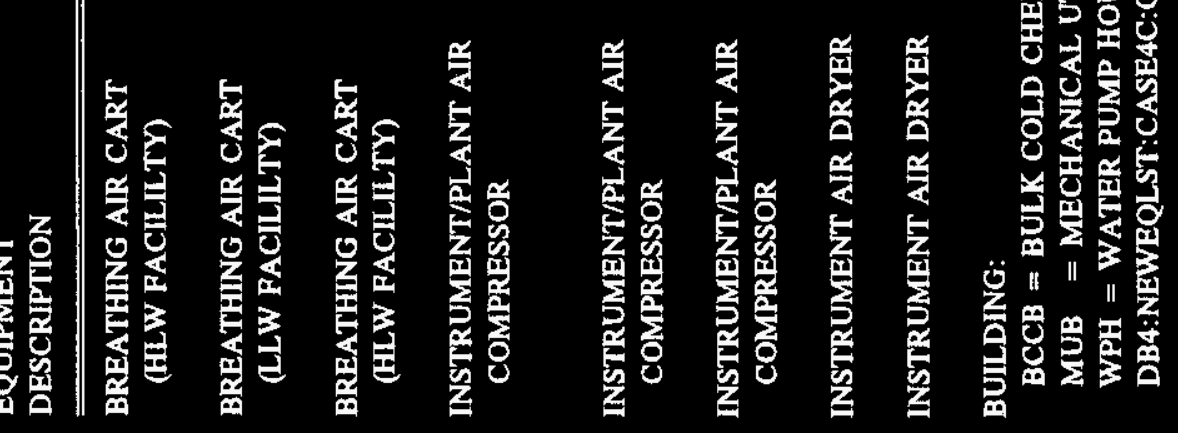




\section{WHC-SD-W378-ES-002 \\ Revision 0}

Equipment list

Configuration 4 Revision 13, Issued on 02/16/95

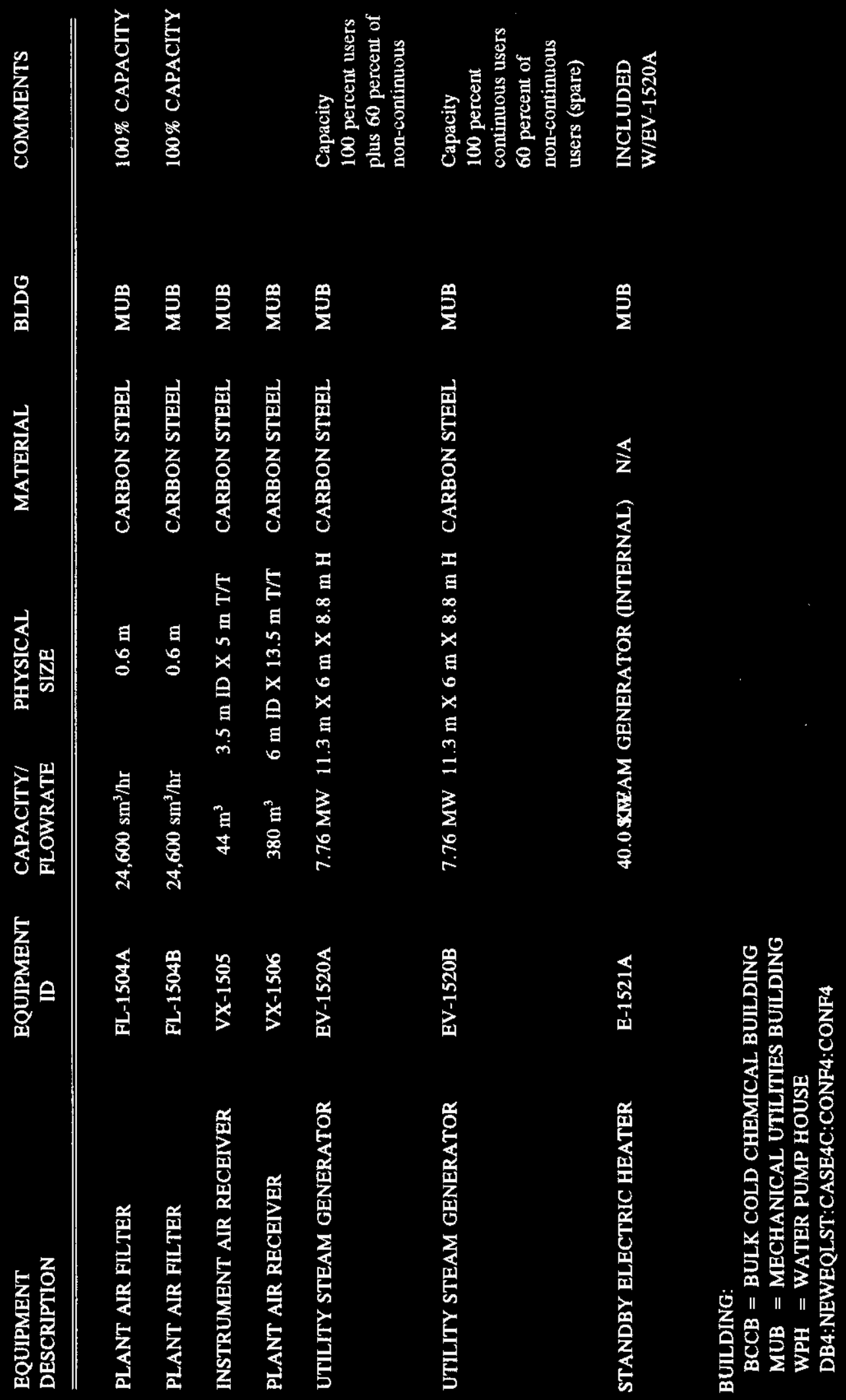




\begin{tabular}{|c|c|c|c|c|c|c|c|c|}
\hline $\begin{array}{l}\text { EQUIPMENT } \\
\text { DESCRIPTION }\end{array}$ & $\begin{array}{l}\text { EQUIPMENT } \\
\text { ID }\end{array}$ & $\begin{array}{l}\text { CAPACITY/ } \\
\text { FLOWRATE }\end{array}$ & $\begin{array}{l}\text { PHYSICAL } \\
\text { SIZE }\end{array}$ & MATERIAL & BLDG & COMMENTS & \multirow{3}{*}{ 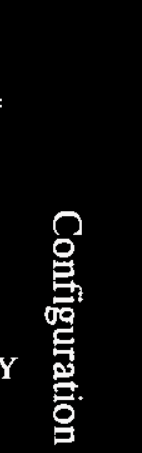 } & \\
\hline STANDBY ELECTRIC HEATER & E-1521B & $40.0 \mathrm{KW}$ & STEAM & N/A & MUB & $\begin{array}{l}\text { INCLUDED } \\
\text { W/EV-1520B } \\
\text { GENERATOR } \\
\text { (INTERNAL) }\end{array}$ & & \multirow{7}{*}{ 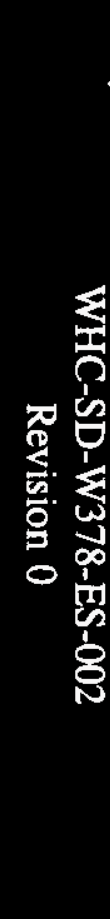 } \\
\hline $\begin{array}{l}\text { UTILITY STEAM GENERATOR } \\
\text { CIRCULATING PUMP }\end{array}$ & P-1522A & $680 \mathrm{~m}^{3} / \mathrm{hr}, 69 \mathrm{kP}$ & $\begin{array}{l}\text { LUDED W/STM } \\
\text { N FOOTPRINT) }\end{array}$ & 304L SS & MUB & $\begin{array}{l}\text { 100\% CAPACITY } \\
\text { EV-1520A }\end{array}$ & & \\
\hline $\begin{array}{l}\text { UTILITY STEAM GENERATOR } \\
\text { CIRCULATING PUMP }\end{array}$ & $P-1522 B$ & $680 \mathrm{~m}^{3} / \mathrm{hr}, 69 \mathrm{kP}$ & $\begin{array}{l}\text { CLUDED W/STM } \\
\text { SN FOOTPRINT) }\end{array}$ & 304L sS & MUB & $\begin{array}{l}\text { 100\% CAPACITY } \\
\text { EV-1520A } \\
\text { (SPARE) }\end{array}$ & $\begin{array}{l}A \\
\text { 要塄 }\end{array}$ & \\
\hline $\begin{array}{l}\text { UTILITY STEAM GENERATOR } \\
\text { CIRCULATING PUMP }\end{array}$ & P-1522C & $680 \mathrm{~m}^{3} / \mathrm{hr}, 69 \mathrm{kP}$ & $\begin{array}{l}\text { LUDED W/STM } \\
\text { IN FOOTPRINT) }\end{array}$ & $3041 \mathrm{SS}$ & MUB & $\begin{array}{l}100 \% \text { capacity } \\
\text { EV- } 1520 \mathrm{~B}\end{array}$ & 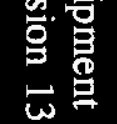 & \\
\hline $\begin{array}{l}\text { UTILITY STEAM GENERATOR } \\
\text { CIRCULATING PUMP }\end{array}$ & P-1522D & $680 \mathrm{~m}^{3} / \mathrm{hr}, 69 \mathrm{kP}$ & $\begin{array}{l}\text { CLUDED W/STM } \\
\text { N FOOTPRINT) }\end{array}$ & 304L SS & MUB & $\begin{array}{l}\text { 100\% CAPACITY } \\
\text { EV-1520B } \\
\text { (SPARE) }\end{array}$ & 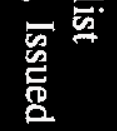 & \\
\hline $\begin{array}{l}\text { STEAM GEN FEED WATER } \\
\text { CHEMICAL INJECTION PUMP }\end{array}$ & P-1523A & $0.23 \mathrm{~m}^{3} / \mathrm{hr}, 1,370 \mathrm{k}$ & $\begin{array}{l}\text { CLUDED W/STM } \\
\text { IN FOOTPRINT) }\end{array}$ & 304L SS & MUB & EV-1520A & $\begin{array}{l}\mathrm{B} \\
\mathrm{N}\end{array}$ & \\
\hline $\begin{array}{l}\text { STEAM GEN FEED WATER } \\
\text { CHEMICAL INJECTION PUMP }\end{array}$ & P-1523B & $0.23 \mathrm{~m}^{3} / \mathrm{hr}, 1,370 \mathrm{k}$ & $\begin{array}{l}\text { CLUDED W/STM } \\
\text { EN FOOTPRINT }\end{array}$ & 304L SS & MUB & EV-1520B & $\frac{\vec{a}}{8}$ & \\
\hline
\end{tabular}

\footnotetext{
BUILDING:

BCCB $=$ BULK COLD CHEMICAL BUILDING

MUB $=$ MECHANICAL UTILITIES BUILDING

WPH = WATER PUMP HOUSE

DB4:NEWEQLST:CASE4C:CONF4:CONF4
} 
WHC-SD-W378-ES-002

Revision 0

Equipment list

Configuration 4 Revision 13, Issued on 02/16/95

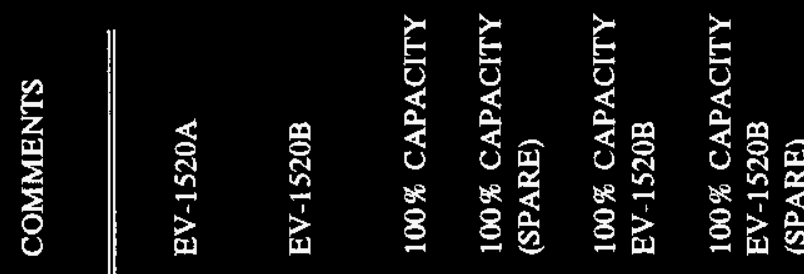

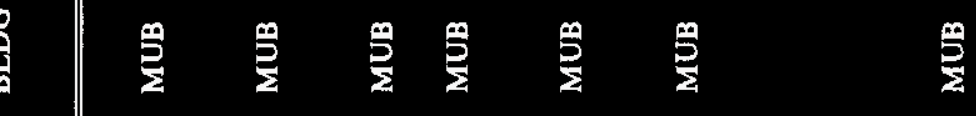

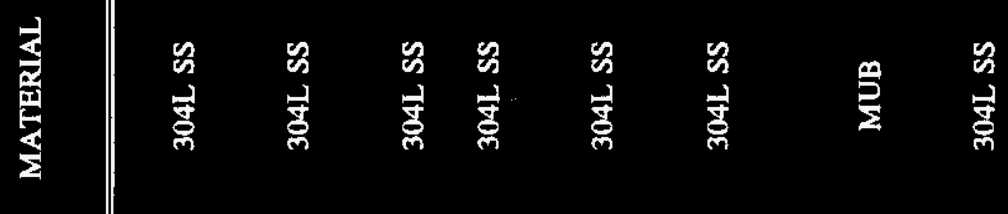

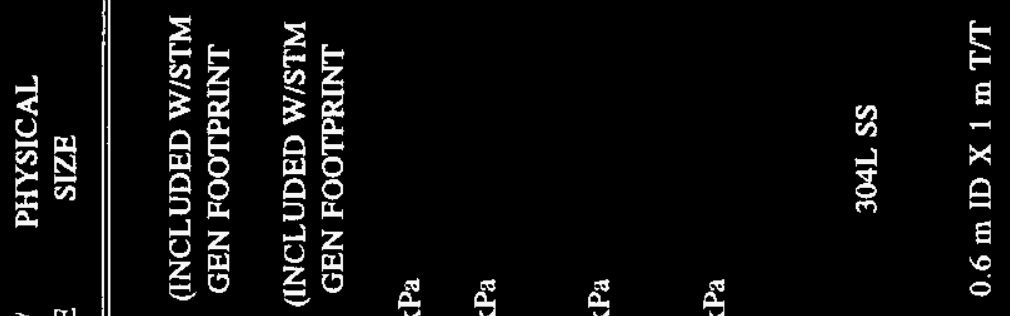

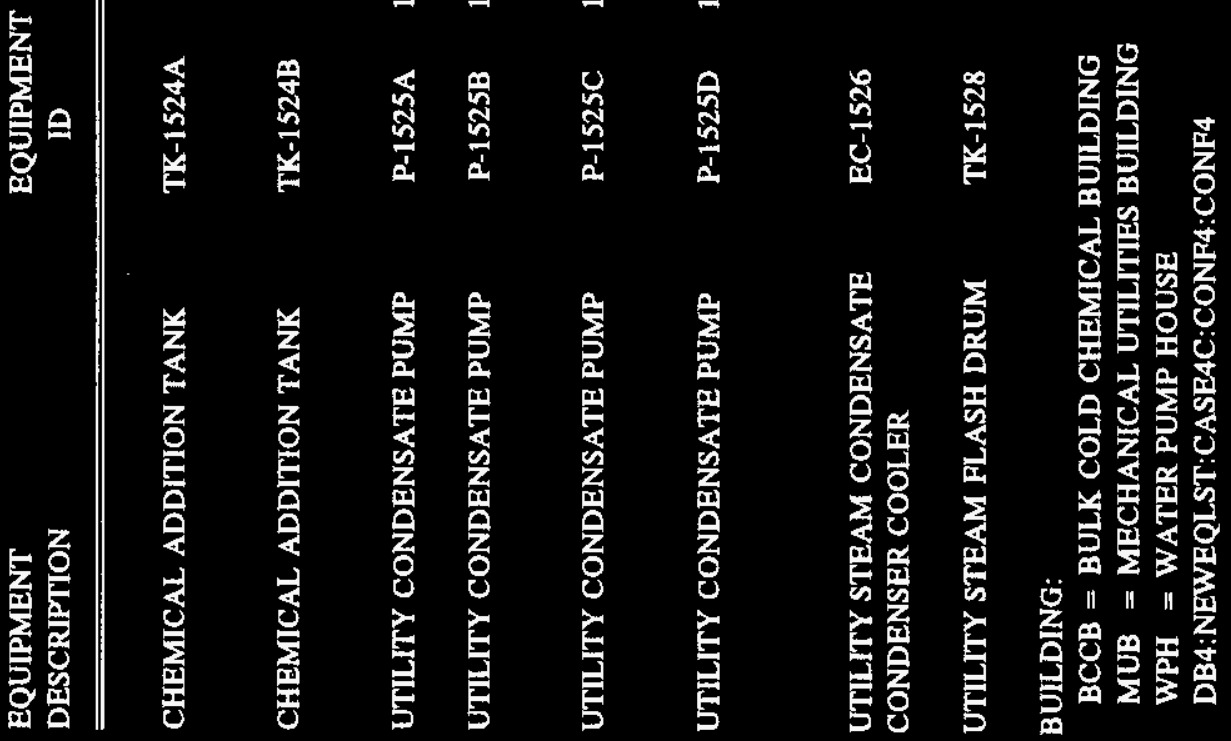

E1-10 


\section{WHC-SD-W378-ES-002 \\ Revision 0}

Equipment list

Configuration. 4 Revision 13, Issued on 02/16/95

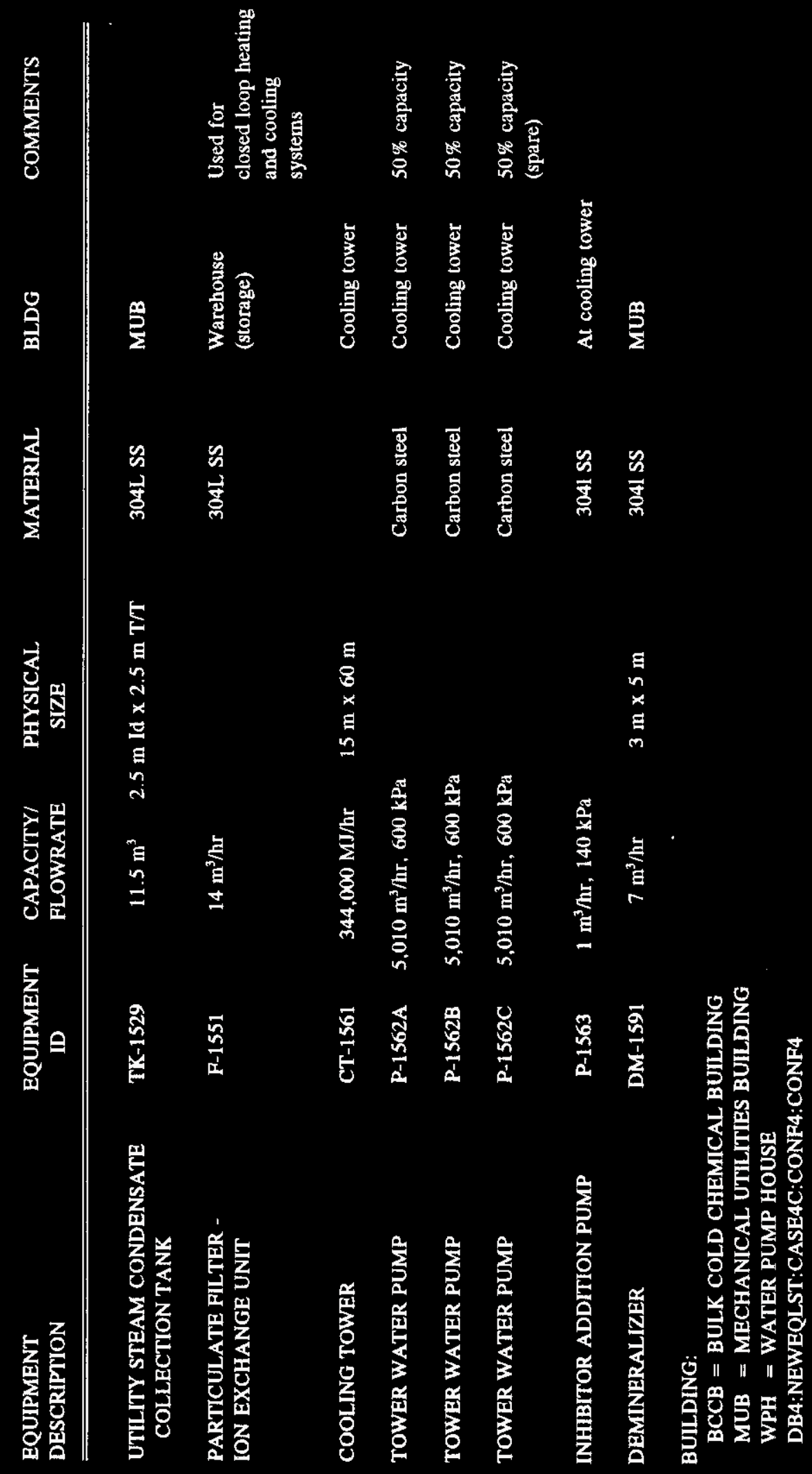


WHC-SD-W378-ES-002

\section{Revision 0}

\section{Equipment list}

Configuration 4 Revision 13, Issued on 02/16/95

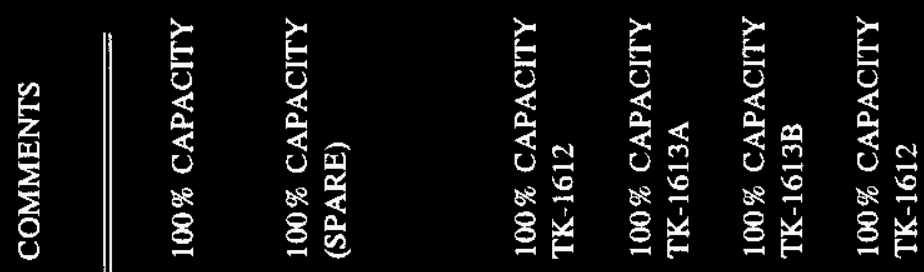

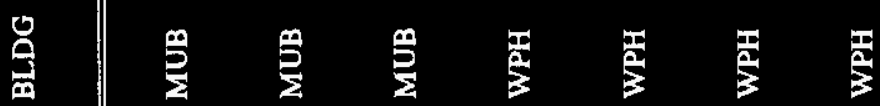

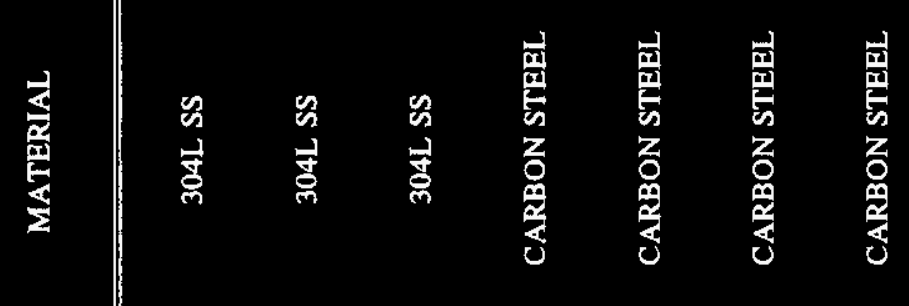

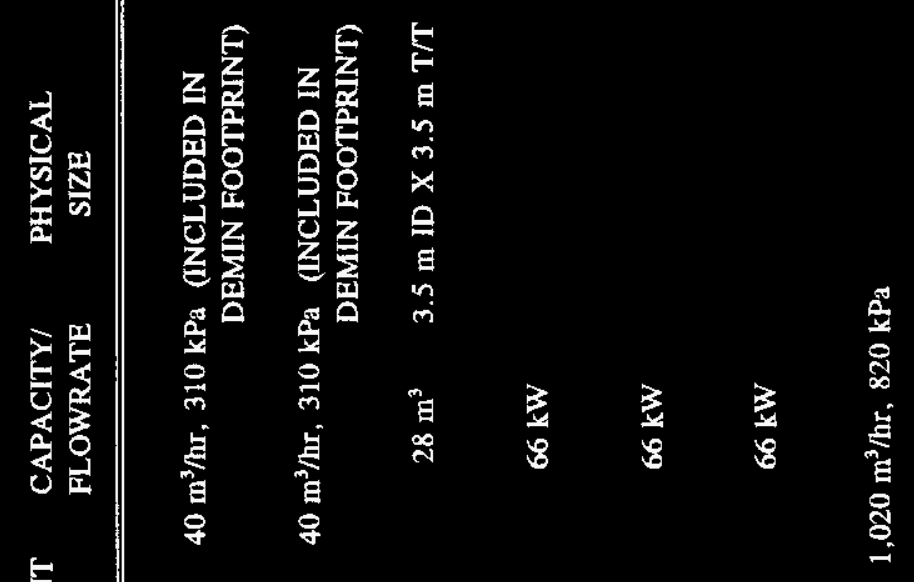

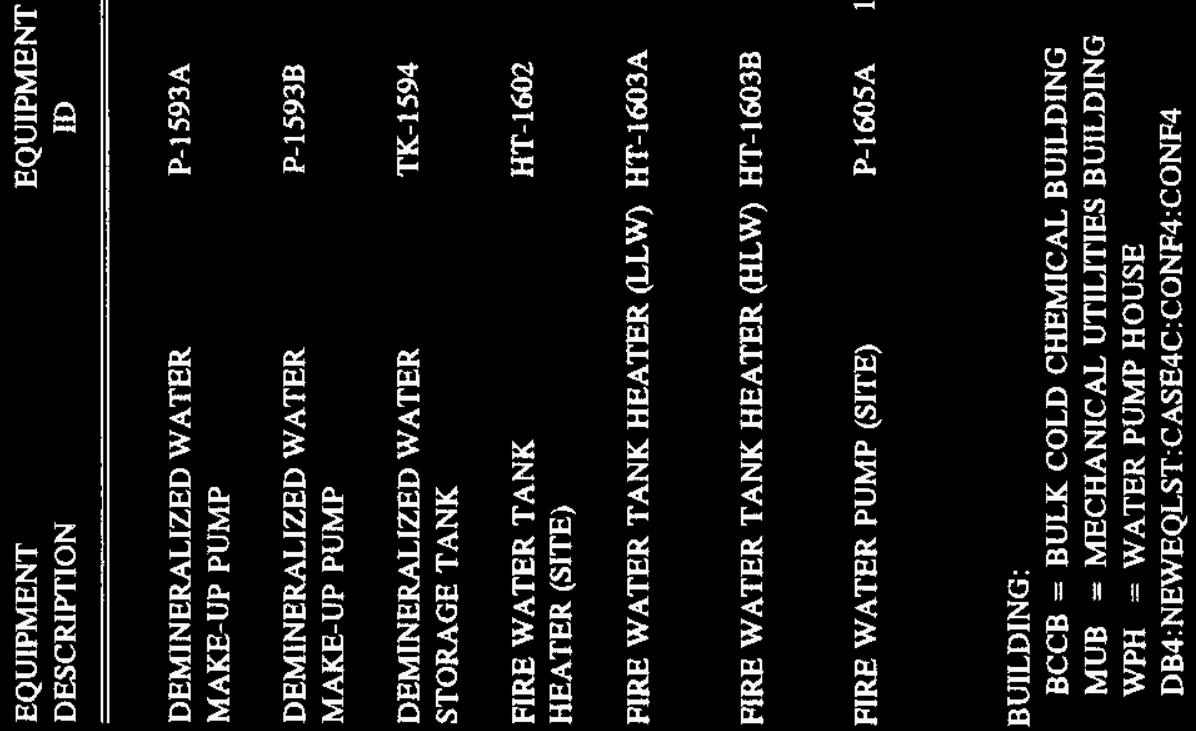

E1-12 


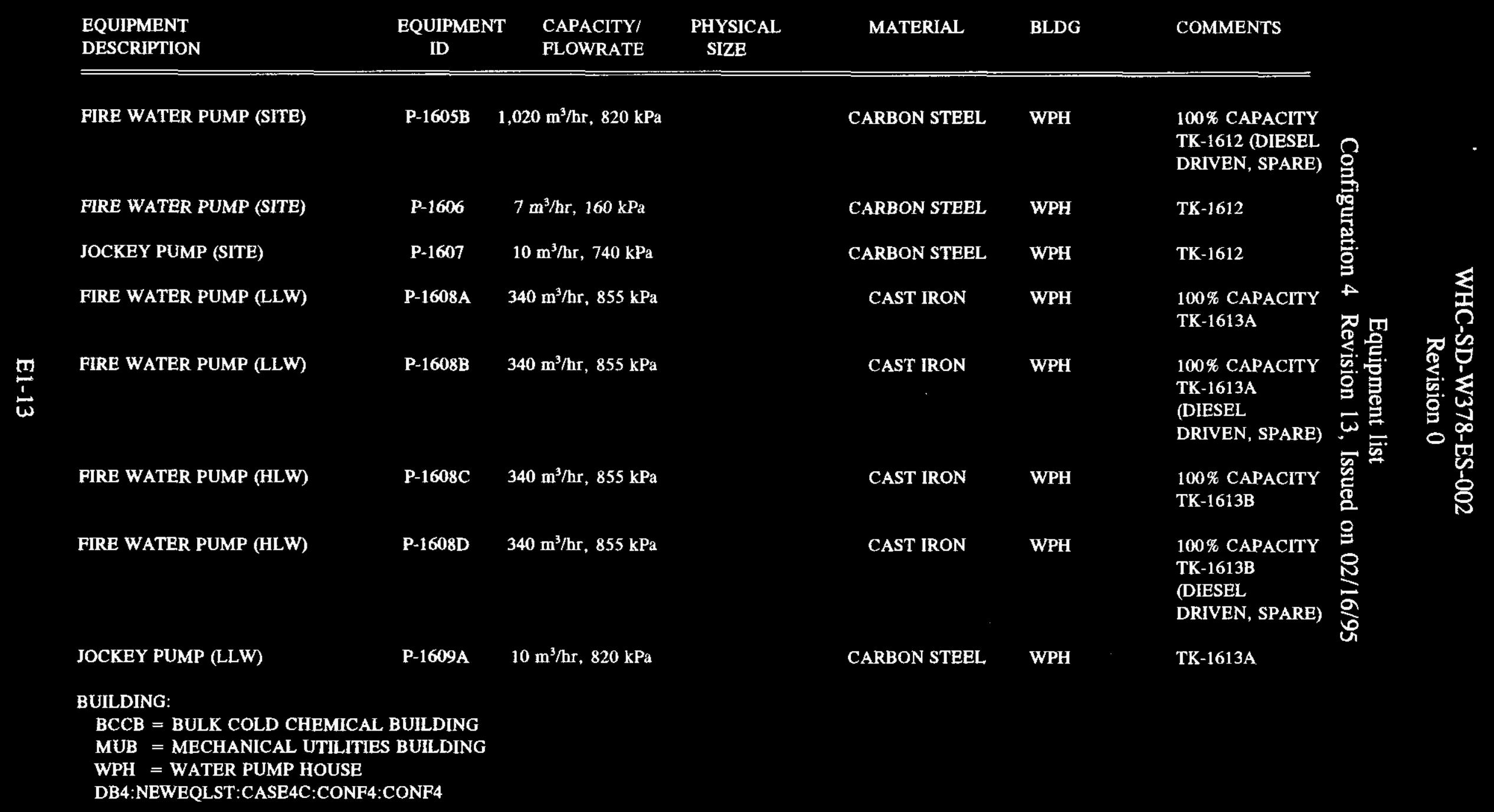


WHC-SD-W378-ES-002

Revision 0

Equipment list

Configuration 4 Revision 13, Issued on 02/16/95

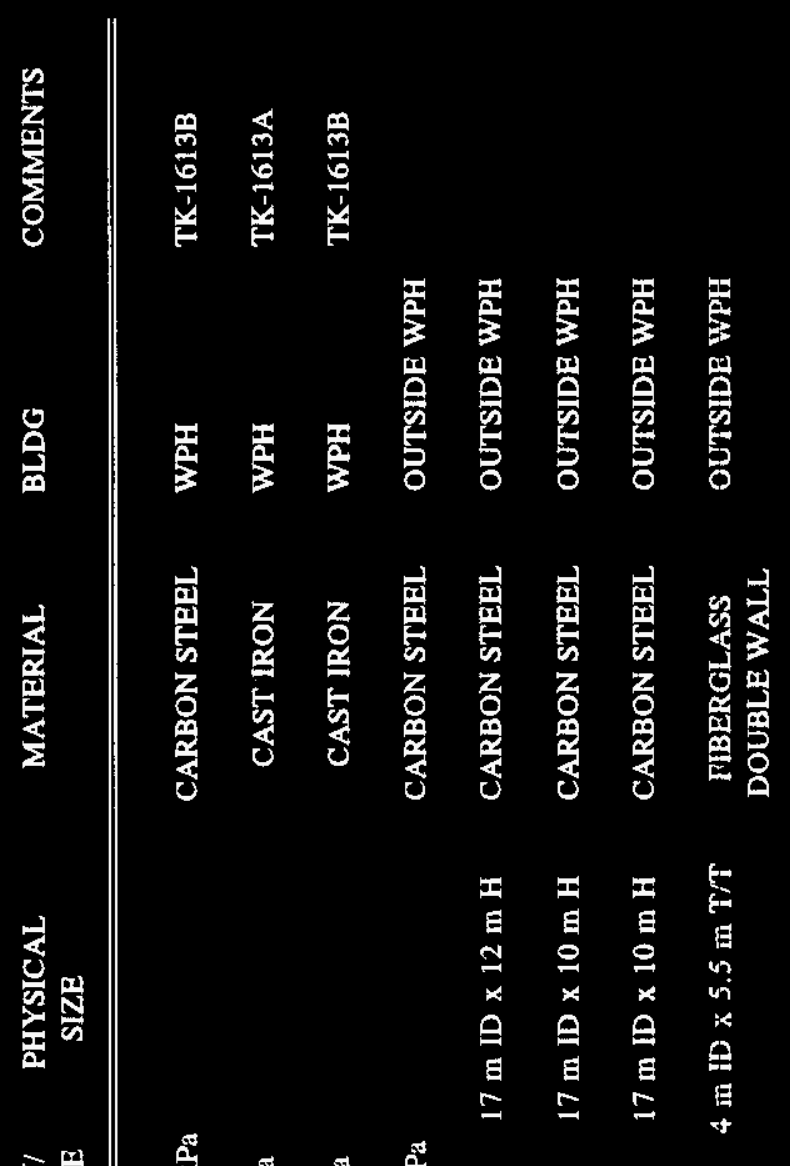

窟

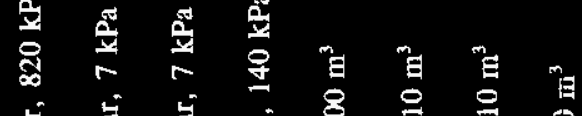

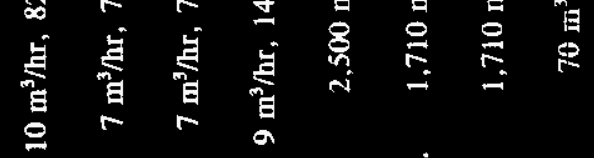

总窟

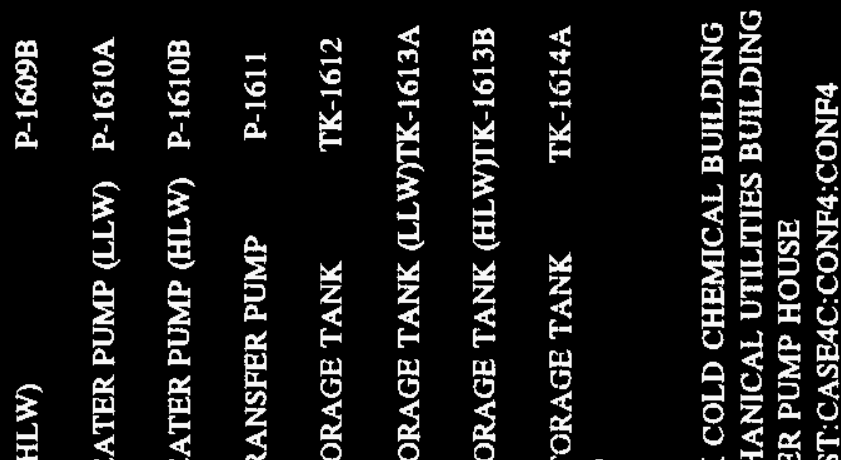

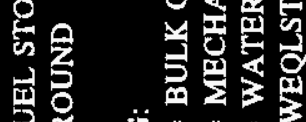

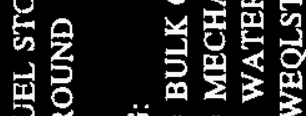

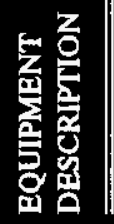

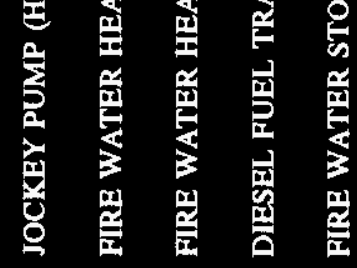

选皆

会兑帠密

党是学 


\section{WHC-SD-W378-ES-002 \\ Revision 0}

Equipment list

Configuration 4 Revision 13, Issued on 02/16/95

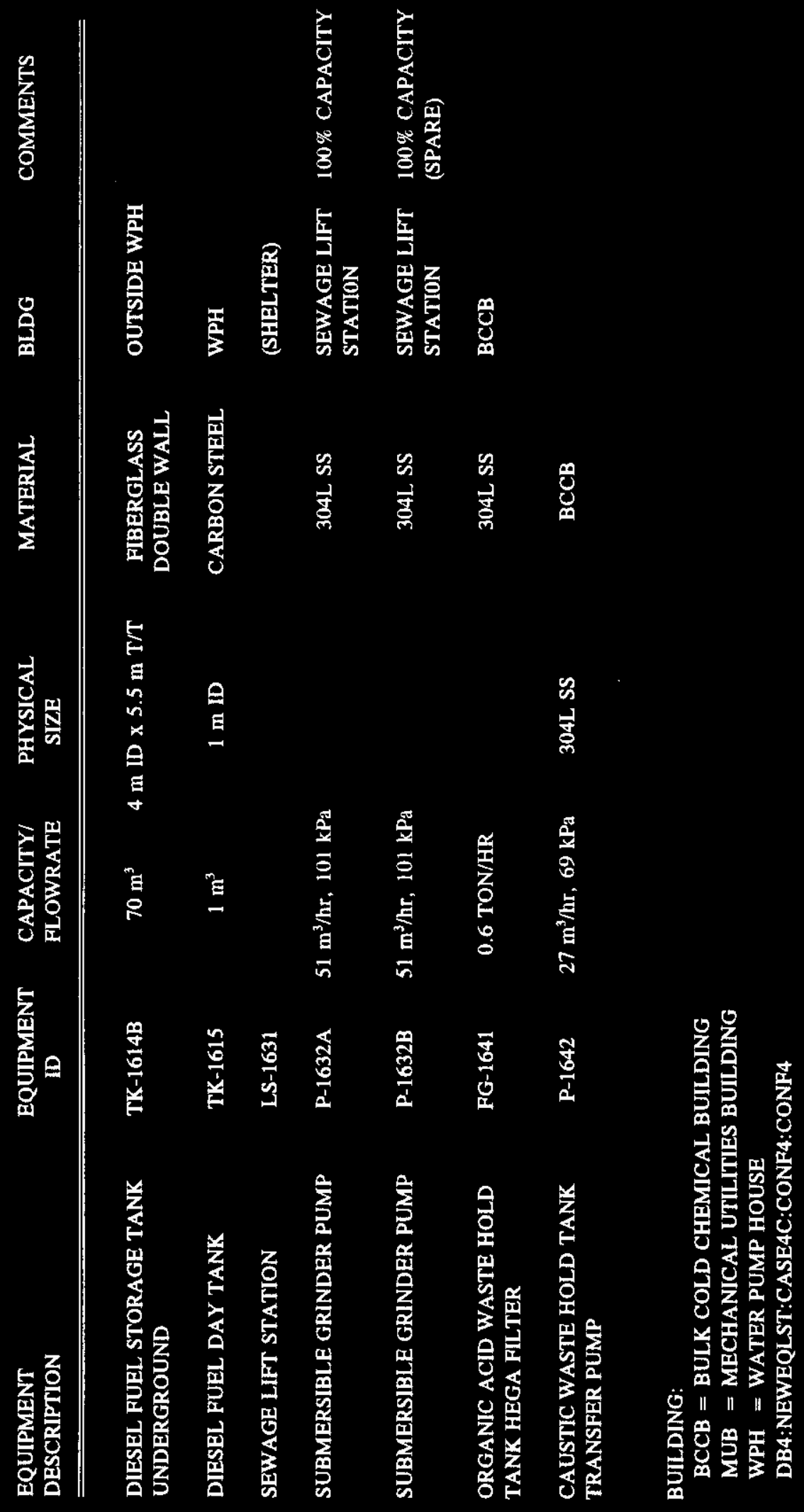

E1-15 
WHC-SD-W378-ES-002

Revision 0

Equipment list

Configuration 4 Revision 13, Issued on 02/16/95

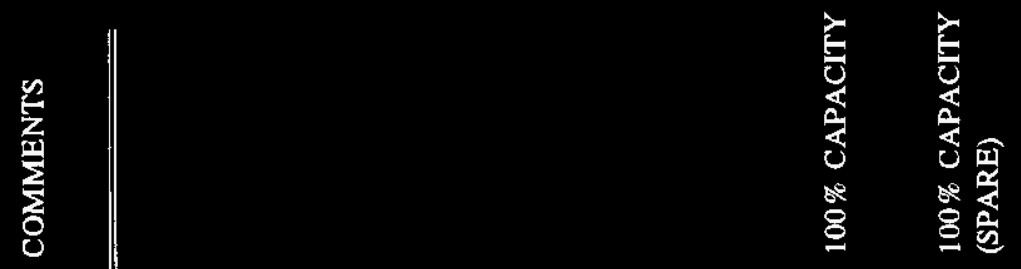

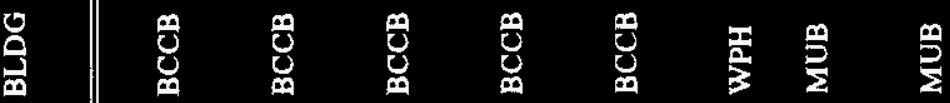

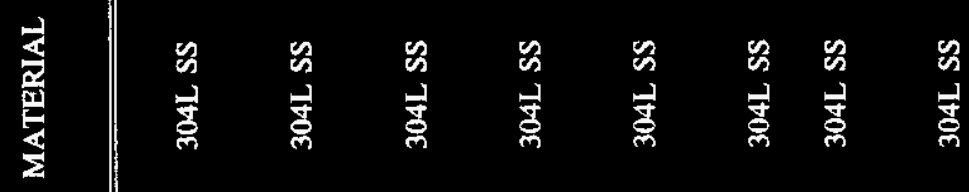

这

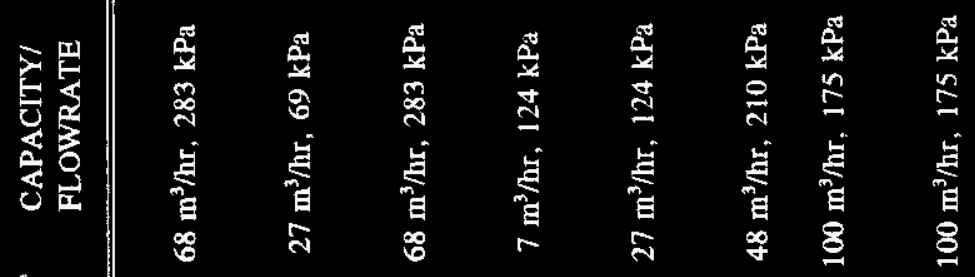

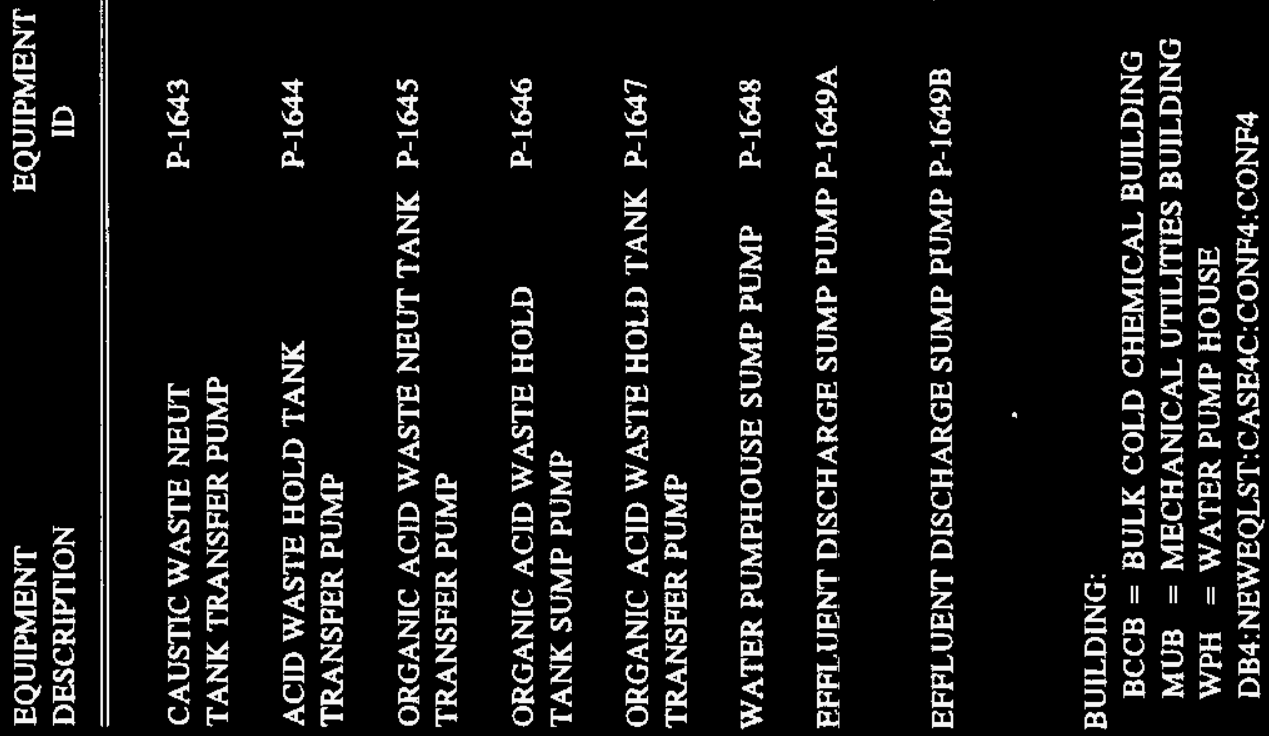

E1-16 


\section{WHC-SD-W378-ES-002}

Revision 0

Equipment list

Configuration 4 Revision 13, Issued on $02 / 16 / 95$

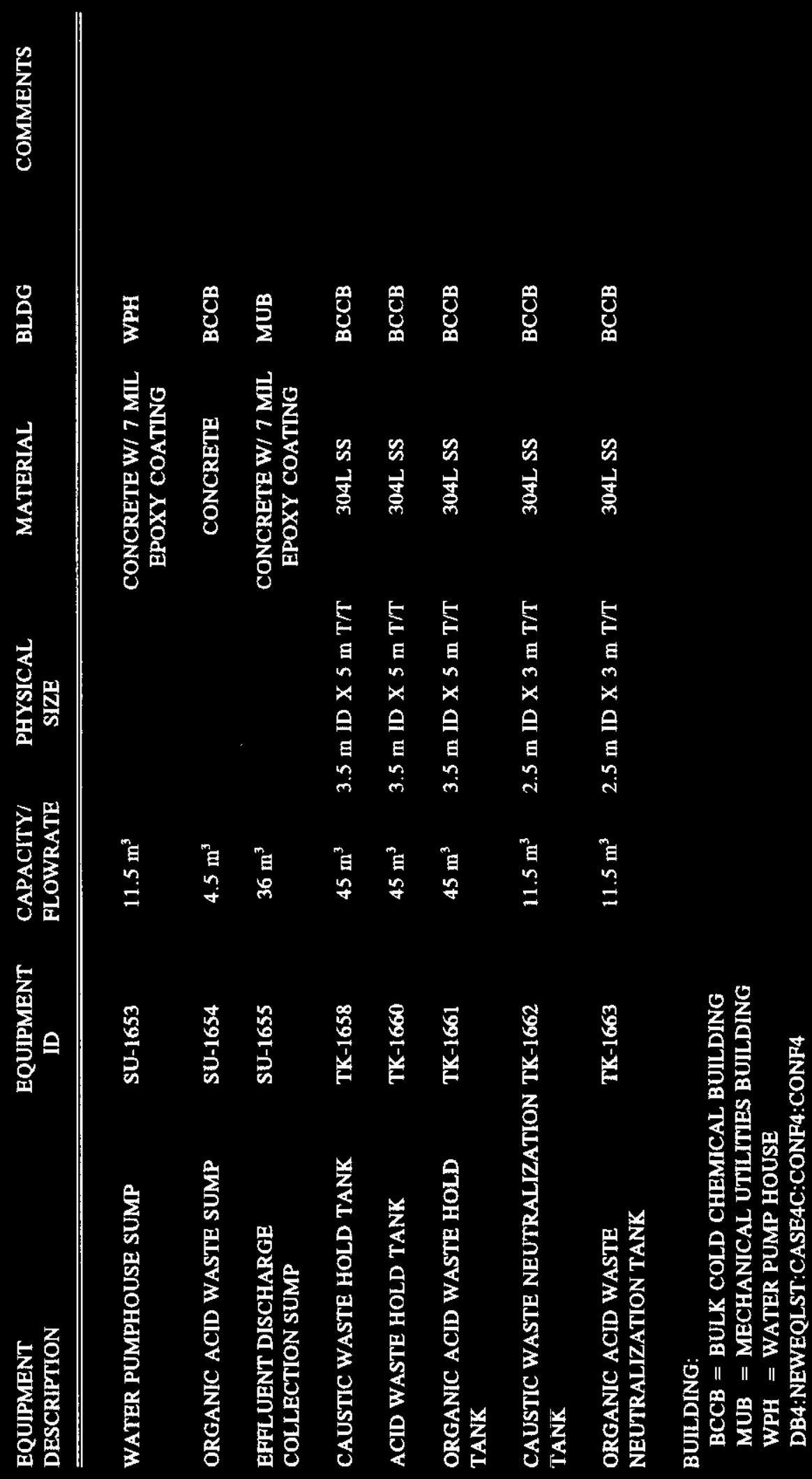

E1-17 


\section{WHC-SD-W378-ES-002 \\ Revision 0}

Equipment list

Configuration 4 Revision 13, Issued on $02 / 16 / 95$

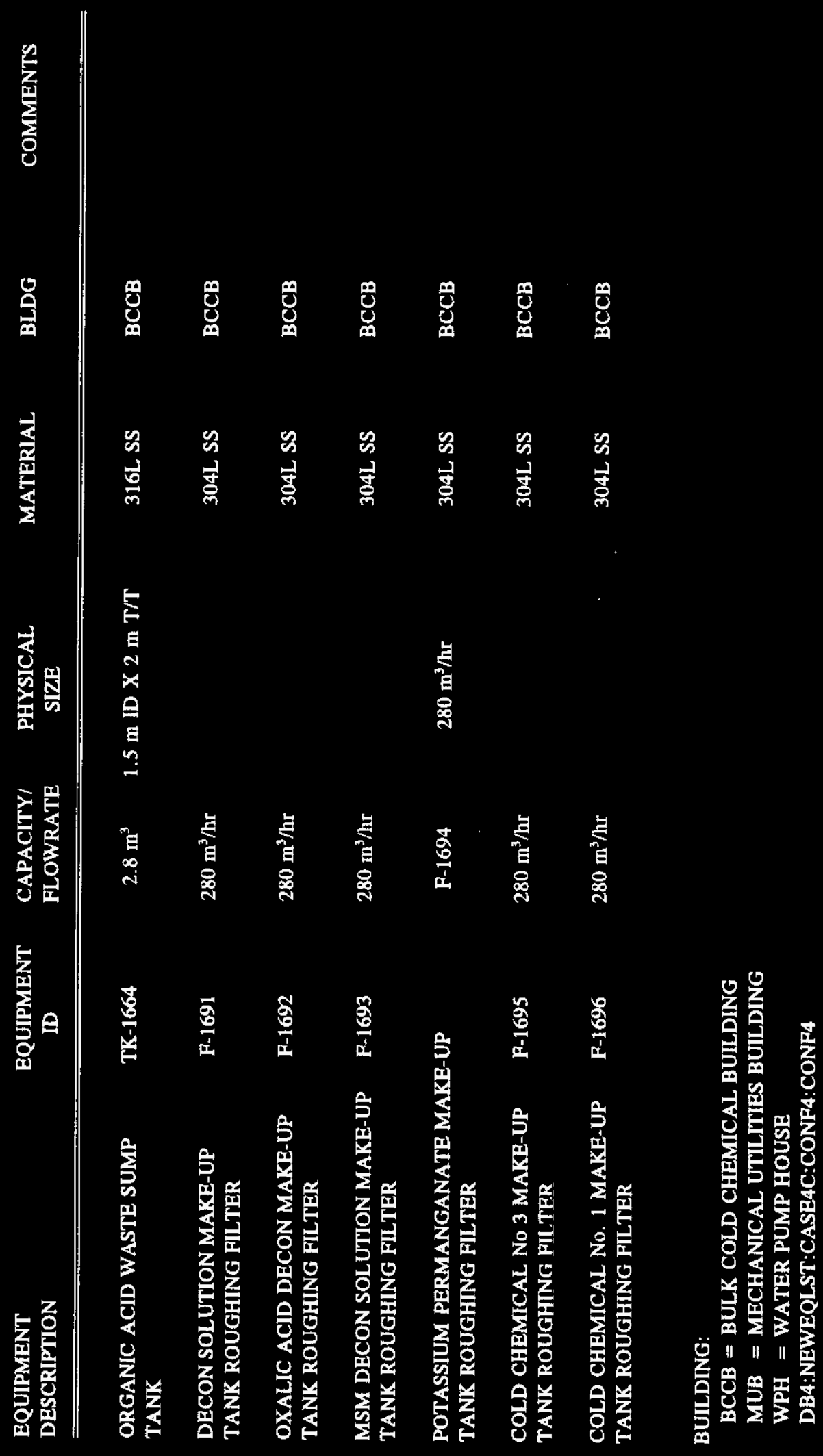

'E1-18 


\section{WHC-SD-W378-ES-002 \\ Revision 0}

Equipment list

Configuration 4 Revision 13, Issued on $02 / 16 / 95$

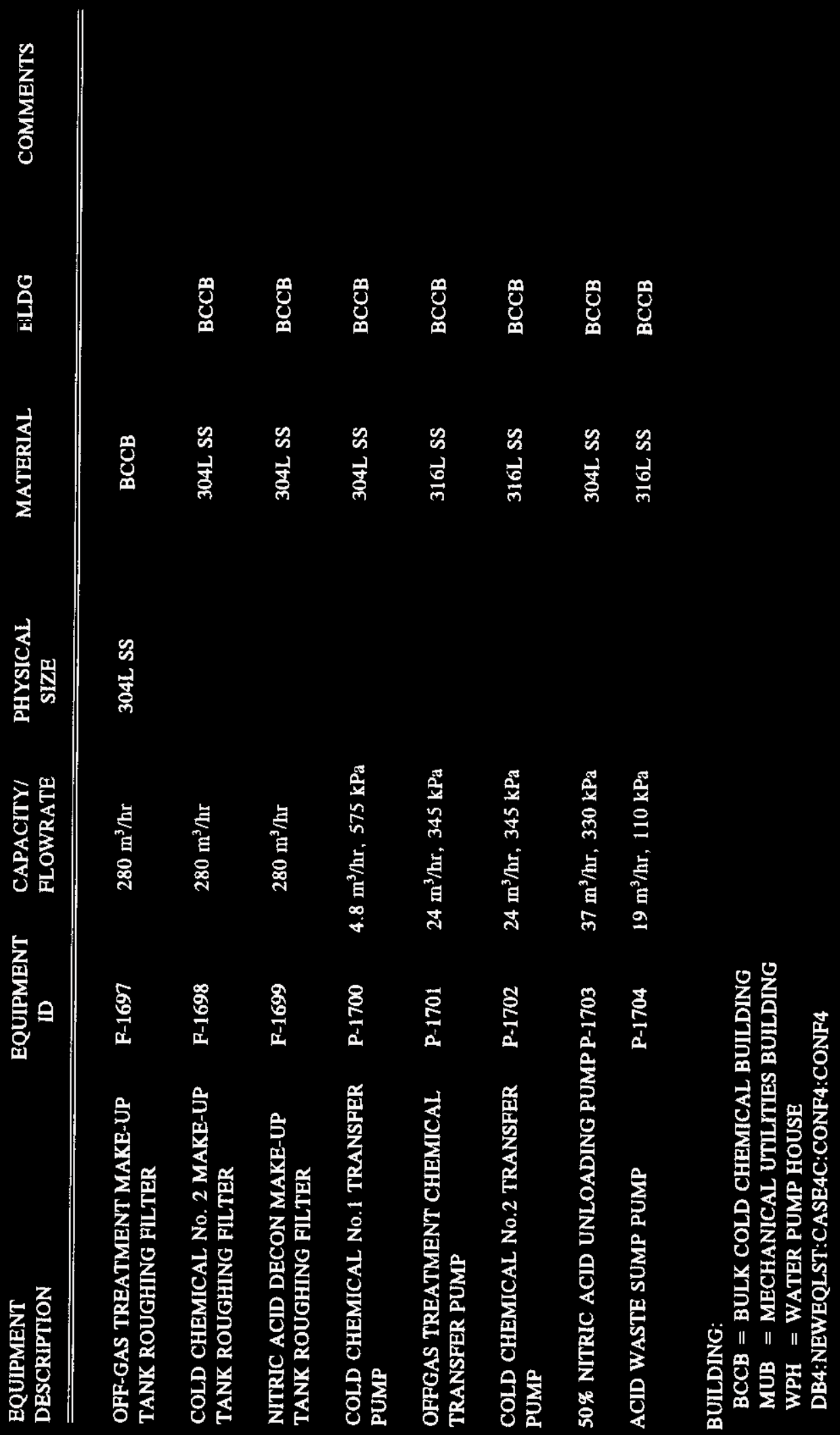


WHC-SD-W378-ES-002

Revision 0

Equipment list

Configuration 4 Revision 13, Issued on 02/16/95

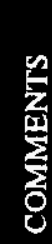

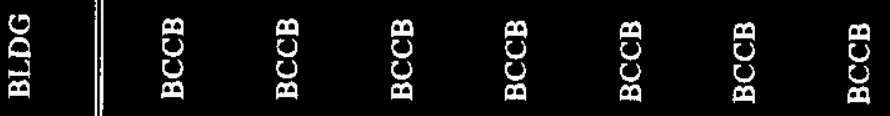

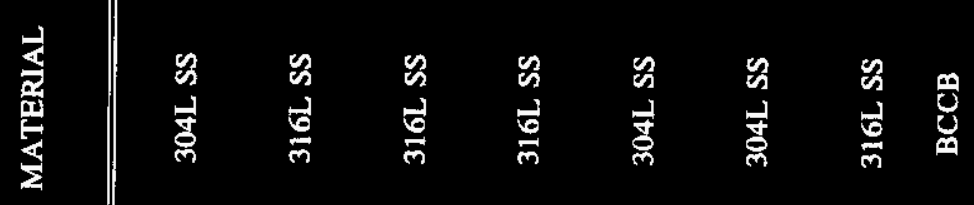

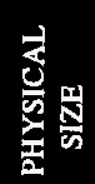

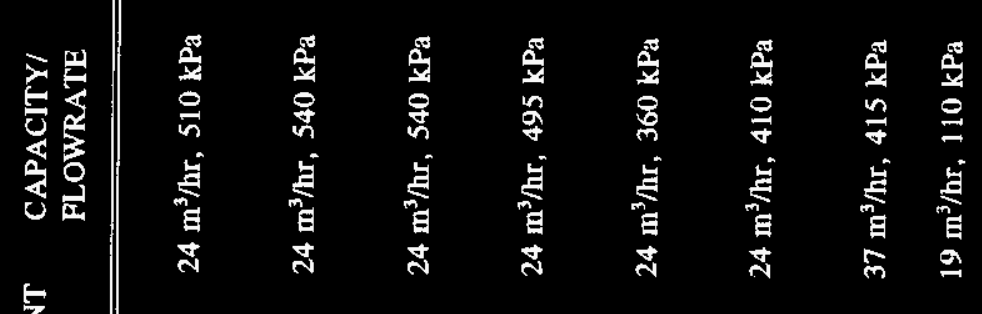

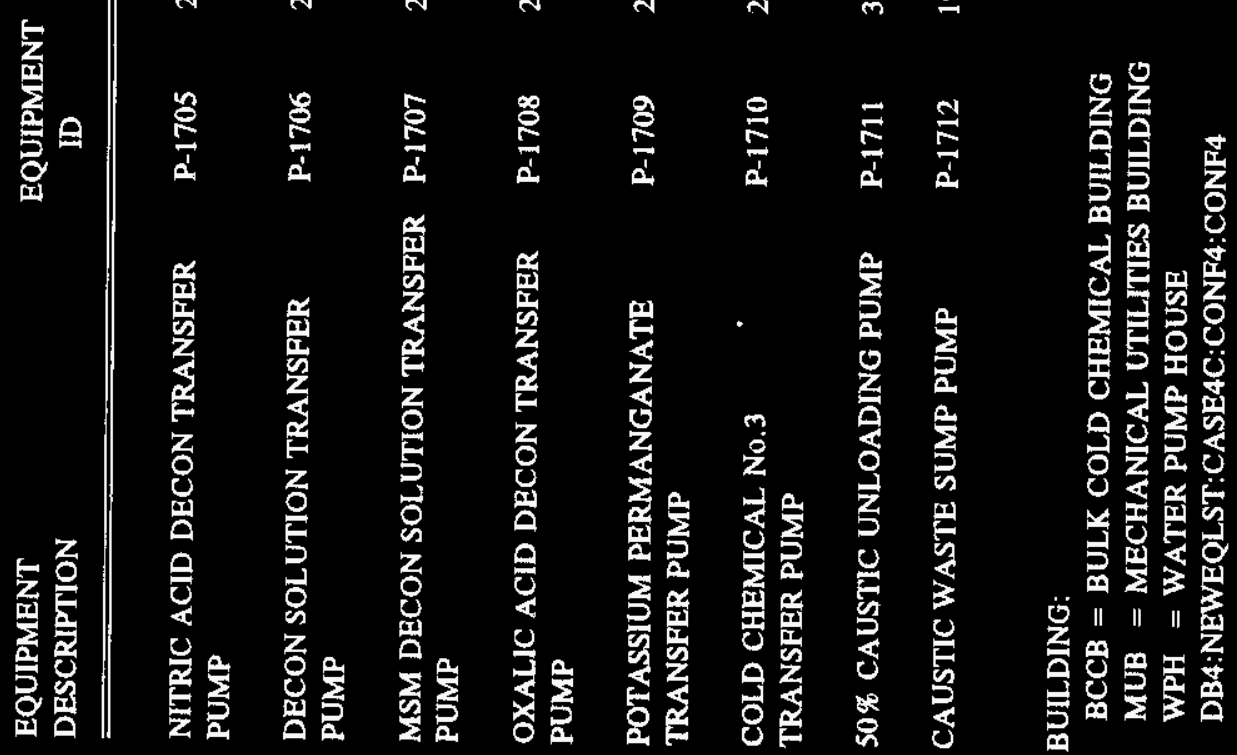




\section{WHC-SD-W378-ES-002 \\ Revision 0}

Equipment list

Configuration 4 Revision 13, Issued on 02/16/95

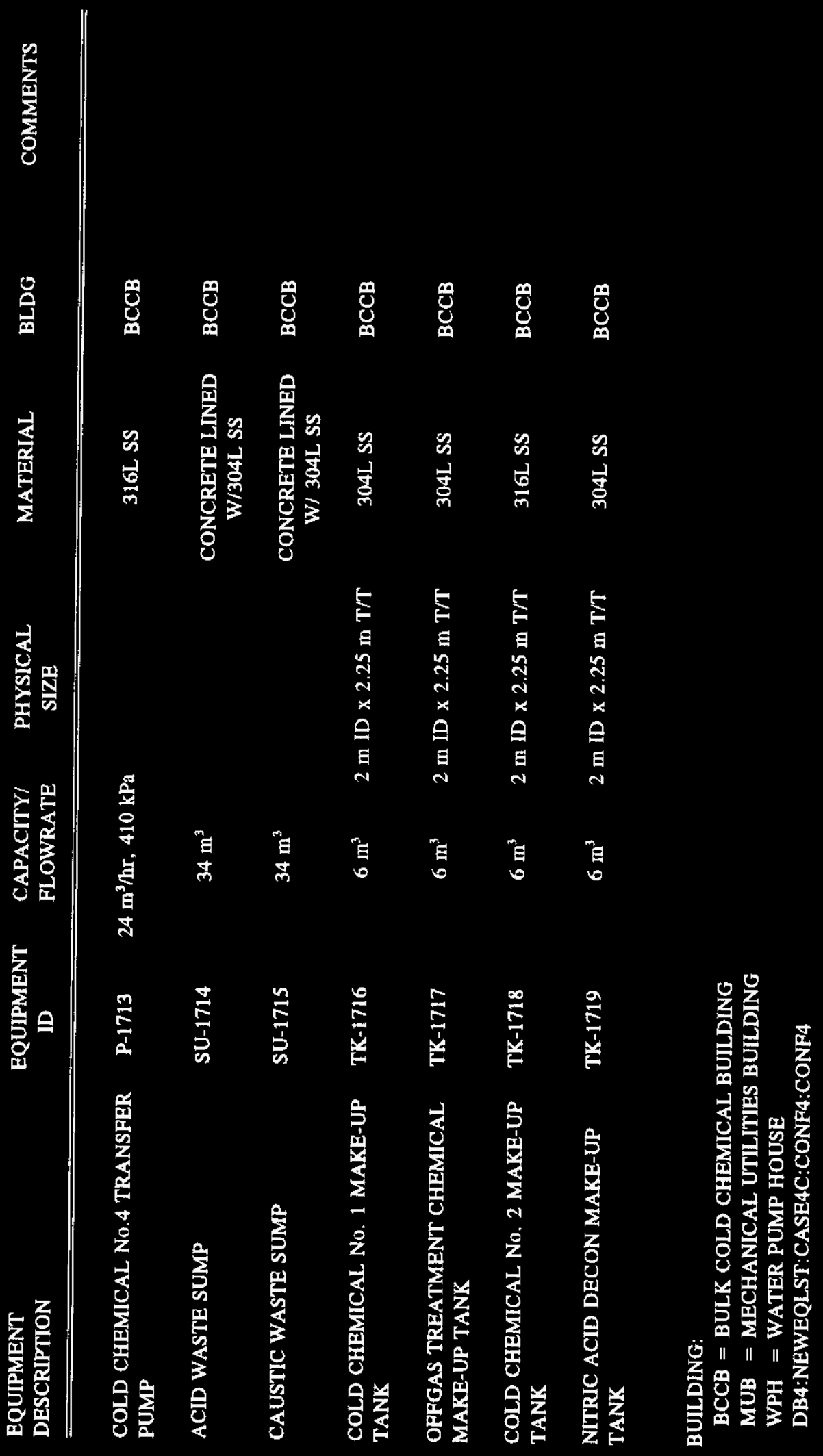

E1-21 


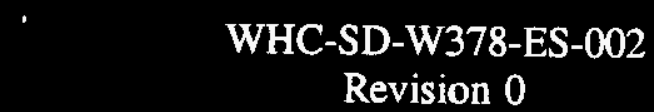

Revision 0

Equipment list

Configuration 4 Revision 13, Issued on $02 / 16 / 95$

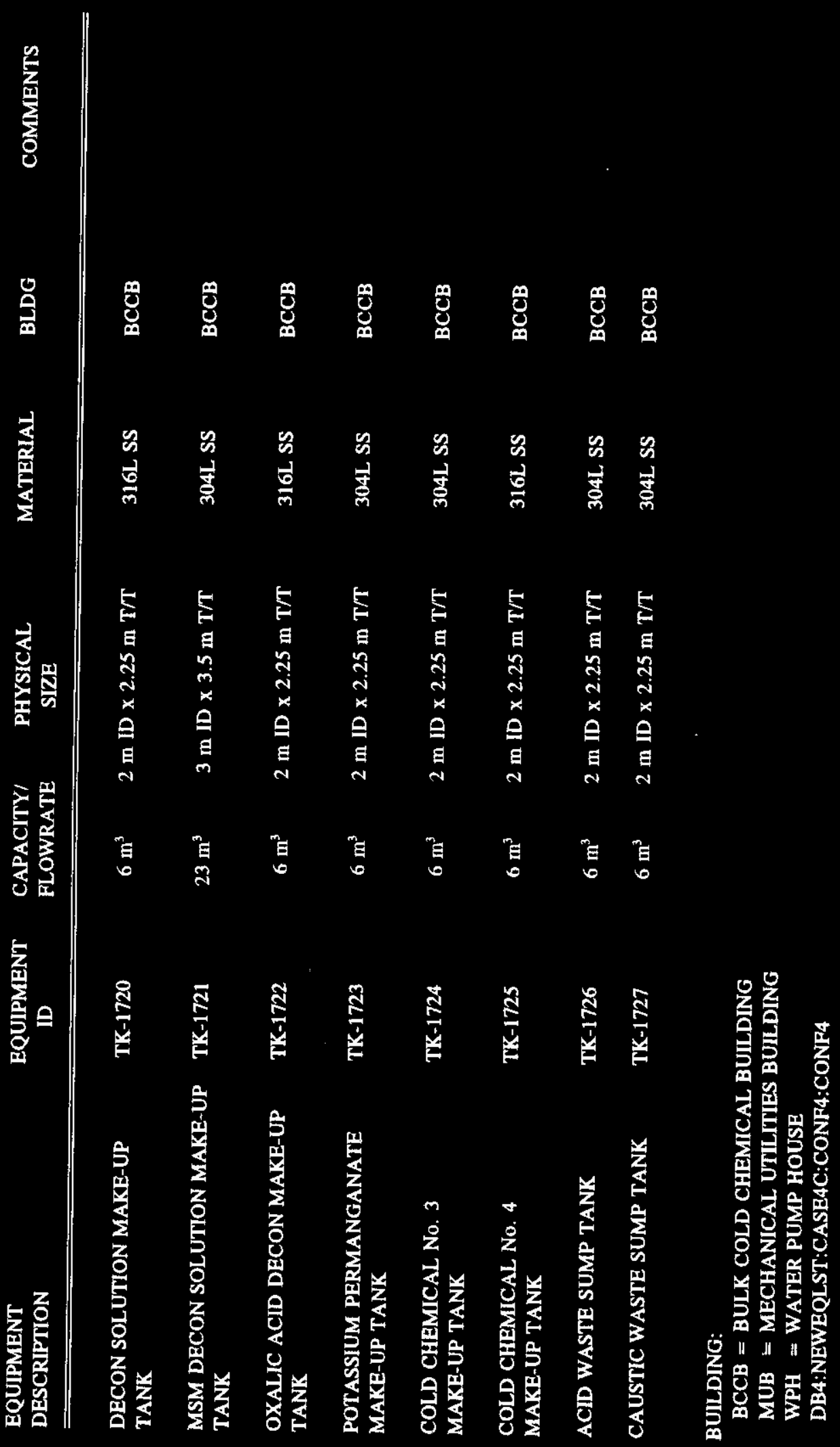




\section{WHC-SD-W378-ES-002 \\ Revision 0}

Equipment list

Configuration 4 Revision 13, Issued on 02/16/95

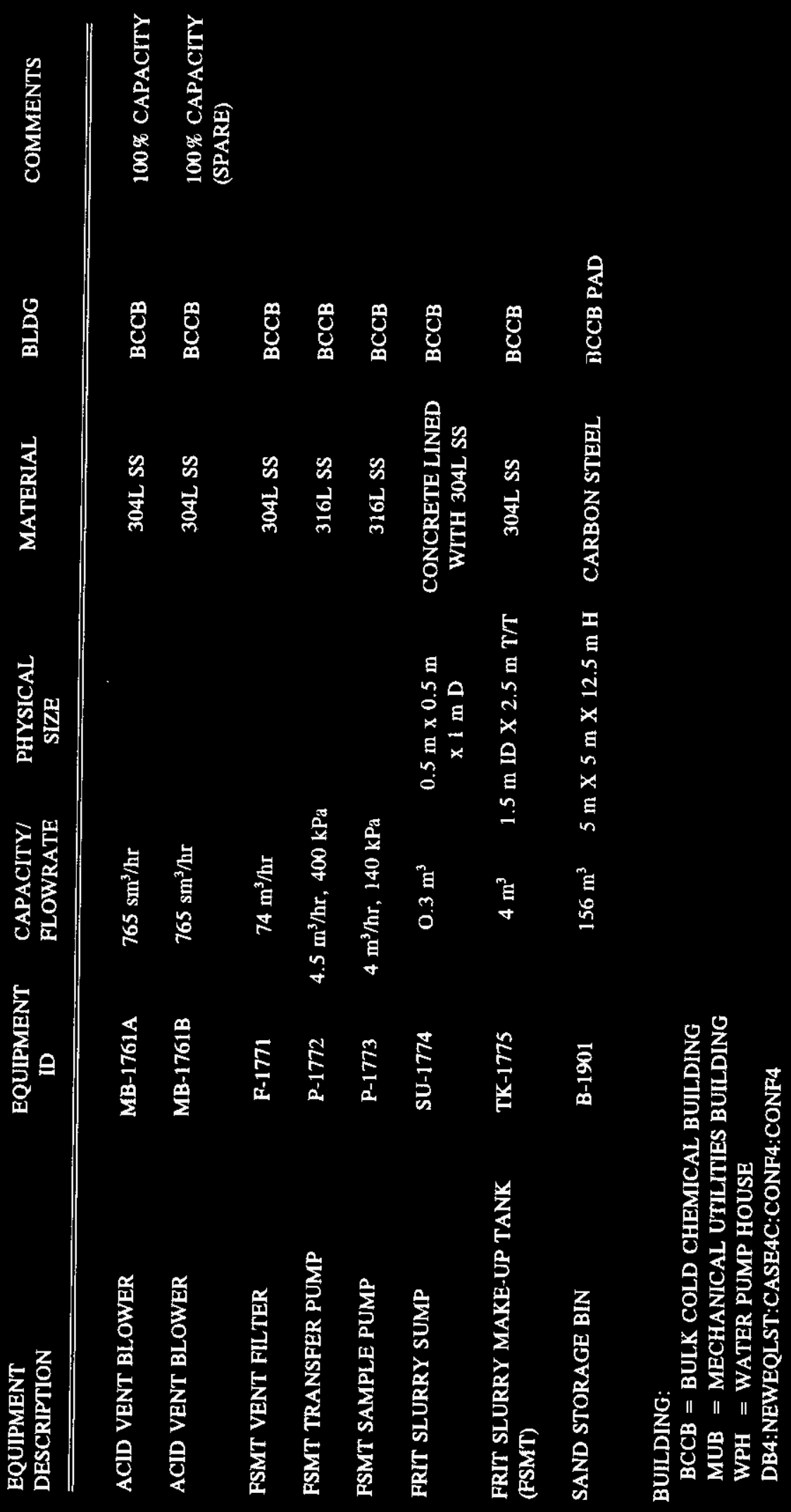




\section{WHC-SD-W378-ES-002}

Revision 0

Equipment list

Configuration 4 Revision 13, Issued on 02/16/95

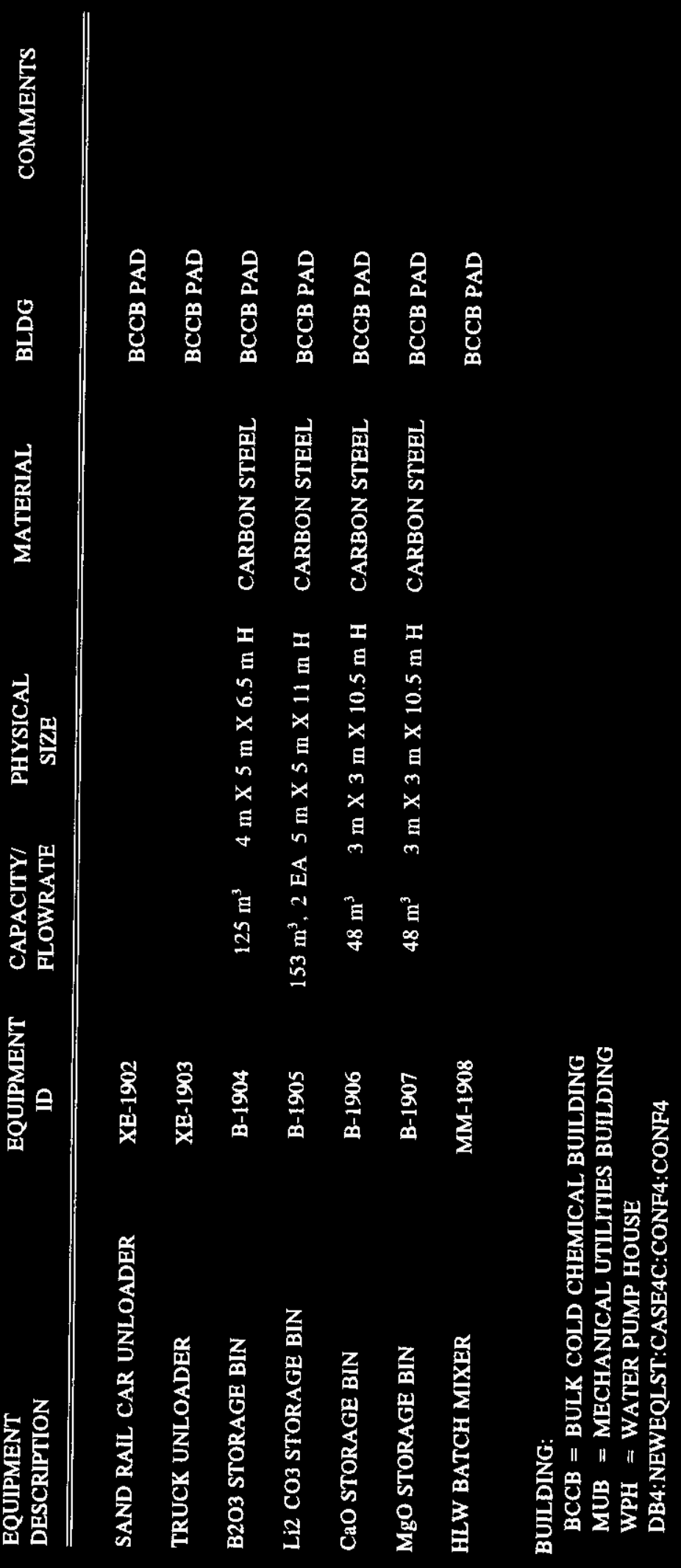

\section{E1-24}




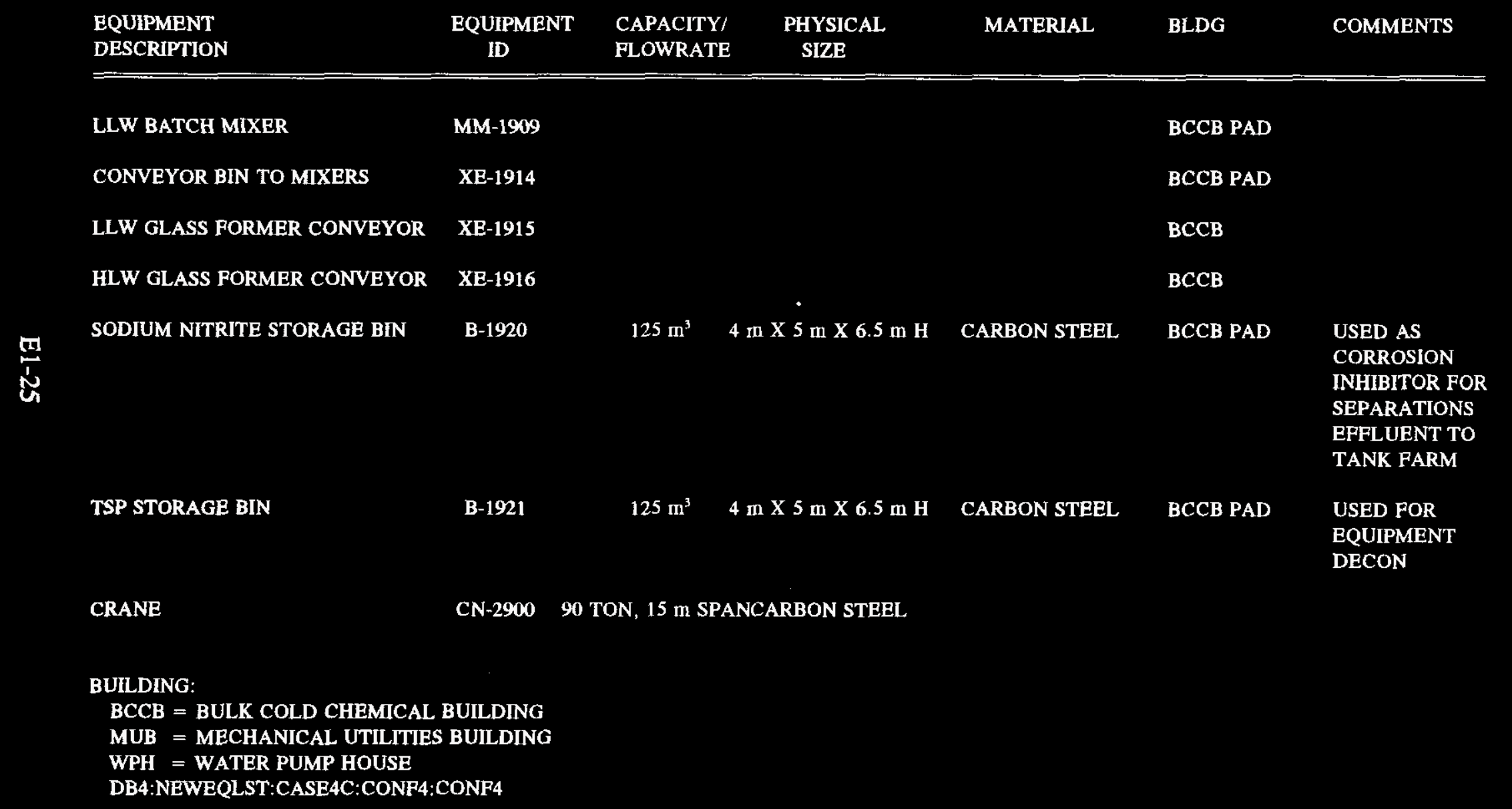




\section{WHC-SD-W378-ES-002 \\ Revision 0}

Equipment list

Configuration 4 Revision 13, Issued on 02/16/95

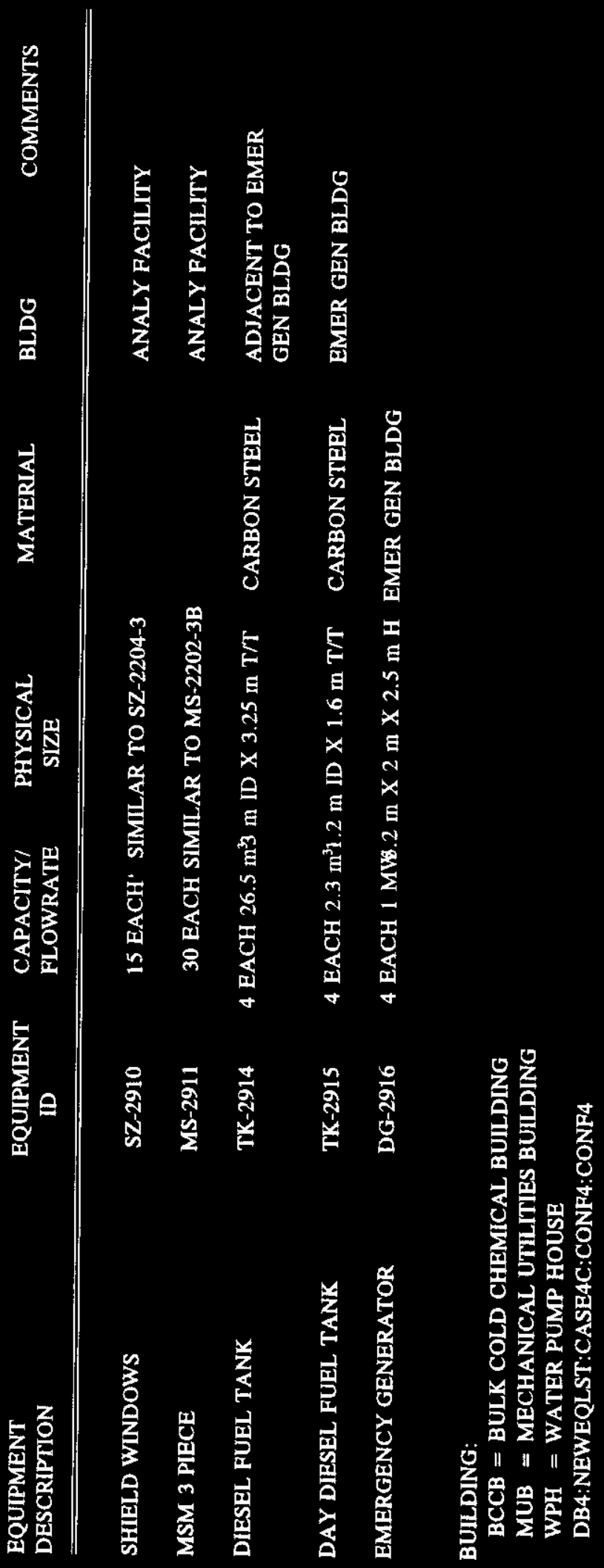

E1-26 
WHC-SD-W378-ES-002

Revision 0

\section{APPENDIX E2}

\section{HIGH-LEVEL WASTE STANDALONE SUPPORT FACILITY EQUIPMENT LIST}


WHC-SD-W378-ES-002

Revision 0

This page intentionally left blank.

E2-2 
ABBREVIATIONS

BQUIPMENT IDENTIFICATION CODE
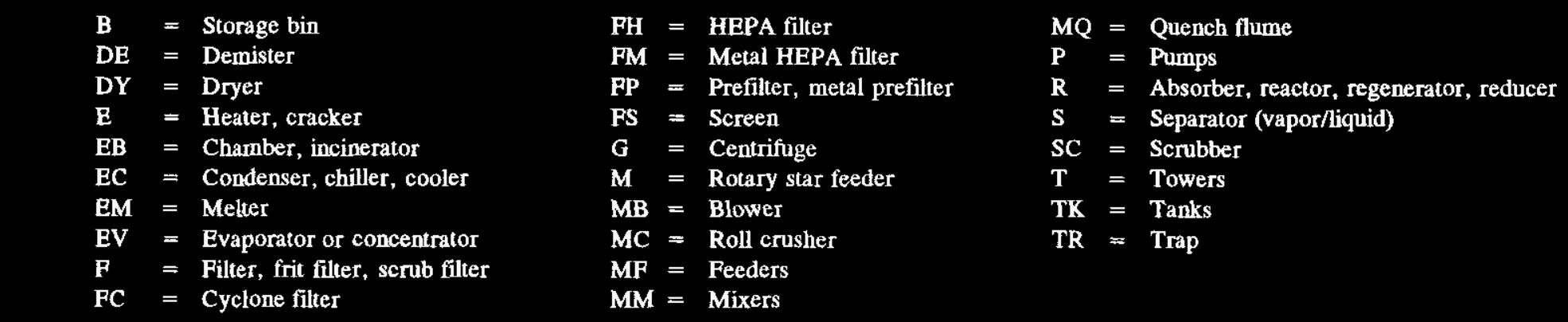

\begin{tabular}{lllll} 
EQUIPMENT & $\begin{array}{l}\text { EQUIPMENT } \\
\text { DESCRIPTION }\end{array}$ & $\begin{array}{c}\text { CAPACITY/ } \\
\text { PLOWRATE }\end{array}$ & $\begin{array}{c}\text { PHYSICAL } \\
\text { SIZE }\end{array}$ & MATERIAL \\
\hline
\end{tabular}

REPAIR SHOP EQUIPMENT 1 LOT

(WELDER, - BAND SAW, GRINDER,

ETC. NO LARGE MACHINE TOOLS)

$\begin{array}{lc}\text { BULK NaOH STORAGE TANK } & \text { TK-1013 } \\ \text { BULK HNO3 STORAGE TANK } & \text { TK-1014 } \\ \text { BULK ANHYDROUS NH3 } & \text { TK-1015 } \\ \text { STORAGE TANK } & \\ & \\ \text { BULDING: } \\ \text { BCCB = BULK COLD CHEMICAL BUILDING } \\ \text { MUB = MECHANICAL UTILTIES BUILDING } \\ \text { WPH = WATER PUMP HOUSE } \\ \text { DB4:CASE4C:CONF4:HLW_ALT }\end{array}$




\section{WHC-SD-W378-ES-002}

Revision 0

Equipment list

Configuration 4 Revision 02, Issued on 02/16/95

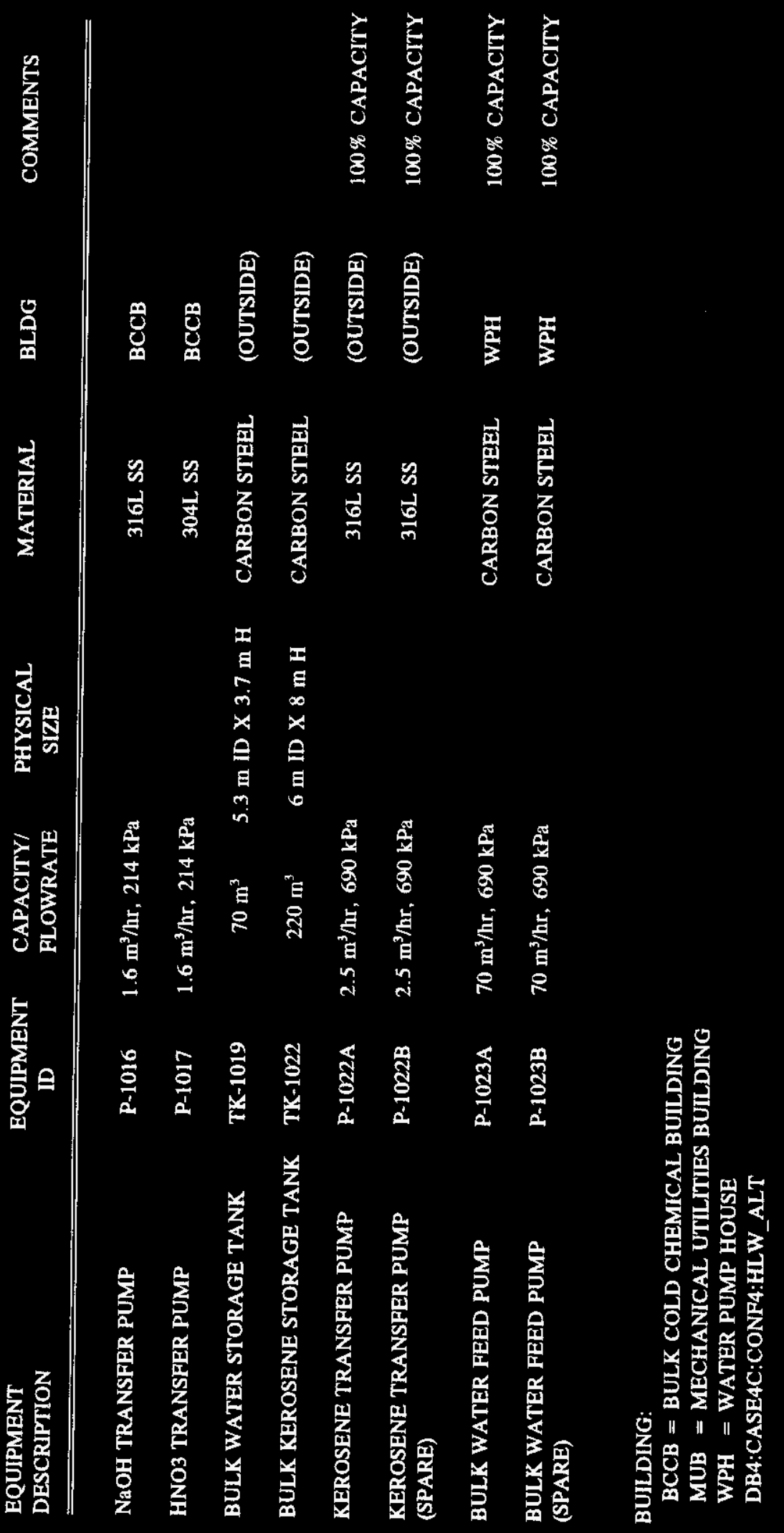


WHC-SD-W378-ES-002

Revision 0

Equipment list

Configuration 4 Revision 02, Issued on 02/16/95

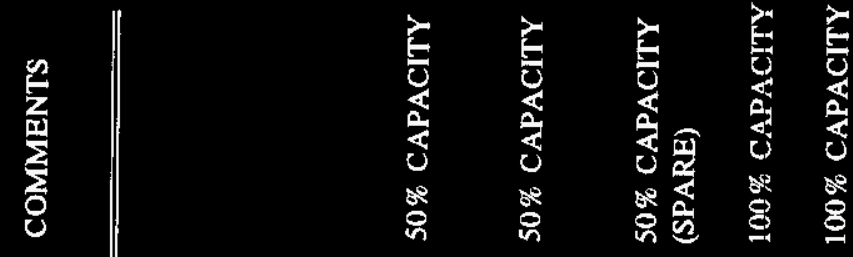

||

焉罢

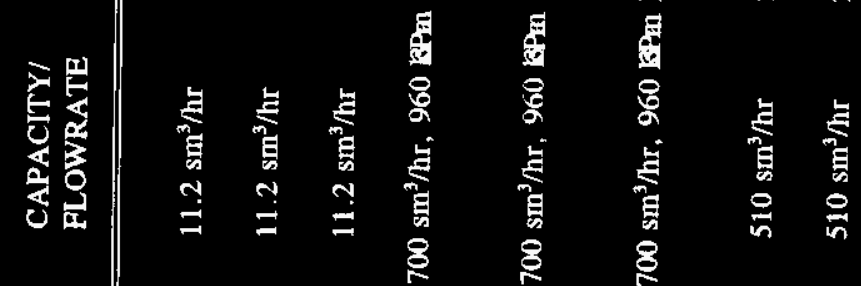

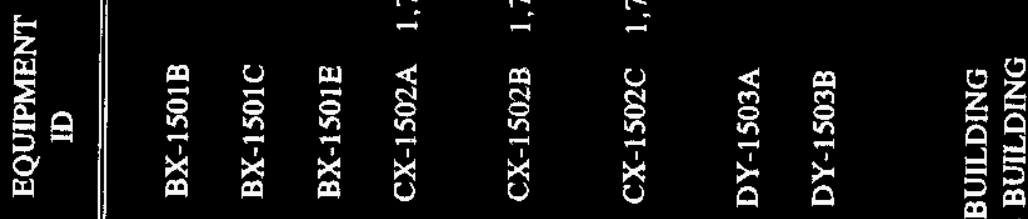

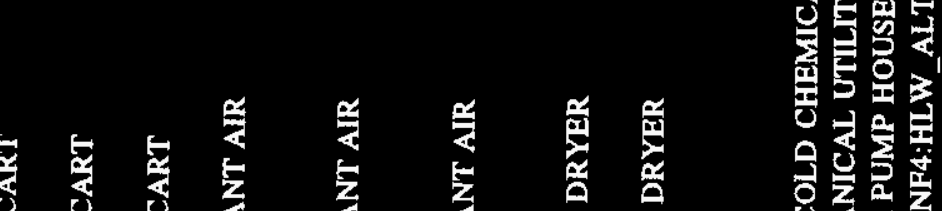

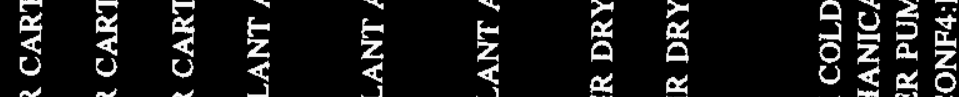

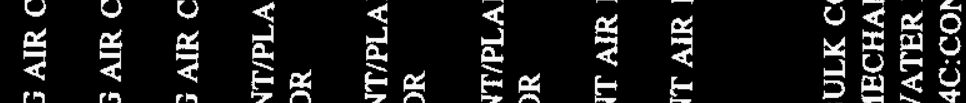




\section{WHC-SD-W378-ES-002 \\ Revision 0}

Equipment list

Configuration 4 Revision 02, Issued on 02/16/95

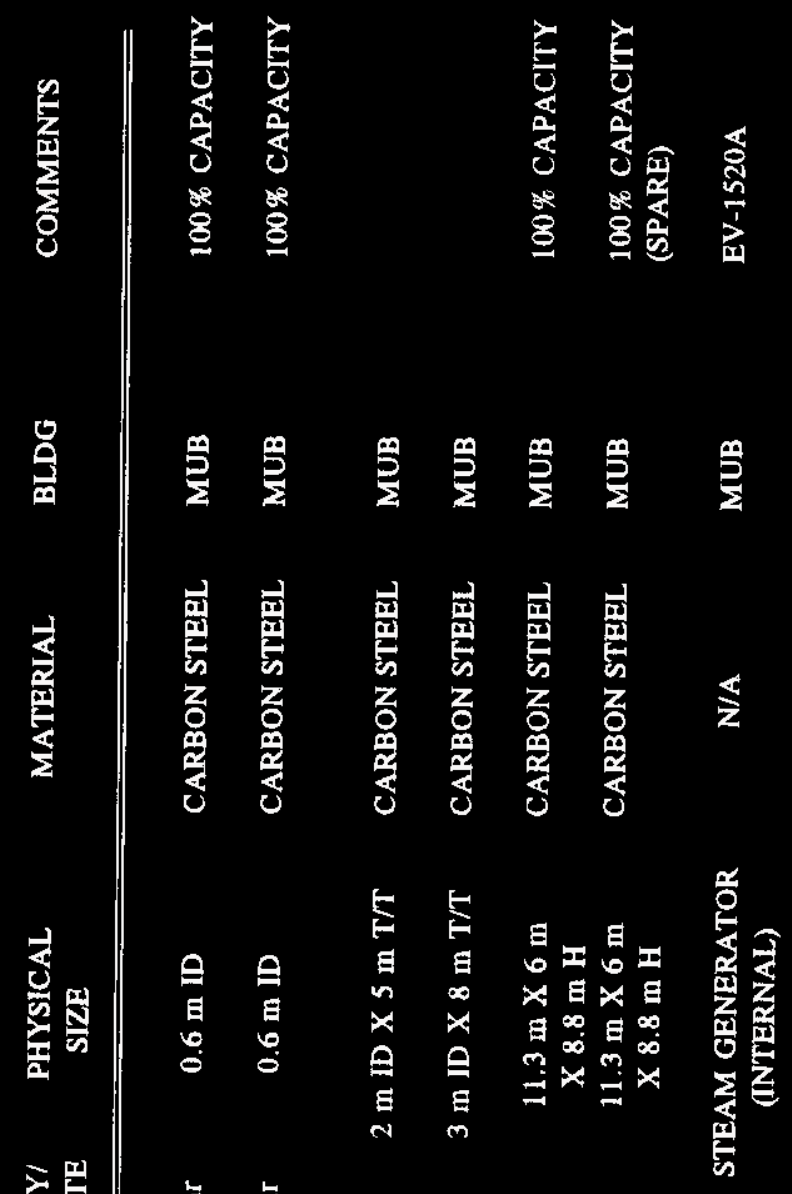

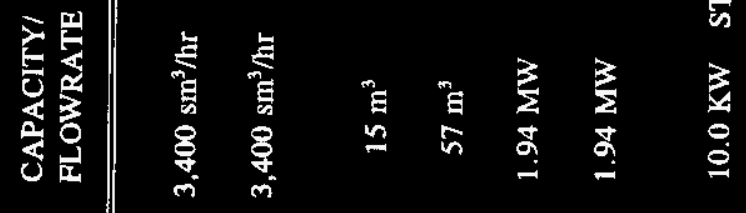

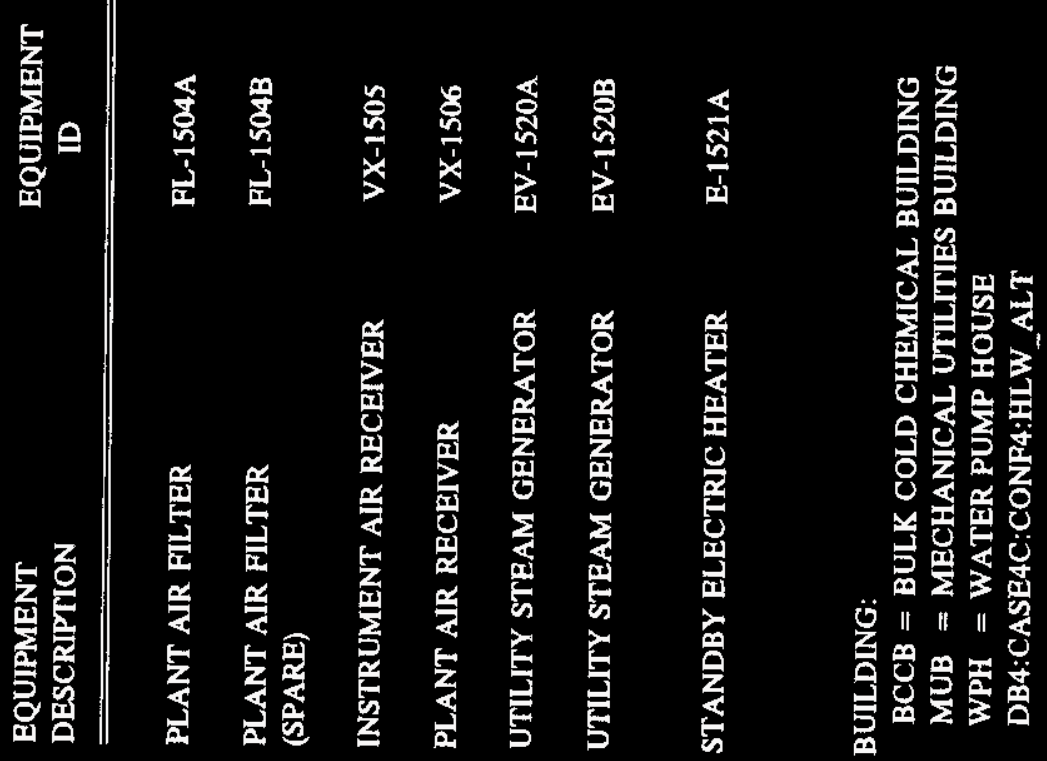




\begin{tabular}{|c|c|c|c|c|c|c|c|c|}
\hline $\begin{array}{l}\text { EQUIPMENT } \\
\text { DESCRIPTION }\end{array}$ & $\begin{array}{l}\text { EQUIPMENT } \\
\text { ID }\end{array}$ & $\begin{array}{l}\text { CAPACITY } \\
\text { FLOWRAT }\end{array}$ & $\begin{array}{l}\text { PHYSICAL } \\
\text { SIZE }\end{array}$ & MATERIAL & BLDG & COMMENTS & \multirow{10}{*}{ 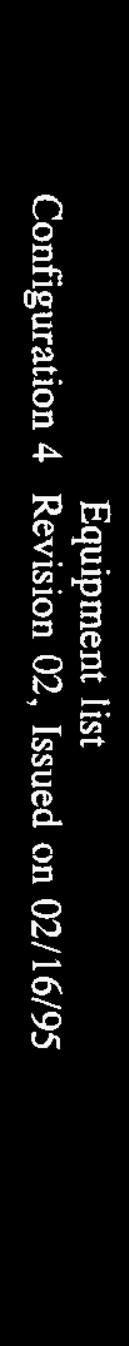 } & \\
\hline STANDBY ELECTRIC HEATER & E-1521B & $10.0 \mathrm{KW}$ & $\begin{array}{l}\text { STEAM GENERATOR } \\
\text { (INTERNAL) }\end{array}$ & N/A & MUB & EV-1520B & & \\
\hline $\begin{array}{l}\text { UTILITY STEAM GENERATOR } \\
\text { CIRCULATING PUMP }\end{array}$ & P-1522A & $\begin{array}{c}170 \mathrm{~m}^{3} / \mathrm{hr} \\
69 \mathrm{kPa}\end{array}$ & $\begin{array}{l}\text { (INCLUDED W/STM } \\
\text { GEN FOOTPRINT) }\end{array}$ & 304L, SS & MUB & $\begin{array}{l}\text { 100\% CAPACITY } \\
\text { EV-1520A }\end{array}$ & & \\
\hline $\begin{array}{l}\text { UTILITY STEAM GENERATOR } \\
\text { CIRCULATING PUMP }\end{array}$ & P-1522B & $\begin{array}{l}170 \mathrm{~m}^{3} / \mathrm{hr} \\
69 \mathrm{kPA}\end{array}$ & $\begin{array}{l}\text { (INCLUDED W/STM } \\
\text { GEN POOTPRINT) }\end{array}$ & 304L SS & MUB & $\begin{array}{l}\text { 100\% CAPACITY } \\
\text { EV-1520A } \\
\text { (SPARE) }\end{array}$ & & 贾 \\
\hline $\begin{array}{l}\text { UTILITY STEAM GENERATOR } \\
\text { CIRCULATING PUMP }\end{array}$ & P-1522C & $\begin{array}{c}170 \mathrm{~m}^{3} / \mathrm{hr} \\
69 \mathrm{kPA}\end{array}$ & $\begin{array}{l}\text { (INCLUDED W/STM } \\
\text { GEN FOOTPRINT) }\end{array}$ & 304L SS & MUB & $\begin{array}{l}\text { 100\% CAPACITY } \\
\text { EV-1520B }\end{array}$ & & 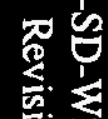 \\
\hline $\begin{array}{l}\text { UTILITY STEAM GENERATOR } \\
\text { CIRCULATING PUMP }\end{array}$ & P-1522D & $\begin{array}{c}170 \mathrm{~m}^{3} / \mathrm{hr} \\
69 \mathrm{kPA}\end{array}$ & $\begin{array}{l}\text { (INCLUDED W/STM } \\
\text { GEN FOOTPRINT) }\end{array}$ & 304L SS & MUB & $\begin{array}{l}\text { 100\% CAPACITY } \\
\text { EV-1520B } \\
\text { (SPARE) }\end{array}$ & & 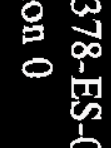 \\
\hline $\begin{array}{l}\text { STEAM GEN FEED WATER CHE } \\
\text { INIECTION PUMP }\end{array}$ & $\mathrm{AB}-1523 \mathrm{~A}$ & $\begin{array}{r}0.23 \mathrm{~m}^{3} / \mathrm{hr} \\
1,370 \mathrm{kPa}\end{array}$ & $\begin{array}{l}\text { (INCLUDED W/STM } \\
\text { GEN POOTPRINT) }\end{array}$ & 304L SS & MUB & EV-1520A & & గ్ర \\
\hline $\begin{array}{l}\text { STEAM GEN FEED WATER CHE } \\
\text { INJECTION PUMP }\end{array}$ & AD-1523B & $\begin{array}{r}0.23 \mathrm{~m}^{3} / \mathrm{hr} \\
1,370 \mathrm{kPa}\end{array}$ & $\begin{array}{l}\text { (INCLUDED W/STM } \\
\text { GEN FOOTPRINT) }\end{array}$ & 304L SS & MUB & EV-1520B & & \\
\hline CHEMICAL ADDITION TANK & TK-1524A & $1 \mathrm{~m}^{3}$ & $\begin{array}{l}\text { (INCLUDED W/STM } \\
\text { GEN ROOTPRINT) }\end{array}$ & 304L SS & MUB & $\mathrm{EV}-1520 \mathrm{~A}$ & & \\
\hline \multicolumn{8}{|c|}{$\begin{array}{l}\text { BUILDING: } \\
\text { BCCB }=\text { BULK COLD CHEMICAL BUILDING } \\
\text { MUB }=\text { MECHANICAL UTILITIES BUILDING } \\
\text { WPH }=\text { WATER PUMP HOUSE } \\
\text { DB4:CASE4C:CONP4:HLW ALT }\end{array}$} & \\
\hline
\end{tabular}




\section{WHC-SD-W378-ES-002}

\section{Revision 0}

Equipment list

Configuration 4 Revision 02 , Issued on $02 / 16 / 95$

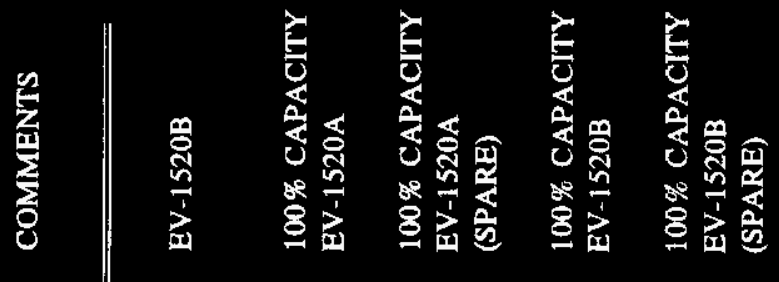

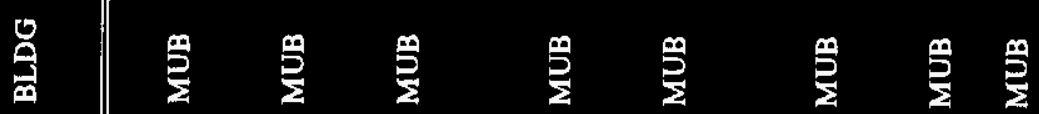

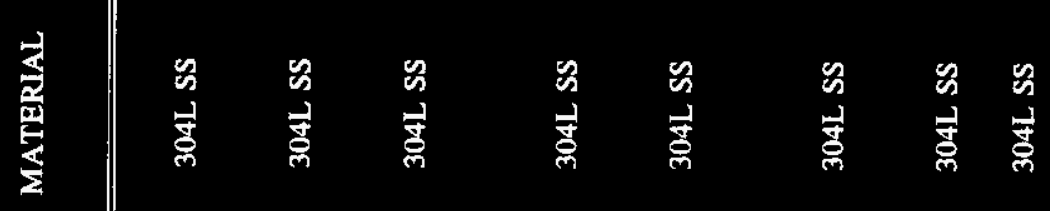

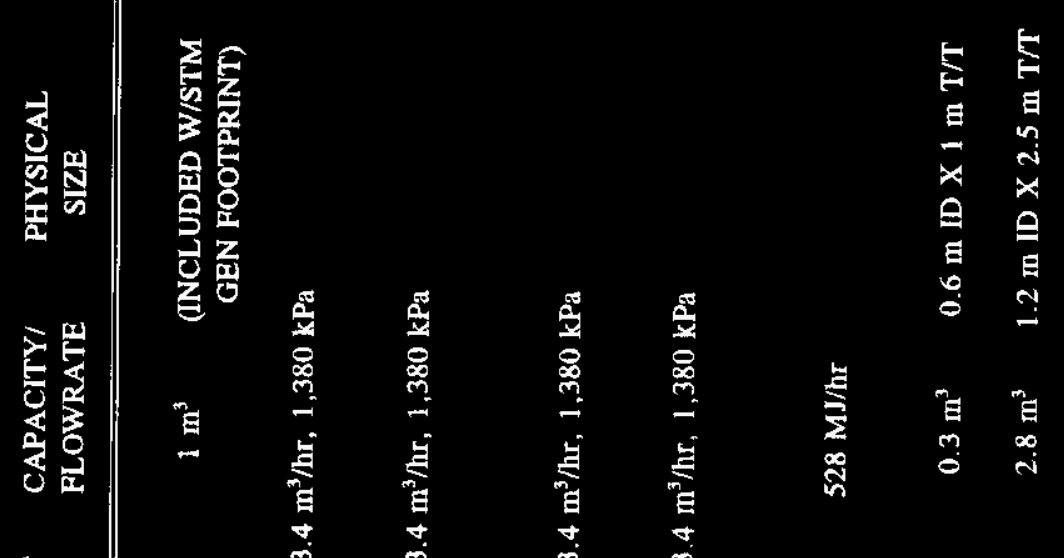

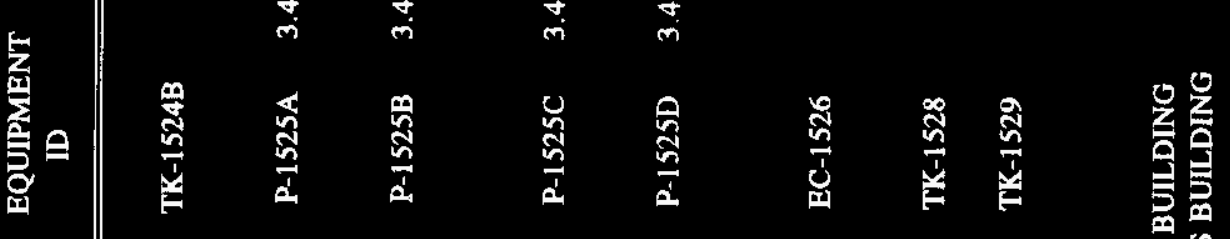

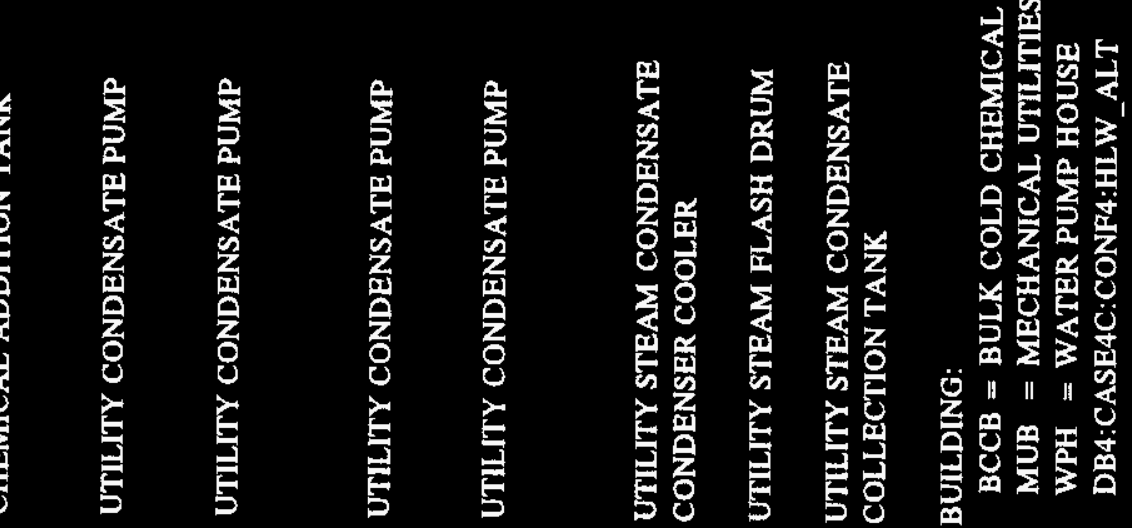




\section{WHC-SD-W378-ES-002 \\ Revision 0}

Equipment list

Configuration 4 Revision 02, Issued on 02/16/95

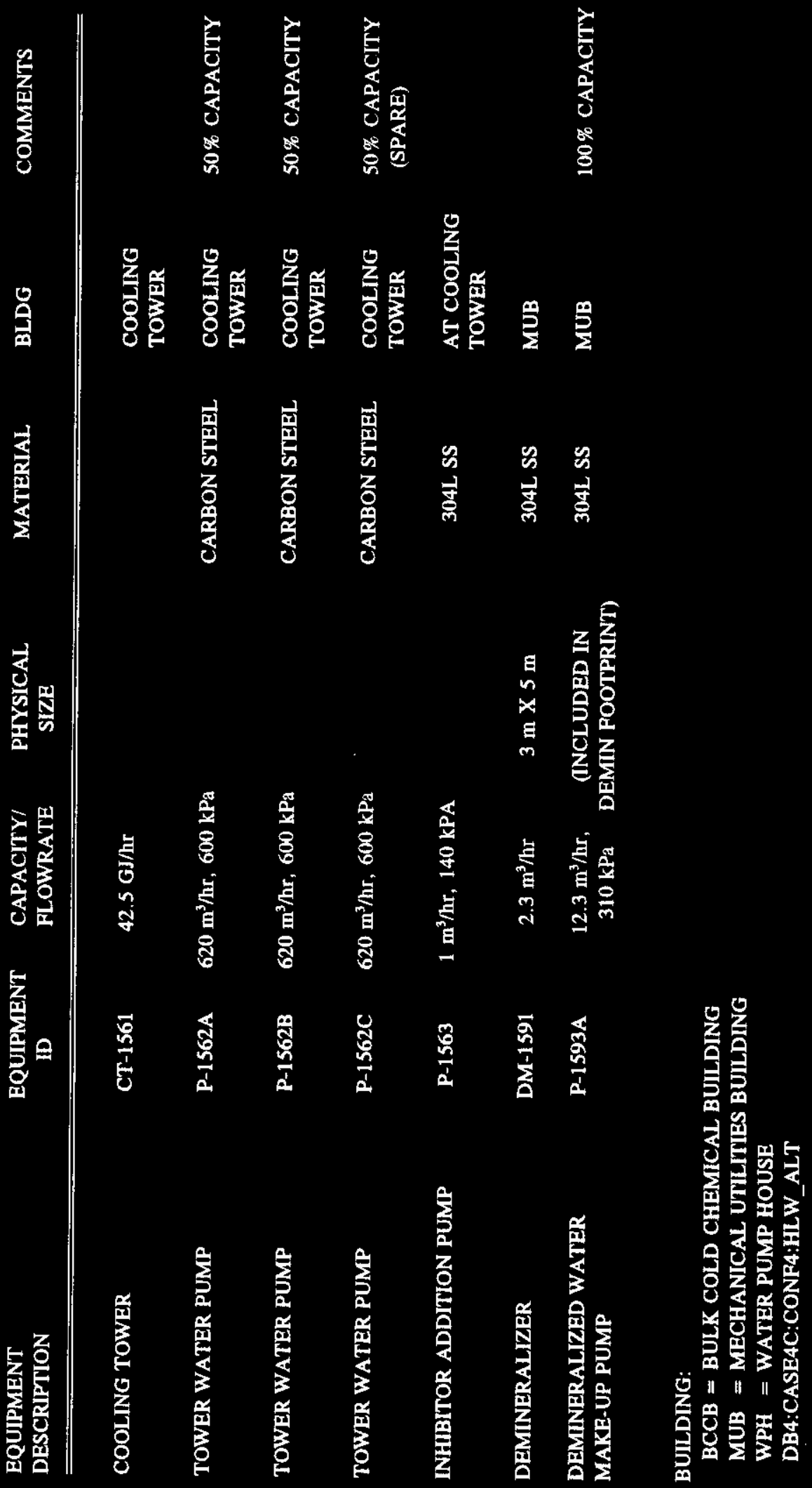




\section{WHC-SD-W378-ES-002}

Revision 0

Equipment list

Configuration 4 Revision 02, Issued on 02/16/95

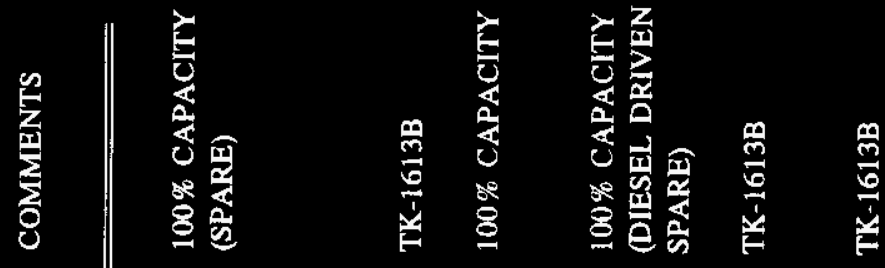

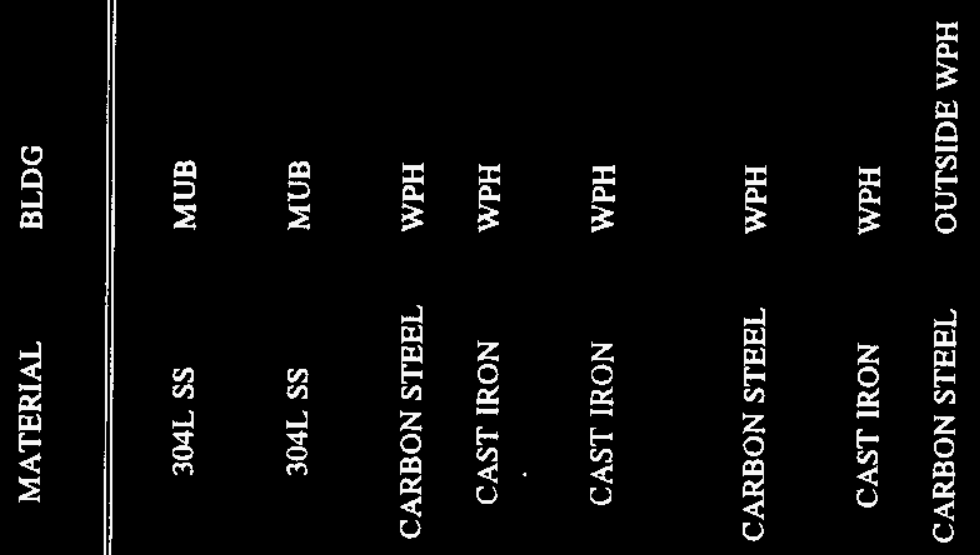

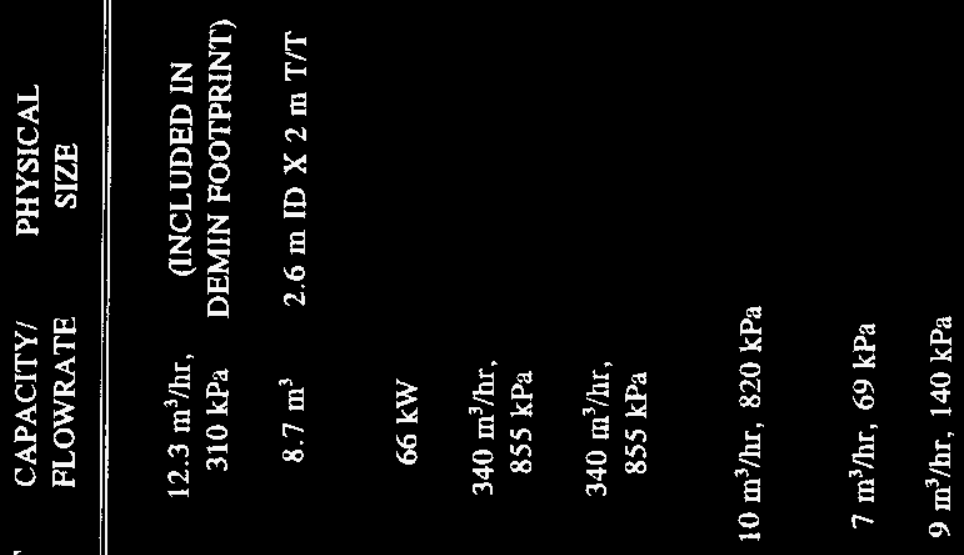

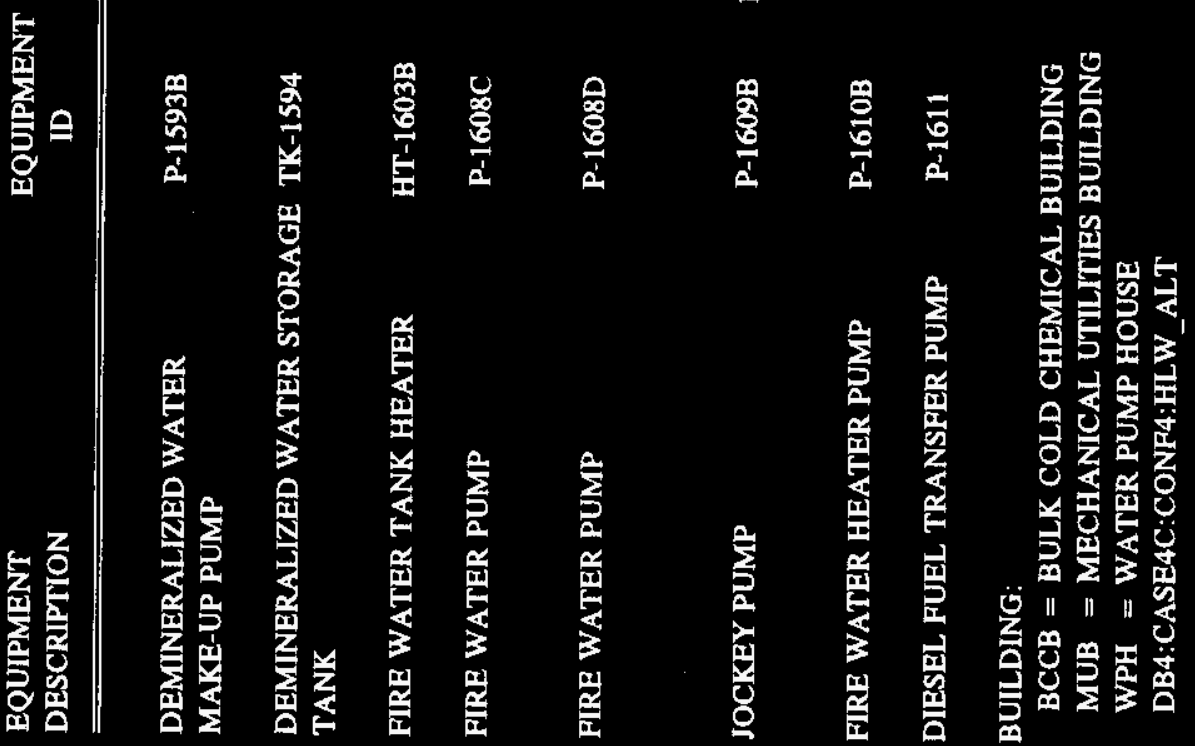


WHC-SD-W378-ES-002

Revision 0

Equipment list

Configuration 4 Revision 02, Issued on 02/16/95

$\sum_{0}^{\frac{1}{2}}$

焉焉

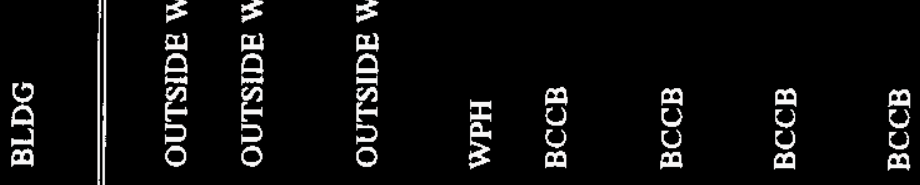

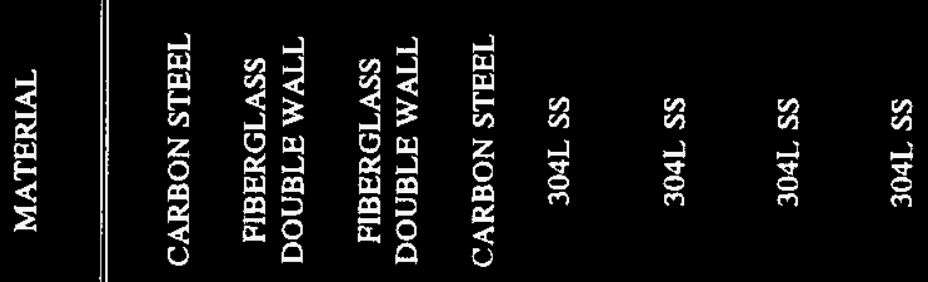

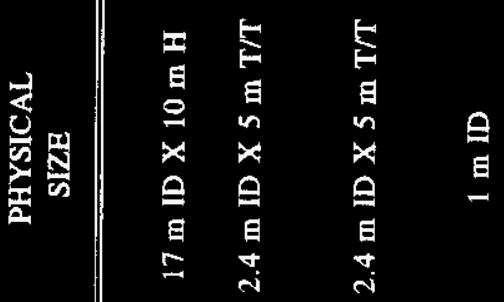

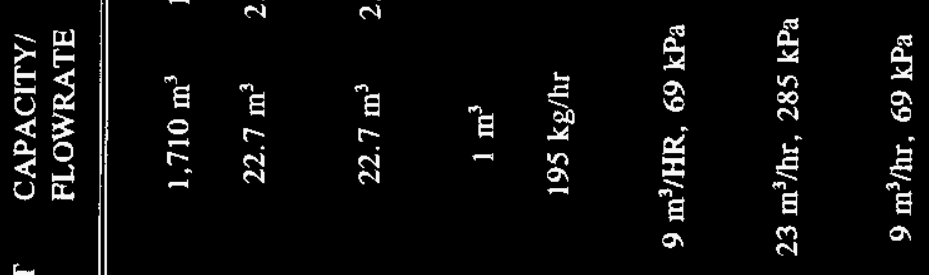

睱

$\frac{m}{\frac{m}{6}}$

$\stackrel{\frac{9}{5}}{\frac{n}{0}} \quad \frac{n}{0}$

㕝

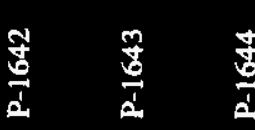

官富

完

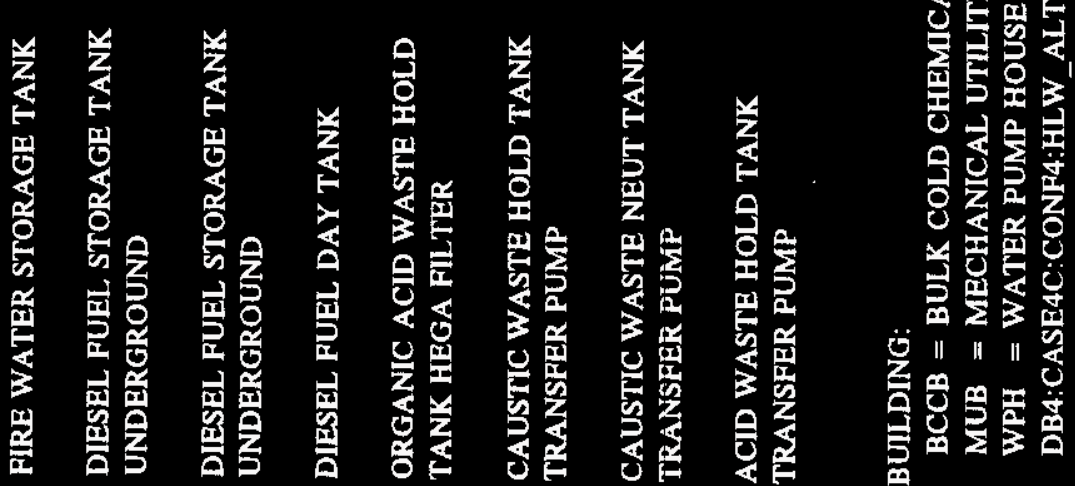

E2-11 


\section{WHC-SD-W378-ES-002 \\ Revision 0}

Equipment list

Configuration 4 Revision 02, Issued on 02/16/95

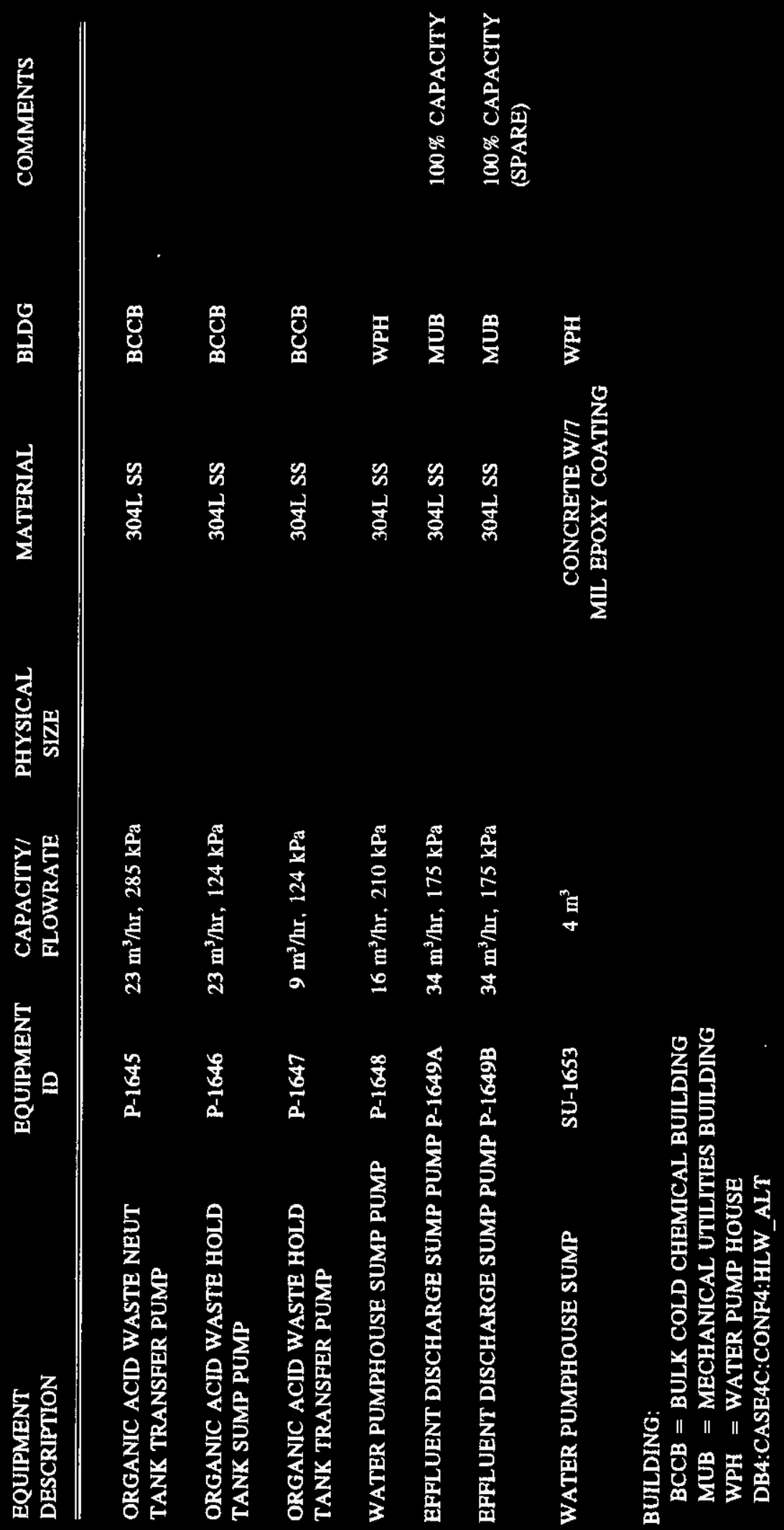

E2-12 


\section{WHC-SD-W378-ES-002 \\ Revision 0}

Equipment list

Configuration 4 Revision 02 , Issued on $02 / 16 / 95$

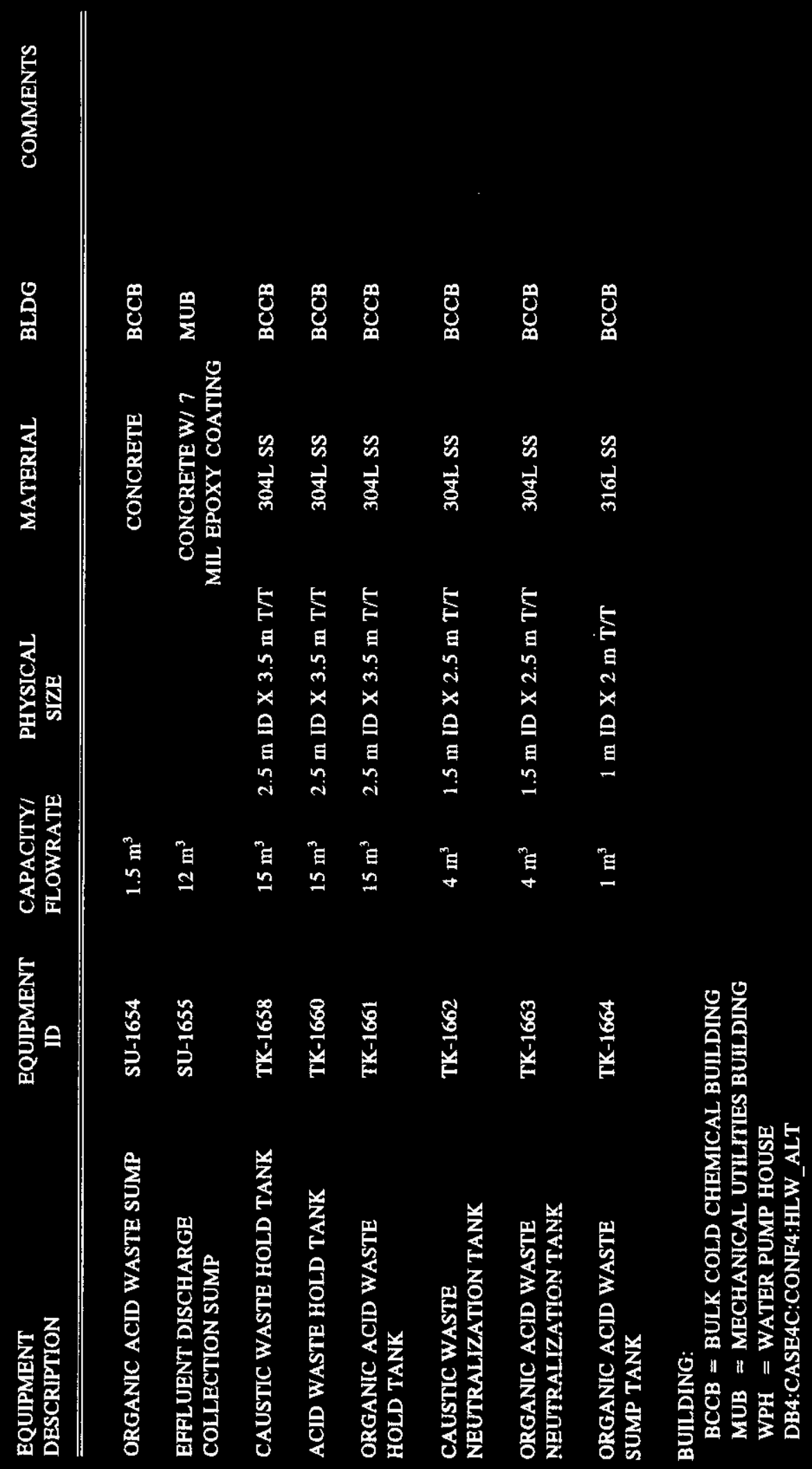




\section{WHC-SD-W378-ES-002}

Revision 0

Equipment list

Configuration 4 Revision 02, Issued on 02/16/95

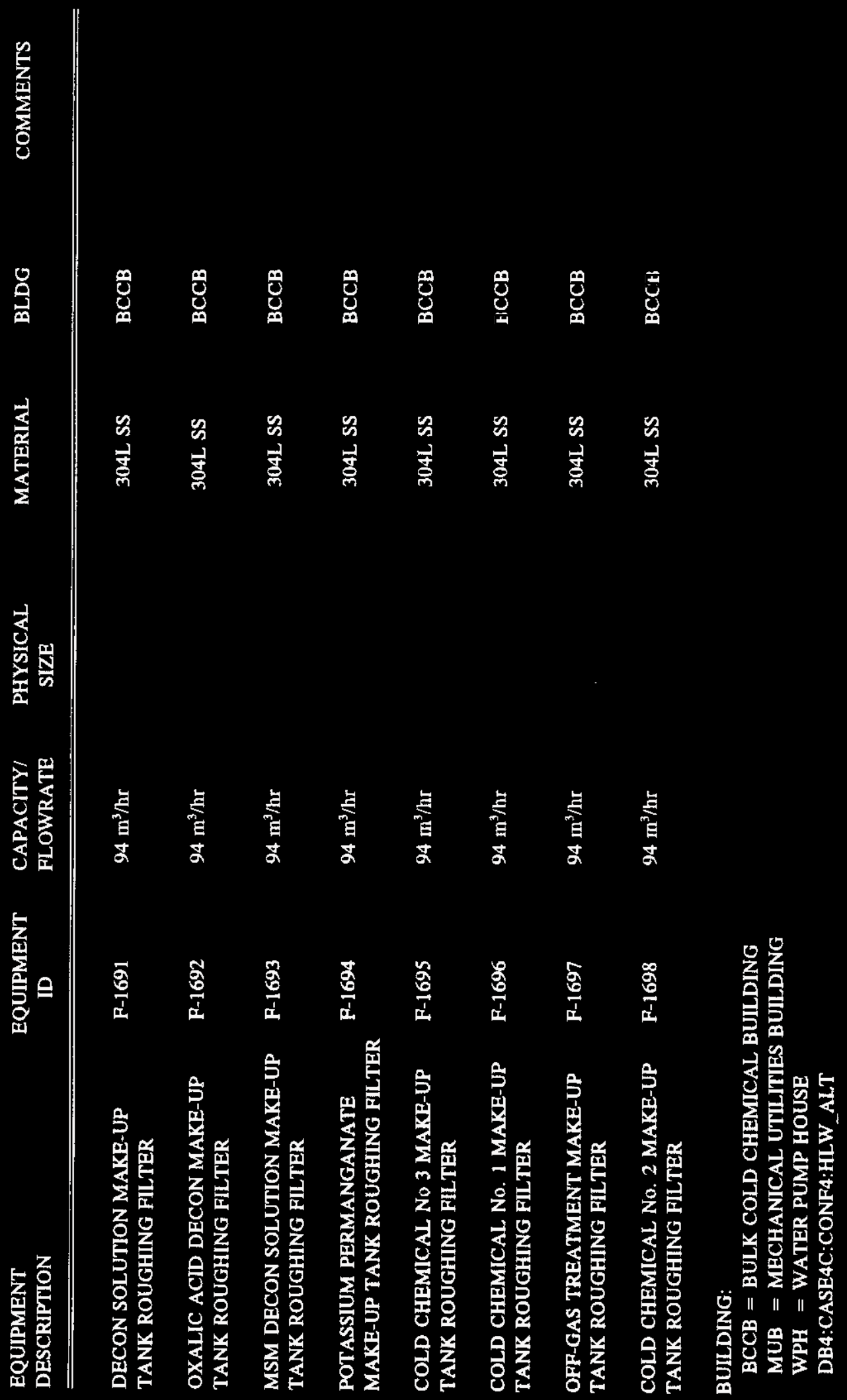




\section{WHC-SD-W378-ES-002 \\ Revision 0}

Equipment list

Configuration 4 Revision 02, Issued on 02/16/95

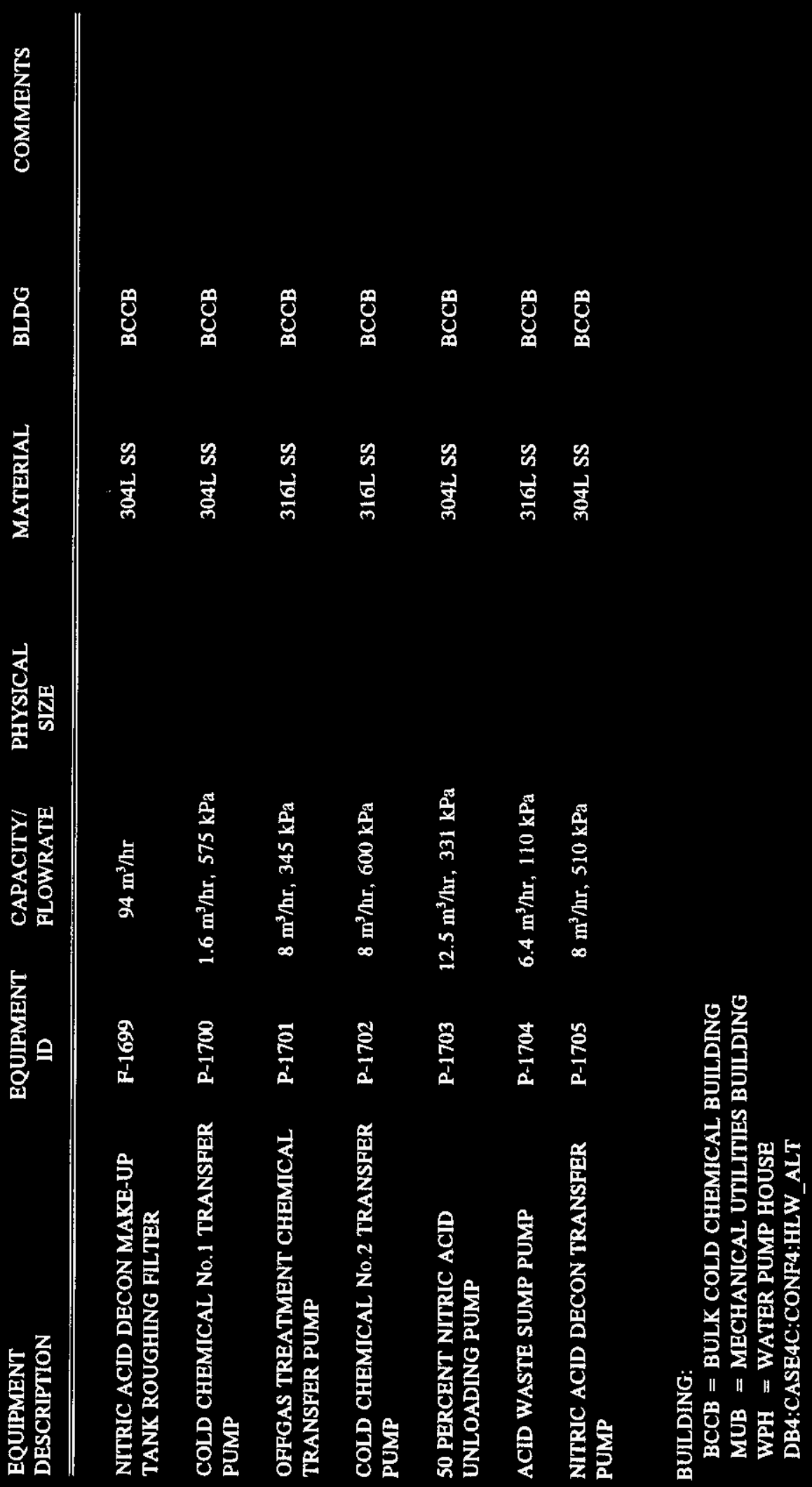




\section{WHC-SD-W378-ES-002 \\ Revision 0}

Equipment list

Configuration 4 Revision 02, Issued on 02/16/95

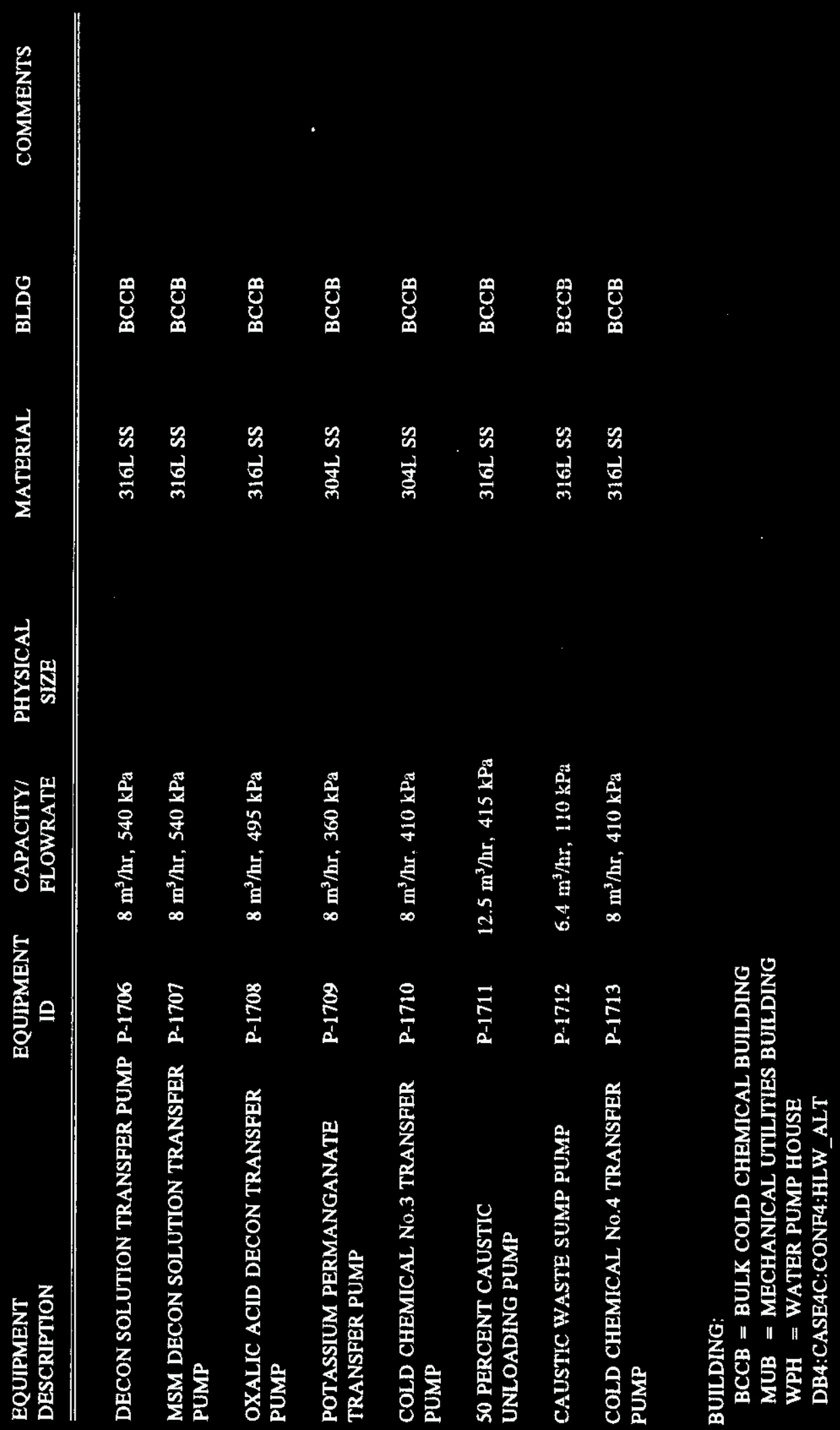

E2-16 


\begin{tabular}{|c|c|c|c|c|c|c|}
\hline $\begin{array}{l}\text { EQUIPMENT } \\
\text { DESCRIPTION }\end{array}$ & $\begin{array}{l}\text { EQUIPMENT } \\
\text { ID }\end{array}$ & $\begin{array}{l}\text { CAPACITY/ } \\
\text { FLOWRATE }\end{array}$ & $\begin{array}{l}\text { PHYSICAL } \\
\text { SIZE }\end{array}$ & MATERIAL & BLDG & COMMENTS \\
\hline ACID WASTE SUMP & SU-1714 & $11.5 \mathrm{~m}^{3}$ & & $\begin{array}{l}\text { CONCRETE LINED } \\
\text { W/304L SS }\end{array}$ & $\mathrm{BCCB}$ & \\
\hline CAUSTIC WASTE SUMP & SU-1715 & $11.5 \mathrm{~m}^{3}$ & & $\begin{array}{l}\text { CONCRETE LINED } \\
\text { W/ 304L SS }\end{array}$ & ВССB & \\
\hline $\begin{array}{l}\text { COLD CHEMICAL No. } 1 \\
\text { MAKE-UP TANK }\end{array}$ & TK-1716 & $2 \mathrm{~m}^{3}$ & $1.2 \mathrm{~m} \mathrm{ID} \mathrm{X} 2 \mathrm{~m} \mathrm{~T} / \mathrm{T}$ & 304L SS & $\mathrm{BCCB}$ & \\
\hline $\begin{array}{l}\text { OPFGAS TREATMENT CHEMICAL } \\
\text { MAKE-UP TANK }\end{array}$ & TK-1717 & $2 \mathrm{~m}^{3}$ & $1.2 \mathrm{~m} \mathrm{ID} \mathrm{X} 2 \mathrm{~m} \mathrm{~T} / \mathrm{T}$ & 304L SS & $\mathrm{BCCB}$ & \\
\hline $\begin{array}{l}\text { COLD CHEMICAL No. } 2 \\
\text { MAKE-UP TANK }\end{array}$ & TK-1718 & $2 \mathrm{~m}^{3}$ & $1.2 \mathrm{~m} \mathrm{ID} \mathrm{X} 2 \mathrm{~m} \mathrm{~T} / \mathrm{T}$ & 316L SS & $\mathrm{BCCB}$ & \\
\hline $\begin{array}{l}\text { NITRIC ACID DECON MAKE-UP } \\
\text { TANK }\end{array}$ & TK-1719 & $2 \mathrm{~m}^{3}$ & $1.2 \mathrm{~m} \mathrm{ID} \mathrm{X} 2 \mathrm{~m} \mathrm{~T} / \mathrm{T}$ & 304L SS & $\mathrm{BCCB}$ & \\
\hline DECON SOLUTION MAKE-UP TANK & TK-1720 & $2 \mathrm{~m}^{3}$ & $1.2 \mathrm{~m} \mathrm{ID} \mathrm{X} 2 \mathrm{~m} \mathrm{~T} / \mathrm{T}$ & 316L SS & ВССB & \\
\hline $\begin{array}{l}\text { MSM DECON SOLUTION } \\
\text { MAKE-UP TANK }\end{array}$ & TK-1721 & $8 \mathrm{~m}^{3}$ & $2 \mathrm{~m} \mathrm{ID} \times 3 \mathrm{~m} \mathrm{~T} / \mathrm{T}$ & 304L SS & $\mathrm{BCCB}$ & \\
\hline \multicolumn{7}{|c|}{$\begin{array}{l}\text { BUILDING: } \\
\text { BCCB }=\text { BULK COLD CHEMICAL BUILDING } \\
\text { MUB }=\text { MECHANICAL UTILITIES BUILDING } \\
\text { WPH }=\text { = WATER PUMP HOUSE } \\
\text { DB4:CASE4C:CONF4:HLW ALT }\end{array}$} \\
\hline
\end{tabular}


WHC-SD-W378-ES-002

Revision 0

Equipment list

Configuration 4 Revision 02, Issued on 02/16/95

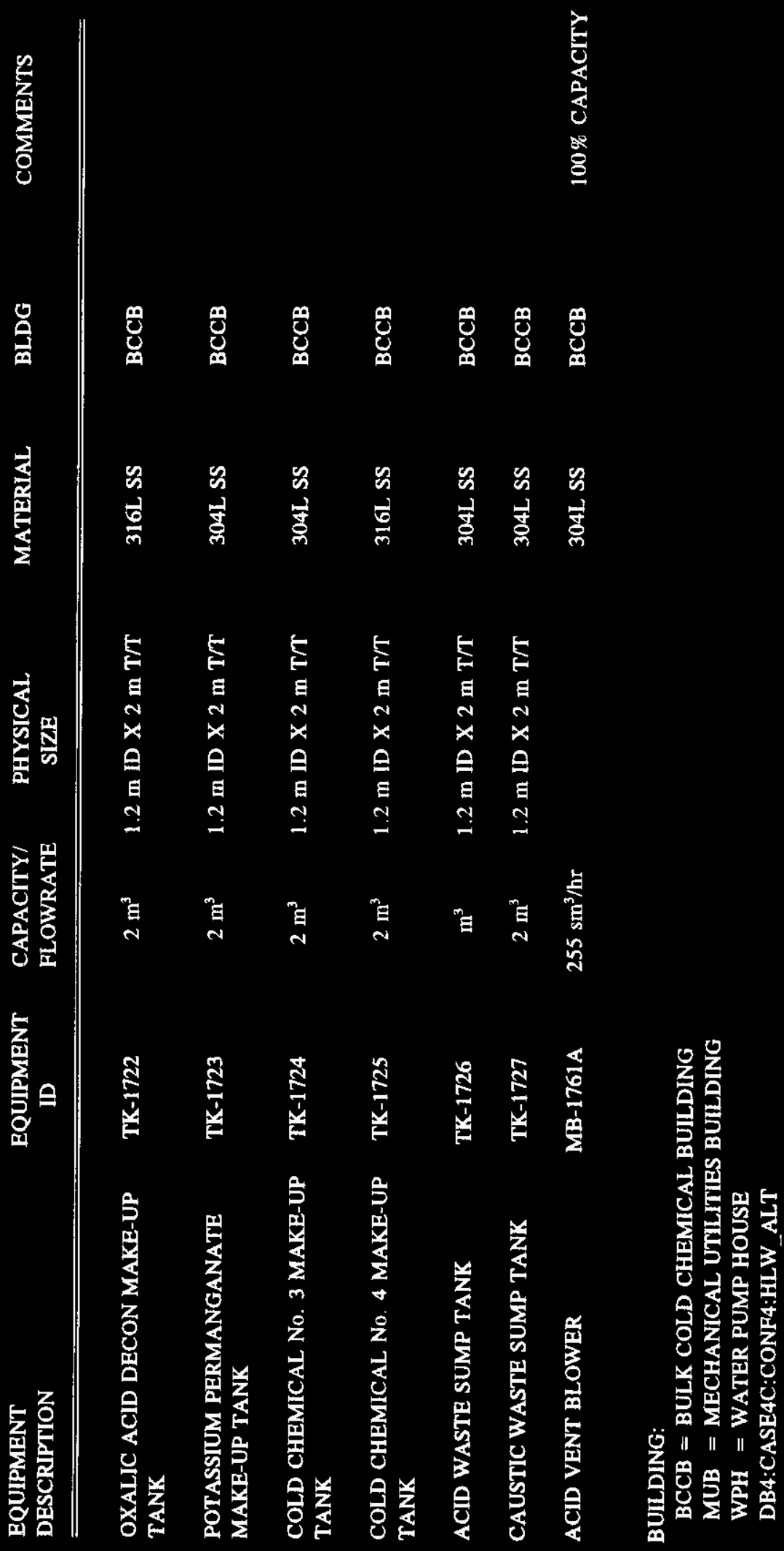




\section{WHC-SD-W378-ES-002 \\ Revision 0}

Equipment list

Configuration 4 Revision 02, Issued on 02/16/95

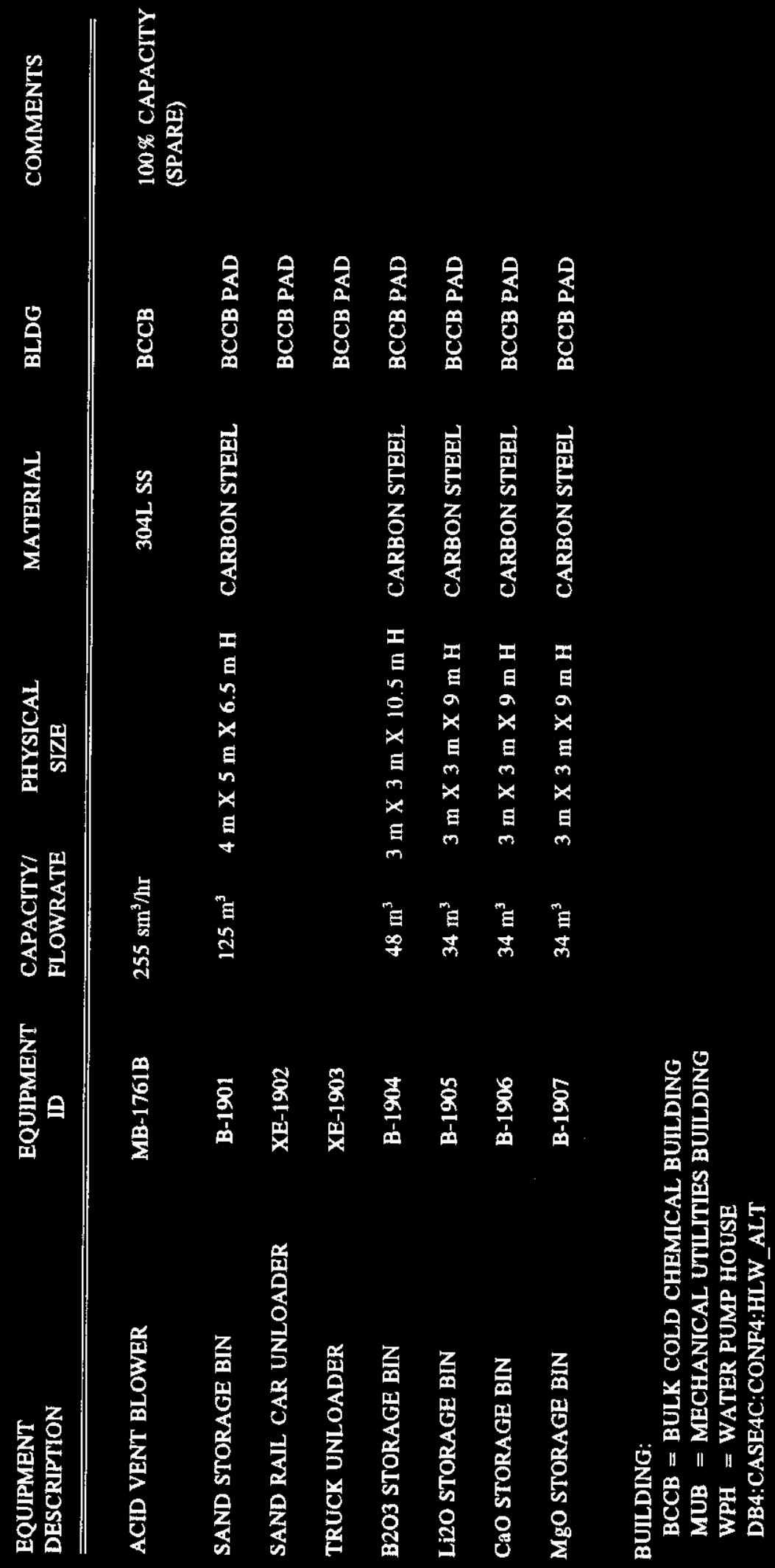




\section{WHC-SD-W378-ES-002 \\ Revision 0}

Equipment list

Configuration 4 Revision 02, Issued on 02/16/95

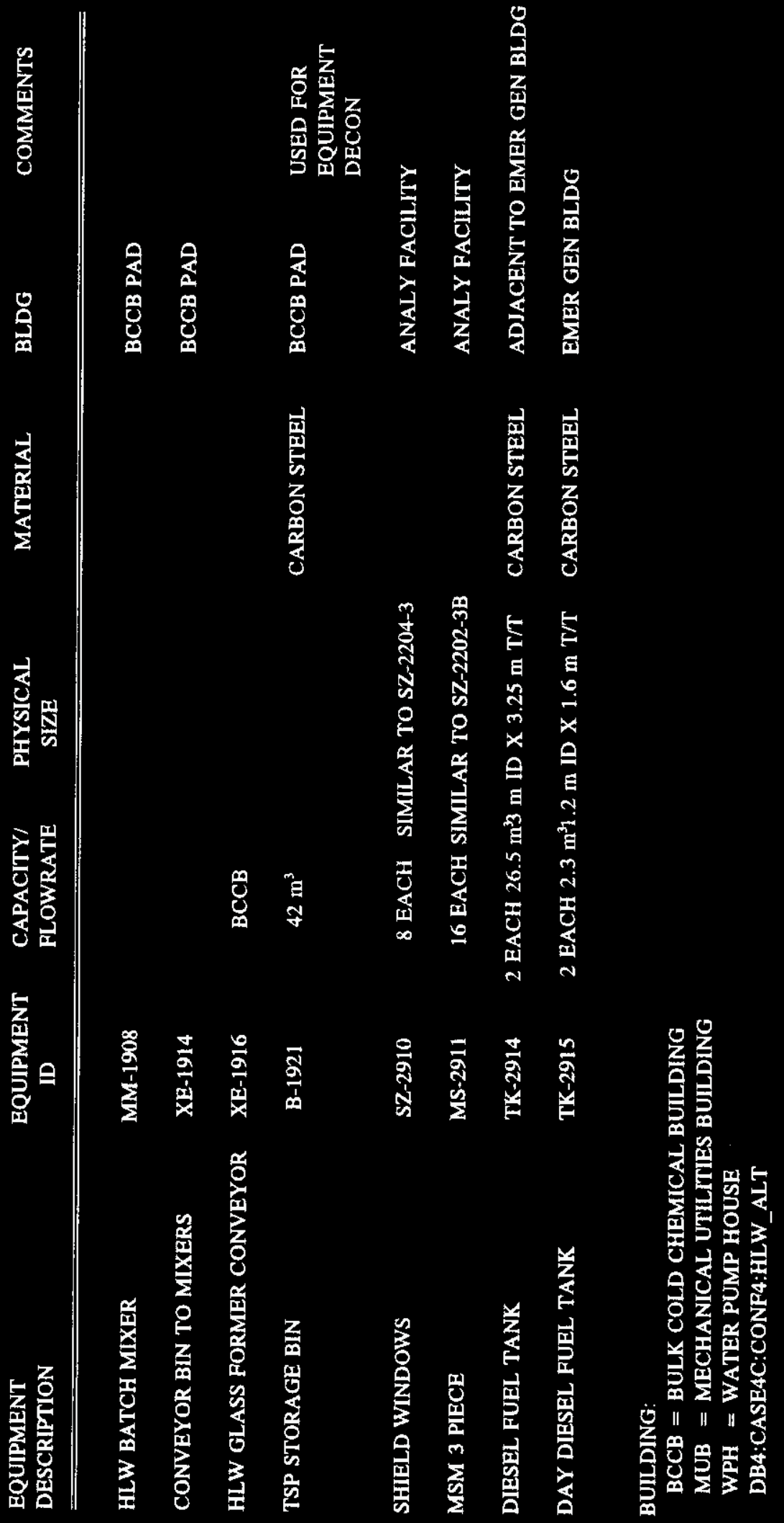




\section{WHC-SD-W378-ES-002 \\ Revision 0}

Equipment list

Configuration 4 Revision 02, Issued on 02/16/95

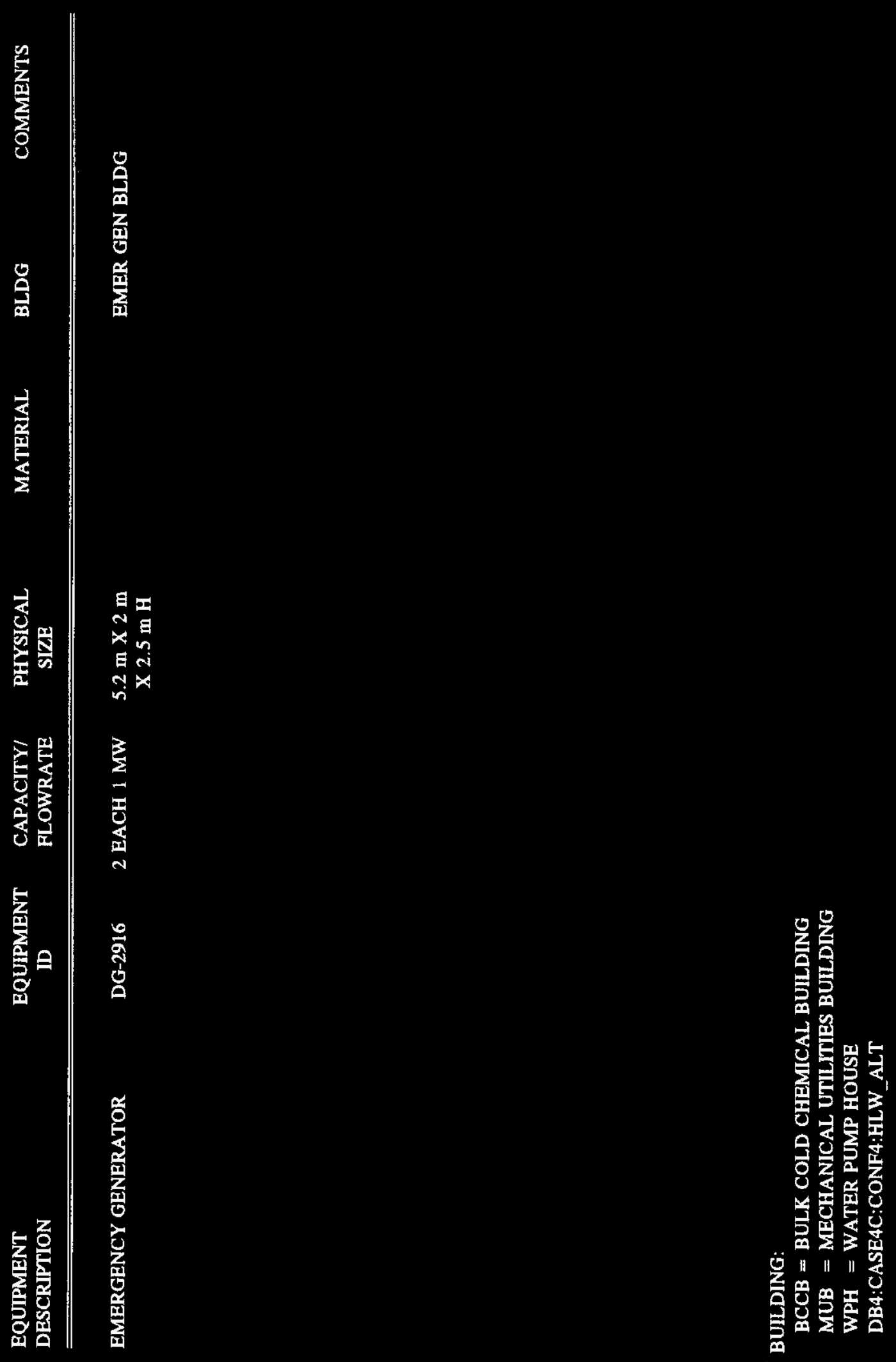


WHC-SD-W378-ES-002

Revision 0

This page intentionally left blank. 
WHC-SD-W378-ES-002

Revision 0

\section{APPENDIX E3}

\section{SEPARATIONS/LOW-LEVEL WASTE STANDALONE SUPPORT FACILITY EQUIPMENT LIST}




\section{WHC-SD-W378-ES-002}

Revision 0

This page intentionally left blank.

E3-2 


\section{WHC-SD-W378-ES-002 \\ Revision 0}

Equipment list

Configuration 4 Revision 02, Issued on 02/16/95

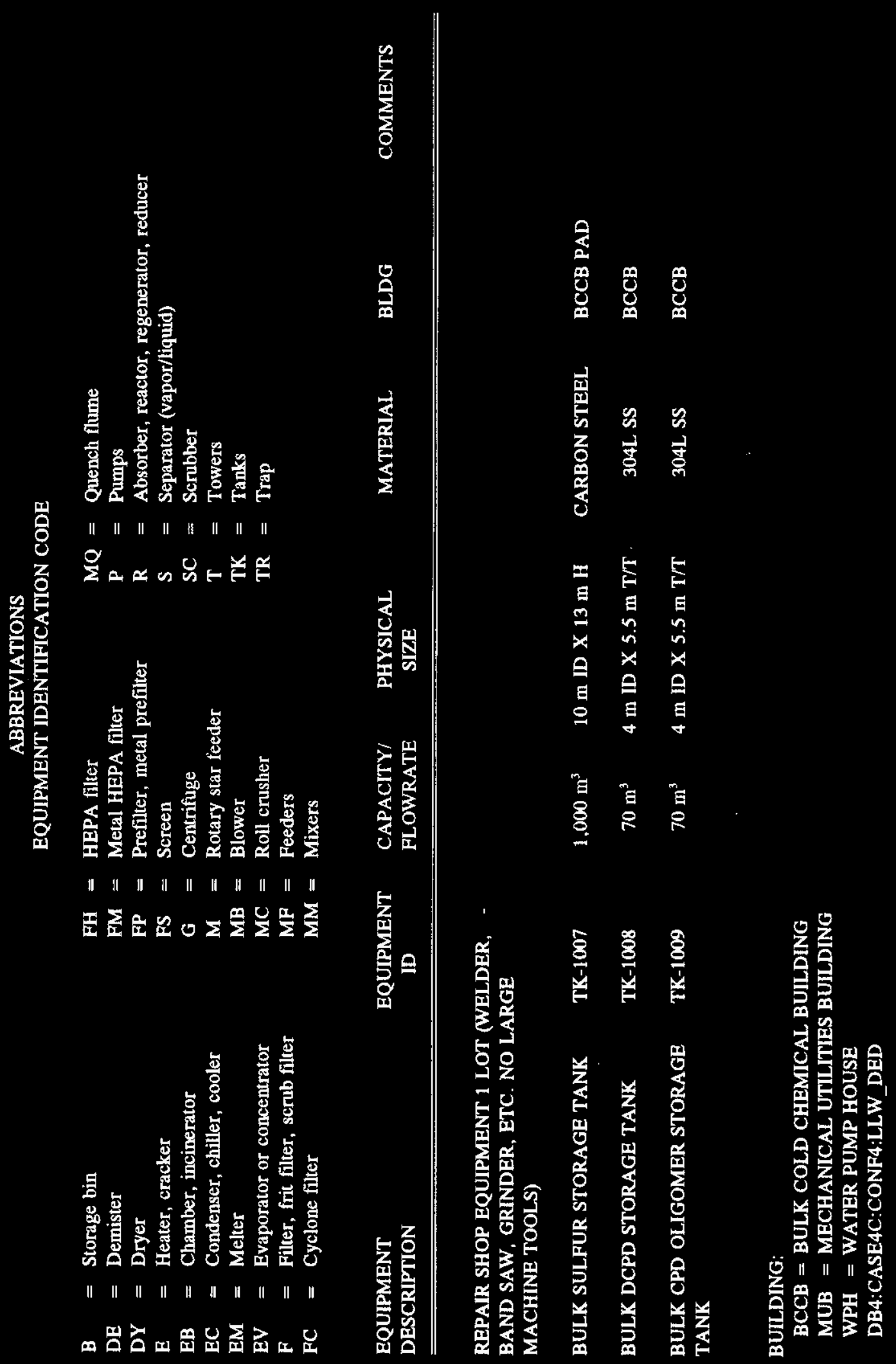




\section{WHC-SD-W378-ES-002 \\ Revision 0}

Equipment list

Configuration 4 Revision 02, Issued on 02/16/95

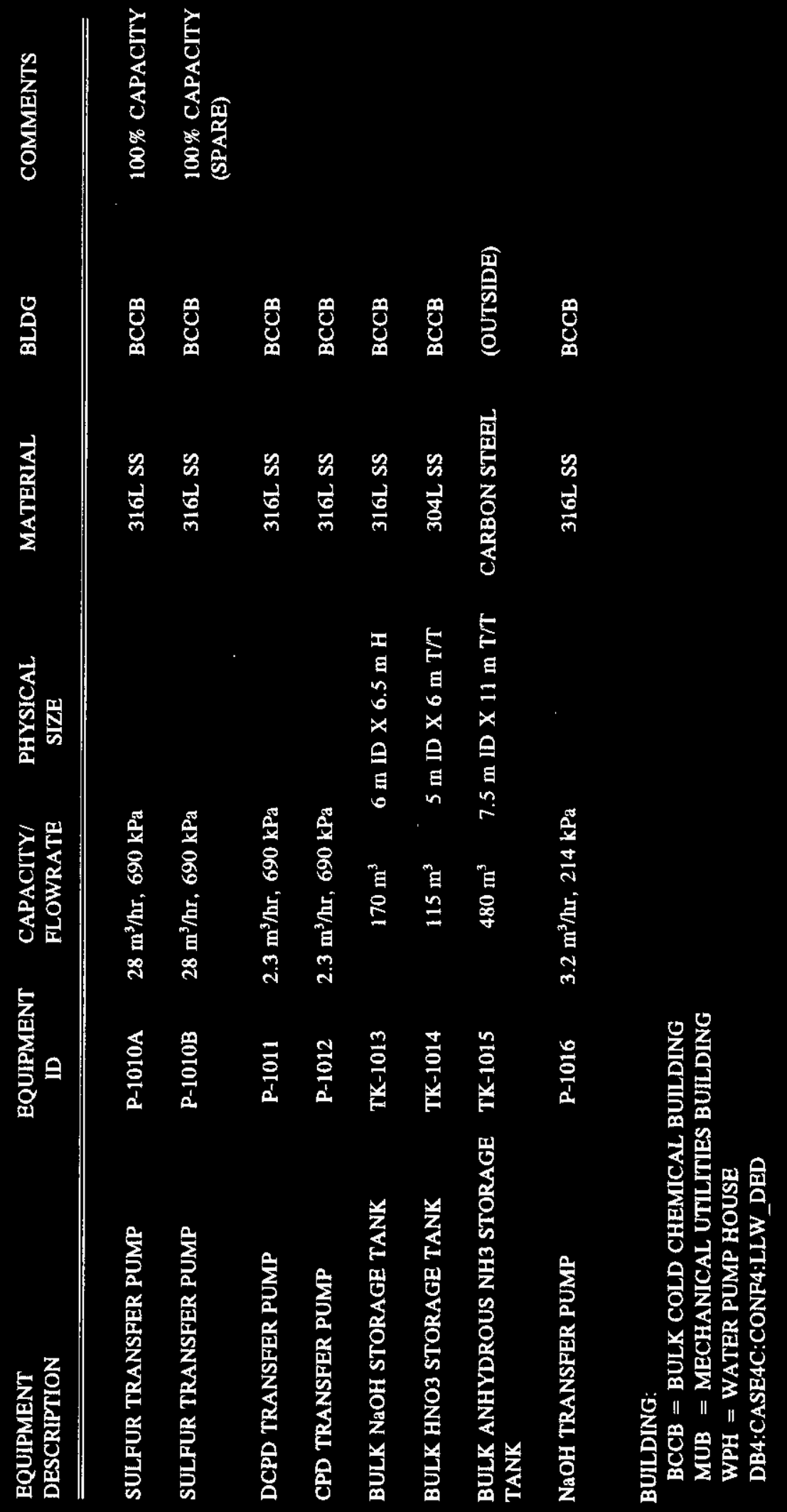

E3-4 
WHC-SD-W378-ES-002

Revision 0

Equipment list

Configuration 4 Revision 02, Issued on 02/16/95

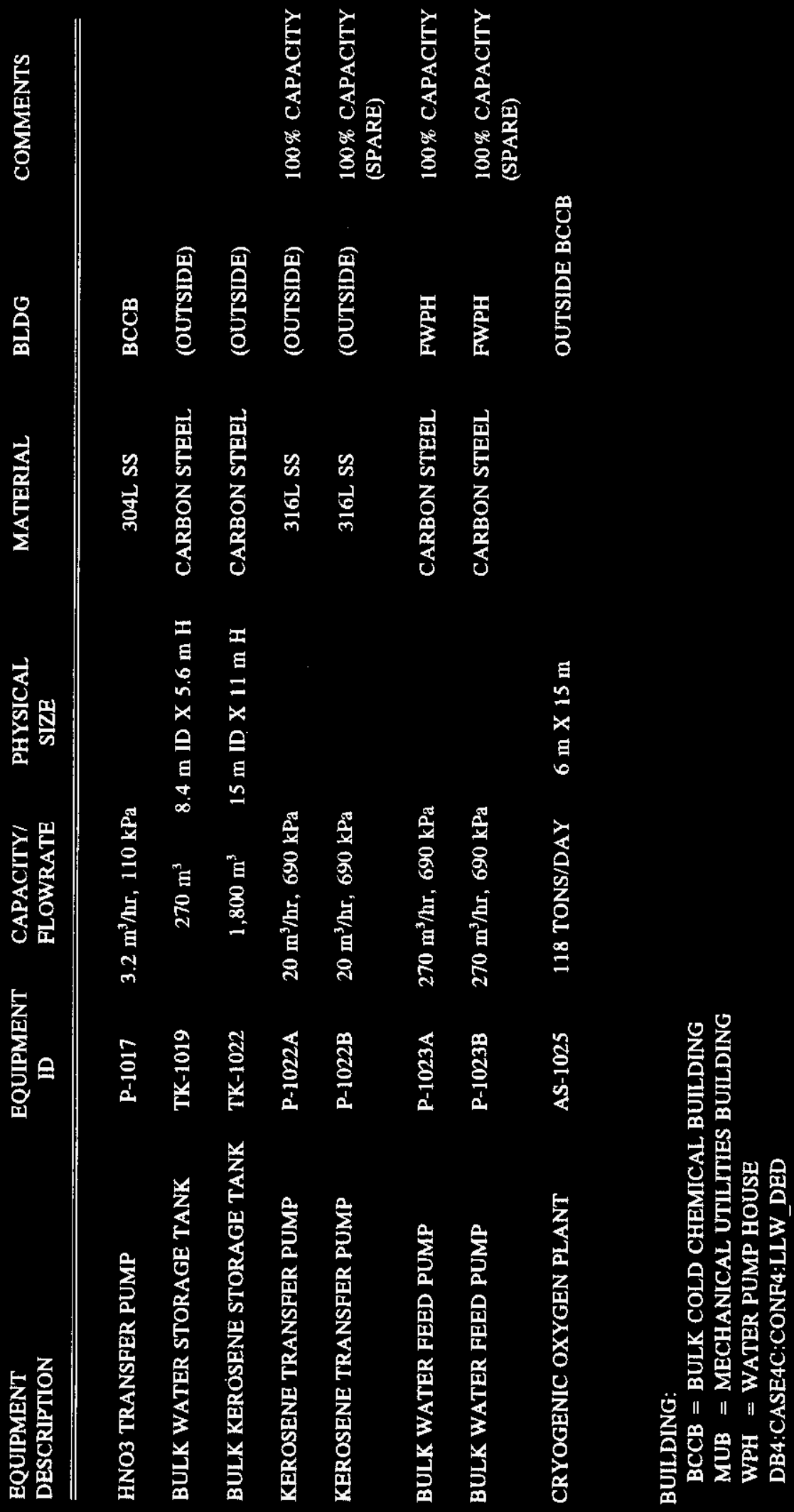




\section{WHC-SD-W378-ES-002 \\ Revision 0}

Equipment list

Configuration 4 Revision 02, Issued on 02/16/95

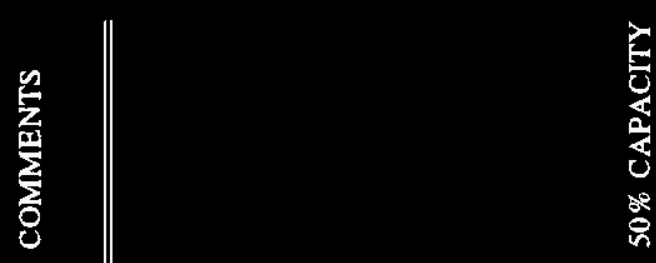

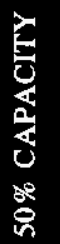

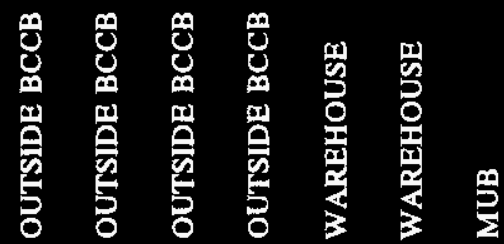

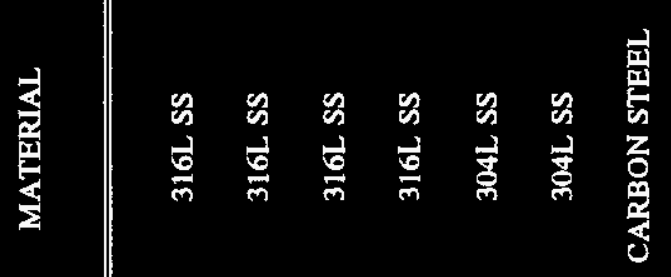

氨

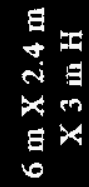

哭

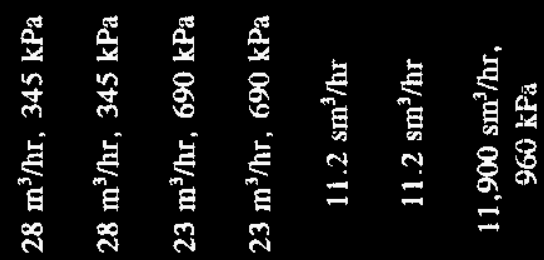

蛋

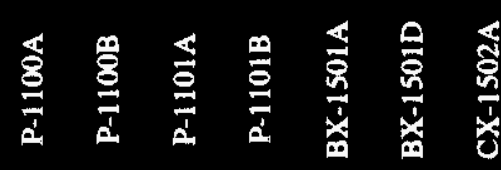

总是

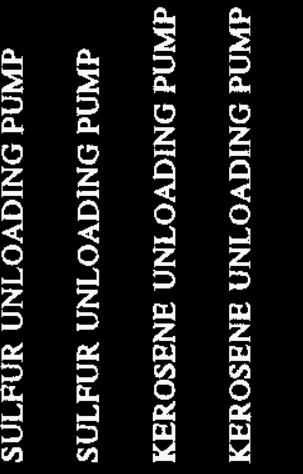

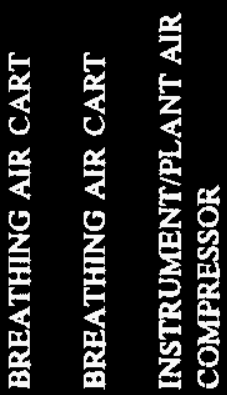

ć.

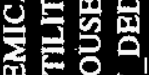

녹

$0 \neq \frac{1}{2}$

을

$8 z$

4 풍

$2 \stackrel{0}{2}$

i

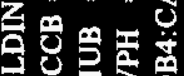

官路家商

E3-6 


\section{WHC-SD-W378-ES-002 \\ Revision 0}

Equipment list

Configuration 4 Revision 02, Issued on 02/16/95

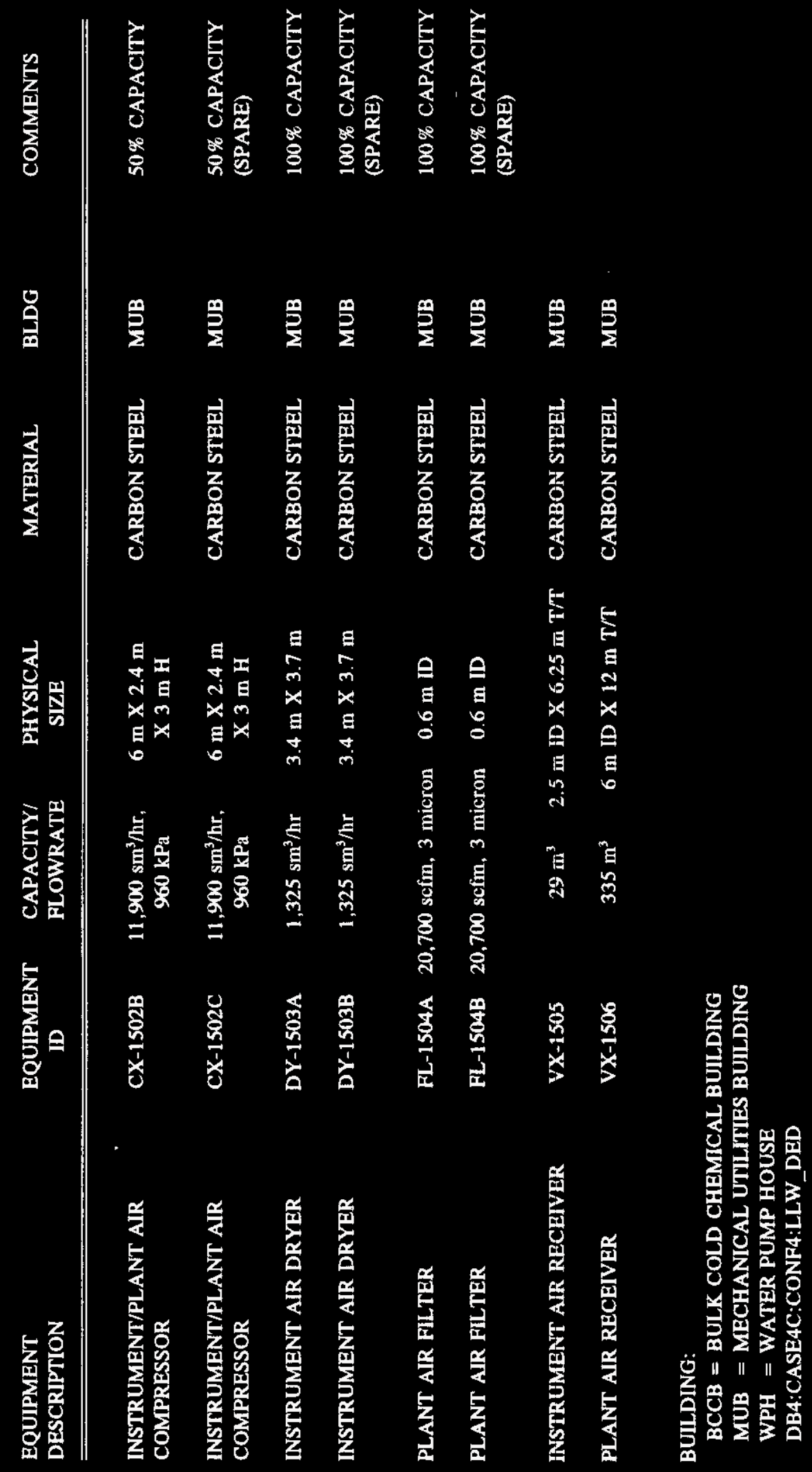




\section{WHC-SD-W378-ES-002 \\ Revision 0}

Equipment list

Configuration 4 Revision 02, Issued on 02/16/95

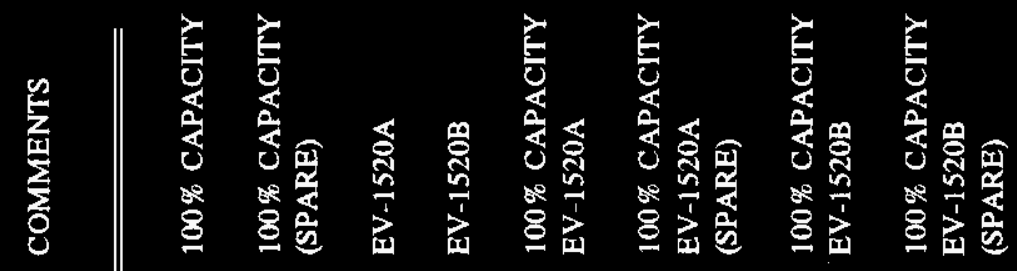

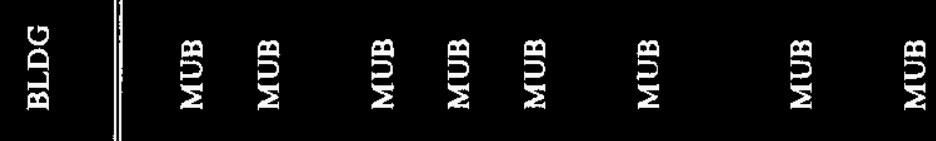

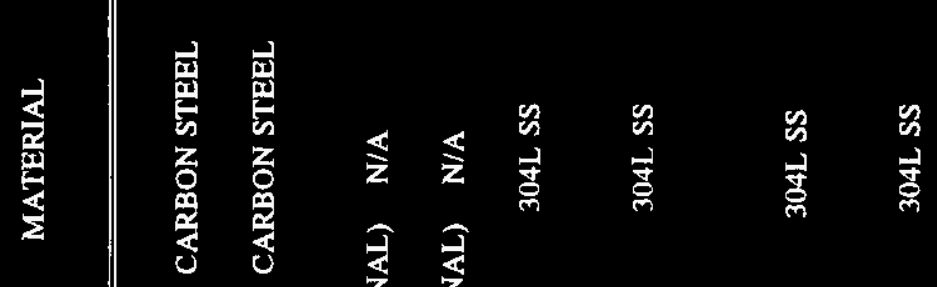

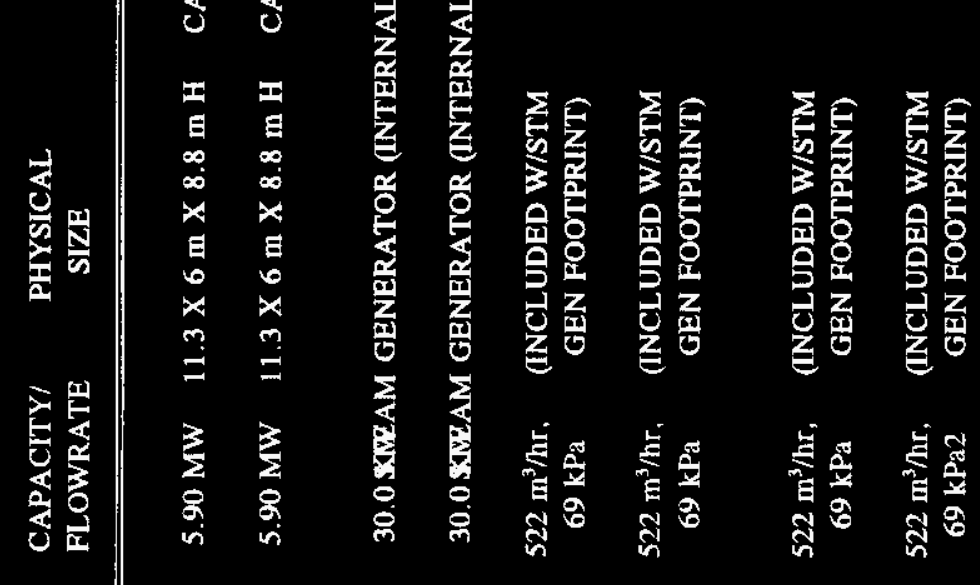

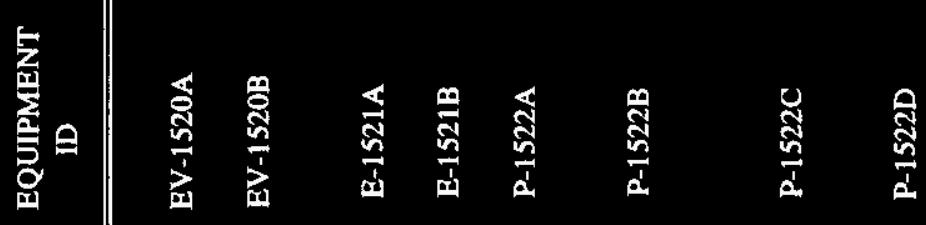

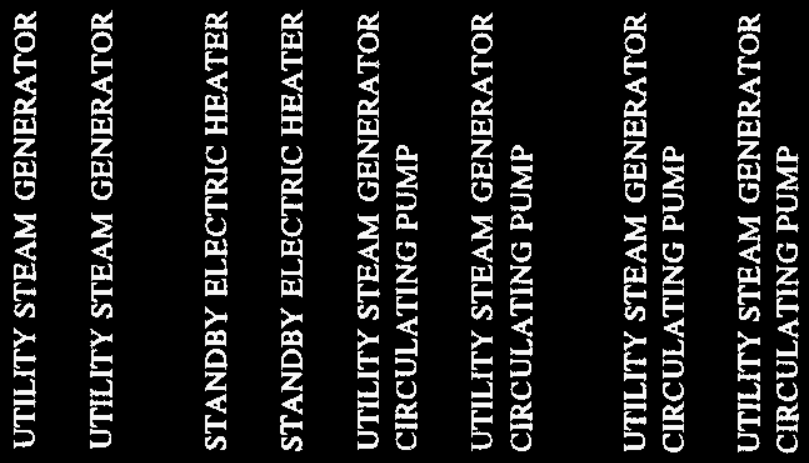

总总

窟

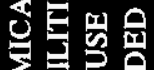

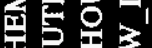

㨁产

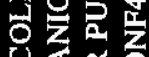

눙용

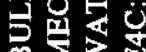

iो "

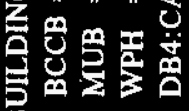


WHC-SD-W378-ES-002

Revision 0

Equipment list

Configuration 4 Revision 02, Issued on 02/16/95

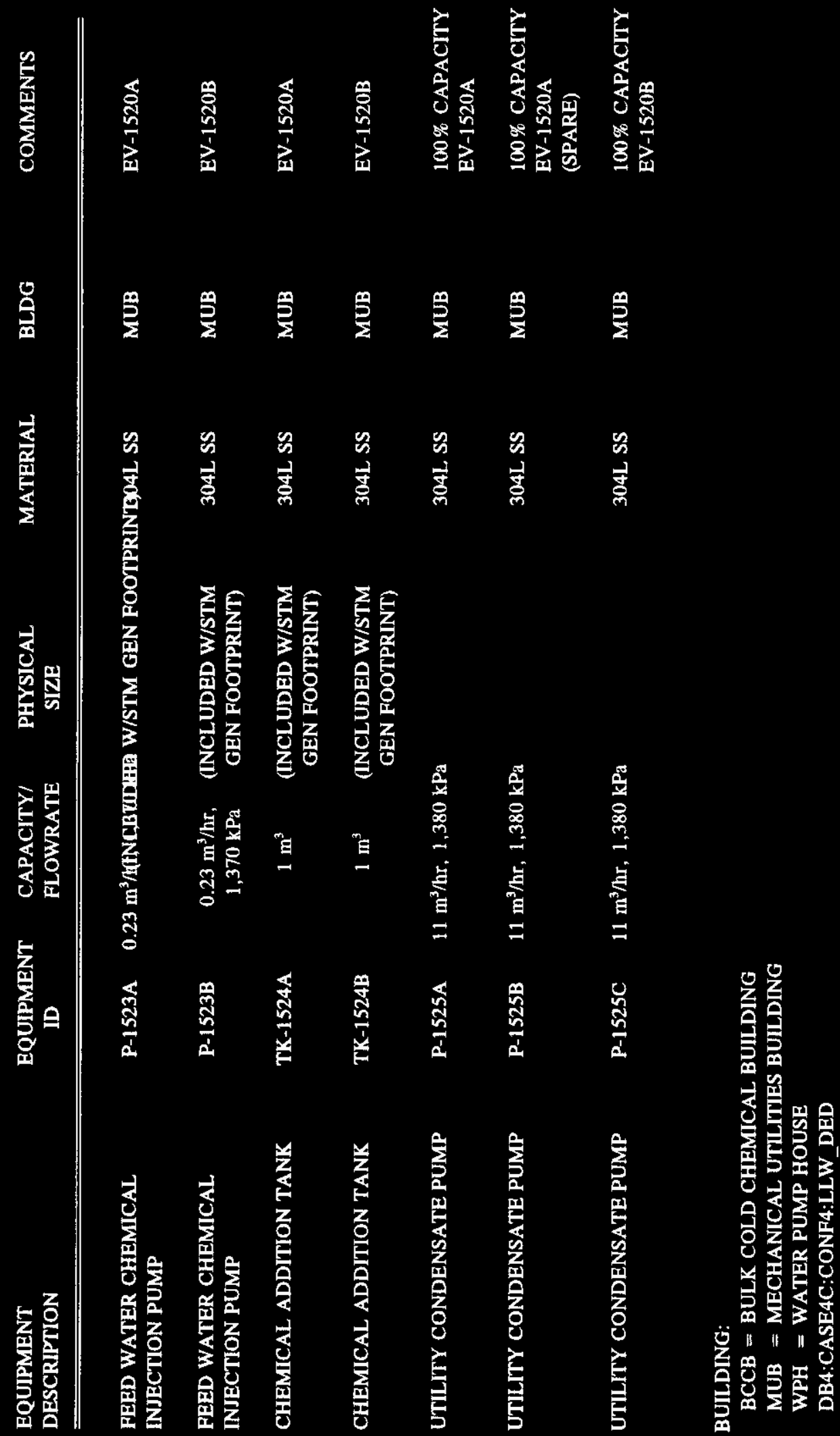




\section{WHC-SD-W378-ES-002 \\ Revision 0}

Equipment list

Configuration 4 Revision 02, Issued on 02/16/95

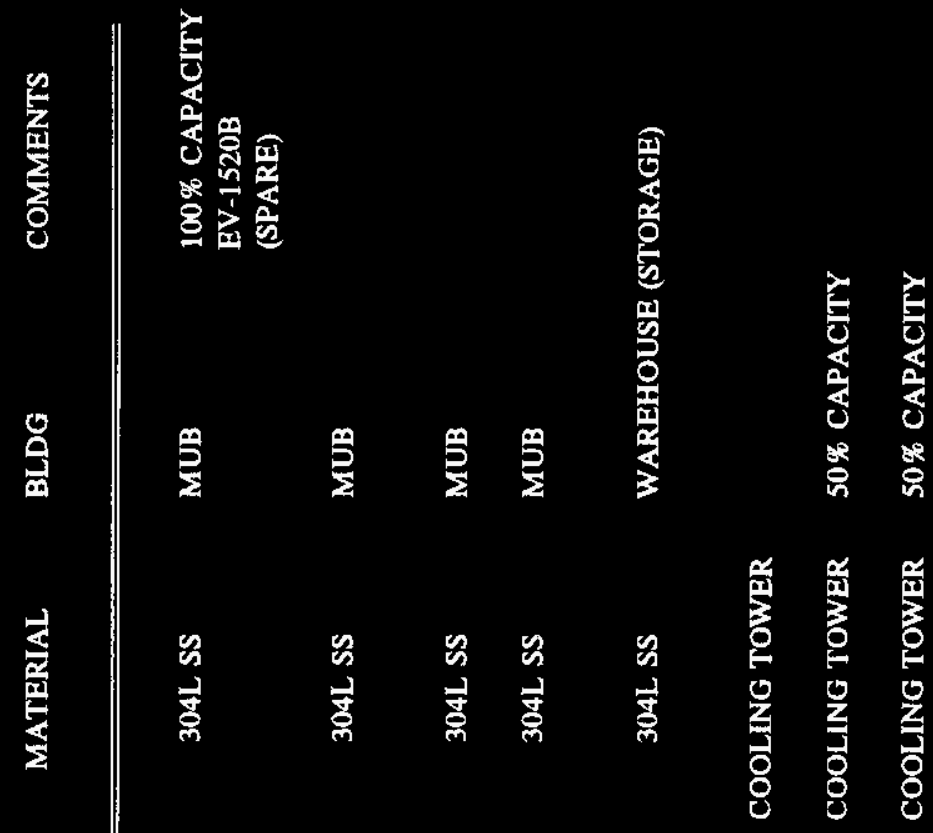

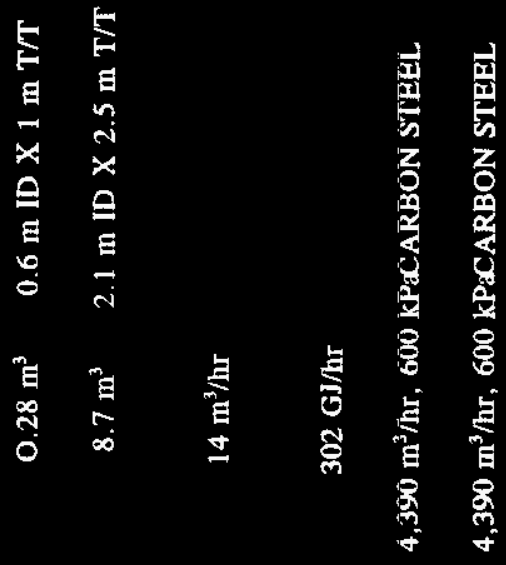

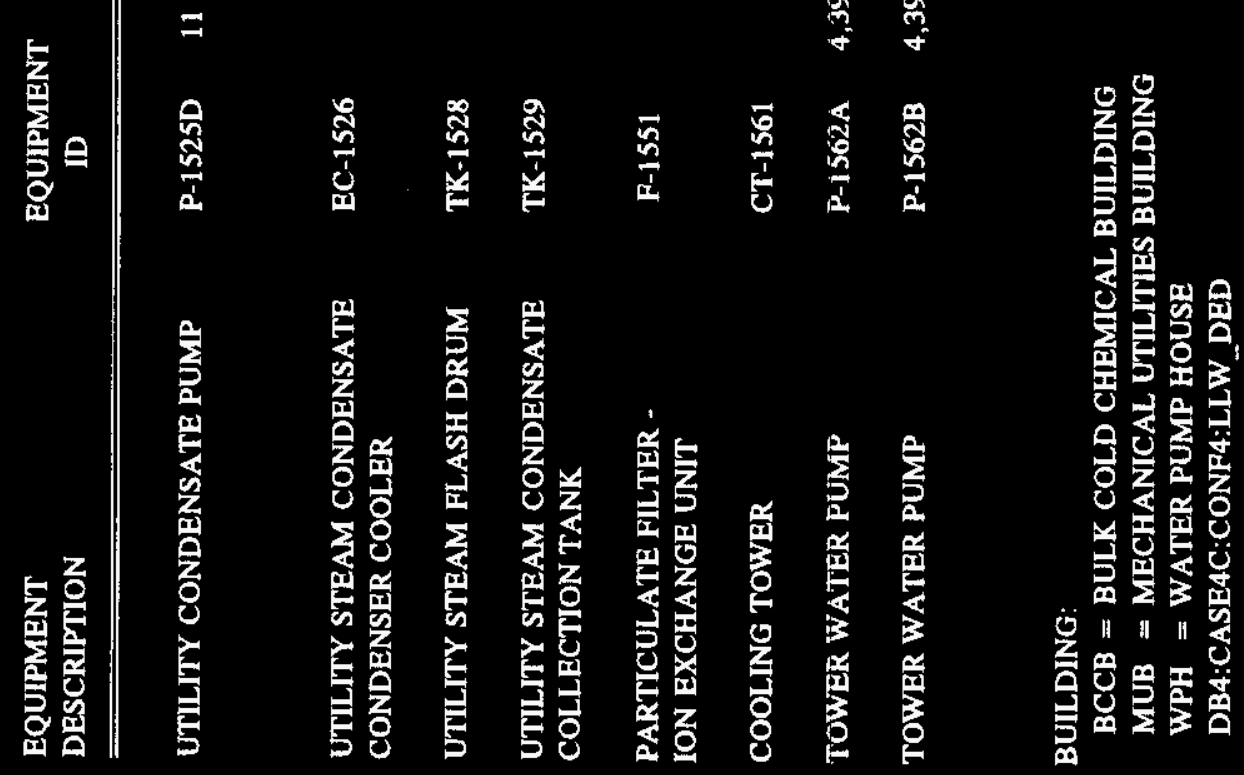

E3-10 
WHC-SD-W378-ES-002

Revision 0

Equipment list

Configuration 4 Revision 02, Issued on 02/16/95

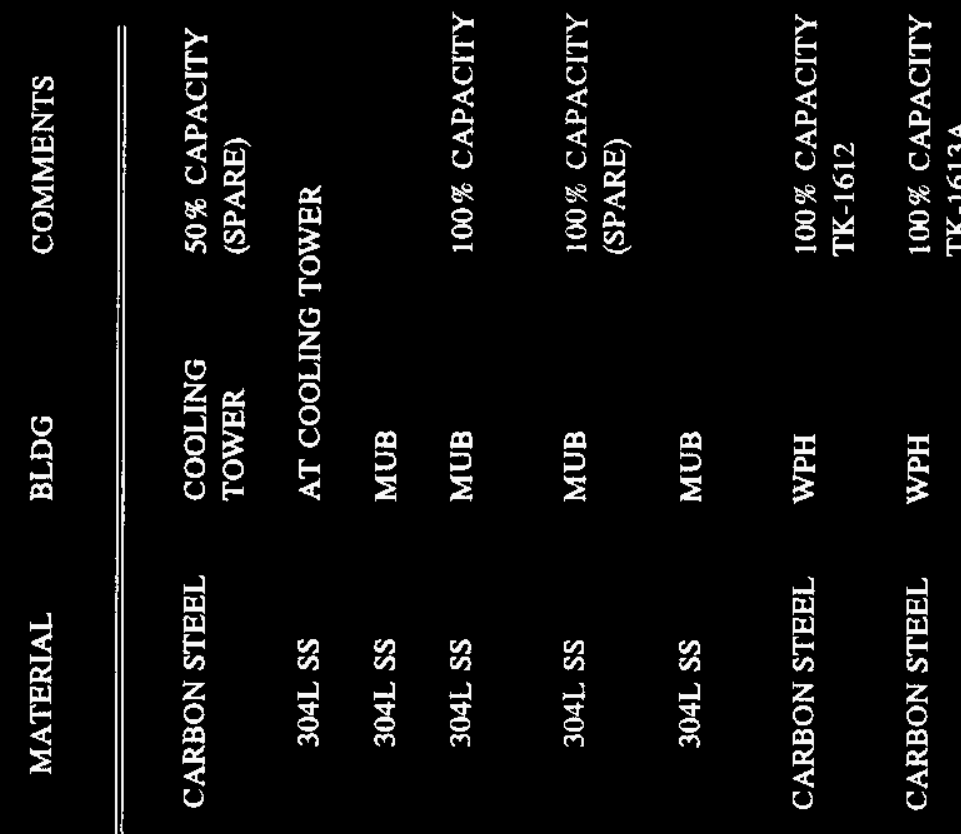

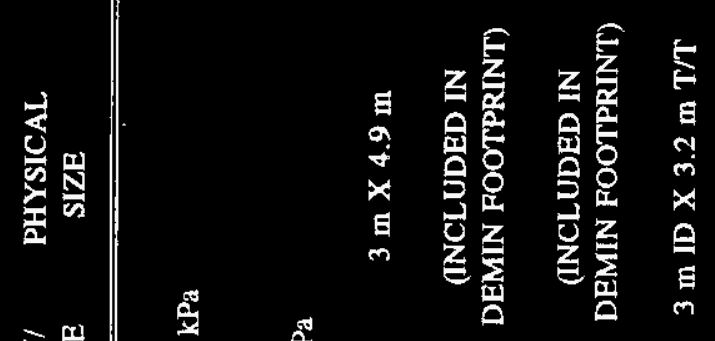

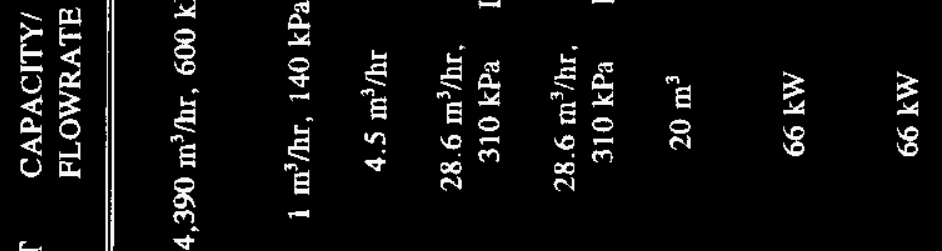

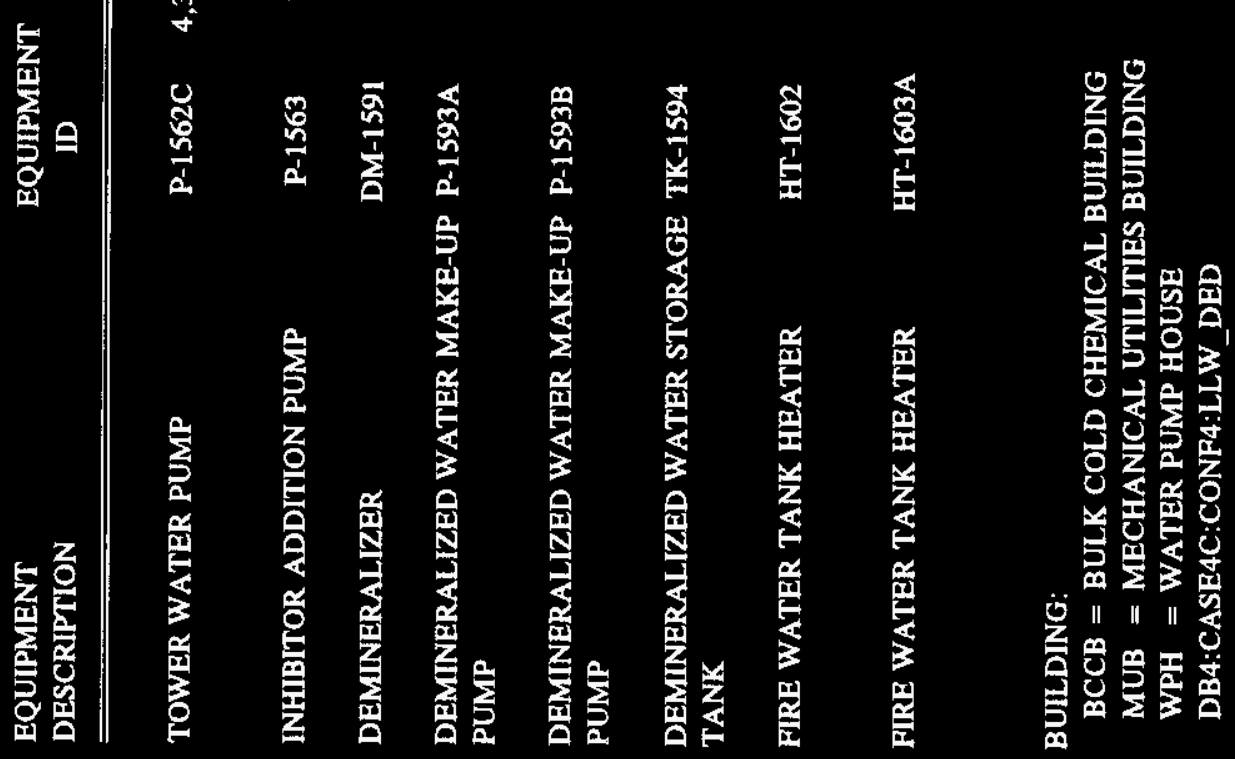




\section{WHC-SD-W378-ES-002 \\ Revision 0}

Equipment list

Configuration 4 Revision 02, Issued on 02/16/95

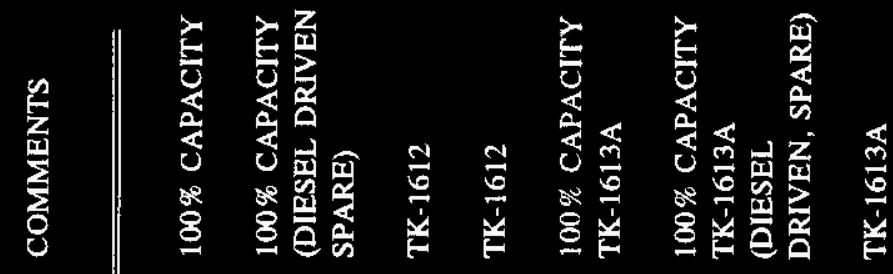

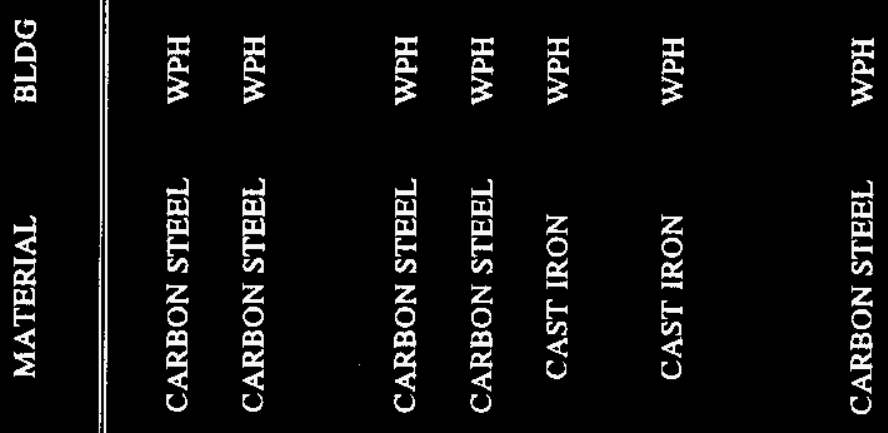

通

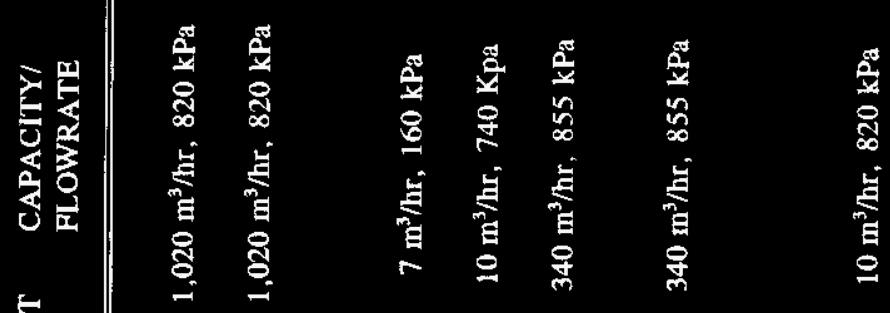

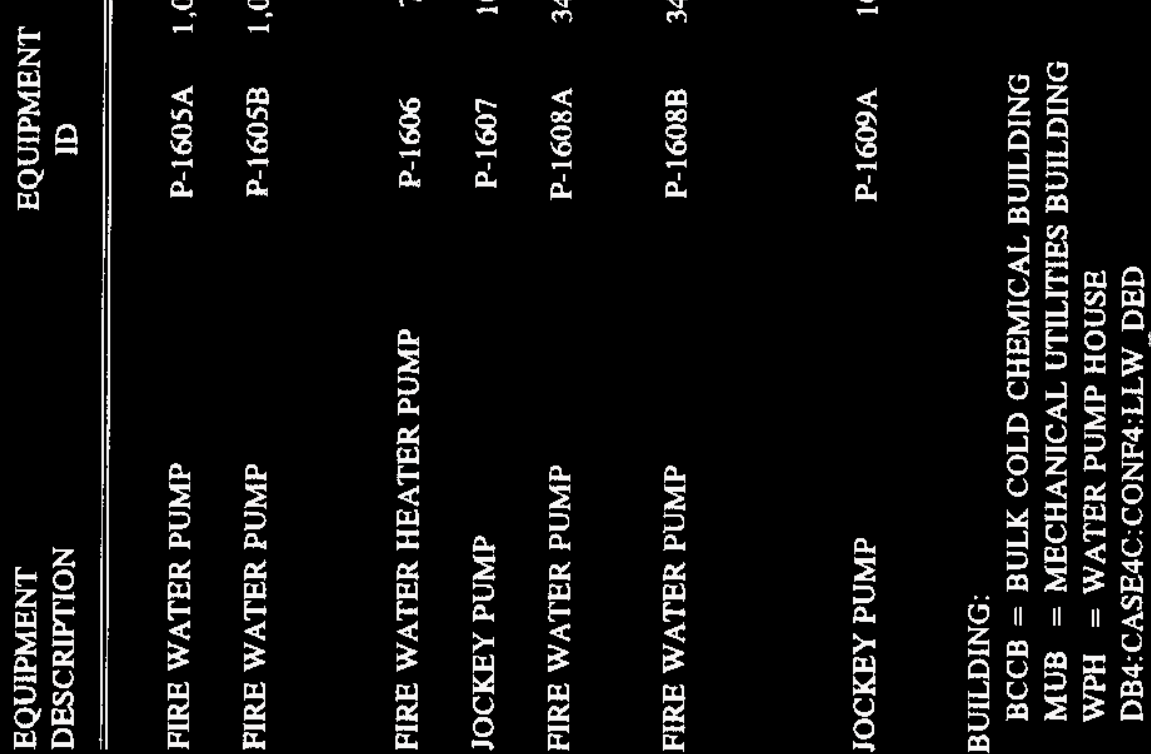

E3-12 


\section{WHC-SD-W378-ES-002}

\section{Revision 0}

Equipment list

Configuration 4 Revision 02, Issued on 02/16/95

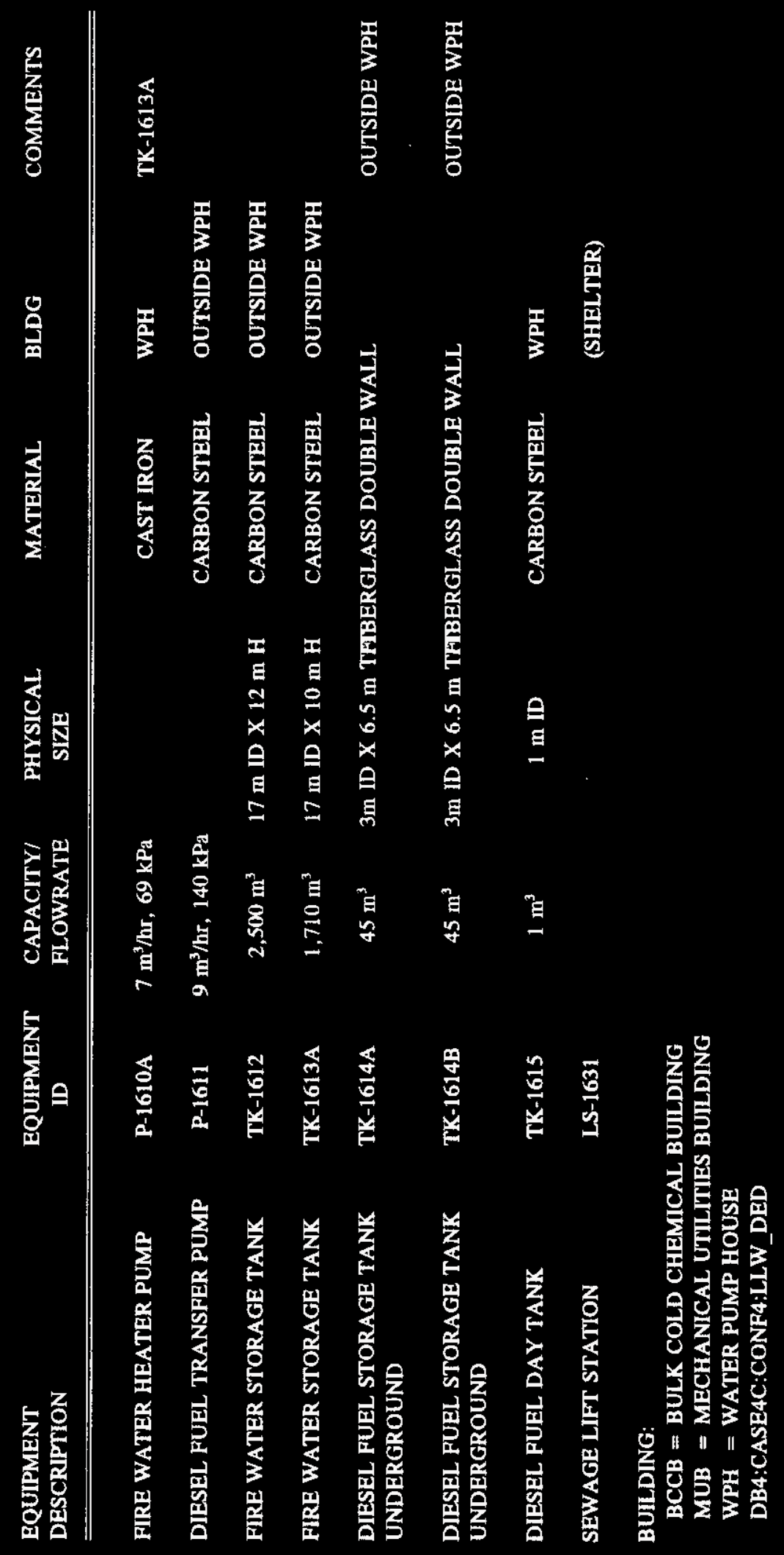

E3-13 


\section{WHC-SD-W378-ES-002}

Revision 0

Equipment list

Configuration 4 Revision 02, Issued on 02/16/95

$\sum_{0}^{2}$

尝

空

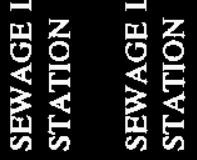

思

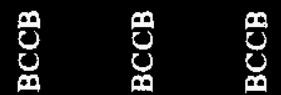

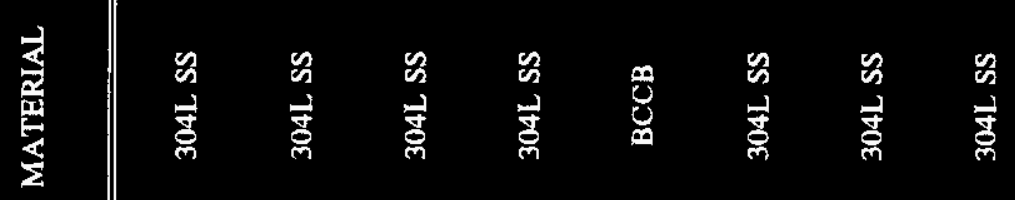

萦瓷

क

禽

窟

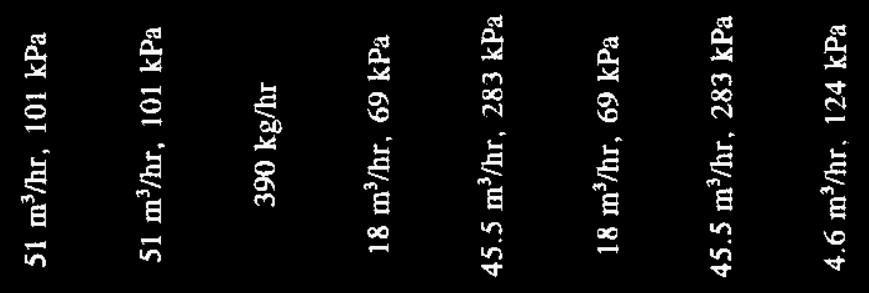

竞

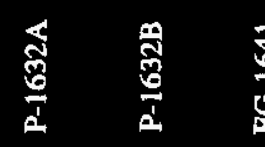

$\frac{8}{6}$

章

$\frac{a^{2}}{\frac{\pi}{2}}$

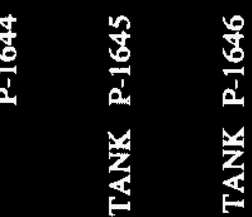

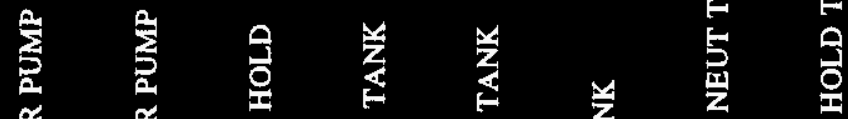

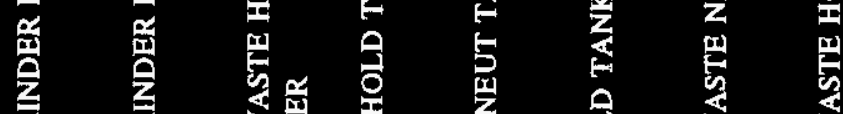

密 紊

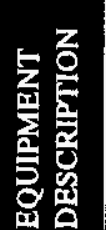

恶

即定

일 월

$\exists$

䱛

誉

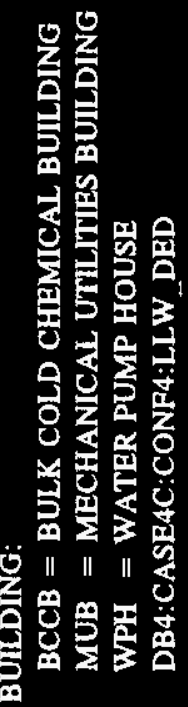




\section{WHC-SD-W378-ES-002 \\ Revision 0}

Equipment list

Configuration 4 Revision 02, Issued on 02/16/95

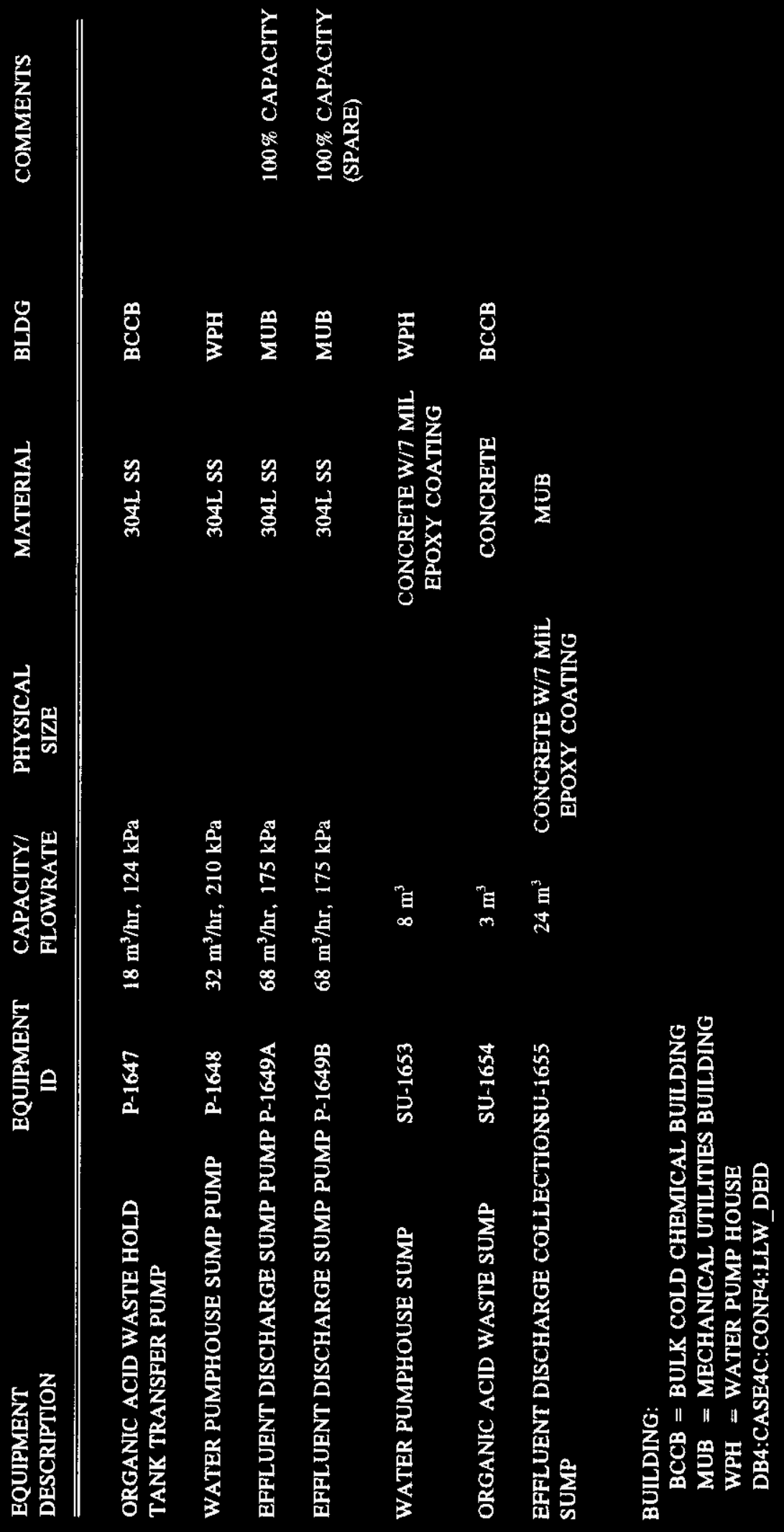




\begin{tabular}{|c|c|c|c|c|c|c|}
\hline $\begin{array}{l}\text { EQUIPMENT } \\
\text { DESCRIPTION }\end{array}$ & $\begin{array}{l}\text { EQUIPMENT } \\
\text { ID }\end{array}$ & $\begin{array}{l}\text { CAPACITY/ } \\
\text { FLOWRATE }\end{array}$ & $\begin{array}{l}\text { PHYSICAL } \\
\text { SIZE }\end{array}$ & MATERIAL & BLDG & COMMENTS \\
\hline CAUSTIC WASTE HOLD TANK & TK-1658 & $30 \mathrm{~m}^{3}$ & $3 \mathrm{~m} \mathrm{ID} \mathrm{X} 4.5 \mathrm{~m} \mathrm{~T} / \mathrm{T}$ & $304 \mathrm{~L}$ SS & BCCB & \\
\hline ACID WASTE HOLD TANK & TK-1660 & $30 \mathrm{~m}^{3}$ & $3 \mathrm{~m} \mathrm{ID} \mathrm{X} 4.5 \mathrm{~m} \mathrm{~T} / \mathrm{T}$ & 304L sS & BCCB & \\
\hline ORGANIC ACID WASTE HOLD TANE & T TK-1661 & $30 \mathrm{~m}^{3}$ & $3 \mathrm{~m} \mathrm{ID} \mathrm{X} 4.5 \mathrm{~m} \mathrm{~T} / \mathrm{T}$ & 304L SS & BCCB & \\
\hline $\begin{array}{l}\text { CAUSTIC WASTE NEUTRALIZATION } \\
\text { TANK }\end{array}$ & TK-1662 & $8 \mathrm{~m}^{3}$ & $2 \mathrm{~m} \mathrm{ID} \mathrm{X} 3 \mathrm{~m} \mathrm{~T} / \mathrm{T}$ & 304L SS & $\mathrm{BCCB}$ & \\
\hline $\begin{array}{l}\text { ORGANIC ACID WASTE } \\
\text { NEUTRALIZATION TANK }\end{array}$ & TK-1663 & $8 \mathrm{~m}^{3}$ & $2 \mathrm{~m} \mathrm{ID} \mathrm{X} 3 \mathrm{~m}$ T/T & 304L SS & $\mathrm{BCCB}$ & \\
\hline ORGANIC ACID WASTE SUMP TANK & TK-1664 & $1.9 \mathrm{~m}^{3}$ & $1.2 \mathrm{~m} \mathrm{ID} \mathrm{X} 2 \mathrm{~m} \mathrm{~T} / \mathrm{T}$ & $316 \mathrm{~L}$ SS & $\mathrm{BCCB}$ & \\
\hline $\begin{array}{l}\text { DECON SOLUTION MAKE-UP TANK } \\
\text { ROUGHING FILTER }\end{array}$ & F-1691 & $187 \mathrm{~m}^{3} / \mathrm{hr}$ & & 304L SS & $\mathrm{BCCB}$ & \\
\hline $\begin{array}{l}\text { OXALIC ACID DECON MAKE-UP } \\
\text { TANK ROUGHING FILTER }\end{array}$ & F-1692 & $187 \mathrm{~m}^{3} / \mathrm{hr}$ & & 304L SS & BCCB & \\
\hline \multicolumn{7}{|c|}{$\begin{array}{l}\text { BUILDING: } \\
\text { BCCB }=\text { BULK COLD CHEMICAL BUILDING } \\
\text { MUB }=\text { MECHANICAL UTILITIES BUILDING } \\
\text { WPH }=\text { WATER PUMP HOUSE } \\
\text { DB4:CASE4C:CONF4:LLW_DED }\end{array}$} \\
\hline
\end{tabular}




\begin{tabular}{|c|c|c|c|c|c|c|}
\hline $\begin{array}{l}\text { EQUIPMENT } \\
\text { DESCRIPTION }\end{array}$ & $\begin{array}{l}\text { EQUIPMENT } \\
\text { ID }\end{array}$ & $\begin{array}{l}\text { CAPACITY/ } \\
\text { FLOWRATE }\end{array}$ & $\begin{array}{l}\text { PHYSICAL } \\
\text { SIZE }\end{array}$ & MATERIAL & BLDG & COMMENTS \\
\hline $\begin{array}{l}\text { MSM DECON SOLUTION MAKE-UP } \\
\text { TANK ROUGHING FILTER }\end{array}$ & F-1693 & $187 \mathrm{~m}^{3} / \mathrm{hr}$ & & 304L SS & BCCB & \\
\hline $\begin{array}{l}\text { POTASSIUM PERMANGANATE } \\
\text { MAKE-UP TANK ROUGHING FILTER }\end{array}$ & F-1694 & $187 \mathrm{~m}^{3} / \mathrm{hr}$ & 304L SS & $\mathrm{BCCB}$ & & \\
\hline $\begin{array}{l}\text { COLD CHEMICAL No } 3 \text { MAKE-UP } \\
\text { TANK ROUGHING FILTER }\end{array}$ & P-1695 & $187 \mathrm{~m}^{3} / \mathrm{hr}$ & 304L SS & $\mathrm{BCCB}$ & & \\
\hline $\begin{array}{l}\text { COLD CHEMICAL No. } 1 \text { MAKE-UP } \\
\text { TANK ROUGHING FILTER }\end{array}$ & F-1696 & $187 \mathrm{~m}^{3} / \mathrm{hr}$ & & 304L SS & $\mathrm{BCCB}$ & \\
\hline $\begin{array}{l}\text { OFF-GAS TREATMENT MAKE-UP } \\
\text { TANK ROUGHING FILTER }\end{array}$ & F-1697 & $187 \mathrm{~m}^{3} / \mathrm{hr}$ & & 304L SS & $\mathrm{BCCB}$ & \\
\hline $\begin{array}{l}\text { COLD CHEMICAL No. } 2 \text { MAKE-UP } \\
\text { TANK ROUGHING FILTER }\end{array}$ & F-1698 & $187 \mathrm{~m}^{3} / \mathrm{hr}$ & & 304L SS & BCCB & \\
\hline $\begin{array}{l}\text { NITRIC ACID DECON MAKE-UP } \\
\text { TANK ROUGHING FILTER }\end{array}$ & F-1699 & $187 \mathrm{~m}^{3} / \mathrm{hr}$ & & 304L SS & $\mathrm{BCCB}$ & \\
\hline $\begin{array}{l}\text { COLD CHEMICAL No. } 1 \text { TRANSFER } \\
\text { PUMP }\end{array}$ & P-1700 & $3.2 \mathrm{~m}^{3} / \mathrm{hr}, 575 \mathrm{kPa}$ & & 304L SS & $\mathrm{BCCB}$ & \\
\hline $\begin{array}{l}\text { BUILDING: } \\
\text { BCCB }=\text { BULK COLD CHEMICAL } \\
\text { MUB }=\text { MECHANICAL UTILITIES } \\
\text { WPH }=\text { WATER PUMP HOUSE } \\
\text { DB4:CASE4C:CONF4:LLW_DED }\end{array}$ & $\begin{array}{l}\text { BUILDING } \\
\text { BUILDING }\end{array}$ & & & & & \\
\hline
\end{tabular}


WHC-SD-W378-ES-002

Revision 0

Equipment list

Configuration 4 Revision 02, Issued on 02/16/95

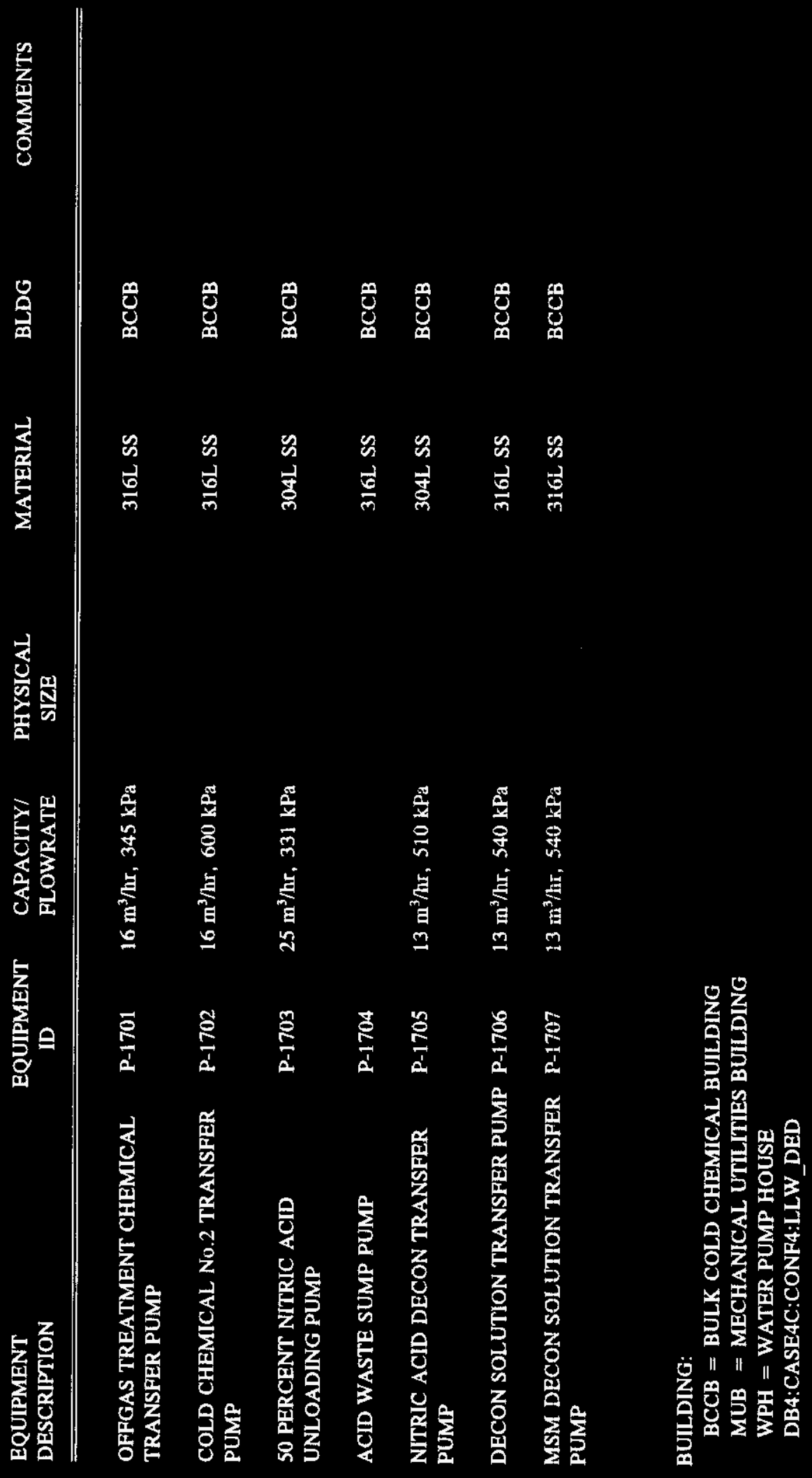

E3-18 


\section{WHC-SD-W378-ES-002}

Revision 0

Equipment list

Configuration 4 Revision 02, Issued on 02/16/95

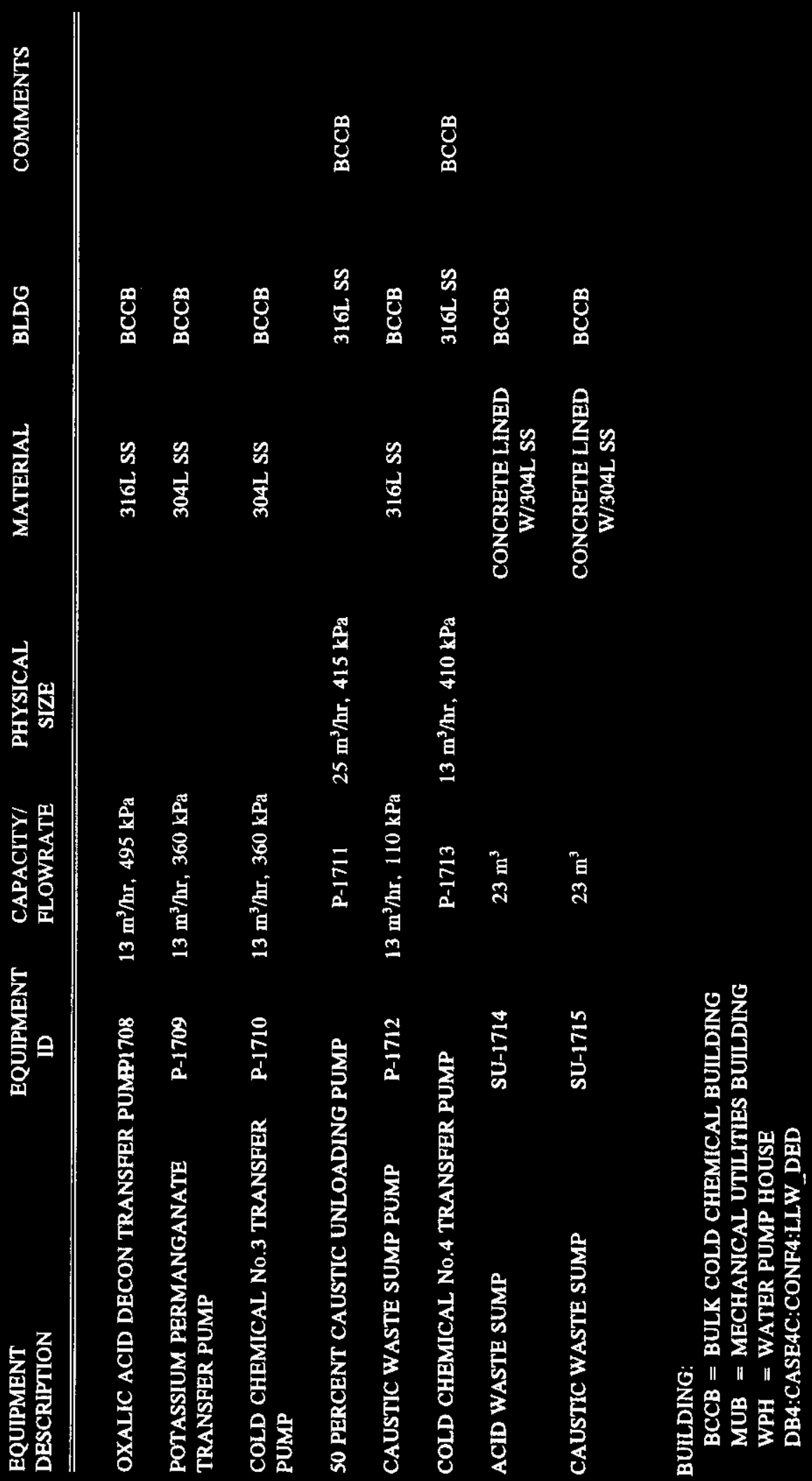




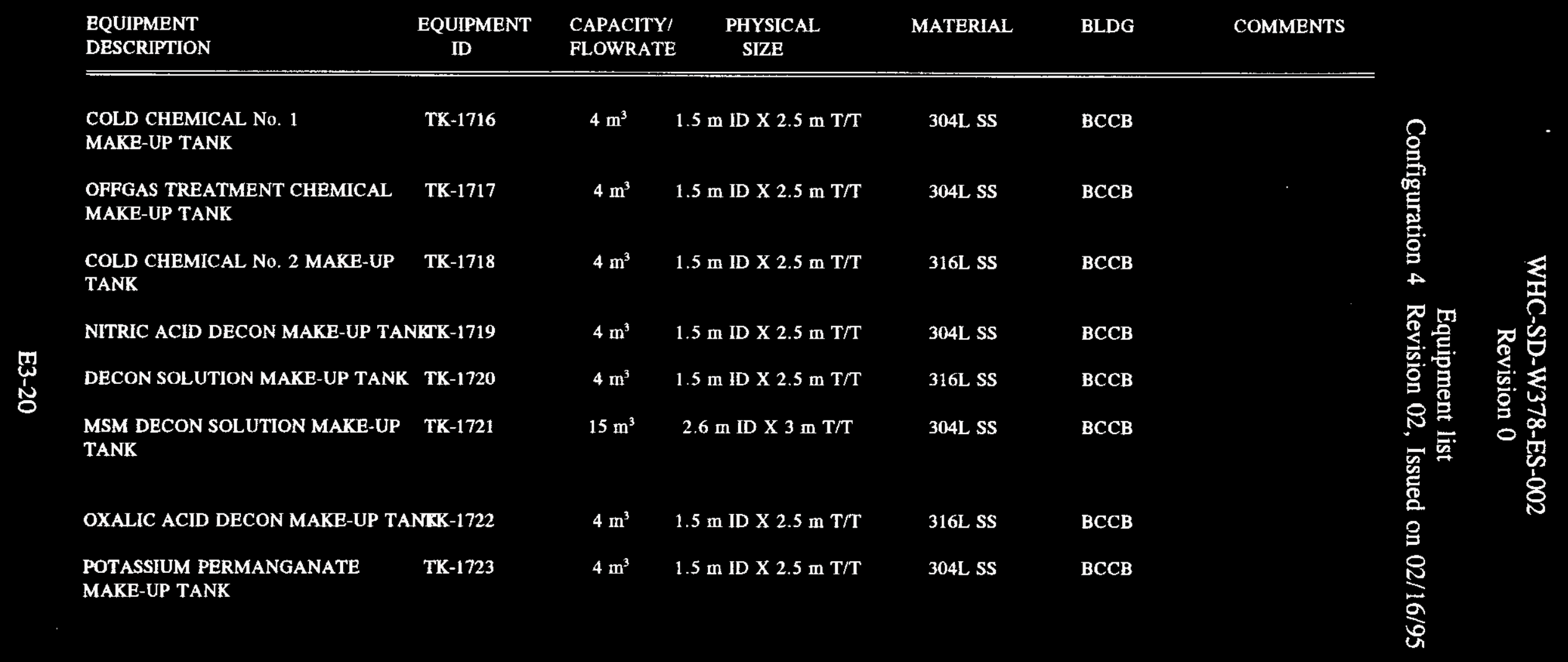

BUILDING:

BCCB = BULK COLD CHEMICAL, BUILDING

MUB $=$ MECHANICAL UTILITIES BUILDING

WPH $=$ WATER PUMP HOUSE

DB4:CASE4C:CONF4:LLW DED 


\section{WHC-SD-W378-ES-002 \\ Revision 0}

Equipment list

Configuration 4 Revision 02, Issued on 02/16/95

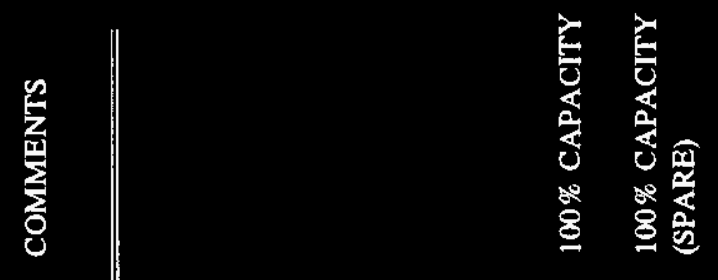

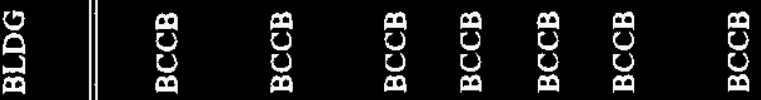

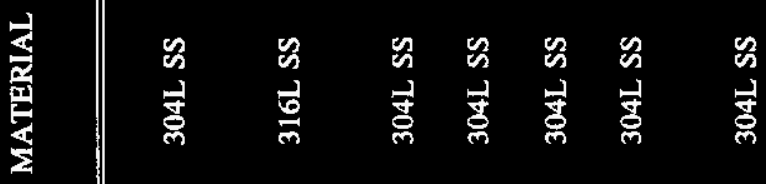

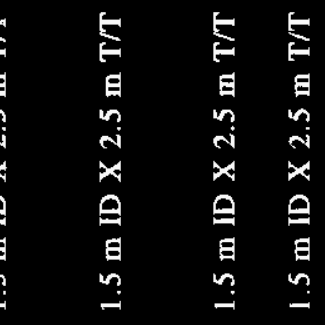

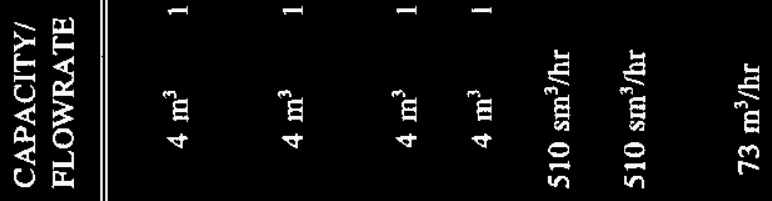

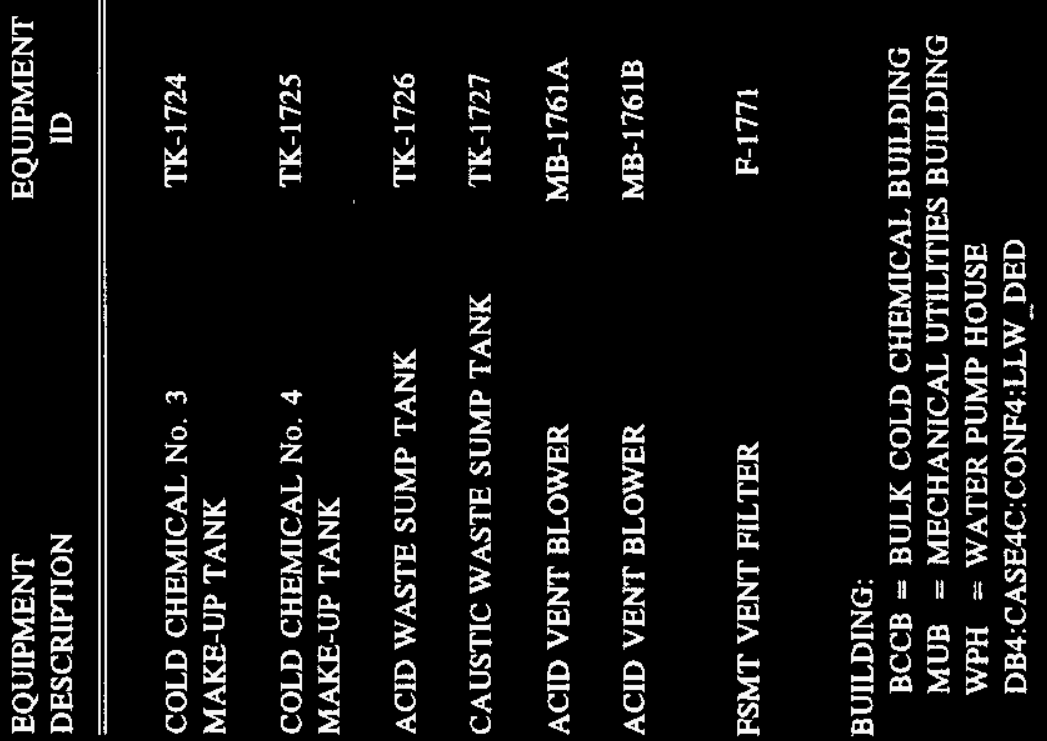


WHC-SD-W378-ES-002

Revision 0

Equipment list

Configuration 4 Revision 02, Issued on 02/16/95

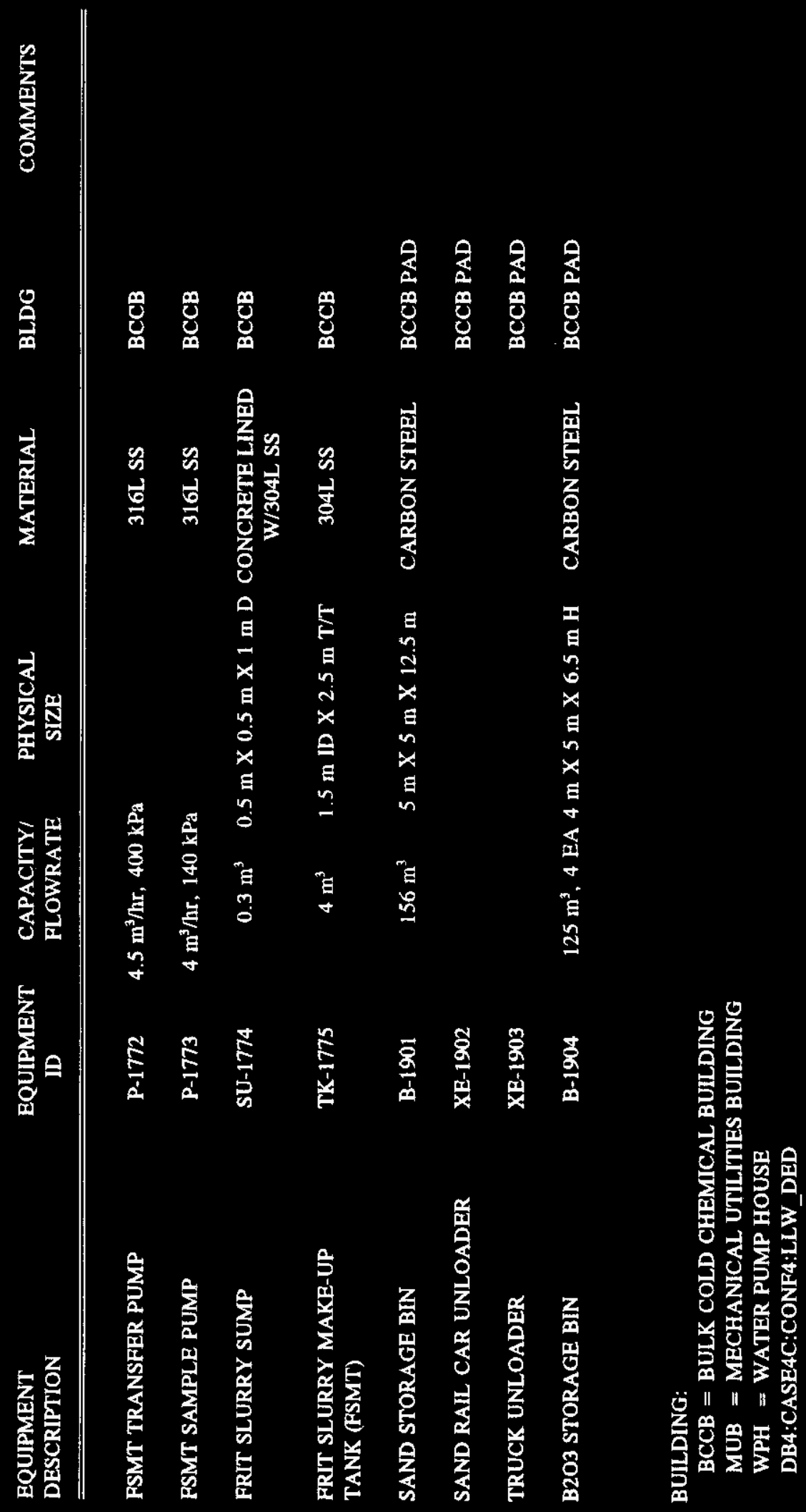




\begin{tabular}{|c|c|c|c|c|c|c|}
\hline $\begin{array}{l}\text { EQUIPMENT } \\
\text { DESCRIPTION }\end{array}$ & $\begin{array}{l}\text { EQUIPMENT } \\
\text { ID }\end{array}$ & $\begin{array}{l}\text { CAPACITY/ } \\
\text { FLOWRATE }\end{array}$ & $\begin{array}{l}\text { PHYSICAL } \\
\text { SIZE }\end{array}$ & MATERIAL & BLDG & COMMENTS \\
\hline Li2 O STORAGE BIN & B-1905 & $153 \mathrm{~m}^{3}, 2 \mathrm{EA}$ & $5 \mathrm{mX} 5 \mathrm{mX} 11 \mathrm{~m} \mathrm{H}$ & CARBON STEEL & BCCB PAD & \\
\hline CaO STORAGE BIN & B-1906 & $43 \mathrm{~m}^{3}$ & $3 \mathrm{mX} 3 \mathrm{mX} 10 \mathrm{~m} \mathrm{H}$ & CARBON STEEL & BCCB PAD & \\
\hline MgO STORAGE BIN & B-1907 & $43 \mathrm{~m}^{3}$ & $3 \mathrm{mX} 3 \mathrm{mX} 10 \mathrm{~m} \mathrm{H}$ & CARBON STEEL & BCCB PAD & \\
\hline LLW BATCH MIXER & MM-1909 & & & & BCCB PAD & \\
\hline CONVEYOR BIN TO MIXER & XE-1914 & & & & BCCB PAD & \\
\hline LLW GLASS FORMER CONVEYOR & XE-1915 & & & & BCCB & \\
\hline SODIUM NITRITE STORAGE BIN & B-1920 & $125 \mathrm{~m}^{3}$ & $4 \mathrm{~m} \mathrm{X} 5 \mathrm{~m} \mathrm{X} 6.5 \mathrm{~m} \mathrm{H}$ & CARBON STEEL & BCCB PAD & $\begin{array}{l}\text { USED AS } \\
\text { CORROSION } \\
\text { INHIBITOR FOR } \\
\text { SEPARATIONS } \\
\text { EFFLUENT TO } \\
\text { TANK PARM }\end{array}$ \\
\hline \multicolumn{7}{|c|}{$\begin{array}{l}\text { BUILDING: } \\
\text { BCCB = BULK COLD CHEMICAL BUILDING } \\
\text { MUB }=\text { MECHANICAL UTILITIES BULDING } \\
\text { WPH }=\text { WATER PUMP HOUSE } \\
\text { DB4:CASE4C:CONF4:LLW DED }\end{array}$} \\
\hline
\end{tabular}


WHC-SD-W378-ES-002

Revision 0

Equipment list

Configuration 4 Revision 02, Issued on 02/16/95

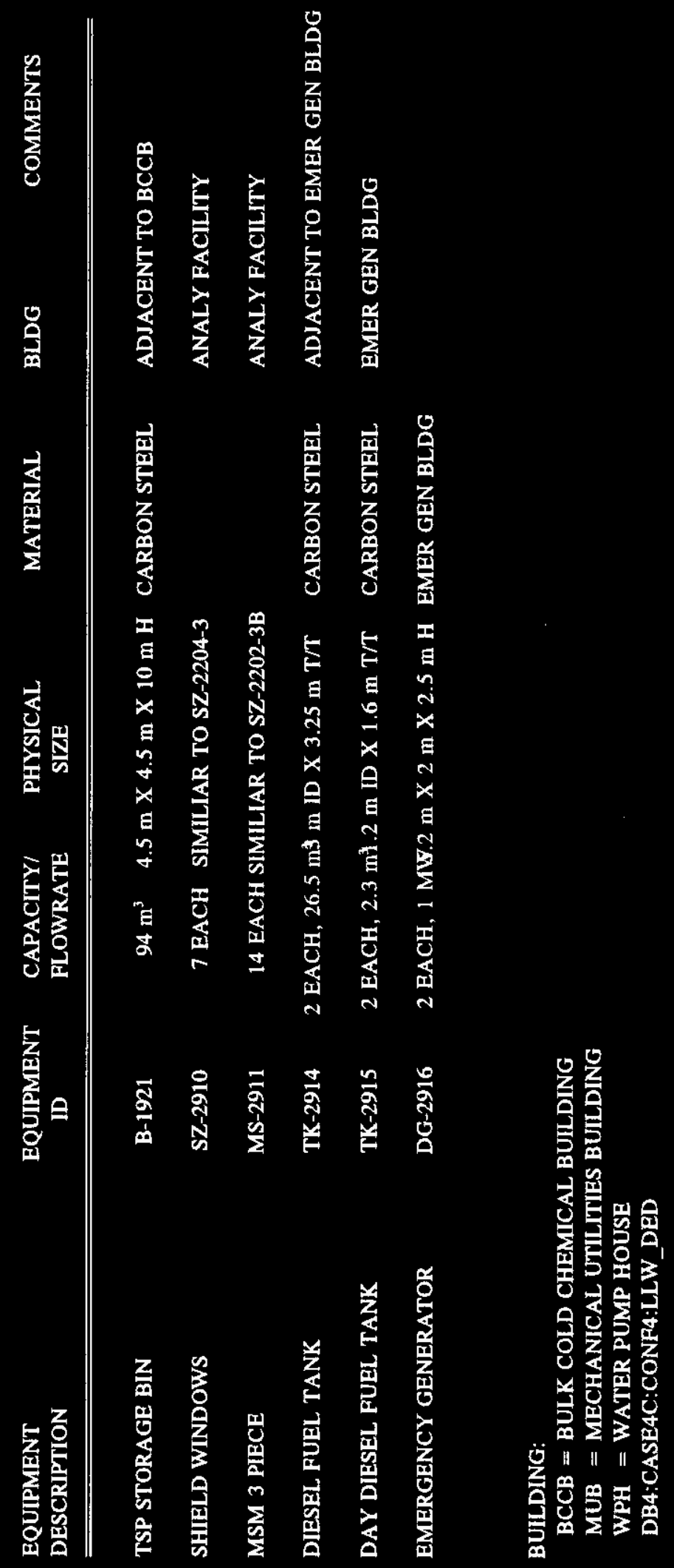




\section{*alls View/Frint Document Cover Sheet tow}

This document was retrieved from the Documentation and Records Manaqement (DRM) ISEARCH System. It is intended for Information only and may not be the most recent or updated version. Contact a Document Service Center (see Hanford Info for locations) if you need additional retrieval information.

Accession \#: D195067281

Document \#: SD-W378-ES-002

Title/Desc:

FACILITY DESIGN PHILOSOPHY TWRS PROCESS SUPPORT \& INFRASTRUCTURE DEFINITION [SEC 3 OF 4]

Pages: 151 
T.TS DOCUMENT WAS TOO LARGE TO SCAN AS A SINGLE

DOCLMENT. TT REQUIRED BREAKING INTO SMALLER SECTIONS.

DOCLMENT NUMBER: SD - W3 $378-\varepsilon S-002$

SECTION: 3 OF 4

TITLE: foulity Design Pholoopphy fand wante

Remudiation septem Procese seypont \& Infraotructure

Definition

AUTHOR: Seach, govleraith

RECIPIENT:

DATE: $12 / 11 / 95$

KEYWORDS:

REFERENCES: $2 D T-6|3| 101$ 
WHC-SD-W378-ES-002

Revision 0

\section{APPENDIX $\mathrm{F}$}

\section{SUPPORT FACILITY LAYOUTS}


WHC-SD-W378-ES-002 '

Revision 0

This page intentionally left blank.

F-2 


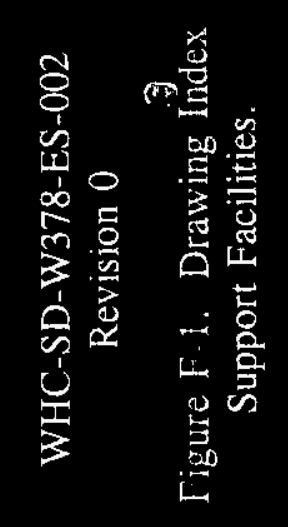
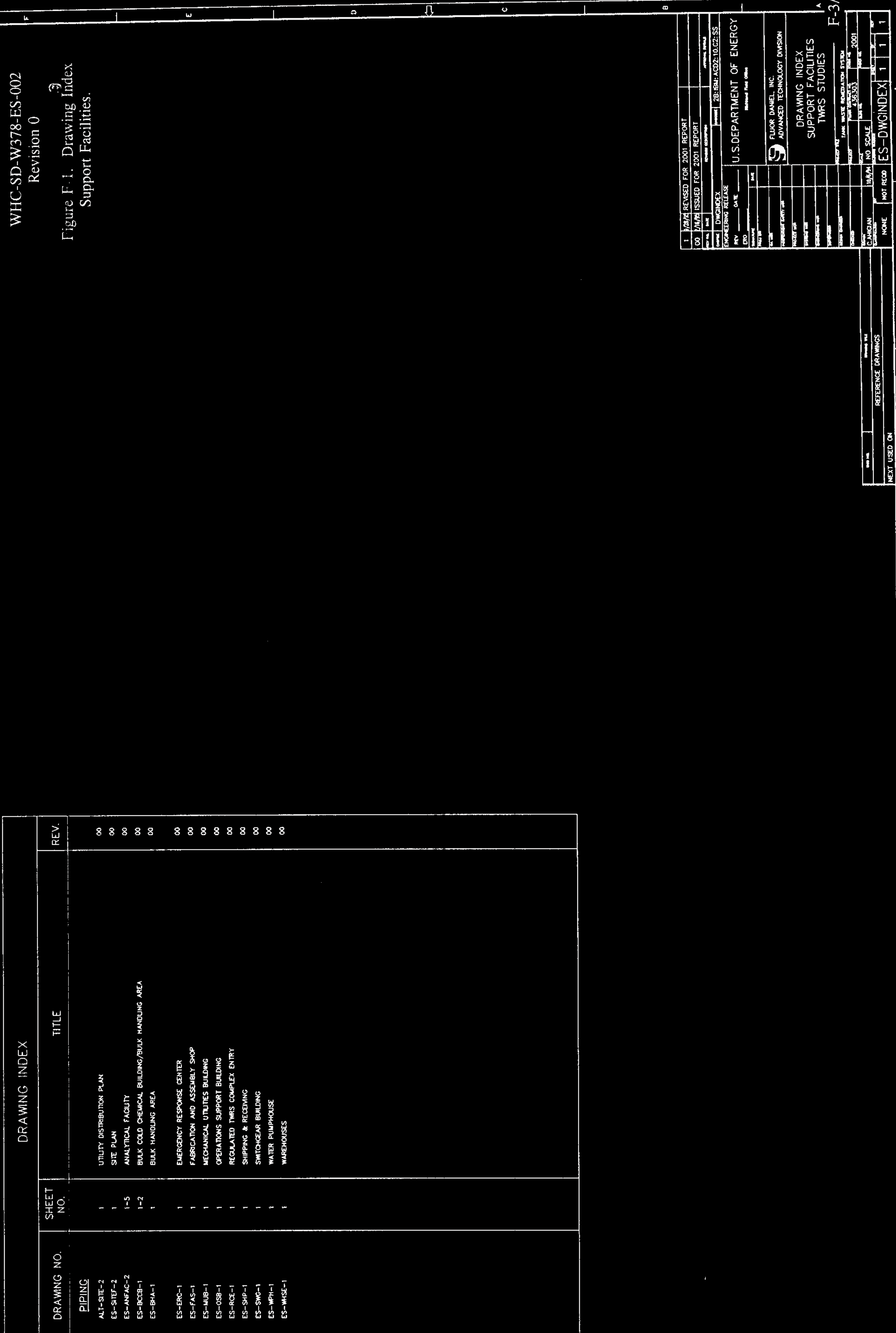


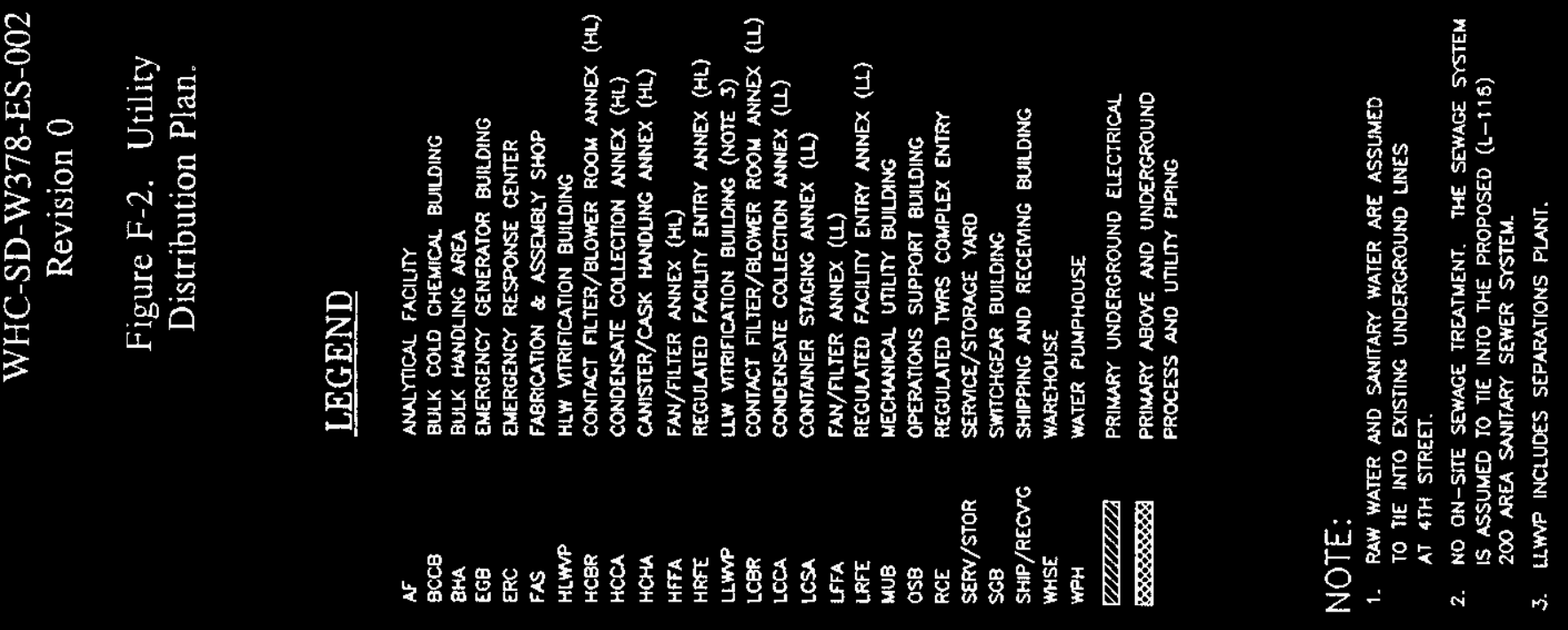

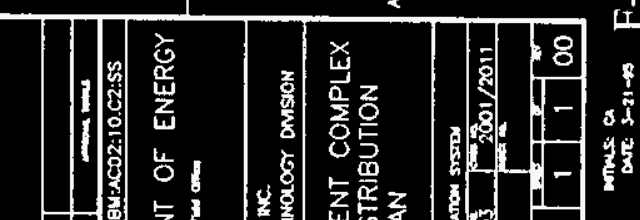

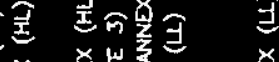

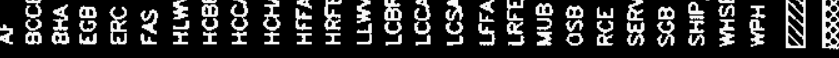
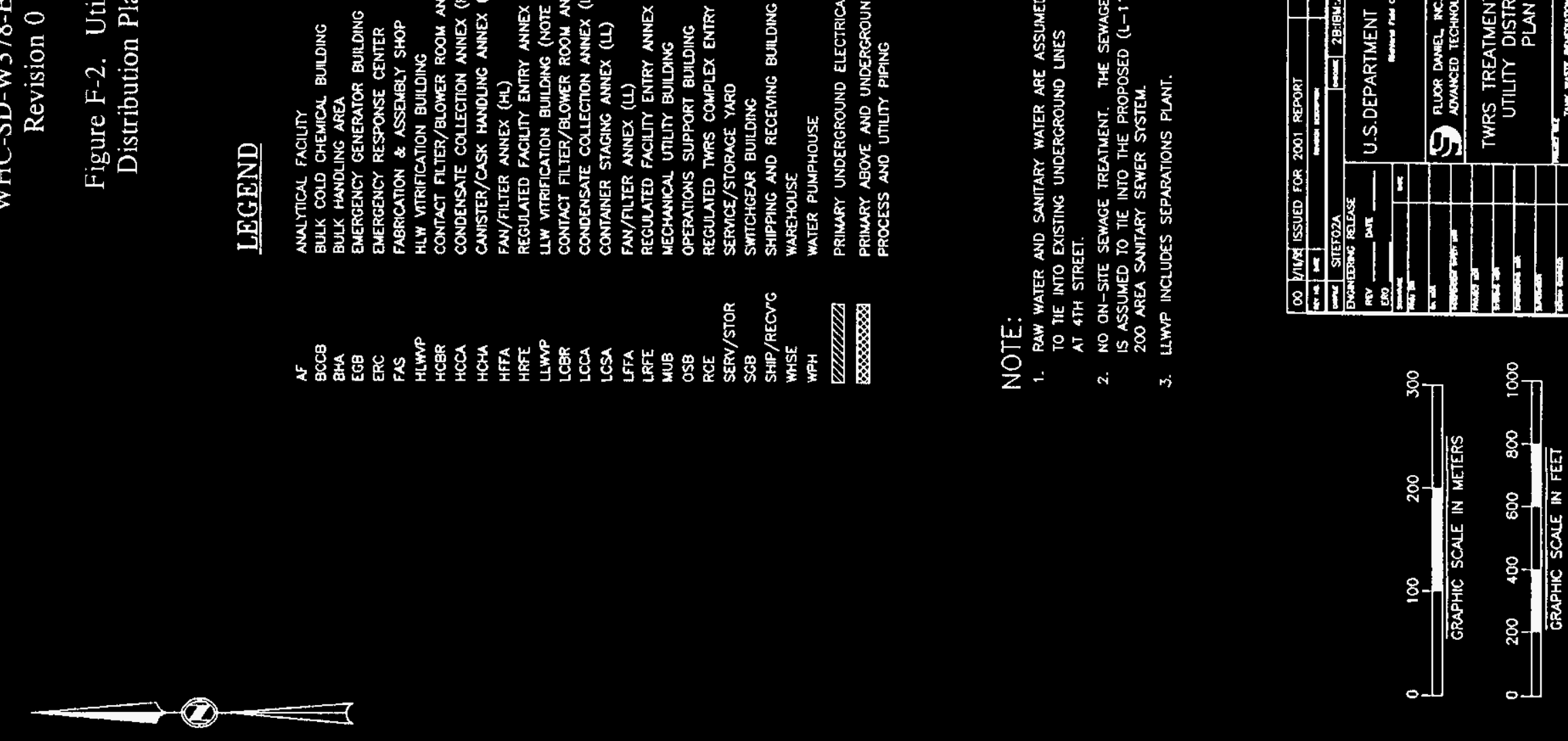

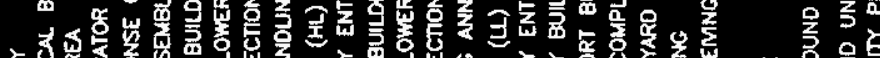

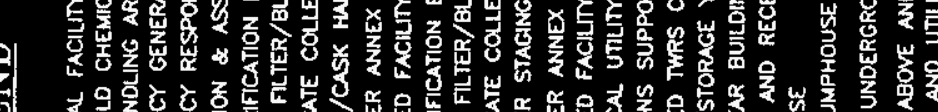

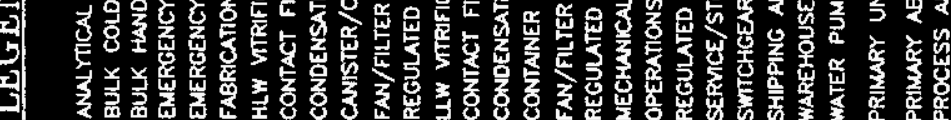

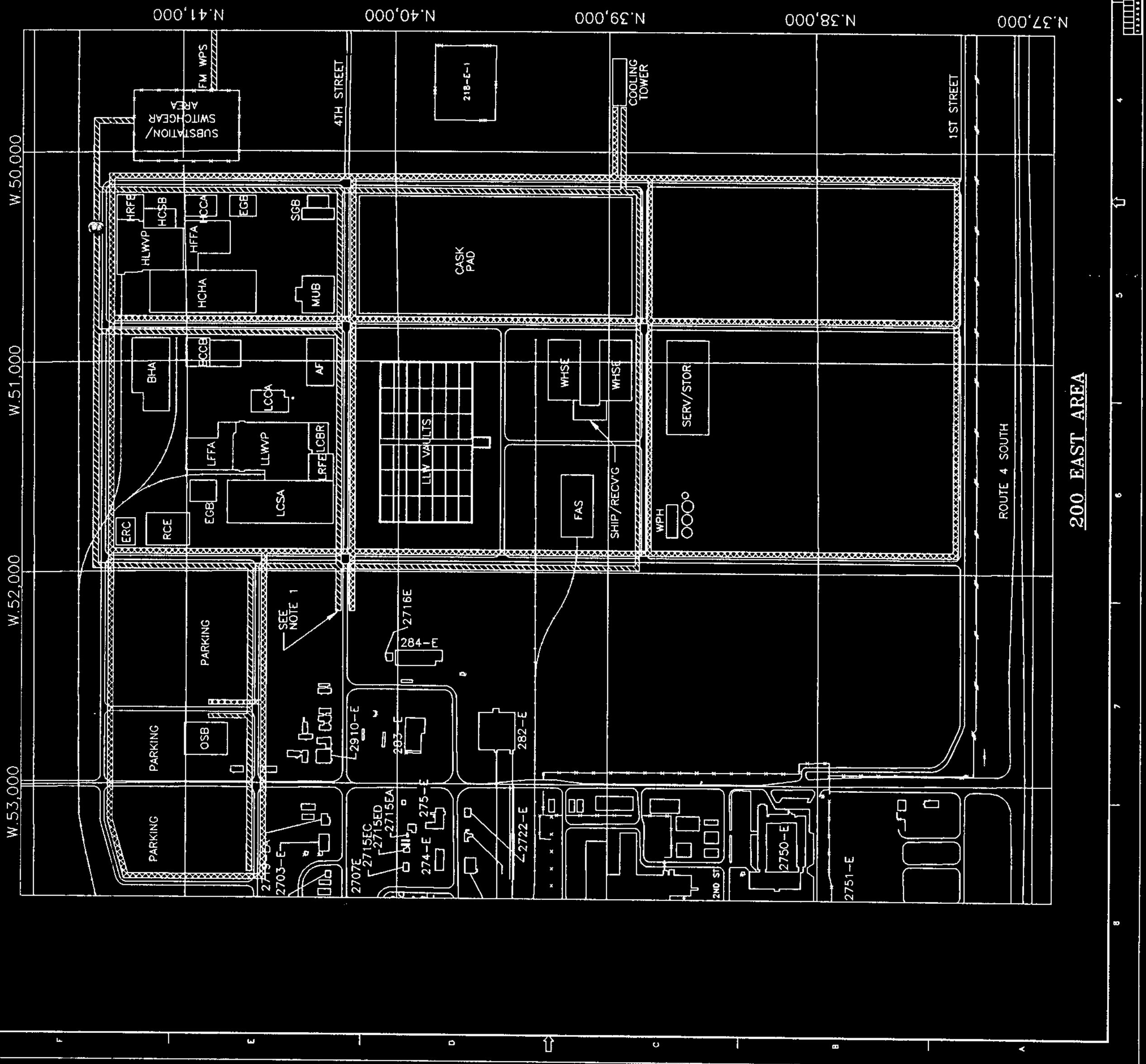




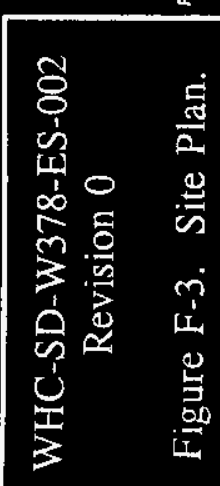

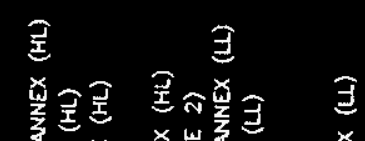

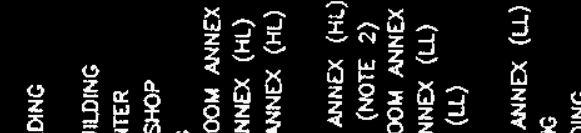

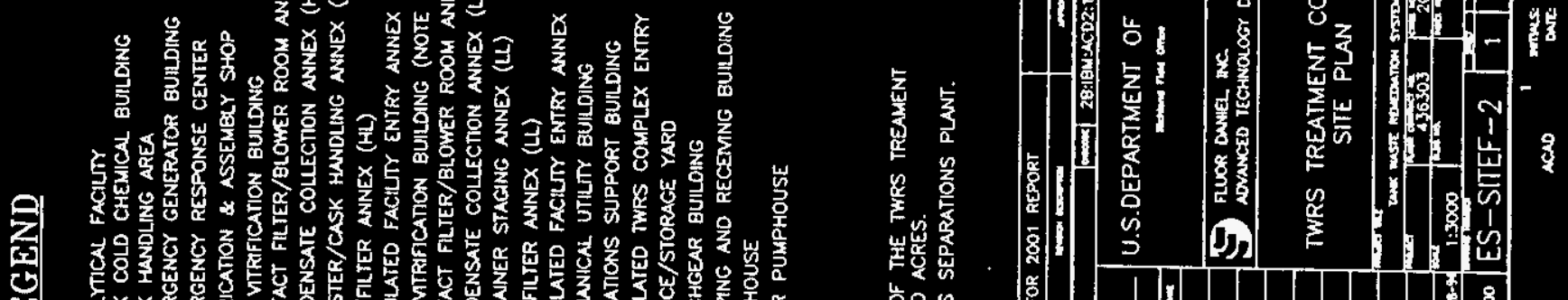

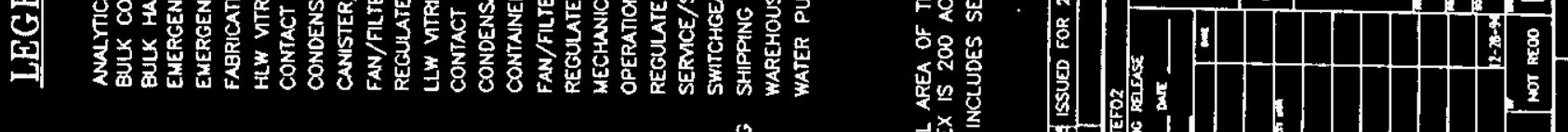

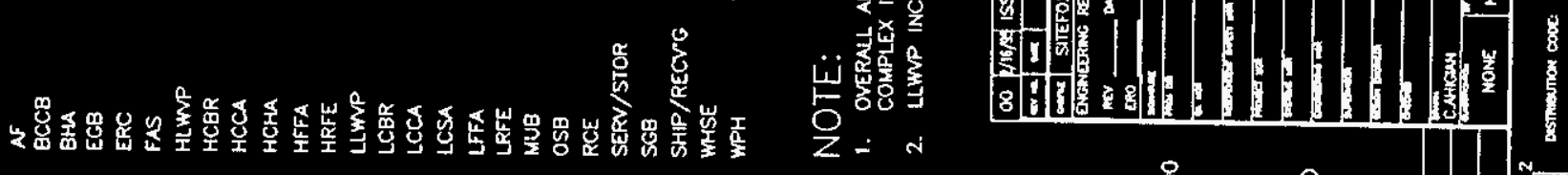

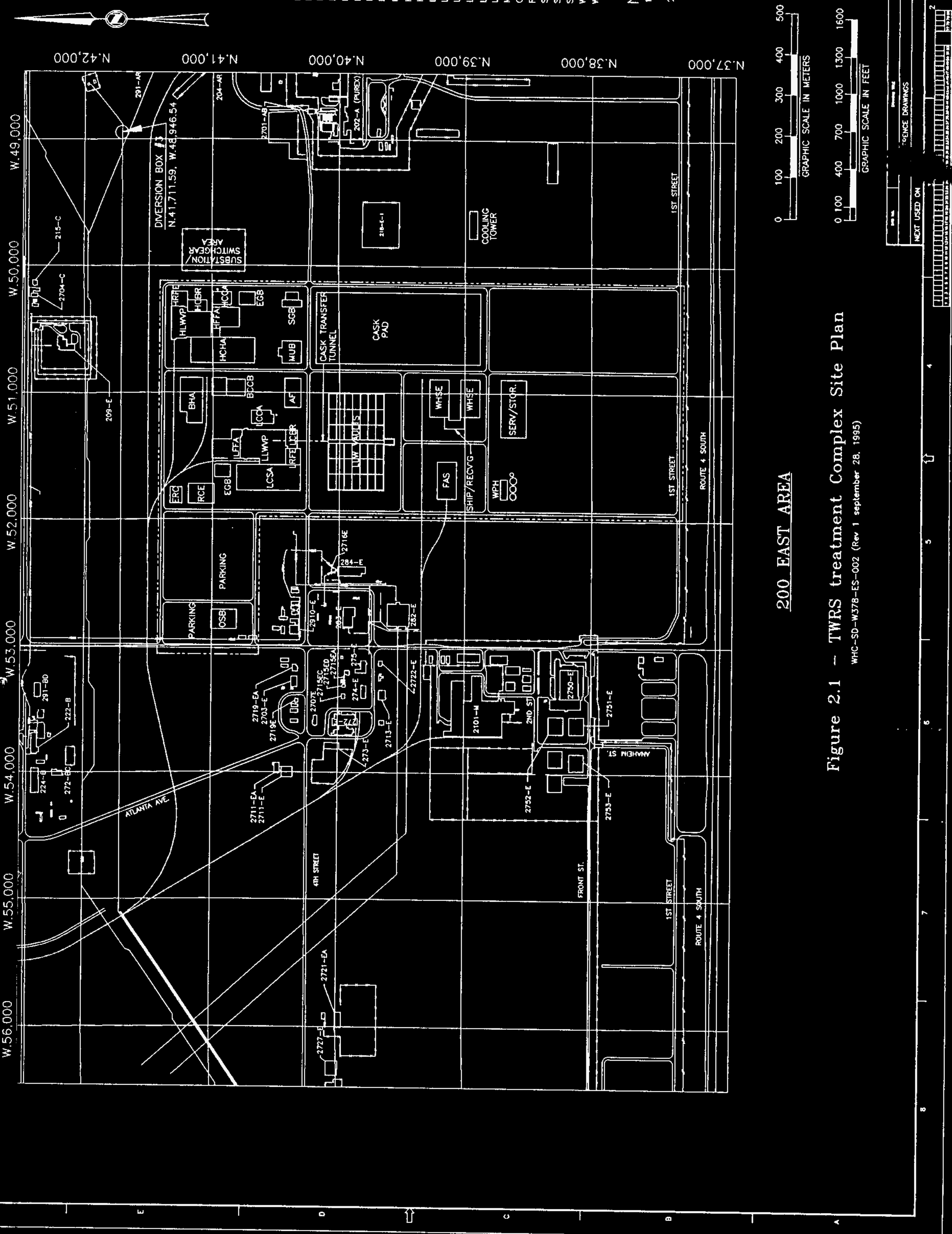



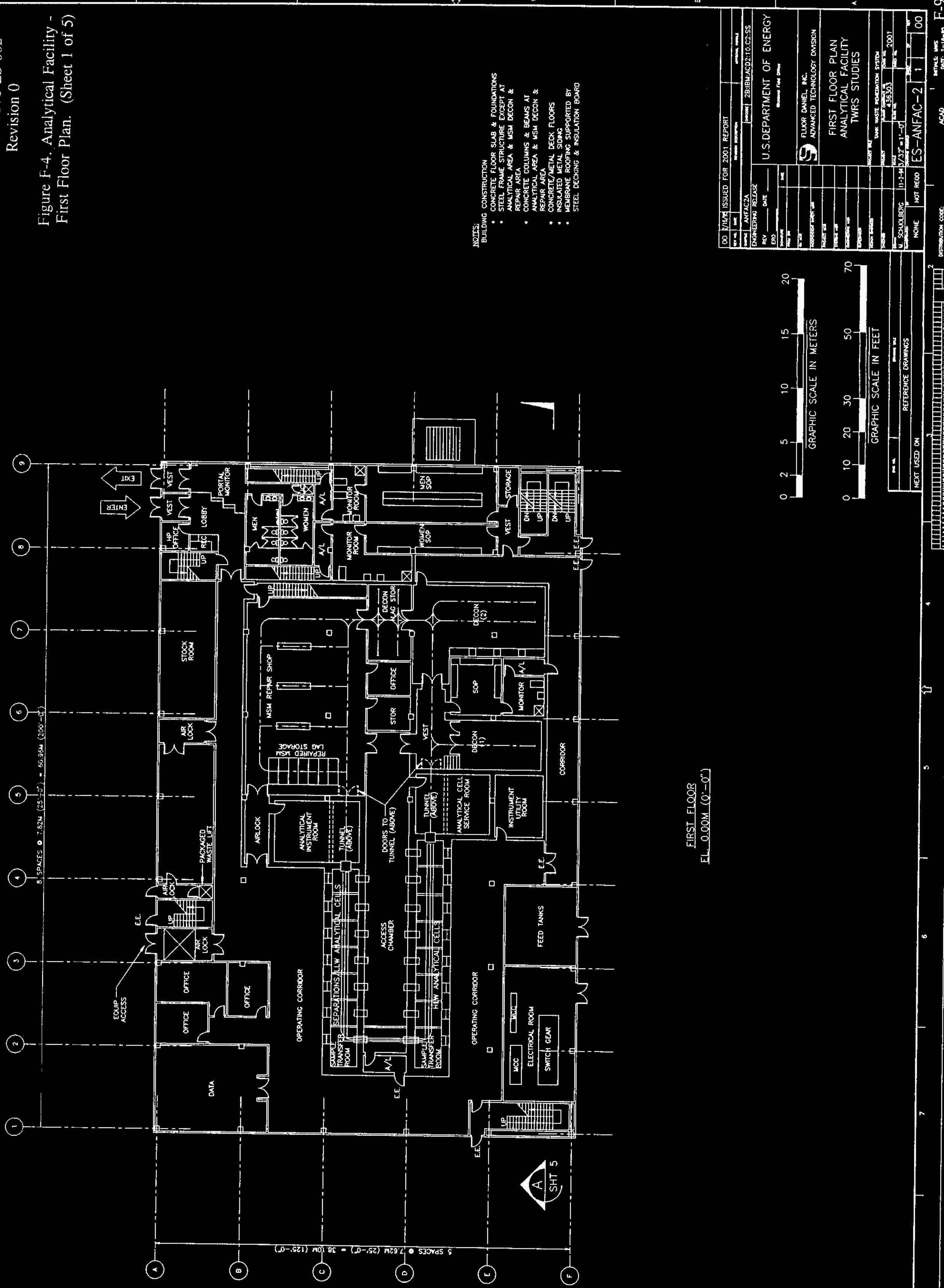


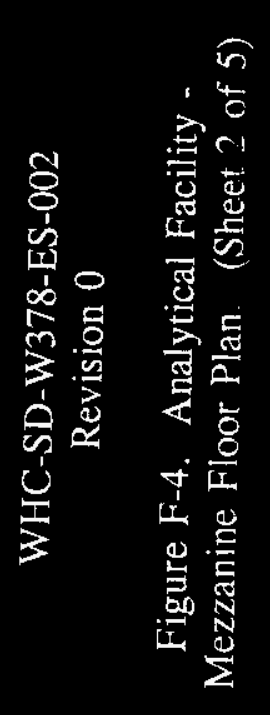
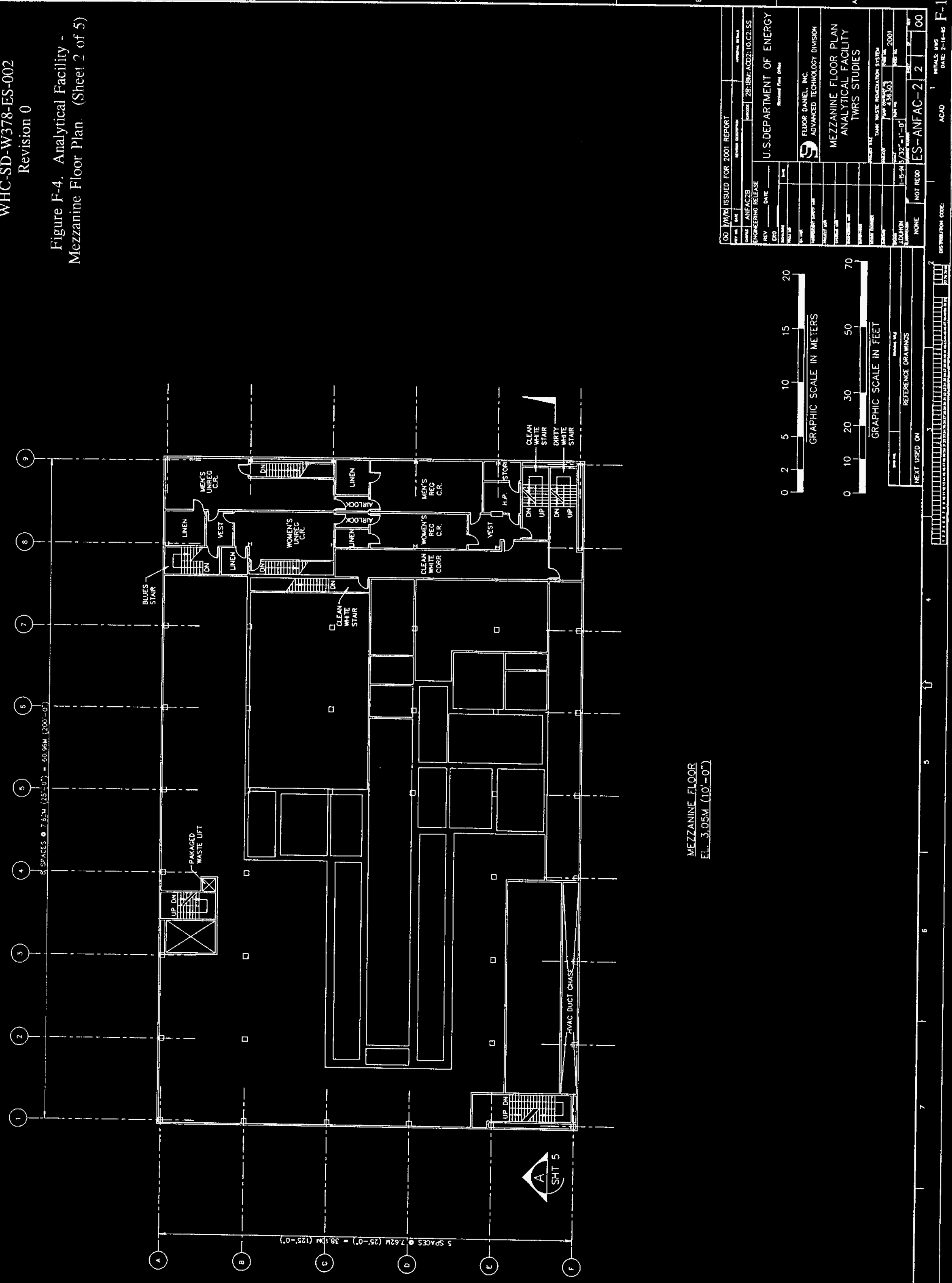

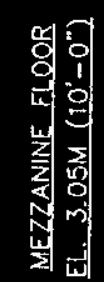



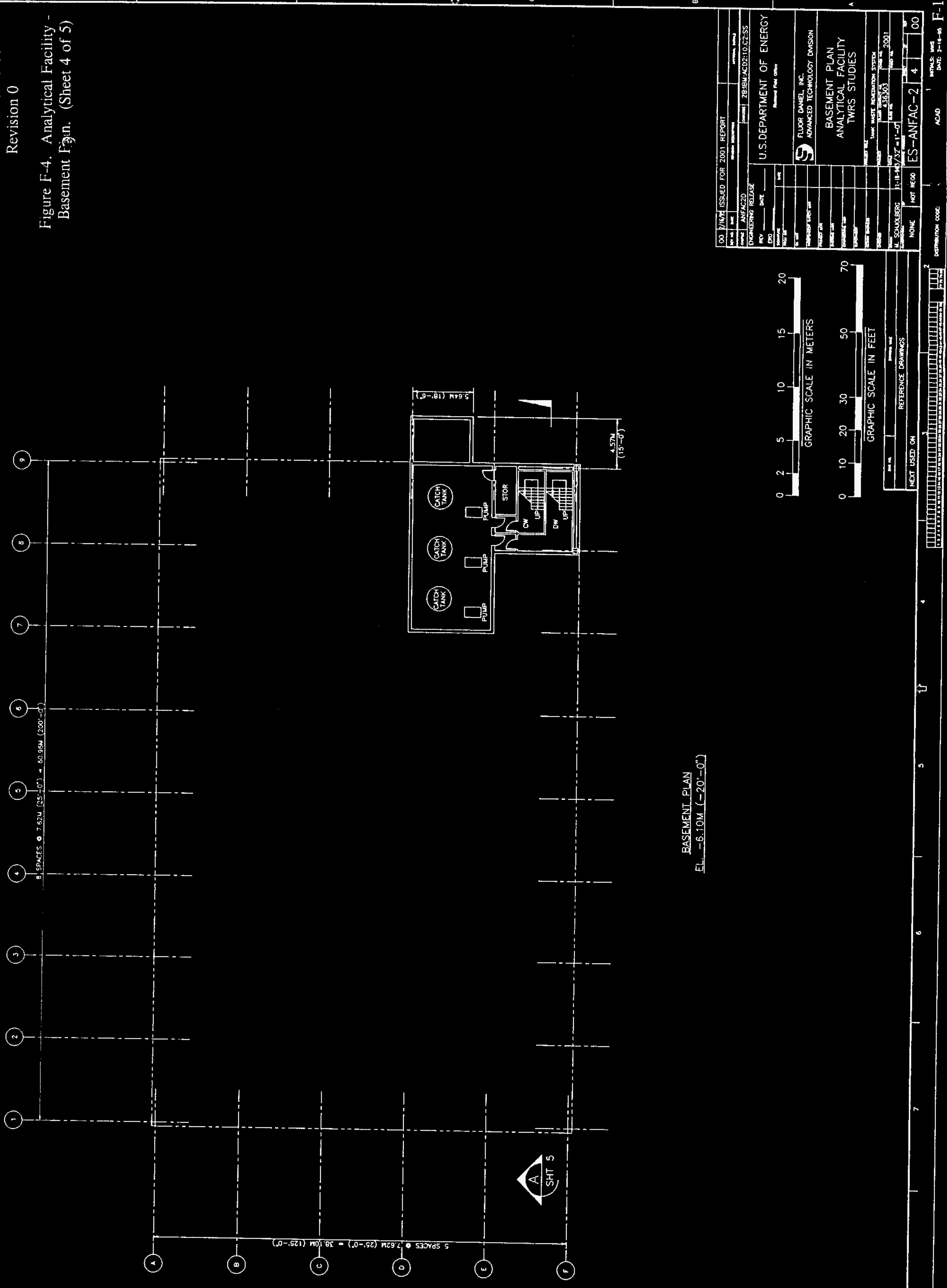

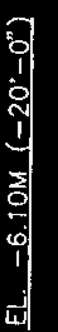


变

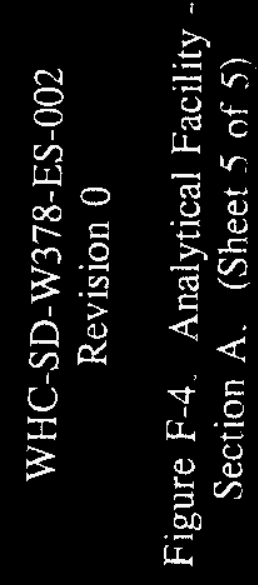
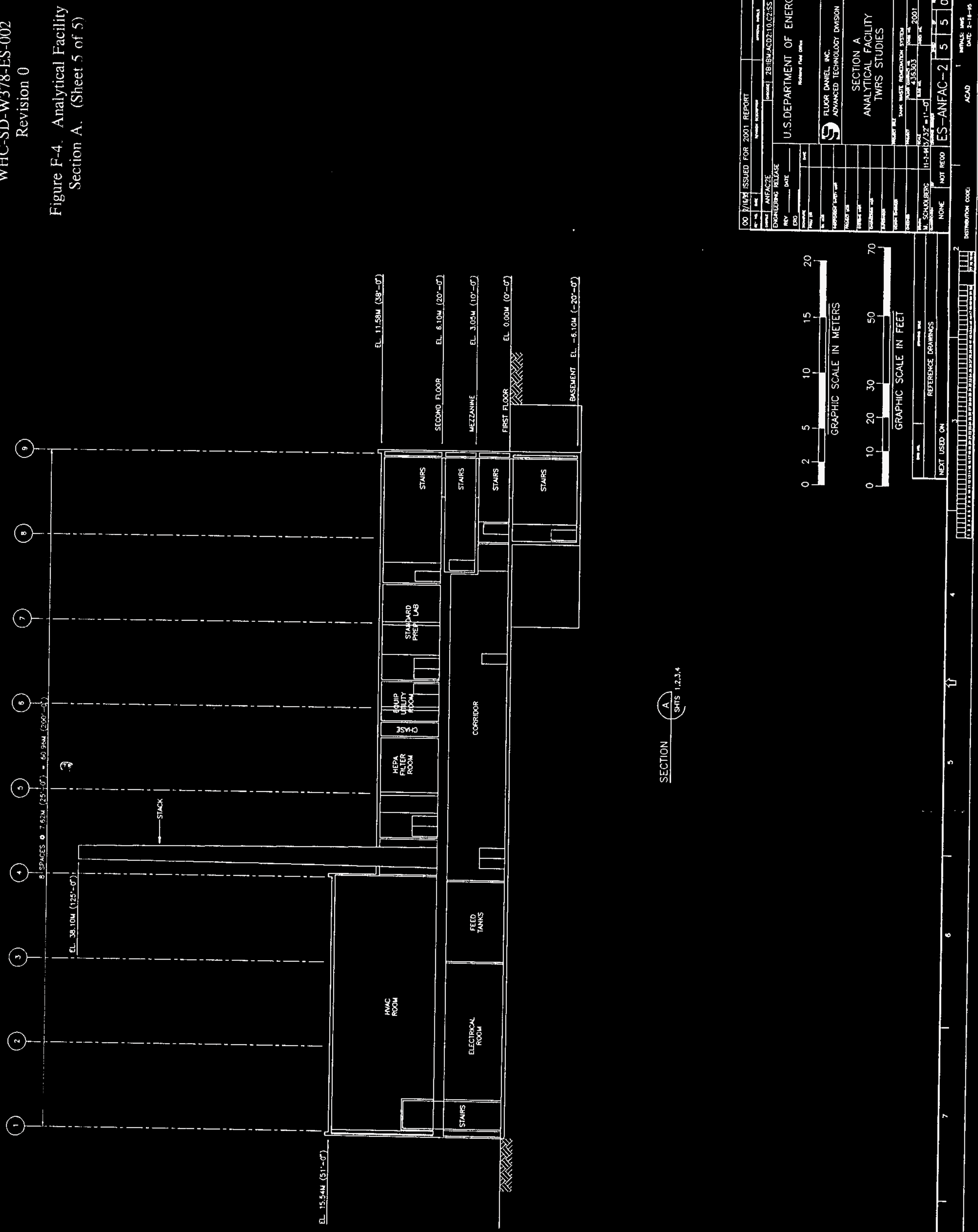

細 


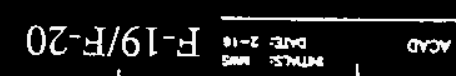

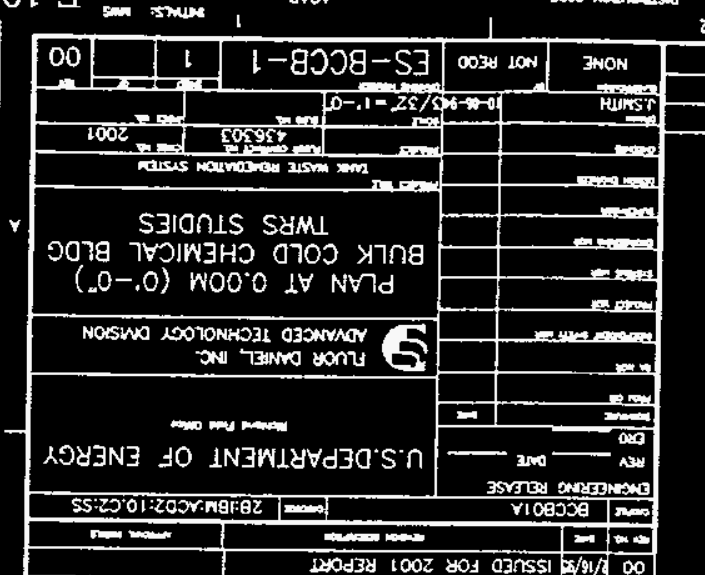

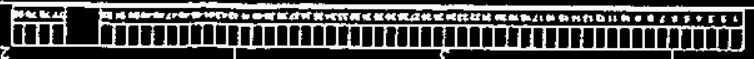

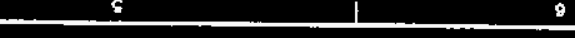

3315.

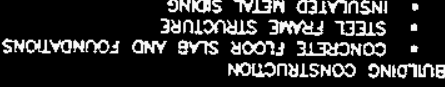

$(\sqrt[1175]{7})$ NOIIOJS

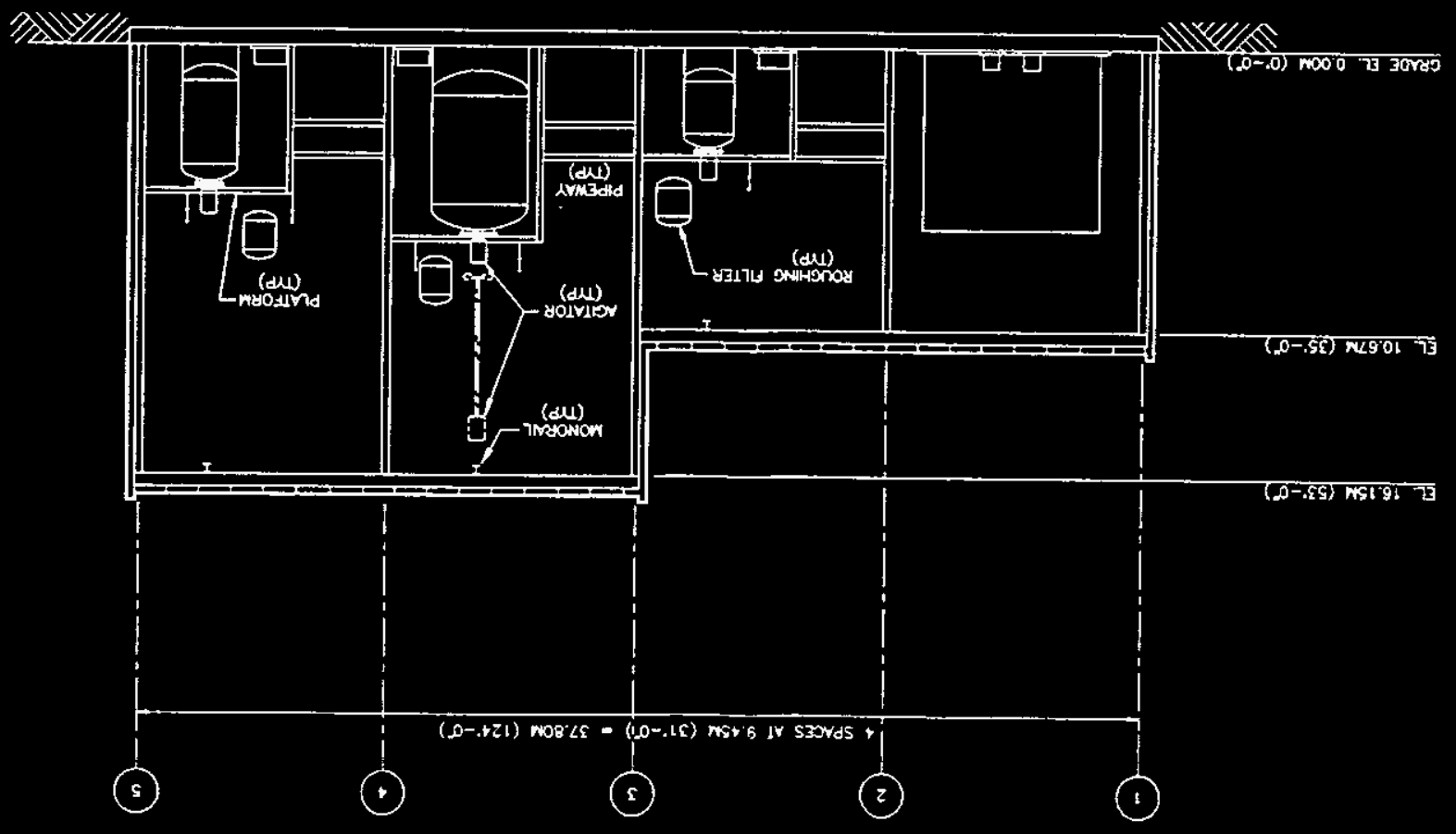

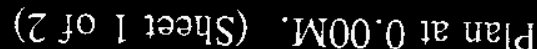

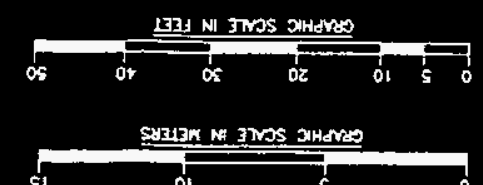

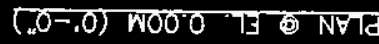

21

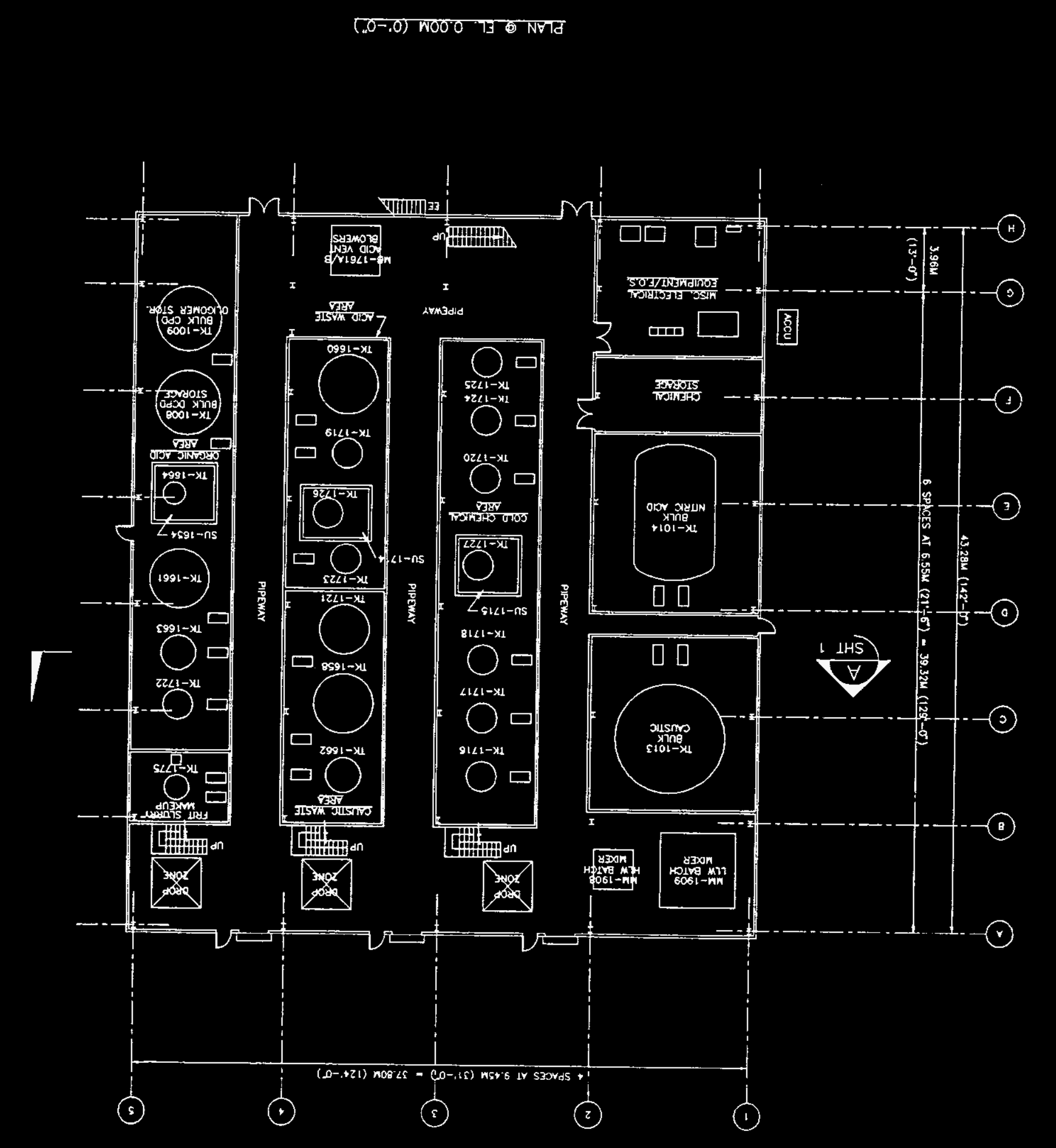

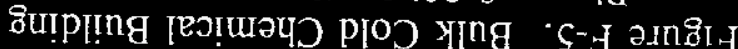

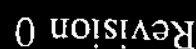

200-SA-8LEM-GS-JHM 

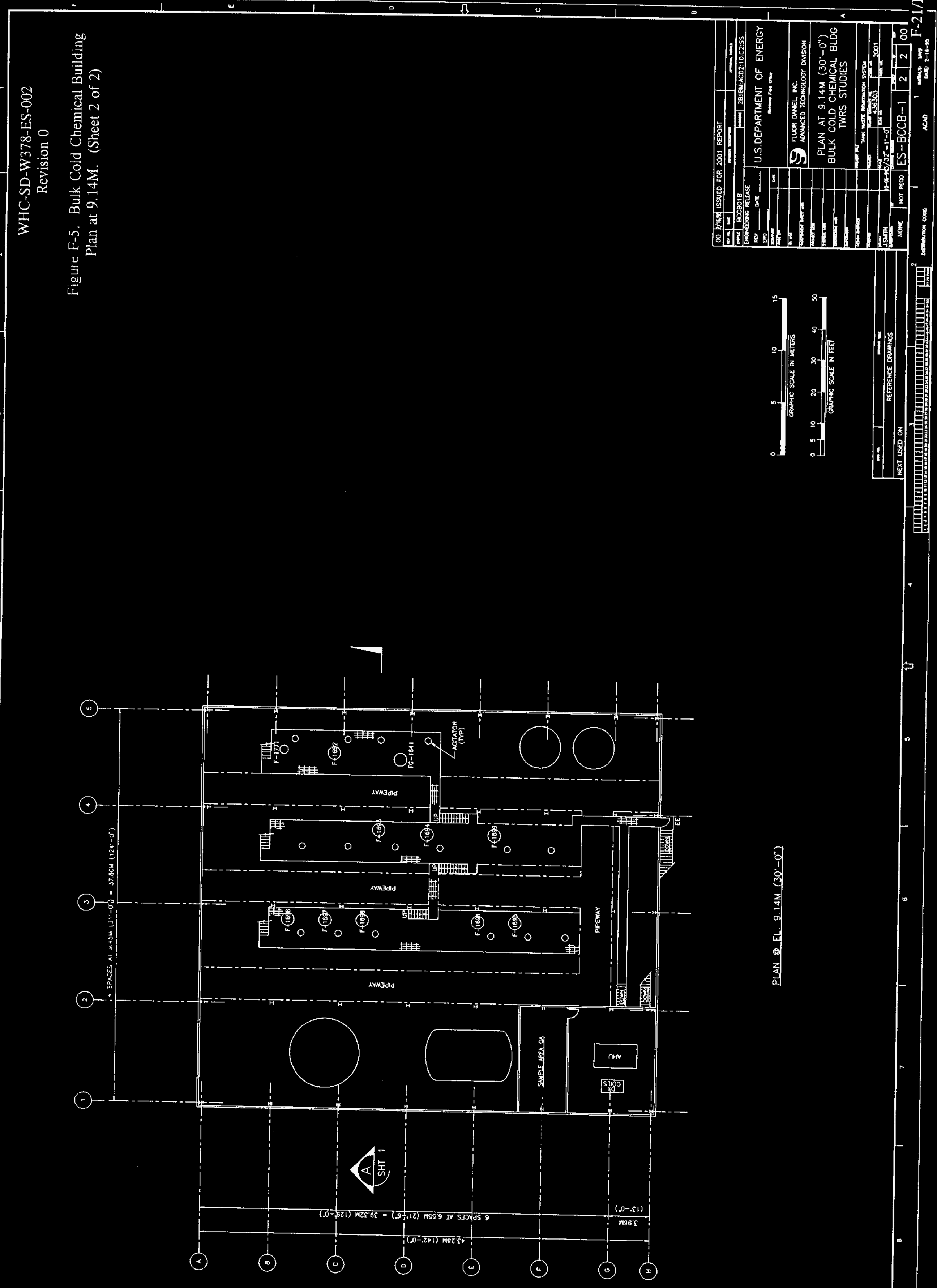

0
0
0
0
0
0
4
0
a
a

\begin{tabular}{l|l|ll}
4 & 1 & 0 & 0
\end{tabular} 

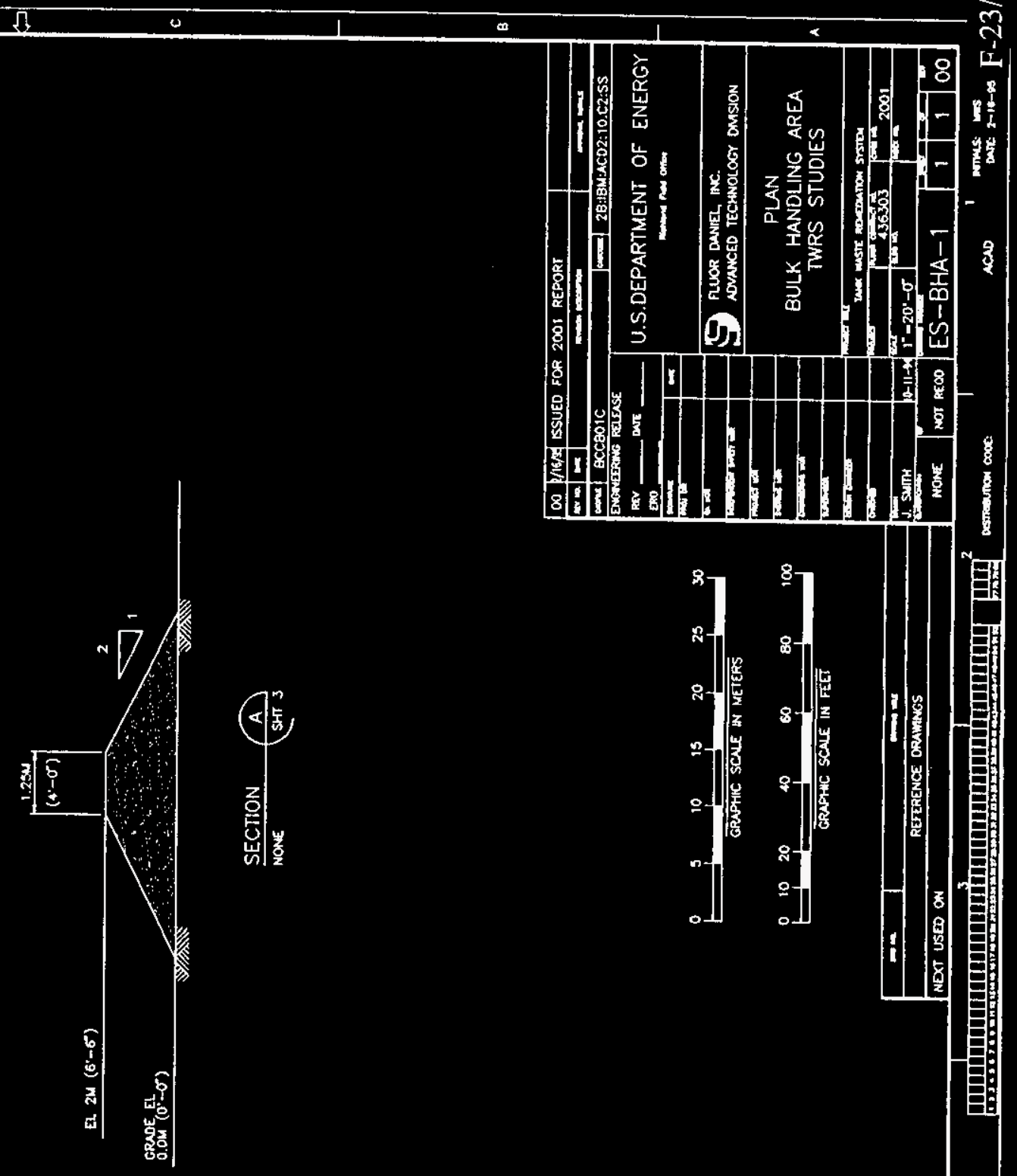

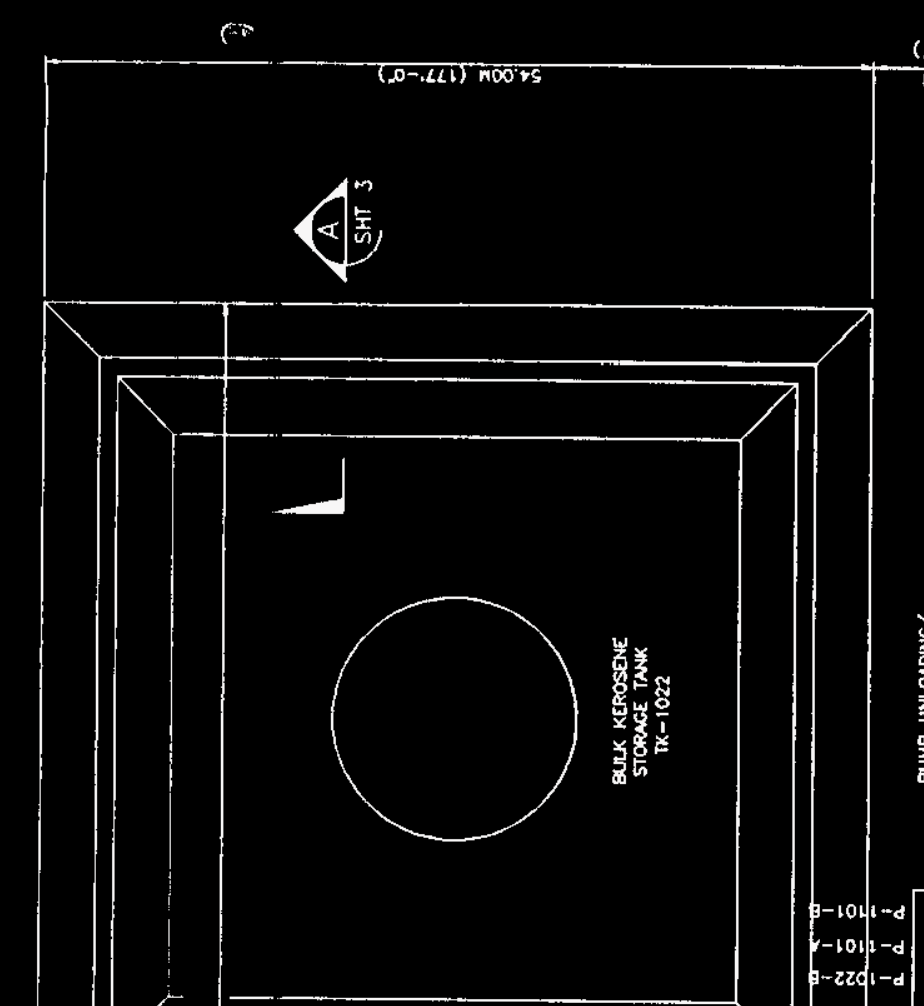

$\infty$

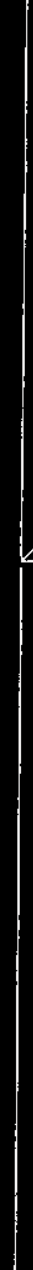

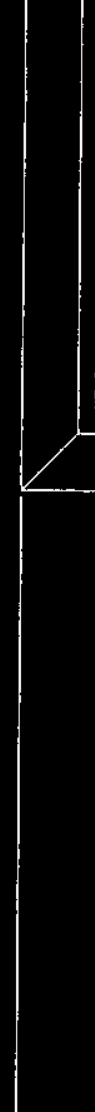

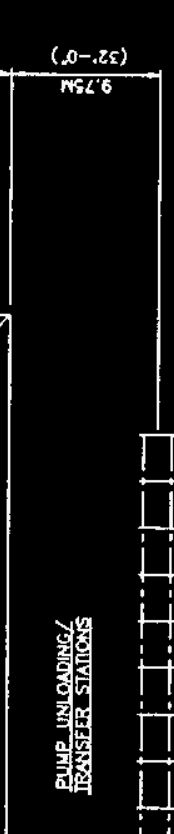

4

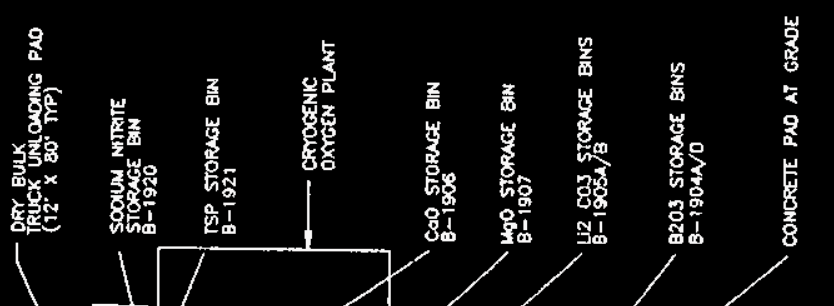

$\left.{ }_{8}^{8}\right]_{8-1}^{8}$

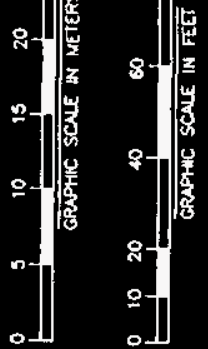

H.

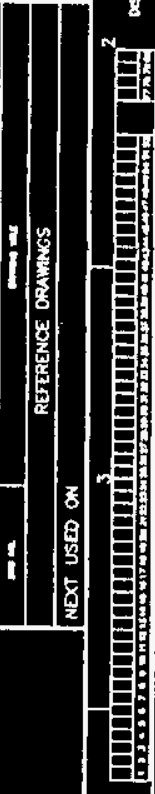




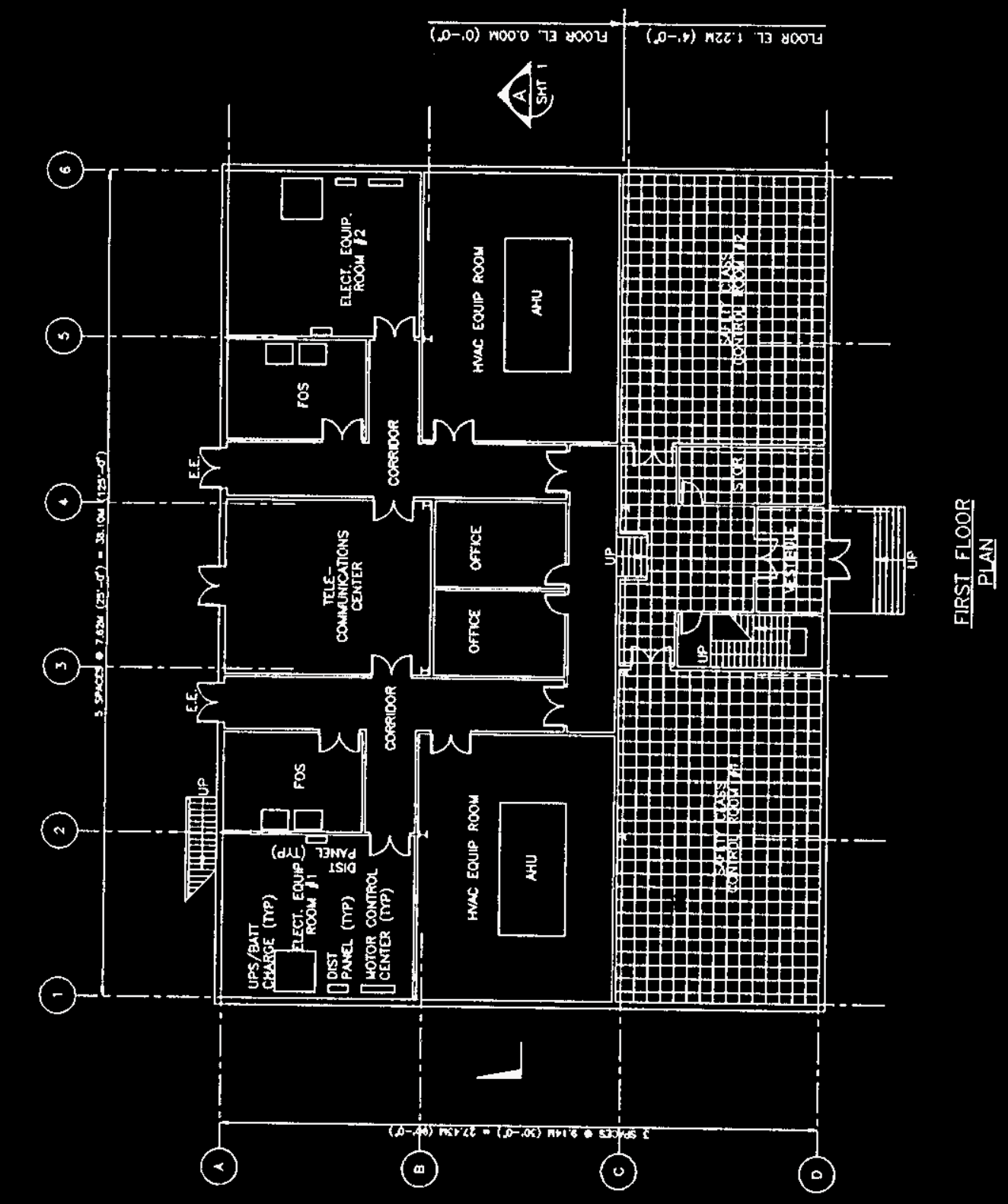
-

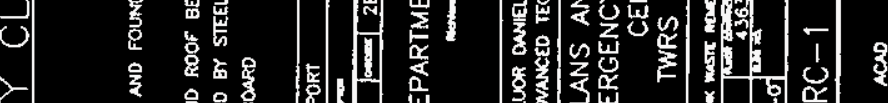

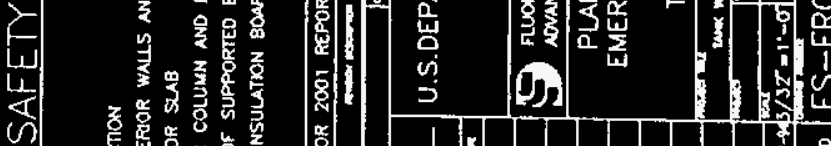

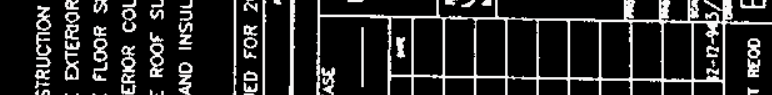

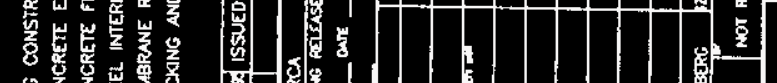

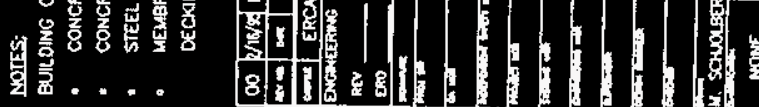
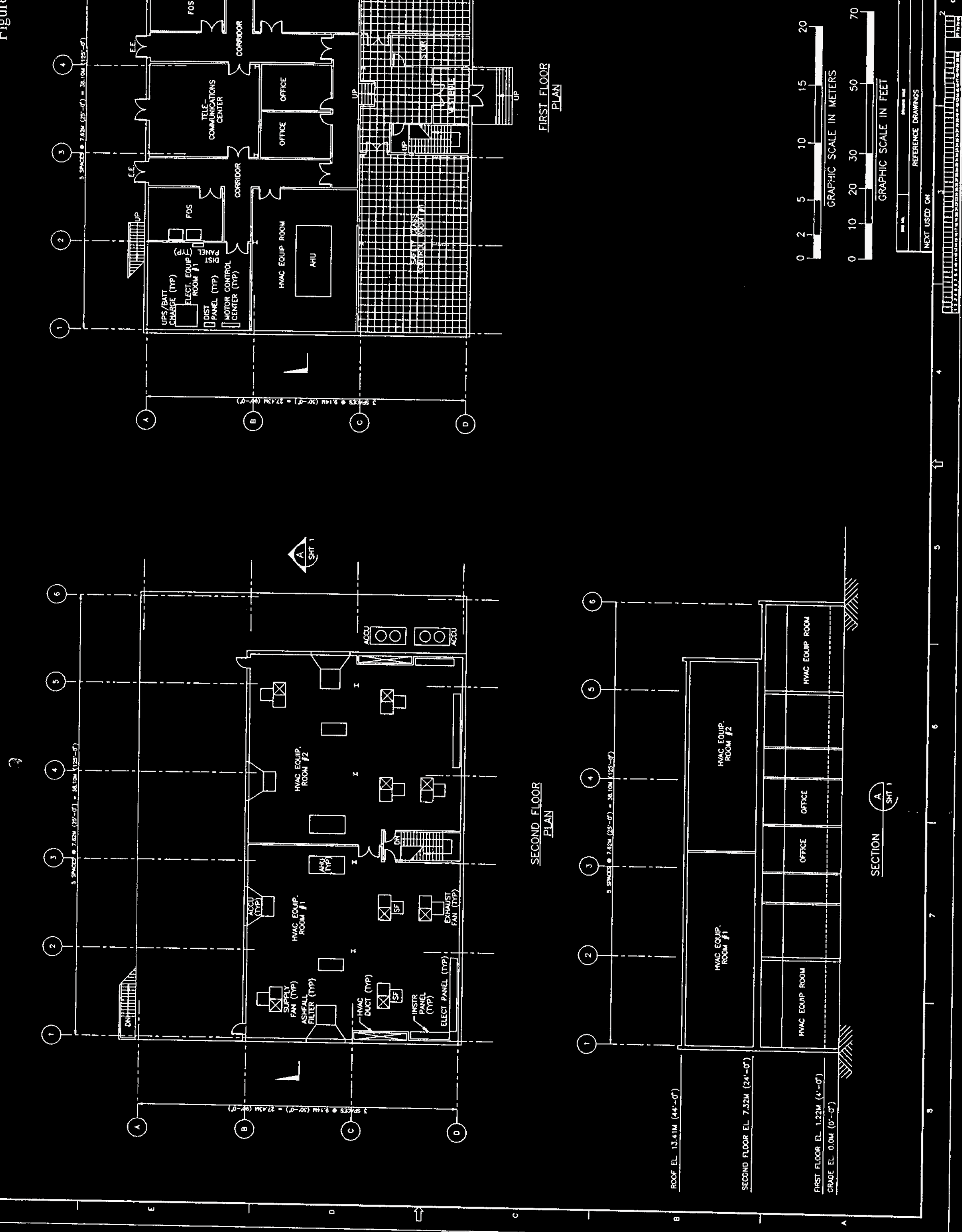

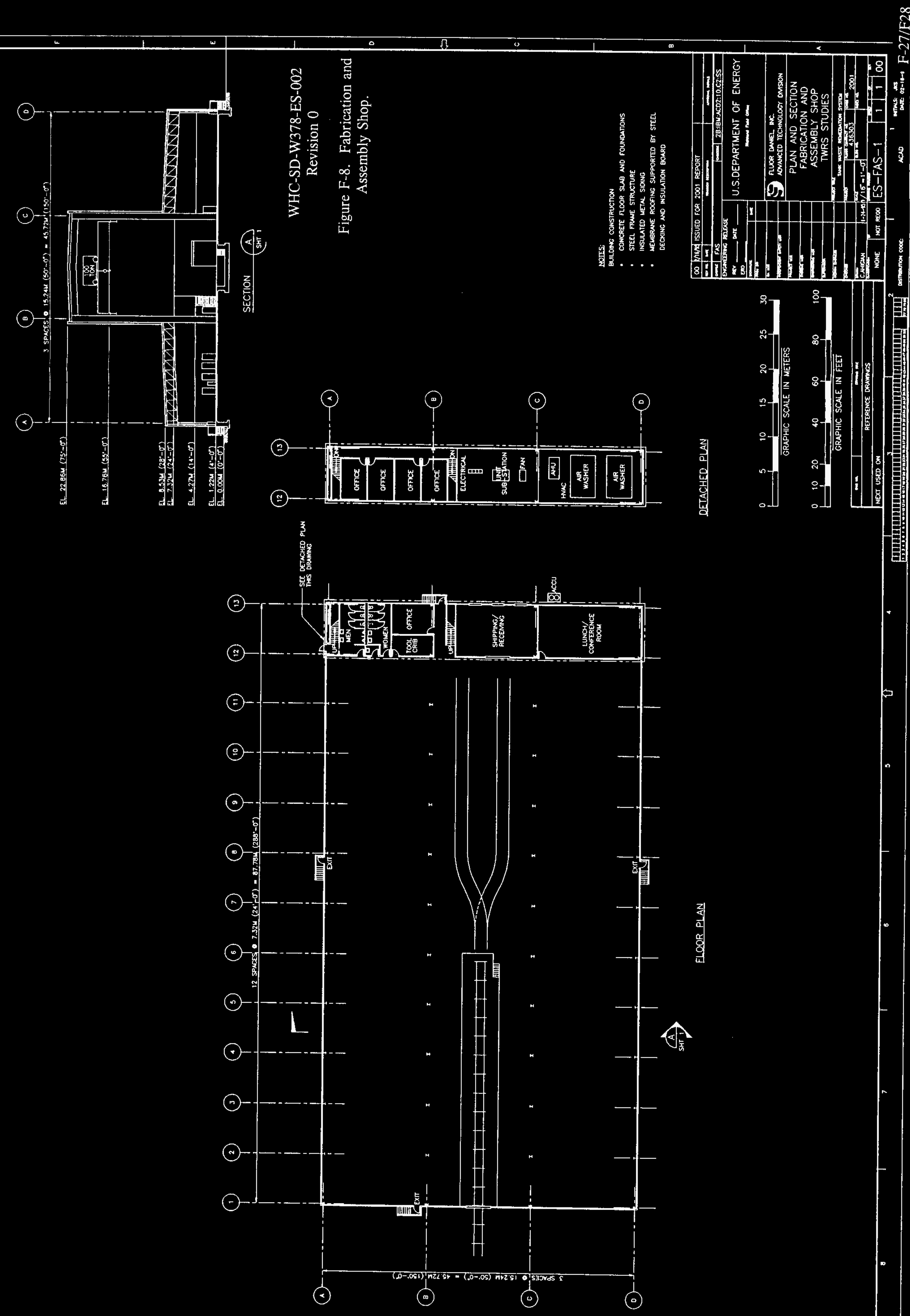

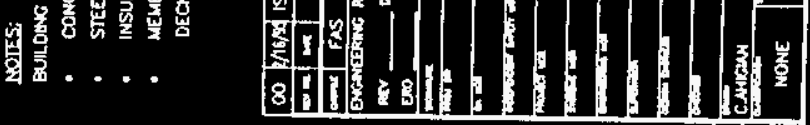



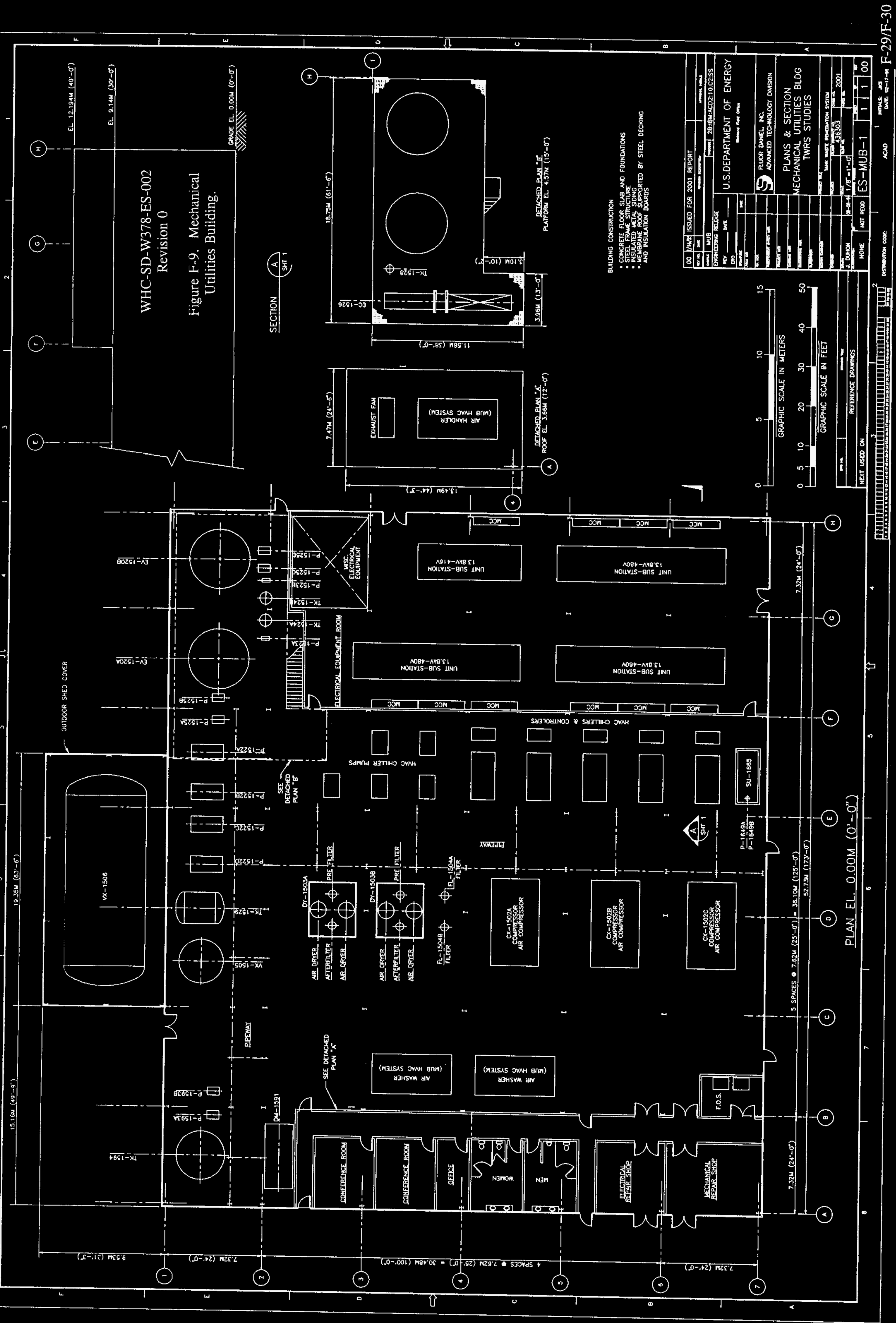


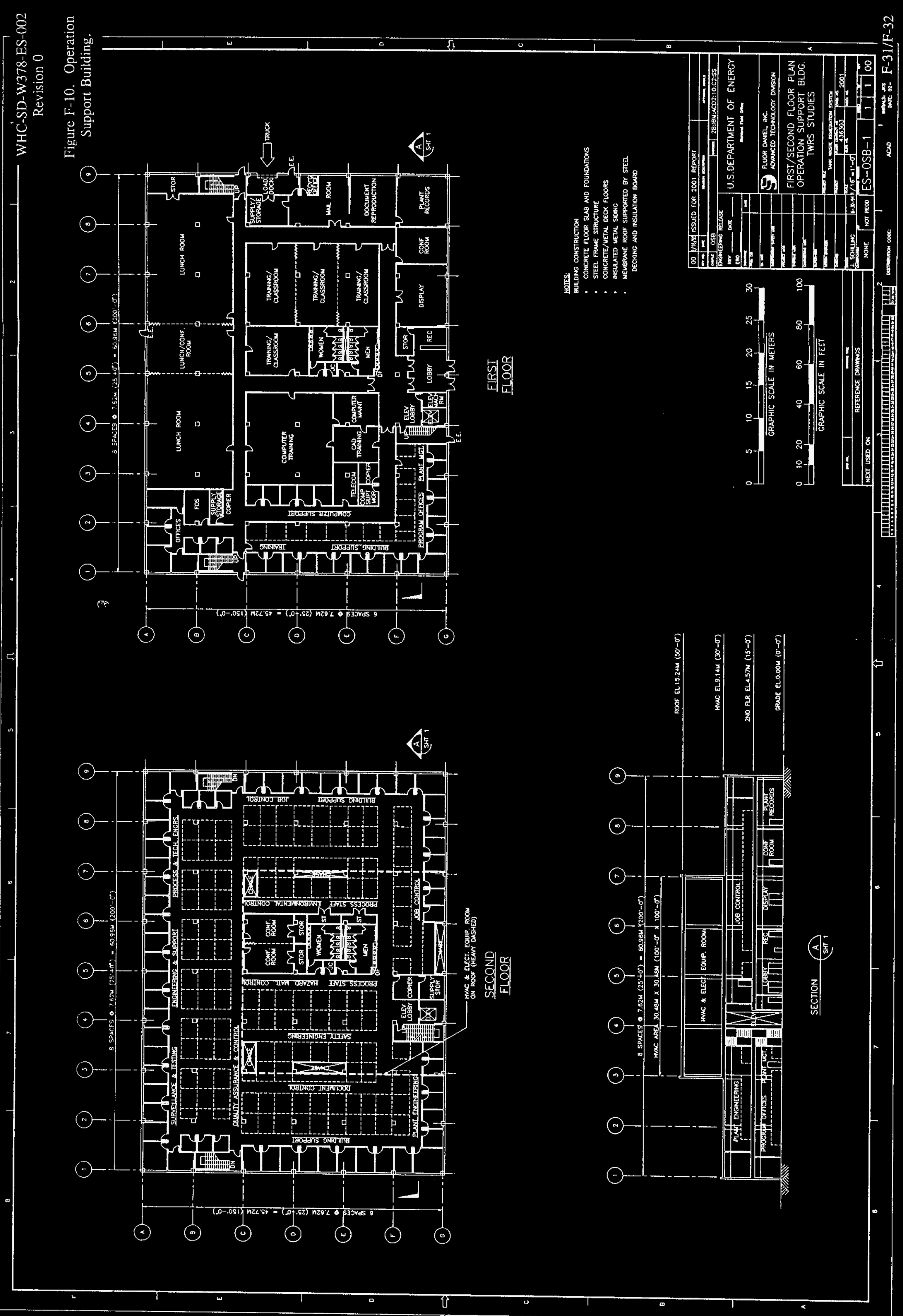




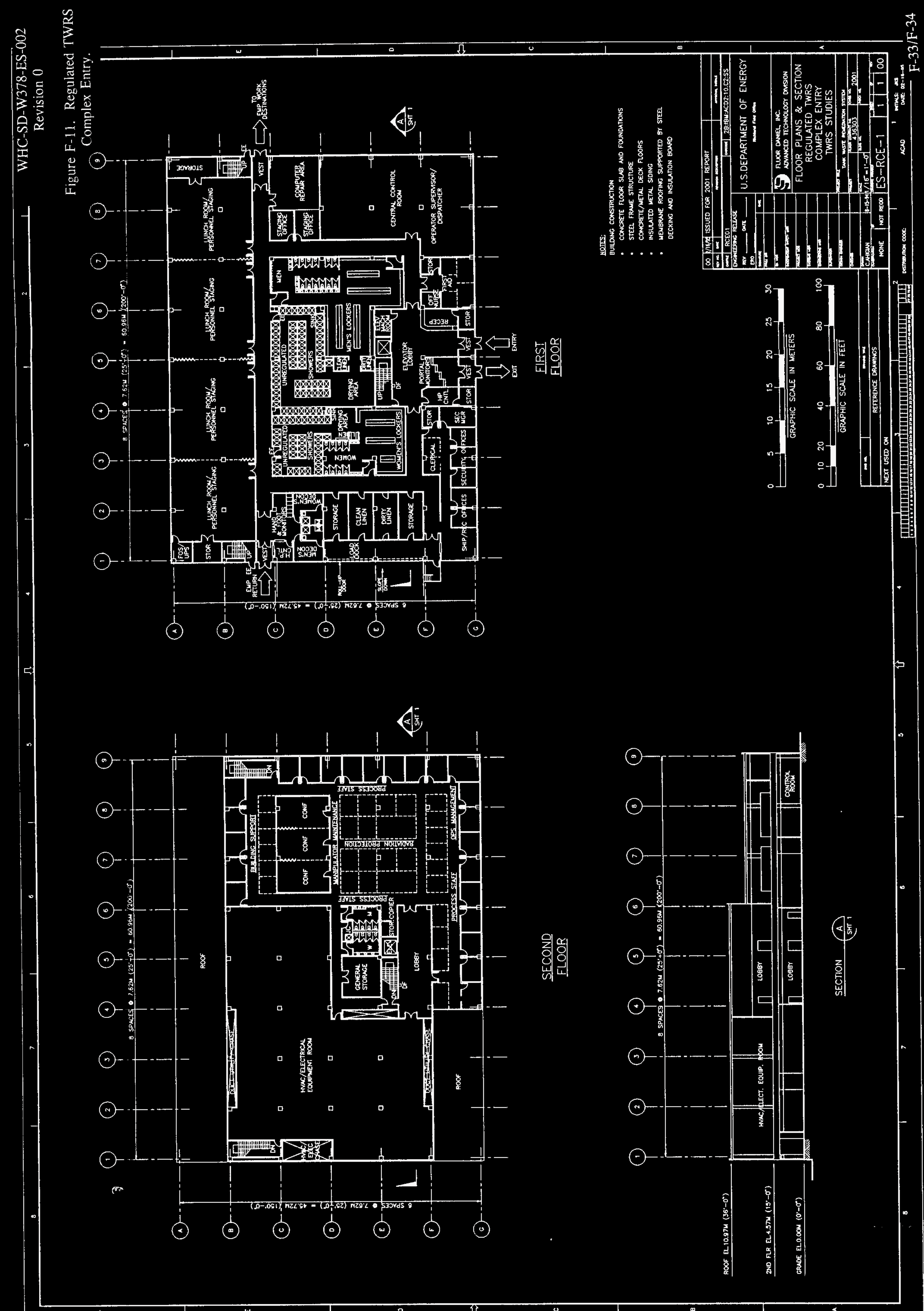



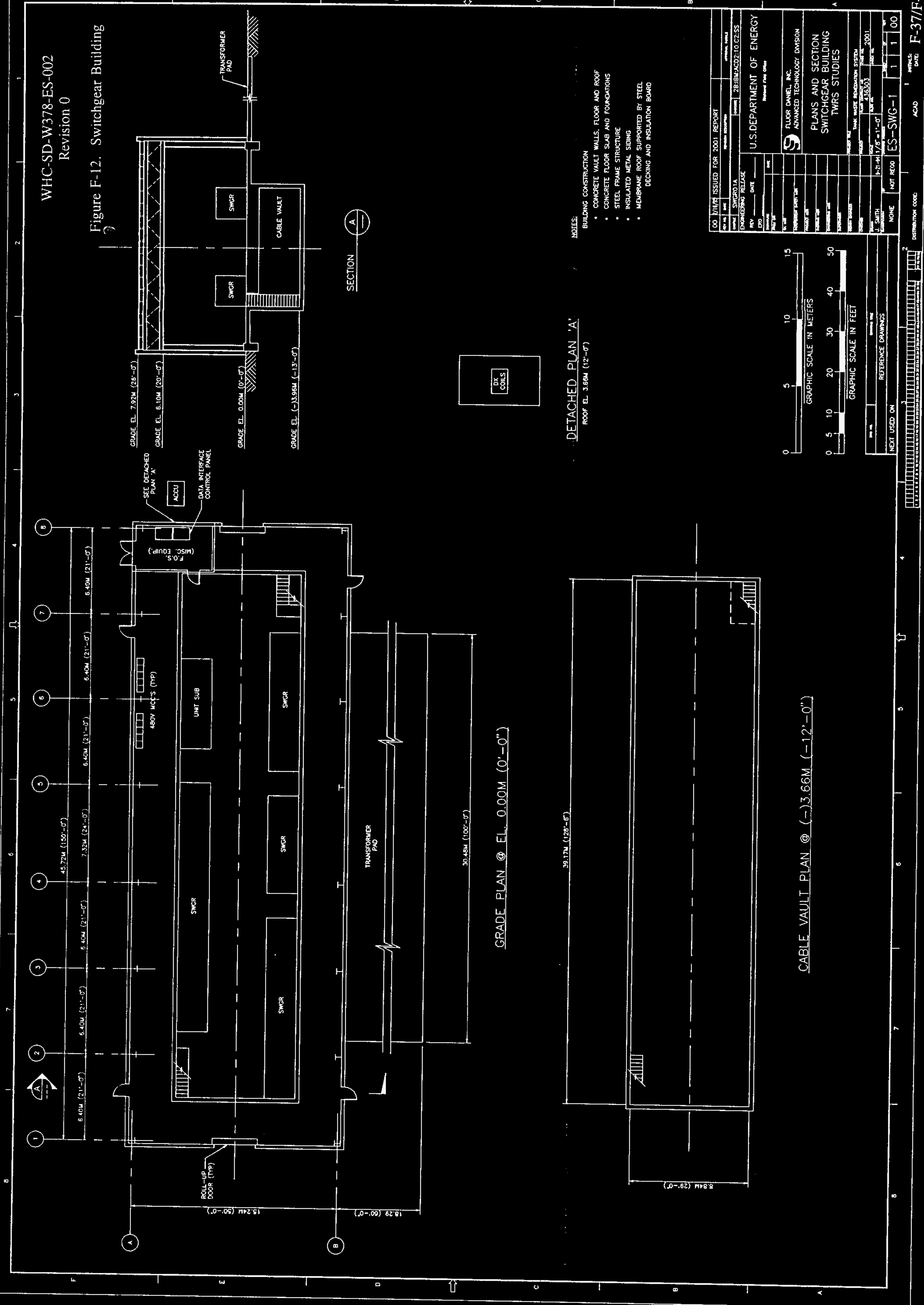


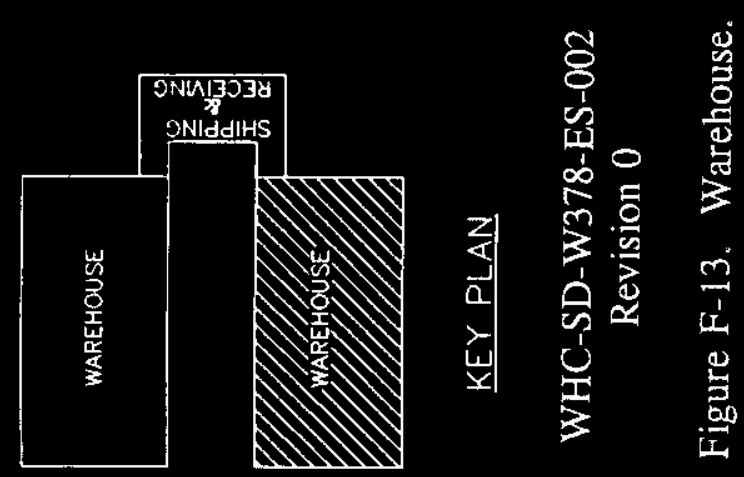

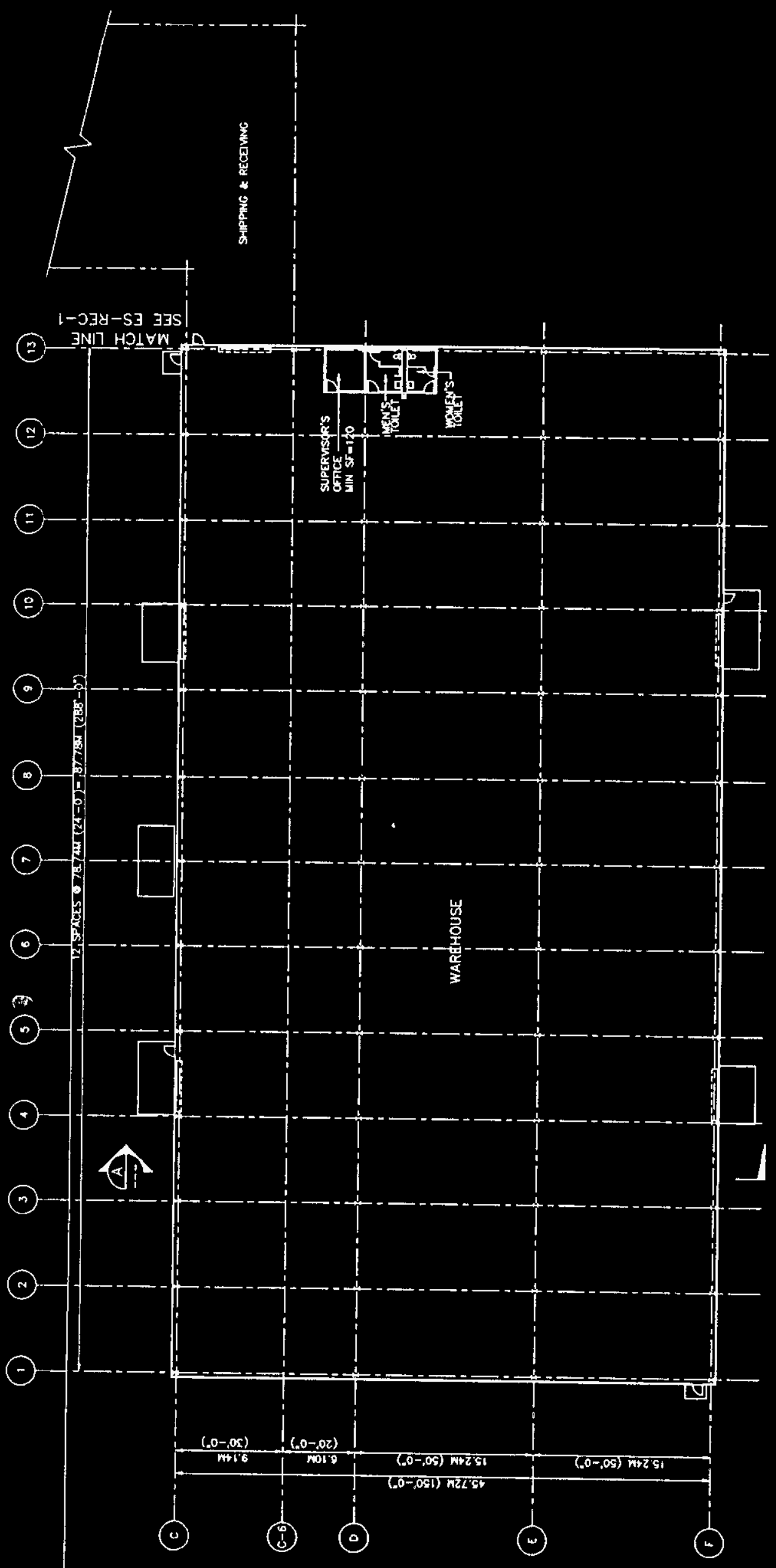

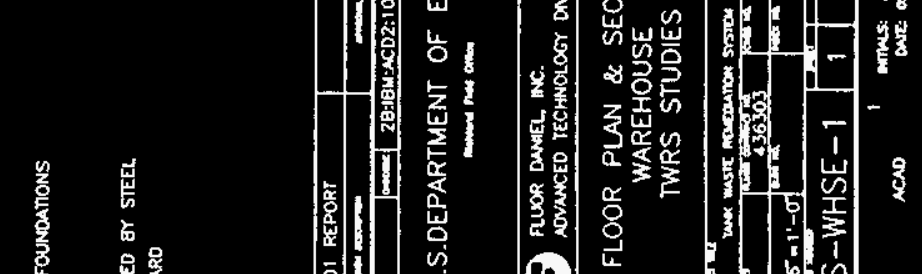

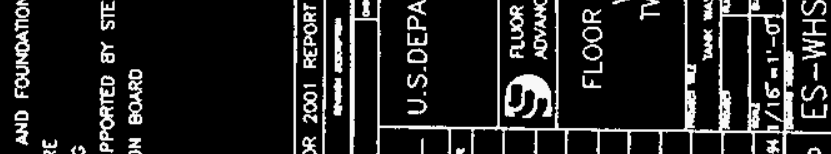

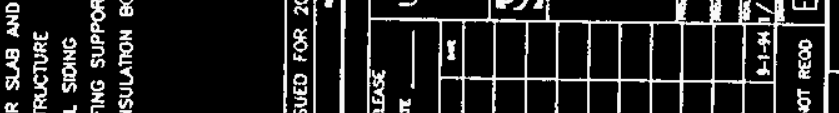

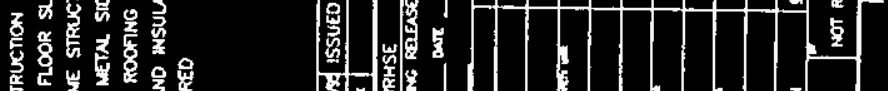

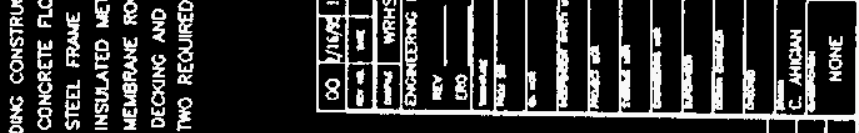
啇.

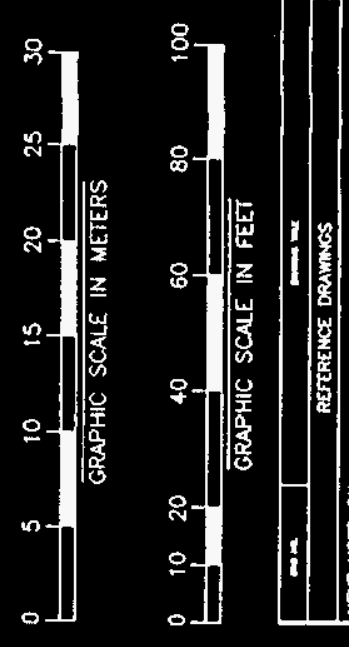

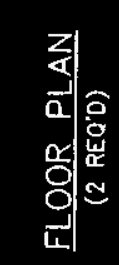

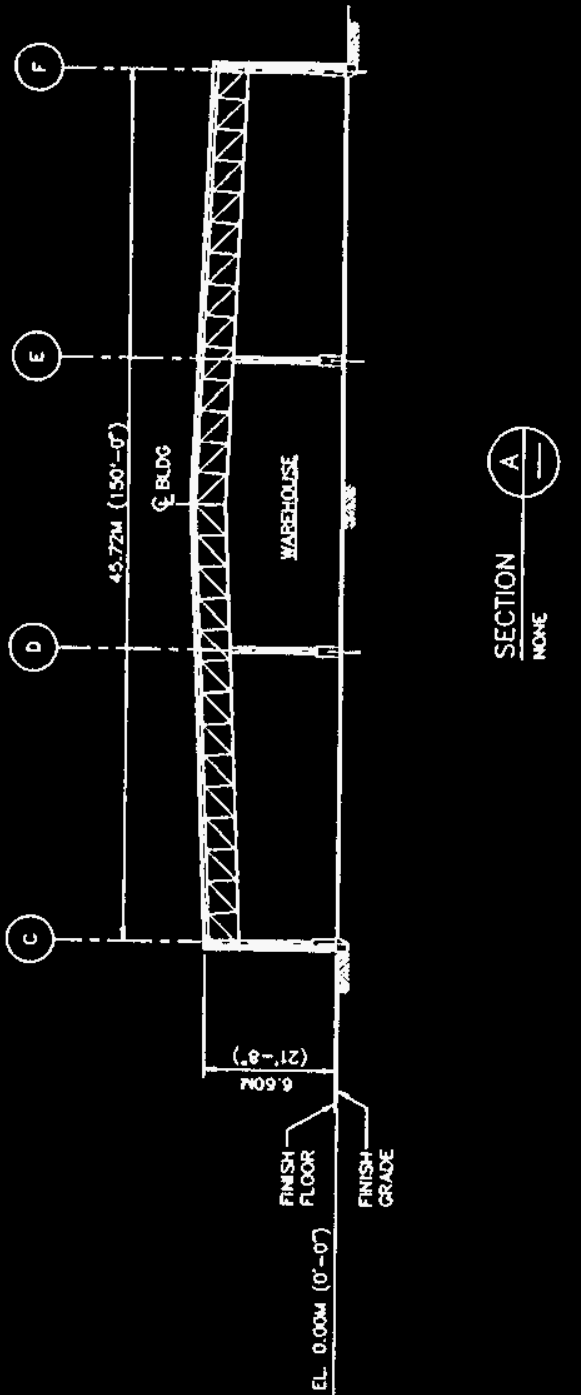



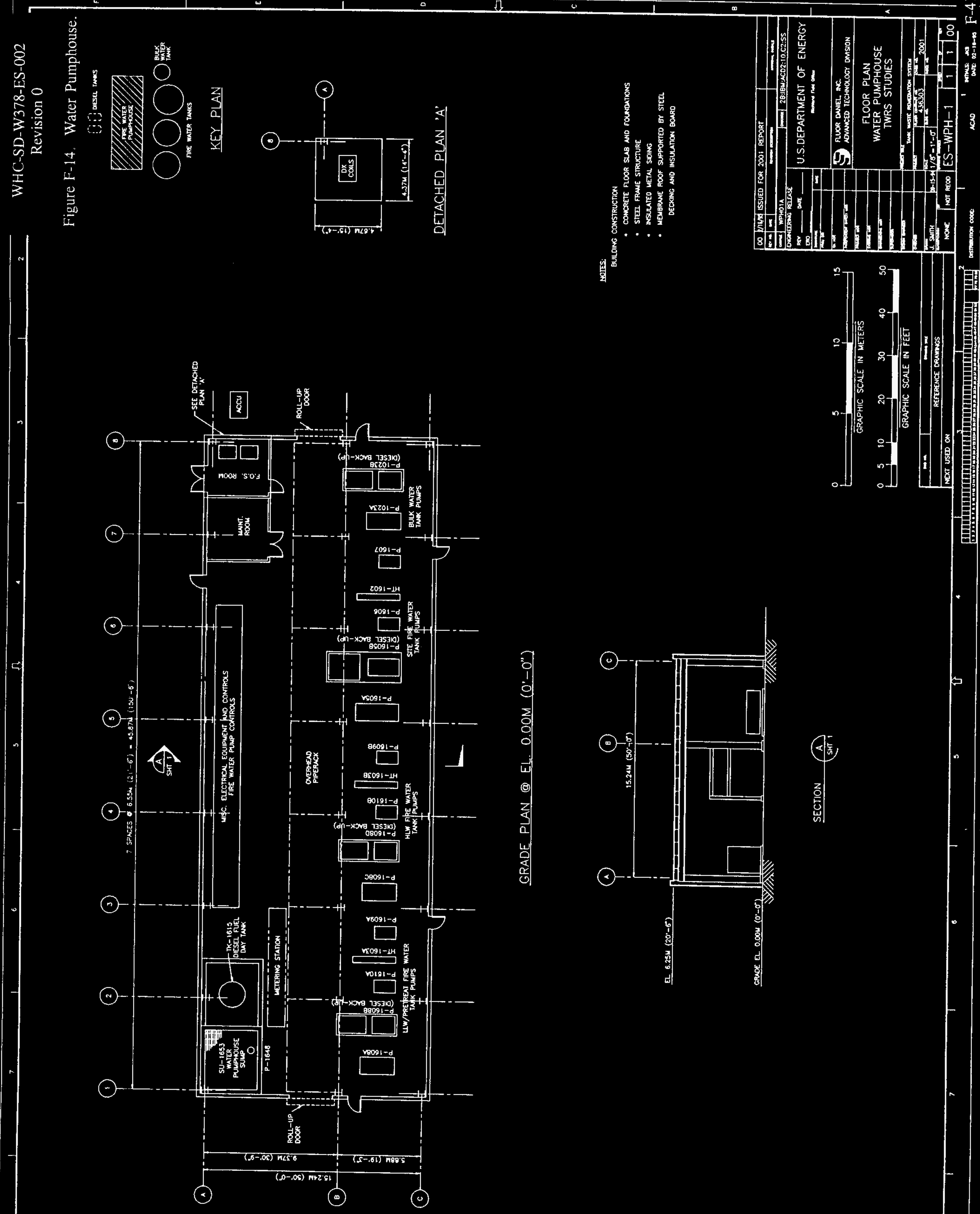

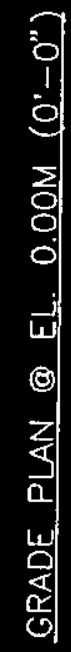

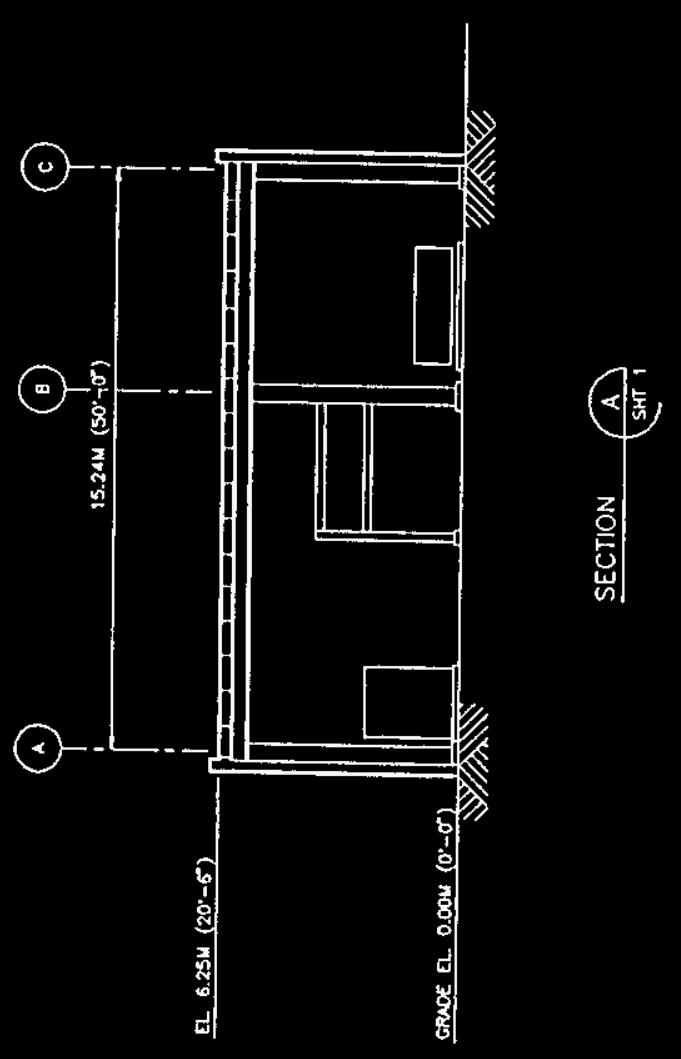


WHC-SD-W378-ES-002

Revision 0

\section{APPENDIX G1}

\section{BASE CASE SUPPORT FACILITY CONFIGURATION COST BASIS}


WHC-SD-W378-ES-002

Revision 0

This page intentionally left blank.

G1-2 
Mr. R. A. Smith, Westinghouse Hanford Company DPC-2 (G6-51)

Post Office Box 1970

2355 Stevens Drive

Richland, WA 99352

Dear Mr. Smith:

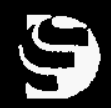

FLUOR DANIEL, INC.

Date: July 1, 1994

Reference: Hanford Waste Vitrification Plant WHC P.0. TVW-SW-370252

Fluor Contract 4363

Transmittal No.: FRT-2531

\section{TRAHSHITTAL}

We enclose_ 1 copy of the items listed below. This is issued for:
[] Approva]
[] Reference
[] Review and Comment
[X] Other Final Issue

Response due to Fluor: N/A

Responds to: N/A

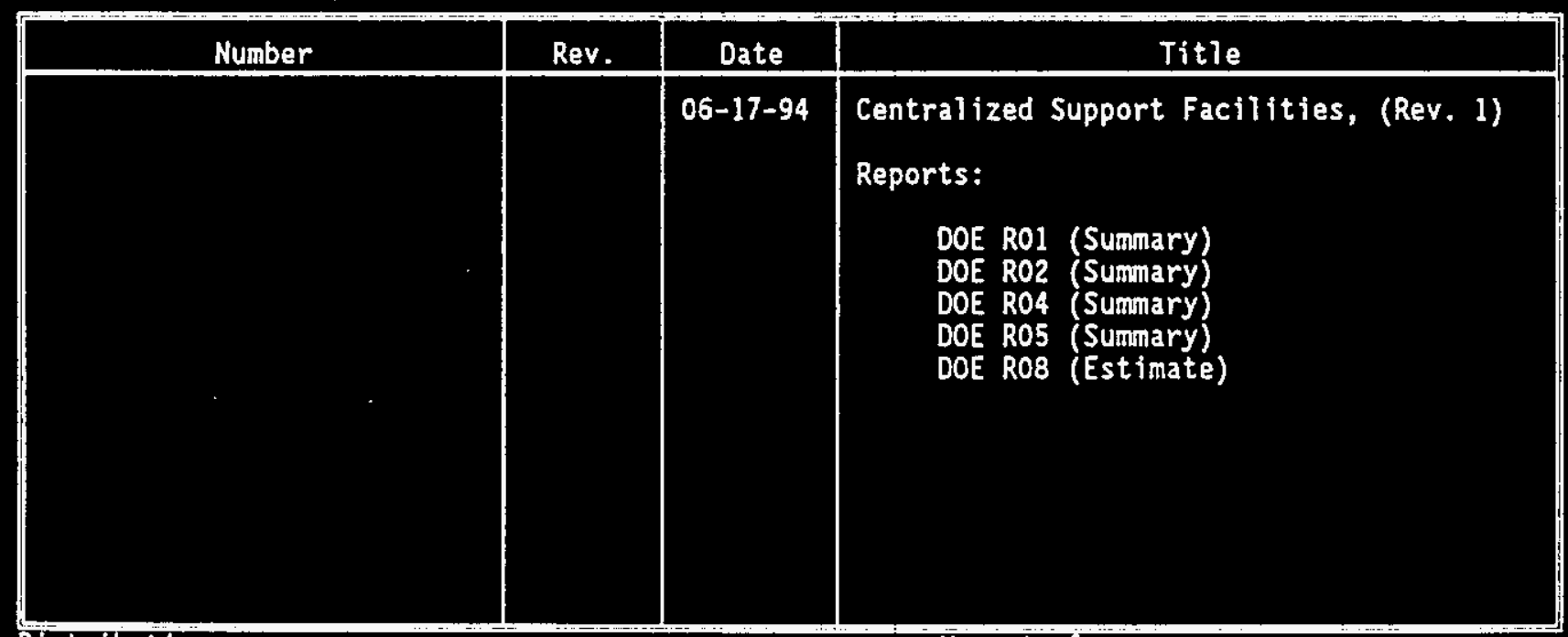

Distribution:

M. D. Talbot, WHC-RL, w/1

K. Boomer, $\mathrm{HHC}-\mathrm{RL}, \mathrm{W} / 1$

J. Garfieid, WHC-RL, W/1

T. Waldo, WHC-RL, W/1

J. Galbraith, WHC-RL, w/I

RSP:LAG: sd
Very truly yours,

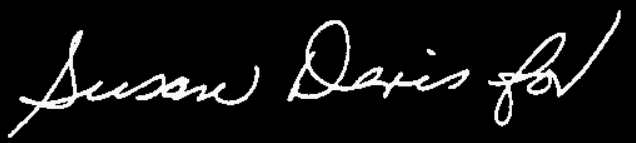

R. S. Poulter

Project Director 


\section{WHC-SD-W378-ES-002 \\ Revision 0}
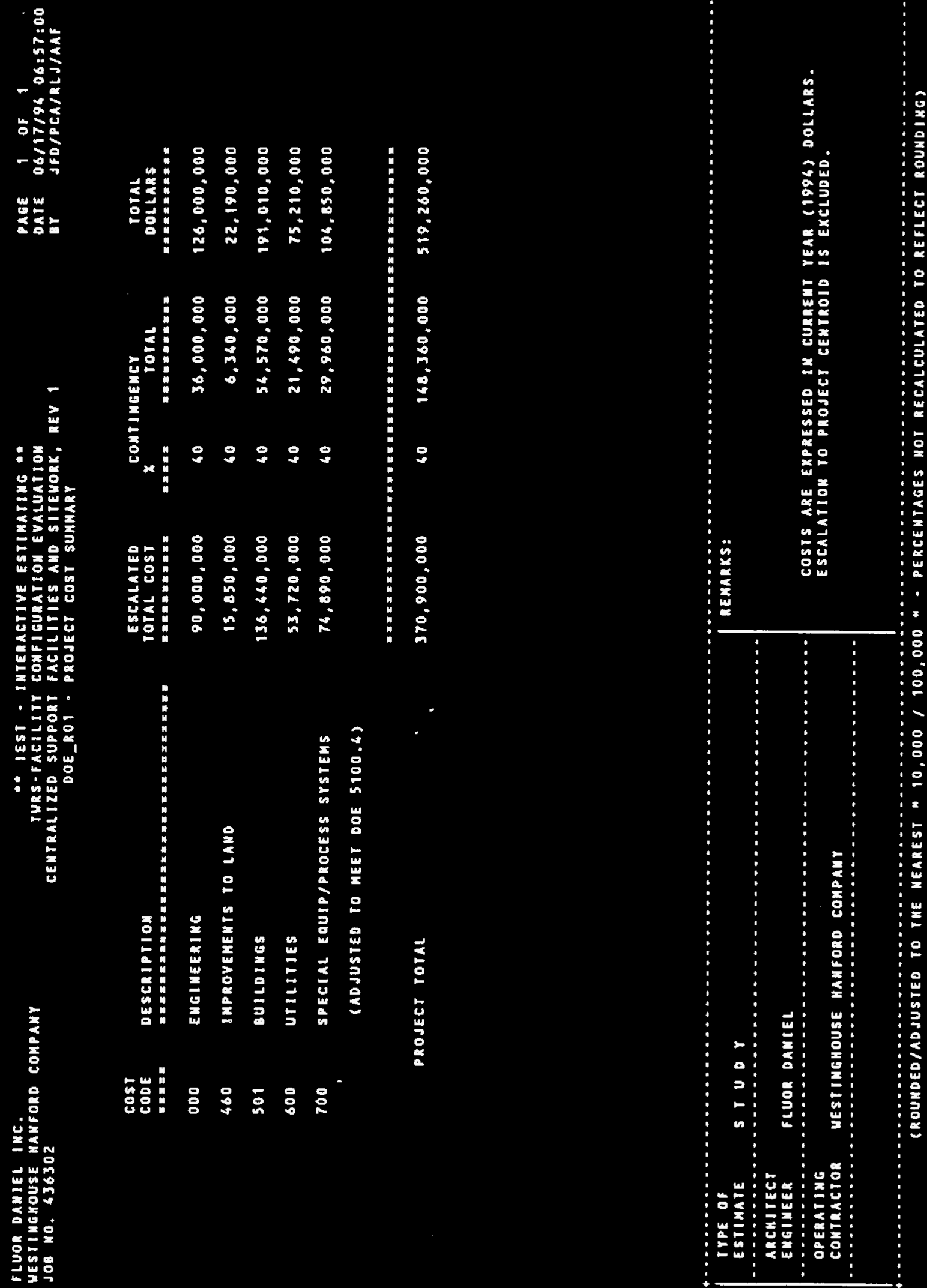

G1-4 


\section{WHC-SD-W378-ES-002 \\ Revision 0}

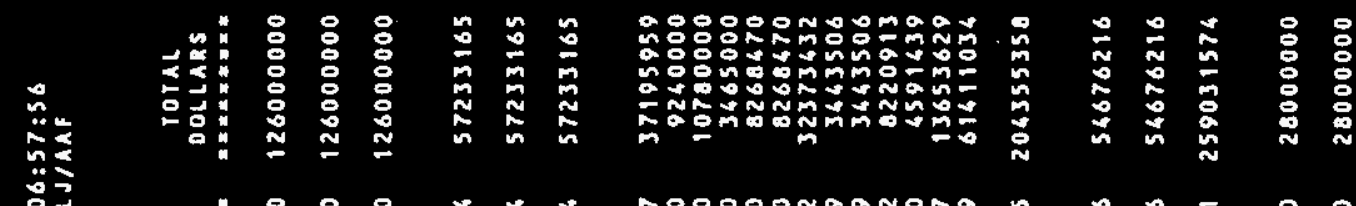

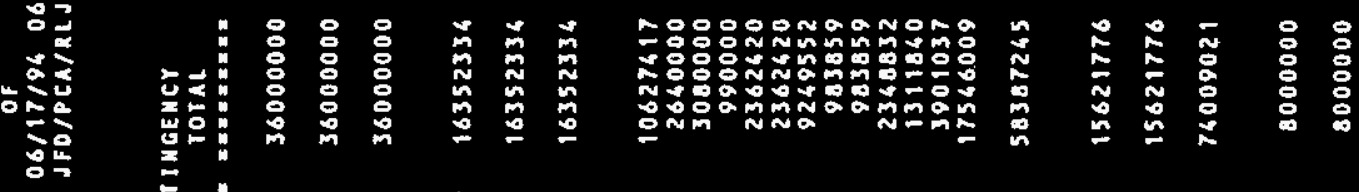

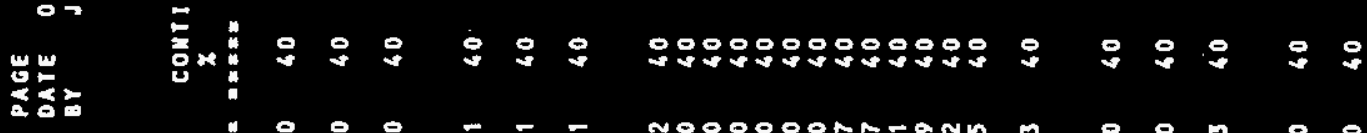

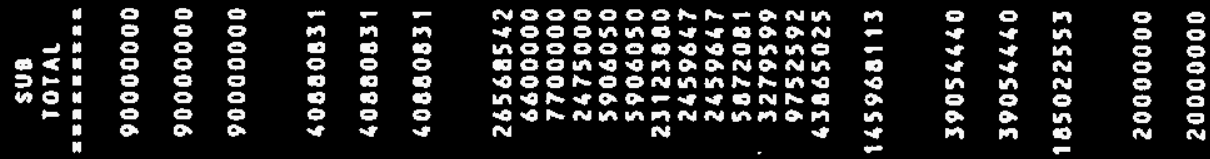

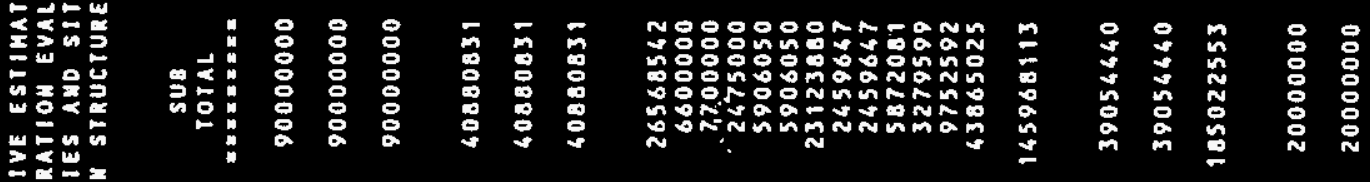

要

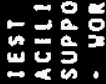

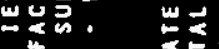

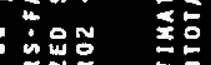

象

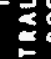

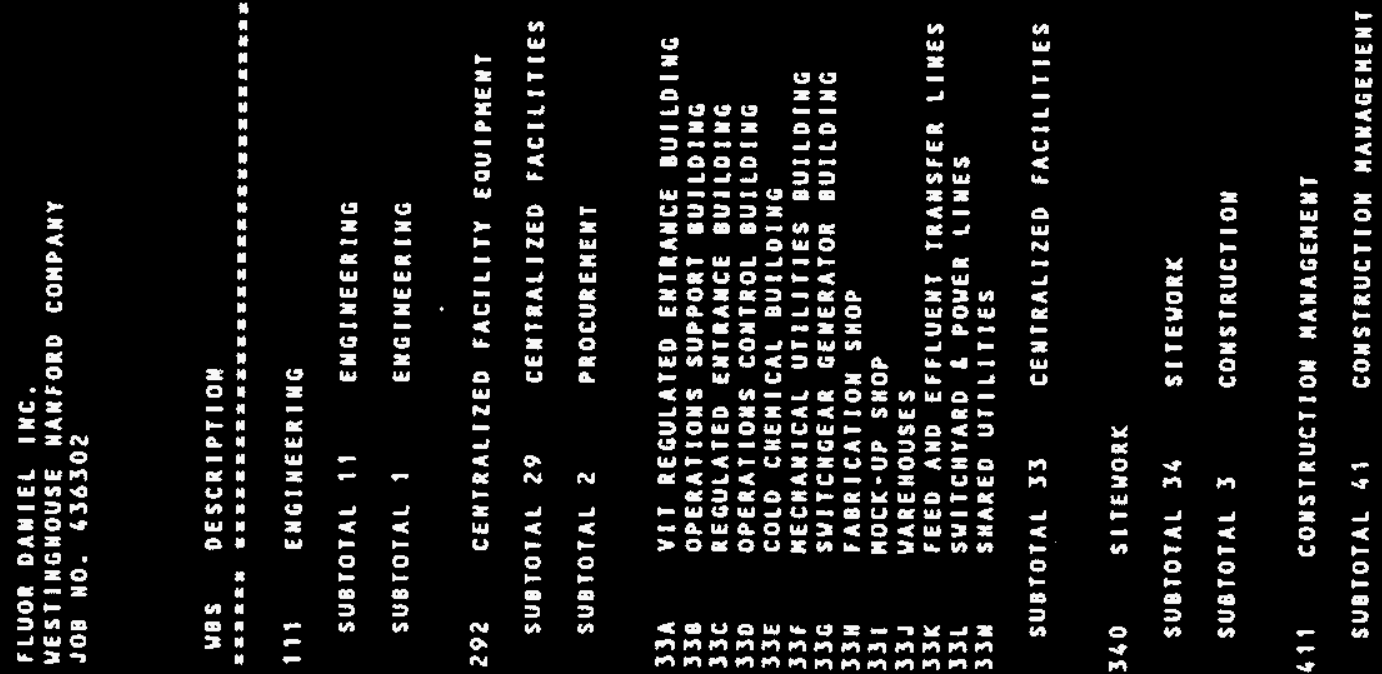

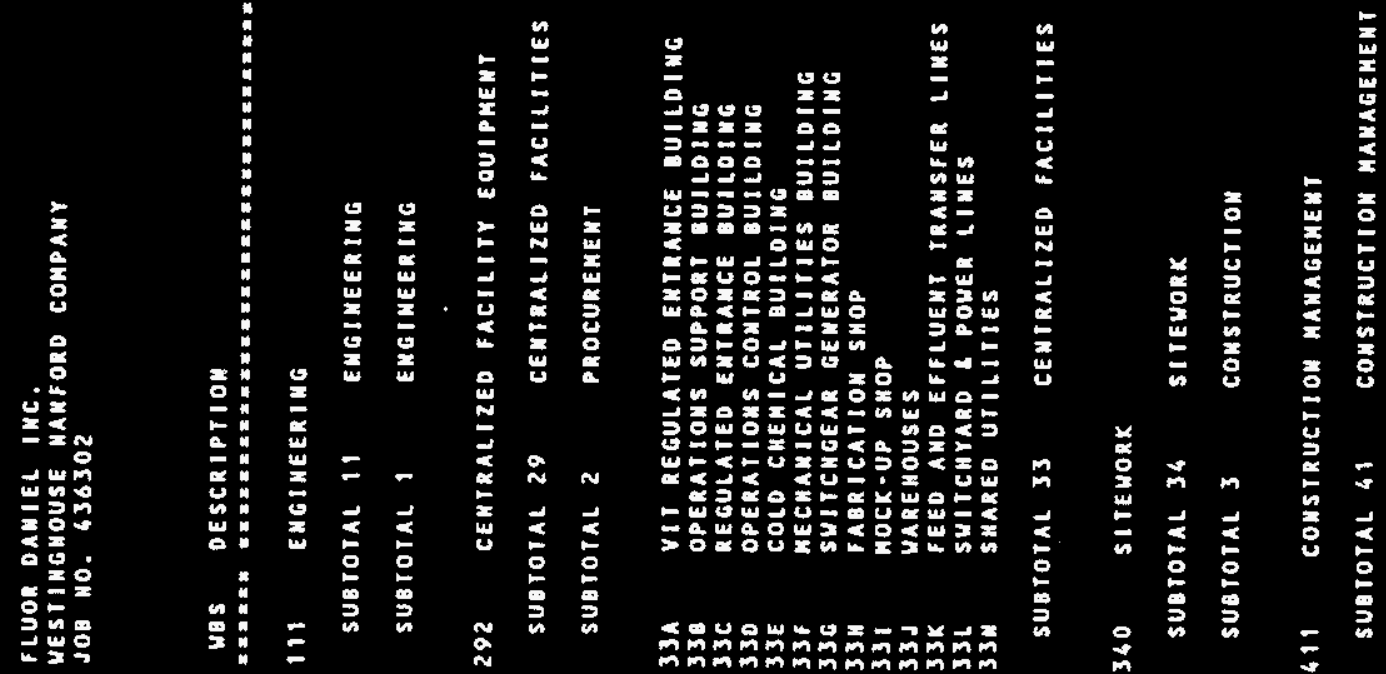

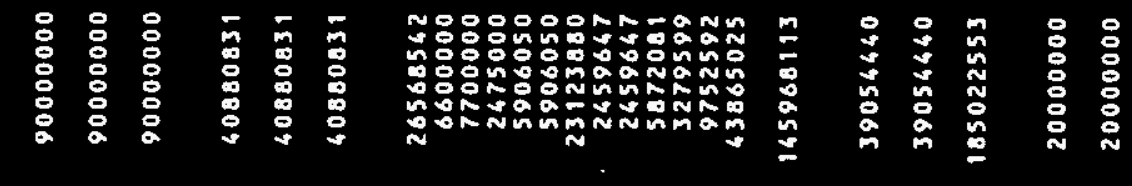


FLUOR DAMIEL TMC. UESI IMGHOUSE HAMFORD COMPANY JoB 40.43630 ?

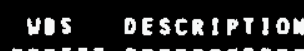

$\underline{a}$

PROJECT TOTAL

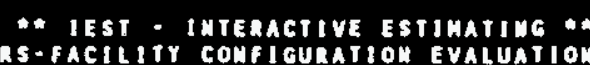
CENTRALIZEO SUPPORT FACILIIIES AHD SITEMORK REV 1

DOE_RO2 - WORK QREAKDOUH STRUCTURE SUAKARY

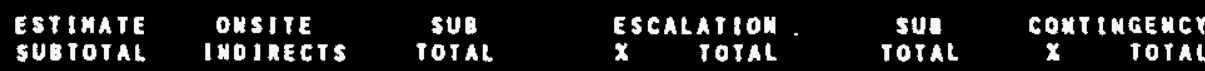

page of

DATE $06 / 17 / 9406: 57: 57$

aY JFO/PCA/RLJIAAF

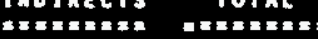

20000000

020000000

35000000

35000000

35000000

35000000

- 35000000

$0 \quad 35000000$

0

$370,903,384$
0.00
0.00
0.00
0.00

0.00

$68,361,35$

$\begin{array}{lllll}20000000 & 40 & 8000000 & 28000000 \\ 35000000 & 40 & 14000000 & 49000000 \\ 35000000 & 40 & 14000000 & 49000000 \\ 35000000 & 40 & 14000000 & 49000000\end{array}$


WHC-SD-W378-ES-002

Revision 0

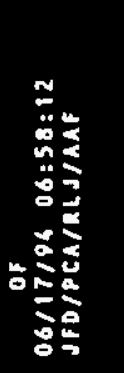

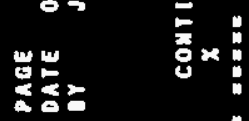

을

- 흘

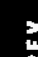

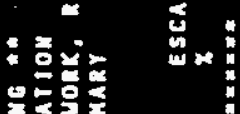

这是要

을

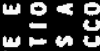

$\sum \Sigma \overline{0}$

두을

두용

- 둥.

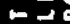

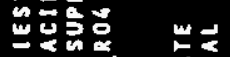

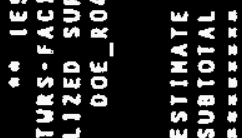

:

믐ำ

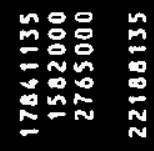

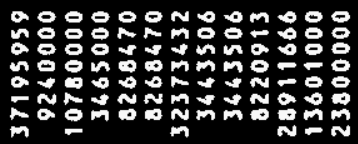

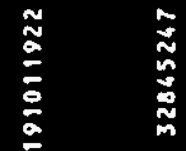

\begin{tabular}{ll}
800 & 8 \\
8 & 8 \\
8 & 8 \\
\hline & $\vdots$
\end{tabular}

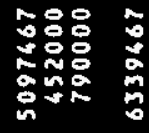

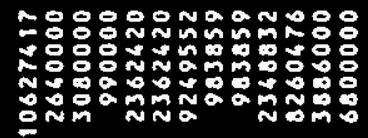

$\begin{array}{ll}n & 0 \\ \vdots & 0 \\ \vdots & 0 \\ n & 0\end{array}$

900: 989:

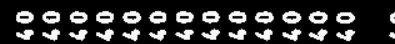

8

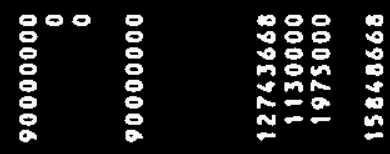

0000

0000

$\begin{array}{ll}888: & 888 \\ 000 & 0 \% 0\end{array}$

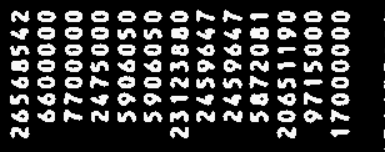

:

0000000000000

$\circ$

$8^{\circ}{ }^{\circ}$

:

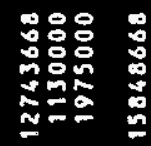

0000
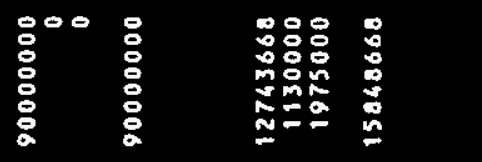

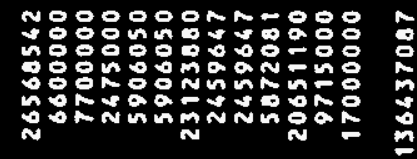

5
$\vdots$
$\vdots$
$\vdots$
$\vdots$

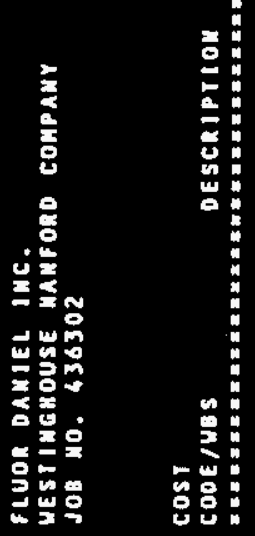

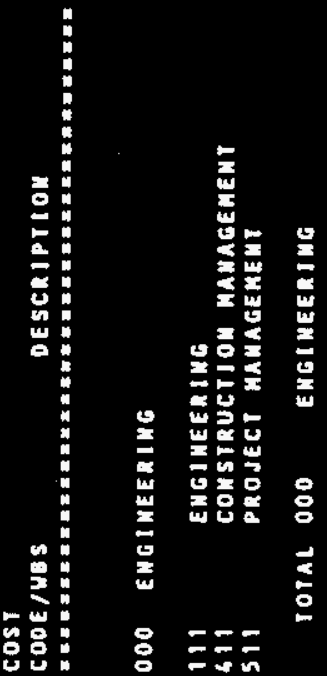

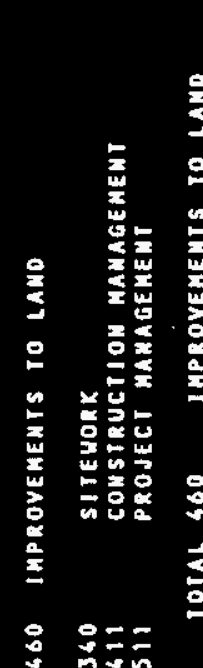

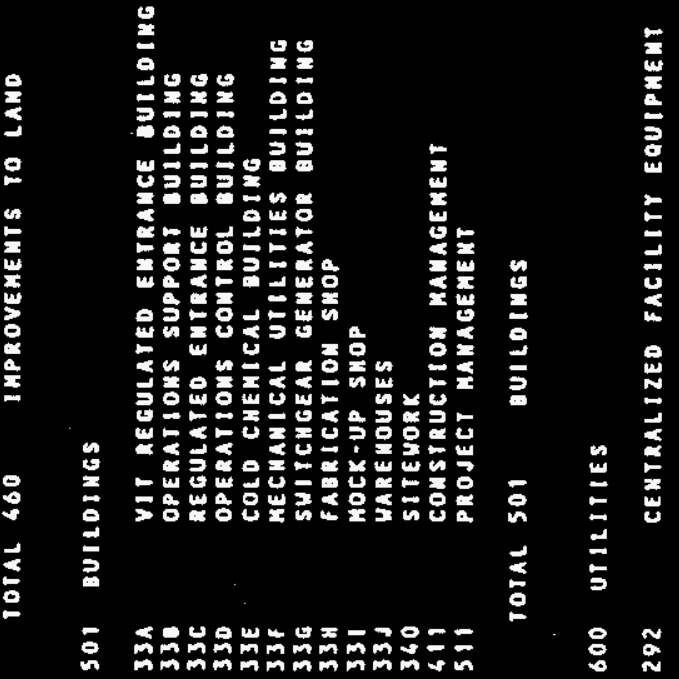


Fluor DAMIEL INC.

UESTINGMOUSE MARFORD COMPANY

JOB NO. 436302

$\cos t$

cooejues

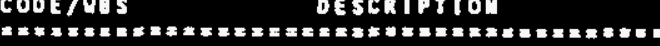

SHARED UTILITIES

SITEHORK
COMSTRUCTION MAMAGEMEH

411 COMSTRUCTION MAMAGEME
511 PROJECT MAMAGEMT

TOTAL 600 UTILITIES

700 SPECIAL EOUTP/PROCESS SYSTEMS

क

SHARED UTHLITHES

COHSTRUCTION MAHAGEMEH

PROJECT MAMAGEMEMT

TOIAL 700

SPECIAL EOUIPTPROCESS SYSTEK
33L SUITCUYARD 2 POUER LIMES

92 CEMTRALIZED FACILITY EOUIPMENT

33K FEED AMD EFFLUET TRAHSFE LIHES

* IEST - IMTERACtIVE ESTIMATIMG *

TURS-FACILITY COHFIGURATION EVALUATION

CEATRALIZED SUPPORT EACILITIES AKO SITEUORK, REV

DOE_ROG - COST CODE ACCOUH SUKHARY

\begin{tabular}{|c|c|c|c|c|c|c|c|c|}
\hline $\begin{array}{l}\text { THKATE } \\
\text { BTOTAL }\end{array}$ & $\begin{array}{l}\text { ONSITE } \\
\text { IMDIRECTS }\end{array}$ & $\begin{array}{l}\text { SUP } \\
\text { roTAL }\end{array}$ & $\begin{array}{l}E s \\
x\end{array}$ & & $\begin{array}{c}\text { SUE } \\
\text { TOTAL }\end{array}$ & $\cos$ & $\begin{array}{l}\text { MENCY } \\
\text { TOTAL }\end{array}$ & $\begin{array}{c}\text { YOTAL } \\
\text { DOLLARS }\end{array}$ \\
\hline $\begin{array}{l}9752592 \\
4329705 \\
5659582 \\
3825000 \\
6695000\end{array}$ & $\begin{array}{l}0 \\
0 \\
0 \\
0 \\
0\end{array}$ & $\begin{array}{l}9752592 \\
4329705 \\
5659582 \\
3825000 \\
6695000\end{array}$ & $\begin{array}{l}0.00 \\
0.00 \\
0.00 \\
0.00 \\
0.00\end{array}$ & $\begin{array}{l}0 \\
0 \\
0\end{array}$ & $\begin{array}{l}9752592 \\
6329705 \\
5659582 \\
3825000 \\
6695000\end{array}$ & $\begin{array}{l}40 \\
40 \\
40 \\
40 \\
40\end{array}$ & $\begin{array}{l}3901037 \\
1731882 \\
2263833 \\
1530000 \\
2678000\end{array}$ & $\begin{array}{r}13653629 \\
6061587 \\
7923415 \\
5355000 \\
9373000\end{array}$ \\
\hline 27 & 0 & 53722770 & 0.00 & ( & 53722770 & 40 & 21489108 & 75211878 \\
\hline
\end{tabular}

PROJECT TOTAL

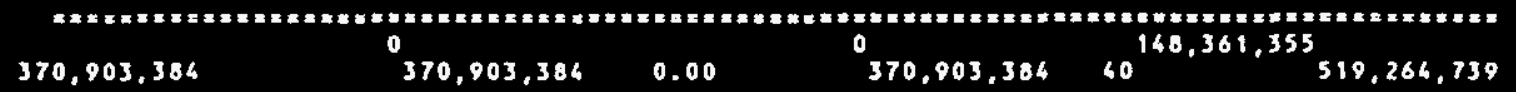

PAGE
OATE OS/17/94 06:58:13
EY JFO/PCA/RLS/AAF

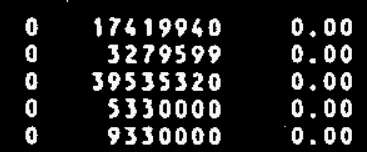

3279599
39535320

5330000

9330000

7489485
- 74894859
- $\quad 53722770$

40

0
0
0 $\quad 32795900$

3279590
39535320

5330000

9330000

74894859

$\begin{array}{rr}40 & 6967978 \\ 40 & 1311860 \\ 40 & 15814127 \\ 40 & 2132000 \\ 40 & 3732000\end{array}$

4387918
4591430

6591439
55349447

7662000

$40 \quad 29957945 \quad 104852804$ 


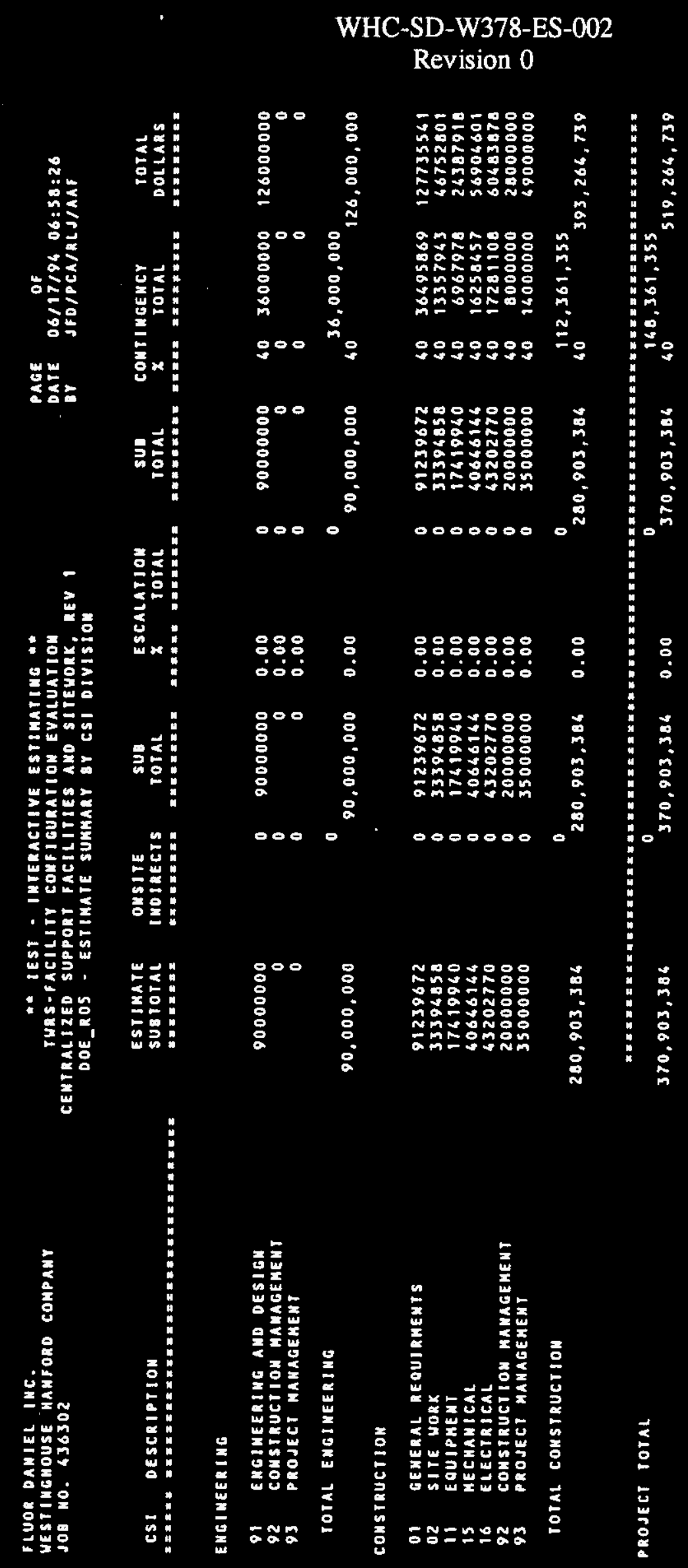

G1-9 


\section{WHC-SD-W378-ES-002}

Revision 0

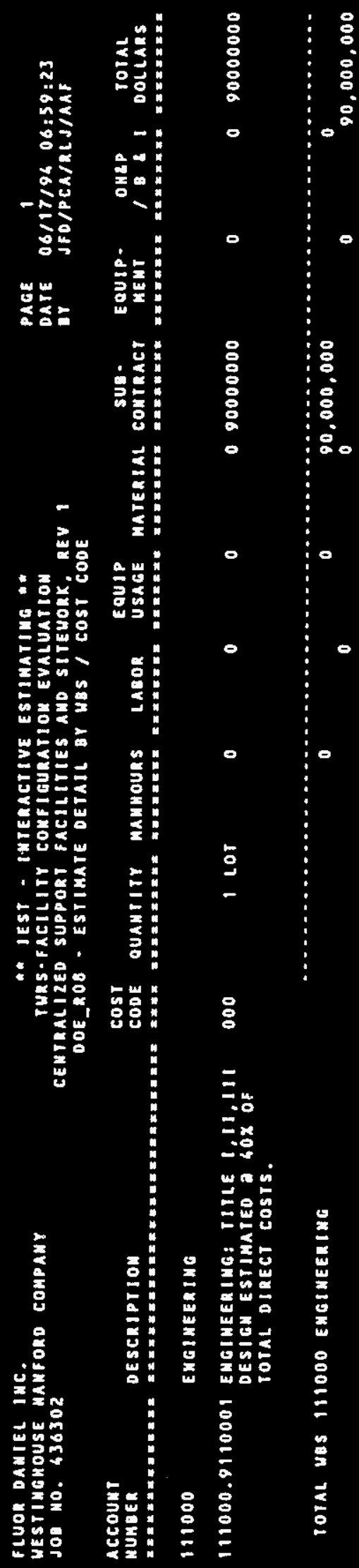

G1-10 


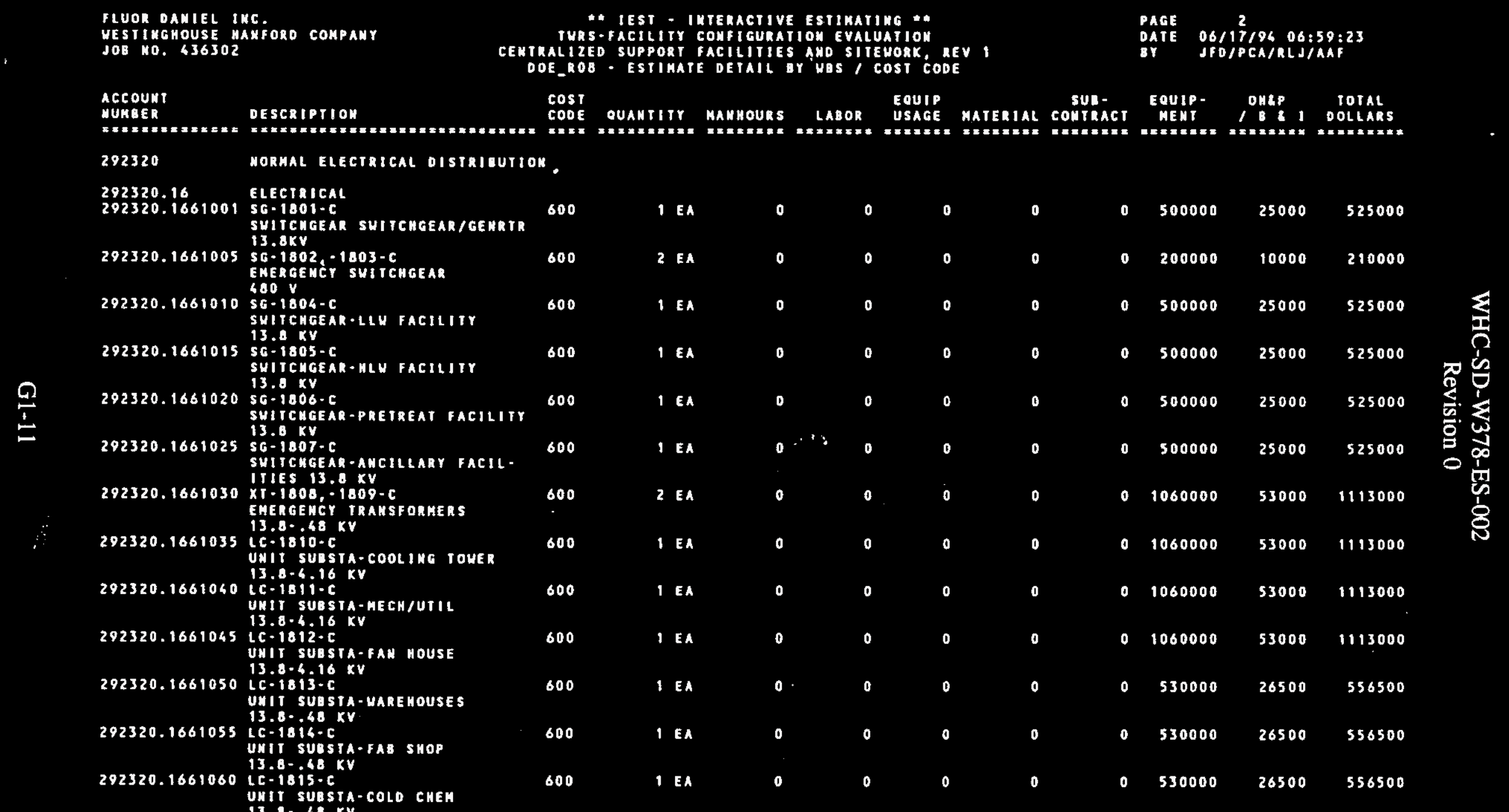




\section{WHC-SD-W378-ES-002 Revision 0}

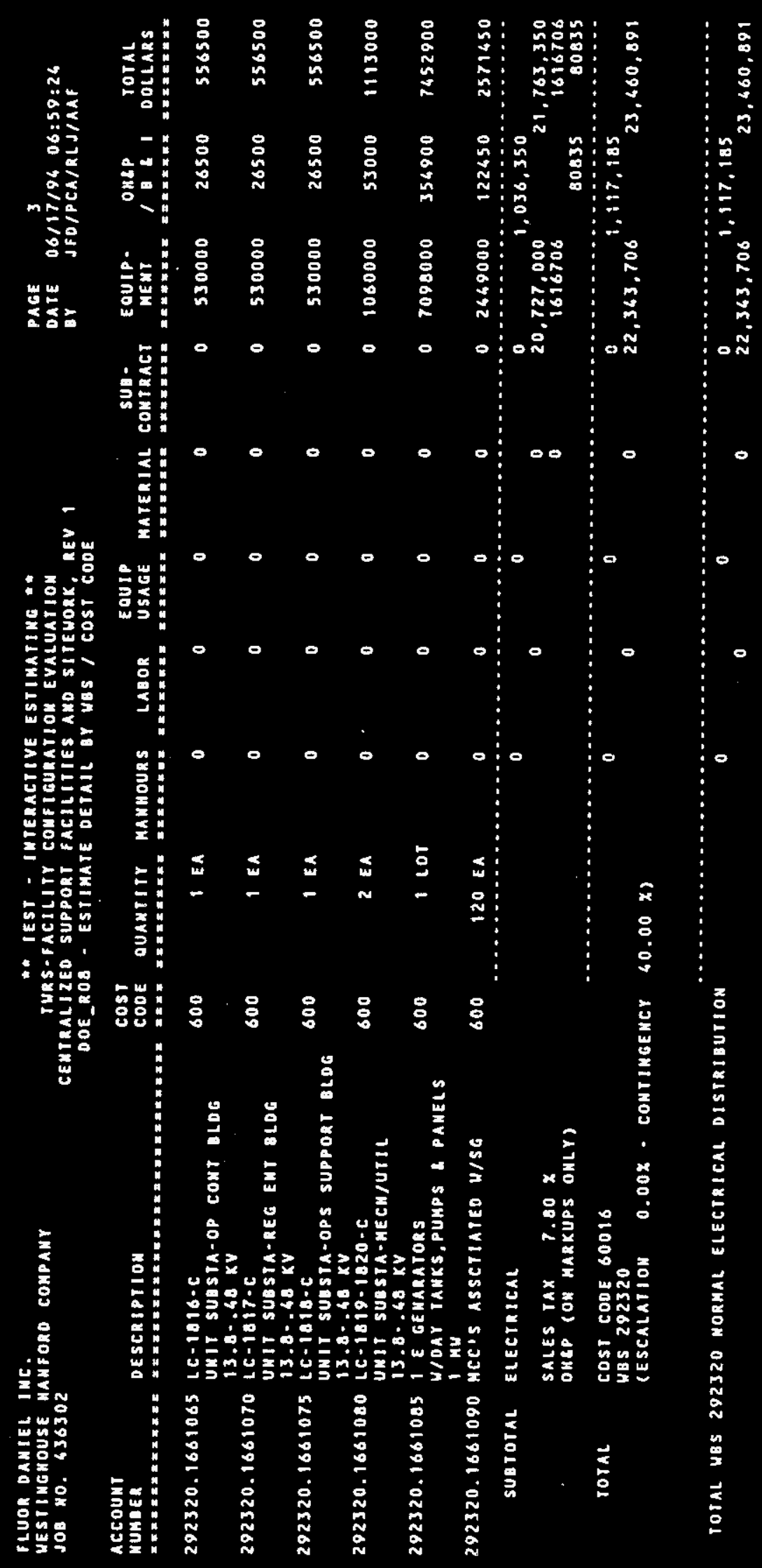


WHC-SD-W378-ES-002

Revision 0

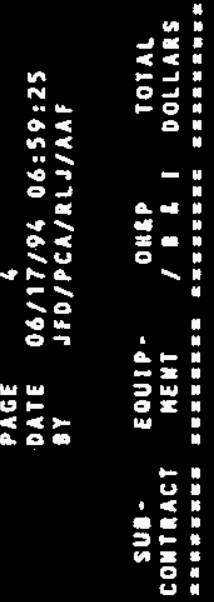

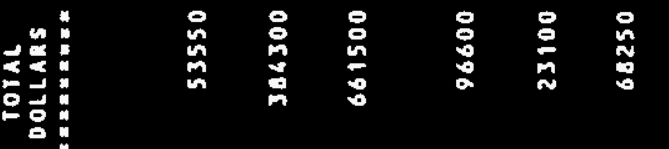

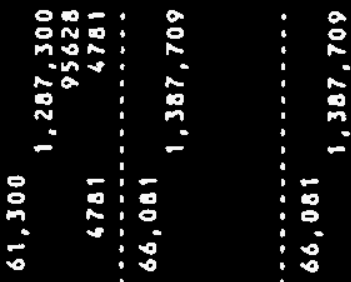

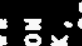

$-$

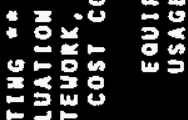

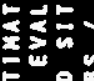

둥훌

응

둔

둥혀을

:

의

ㄴ.

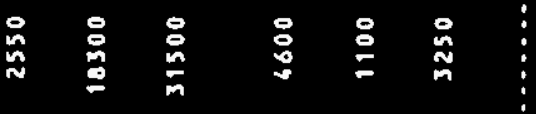

용 8

$\begin{array}{lll}8 & 8 & 8 \\ \stackrel{8}{0} & \stackrel{8}{0} & 8 \\ 0 & \text { N } & \end{array}$

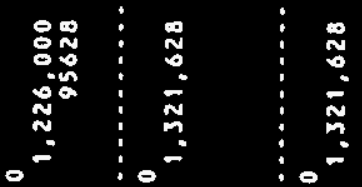

- 26

世원

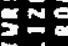

㩆:

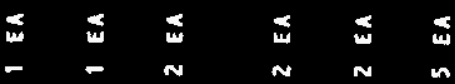

o

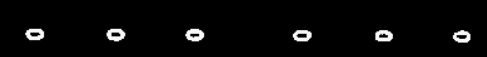

$\circ \quad 0 \quad 0 \quad 0 \quad 00$

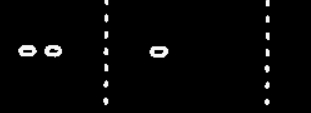

응

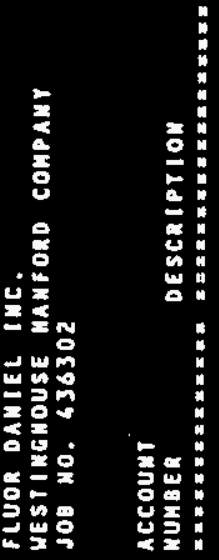

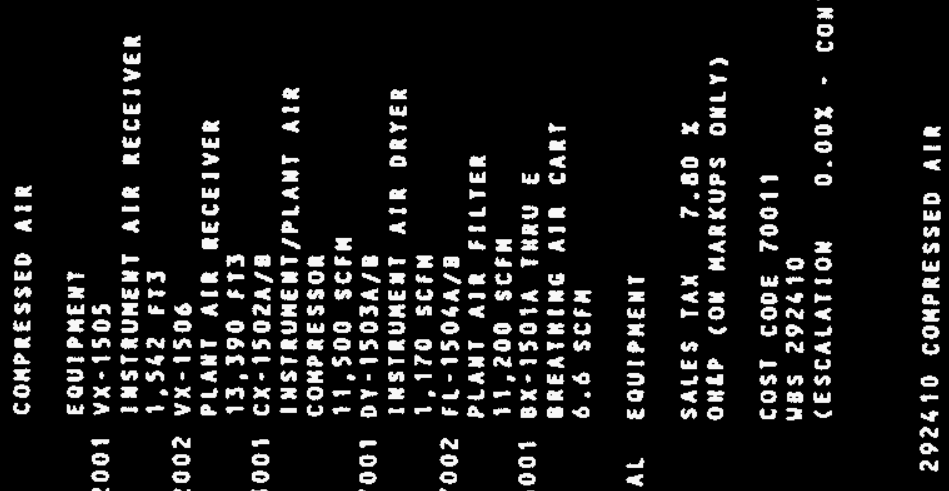

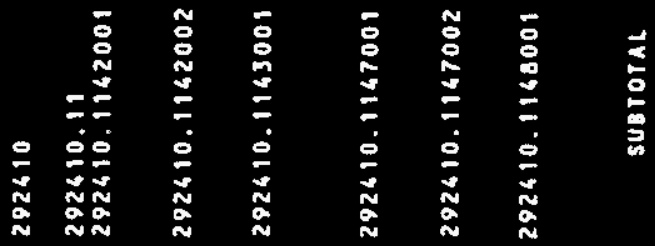

$\underline{5}$

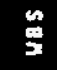




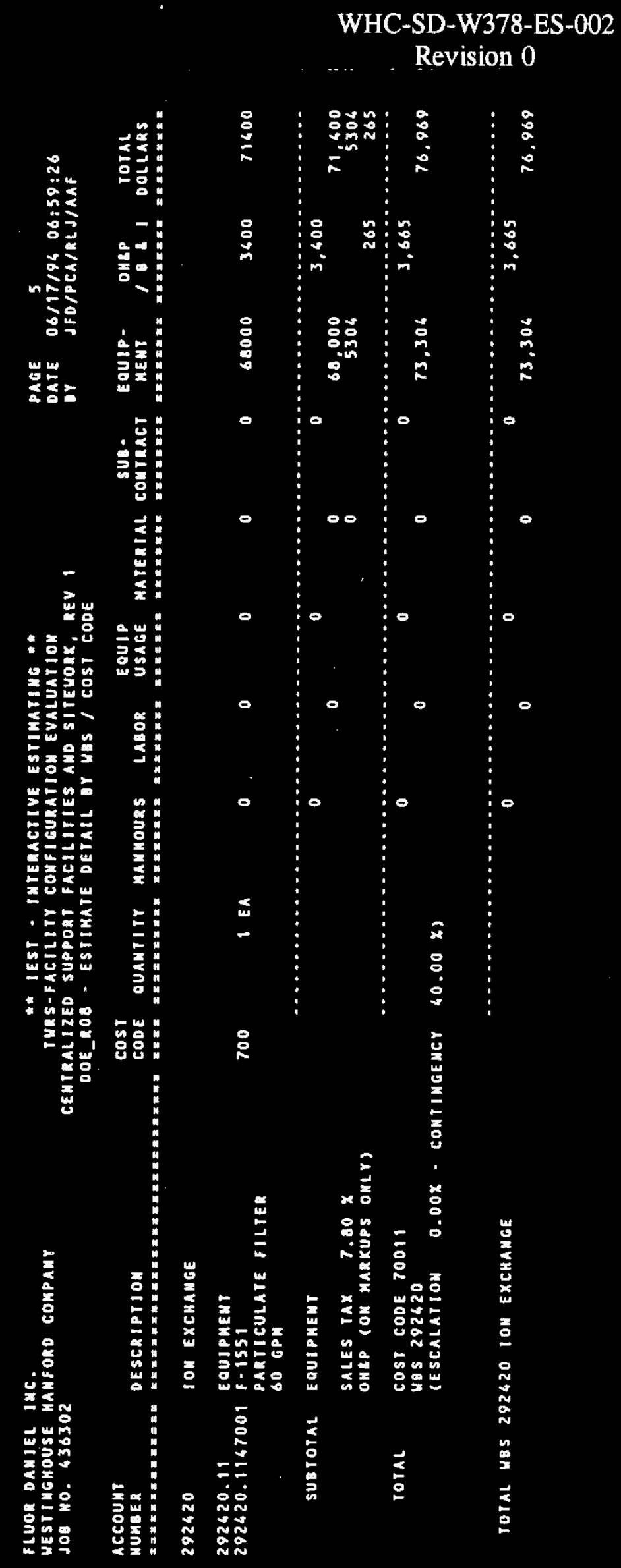

G1-14 


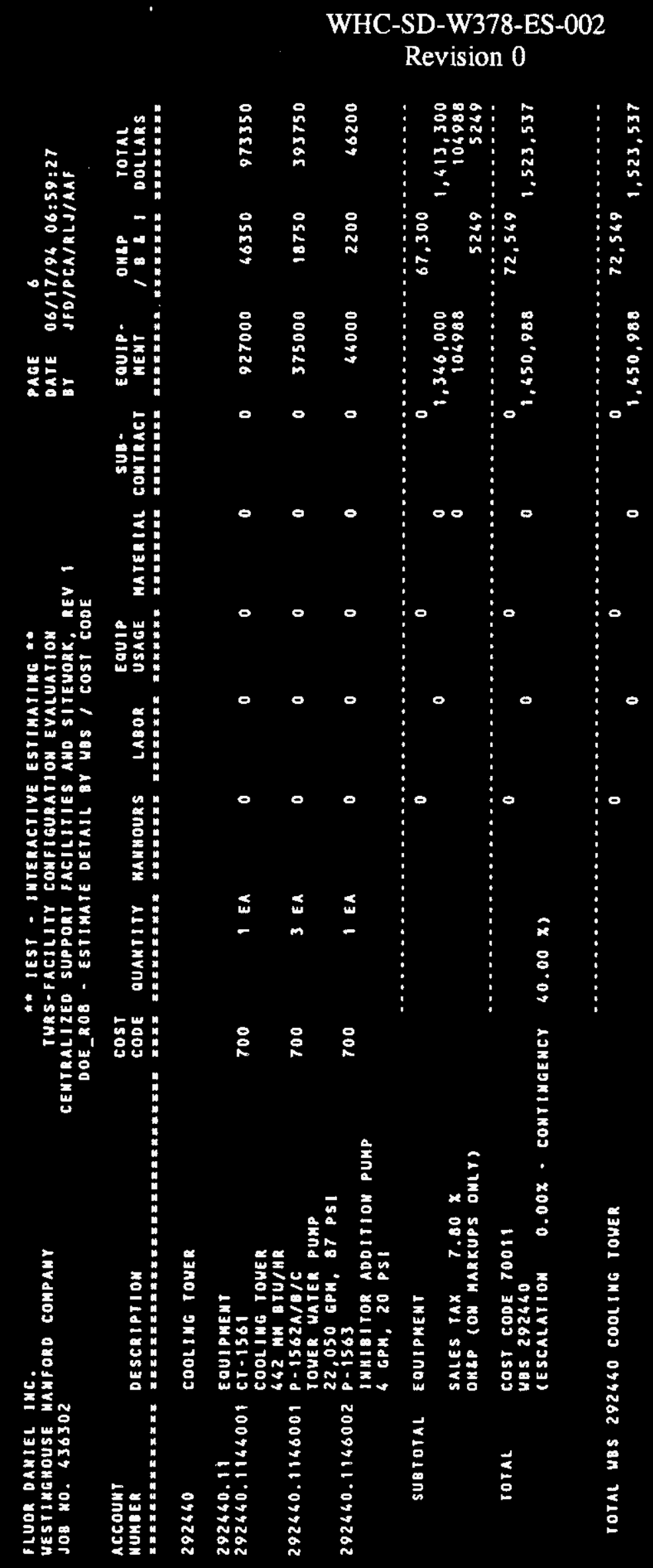

G1-15 


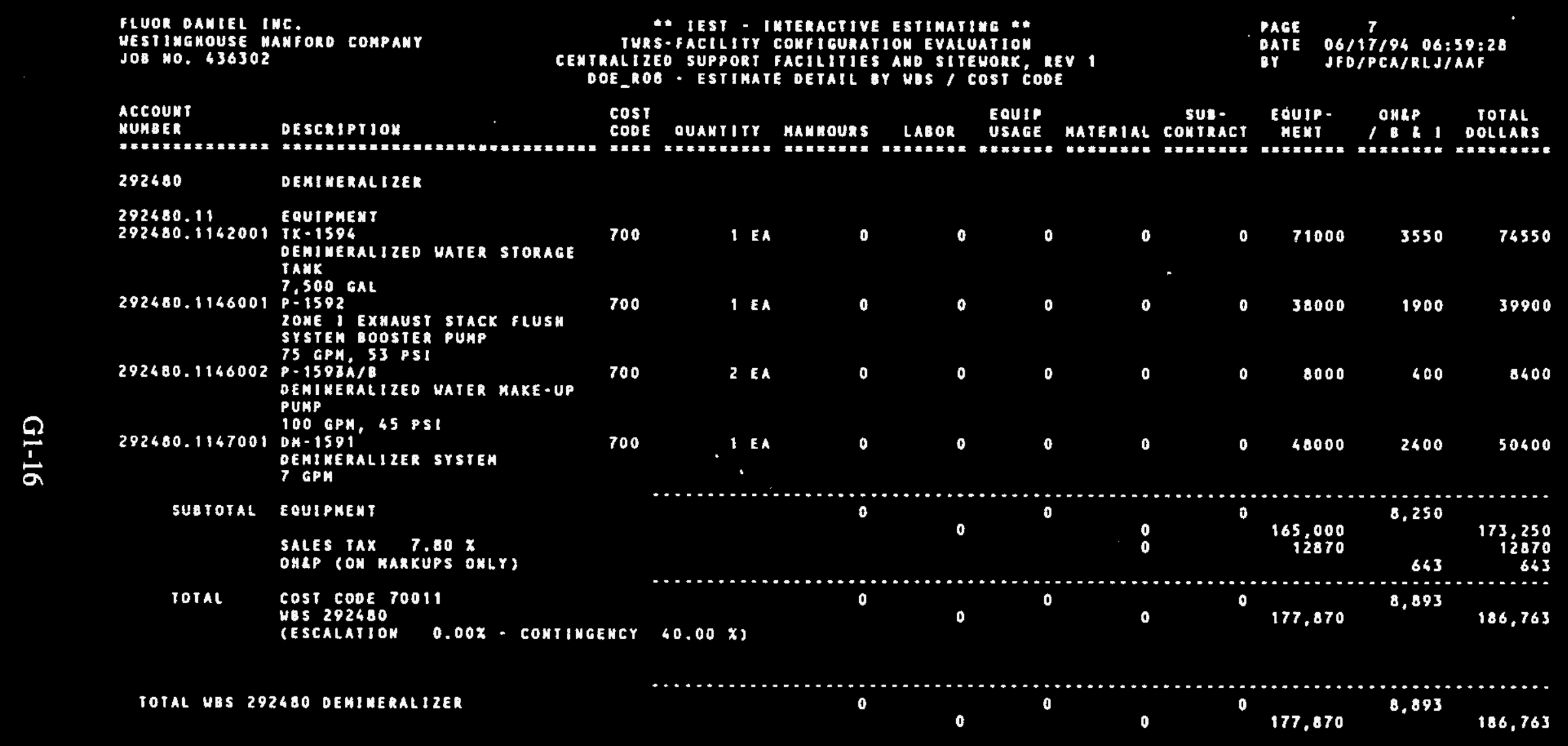




\section{WHC-SD-W378-ES-002}

Revision 0

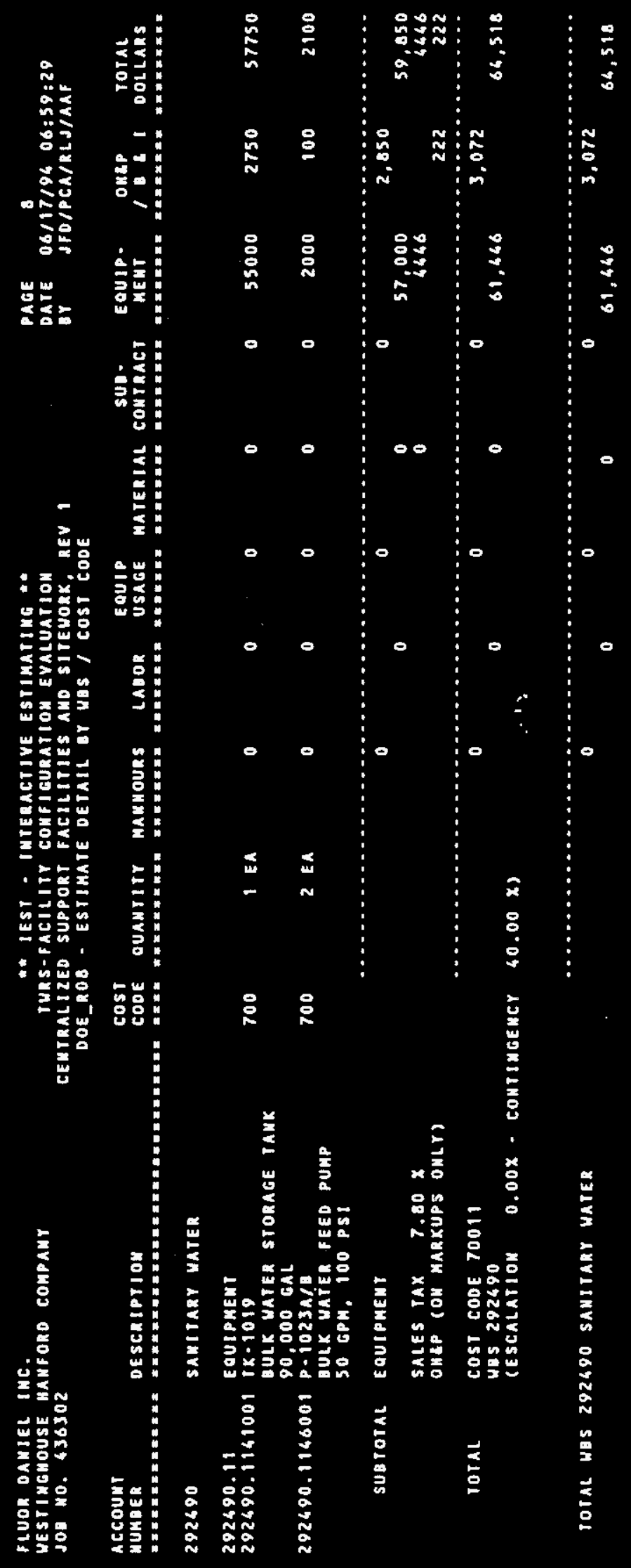


WHC-SD-W378-ES-002

Revision 0

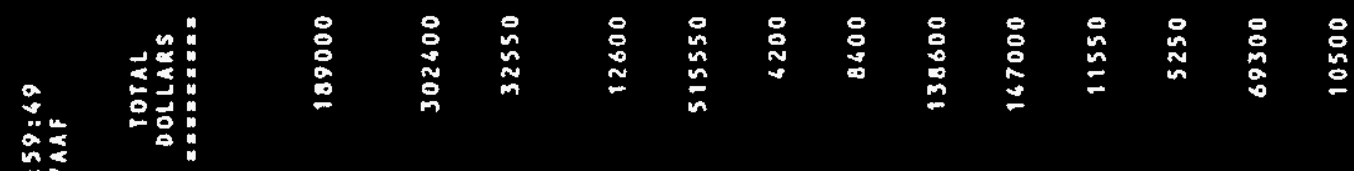

要

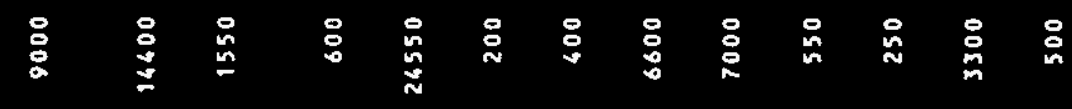

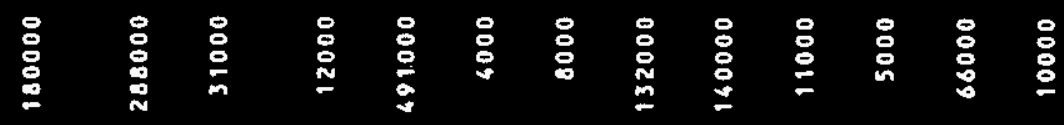

$\circ 0000000000000$

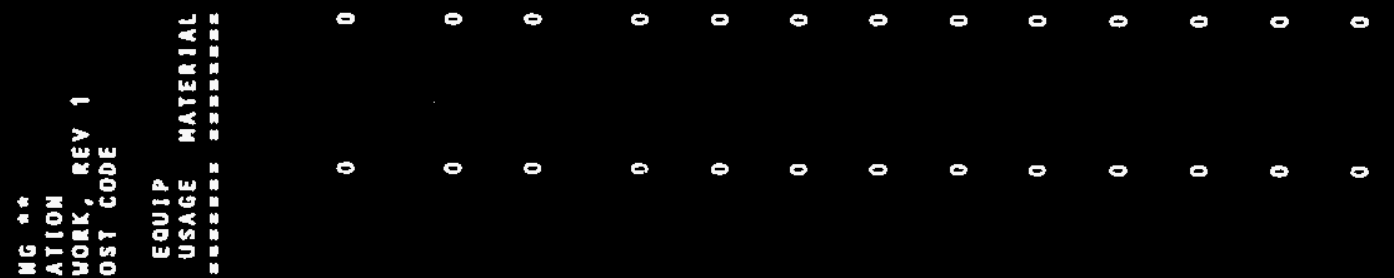

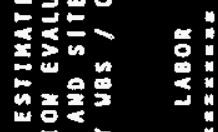

$\sum x^{2}$

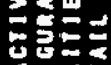

:

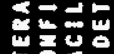

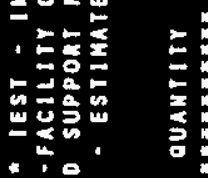

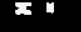

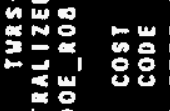

:

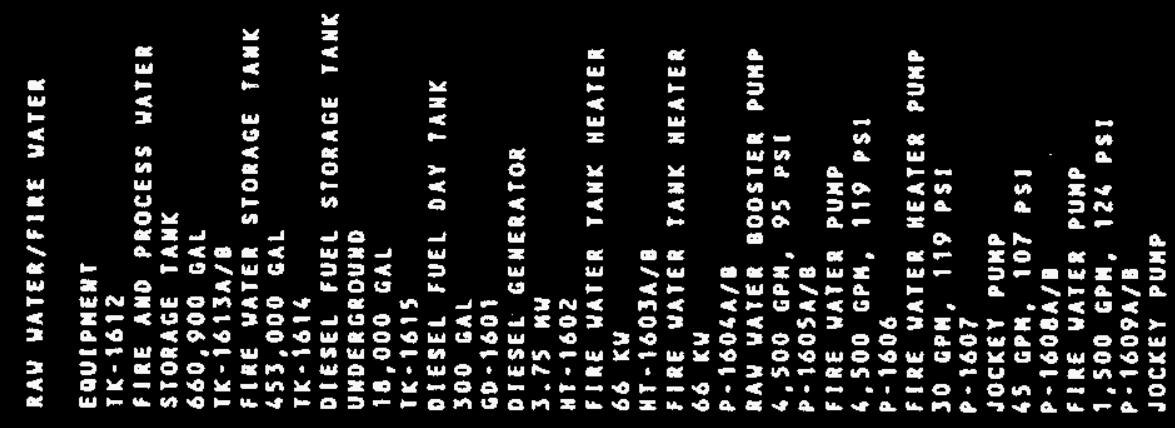

梁

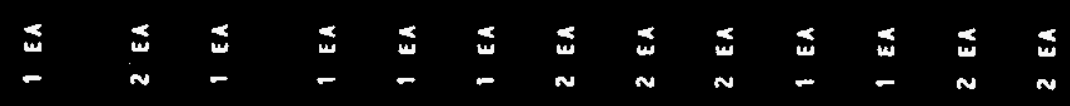

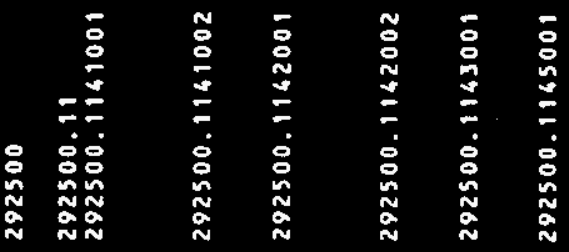

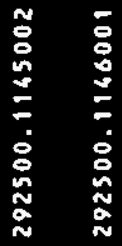

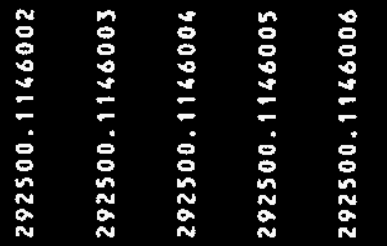




\section{WHC-SD-W378-ES-002}

Revision 0

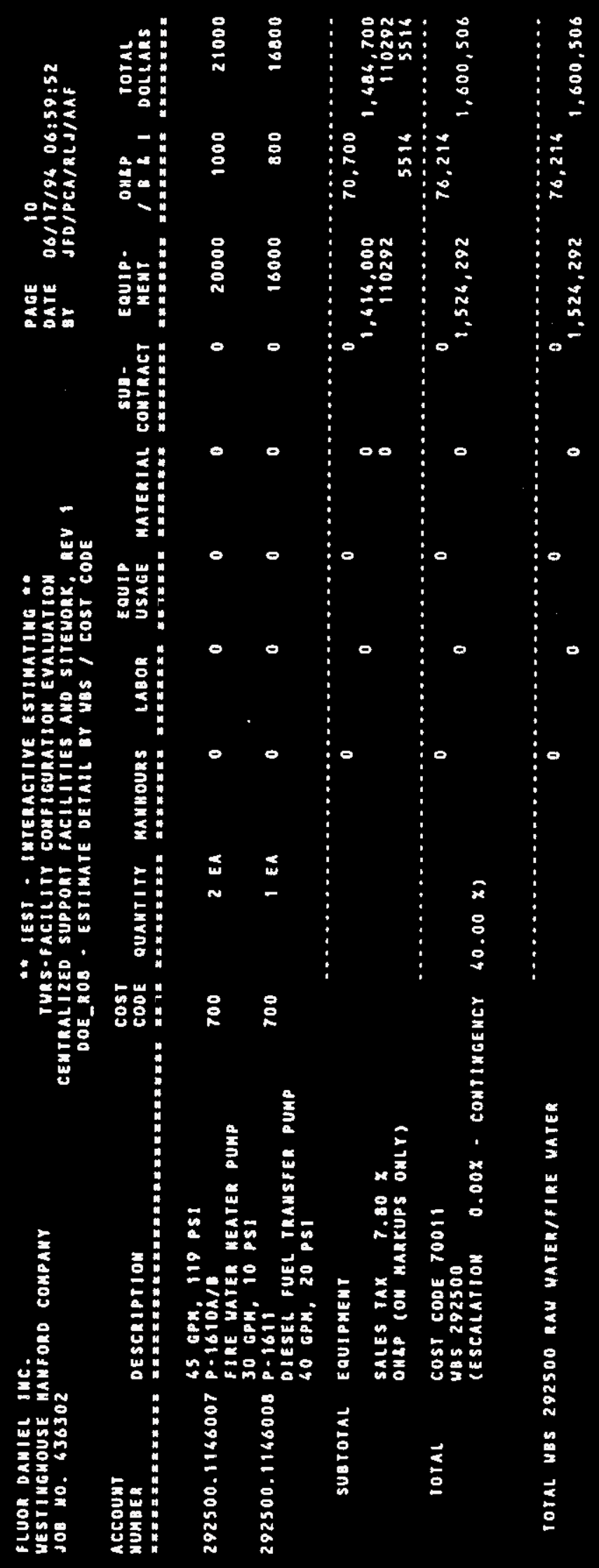

G1-19 


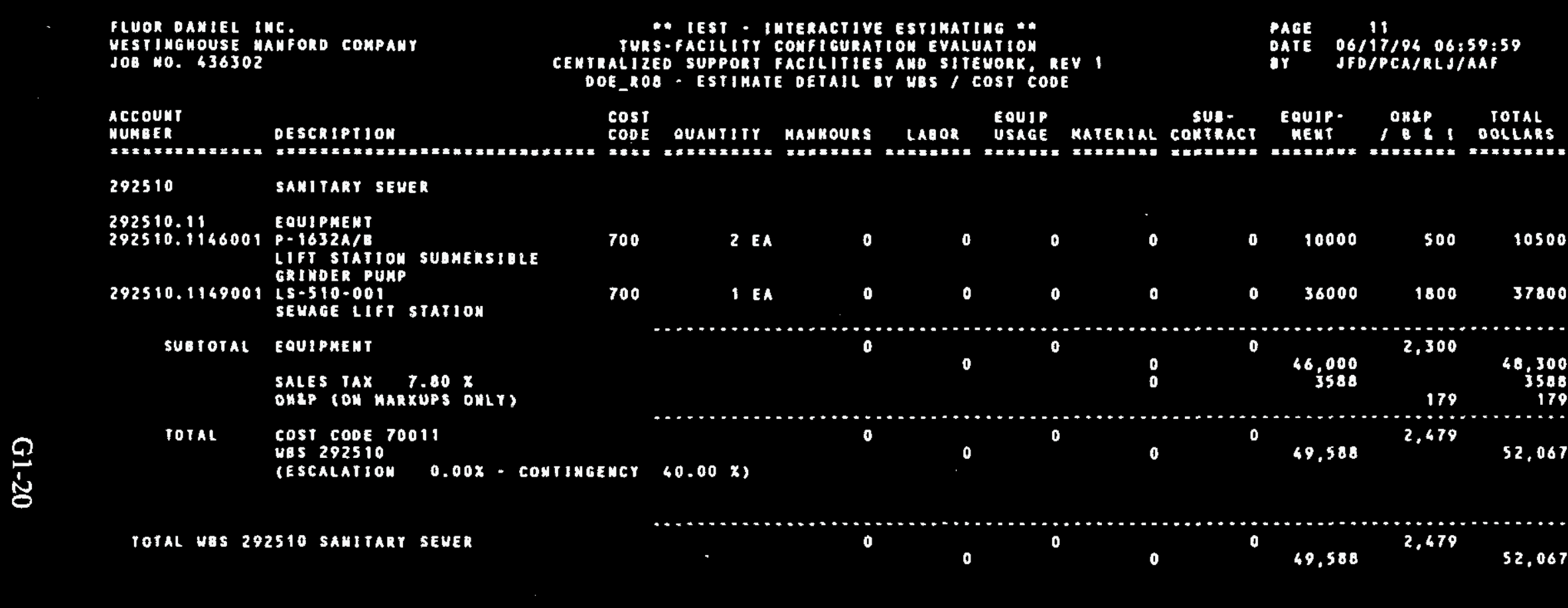




\section{WHC-SD-W378-ES-002}

Revision 0

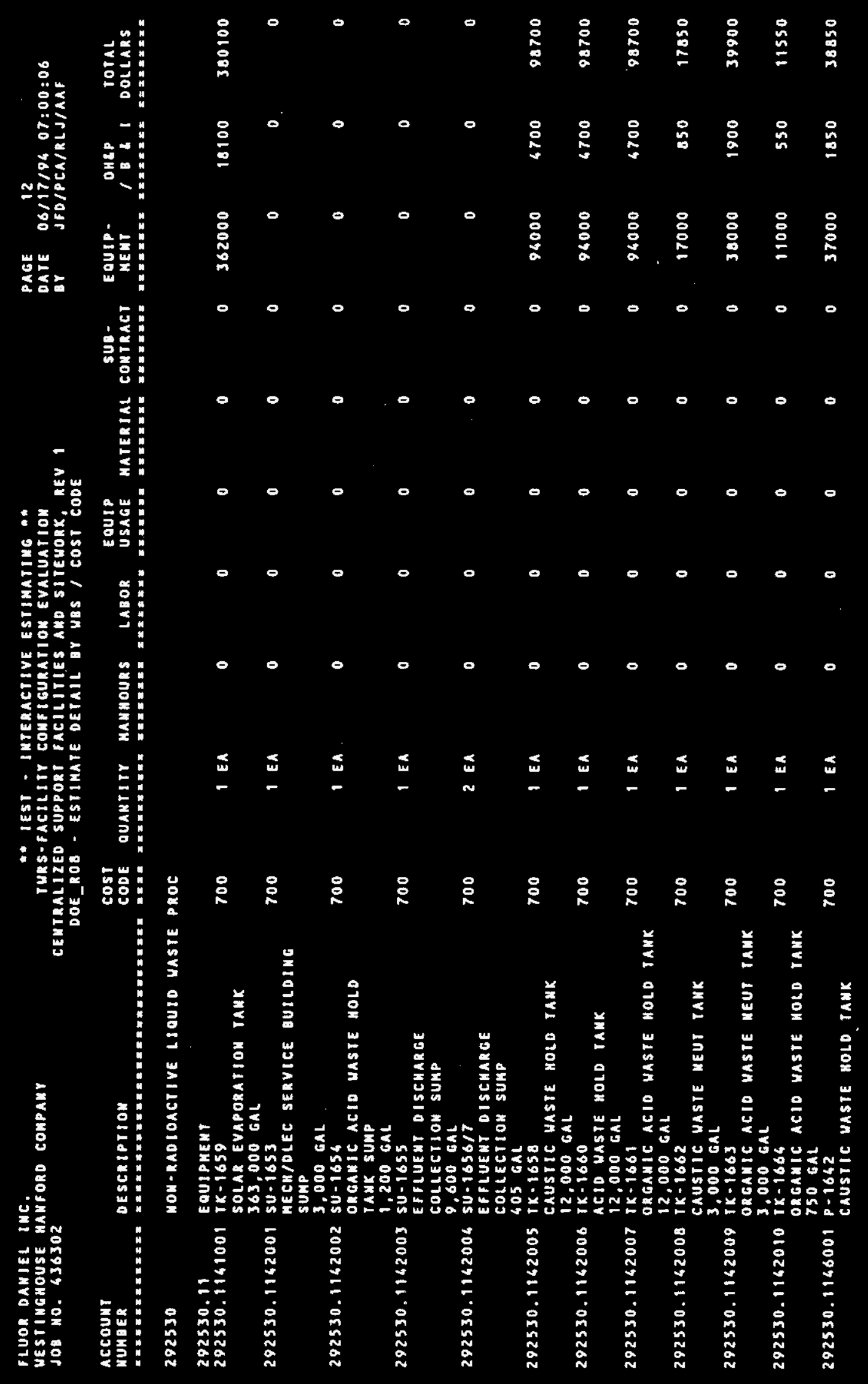




\section{WHC-SD-W378-ES-002 \\ Revision 0}

(19)

:

(1)

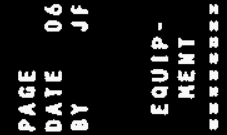

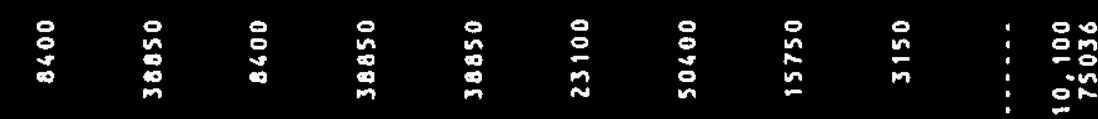

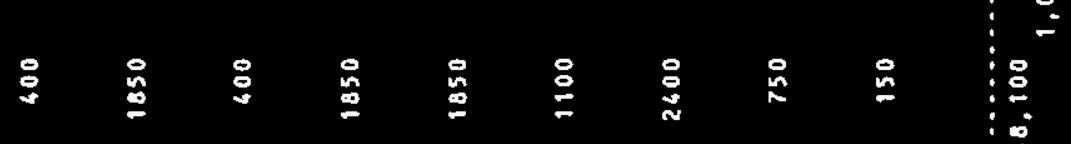

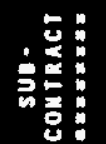

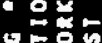

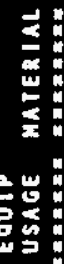

E措

준

Ex을

$\longrightarrow w^{2}$

붕를

든

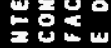

:

$\therefore=-\frac{2}{2}$

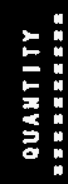

$\stackrel{8}{8}$

$\stackrel{\circ}{\circ} \stackrel{\circ}{\circ}$

$\stackrel{8}{8} \underset{m}{\stackrel{0}{m}}$

ind

홍

할

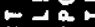

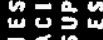

$\div 0$

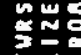

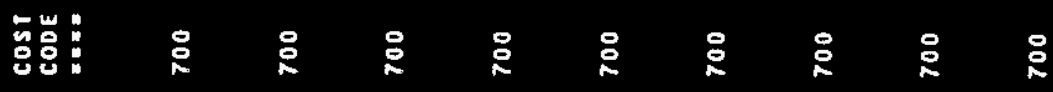
害号

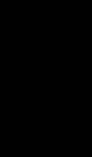

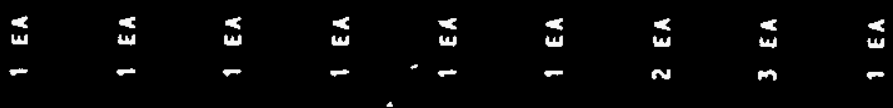

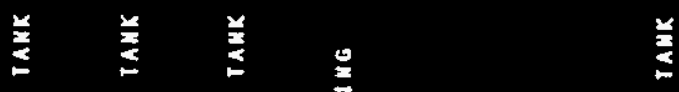

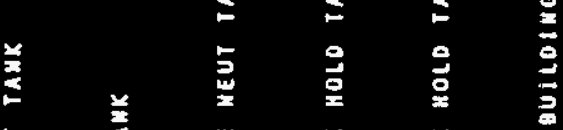

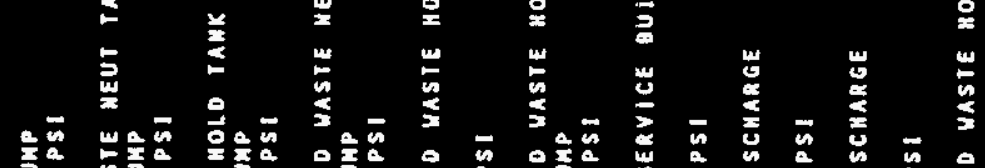

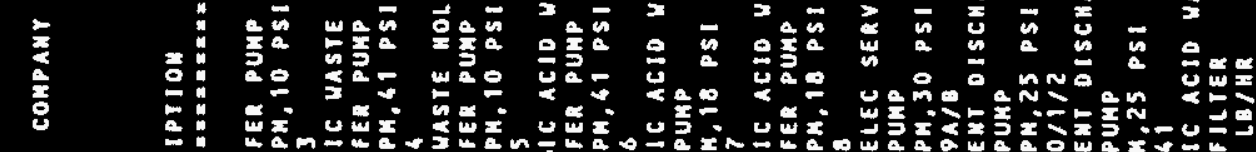

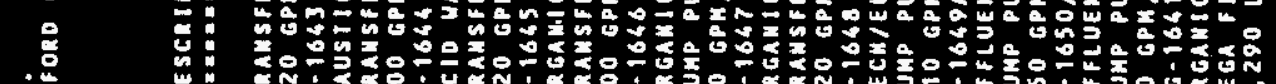
EN

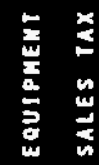




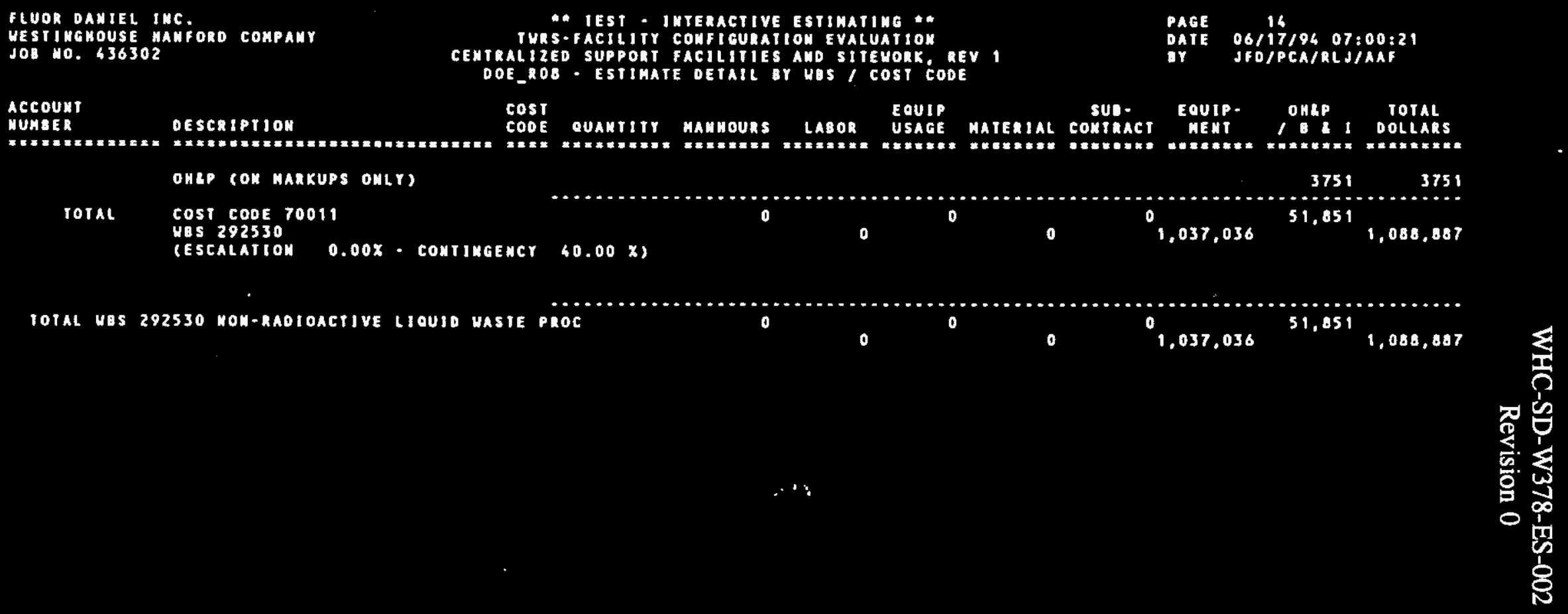




\section{WHC-SD-W378-ES-002 \\ Revision 0}

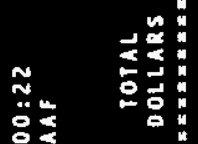

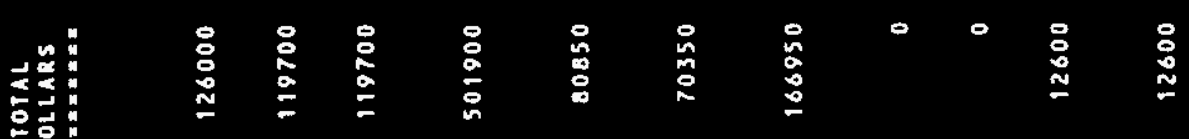

范

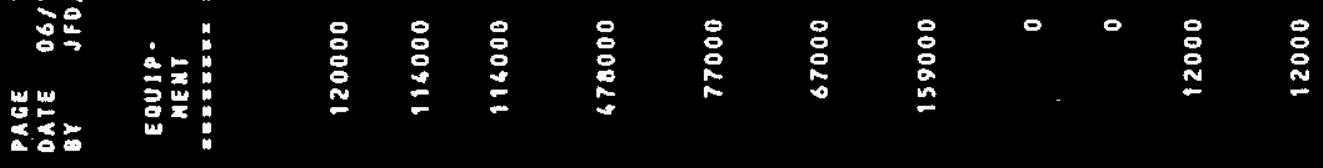
政:

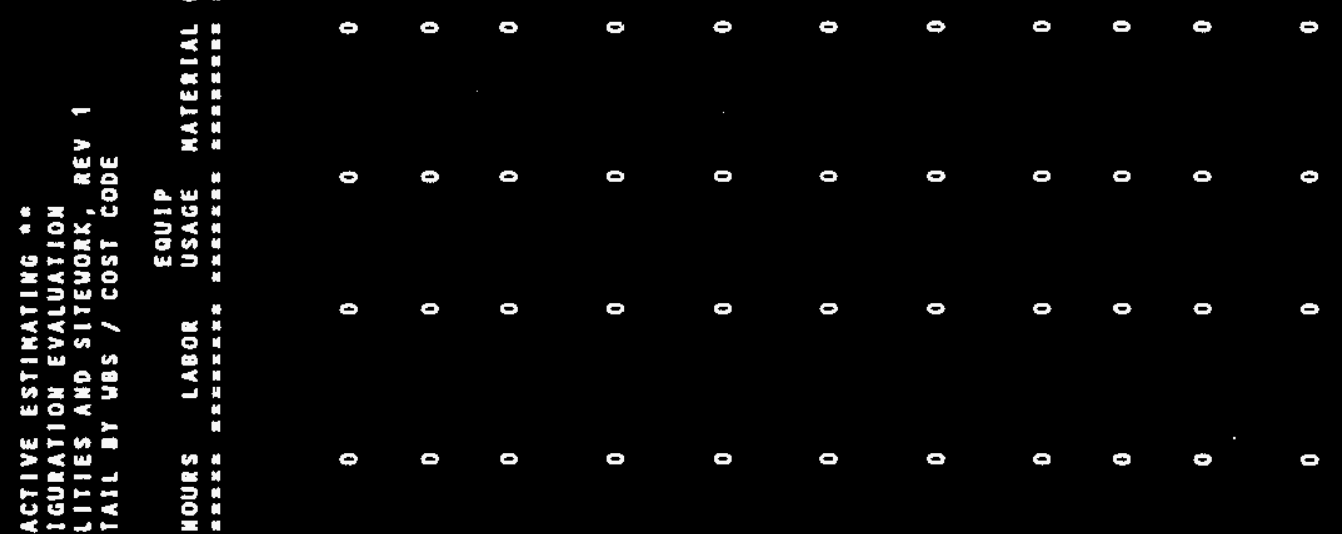

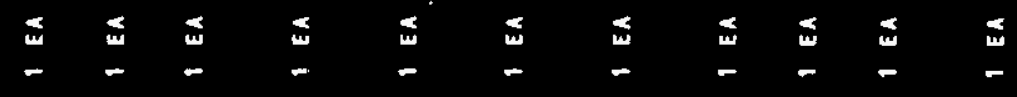

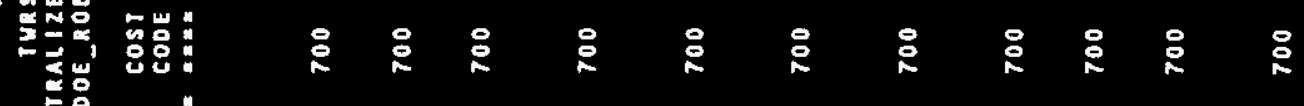

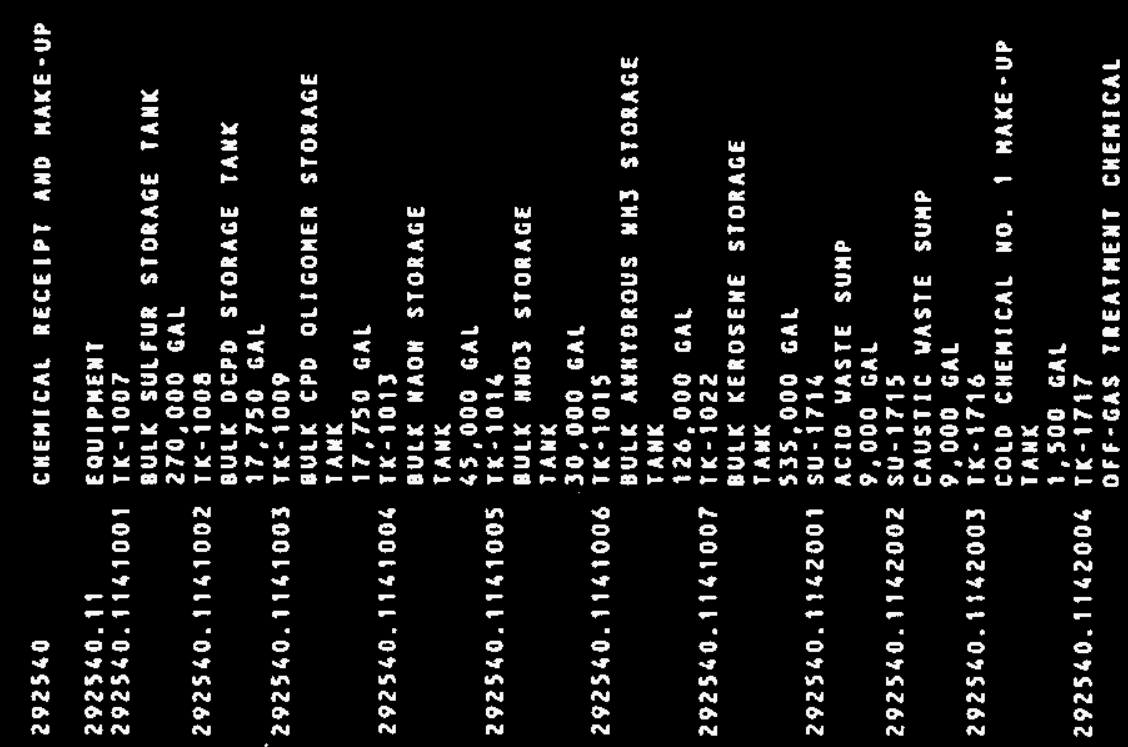




\section{WHC-SD-W378-ES-002 \\ . Revision 0}

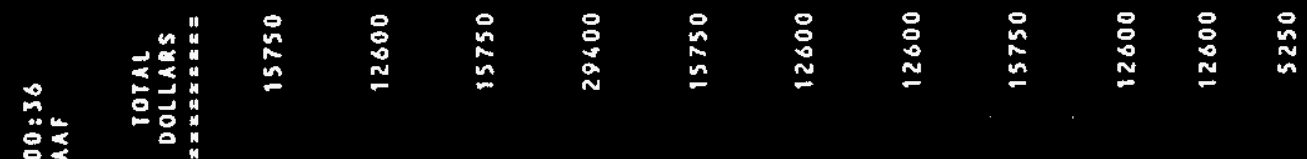
落

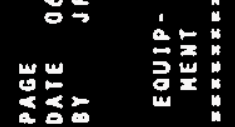

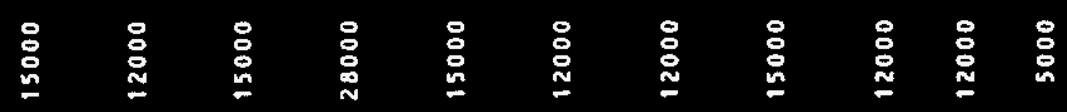
薄

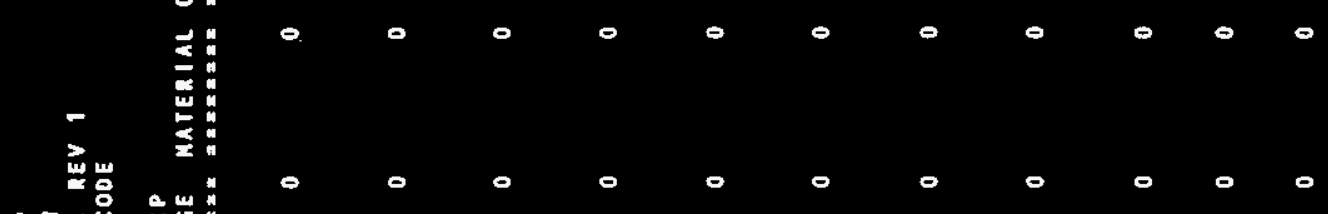

:

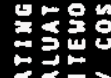

농 离部是

政

흘

눙후웅

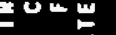

- 등

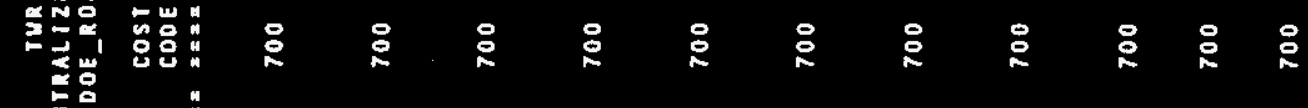

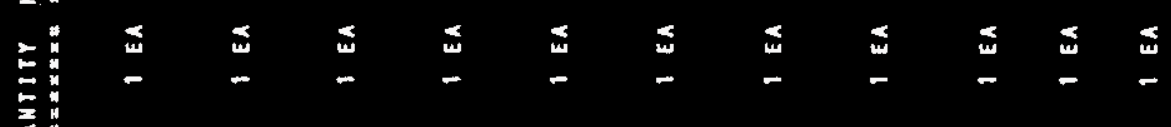

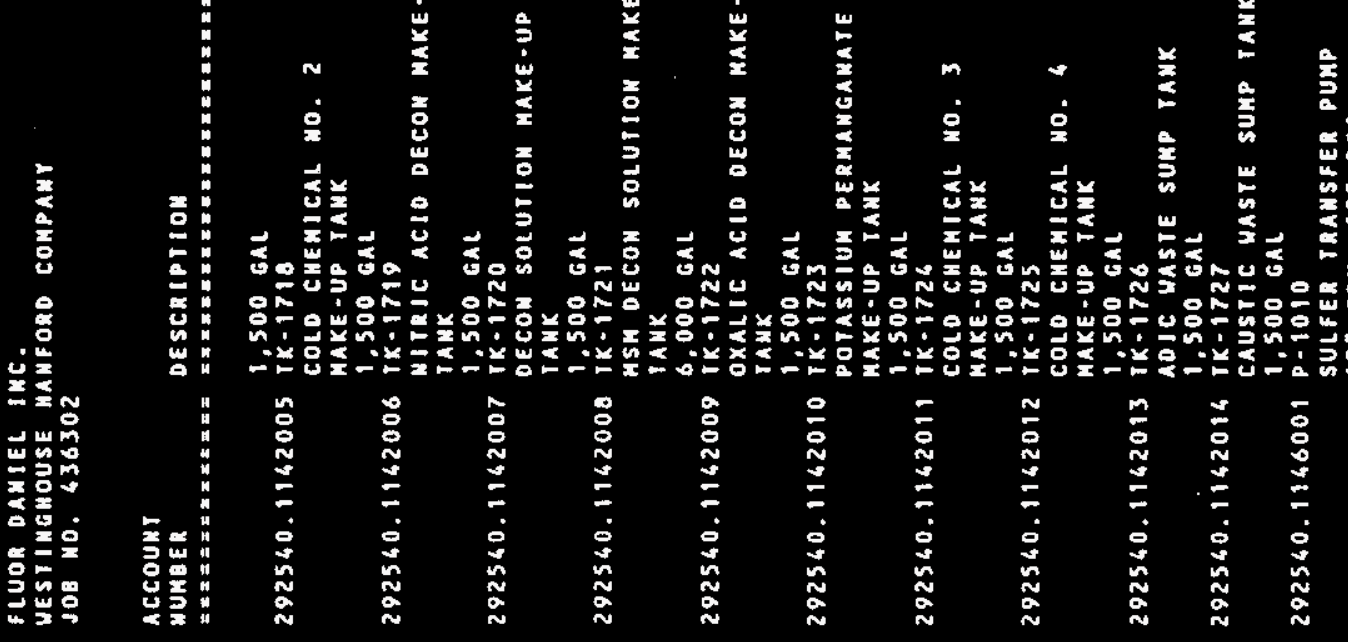




\section{Revision 0}

䓈

官

$=\frac{0}{0}$

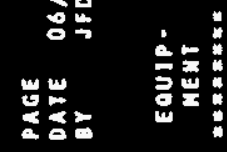

品

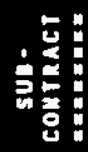

:

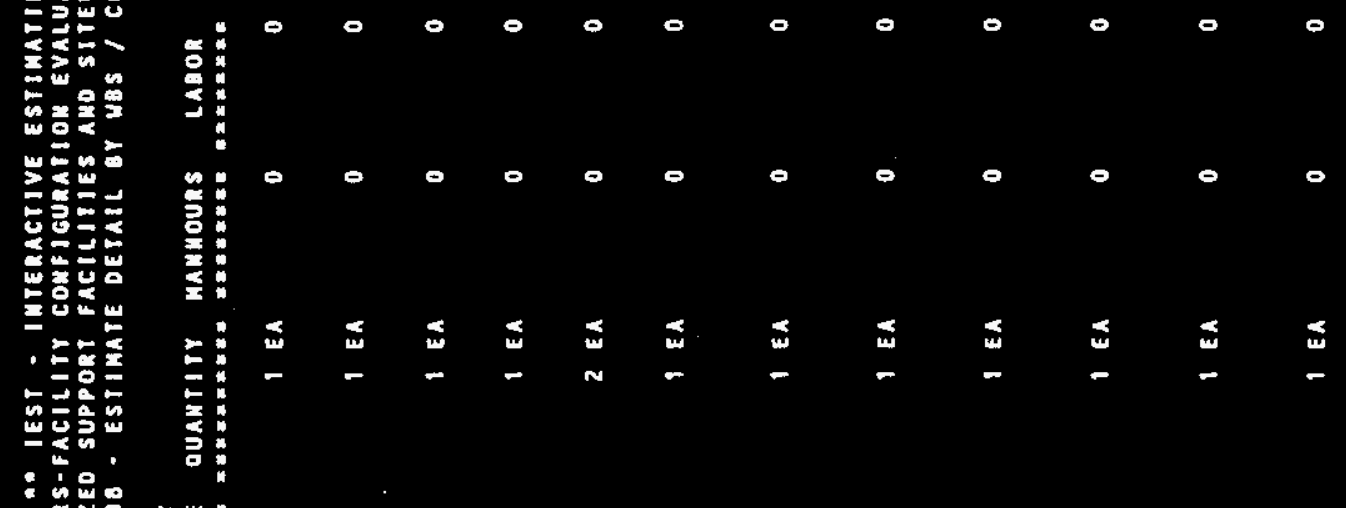

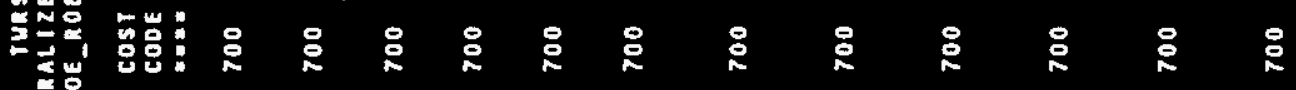

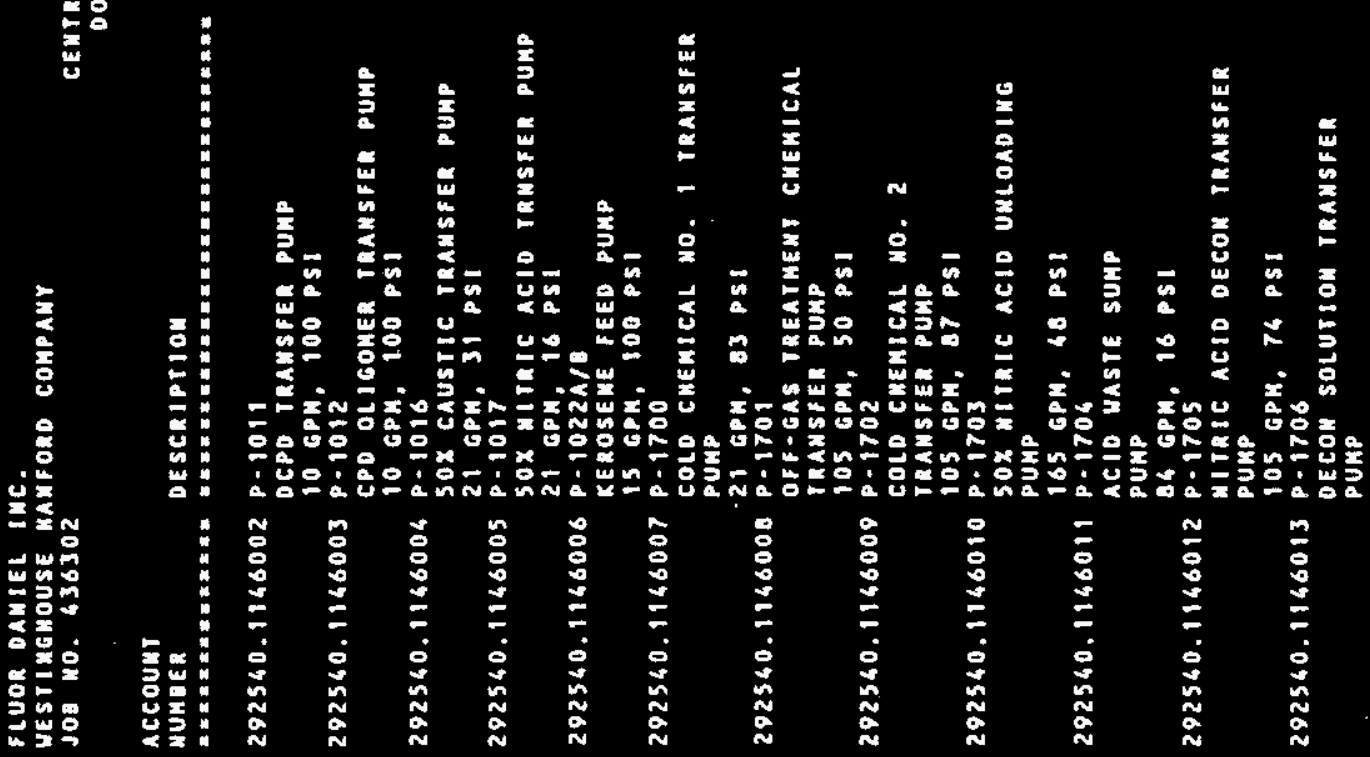




\section{WHC-SD-W378-ES-002 \\ Revision 0}

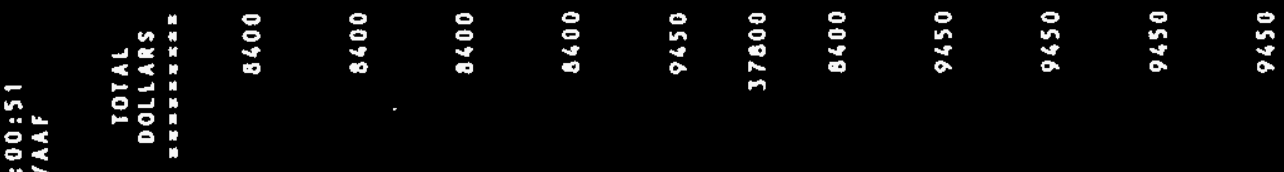

落

送

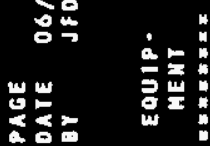

竞:

:

:

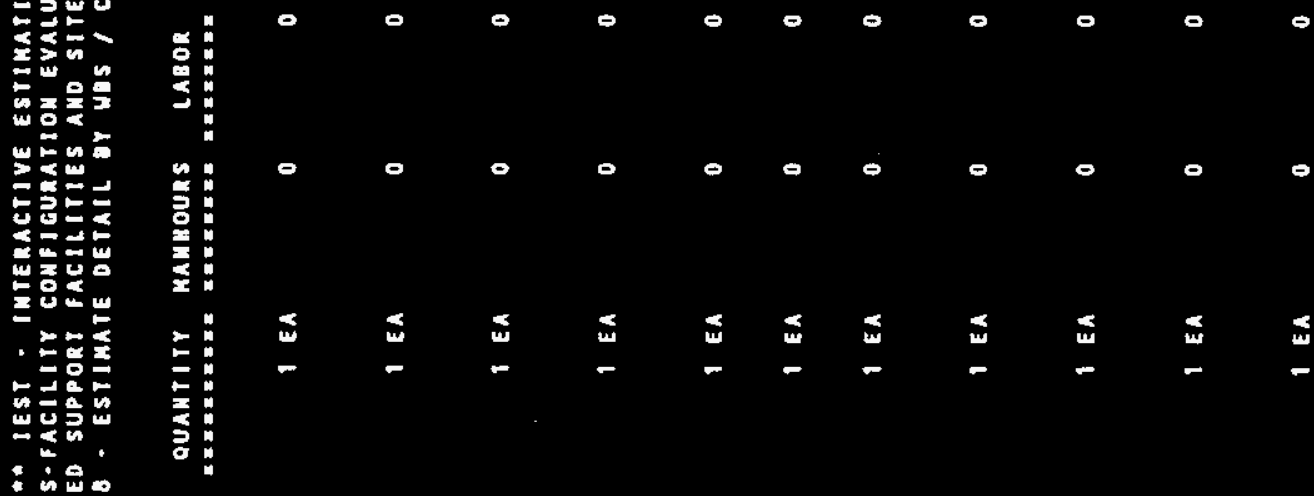

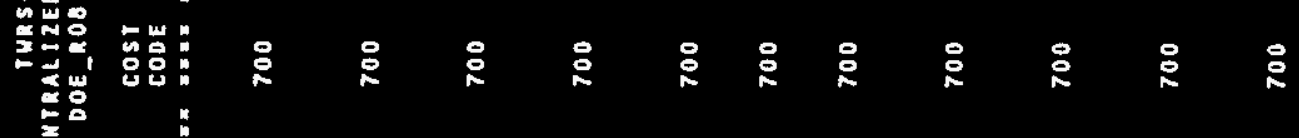

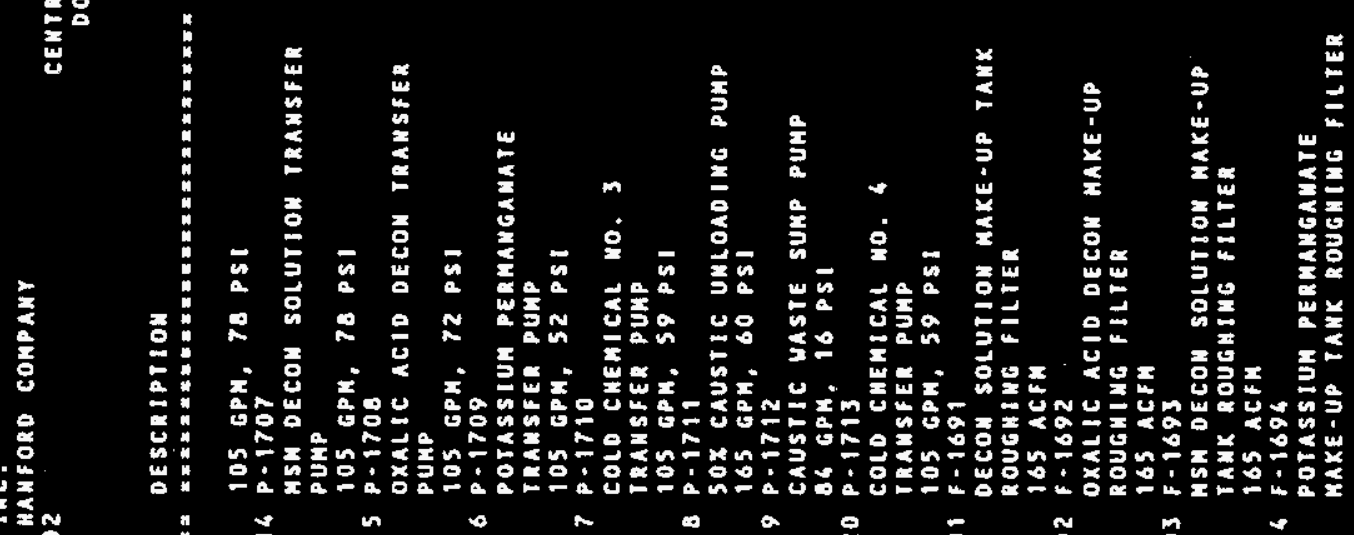




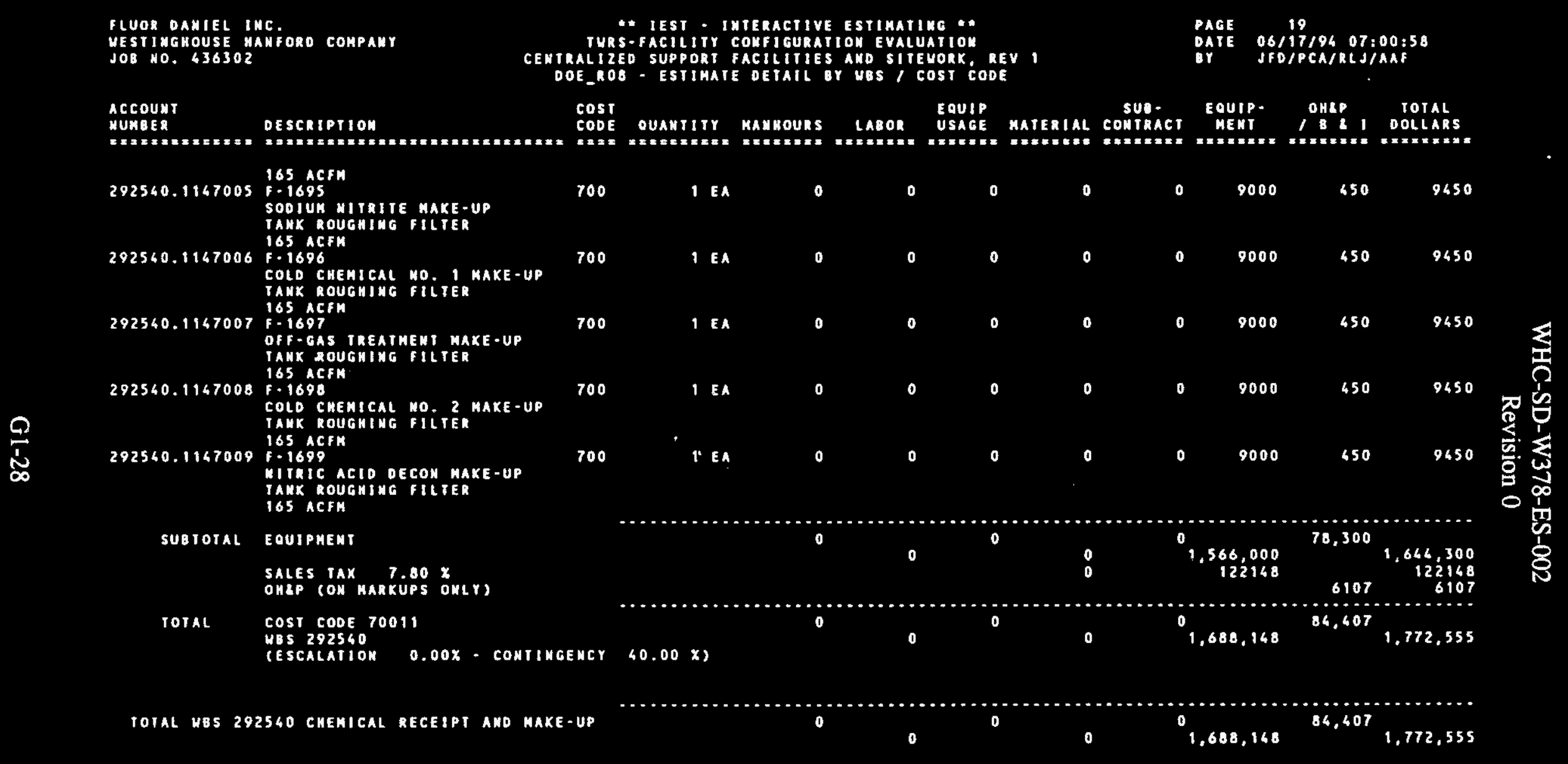


FLUOR DAMIEL IMC.

USE MANFORD COAPAKY

10. 436302

\section{Account}

MUKBER

DESCRIPTION

CODE OUAMTITY MAMHOURS LABOR USAGE

"* IEST - JATERACTIVE ESTIMATIMG CENTRALIZEO SUPPORT FACILIIIES AMD SITEUORK, REV

DOE_ROB. ESTIMATE DETAIL OY HBS/ COST CODE
PAe

$06 / 1719407: 01: 05$

ir JFD/PCA/RLJiAAF

292550

BULK COLO CHEHICAL VEMT SYSTEM

292550.11 EQUIPHENT

292550.1163001 MB-1661A/B
AC1D VENT BLOUER

700

2 EA

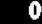

$\mathbf{0}$

SUb. EOUIP. OHEP, TOTAL

SUE. EQUIP- OHEP, TOTAL

MATERIAL CORTRACT MENT

450 SCFM

SUBTOTAL EQUIPHECI

SALES taX $7.00 x$

OHLP (ON MARKUPS ONLY)

TOIAL

COST CODE 70011
USS 292550

CESCALATION

$0.00 X$ - contingency

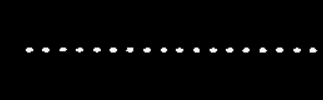

0

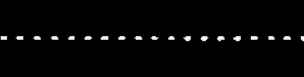

$40.00 x$

0

0

0

0

21.560

1,078 


\section{WHC-SD-W378-ES-002 Revision 0}

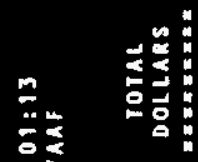

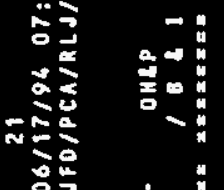

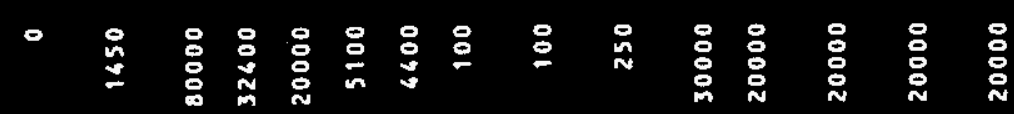

崖皆

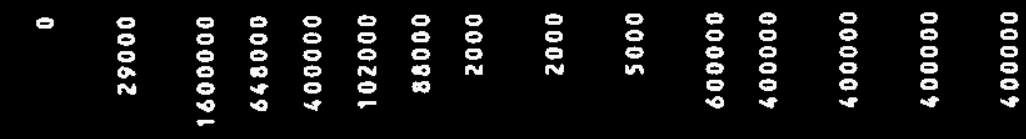

竞:

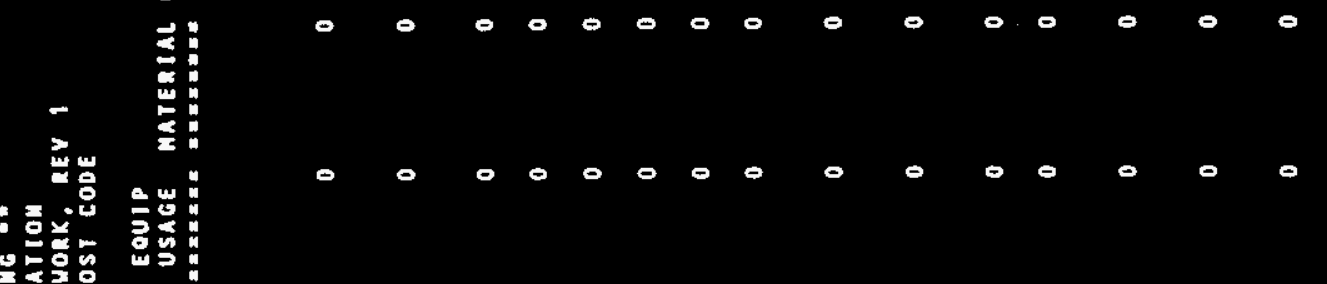

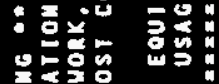

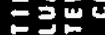

依중을

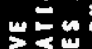

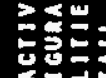

送象

욜

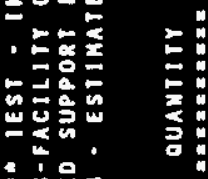

출,

훙

$\circ$

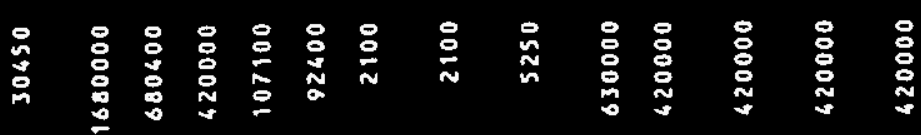

00000

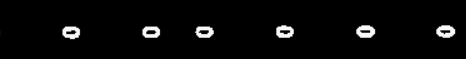

:

융유요요요용

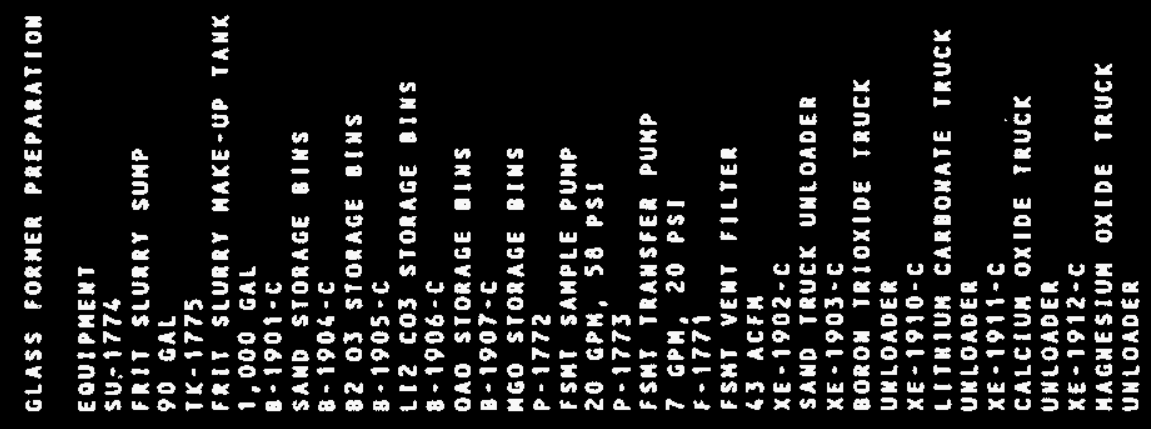

年

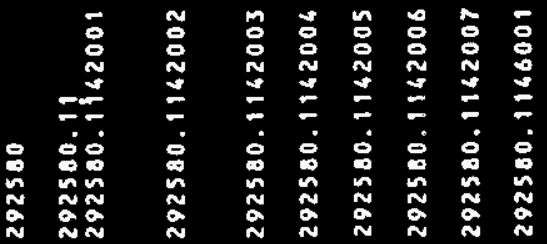

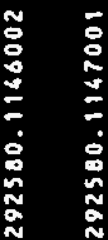

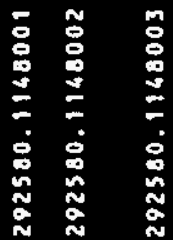

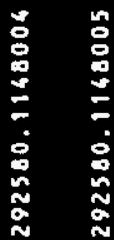

G1-30 


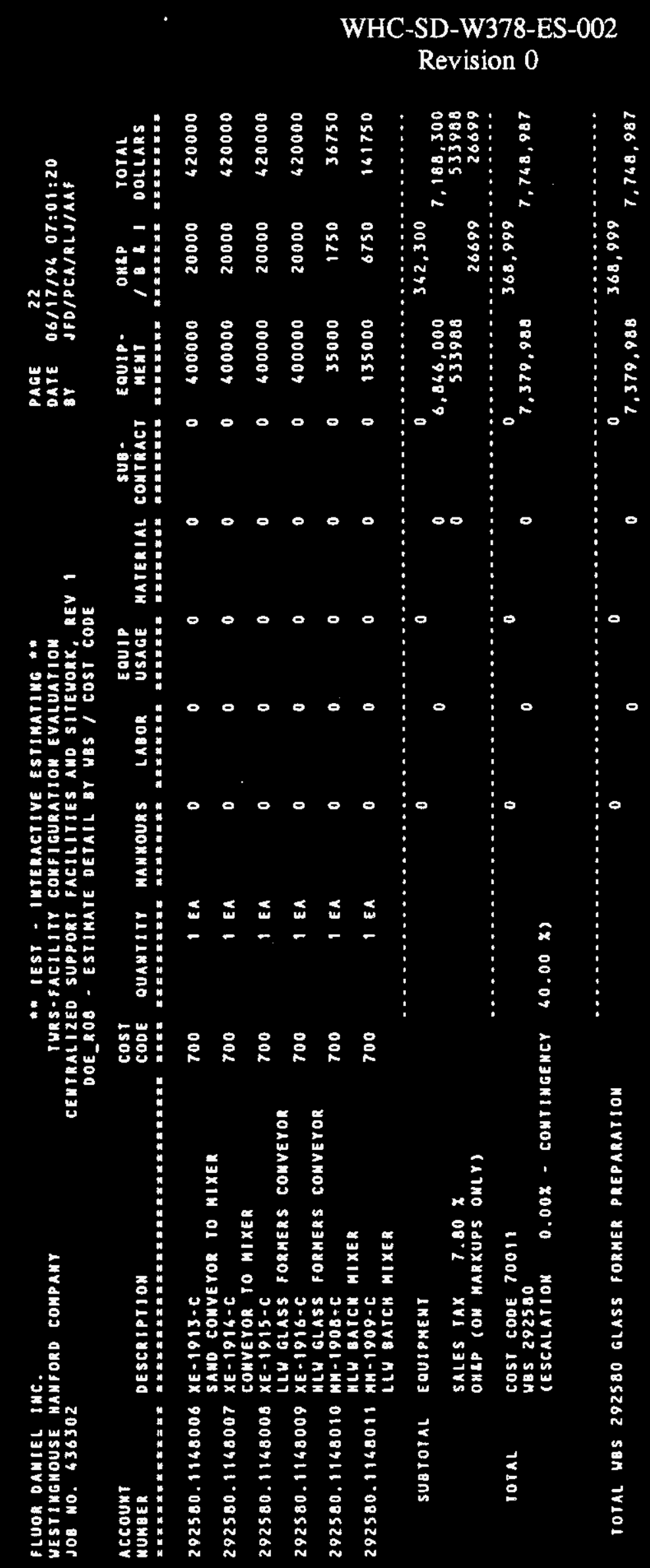

G1-31 


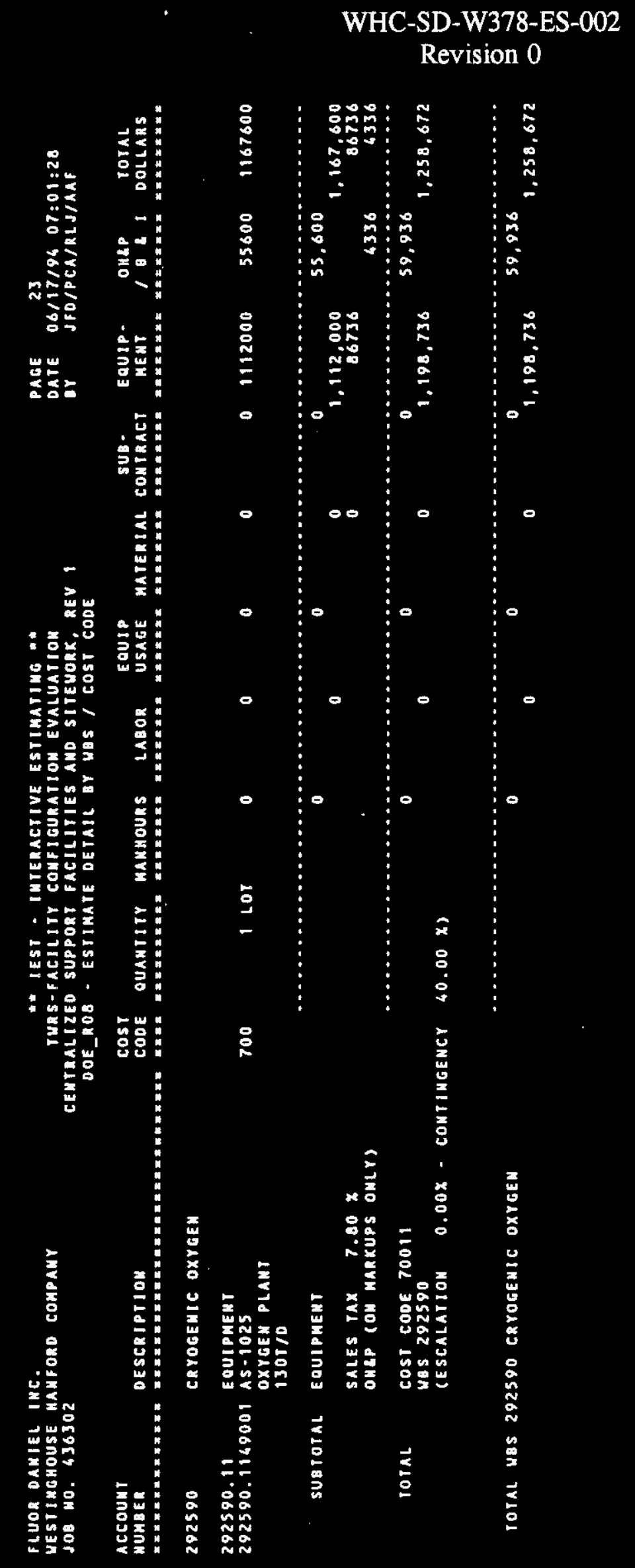

G1-32 


\section{Revision 0}

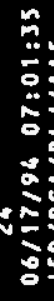

整

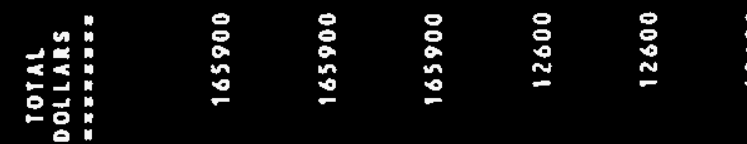

:

¿

漕

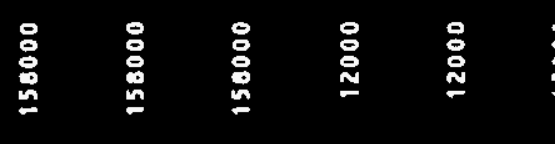

蒀

:

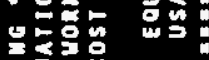

经

跬

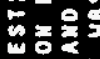

:

$\sum \leqslant$

두을

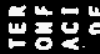

.

整

부ㅇㅝㅜ

a

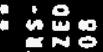

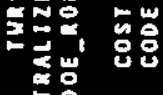

๕

?

告

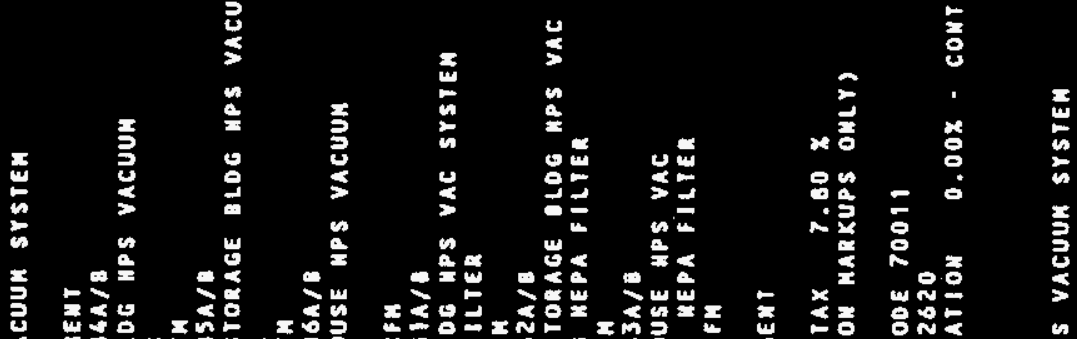

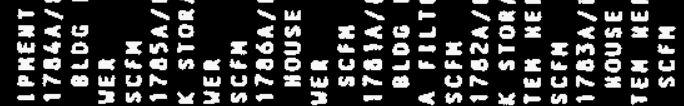

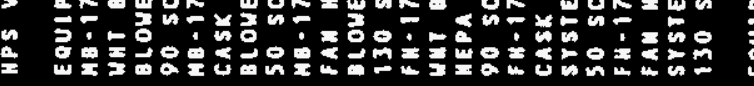

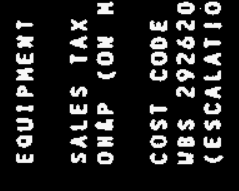

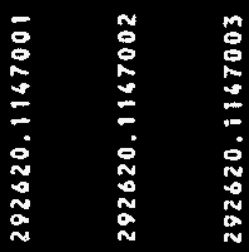

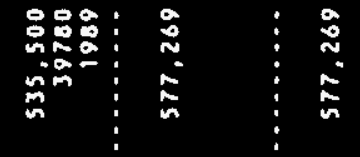

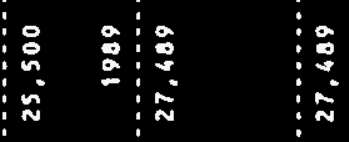

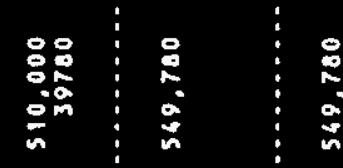




\section{WHC-SD-W378-ES-002 Revision 0}

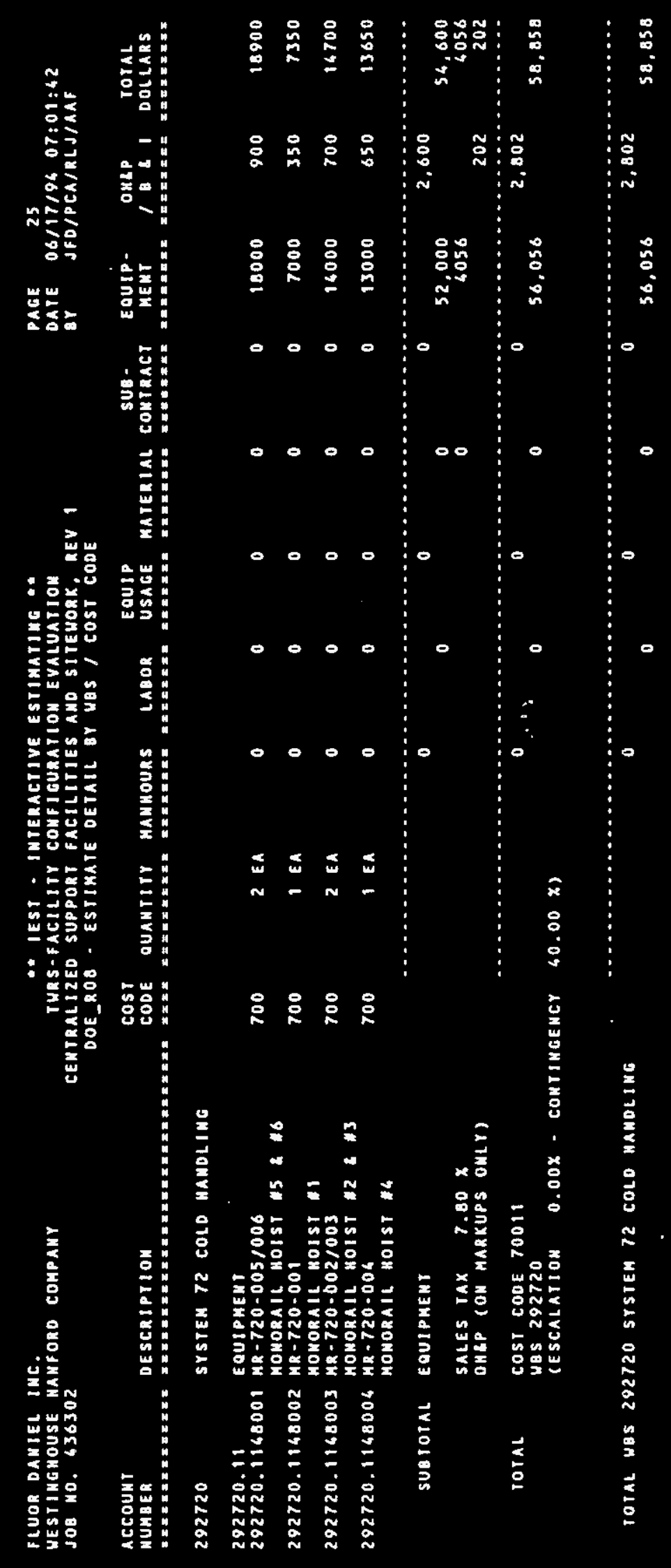




\section{WHC-SD-W378-ES-002 \\ Revision 0}

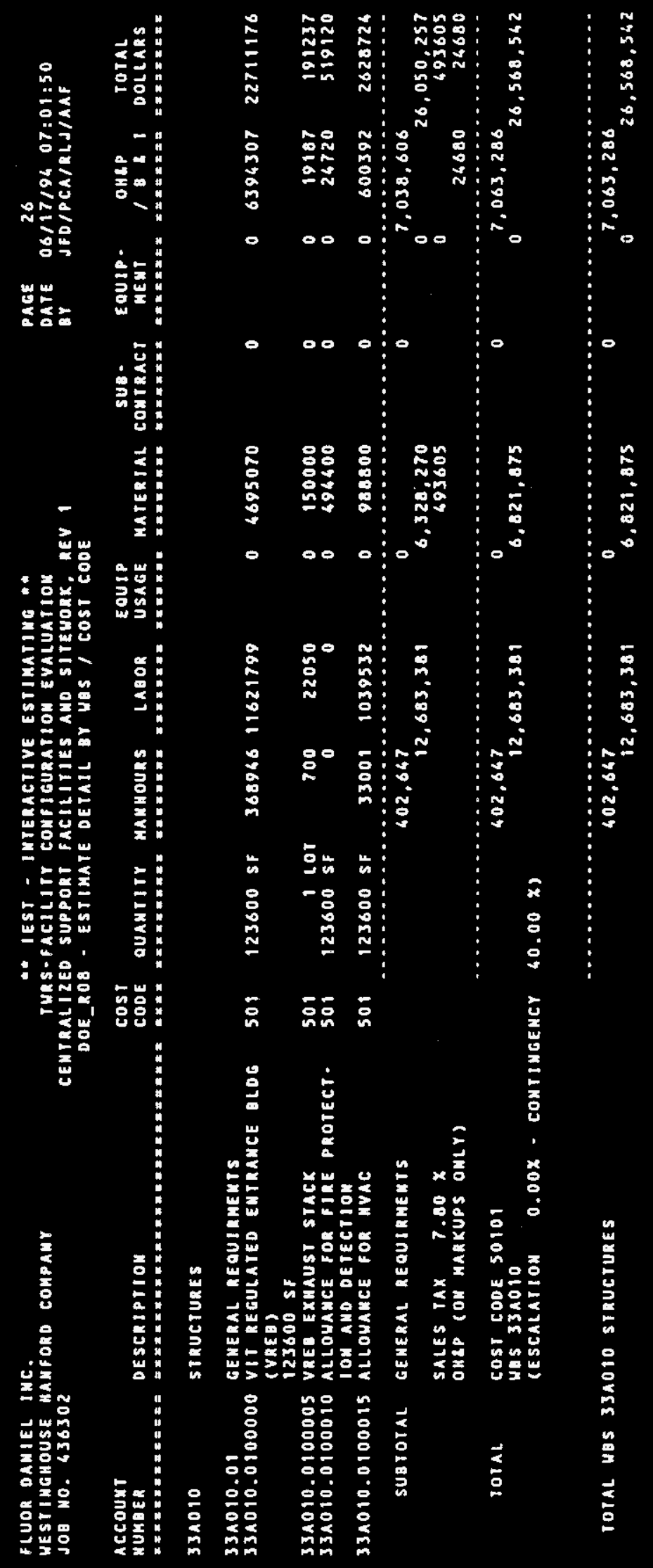




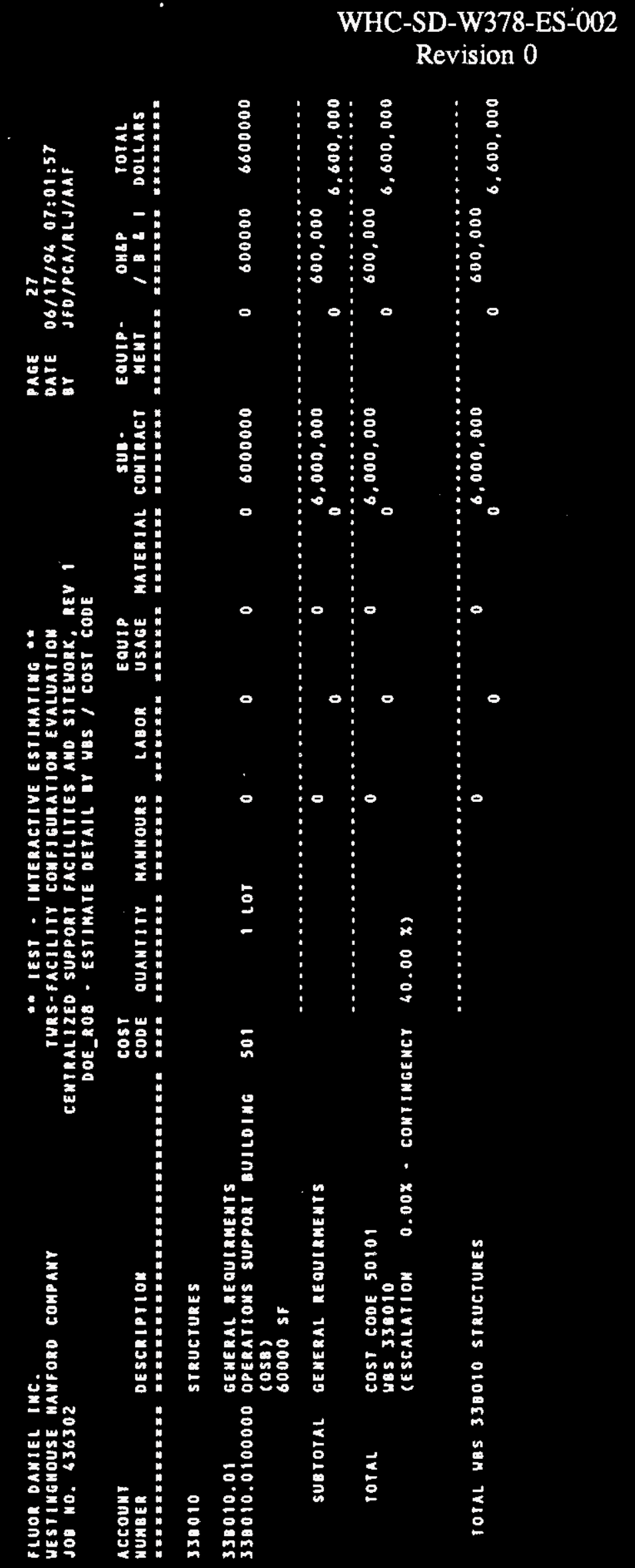

G1-36 


\author{
FLUOR DAHIEL INC. \\ WESTIMGHOUSE MAMFORD COMPAKY \\ Jo8 00.436302
}

Account
nUMBE:

Description

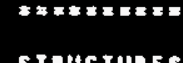

330010

STRUCTURES

330010.01 GEMERAL REOUTRMEUT

33C010.0100000 REGULATED EMTRANCE DUILOING 501 (REB)

SUBTOTAL

GEWERAL REQU TRMEWTS

TOTAL

UES 33 CO10
CESCALATION

$0.00 x-\operatorname{contingency}$

$60.00 \times 1$

$\cos t$
COST $\operatorname{coDE} 50101$
MES $33 \cos 10$

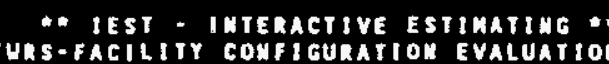

CEMTRALI2ED SUPPORT GACILURATIOR EVALUATIOK DOE_ROS - EstinATE DETAlL OY WAS / COST CODE

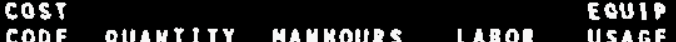

$$
\begin{aligned}
& \text { PAGE } \\
& \text { DATE O6/17/94 OT:02:06 } \\
& \text { BY JFD/PCA/RLJ/AAF }
\end{aligned}
$$

EOUIP. OKLP TOIAL MENT 1 B I DOLLARS

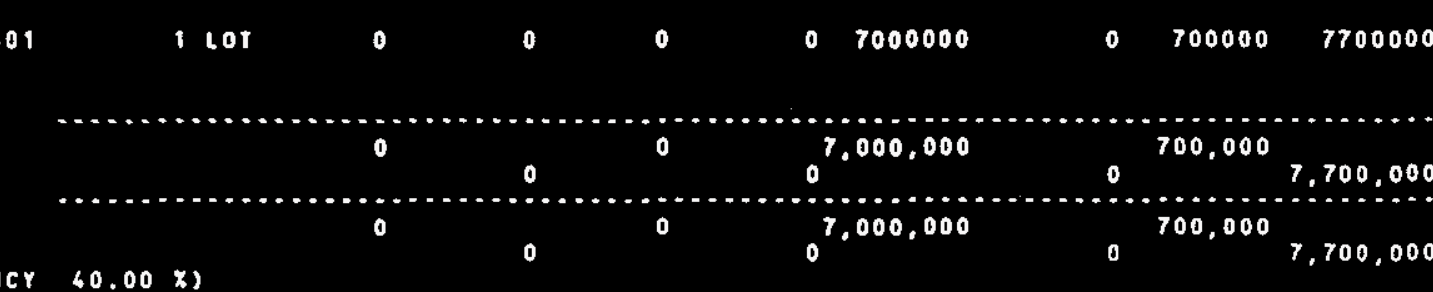

a

........

0

$7,000,000$

700.000

$7,700,000$ 
FLUOR DAHIEL IMC.

USE MANFORD COMPANY

636302

\section{ACCOUNT \\ HUMBER DESCRIPTION}

330010

STRUCTURES

330010.0100000 OPERATIONS CONTROL BUILOIMG 501 (OCS)

$$
22500 \text { sf }
$$

SUBTOTAL GEMERAL REQUIRMENTS

rotAL

\section{$\cos \operatorname{coDE} 50101$} UBS 330010
PECALATION

$0.00 x$ - Contingency
"* IEST - INTERACTIVE ESTIMATING "*

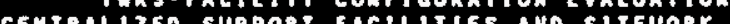

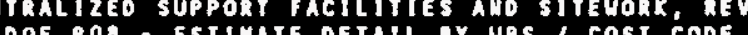

PAgE 29

DATE 06/17/94 07:02:05

DATE JPDCA/RLJ/AAF

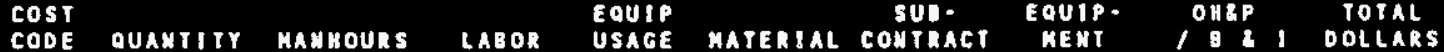

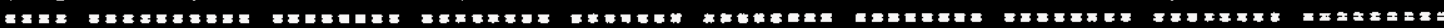

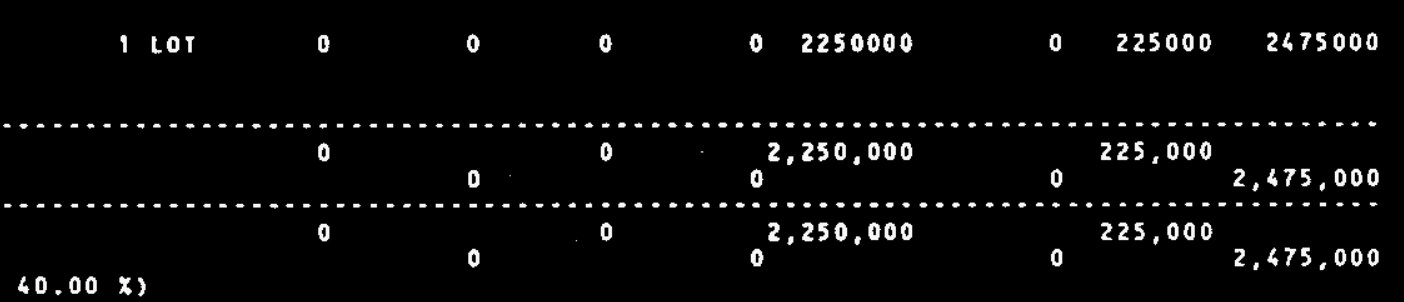




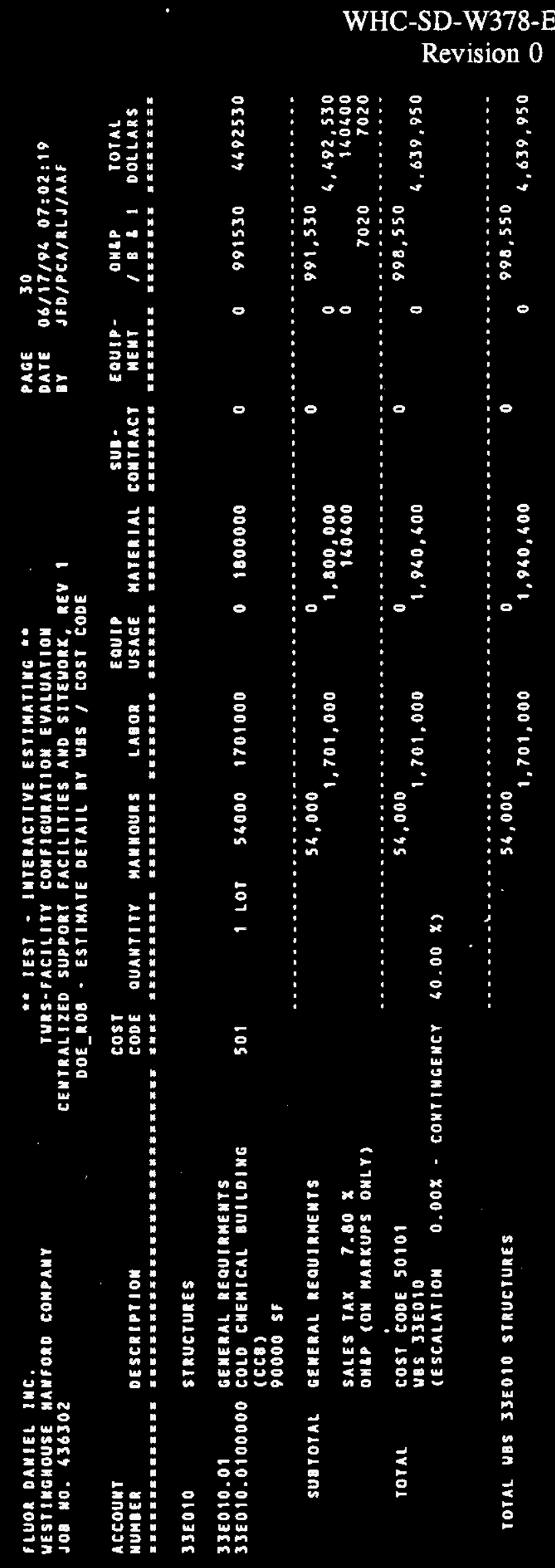

G1-39 


\section{FLOR DAMIEL INC. \\ ESTIMGOUSE MAMFORO COHPANY \\ 108 No. 436302}

Account

MUHAE R

\section{DESCRIPTION}

335020

Fine photection, hYAC AMD LIGHTIMG

335020.0

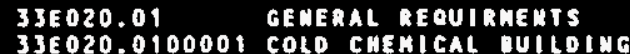

(S/C ALLOUACE FOR FIRE PROT

HVAC AHD (IGHTING)

SUBTOTAL GEMERAL' REOUTMENTS

501

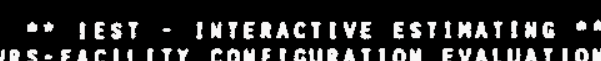

TURS-FACILITY COHFIGURATION EYALUATIOA

DOE

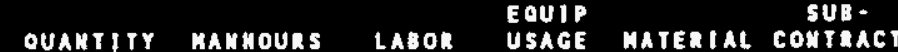

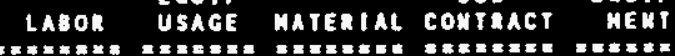

101

0

0

$0 \quad 1151000$

- . . . . . . . . . . .

PAGE 31 OSTE $06: 02: 27$

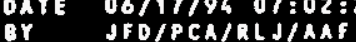

IOTAL

\section{$\cos T$ CODE 50101
UBS 330020}

CESCALATION

$0.00 \mathrm{X}$ - CONTINGEMC

$0.00 x$

$1,266,100$

$1,151,000$

-
TOTAL UQS $33 E 020$ FIRE PROTECTION, HVAC AND LIEMTIKG o
$1,151.000$

0
115,100

$1,266,100$ 


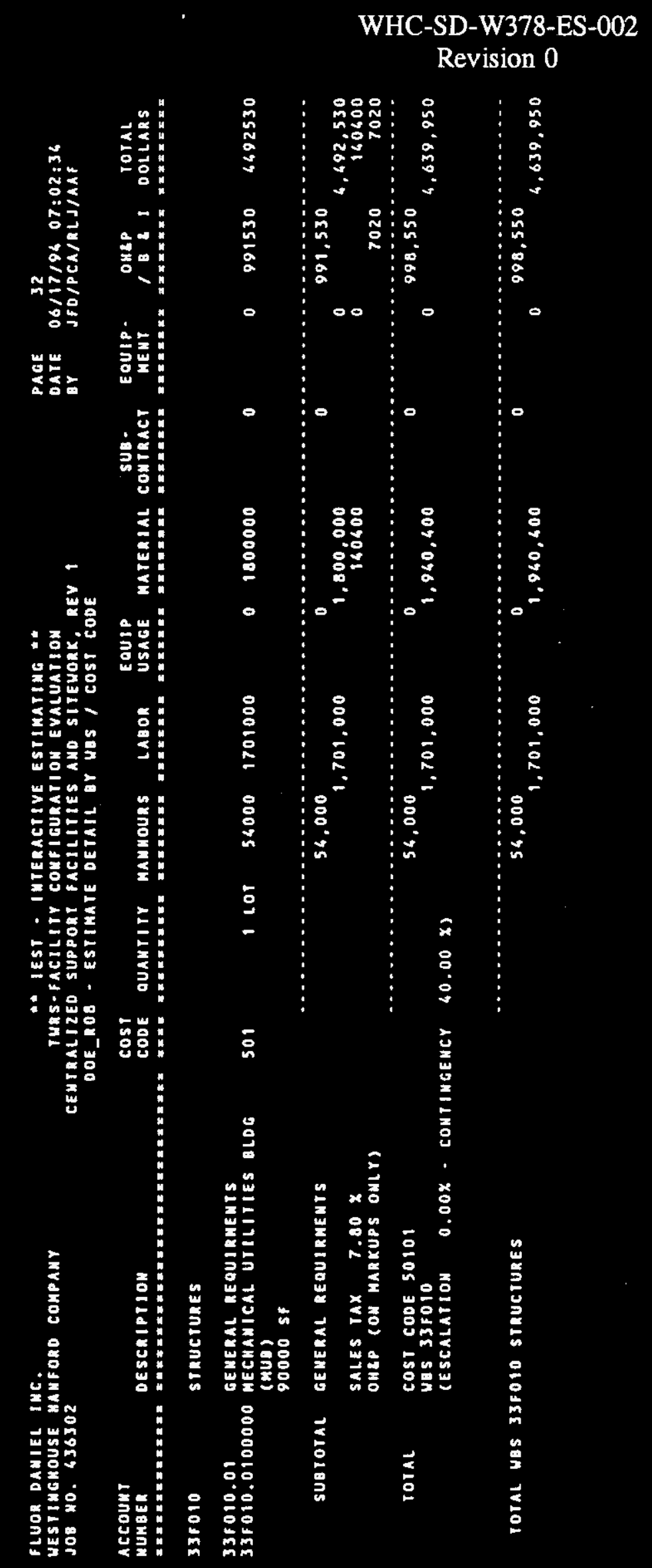




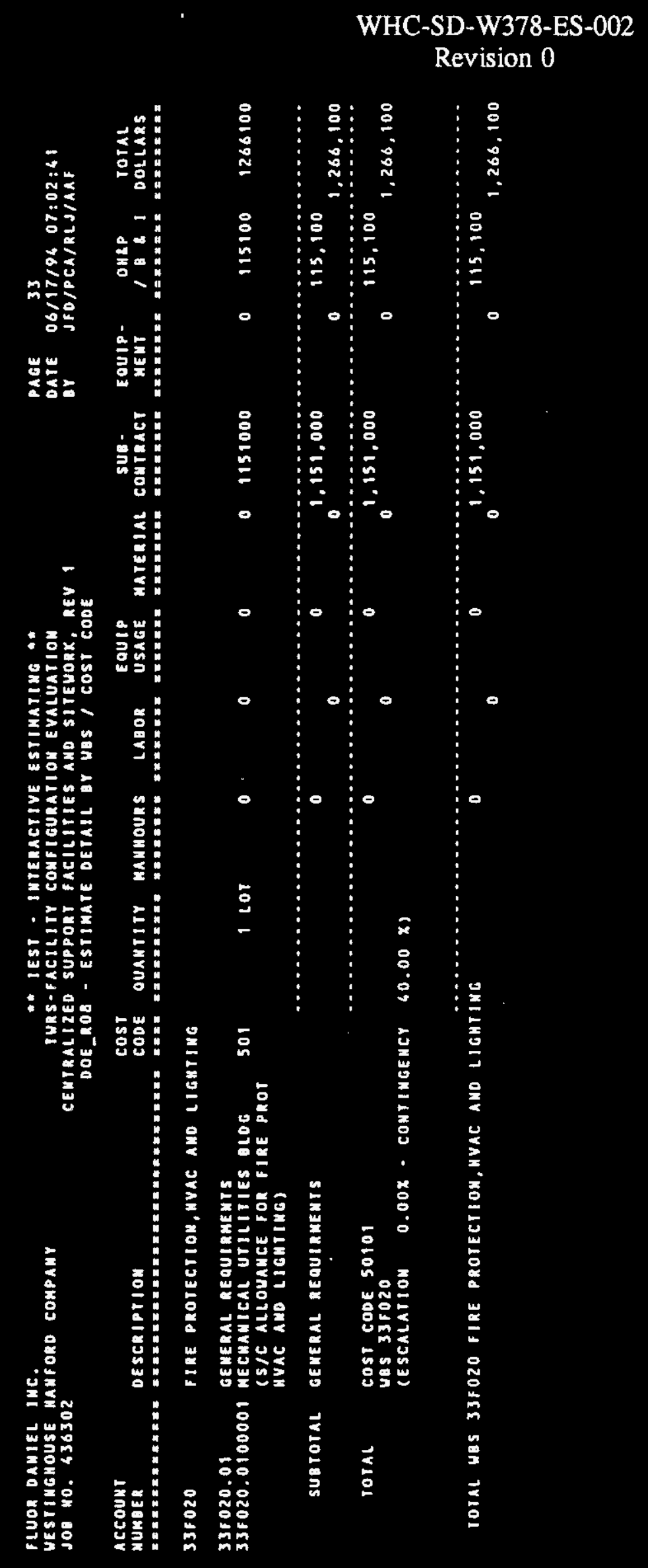

G1-42 


\section{WHC-SD-W378-ES-002 \\ Revision 0}

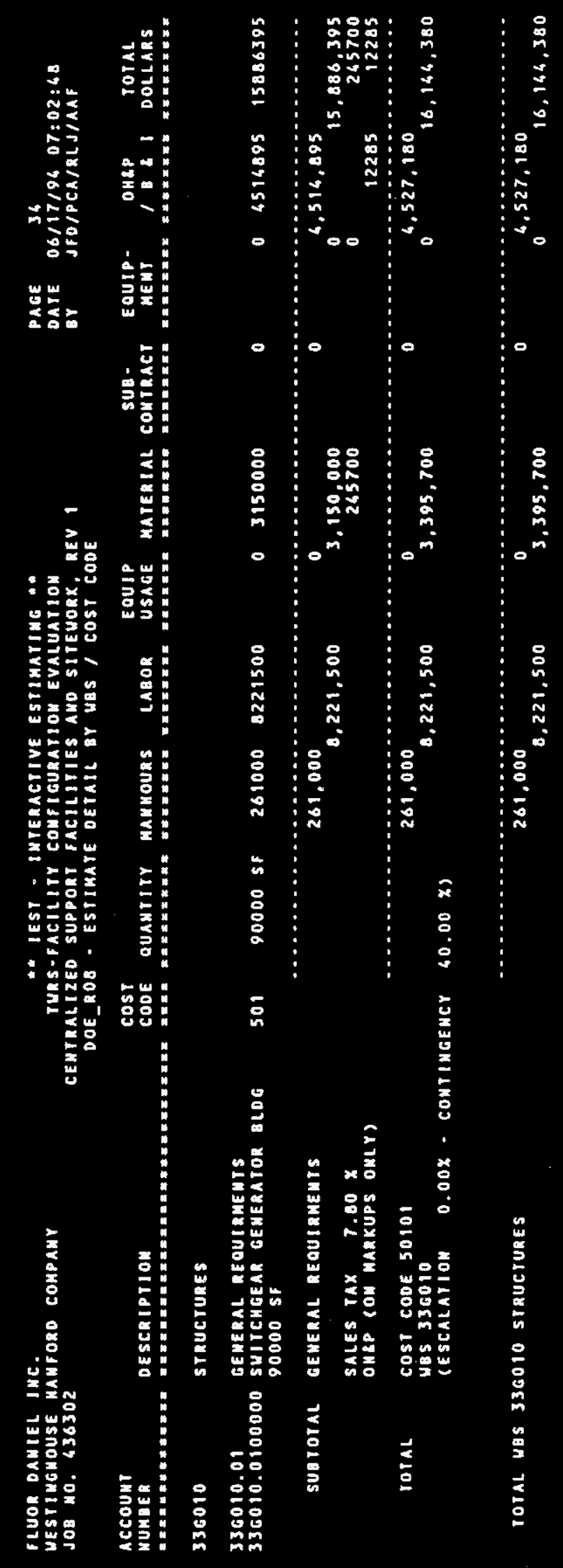

G1-43 
WHC-SD-W378-ES-002
Revision 0

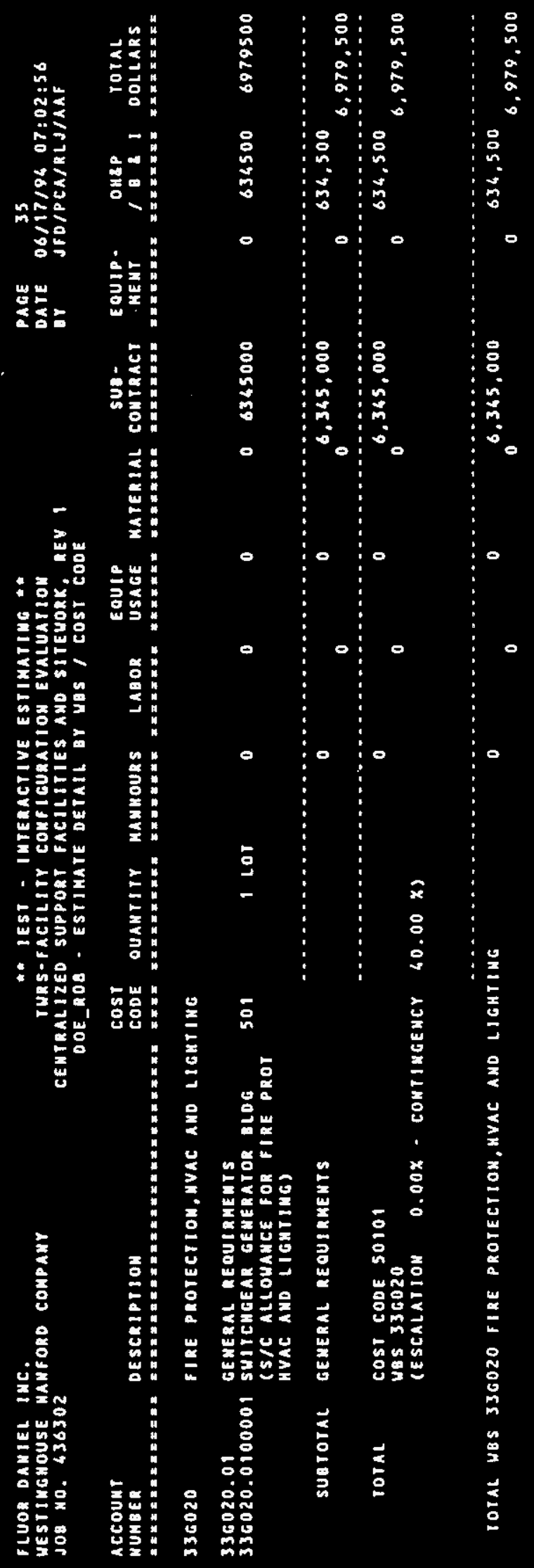




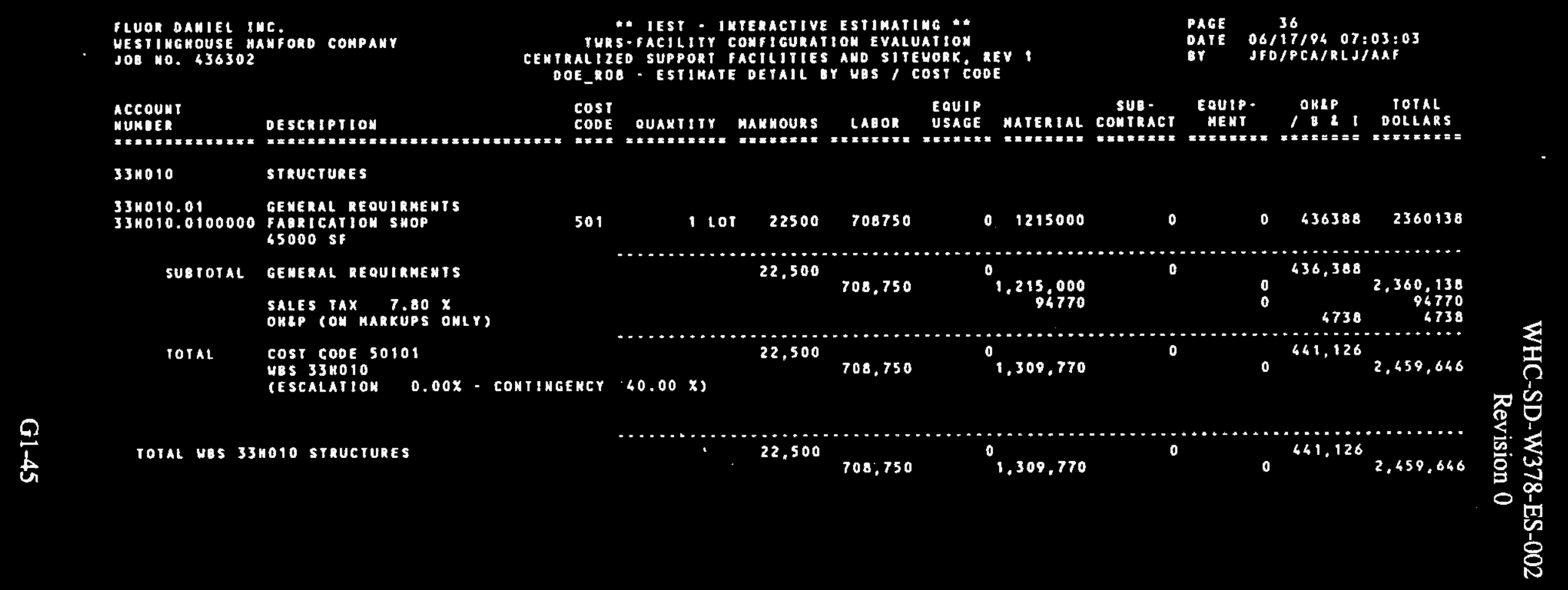




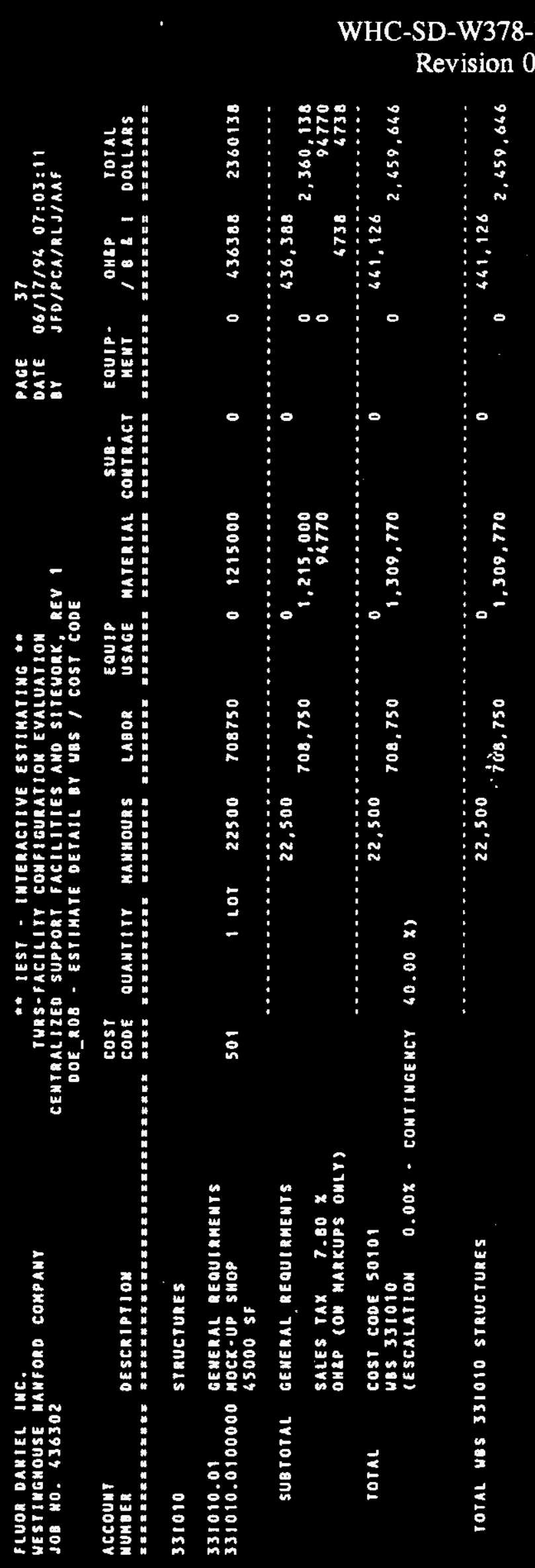

G1-46 


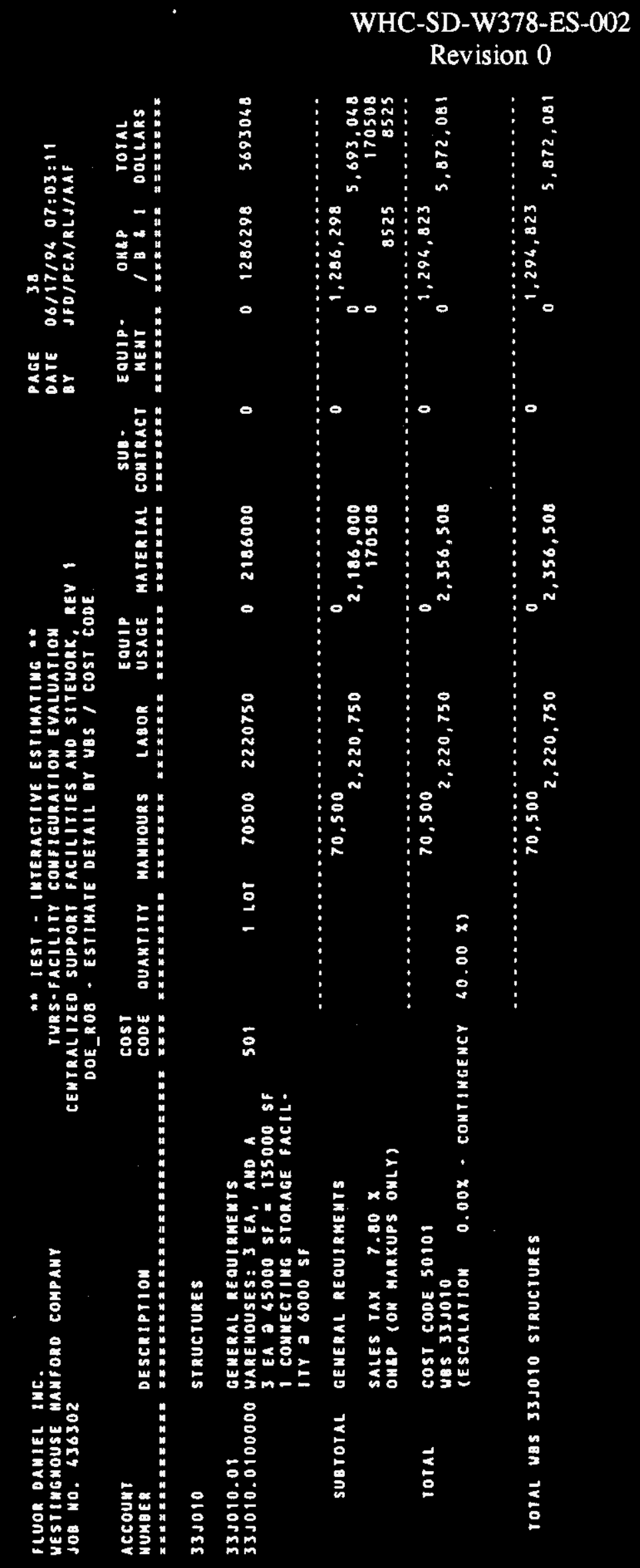




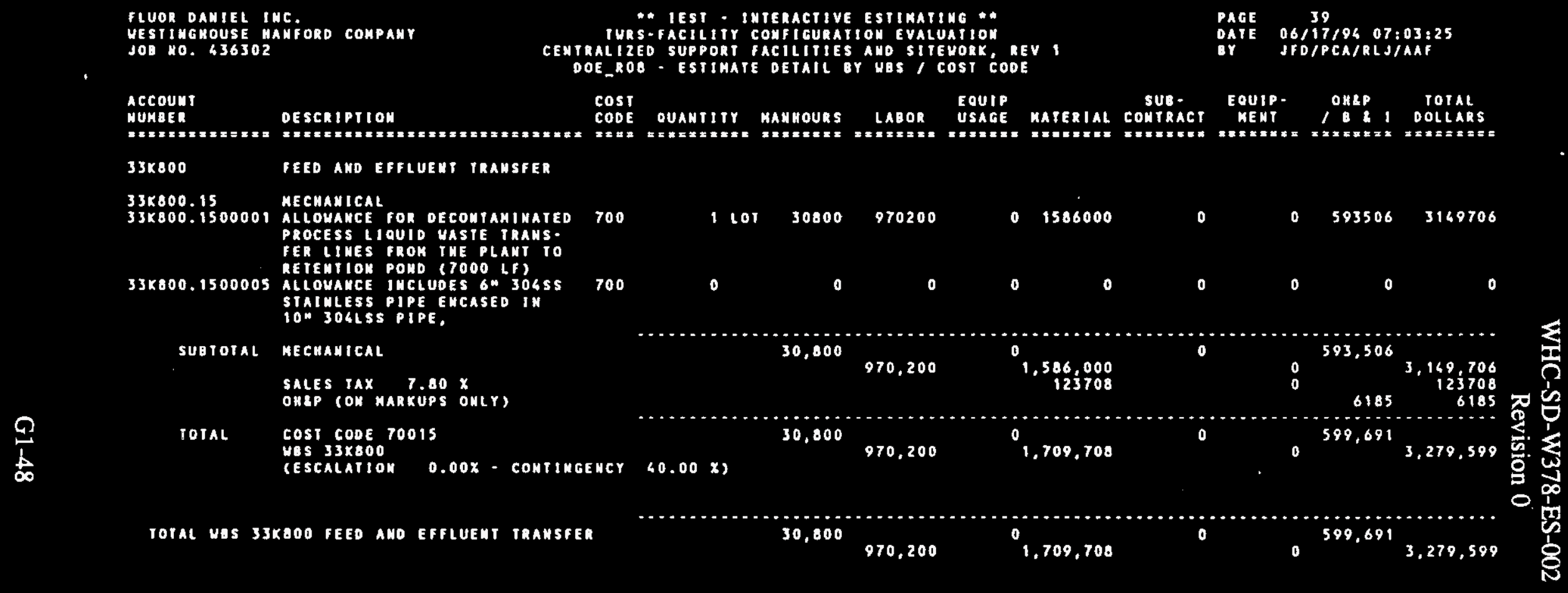




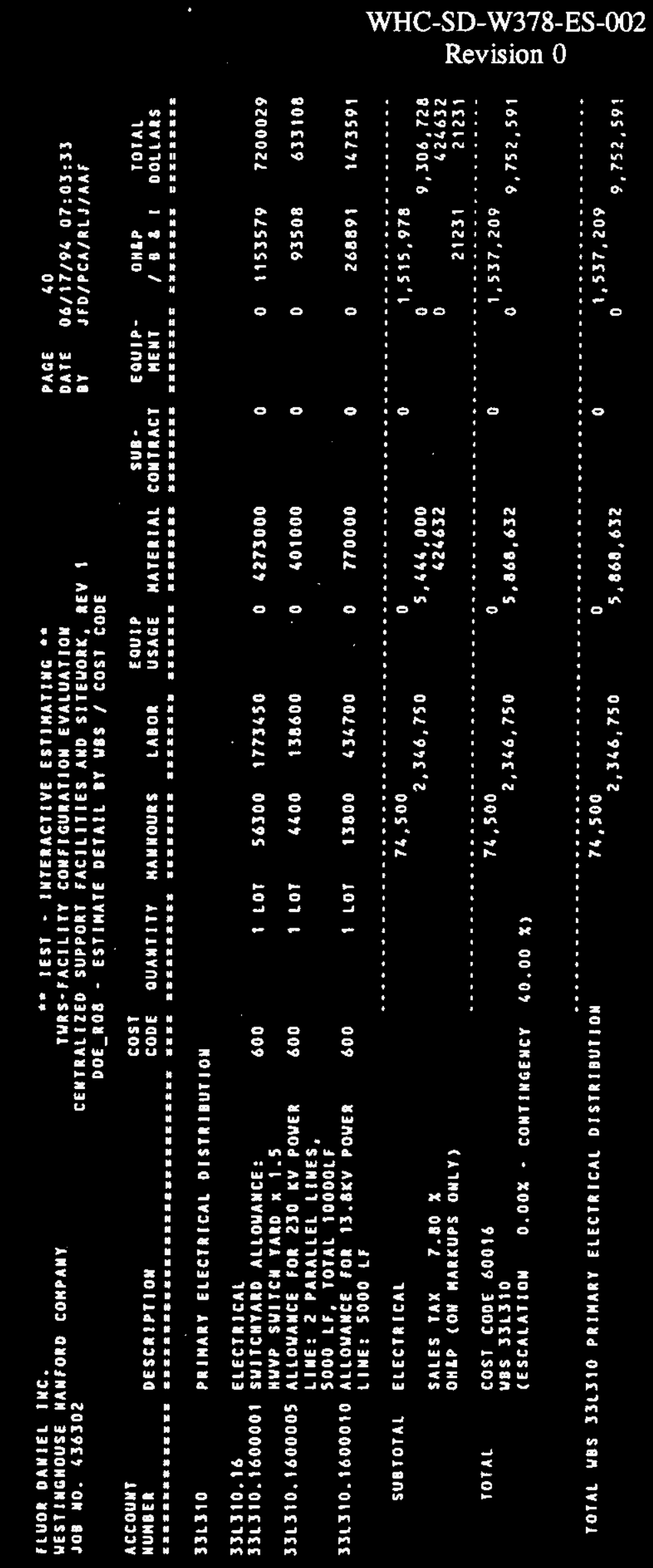

G1-49 
FLUOR DARBEL INC.

UESTINGMOUSE MANFORD COMPANY

JOB 10.436302

\section{Account}

HUMBER

334099 Construction acceptance testim

334099.01

334009.010000 ? COHSTRUCTIOH ACCEPTAKCE TESTING OJX OF DIRECT LABOR

SUBTOTAL GEMERAL REQURRENTS

TOTAL

$\cos t \cos 70001$

UBS $33 \mu 099$

CESCALAT

$0.00 X \cdot \operatorname{contingenCY}$

$40.00 \times 3$

700

1 to

$45000 \quad 1617500$
$\ldots \ldots \ldots \ldots \ldots \ldots \ldots \ldots$
45.000
$\ldots \ldots \ldots \ldots .617 .500$
45.000

TOTAL UBS 33W099 CONSTRUCTIOH ACCEPTANCE TESTING

$\frac{a}{b}$

* test - Interactive estimatiug *"

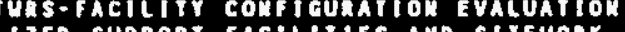

TRALIZED SUPPORT FACILITIES AKD SITEMORK, REV
DOE ROB. ESTIMATE DETAIL OY UBS / COSI CODE
45,000

$1,417,500$
PAGE
DATE $06 / 17 / 96 \quad 07: 03: 60$

BY JFD/PCARLJIAAF

..

(1)

.

.

0

751,27

751,275


FLUOR DAMIEL JMC.

WESTIMGHOUSE MANFORD COMPANY

J08 10.636302

ACCOUNT

MUMBER

DESCRIPTIOK

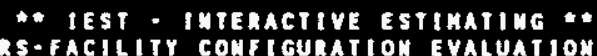
CEMTRALIZEO SUPPOR FACILITIES AMO SITEUORK, DEV DOE ROB. ESTIMATE DETAlL oY wes, cost CODE

cost EQUIP
PAGE

DATE $06 / 17 / 94$ 07:03:4

BY JFD/PCA/RLJIAAF

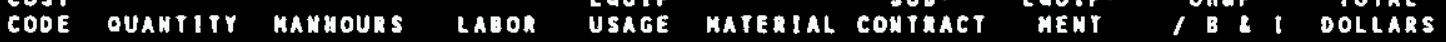

sug -

Eoutp. OHe

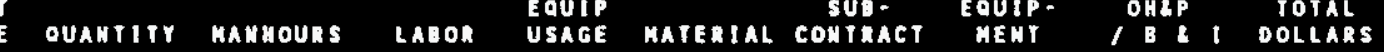

33 3320 HORKAL ELECTRICAL DISRIBUTION

$33 \times 320.16$ ELECTRICAL

33W320.1661001 56-1801-C 600 SHITCHGEAR SUITCHGEAR/GEMRTR $13.8 \times Y$

334320.1661005 EMERGEHCY SHITCHGEAR

$33 \times 320.1661010 \begin{gathered}480 \text { V } \\ 56 \cdot 1806 \cdot C\end{gathered}$

SUITCMGEAR-LLU FACBLITY SUItches

334320.1661015 S6.1805-C se- $1805-c$ -

\section{IEA}

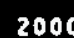

63000

2EA $\quad 1000 \quad 31500$

$1 E A \quad 2000$

63000

$1 E A \quad 2000$

63000

$1 E A \quad 2000$

63000

$1 E A^{\prime}$

2000

63000

$2 E A \quad 4000 \quad 126000$

000

$1 E$

4000

126000

600

1 EA

4000

126000

600

1 EA

4000

126000

1 EA

2000

63000

$1 E A$

2000

63000

1 EA

2000

63000

(2)

(1)

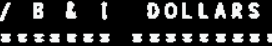

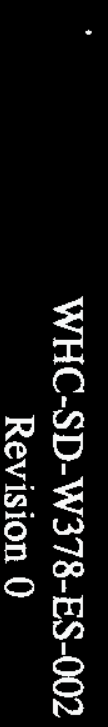




\section{Revision 0}

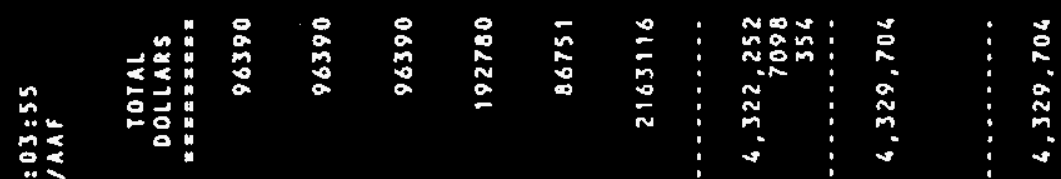

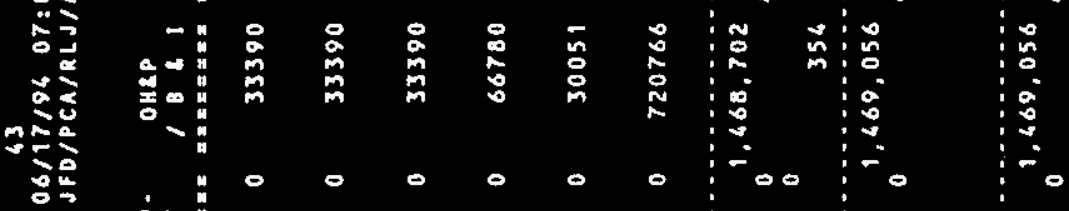

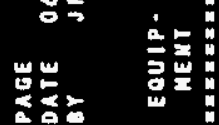

諳:

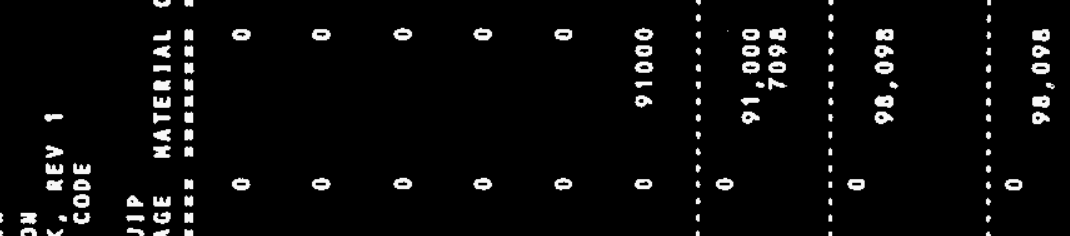

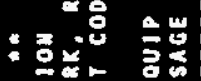

능용

를

xin

:

$\begin{array}{ll}8 & 8 \\ 0 & 0 \\ 0 & 0 \\ 0 & 0\end{array}$

(1)

紧紧

흐을

递要

ind

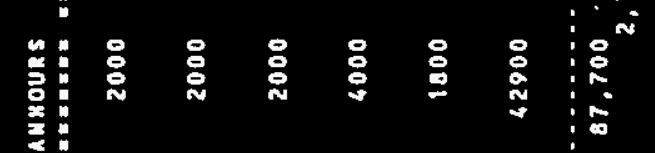

$\leqslant \leq \leqslant \leq 5$

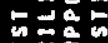

눙

:

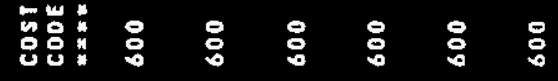

हैँ

은
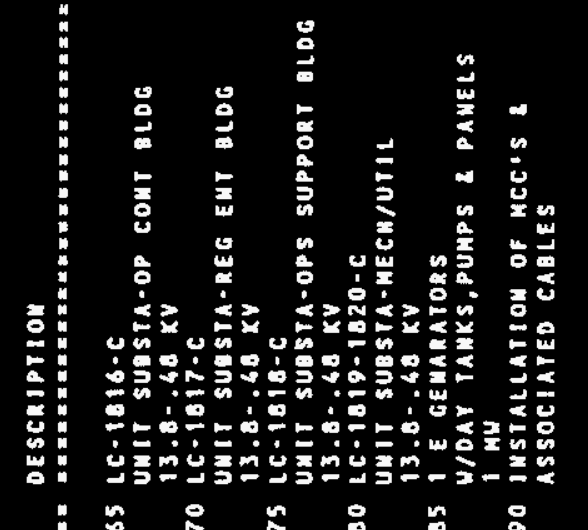

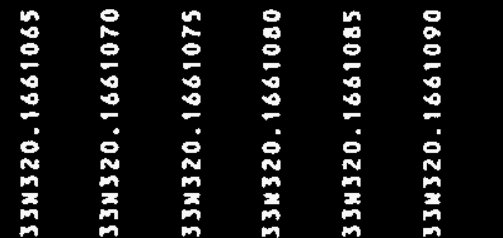

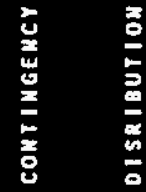

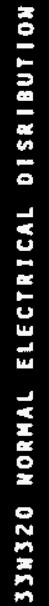




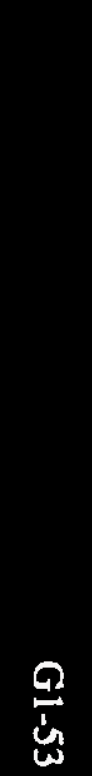

FLUOR OAHIEL INC.
WESTIMGHOUSE MAMFORD COMPANY JOS $\mathrm{N0.} 436302$

"* IEST - INTERACTIVE ESTIMATIMG *0

TURS-FACILITY COMFIGURATIOK EVALUATION CENTRALIZED SUPPORT FACILITIES AUO SITENOKK. DOE_ROD - ESTIMATE DETAIL UT uBS/ COST CODE

PAGE $06 / 17 / 96 \quad 07: 06: 03$

BY JFD/PCA/RLJ/AAF

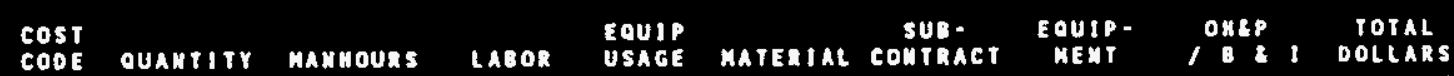
CODE QUAMTITY MANHOURS LABOR USAGE MATERTAL COMTRACT MEXT NUMBE: DESCRIPTION COMPRESSED AIR

$33 \times 410$ MecuAntCat

$33 \times 410.15$

33W410.1500001 ALLOUAMCE FOR LABOR AMD DULK MATERIALS ASSOCIATED UITH THE INSTALLATIOH Of THE
700

120

32800

1 717000

$0 \quad 583446 \quad 2333646$

\section{SALES TAX $7.80 x$} OHEP (OH MARKUPS OWLY

$\operatorname{TotA}$

cosi CODE 70015

$$
\text { U⿺s } 334610
$$

CESCALATIO

$0.00 x-$ CONYIMGENCY$$
\ldots
$$

32.800

$1,03.200$

$1,033,200$

0

717,000
5592

32,800

$40.00 \times 3$

772,926

$1,033,200$

0

583,446

0

32,800

$32,800,033,200$

o

772,926

0

TOTAL UBS $33 \% 410$ COMPRESSED AIR 
FLOR DAMIEL IMC.

UESTIMGMUSE HAMFORD CONPANY 10840.436302

Account

NUABER

$33 \times 430$

334630.15

$33 \times 430.1500001$ ALLOUAYCE FOR LABOR AHO

ALloUA.TE

UITH IHE IMSTALCATIOA OF THE SYSTEM 43 EQUIPAENT.

SUB TOTAL hECHAMICAL

SALES TAX 7.80 $X$
OHBP (OU MARKUPS ONLY)

Totat

$\cos 1$ CODE 70015

CEScALAT ton

$0.00 x-$ COntIMgency

$\stackrel{Q}{\stackrel{d}{\dot{A}}}$

DESCRIPTION

700

TOTAL UBS $33 \% 430$ IOH EXCHAMGE

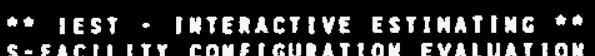

CERTRALIZED SUPPORT FACILITIES AMD SITEHORK, REV

DOE $R O B$. ESTIKATE DETAIL OY UBS $/$ COST COOE

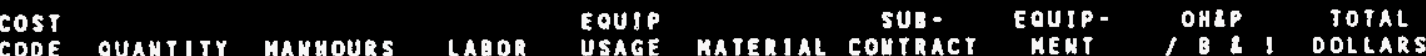

PAGE 45
OATE $06 / 17 / 94$ OT:04:10
BY JFD/PCA/RLJAMF

EQUIP- OHEP TOTAL

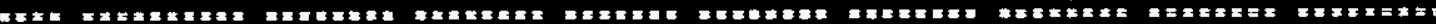

1 tor

$900 \cdot 28350$

$0 \quad 12000$

0

$0 \quad 15626$

55976

$\ldots \ldots \ldots$

900

28,350

0

12,000

o

15,626

55,976
936

.................

28,350

$40.00 \times 3$

12,936

o

5,67

56,958
900

28,350

12,936 


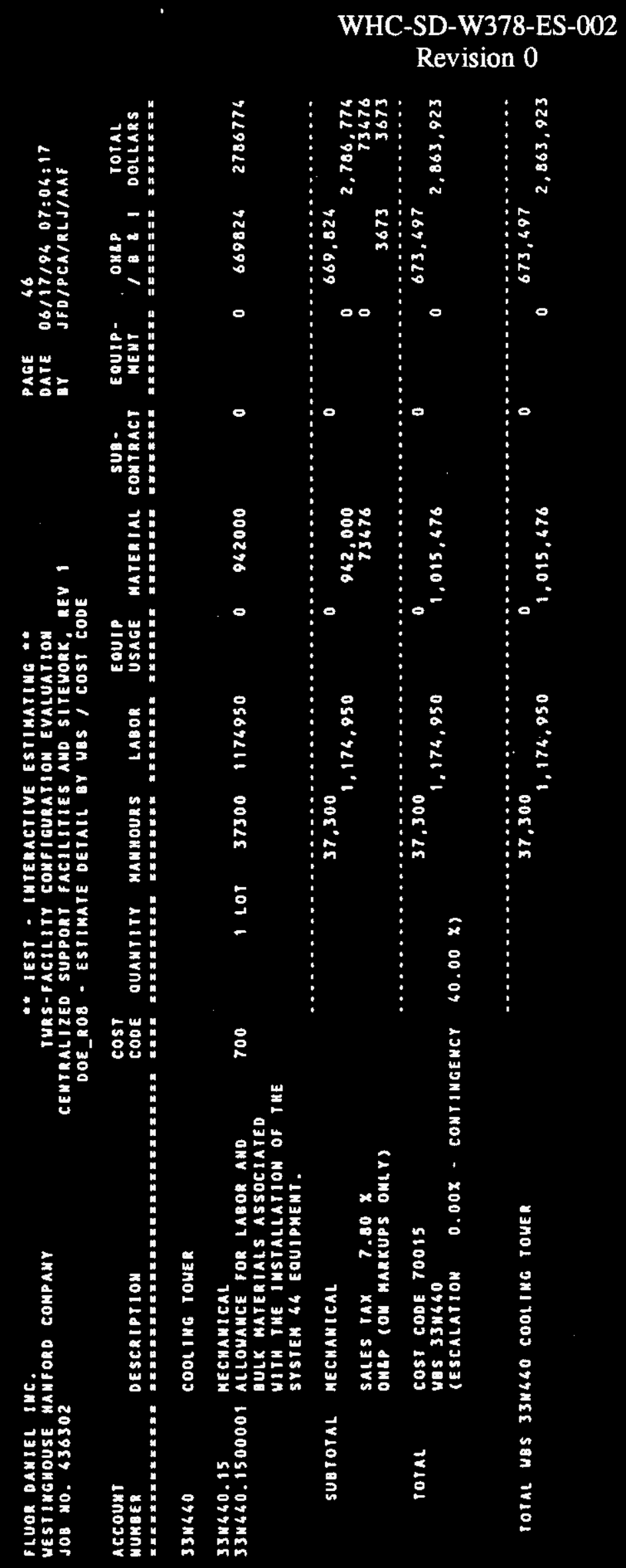

G1-55 


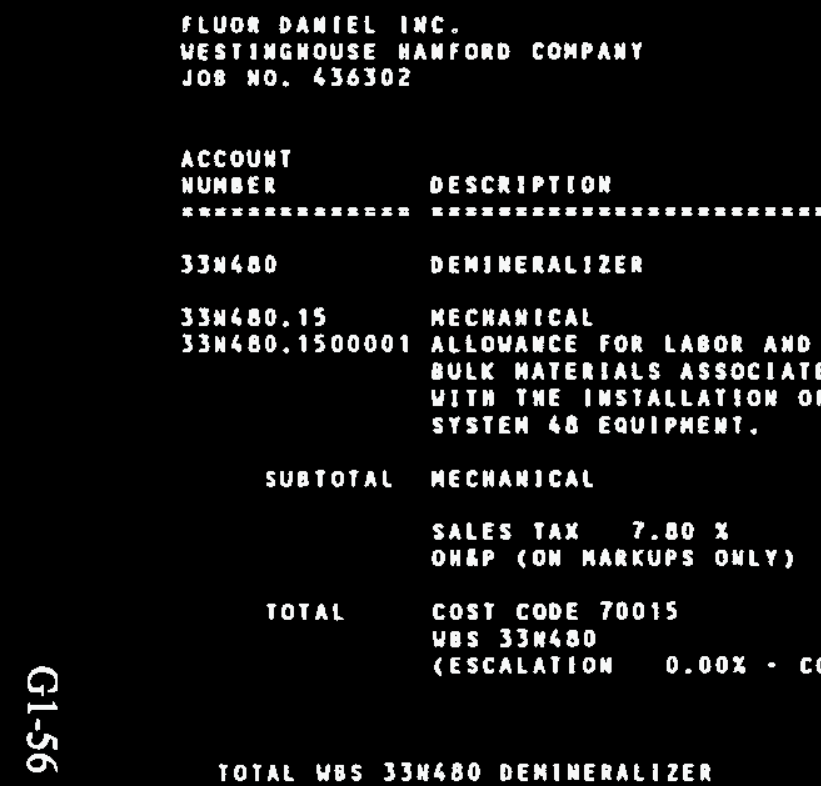

TOTAL HBS 334480 DEMINERALI $2 E R$

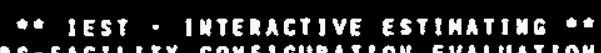
CERTRALT2ED SUPPORT CACILURATS AMD SITEUORK. REY

ERTRALIZED SUPPORT FACILITIES AMD SITEUORK, REV
DOE_ROS. ESTIMATE DETAIL OY UBS $/$ COST CODE

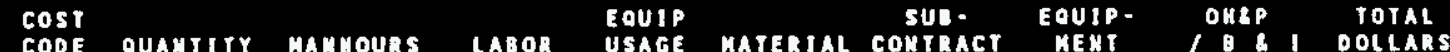

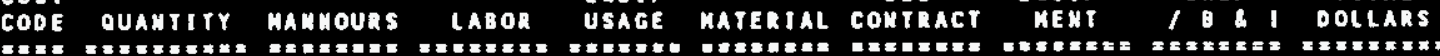

PAGE
DATE $06 / 17 / 94$ O $07: 04: 24$
BY

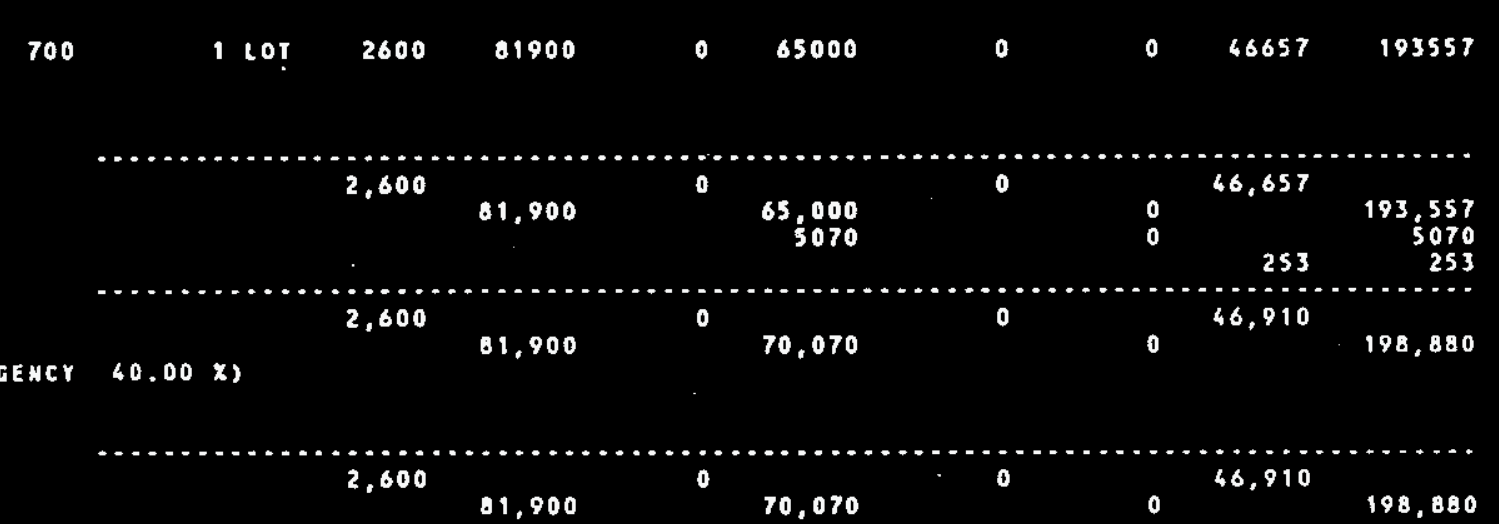


TLUOR DANIEL IMC.

UESIIMGHOUSE HANFORO COMPANY

J08 40.46302

Account

MUKBE

$33 \% 690$

334690.15

$33 \times 690.1500001$ ALLOUANCE FOR LABOR AMO

MECHANICAL

cuir Matenials assoctate

WITH THE IMSTALLATION OF THE

SYSTEN 49 EQUIPHENT.

SUBtotal MECHAMJCAL

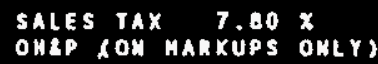

TOTAL

$\cos 1$ CODE 70015
YBS $33 \% 690$

YQS 33 H490

$0.00 x \cdot$ COnTIMGEnCY

TOTAL UBS $33 \% 490$ SANTTARY WATER

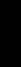

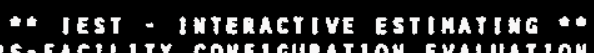

TURS-FACILITY COHF GURATION EVALUATION

CEMTRALIZED SUPPORT FACILITIES AND SITEUORX, REY
DOE ROB. ESTIMATE DETAIL BY UBS / COST CODE
CODE QUANTITY MAMHOURS LABOR USAGE

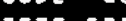

Material contract

PAGE
DATE $06 / 17 / 94 \quad 07: 04: 32$

QY JFO/PCARLJ/AAF

EOUIP- OHEP TOTAL MEUT $I B \& 1$ DOLLARS

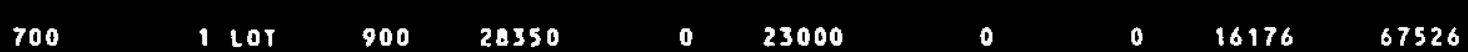

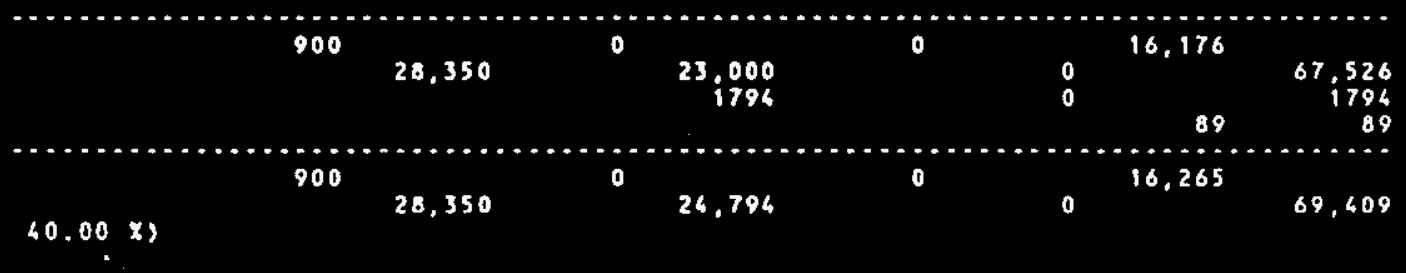

900

28,350

24.794

0

o

16,265

69,609 


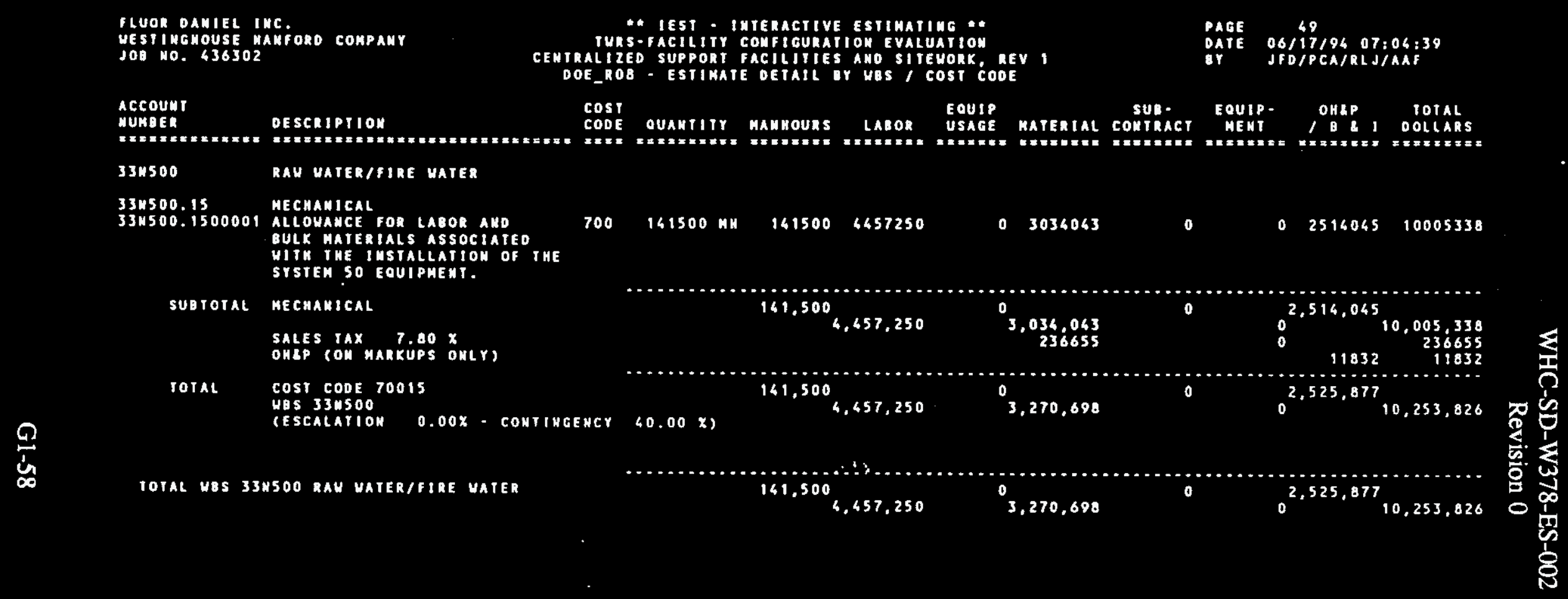




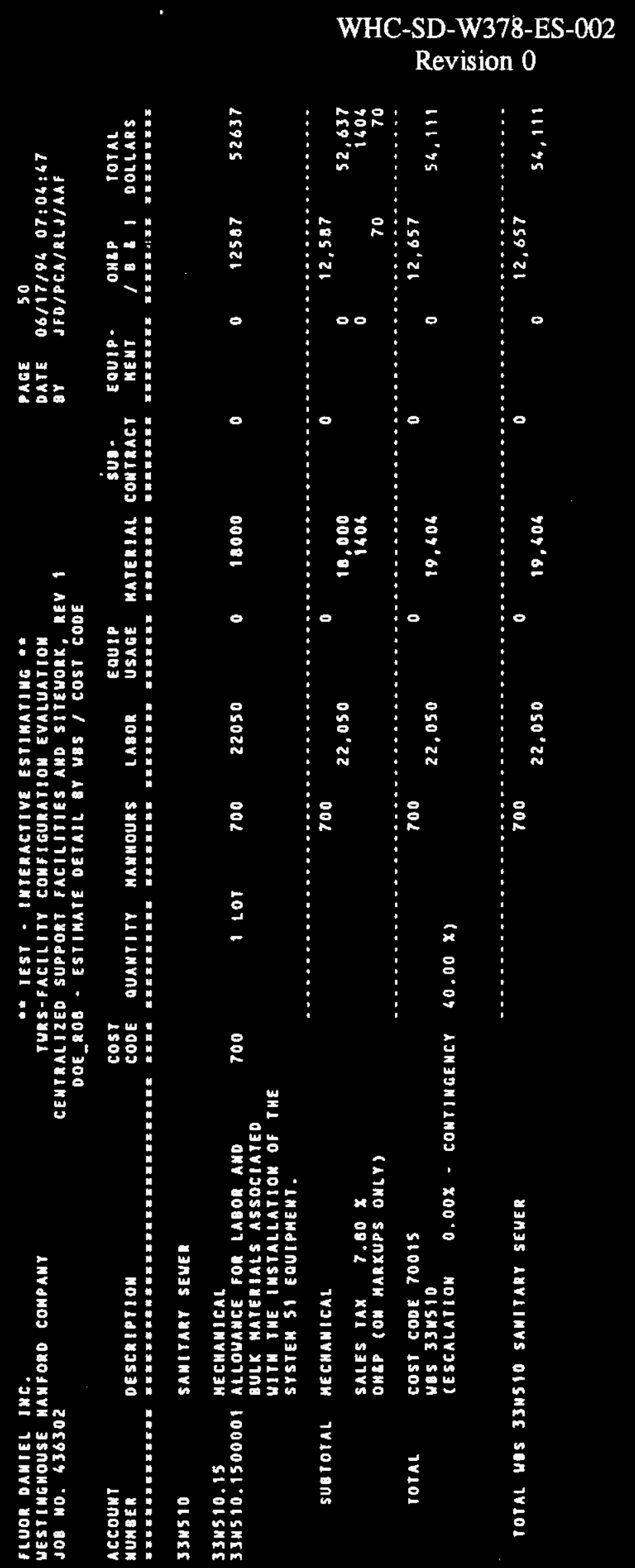

G1-59 


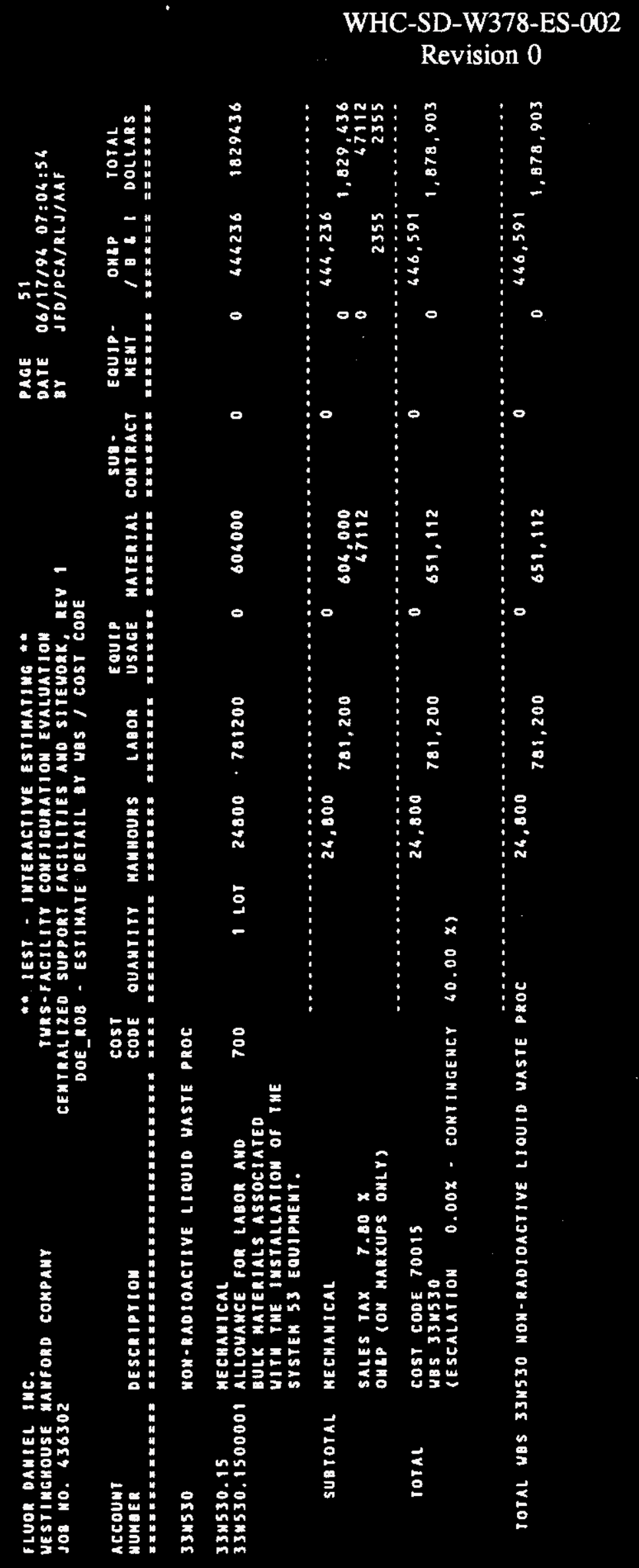




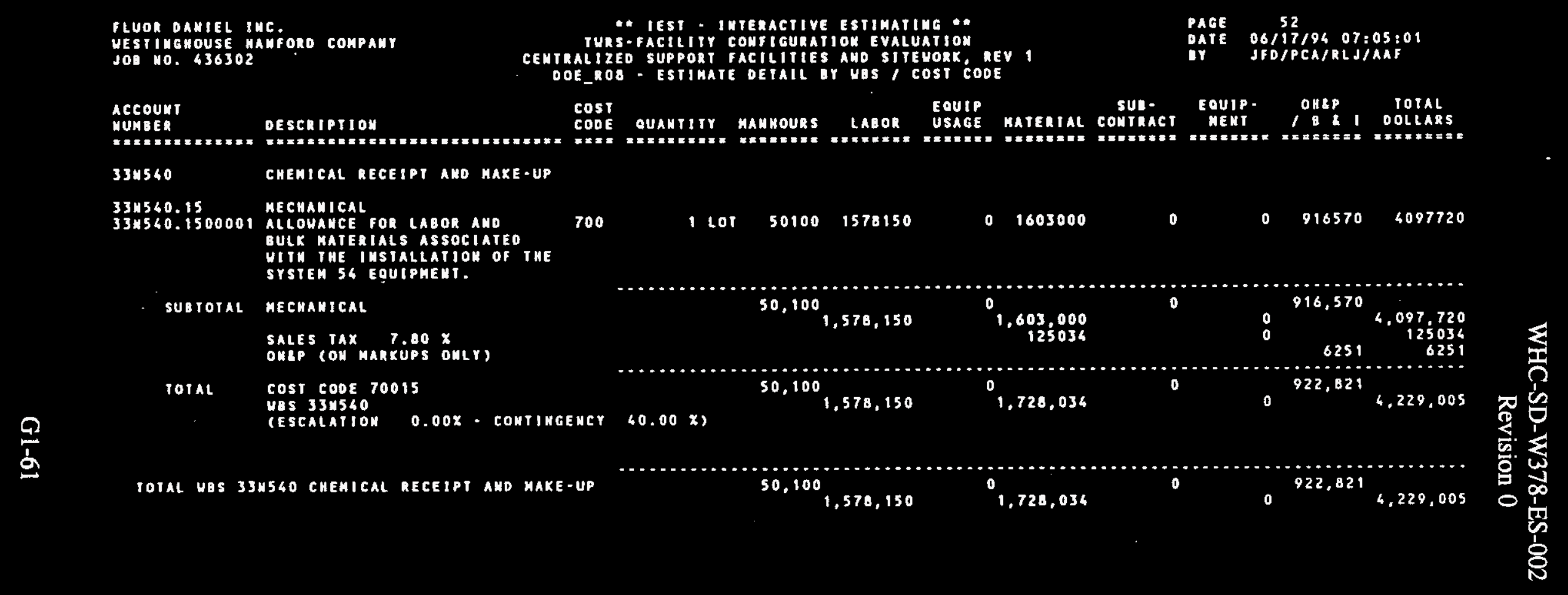




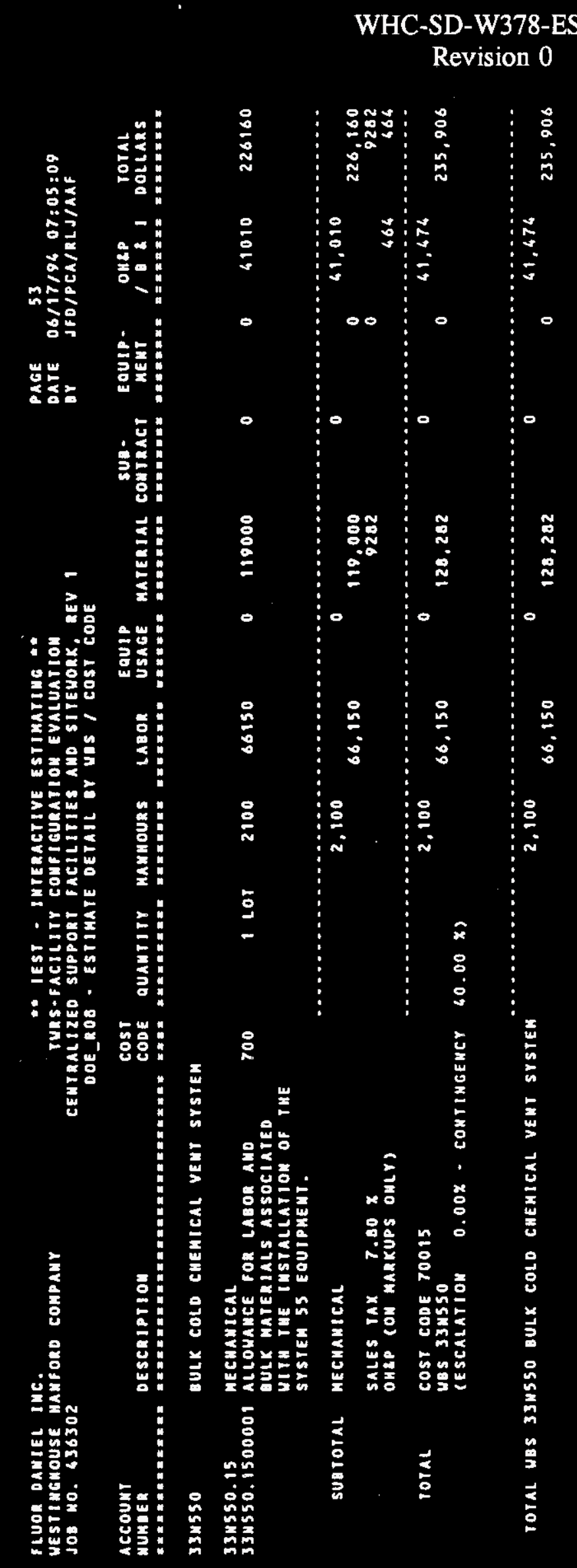

G1-62 
FLUOR DANIEL IHC.

COMPANY

108 40.436302

Account

MUABER

334580

$33 \times 580$.

334580.1500001 ALLOUAHCE FOR LABOR AHD

UITH THE IMSTALCATIOA OF THE

SYSTEM 50 EQuIPHENT.

SUBTOTAL MECMANICAL

SALES TAX $7.80 x$

OHBP, (ON KARKUPS ONLY)

TOTAL

COST CODE 70015

CESCALATION

$0.00 x$ - CONIINGEnCY

700
- IEST - IHTERACTIVE ESTIMATIMG *

TURS-FACILITY COHFIGURATIOK EYALUATIOH

CEMTRALIZEO SUPPORT FACILITIES AKO SITEUORK, REV

DOE ROS - ESTIMATE DETAlL BY WES/ COST CODE

COST EOUIP SUD. EQUIP. ONLP TOTAL

CODE QUANTITY MAMUOURS LABOR USAGE MATERIAL COMTRACT MENT

PAGE 56
DATE OS/17/94 O7:05:16
BY JFD/PCA/RLJ/AAF

104300 й $106300 \quad 3285650$

$0 \quad 2635974$

0

$0 \quad 1873087$

7794511

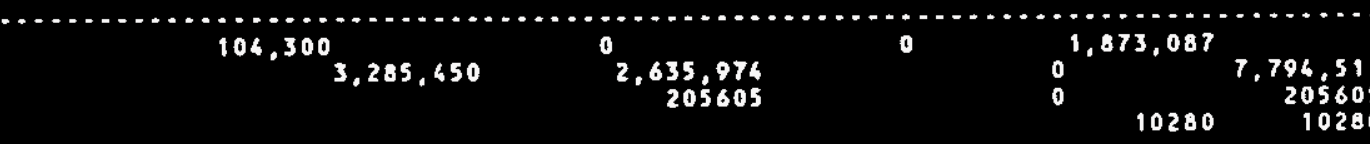

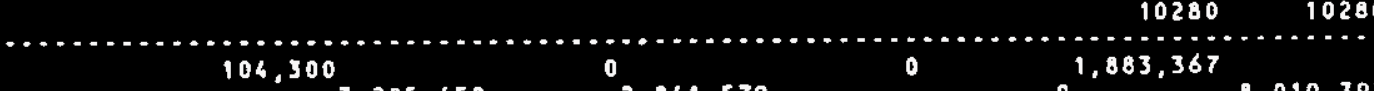

$40.00 \times 3$

$2,841,579$

0

total yBS 33 Hoo glass forher preparation
104,300

$3,285,450$
$2,861,579$
$1,883,367$

$8,010,397$ 


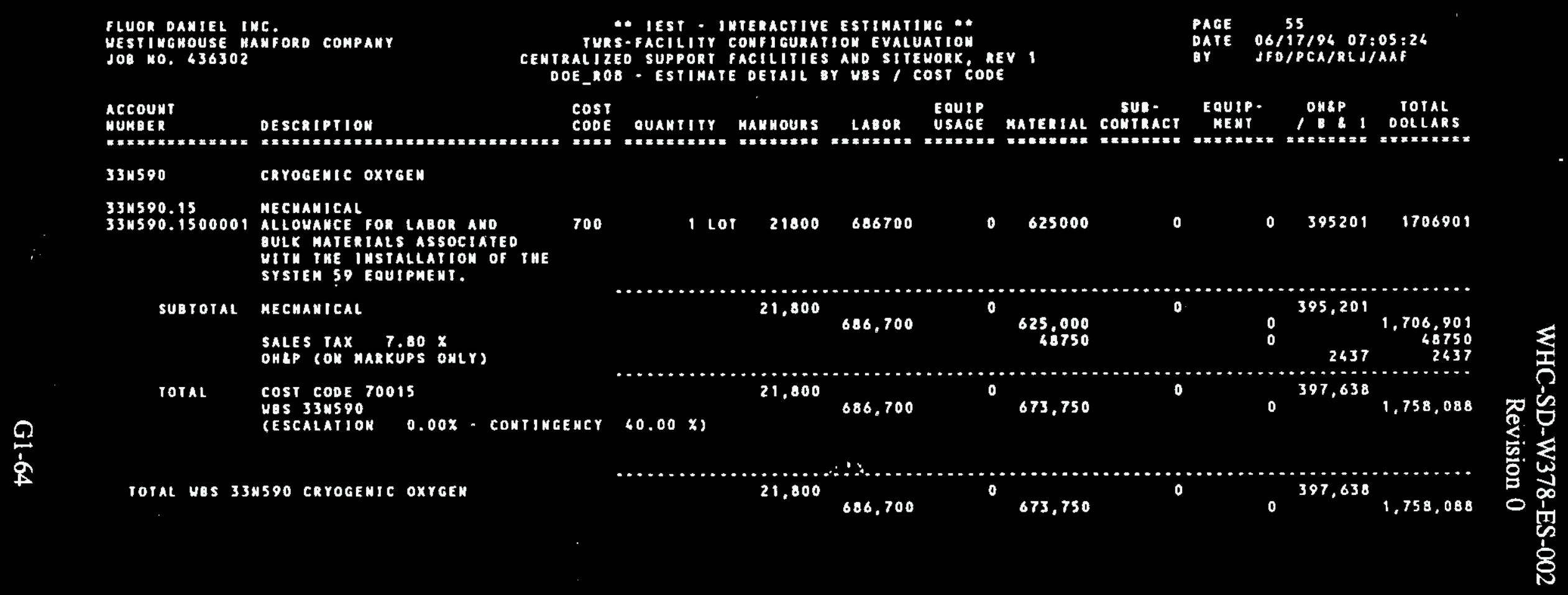


FLUOR DAMIEL INC.

HESTIMGMOUSE KAMFORD COMPAMY JOE 10.436302

\section{AccoUnt \\ nUMDE R}

$33 \times 600$

$33 \% 600.15$ MECHAMICAL

LLOYANCE FOR LABOR AHD ULK MATERIALS ASSOCIATEO Sith The Installation of THE

SUBTotal hechanical SALES TAX $7.80 x$
OHLP (ON MARKUPS ONLY)

TOTAL COST CODE 70015

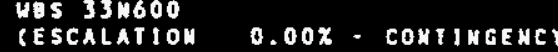
CODE QUARTITY MAMHOURS LABOR USAGE MATERIAL COMTRACT MEMT

PAGE 56

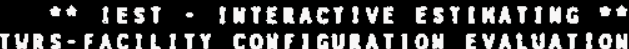
CETRALIZED SUPPORT FACILITIES ANO SITENORK, REV 1 DOE_ROB - EStIMATE deTAIL OY MES / COST CODE

cost EQU1P

730002299500

1526000

73,000

$2,299,500$

0

$1,524.000$

o

73,000

$73,000,299,500$

${ }^{0}, 642,872$

$40.00 \times 3$

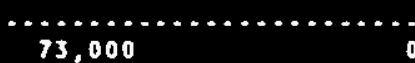

2 ,

TOTAL WBS $33 M 600$ SHARE FAC UTILITY PIPINO
73,000 o

$1,642,872$
$1,300,878$ 


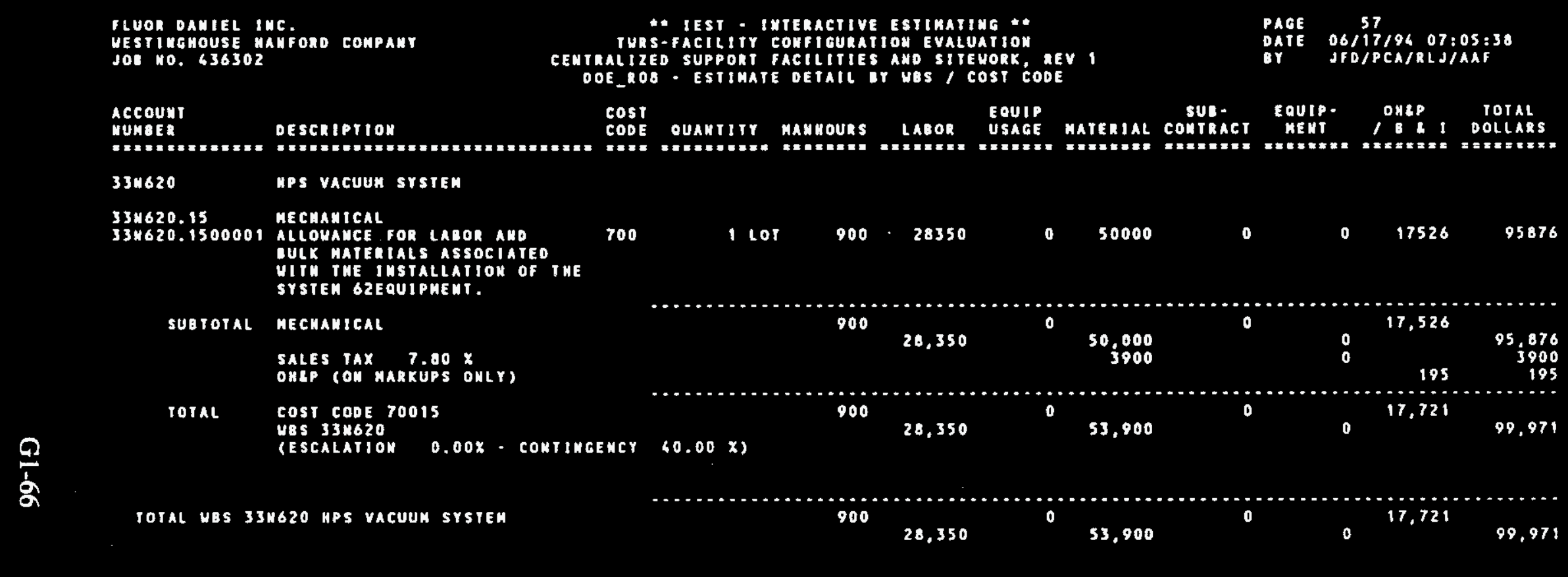




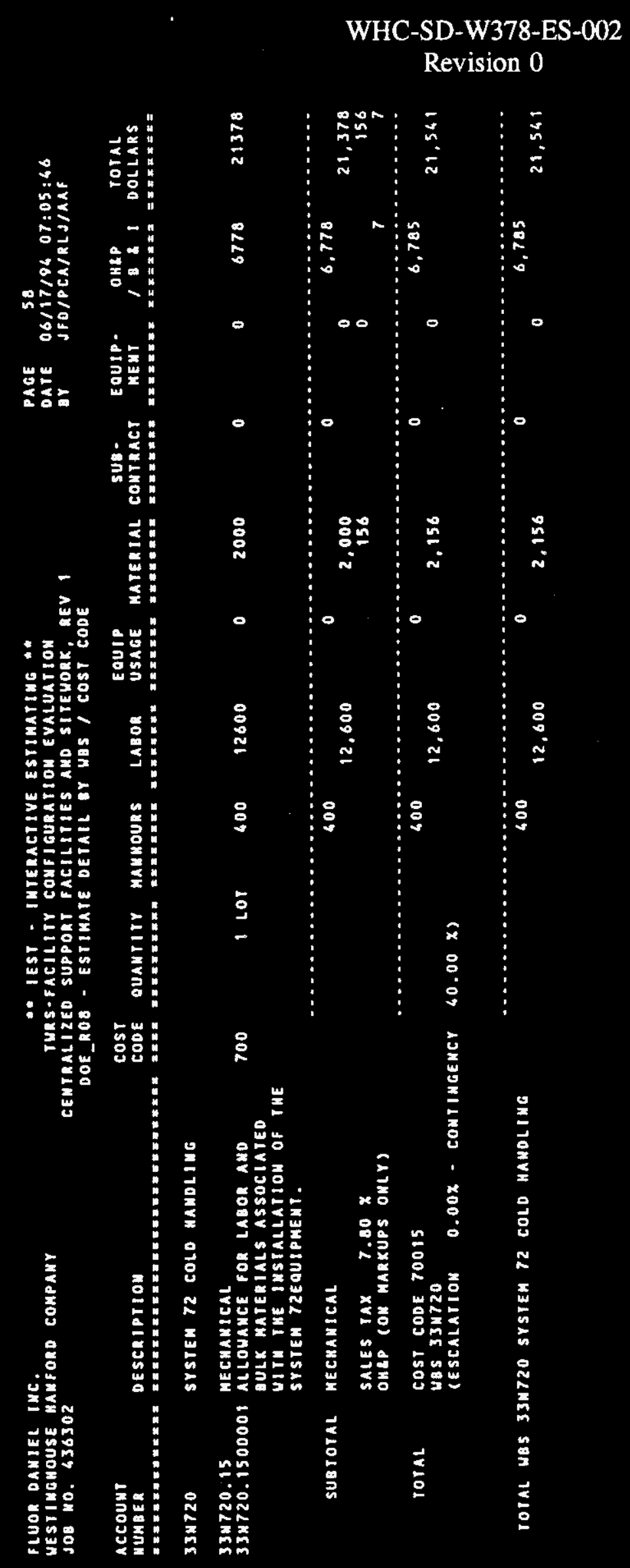

G1-67 


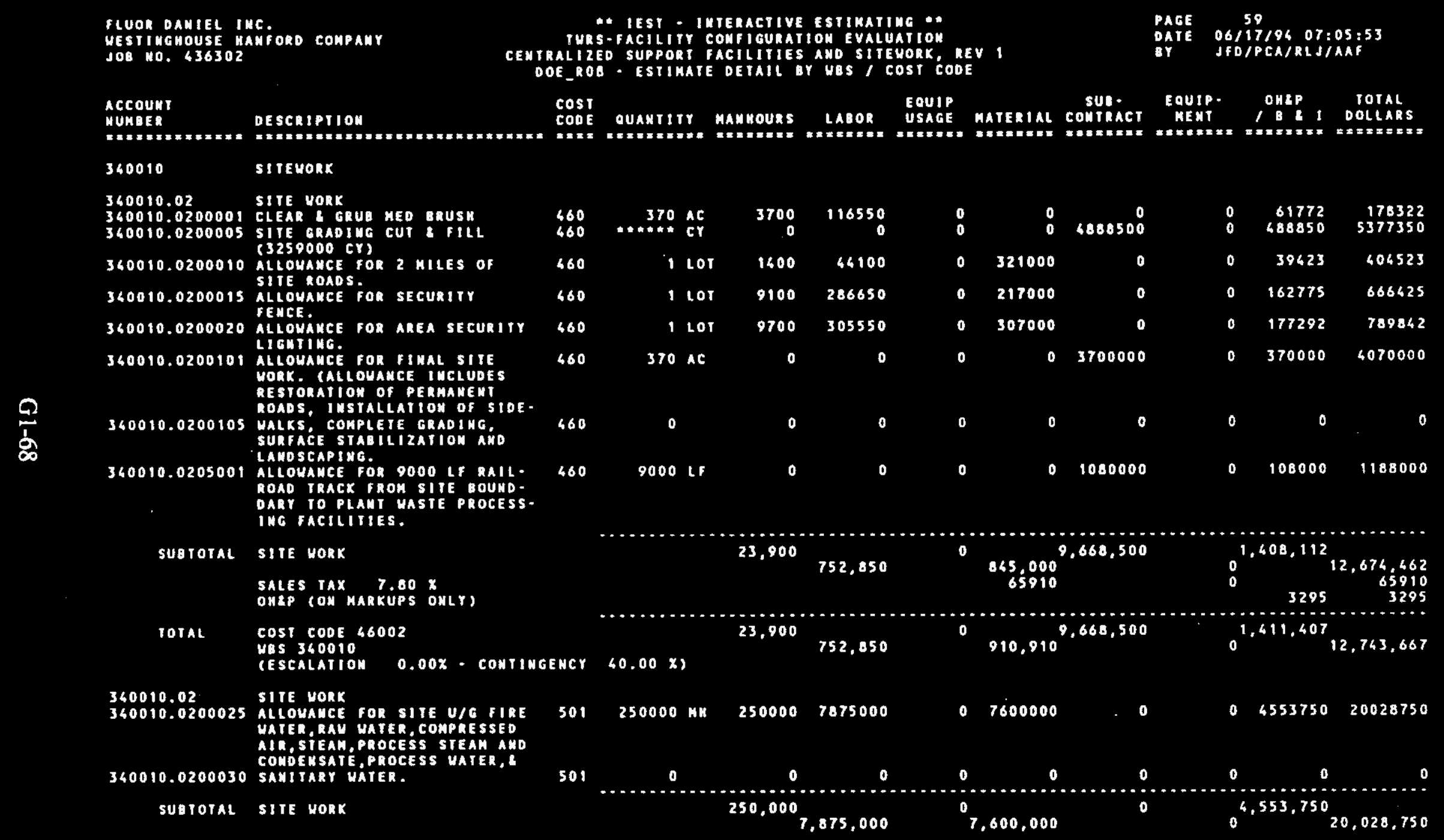




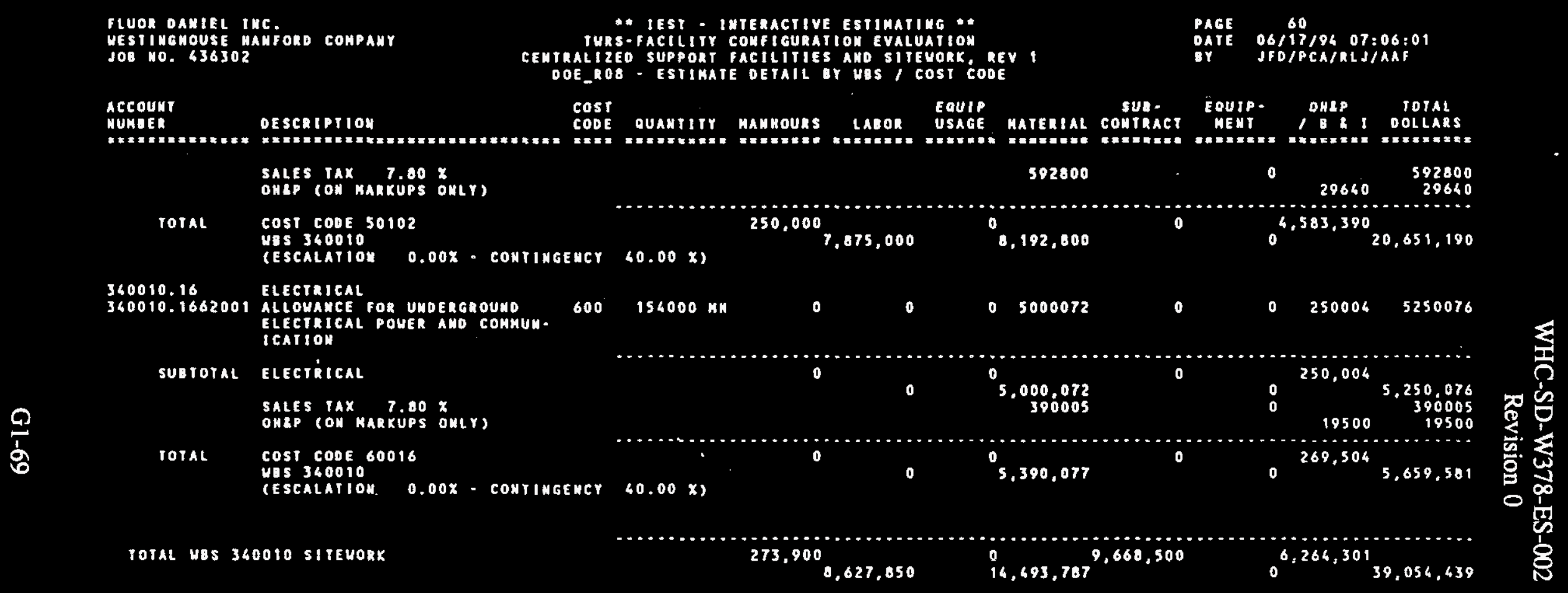




\section{WHC-SD-W378-ES-002 Revision 0}

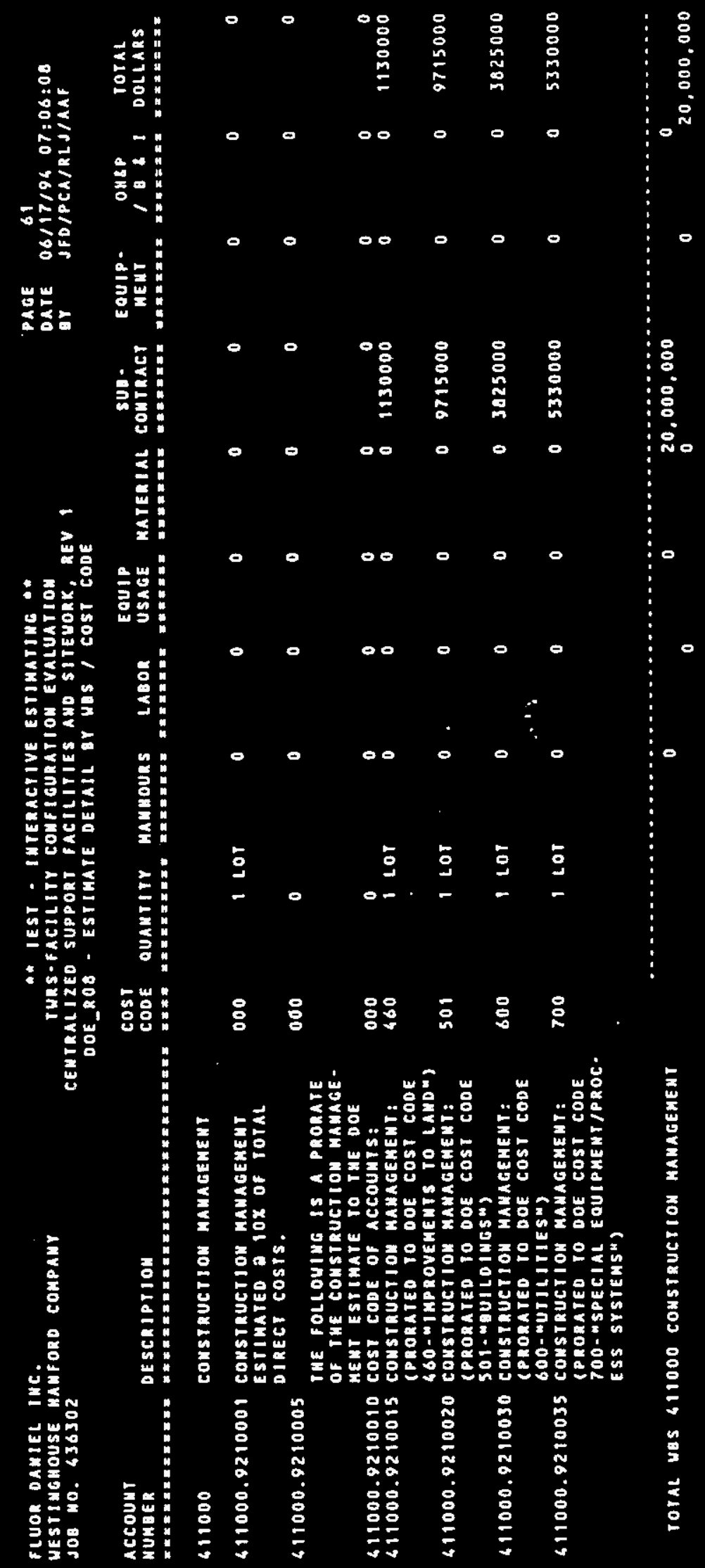




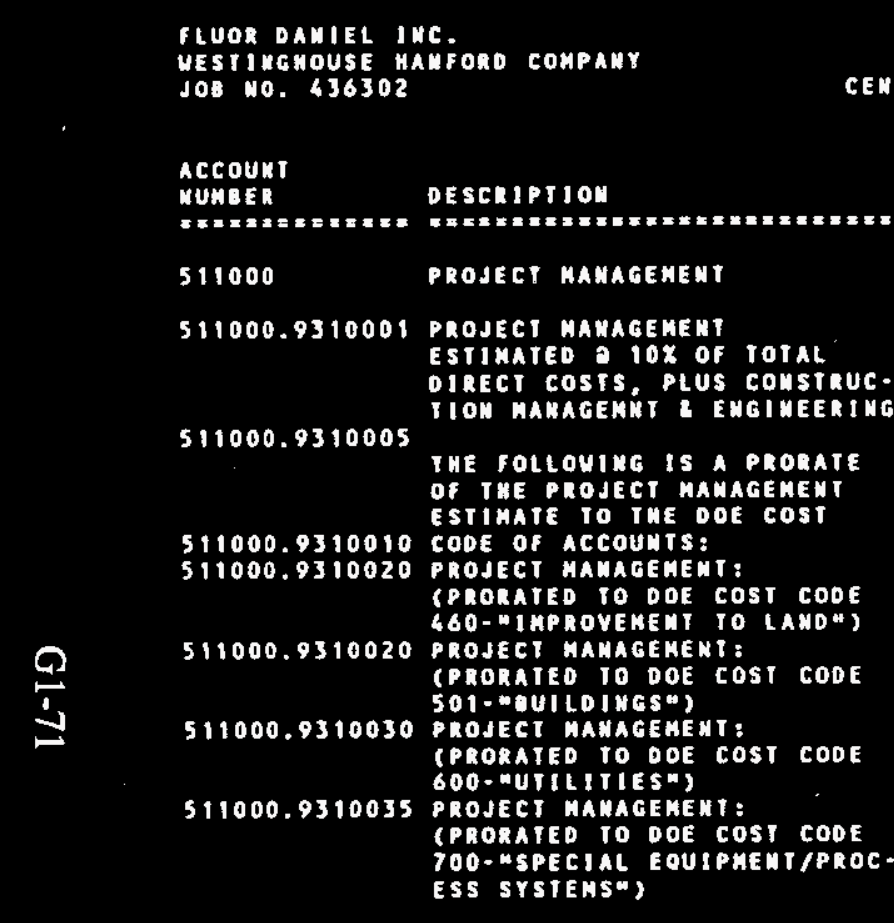

ME" IEST - IMTERACTIVE ESTIMATING "* CENTRALI IEO SUPPORT PACILITIES AHO SITEMORK, REV DOE_ROB. - ESTIMATE DETALL OY HBS $/$ COST CODE

PAGE $06 \% 2 / 17 / 96 \quad 07: 06: 15$ BY JFD/PCA/RLJ/AAF

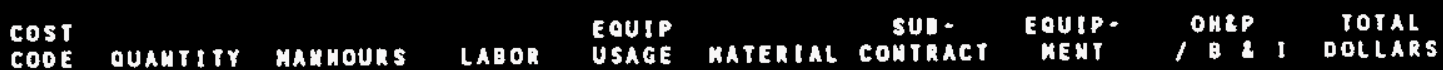
TAx Description

000
000
000
460
501
600
700

000

000

000

60

501

600

700

TOTAL WBS 511000 PROJECT MAMAGEKENT

0

6

1 LOT

I Lot

1 Lor

1201

(10)

$\begin{array}{ll}0 & 0 \\ 0 & 0 \\ 0 & 0 \\ 0 & 0 \\ 0 & 0 \\ 0 & 0 \\ 0 & 0\end{array}$

0
0
0
0
0
0
0

0
0
0
0
0
0

0

$\begin{array}{lll}0 & 0 & 0 \\ 0 & 0 & 0\end{array}$

0

$\begin{array}{rrrrr}0 & 0 & 0 & 0 & 0 \\ 0 & 1975000 & 0 & 0 & 1975000\end{array}$

$017000000 \quad 0 \quad 017000000$

D $6695000 \quad 0 \quad 06695000$

$09330000 \quad 0 \quad 09330000$ 
FLUOR DAHIEL INC. 108 10.436302

Account

MUнBe日

REPORT TOTAL

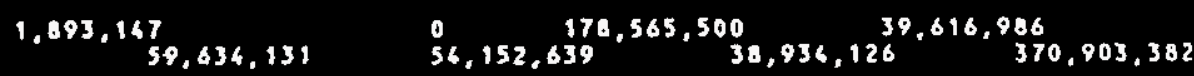

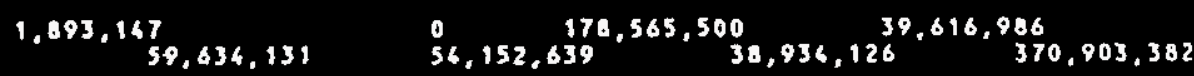

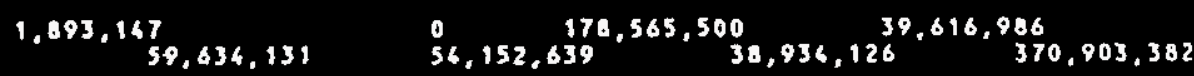

sus:

STract

PAGE 63
DATE O6/17/96 07:06:23
DY DFD/PCA/RLJ/AAF

TuRs-Facilitr configuration Evacuation DOE_ROB - Estimate detail or ues / cost code

EOUIP

cone ounutity haumouns tapos uster

EQuip: Onzp, Torat

MENT $I$ B I I DOLLARS 
WHC-SD-W378-ES-002

Revision 0

\section{APPENDIX G2}

\section{ALTERNATE CASE SUPPORT FACILITY CONFIGURATION COST BASIS}


WHC-SD-W378-ES-002

Revision 0

This page intentionally left blank. 
FLUOR DANIEL ING.

WESTINGHOUSE HANFORD COMPANY

JOB NO. 436303 WBS, 2001
$17-F a b-95$

INTECATTED VS DISTRIBUTED

SUPPORI FUNCTIONS
BY PCNAF

COMPAAISON-BASE GASE VERSUS STANDALONE

\begin{tabular}{|c|c|c|c|c|c|c|c|}
\hline FACHLTY/DUlLOUNG & $\begin{array}{l}\text { DIREGT COST } \\
\text { BASE CASE } \\
\text { (E } M\end{array}$ & 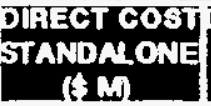 & $\begin{array}{l}\text { HAECT COST } \\
\text { DELTA } \\
\text { (E } M)\end{array}$ & $\begin{array}{l}\text { ENG } \\
\text { PM/CM(B) } \\
(t, M)\end{array}$ & 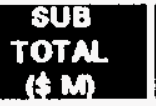 & $\begin{array}{c}\operatorname{coTh} \\
\operatorname{ToT}{ }_{(1)}(t)\end{array}$ & $\begin{array}{c}\text { POTAL COST } \\
\text { DELTA } \\
(1) M\end{array}$ \\
\hline 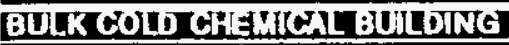 & $11,82.0$ & $17,051.3$ & $6,000.8$ & 3.05 .7 & 9.914 .5 & 3905.0 & $13,860.3$ \\
\hline BULK HANDUNG AREA & $10,381.0$ & $12,320.0$ & 1.848 .0 & $1,206.2$ & $3,214.2$ & $1,205.7$ & 4.499 .9 \\
\hline MECHATICAL UTUTIES DLDC & $15,005.0$ & 24.609 .0 & $9,526.0$ & $6,191.9$ & $15,717.9$ & 6.267 .2 & $22,005.1$ \\
\hline ANALITLA FACIVTY & $\pi, 710.0$ & $82,193.0$ & $4,474.0$ & $2,806.1$ & $7,302,1$ & $2,952.8$ & $10,334.9$ \\
\hline COOLNG TOWEA & $5,531.0$ & 6.549 .0 & $1,163.0$ & 759.2 & 1.927.2 & 770.9 & $2,698.1$ \\
\hline & & & & & & & \\
\hline & & & & & & & \\
\hline \multicolumn{8}{|l|}{ SOUD WASTE HANDLING } \\
\hline \multicolumn{8}{|l|}{ DEDICATED } \\
\hline LLW - $10 T$ DLFCW & 9,768.0 & & & & & & \\
\hline \multicolumn{8}{|l|}{ HLW - I0TOS Sh } \\
\hline \multirow{2}{*}{\multicolumn{8}{|c|}{ SUB-TOTh-DEDKAIEO }} \\
\hline & & & & & & & \\
\hline \multicolumn{8}{|l|}{ CENThAUZaD STA FACIWT } \\
\hline \multirow{2}{*}{\multicolumn{8}{|c|}{ SUB-TOTh SWHFAcIUI? }} \\
\hline & & & & & & & \\
\hline & & & & & & & \\
\hline & & & & & & & \\
\hline & & & & & & & \\
\hline & & & & & & & \\
\hline & & & & & & & \\
\hline & & & & & & & \\
\hline & & & & & & & \\
\hline & & & & & & & \\
\hline TOTAL & 134.984 .0 & $174,035.8$ & 39.051 .0 & $25,303.7$ & 64.455 .5 & 25.774 .2 & $90,209.7$ \\
\hline
\end{tabular}

NOTES:

1) PRICES NAE EXPRESSED iN 1994 DOLLARS

2) ESCNLATION TO PFOJEGT CENTROIDS IS EXCLUDED

5)BASE CASE MECH/JTL BLDG. EXCLUDES OXYGEN PLANT.

3) ALLOWANGES FOR ENCRPMCM ARE:

G)BASE CASE SWTTCHGEAR BLDG. EXCLUDES GENERATOR

A EMEACENGY SWTCHGEAR \& EMERGENGY TRANSFORMEAS.

ENGINEERING $40 \%$ OF DIRECT COST

CONSTRUCTION MANAGEMENT(CM) O 10\% OF DIAECT COST

PROJECT MANACEMENT (PM) Q10\% OF DIRECT COST + ENG + CM

4)CONTINGENCY $940 \%$ 
$x$ or 0 AONBSNINOOL

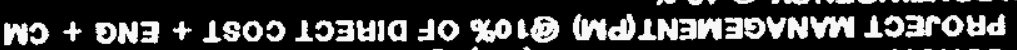

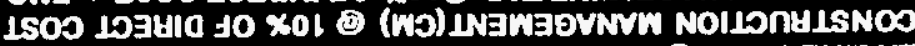

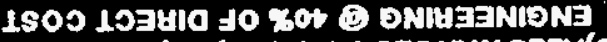

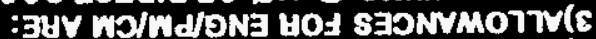

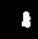

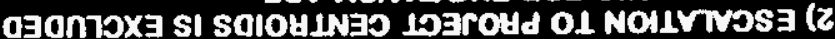

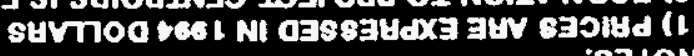

\begin{tabular}{|c|c|c|c|c|c|c|c|}
\hline EZIGIEE & CLL66 & S76L'0Q8 & Lस्द्ध 86 & PISER & 005350 & DEas & T101 \\
\hline & & & & & & & \\
\hline & & & & & & & \\
\hline & & & & & & & \\
\hline & & & & & & & \\
\hline & & & & & & & \\
\hline & & & & & & & \\
\hline & & & & & & & \\
\hline & & & & & & & \\
\hline & & & & & & & \\
\hline & & & & & & & \\
\hline & & & & & & & \\
\hline & & & & & & & \\
\hline & & & & & & & \\
\hline & & & & & & & \\
\hline & & & & & & & \\
\hline EOAB GI & $\cos ^{3}$ & $6 \cos 01$ & GOEW & $006 \sin ^{2}$ & ELQ'? & 2LST & YEMOL DMIRoO2 \\
\hline 0998601 & TLER & Sris Gal & 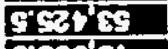 & 0 & $0 \operatorname{sen}$ & $0 \cos 28$ & 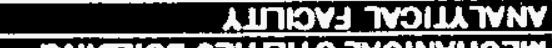 \\
\hline 9928's9 & Gitzor & 520901 & Gesges & $\operatorname{acos} 2$ & Oersint & agke ol & 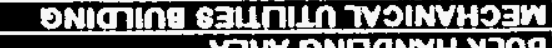 \\
\hline $008 y^{2} \mathrm{~g}$ & 12818 & 626502 & Ge100 & 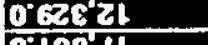 & 024500 & $\cos 2$ & 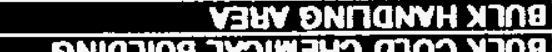 \\
\hline GigLE & 0.69211 & cosyes & $\operatorname{Cos} \pi$ & Bris: & arson & Gose? & 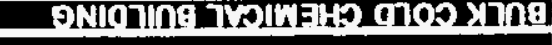 \\
\hline $\begin{array}{c}\text { Mis } \\
\text { N101 } \\
221\end{array}$ & $\begin{array}{c}(\pi) \\
(0) T 101 \\
1100\end{array}$ & $\begin{array}{c}03 \\
\text { w10 } 1 \\
\operatorname{ans}\end{array}$ & $\begin{array}{l}\text { (c)molind } \\
\text { MNB }\end{array}$ & $\begin{array}{c}0 \% \\
1500 \\
102 \pm 10010\end{array}$ & $\begin{array}{c}0 \\
1500 \\
102: 10 \mathrm{M}\end{array}$ & 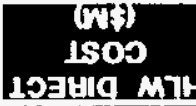 & owiouing/A.nibys \\
\hline
\end{tabular}

\section{Atywunn zxorrowyss}

\section{INTNDA:A8}

$96-98-4-21$
SNOILNA IHOdans

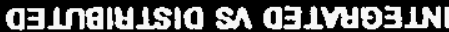

1002 'Sgm cocest 'ON 8or AMVAmos OyOaNYH asnohoNISEM - ont jainva yonzt 
x ot 0 ADNBONILNOS(t

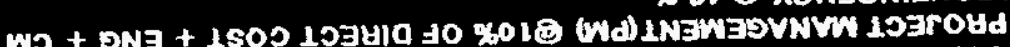

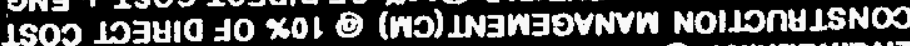

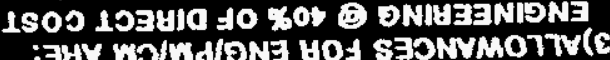

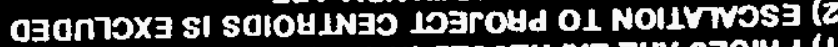

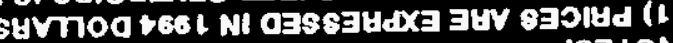

\begin{tabular}{|c|c|c|c|c|}
\hline $7665+81$ & $b^{\circ} \cot 0$ & 0.99083 & $2 \cos 28$ & $\boldsymbol{\theta}$ \\
\hline & & & & \\
\hline & & & & \\
\hline & & & & \\
\hline & & & & \\
\hline & & & & \\
\hline & & & & \\
\hline & & & & \\
\hline & & & & \\
\hline & & & & \\
\hline & & & & \\
\hline & & & & \\
\hline & & & & \\
\hline & & & & \\
\hline & & & & \\
\hline & & & & \\
\hline & & & & \\
\hline 9029' & $2000^{\circ} \mathrm{L}$ & roosz & $1+201$ & a \\
\hline 632099 & LoOS & 66919 & 61128 & 0 \\
\hline $9 \angle 9 L^{\circ} \times 6$ & 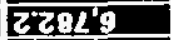 & 029691 & $869^{\circ} 9$ & $\overline{0}$ \\
\hline $194 t^{2}$ & 1942 & cons & '8091' & 9 \\
\hline $6^{\circ}+569$ & sites & [OLIC! & GOLLV & \\
\hline $\begin{array}{c}\text { To } \\
W 101 \\
0 \text { E1 }\end{array}$ & $\begin{array}{l}\text { (1) } 14101 \\
1 \times 00\end{array}$ & $\begin{array}{l}\text { Tis } \\
\text { wiol } \\
\text { ans }\end{array}$ & $\begin{array}{l}\text { (a) } \\
\text { lonelid }\end{array}$ & \\
\hline
\end{tabular}

\section{9}

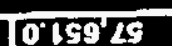

DSOL2

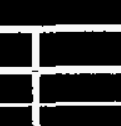

TIOL SEILN

JWNod :Aa

$96-98 y-21$ 
FLUOA DANIEL INC.

WESTINGHOUSE HANFOAD COMPANY

JOB NO. 496303 WBS, 2001

INTEGRATED VS DISTAIBUTED

SUPPOFI FUNGTIONS

LLW(PT) ALTEPNATE GASE STANDALONE

\begin{tabular}{|c|c|c|c|c|c|c|c|}
\hline 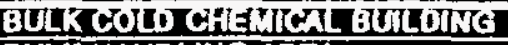 & 1,755 & 22982 & $10,482.0$ & G.819.0 & $17,317.0$ & 6.924 .7 & $24,236.5$ \\
\hline MBCANUIGAL UTIUIIBS BLOA & 2981 & 20154 & $14,3 \times 50$ & $9,316.5$ & E649.5 & $9,459.8$ & $33,100.2$ \\
\hline ANAFTICAL FACUIY & 3,070 & 16,170 & $4,945.0$ & $20,214.3$ & $74,159.3$ & $20,603.7$ & $103,023.0$ \\
\hline COOLING TOWE & NA & WA & $4,973.0$ & 3,2325 & $0,205.5$ & 3,2022 & $11,487.6$ \\
\hline & & & & & & & \\
\hline & & & & & & & \\
\hline & & & & & & & \\
\hline & & & & & & & \\
\hline & & & & & & & \\
\hline & & & & & & & \\
\hline & & & & & & & \\
\hline & & & & & & & \\
\hline & & & & & & & \\
\hline & & & & & & & \\
\hline & & & & & & & \\
\hline TOTAL & $14,276.0$ & 64.836 .0 & $85,290.0$ & $55,438.5$ & 140.728 .5 & $56,291.4$ & $197,019.9$ \\
\hline
\end{tabular}

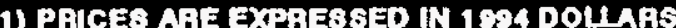

2) ESCNATION TO PROJSGT CENTAOIDS IS EXCLUDED

3) ALLOWANCES FOA ENGPMNCM ARE:

ENEINEEAIMC $O 40 \%$ OF DIAECT COST

CONSTRUGION MANACEMENT(CM) 10 10\% OF DIREGT COST

PAOJECT MANAGEMENT (PM O10\% OF DIRECT COST + ENG + CN

4)CONTINGENGY \& $40 \%$ 
WHC-SD-W378-ES-002

Revision 0

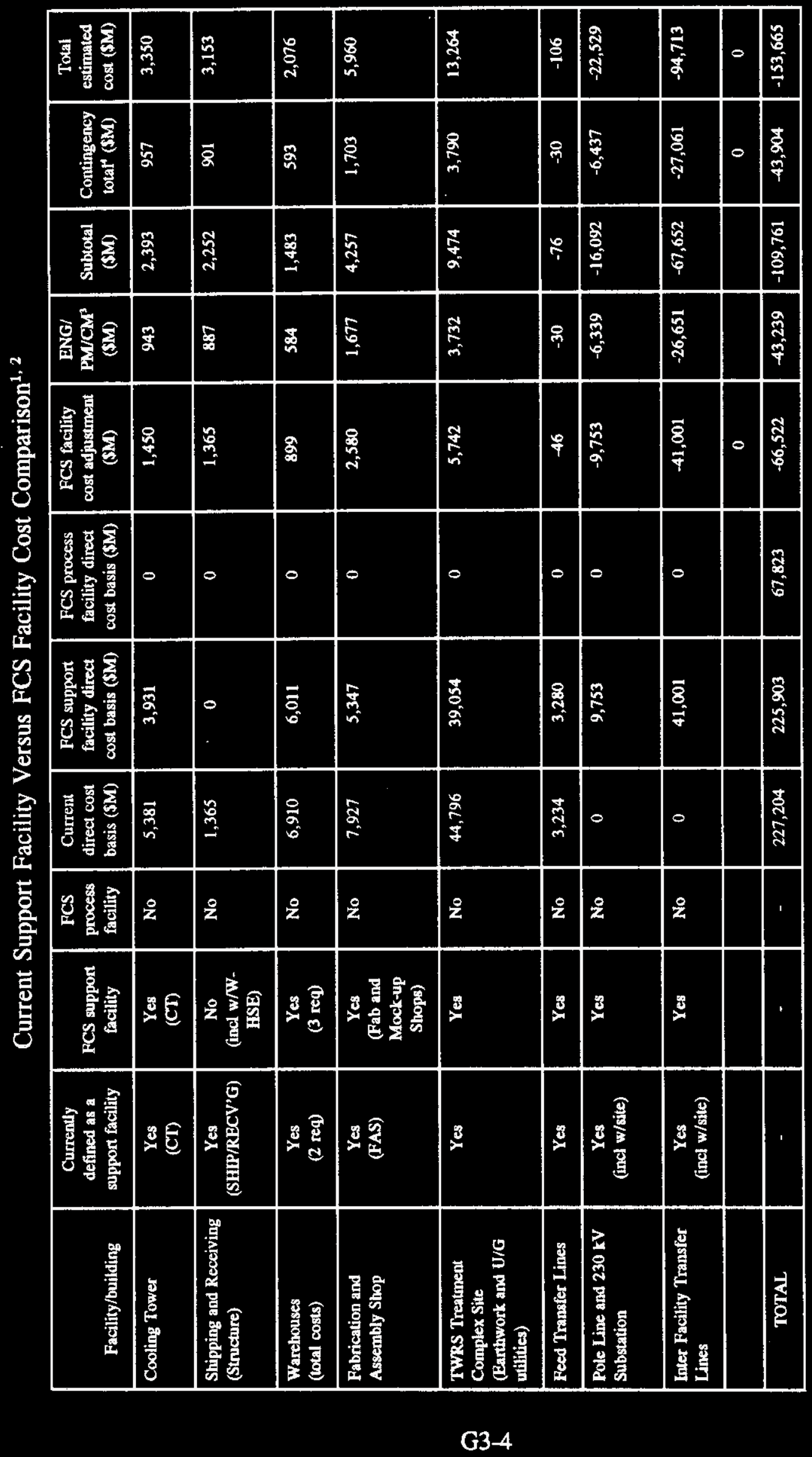


Current Support Facility Versus FCS Facility Cost Comparison ${ }^{1,2}$

\begin{tabular}{|c|c|c|c|c|c|c|c|c|c|c|c|}
\hline Facility/building & $\begin{array}{l}\text { Currently } \\
\text { defined as a } \\
\text { support facility }\end{array}$ & $\begin{array}{l}\text { FCS support } \\
\text { facility }\end{array}$ & $\begin{array}{l}\text { FCS } \\
\text { process } \\
\text { facility }\end{array}$ & $\begin{array}{c}\text { Current } \\
\text { direct cost } \\
\text { basis }(\$ M)\end{array}$ & $\begin{array}{c}\text { FCS support } \\
\text { facility direct } \\
\text { cost basis ( } \$ M)\end{array}$ & $\begin{array}{c}\text { FCS process } \\
\text { facility direct } \\
\text { cost basis ( }(\mathbf{M})\end{array}$ & $\begin{array}{c}\text { FCS facility } \\
\text { cost adjustment } \\
\text { (SM) }\end{array}$ & $\begin{array}{c}\text { ENG/ } \\
\text { PM/CM }^{3} \\
(\mathbf{S M})\end{array}$ & $\begin{array}{c}\text { Subtotal } \\
\text { (\$M) }\end{array}$ & $\begin{array}{l}\text { Contingency } \\
\text { total" (\$M) }\end{array}$ & $\begin{array}{c}\text { Total } \\
\text { estimated } \\
\text { cost }(\mathbf{S M})\end{array}$ \\
\hline
\end{tabular}

$\begin{array}{ll}\text { Case 3B FCS TEC Cost Adjustment (\$M) } & =-66,221 \\ \text { Case 4C FCS TEC Cost Adjustment (\$M) } & =-90,450 \\ \text { Support Facility FCS TEC Cost Adjustment }(\$ M) & =3,006 \\ \text { Total FCS TEC Cost Adjustment }(\$ M) & =-153,665\end{array}$

FCS $=$ Tank Waste Remediation System Facility Configureation Study (Boomer et al. 1994)

HLW = High-level waste

LLW = Low-level waste

TEC = Total estimated cost

TWRS = Tank Waste Remediation System

'Prices are expressed in 1994 dollars.

${ }^{2}$ Escalation to project centroids is excluded.

${ }^{3}$ Allowances for eng $/ \mathrm{pm} / \mathrm{cm}$ are: Engineering at 40 percent of Direct Cost, Construction Management(cm) at 10 percent of Direct Cost, Project Management(pm) at 10 percent of Direct Cost + Eng + CM.

${ }^{4}$ Contingency at $\mathbf{4 0}$ percent.

${ }^{5}$ Costs for buildings include costs for HVAC and other costs associated with the structure.

${ }^{6}$ Site cost includes clearing and grubbing, grading, two miles of roads, security fence, misc. unit substations, $230 \mathrm{kV}$ line, Substation/Switchgear area, area lighting, a sewer lift station, U/G fire water, raw water, sewer, steam and condensate, process water, compressed air, U/G electrical power and communication systems, railroad track, final site grading, walkways and landscaping.

${ }^{7}$ BCCB also includes Chemical Supply System, glass former preparation.

${ }^{8}$ Water Pumphouse also includes fire and bulk water storage tanks, diesel tanks and pumps.

${ }^{9}$ Bulk Handling Area also includes the 130 T/D oxygen plant. 
WHC-SD-W378-ES-002

Revision 0

2001 Analysis

2001 versus FCS

\begin{tabular}{|l|c|c|c|c|c|}
\hline & 2001 & FCS & $\begin{array}{c}2001 \\
(\$ M)\end{array}$ & $\begin{array}{c}\text { FCS } \\
(\$ M)\end{array}$ & $\begin{array}{c}\Delta \\
(\$ M)\end{array}$ \\
\hline BCCB & Yes & Yes & 11,823 & 9,331 & 2,492 \\
\hline BHA & Yes & W/BCCB & 10,831 & W/BCCB & 10,831 \\
\hline S-T & & & 22,204 & 9,331 & 12,873 \\
\hline OSB & Yes & Yes & 9,982 & 6,618 & 3,364 \\
\hline REC & Yes & Yes (REB) & 11,145 & 8,533 & 2,612 \\
\hline ERC & Yes & $\begin{array}{c}\text { No (in } \\
\text { OCB) }\end{array}$ & 6,269 & W/OCB & 6,269 \\
\hline OCB & No & Yes & 0 & 3,035 & $<3,03$ \\
\hline S-T & & & 17,414 & 11,568 & 5,846 \\
\hline MUB & Yes & Yes & 15,083 & 9,376 & 5,707 \\
\hline FAAS & Yes & $\begin{array}{c}\text { Yes } \\
\text { (Fab and } \\
\text { Mock) }\end{array}$ & 7,927 & 5,347 & 2,580 \\
\hline WHSS & Yes & Yes & 6,910 & 6,011 & 899 \\
\hline S\&R & Yes & W/WHSS & 1,365 & 0 & 1,365 \\
\hline $\begin{array}{l}\text { S-T } \\
\text { DFC }\end{array}$ & & 8,275 & 6,011 & 2,264 \\
\hline & & & & \\
\hline
\end{tabular}


WHC-SD-W378-ES-002

Revision 0

2001 Analysis

2001 versus FCS

Sheet 2

\begin{tabular}{|l|c|c|c|c|c|}
\hline & 2001 & FCS & $\begin{array}{c}2001 \\
(\$ M)\end{array}$ & $\begin{array}{c}\text { FCS } \\
(\$ \mathrm{M})\end{array}$ & $\begin{array}{c}\Delta \\
(\$ \mathrm{M})\end{array}$ \\
\hline SGB & Yes & Yes & 9,370 & 38,083 & $<28,713\rangle$ \\
\hline CT & Yes & Yes & 5,381 & 3,931 & 1,450 \\
\hline PH & Yes & No & 5,819 & 0 & 5,819 \\
\hline EGB & Yes & No & 28,114 & 0 & 28,114 \\
\hline AF & Yes & No & 77,719 & 0 & 77,719 \\
\hline VREB & No & Yes & 0 & 42,550 & $<42,550\rangle$ \\
\hline S-T & & & 77,719 & 42,550 & 35,169 \\
\hline Total & & & 207,288 & 132,815 & 74,473 \\
\hline Transf Lines & No & Yes & 0 & 3,280 & $<3,280>$ \\
\hline Power Lines & No & Yes & 0 & 9,753 & $<9,753>$ \\
\hline Shared Utilities & No & Yes & 0 & 41,001 & $<41,001\rangle$ \\
\hline Site & Yes & Yes & 44,796 & 39,054 & 5,742 \\
\hline Total DFC & & & 252,084 & 225,903 & 26,181 \\
\hline
\end{tabular}


2001 Analysis

2001 versus FCS

\begin{tabular}{|c|c|c|c|}
\hline & 2001 & Cost & $\Delta$ \\
\hline 1) Equip & 130,694 & 40,881 & 89,813 \\
\hline $\begin{array}{l}\text { 2) Construction } \\
\text { a) Common } \\
\text { b) Added } \\
\text { c) Deleted }\end{array}$ & $\begin{array}{l}44,744(32,600 \text { SF }) \\
31,850(149,300 \text { SF }) \\
--\end{array}$ & $\begin{array}{l}62,890(632,000 \mathrm{SF}) \\
83,078(146,100 \mathrm{SF})\end{array}$ & $\begin{array}{c}\langle 18,146\rangle \\
31,850 \\
<83,078>\end{array}$ \\
\hline 3) Site & $\begin{array}{c}76,594(470,900 \mathrm{SF}) \\
163 \$ / \mathrm{SF} \\
44,796\end{array}$ & $\begin{array}{c}145,968(778,100 \mathrm{SF}) \\
188 \$ \mathrm{SF} \\
39,054\end{array}$ & $\begin{array}{c}<69,374> \\
5,742\end{array}$ \\
\hline Total & 252,084 & 225,903 & 26,181 \\
\hline
\end{tabular}




\section{WHC-SD-W378-ES-002}

Revision 0

2-8-95

Sheet 2

1) Equipment 89,813

a) Analytical Facilites $\quad 59,401$

b) EGB 21,905

81,306

$$
81,300 / 89,813=91 \%
$$

2) Structures

From $778,100 \mathrm{SF}$ to $470,900 \mathrm{SF}$

$(470,900 / 778,100) \times 145,968=88,340$

88,340 vs $76,594 \quad 87 \%$

3) Site

5,742

Addition of Unit substations, etc. 
WHC-SD-W378-ES-002

Revision 0

This page intentionally left blank.

G3-10 
WHC-SD-W378-ES-002

Revision 0

\section{APPENDIX H1}

SEPARATIONS/LOW-LEVEL WASTE ANALYTICAL FUNCTION STUDY 


\section{WHC-SD-W378-ES-002}

Revision 0

This page intentionally left blank. 
WHC-SD-W378-ES-002

Revision 0

CONTENTS

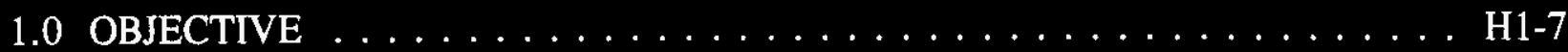

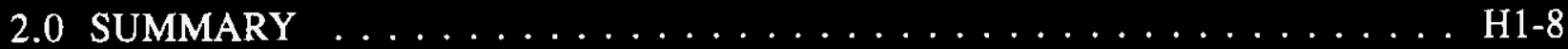

3.0 TECHNICAL FINDINGS AND CONCLUSIONS $\ldots \ldots \ldots \ldots \ldots \ldots$ H1-8

4.0 INITIAL ESTIMATES OF ANALYTICAL REQUIREMENTS $\ldots \ldots \ldots \ldots$. . . H1-9

5.0 DISCUSSION OF ALTERNATIVES $\ldots \ldots \ldots \ldots \ldots \ldots \ldots \ldots$. . . . . . . .

5.1 ASSUMPTIONS AND UNCERTAINTIES . . . . . . . . . . . . H1-11

5.2 SUMMARY OBSERVATIONS . . . . . . . . . . . H1-14

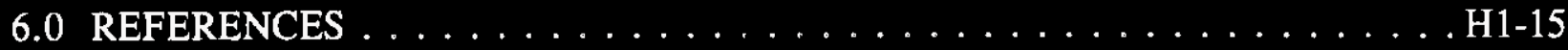

\section{LIST OF TABLES}

H1-1A. Process Liquid and Process Solid Sampling Frequency

Separations Function. . . . . . . . . . . . . . . . . . . . . . . H1-16

H1-2A. Location of Analyses Serparations Function $\ldots \ldots \ldots \ldots \ldots$. . . . H1-17

H1-3A. Average Process Sampling Frequency Separations Function . . . . . . . H1-18

H1-4A. Time Per Week for Analytical Cell Sample Analysis Separations Function. . . . . . . . . . . . . . . . . . H1-19

H1-5A. Analytical Cell Time Required for Sample Preparation for Analytical Laboratory Analysis Separations Function. . . . . . . . . . . . . . H1-20

H1-6A. Analytical Cell Sample Analysis and Preparation Time Separations Function . . . . . . . . . . . . . . . . . H1-21

H1-7A. Analytical Cell Availability. . . . . . . . . . . . . . H1-22 


\section{WHC-SD-W378-ES-002 \\ Revision 0 \\ LIST OF TABLES (continued)}

H1-8A. Simplified Time and Motion Study of Analytical Cell Requirements

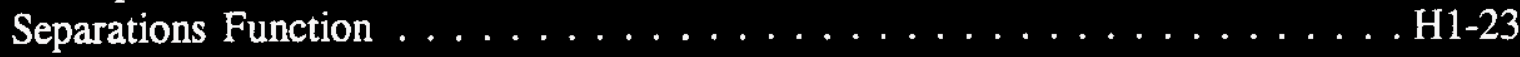

H1-9A. Simplified Time and Motion Study - Analytical Laboratory Separations Function . . . . . . . . . . . . . . . . . . H1-24

H1-10A. Equipment Requirements/Assessment Separations Function $\ldots \ldots \ldots$ H1-25

H1-11A. Analytical Laboratory Equipment Requirements Separations

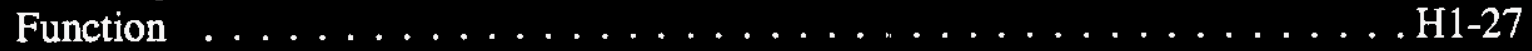

H1-12A. Additional Analytical Equipment Consideration Separations

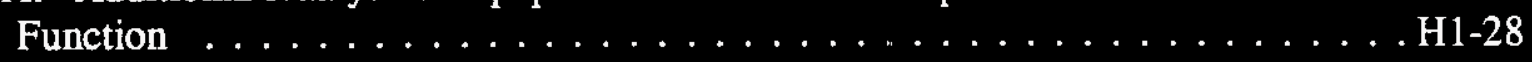

H1-13A. Analytical Facility Estimated Space Requirements . . . . . . . . . . H1-29

H1-1B. Process Gas, Liquid and Solid Sampling Frequency Low-Level Waste

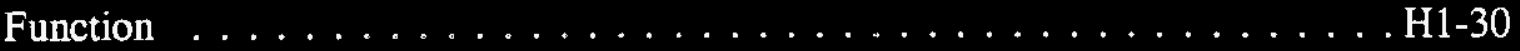

H1-2B. Location of Analyses Low-Level Waste Function . . . . . . . . . . . H1-32

H1-3B. Average Process Sampling Frequency Low-Level Waste Function . . . . . H H1-33

H1-4B. Time Per Week for Analytical Cell Sample Analyses Low-Level Waste

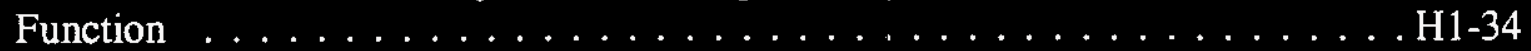

H1-5B. Analytical Cell Time Required for Sample Preparation Analytical Laboratory Analysis Low-Level Waste Function . . . . . . . . . . . . . . . H1-35

H1-6B. Analytical Cell Sample Analysis and Preparation Time Low-Level Waste

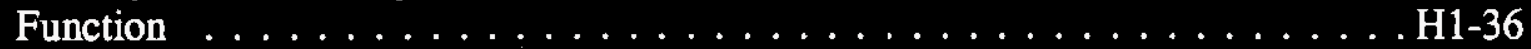

H1-7B. Analytical Cell Availability. . . . . . . . . . . . . . . . H1-37

H1-8B. Simplified Time and Motion Study of Analytical Cell Requirements Low-Level Waste Function . . . . . . . . . . . . . . . . . H1-38

H1-9B. Simplified Time and Motion Study - Analytical Laboratory Low-Level Waste Function . . . . . . . . . . . . . . . . . . . . H1-39 


\section{WHC-SD-W378-ES-002 \\ Revision 0}

\section{LIST OF TABLES (continued)}

H1-10B. Equipment Requirements/Assessment Low-Level Waste Function . . . . . H H1-40

H1-11B. Analytical Laboratory/Instrument Room Equipment Requirements Low-Level Waste Function . . . . . . . . . . . . . . . . . . . . H1-42

H1-12B. Additional Analytical Equipment Consideration Low-Level Waste Function $\ldots \ldots \ldots \ldots \ldots \ldots \ldots \ldots \ldots \ldots \ldots \ldots \ldots \ldots \ldots$

H1-13B. Analytical Facility Estimated Space Requirements $\ldots \ldots \ldots \ldots \ldots$ H1-44.

H1-14B. Hood Requirements for Analytical Facility Rooms Low-Level Waste

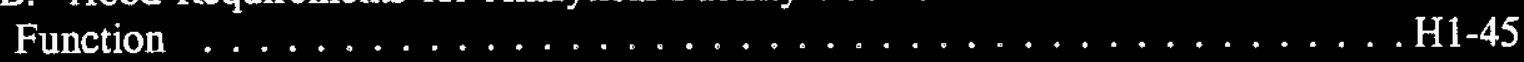




\section{WHC-SD-W378-ES-002}

Revision 0

This page intentionally left blank.

H1-6 
WHC-SD-W378-ES-002

Revision 0

APPENDEX H1

SEPARATIONS/LOW-LEVEL WASTE

ANALYTICAL FUNCTION STUDY

\subsection{OBJECTIVE}

This appendix presents a simplified time and motion study of the analytical capabilities associated with the Separations/low-level waste (LLW) combined analytical function. The analytical requirements, developed in this appendix, are used to develop the requirements for analytical cells, analytical laboratories, and other associated rooms. For the purpose of this appendix, the following definitions are used:

Analytical Cells. This term refers to the areas where undiluted, high radiological activity samples are remotely handled. Sample preparation, dilution, and limited sample analysis occurs in analytical cells.

Analytical Laboratories. This term refers to the areas where diluted and/or low radiological activity samples are analyzed. Analyzers within the laboratories are located in hoods to contain radioactivity.

Other Associated Rooms. This term refers to the miscellaneous support areas that are outside of the analytical cells and analytical laboratories. These rooms include service rooms, receiving rooms, counting rooms, equipment and stock rooms, waste handling areas, and analytical instrument rooms.

This appendix identifies the critical sample analyses required to support the process, such as process control and waste form qualification. Supplemental analyses, such as offgas and environmental samples, are also addressed. Limited on-line sample analyses assumed to occur within the process facility are identified. Potential analytical needs associated with incoming waste safety issues, such as criticality, have not been considered here.

This appendix has profitted substantially from the design of the Hanford Waste Vitrification Plant (HWVP) analytical function. As such, it incorporates lessons learned at the Defense Waste Process Facilities (DWPF). 
WHC-SD-W378-ES-002

Revision 0

\subsection{SUMMARY}

This appendix develops the technical requirements for the Separations/LLW analytical function. The initial step is to establish a sample schedule to support process control and waste form qualification. For purposes of developing the analytical laboratory requirements, the schedule also includes offgas and environmental samples.

A simplified time and motion study is then performed to develop the requirements for the analytical cells and analytical laboratories. Major equipment and instrumentation items are identified and major plant utilities and service interfaces are established. Initial analytical cell and analytical laboratory arrangements are developed to support Analytical Facility (AF) layouts.

The requirements are developed separately for the Separations and LLW function in this appendix and then summed. Appendix $\mathrm{H} 2$ develops the requirements for the high-level waste (HLW) function. This approach highlights the requirements attributable to each function and the potential areas of consolidation. Some consolidation is expected even though the appendixes do not evaluate the impact of consolidation. The AF layouts are based on the assumption that a 20 percent reduction in the analytical laboratories can be achieved by combining the Separations, LLW, and HLW analytical functions. Additional study is required to validate this assumption.

\subsection{TECHNICAL FINDINGS AND CONCLUSIONS}

The simplified time and motion study for the analytical cells indicates that six analytical cells are required for the Separations/LLW combined function. The time and motion study is based on 70 percent staff availability, 100 percent Total Operating Efficiency (TOE) in the process facility, and product glass sampling to confirm product quality. The staff availability is based on operator breaks, meetings, scheduled training, etc. The analytical requirements do not rely on slack time caused by operating inefficiencies in the process facility. Further evaluation of the bases may indicate that more or less analytical cells are required.

The simplified time and motion study also indicates that three analytical laboratories are required to support the Separations/LLW combined analytical function. The study includes an assessment of the equipment requirements, the space requirements for each piece of equipment, and the resulting total analytical laboratory space requirements. Redundant spare equipment and instruments are included in the analytical laboratory requirements. Further evaluation should confirm the redundancy requirements and also the analytical laboratory space requirements. 
WHC-SD-W378-ES-002

Revision 0

Product qualification, rather than process qualification, is the assumed method of LLW waste form qualification. Statistically significant sampling of the LLW product glass cullet is required to ensure product quality. This appendix assumes that a method of frequently sampling glass cullet can be developed. Further study is required to confirm this assumption.

\subsection{INITIAL ESTIMATES OF ANALYTICAL REQUIREMENTS}

The results of this appendix are presented in a series of tables as discussed below. Separate series of tables are provided for the (a) Separations and (b) LLW functions. Unless otherwise stated, the table numbers refer to both Separations and LLW tables.

- Samples that require processing through the analytical cells and analytical laboratory are identified in Table H1-1. Sample frequency (occasions), sample purpose and analysis required are also given in Table H1-1.

- Table H1-2 define the analyses that are performed in an analytical cell and those that are analyzed in an analytical laboratory. For those functions that are combined in the combined Separations/LLW facility, the samples and analyses are shown on the Table H1-1B associated with LLW. Initial estimates of process gas samples and other waste/wastewater and environmental samples are also included. These values could change greatly depending on future requirements for additional sample analyses.

- The daily analytical requirements for analyses performed in an analytical cell are identified in Table H1-3. The requirements for each type of analysis are totaled, and the total analytical demand is also indicated.

- Table H1-4 summarizes the time requirements for analyses performed in the analytical cells. Total analysis requirements from Table H1-3 are multiplied by the time required for each analysis and the total time is indicated.

- Table H1-5 defines the analyses that occur in the analytical laboratories, but that require the sample preparation time in the analytical cells. The total analytical cell sample preparation time required is indicated.

- Table H1-6 provides the total analytical cell time requirements. The requirements include the analyses performed in the analytical cells and the sample preparation time for those performed in the analytical laboratories. Additional requirements for sample reruns and standards and estimated sample load-out times as well as credit for parallel testing are also included. 


\section{WHC-SD-W378-ES-002 \\ Revision 0}

- Analytical cell availability is calculated in Table H1-7. The availability is based on an assumed staff availability of 70 percent, manipulator downtime, cleanup time and equipment availability. Analytical cell availability at 100 percent staff availability is also indicated.

- In Table H1-8 the number of analytical cells is determined by dividing the total time required by the available time per analytical cell. The base case evaluation is based on 70 percent staff availability and 100 percent process facility TOE. Table H1-8 also provides a sensitivty analysis of staff availabilty and TOE.

- Table H1-9 provides estimates of the time requirements for analyses performed in the analytical laboratory.

- Table H1-10 provides initial estimates of sample turnaround time requirements and equipment reliability. This table will assist in developing duplicate and spare equipment needs.

- Table H1-11 provides approximate space requirements and plant utility interfaces required to support the analytical laboratory equipment.

- Table H1-12 lists additional equipment requirements for safe and efficient operation of the AF. These items do not directly impact the initial AF layouts or cost, however, they must be considered so that space can be allocated and supporting services can be planned.

- Table H1-13 presents the estimated space requirements for the various working areas of the Analytical facility. The space requirements of the Separations function are given in the column headed "SEP." The space requirements for the Separations and LLW are summed and are given in the column headed "SEP+LLW." The HLW space requirements, that are provided in Appendix $\mathrm{H} 2$, is indicated, and the requirements for the three functions are summed. These cells, rooms and laboratories are included in the layout of a combined Separations/LLW/HLW AF. The facility AF layout is based on the assumption that a 20 percent reduction in the analytical laboratories can be achieved by combining the Separations, LLW, and HLW analytical functions.

- Table H1-14B, provided for LLW only, provides an estimate of the number of analytical laboratory hoods required to support the LLW function. The estimated 18 hoods are located in several laboratories. 
WHC-SD-W378-ES-002

Revision 0

\subsection{DISCUSSION OF ALTERNATIVES}

\subsection{ASSUMPTIONS AND UNCERTAINTIES}

This section identifies the assumptions made for this appendix. A brief discussion of each is given to illustrate the importance and uncertainties of each assumption.

- The sample schedule is based on the process flow diagrams (PFDs) for the combined Separations/LLW facility and the detached HLW facility from the Facility Configuration Study, (Boomer et al. 1994). The PFDs are used to identify sample locations, frequencies of sample collection, and the types of analyses required. The sample schedule is designed to support process diagnosis, control and history and waste form qualification. Emphasis is placed on the use of on-line analyzers and Inductively Coupled Plasma-Mass Spectrometer (ICP-MS) analysis to reduce the load on analytical cells and laboratories. Laser ablation is assumed to prepare ICP-MS samples, where appropriate. In addition, no process time and motion analysis has been performed on the process itself. Any changes in the number of sample locations and particularly in the frequencies of sampling and type of analyses could impact the analytical cell and laboratory needs.

- Product glass waste form qualification is based on sampling the product glass cullet and recycling any offspec glass produced (i.e., product qualification, rather than process qualification). Providing statistically significant sampling and analysis of the product glass results in a large number of glass cullet samples. Changes to the waste form qualification method or the number of samples required to provide statistically significant analysis impacts the number of analytical cells required.

- This appendix assumes that the AF receives samples around the clock, rather than simultaneously. The analytical cell requirements include no allowances for concurrant analysis and/or sample preparation of all of the samples.

- Analytical cell operations are to be fully supported by the analytical laboratory. Although no complete time and motion study in the main laboratory is available, it is assumed this laboratory is self sufficient and that adequate laboratory capacity is available so as not to limit analytical cell throughput.

- The number of analytical hot cells and associated facilities is based on the liquid, slurry, and solid (cullet) samples. The layouts for the analytical laboratory and other contact areas are based on both the samples from the hot cells and additional contact-handled samples. The contact-handled samples 
include process gas samples and environmental samples. Layouts for the Bulk Cold Chemical Building include space for cold chemical testing.

- AF waste handling (both liquid and solid) is extremely important. Personnel, equipment, and facilities must be provided to sort, combine, absorb, package and stage waste for transfer to a treatment, storage or disposal facility. Space must be provided for load-out from the analytical cells and other laboratory and counting room areas.

- Analytical facilities outside the TWRS complex are assumed to be not available. As a result, enough overlap and redundancy must be built into the laboratory design so that analytical results are available to support plant operations. It is also assumed that the AF is not required to support other Hanford Site operations.

- Table H1-1 identifies the samples that must be processed through the analytical cells. Any additional samples not included in Table H1-1 would increase analytical cell requirements. Samples which may be borderline for analytical cell processing due to radioactivity are included in Table H1-1 to be conservative.

- Several properties are assumed to be inferred from the ICP-MS analysis, thereby reducing the number of samples and analyses required. In particular, the rates of disintegration and emitted energies of radionuclides may be inferred from the measured isotopic composition. Also, the crystallinity, density, and PCT properties of the product glass are assumed to be inferred from the measured composition and the glass phase diagram. Correlation of the glass compositon with the phase diagram is assumed to occur in nonradioactive laboratories outside the AF.

- Analytical cell analysis requirements are identified in Table H1-2. Determination of the sample solids content and rheology and sample preparation (including dissolutions and separations) are assumed to be performed in the analytical cells. Elemental and anion analyses as well as radionuclide counting are assumed to be performed in the analytical laboratory, rather than analytical cell.

- Analyses and sample preparation time requirements are as identified in Table H1-4 and Table H1-5. Some are estimates but most are based on Hanford and other analytical laboratory experience.

- Staff availability is assumed to be 70 percent for the base case. This figure is derived from Hanford experience of chemical technologist availability of 5.5 hours per 8 hour shift. This operator availability is based on operator breaks, 


\section{WHC-SD-W378-ES-002 \\ Revision 0}

meetings, scheduled training, etc. A sensitivity study examines the 100 percent staff availability case (Table $\mathrm{H} 1-8$ )

- Manipulator availability is assumed to be 93 percent, that is the same as the Hanford experience with the CRL Model F MSM. Although manipulator availability could be improved with the System 50 manipulator, that is expected to be used in the AF, the availability is not now known. When a manipulator fails, a replacement is assumed to be ready for installation. The AF layouts include a manipulator repair/replacement system to support manipulator failure and recycle.

- A 6 percent downtime is assumed for dedicated cell cleanup. This is based on experience where 30 minutes per eight hour shift is used for cleaning. Maintaining a "clean-cell" policy has been found to be extremely effective in maintaining continuity of operations.

- A 10 percent downtime is assumed for equipment failure. For equipment or procedures requiring newly developed equipment this assumption may need to be increased.

- Additional time for standards (10 percent) and reruns (5 percent) is assumed. Additional quality control related analyses (blanks, duplicates, spikes) may be necessary due to equipment requirements and/or environmental protocols.

- Sample load-outs into rabbit containers from the analytical cells is assumed to require five minutes each. This assumes that multiple load-out techniques are possible.

- The size of the analytical laboratory is based on the space requirements for individual equipment and instruments. The analytical laboratory requirements benefit from detailed layouts that was developed during HWVP. However, additional study is required to validate this assumption.

- The requirements are developed separately for the Separations and LLW function in this appendix and then summed. Appendix $\mathrm{H} 2$ develops the requirements for the HLW function. Some consolidation is expected even though the appendices do not evaluate the impact of consolidation. The facility AF layouts are based on the assumption that a 20 percent reduction in the analytical laboratories can be achieved by combining the Separations, LLW, and HLW analytical functions. Additional study is required to validate this assumption. 
WHC-SD-W378-ES-002

Revision 0

\subsection{SUMMARY OBSERVATIONS}

Some specific observations on the number of analytical cells required and the needs of the analytical laboratory are presented below.

Tables H1-1 through H1-3 indicate that a wide variety of analytical analyses are required. The largest sample demands involve the analyses of the final waste form, glass cullet ( 24 of the 51.7 LLW samples taken per day). The product qualification method of ensuring glass quality. requires sampling and analysis of a statistically significant portion of the glass product. In consideration of the reduced residence time in the combustion melter, it is initially assumed that the glass product should be sampled at least once every 2 hours for each melter train.

The baseline analytical cell availability is determined to be 55 percent (Table H1-7). This includes 7 percent downtime for manipulators, 6 percent downtime dedicated to cell clean-up and 10 percent downtime for equipment failures. The major variable is the 70 percent work force availability factor; at 100 percent work force availability, the cell availability increases to 79 percent. By addressing this staffing issue, the analytical cell requirements could be reduced (Table H1-8).

Table H1-8 indicates that six analytical cells are sufficient for the Separations/LLW combined function, particularly if the staff availablity can be increased or the process facility TOE can be considered.

Tables H1-9 through H1-11 provide initial estimates of the number of samples, approximate size/space and plant utility interfaces required to support the Analytical Laboratory equipment for the Separations-LLW combined function. Equipment requirements will need to be revised as additional (or new) measurement methods are identified and developed. Analyses and analytical methods, and therefore equipment, will also be a function of the required detection levels and turnaround times.

Table H1-12 lists some additional items that need to be considered since these contribute to the safe and efficient operation of the analytical facility. An additional item of importance to be considered is the waste handling operations for both solids and liquids. Facilities and personnel need to be provided to sort, combine, absorb, package and stage wastes from the analytical cells, the analytical laboratories and counting rooms for transfer to a treatment, storage or disposal facility. 
WHC-SD-W378-ES-002

Revision 0

The design with respect to waste handling, particularly solids and organic liquid handling, is discussed only to a level that shows allocation of space and interfaces between waste handling and other AF activities. There are many details to waste handling that have yet to be investigated, which may have significant impacts on the layout of laboratory operating areas. An additional effort will be needed to determine further details of design to fully accommodate the waste handling tasks, e.g. special handling of hazardous and radioactive mixed wastes.

\subsection{REFERENCES}

Boomer, K. D., J. M. Colby, T. W. Crawford, J. S. Garfield, J. D. Galbraith, C. E. Golberg, C. E. Leach, D. E. Mitchell, F. D. Nankani, E. J. Slaathaug, L. M. Swanson, T. L. Waldo, C. M. Winkler, June 1994, Tank Waste Remediation System Facility Configuration Study WHC-SD-WM-ES-295, Rev. 0, Westinghouse Hanford Company, Richland, Washington. 


\section{WHC-SD-W378-ES-002}

Revision 0

Table H1-1A. Process Liquid and Process Solid Sampling frequency Separations Function. (Low Cs DF Made of Operation)

\begin{tabular}{|c|c|c|c|c|c|}
\hline \multicolumn{2}{|r|}{ Sanple Point } & $\begin{array}{l}\text { Grab Sample } \\
\text { Frequency }\end{array}$ & $\begin{array}{c}\text { Samples/ } \\
\text { Day }\end{array}$ & $\begin{array}{l}\text { Sample } \\
\text { Purpose }\end{array}$ & Analyses Required \\
\hline 1. & $\begin{array}{l}\text { Receipt/Sample } \\
\text { Tanks (TK-131A, B, } \\
\text { C, D, E \& F) }\end{array}$ & $\begin{array}{l}\text { Once every } 10 \\
\text { days/tank }\end{array}$ & $\begin{array}{l}2 \text { (worst } \\
\text { case in } \\
\text { one day) }\end{array}$ & $\begin{array}{l}\text { PC (Verify } \\
\text { Tank Farm } \\
\text { Analyses) } \\
\end{array}$ & $\begin{array}{l}\text { SpG, TDS, TSS, PH and/or acid } \\
\text { denand, Elenents and Radionuclides } \\
\text { (ICP-MS) }\end{array}$ \\
\hline 2. & $\begin{array}{l}\text { Evaporator Feed } \\
\text { Tank (TK-135) }\end{array}$ & $\begin{array}{l}\text { Not required on } \\
\text { rout ine bas is }\end{array}$ & $\cdots$ & & \\
\hline 3. & $\begin{array}{l}\text { Process Condensate } \\
\text { from Condenser } \\
(\mathrm{EC}-140)\end{array}$ & Not applicable & $\cdots$ & PD & $\begin{array}{l}\text { Cont inuous on- } t \text { ine analysis for } \\
\text { radioactivity }\end{array}$ \\
\hline 4. & $\begin{array}{l}\text { Concentrated } \\
\text { Supernatant Catch } \\
\text { Tank }(T K-141) \\
\end{array}$ & $\begin{array}{l}\text { Not required on } \\
\text { rout ine basis }\end{array}$ & - & & \\
\hline 5. & $\begin{array}{l}\text { Concentrated } \\
\text { Supernatant Sample } \\
\text { Tank (TK-143) }\end{array}$ & $\begin{array}{l}\text { One sample every } \\
24 \text { hours }\end{array}$ & 1 & PC & $\begin{array}{l}\text { SpG, Elements and Radionuclides } \\
\text { (ICP-MS), pH and/or acid denand, } \\
\text { anions }\end{array}$ \\
\hline & $\begin{array}{l}\text { Transfer Tank (TK- } \\
\text { 146) }\end{array}$ & $\begin{array}{l}\text { One sample every } \\
24 \text { hours }\end{array}$ & 1 & PC & $\begin{array}{l}\text { PH and/or acid demand and anion } \\
\left(\mathrm{NO}_{3}^{-}, \mathrm{NO}_{2}^{-}\right)\end{array}$ \\
\hline 7. & $\begin{array}{l}\text { Cs Ion Exchange } \\
\text { Feed Adjust Tank } \\
\text { (TK-136) }\end{array}$ & $\begin{array}{l}\text { One sample every } \\
24 \text { hours }\end{array}$ & 1 & $\mathrm{PC}$ & $\begin{array}{l}\mathrm{PH} \text { and/or acid denand, cations (Na'), } \\
\text { and certain anions (free } \mathrm{OH}^{-} \text {) }\end{array}$ \\
\hline & $\begin{array}{l}\text { Cs IX Feed Tank } \\
(\mathrm{TK}-200)\end{array}$ & $\begin{array}{l}\text { Not required on } \\
\text { rout ine bas is }\end{array}$ & -- & & \\
\hline & $\begin{array}{l}\text { Filter Bed Catch } \\
\text { Tank (TK-203) }\end{array}$ & $\begin{array}{l}\text { Sample once per } \\
\text { operating cycle; } \\
\text { 1/week }\end{array}$ & $\cdots$ & PH & $\begin{array}{l}\text { pH and/or acid denand, TSS, TDS, } \\
\text { El ements and Radionucl ides (ICP-MS) }\end{array}$ \\
\hline 10. & $\begin{array}{l}\text { Cs IX Acid Regen } \\
\text { Feed Tank (TK-206) }\end{array}$ & Not appl icable & $\cdots$ & PD & $\begin{array}{l}\text { Continuous on-line analysis for } \\
\text { radioactivity }\end{array}$ \\
\hline 11. & $\begin{array}{l}\text { Acid Recycle Tank } \\
(\mathrm{Tx}-210)\end{array}$ & $\begin{array}{l}\text { One sample every } \\
24 \text { hours }\end{array}$ & 1 & PC & PH, cations (ICP-MS), anions \\
\hline & $\begin{array}{l}\text { Cs IX Caustic } \\
\text { Regen Feed Tank } \\
(\text { TK-214) }\end{array}$ & $\begin{array}{l}\text { Not required on } \\
\text { rout ine basis }\end{array}$ & $\cdots$ & & (cold tank) \\
\hline 13. & $\begin{array}{l}\text { Cs IX Colums } \\
\text { Loading/Regenerati } \\
\text { on }\end{array}$ & Not appl icable & -- & PC & $\begin{array}{l}\text { Cont inuous on- } l \text { ine analyses of } \\
\text { treated effluent strean (Cs-137/ } \\
\text { Ba-137) }\end{array}$ \\
\hline 14. & $\begin{array}{l}\text { Sol id } \\
\text { Product/Spent } \\
\text { Resins }\end{array}$ & $\begin{array}{l}\text { One sample per } \\
\text { week }\end{array}$ & - & PH & Elements and Radionucl ides (ICP-MS) \\
\hline & $\begin{array}{l}\text { Cs IX Eltuant Catch } \\
\text { Tank (TK-1531) }\end{array}$ & $\begin{array}{l}\text { Not required on } \\
\text { routine bas is }\end{array}$ & - & & \\
\hline 16. & $\begin{array}{l}\text { Cs IX } \\
\text { Concentration } \\
\text { Catch Tank } \\
\end{array}$ & $\begin{array}{l}\text { One sauple every } \\
24 \text { hours }\end{array}$ & 1 & PC & $\begin{array}{l}\text { pH and/or acid demand, TSS, TOS, } \\
\left.\text { anions ( } \mathrm{NO}_{3}^{-}, \mathrm{NO}_{2}^{-}\right) \text {, El enents and } \\
\text { Radionuclides (ICP-MS) }\end{array}$ \\
\hline 17. & $\begin{array}{l}\text { Cs IX Haste Tank } \\
(T K-1502)\end{array}$ & $\begin{array}{l}\text { Not required on } \\
\text { rout ine basis }\end{array}$ & - & & \\
\hline 18. & $\begin{array}{l}\text { Cs IX Waste Sample } \\
\text { Tank (TK-1504) }\end{array}$ & $\begin{array}{l}\text { One sample every } \\
24 \text { hours }\end{array}$ & 1 & PC & $\begin{array}{l}\text { pH and/or acid demand, TSS, TDS, } \\
\text { Elements and Radionucl ides (ICP-MS) }\end{array}$ \\
\hline & & TOTAL & 8 & & \\
\hline
\end{tabular}

Notes: PC=Process ControlTDS=Total Dissolved Solids PD=Process DiagnosticTSS=Total Suspended Sol ids $\mathrm{PH}=\mathrm{Process} \mathrm{H}$ istoryICP-MS=Induct ively Coupled Plasma-Mass Spectroneter SpG=Specific GravitypH=Acid Content or Denand

" Assumes two tanks are analyzed in one day when fresh feed is introduced in the plant. 
WHC-SD-W378-ES-002

Revision 0

Table H1-2A. Location of Analyses

Serparations Function

ANALYTICAL CELL

(Undiluted samples)

pH

SpG

Solids-work: TSD, TDS, TSS

Elements and Radionuclides: ICP-MS closely coupled to the Analytical Cells allowing processing of undiluted or slightly diluted $(1: 10)$ samples

Anions: Sample preparation

Dilution

PCT (Product Consistency Test)

Crystallinity/Density
ANALYTICAL LABORATORY

(Diluted/low level and cold samples)

$$
\begin{aligned}
& \text { OTR } \\
& \text { pH } \\
& \text { SpG }
\end{aligned}
$$

Solids-work: TSD, TDS, TSS

Anions: HPLC, Dionex

Elements:

ICP-MS

ICP-AES

AAS

Spectrophotometer

Fluorometer

Radionuclide Separations

(prior to radionuclide analyses):

Extractions

Precipitations

HPLC

Ion Exchange

Radionuclide Analysis:

IPC-MS

Total Alpha

AEA

Total Beta

GEA

Beta Sci

Titrations

Gas Chromatography 


\begin{tabular}{|c|c|c|c|c|c|c|c|c|c|c|c|}
\hline \multirow{12}{*}{ 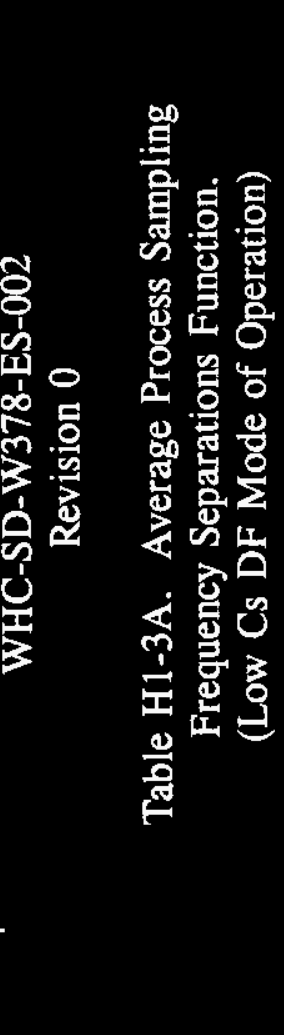 } & LIZ & IE & $t$ & $s$ & $\varepsilon$ & $\varepsilon$ & $\tau$ & $t$ & $\mathbf{0 t}$ & - & STVLOL \\
\hline & $\mathfrak{S E}$ & $s$ & & I & I & $\mathrm{I}$ & I & $\mathrm{I}$ & & 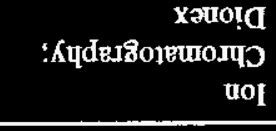 & suopury \\
\hline & $6 t$ & $L$ & I & I & I & I & & I & 2 & SW-dDI & $\begin{array}{l}\text { sep!̣onuolpey } \\
\text { pue suarura }\end{array}$ \\
\hline & & & & & & & & & & 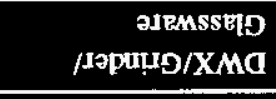 & LOd \\
\hline & & & & & & & & & & วभนघีย & Kỵsued \\
\hline & & & & & & & & & & uonperytp kry-X & 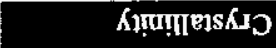 \\
\hline & 82 & $t$ & I & $t$ & & & & & $z$ & 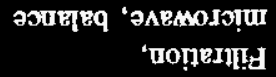 & $\begin{array}{r}\text { sp!Ios pepriadsnS } \\
\text { [1]OL SSL }\end{array}$ \\
\hline & 82 & $t$ & I & I & & & & & $\tau$ & 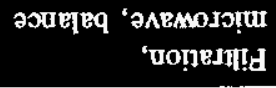 & $\begin{array}{r}\text { sptios panjossta } \\
\text { IBOL SAL }\end{array}$ \\
\hline & & & & & & & & & & 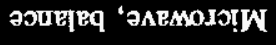 & (p!्य) GSL \\
\hline & IZ & $\varepsilon$ & & & & & & I & $z$ & 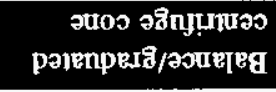 & ods \\
\hline & 9S & 8 & I & I & I & I & I & I & $\tau$ & әродрәәР 'Јәэәи $\mathbf{H}^{\mathrm{d}}$ & $\mathbf{H}^{\mathrm{d}}$ \\
\hline & $\begin{array}{l}\text { XәәM/ } \\
\text { S[в]оL }\end{array}$ & $\begin{array}{l}\text { Red/ } \\
\text { steloL }\end{array}$ & 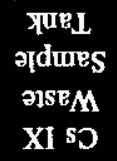 & 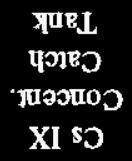 & 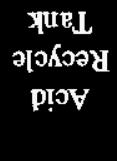 & 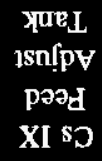 & 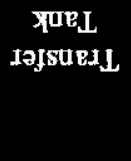 & 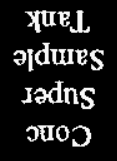 & 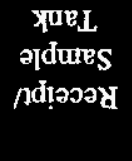 & $\begin{array}{l}\text { uondụssad } \\
\text { marudụnba }\end{array}$ & 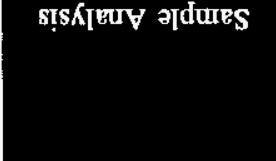 \\
\hline
\end{tabular}


WHC-SD-W378-ES-002

Revision 0

Table H1-4A. Time Per Week for Analytical Cell

Sample Analysis Separations Function.

(Low Cs DF Mode of Operation)

\begin{tabular}{|l|c|c|c|}
\hline \multicolumn{1}{|c|}{ Type of Analysis } & $\begin{array}{c}\text { Number of } \\
\text { Determinations } \\
\text { Per Week }\end{array}$ & $\begin{array}{c}\text { Time/Analysis } \\
\text { (Hours) }\end{array}$ & $\begin{array}{c}\text { Total Analysis } \\
\text { Time } \\
\text { (Hours/Week) }\end{array}$ \\
\hline pH & 56 & 0.5 & 28 \\
\hline SpG & 21 & 0.5 & 10.5 \\
\hline TSD (Dried) & & 1.0 & \\
\hline TDS & 28 & 1.12 & 31.4 \\
\hline TSS & 28 & 1.12 & 31.4 \\
\hline Crystallinity & & & \\
\hline PCT & & & \\
\hline & 133 & & 101.3 \\
\hline \multicolumn{1}{r|}{ TOTALS } & & & \\
\hline
\end{tabular}


WHC-SD-W378-ES-002

Revision 0

Table H1-5A. Analytical Cell Time Required for Sample Preparation for Analytical Laboratory Analysis Separations Function.

(Low Cs DF Mode of Operation)

\begin{tabular}{|l|c|c|c|}
\hline \multicolumn{1}{|c|}{ Type of Analysis } & $\begin{array}{c}\text { Number of } \\
\text { Analyses Per } \\
\text { Week }\end{array}$ & $\begin{array}{c}\text { Analytical Cell } \\
\text { Preparation } \\
\text { Time } \\
\text { (Hours) }\end{array}$ & $\begin{array}{c}\text { Total } \\
\text { Preparation } \\
\text { Time } \\
\text { (Hours/Week) }\end{array}$ \\
\hline $\begin{array}{l}\text { Elements and } \\
\text { Radionuclides }\end{array}$ & 49 & 0.3 & 14.7 \\
\hline Anions & 35 & 1.5 & 52.5 \\
\hline Mixing (Homogenize) & & & \\
\hline Splits & & & \\
\hline Dissolutions & & & \\
\hline Dilutions & & & \\
\hline Separations & & & 67.2 \\
\hline \multicolumn{1}{|c|}{ TOTALS } & 84 & & \\
\hline
\end{tabular}


WHC-SD-W378-ES-002

Revision 0

Table H1-6A. Analytical Cell Sample Analysis and Preparation Time Separations Function.

(Low Cs DF Mode of Operation)

\begin{tabular}{|c|c|c|}
\hline & Factor & Hours Per Week \\
\hline Analysis Time & Table Value & 101.3 \\
Add time for reruns & $5 \%$ & 5.1 \\
Add time for standards & $10 \%$ & 10.1 \\
& Subtotal & 116.5 \\
\hline
\end{tabular}

Sample Preparation Time

Add time for reruns

Add time for standards

Add time for sample load-out

\begin{tabular}{|c|r|}
\hline Table Value & 67.2 \\
$5 \%$ & 3.4 \\
$10 \%$ & 6.7 \\
5 min./sample & 2.9 \\
Subtotal & 80.2 \\
\hline
\end{tabular}

\begin{tabular}{|l|l|c|}
\hline Total Analysis and Preparation Time & & 196.7 \\
\hline Credit for Parallel Tests & Less 9\% & 17.7 \\
\hline
\end{tabular}


Table H1-7A. Analytical Cell Availability.

\begin{tabular}{|c|c|c|}
\hline & Factor & Hours/Week \\
\hline Hours available per week per cell & $7 \times 24$ & 168.0 \\
\hline Workforce available (percent) & 70 & 117.6 \\
\hline Manipulators available (percent) & 93 & 109.4 \\
\hline Not devoted to cleanup (percent) & 94 & 102.8 \\
\hline Equipment available (percent) & 90 & 92.5 \\
\hline
\end{tabular}

Note: $92.5 / 168(100)=55$ percent availability

\begin{tabular}{|c|c|c|}
\hline & Factor & Hours/Week \\
\hline Hours available per week per cell & 7 X 24 & 168 \\
\hline Workforce available (percent) & 100 & 168 \\
\hline Manipulator available (percent) & 93 & 156.2 \\
\hline Not devoted to cleanup (percent) & 94 & 146.9 \\
\hline Equipment available (percent) & 90 & 132.2 \\
\hline
\end{tabular}

Note: $132.2 / 168(100)=79$ percent availability 
WHC-SD-W378-ES-002

Revision 0

Table H1-8A. Simplified Time and Motion Study of Analytical Cell Requirements Separations Function.

(Low Cs DF Mode of Operation)

\begin{tabular}{|c|c|c|c|c|}
\hline 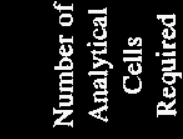 & $\frac{\hbar}{\Rightarrow}$ & $\stackrel{\leftrightarrow}{\stackrel{n}{\sim}}$ & $\stackrel{n}{\stackrel{m}{-}}$ & 台 \\
\hline 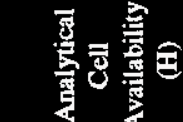 & $\stackrel{)}{\alpha}$ & $\tilde{\dot{m}}$ & $\tilde{\alpha}$ & $\begin{array}{l}\stackrel{\sim}{\mathcal{N}} \\
\underline{\underline{N}}\end{array}$ \\
\hline 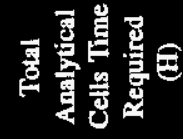 & \begin{tabular}{l}
0 \\
$\vdots$ \\
\hdashline
\end{tabular} & I̊ & $\underset{\stackrel{m}{M}}{\stackrel{m}{a}}$ & $\underset{m}{m}$ \\
\hline 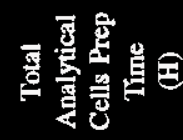 & 今ั & $\stackrel{\widetilde{H}}{\text { ஸे }}$ & $\overline{\dot{n}}$ & $\bar{\circ}$ \\
\hline 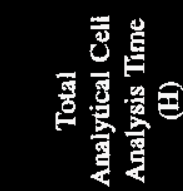 & $\begin{array}{l}\text { nf } \\
\stackrel{0}{\circ}\end{array}$ & $\begin{array}{l}\stackrel{n}{n} \\
\stackrel{0}{0}\end{array}$ & 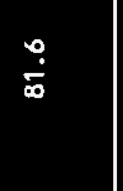 & $\stackrel{\circ}{\frac{1}{\infty}}$ \\
\hline 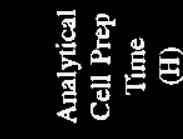 & กิ & $\stackrel{\widetilde{1}}{\tilde{6}}$ & $\stackrel{0}{\hat{f}}$ & $\stackrel{?}{\mathrm{j}}$ \\
\hline 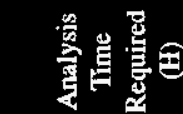 & $\frac{m}{\circ}$ & $\stackrel{m}{\underline{c}}$ & $\stackrel{a}{\dot{c}}$ & $\stackrel{a}{i}$ \\
\hline 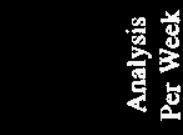 & $\hat{\sim}$ & $\hat{N}$ & $\check{2}$ & $\tilde{Z}$ \\
\hline of & 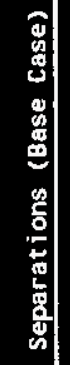 & 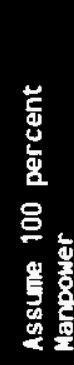 & 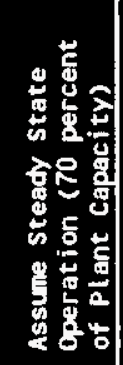 & 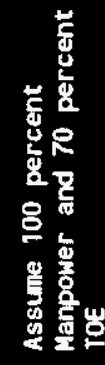 \\
\hline
\end{tabular}


WHC-SD-W378-ES-002

Revision 0

Table H1-9A. Simplified Time and Motion Study -

Analytical Laboratory Separations Function.

(Low Cs DF Mode of Operation)

\begin{tabular}{|c|c|c|c|c|}
\hline Type of Analyses & $\begin{array}{l}\text { Samples from } \\
\text { Analytical } \\
\text { Cells Per } \\
\text { Week }\end{array}$ & $\begin{array}{l}\text { Process Gas Samples, } \\
\text { Other } \\
\text { Waste/Wastewater and } \\
\text { Environmental Samples }\end{array}$ & Hours/Analysis & $\begin{array}{l}\text { Total } \\
\text { Hours Per } \\
\text { Week }\end{array}$ \\
\hline OTR & 35 & 10 & 0.1 & 4.5 \\
\hline pH & & 15 & 0.25 & 3.8 \\
\hline SpG & & 20 & 0.25 & 5.0 \\
\hline $\begin{array}{l}\text { Visual: } \\
\text { Color } \\
\text { Percent Settled Solids } \\
\text { Percent Centrifuged } \\
\text { Solid } \\
\end{array}$ & & $\begin{array}{l}10 \\
10\end{array}$ & $\begin{array}{l}0.1 \\
1.0\end{array}$ & $\begin{array}{r}1.0 \\
10.0\end{array}$ \\
\hline TSD (Dried) & & 15 & 1.0 & 15 \\
\hline TSC (Calcined) & & & 1.25 & \\
\hline TDS & & & 1.12 & \\
\hline TSS & & & 1.12 & \\
\hline TOC/Total Carbon & & & 2.0 & \\
\hline \multicolumn{5}{|l|}{ Control Elements } \\
\hline Elements and Radionuclides & & 10 & 0.1 & 1.0 \\
\hline \multicolumn{5}{|l|}{ Isotopes } \\
\hline Anions & 35 & 15 & 0.5 & 25 \\
\hline GEA & & 10 & 0.5 & 5 \\
\hline Total Alpha & & 35 & 0.5 & 17.5 \\
\hline $\mathrm{AEA}$ & & & 0.5 & \\
\hline Total Beta & & 35 & 0.5 & 17.5 \\
\hline Beta Sci & & & 0.5 & \\
\hline Soluble Cs-137 & & & 0.5 & \\
\hline Soluble Sr-90 & & & 0.5 & \\
\hline$G C$ & & 5 & 1.0 & 5 \\
\hline Titrations & & 18 & 0.5 & 9 \\
\hline \multicolumn{2}{|c|}{$\begin{array}{l}\text { SUBTOTAL } \\
\text { Add time for reruns ( } 5 \text { percent) } \\
\text { Add time for standards (10 percent) }\end{array}$} & & & $\begin{array}{r}119.3 \\
6.0 \\
11.9 \\
\end{array}$ \\
\hline TOTAL & 70 & 208 & & 137.2 \\
\hline
\end{tabular}




\section{WHC-SD-W378-ES-002 \\ Revision 0}

Table H1-10A. Equipment Requirements/Assessment

Separations Function.

(Low Cs DF Mode of Operation)

\begin{tabular}{|c|c|c|c|c|c|c|}
\hline Analysis & $\begin{array}{l}\text { Freq } \\
\text { (\# Determin } \\
\text { Analytical } \\
\text { Cell } \\
\end{array}$ & $\begin{array}{l}\text { tioncy } \\
\text { Analytical } \\
\text { Laboratory }\end{array}$ & $\begin{array}{l}\text { Turnaround } \\
\text { Time } \\
\text { Required } \\
\text { (Hours) } \\
\end{array}$ & $\begin{array}{l}\text { Equipment } \\
\text { Description }\end{array}$ & $\begin{array}{l}\text { Estimated } \\
\text { On-Line } \\
\text { Time } \\
(\%)\end{array}$ & $\begin{array}{c}\text { Spare } \\
\text { Needed }\end{array}$ \\
\hline OTR & & 45 & 4 & $\begin{array}{l}\text { Fixed Detector } \\
\text { (Shielded) }\end{array}$ & $100 \%$ & Yes \\
\hline $\mathrm{pH}$ & 56 & 15 & 4 & $\begin{array}{l}\text { pH Meter, } \\
\text { Electrode }\end{array}$ & 100 & $\begin{array}{c}\text { Yes } \\
\text { (meter, } \\
\text { electrode) }\end{array}$ \\
\hline SpG & 21 & 20 & 4 & $\begin{array}{l}\text { Balance/graduated } \\
\text { centrifuge cone }\end{array}$ & 90 & Yes \\
\hline $\begin{array}{c}\text { Visual: Color } \\
\text { \% Settled Solids } \\
\% \text { Centrified Solids }\end{array}$ & & $\begin{array}{l}10 \\
10\end{array}$ & $\begin{array}{l}4 \\
4\end{array}$ & $\begin{array}{c}\text { Boroscope } \\
\text { Glassware, Cone } \\
\text { Cone, Centrifuge }\end{array}$ & $\begin{array}{l}100 \\
100 \\
100\end{array}$ & $\begin{array}{l}\text { Yes } \\
\text { Yes } \\
\text { Yes }\end{array}$ \\
\hline TSD (Dried) & & 15 & 8 & $\begin{array}{l}\text { Microwave, } \\
\text { balance }\end{array}$ & 90 & Yes \\
\hline TSC (Calcined) & & & 8 & Furnace, balance & 90 & Yes \\
\hline TDS & 28 & & 8 & $\begin{array}{c}\text { Glassware, } \\
\text { microwave, } \\
\text { balance }\end{array}$ & 100 & Yes \\
\hline TSS & 28 & & 8 & $\begin{array}{c}\text { Glassware, } \\
\text { microwave, } \\
\text { balance }\end{array}$ & 100 & Yes \\
\hline $\begin{array}{l}\text { COD (Reducing } \\
\text { potential) }\end{array}$ & & & 8 & Autotitrator & 90 & Spare \\
\hline OH Equivalent & & & 4 & Autotitrator & 90 & Spare \\
\hline TOC/Total Carbon & & & 8 & TOC Analyzer & 70 & Yes \\
\hline Yield Stress/Viscosity & & & 4 & Viscometer & 90 & Yes \\
\hline $\mathrm{Fe}^{2+} / \mathrm{Fe}^{3+}$ & & & 8 & $\begin{array}{c}\text { Furnace, } \\
\text { UV-Visual } \\
\text { Spectrophotometer }\end{array}$ & 90 & No \\
\hline Crystallinity & & & (8 days) & X-Ray Diffraction & 90 & No \\
\hline PCT & & & (8 days) & $\begin{array}{c}\text { DWX/Grinder/ } \\
\text { Glassware }\end{array}$ & 100 & Yes \\
\hline $\begin{array}{l}\text { Elements and } \\
\text { Radionuclides }\end{array}$ & 49 & 10 & 8 & ICP-MS & 85 & \\
\hline Anions & & 50 & 8 & $\begin{array}{c}\text { Ion } \\
\begin{array}{c}\text { Chromatography } \\
\text { (Dionex) }\end{array} \\
\end{array}$ & 80 & Column \\
\hline GEA & & 10 & 24 & $\begin{array}{l}\text { Gamma } \\
\text { Scintillation } \\
\text { (HPGE) }\end{array}$ & 100 & Detector \\
\hline
\end{tabular}


WHC-SD-W378-ES-002

Revision 0

Table H1-10A. Equipment Requirements/Assessment

Separations Function. (Low Cs DF Mode of Operation)

(continued)

\begin{tabular}{|l|c|c|c|c|c|c|}
\hline \multicolumn{1}{|c|}{ Analysis } & \multicolumn{2}{|c|}{$\begin{array}{c}\text { Frequency } \\
\text { (\#) Determinations/Week) } \\
\text { Analytical } \\
\text { Cell }\end{array}$} & $\begin{array}{c}\text { Analytical } \\
\text { Laboratory }\end{array}$ & $\begin{array}{c}\text { Turnaround } \\
\text { Time } \\
\text { Required } \\
\text { (Hours) }\end{array}$ & $\begin{array}{c}\text { Estimated } \\
\text { On-Line } \\
\text { Time } \\
\text { Equipment } \\
\text { Description }\end{array}$ & $\begin{array}{c}\text { Spare } \\
\text { Needed }\end{array}$ \\
\hline Total Alpha & & 35 & 24 & $\begin{array}{c}\text { Alpha Proportional } \\
\text { Counter }\end{array}$ & 100 & \\
\hline AEA & & 35 & 24 & Beta Proportional & 100 & \\
\hline Total Beta & & & 24 & Beta Scintillation & 100 & \\
\hline Beta Sci & & & 8 & $\begin{array}{c}\text { Gamma } \\
\text { Scintillation } \\
\text { (HPGE) }\end{array}$ & 100 & Detector \\
\hline Soluble Cs-137 & & & 8 & Beta Proportional & 100 & \\
\hline Soluble Sr-90 & & 5 & 8 & $\begin{array}{c}\text { Gas } \\
\text { Chromatograph }\end{array}$ & 90 & Columns \\
\hline Gas Chromatograph & & 18 & 8 & Autotitrator & 90 & Spare \\
\hline Titrations & & & & & & \\
\hline
\end{tabular}


FLUOR DAUIEL INC.

YESTIMGHOUSE MAMFORD COMPAMY

Jo8 10.436303 Y85200
* IESt - threnactive estimating **

TURS-FACILITY COHF IGURATIOA EVALUATION DELTA COST ALTERHATE - LOH LEVEL UASTEIPT
PAGE
OATE $02 / 20 / 95 \quad 14: 16: 05$
BY JFD/PCA/AAF/CD

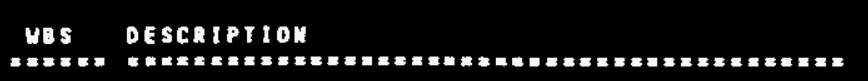

23A BULK COLO CHEM. BLDE. EO.

23E MECHANICAL UYTL BLDG. EQ.

23L COOLINE TOUER EOUIPMEMT

SUBTOTAL 23 MECMANICAL

SUBTOTAL 2 MECHANICAL

Q 33A CULK COLD CMEAICAL BUILOIMG

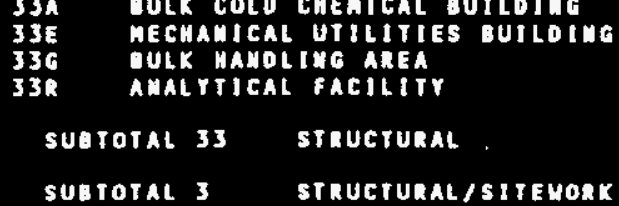

PROJECT TOTAL
OVERHEAO TOTAL

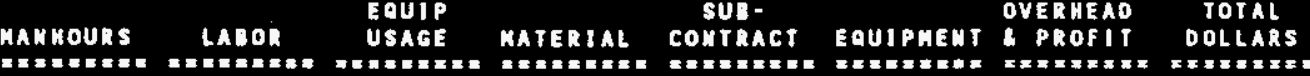

$\begin{array}{llllllll}0 & 0 & 0 & 0 & 0 & 2301623 & 115085 & 2416708 \\ 0 & 0 & 0 & 0 & 0 & 3576925 & 178846 & 3755771\end{array}$

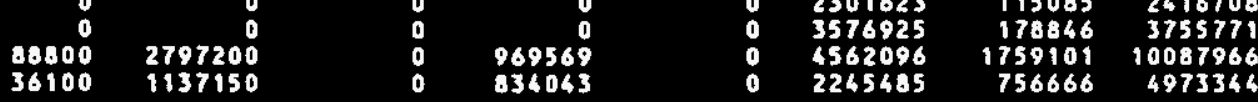
$\begin{array}{llllllll}124900 & 3936350 & 0 & 1803612 & 0 & 12686129 & 2809698 & 21233789\end{array}$ $\begin{array}{llllllll}124900 & 3934350 & 0 & 1803612 & 0 & 12686129 & 2809698 & 21233789\end{array}$

$\begin{array}{llllllll}93637 & 2943236 & 0 & 3253833 & 0 & 168225 & 1730016 & 8075308\end{array}$

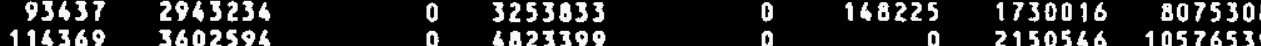

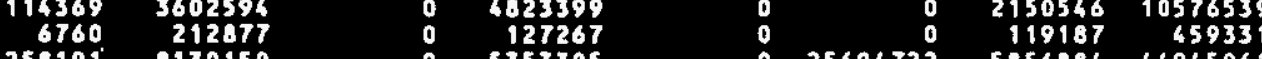

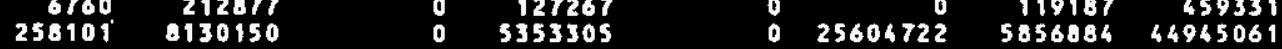

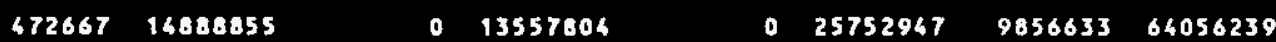
$472667 \quad 14888855$

$\begin{array}{lll}25752947 & 9856633 & 64056239 \\ 25752947 & 9856633 & 64056239\end{array}$
597,567

$18,823,205$
$15,361,416$
$0012,666,331$ 
FLUOR DANIEL INC.

WESTI HGHOUSE HAMFORD COMPANY
JOB NO. 436303 HBS200t
* iest - interactive estimating * *

TURS-FACILITY COUFIEURATION EVALUATION
PAGE OF

JFD
HBS DESCIPTION

$23 A 530$ LIOUID HASTE PROCESSIMG

Takeup

$23 A 550$ BULK COLD CMEMICAL YEMT SYSTEM

$23 A 580$ GLASS FORMER PREPARATIOI

$23 A 720$ COLD HANOLINE

SUBtotAl 23A GULK COLB CHEK. BLDG. EQ.

$23 E 320$ MORMAL ELECTRICAL DISTRIBUTION

DRESSEO AI

EXHAMGE

23E530 LIQUID VASTE PROCESSINO

SUBtotal 23 mecmanical UTIL. BLOG. EQ.

230540 CHEM RECEIPY, MAKE UP 2 DIST:

236500 FRIT RECEIPT \& MAKE UP

236590 (Descrlption not avellable)

$236 \times \times 0$ OULK HAMOLING AREA

SUBTotal 236 gULK MANDLIMG area EQUTP.

23 L320 MORMAL ELECTRICAL DISTRIBUTION

$23 L 440$ COOLING TOUER EOUIPAEUT

$23 L \times \times O$ ERECTIOK/OULK

$\begin{array}{ll}\text { SURTOTAL } 23 L & \text { COOLIMG TOMER EQUTPMENT } \\ \text { SUBTOTAL } 23 & \text { MECMAMICAL } \\ \text { SUBTOTAL } 2 & \text { MECMAMICAL }\end{array}$

SUBTOTAL 2 MECMAMICAL

$33 \wedge 010$ STRUCTURES

$33 A \times X O$ EQUIPHENT LABOR/BULXS

SUBtotal $33 A$ GULK COLD CHEMICAL BUILOING

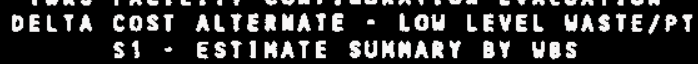

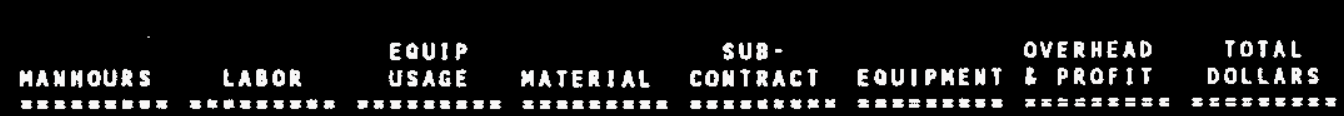
$\begin{array}{llllllll}0 & 0 & 0 & 0 & 0 & 435267 & 21763 & 457010 \\ 0 & 0 & 0 & 0 & 0 & 1340635 & 67035 & 1407670\end{array}$ $\begin{array}{rr}672164 & 23608 \\ 3650 & 695772\end{array}$ $\begin{array}{lrr}36652 & 1833 & 38485\end{array}$

$\begin{array}{llllllll}0 & 0 & 0 & 0 & 0 & 36652 & 1835 & \\ 0 & 0 & 0 & 0 & 0 & 2301623 & 115085 & 2416708\end{array}$

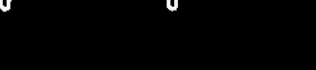

$\begin{array}{lll}0 & \\ 0 & 0 \\ 0 & 0 \\ 0 & 0\end{array}$

$$
\begin{aligned}
& 0 \\
& 0 \\
& 0 \\
& 0 \\
& 0 \\
& 0
\end{aligned}
$$

00

$\begin{array}{rr}0 & 0 \\ 0 & 0 \\ 0 & 88000\end{array}$$$
\begin{aligned}
& \mathbf{0} \\
& 0 \\
& 0 \\
& 0
\end{aligned}
$$

$88800 \quad 2797200$

$\begin{array}{rr}0 & 0 \\ 0 & 0 \\ 36100 & 1137150^{0}\end{array}$

$36100^{\circ} 1137150$

$124900 \quad 3934350$

$124900 \quad 3934350$

$\begin{array}{ll}36437 & 1086734 \\ 59000 & 1858500\end{array}$

$93437 \quad 2943236$
0
0
0
0
0

\section{0} 1190736

969569

\section{$\begin{array}{ll}0 & 0 \\ 0 & 0\end{array}$}

- 1803612

o 1803612

o 1315626

- 3253833
0.836043

$\begin{array}{rr}0 & 1142680 \\ 0 & 1170676 \\ 0 & 1070455 \\ 0 & 169398 \\ 0 & 23716 \\ 0 & 3576925\end{array}$

- 3576925

\section{$0 \quad 382690$} 3980670
1198736

4562096

$57134 \quad 1199814$

$58533 \quad 1229209$

$\begin{array}{ll}53523 & 1229209 \\ 8 & 1123978\end{array}$

$\begin{array}{rr}8470 & 1123978 \\ 1186 & 26902\end{array}$

$178846 \quad 3755771$

19135401825

$\begin{array}{rr}59937 & \$ 258673 \\ 1530995 & 5297764\end{array}$

\section{$\begin{array}{lll}1055362 & 52768 & 1108130\end{array}$}

- 2245485 $756666 \quad 4973344$

- $12686129 \quad 2809698 \quad 21233789$

$\begin{array}{llll}0 & 12686129 & 2809698 & 21233789 \\ 0 & 12686129 & 2809698 & 21233789\end{array}$

3196686

$\begin{array}{rrrr}0 & 148225 & 648101 & 3196686 \\ 0 & 1 & 1081915 & 4878622\end{array}$

$\begin{array}{llll}0 & 148225 \quad 1730016 \quad 8075308\end{array}$
$149034 \quad 3129704$

$1759101 \quad 10087966$

$1190123 \quad 59507 \quad 1249630$ 
FLUOR OANIEL IMC. WESTIMGHOUSE MAMFORD COMPAWY JOB NO. 436303 YBS2OOI
"* IEST - IMTERActive estimating "* TURS. FACILITY COMF I GURATION EVALUATIOH

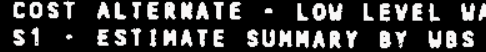

$\begin{array}{ll}\text { PAGE } & \text { OF } \\ \text { DATE } & 02 / 20 / 95 \quad 14: 16: 67 \\ \text { BY } & \text { JFD/PCA/AAF/CD }\end{array}$

WBS DESCRIPTION

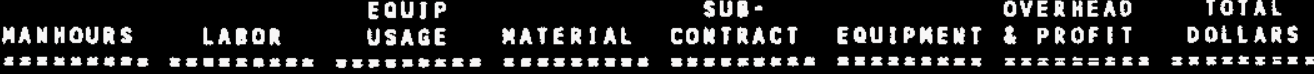

EQUJP

sus.

OVERHEAO

TOTAL

\section{$33 E 010$ STRUCTURES \\ $33 E 030$ CENTRAL REFR1GERATIOH \\ 3EXXO EQUIPHENT LABOR/BULKS}

SUBTOTAL 33 MECHANICAL UTILITIES BUILO

330010 STRUCTURES

336011 BCCB PAO

SUBTOTAL 336 BULK MANDLIMG AREA

$33 R 010$ STRUCTURES

SUBTOTAL 33R AMALYTICAL FACILITY

SUBTOTAL 33

STRUCTURAL

SUBTOTAL 3

STRUCTURAL/SITEMORK

$\begin{array}{rrrr}45669 & 1438544 & 0 & 1536577 \\ 20700 & 652050 & 0 & 192852 \\ 48000 & 1512000 & 0 & 1358280 \\ 116369 & 3602594 & 0 & 4823399 \\ & & & \\ 4611 & 145215 & 0 & 68777 \\ 2149 & 67662 & 0 & 58490 \\ 6760 & 212877 & 0 & 127267 \\ 258101 & 8130150 & 0 & 5353305 \\ 258101 & 8130150 & 0 & 5353305 \\ 472667 & 14888855 & 0 & 13557804 \\ 472667 & 14888855 & 0 & 13557804\end{array}$

0
0
0

$839258 \quad 3816379$ 3022606

$2150546 \quad 10576539$

$0 \quad 0 \quad 80403 \quad 294395$

$119187 \quad 45933$

0 $25604722 \quad 5856884 \quad 44945061$

- $25604722 \quad 5856884 \quad 44945061$

- 25752947985663364056239

D $257529479856633 \quad 64056239$

PROJECT TOTAL

597,567

$18,823,205$
$15,361,616$
$0_{38,439,076} 12,666,33$

$85,290,028$ 
0

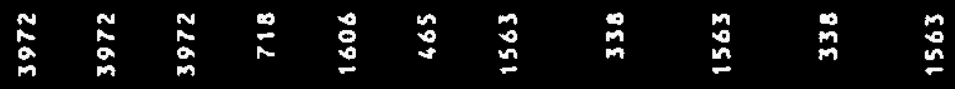
䇾锤

总 䭈

: 撞

整新

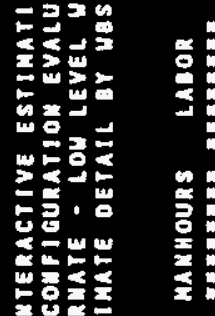

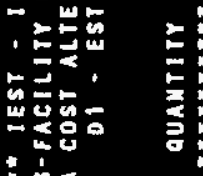

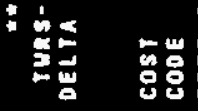

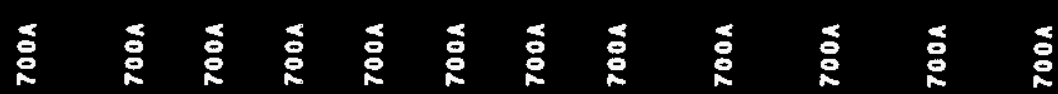

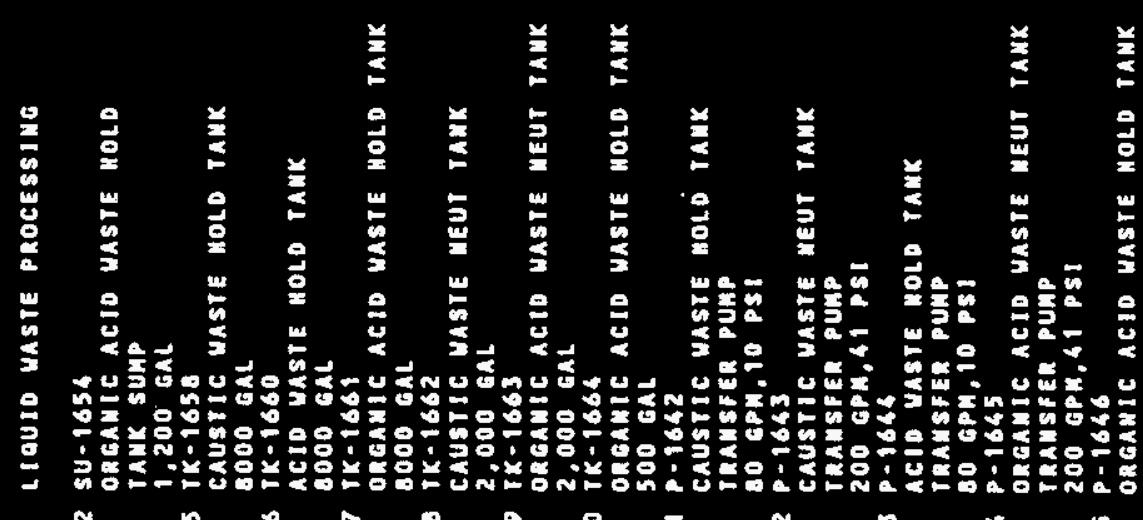

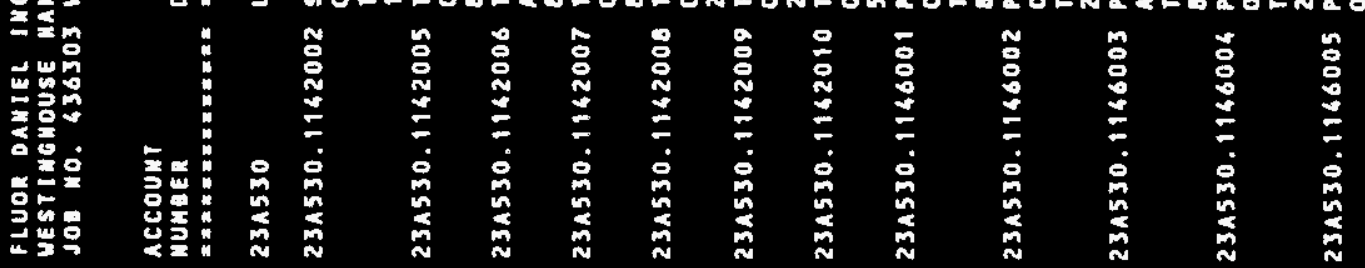




\section{WHC-SD-W378-ES-002}

Revision 0

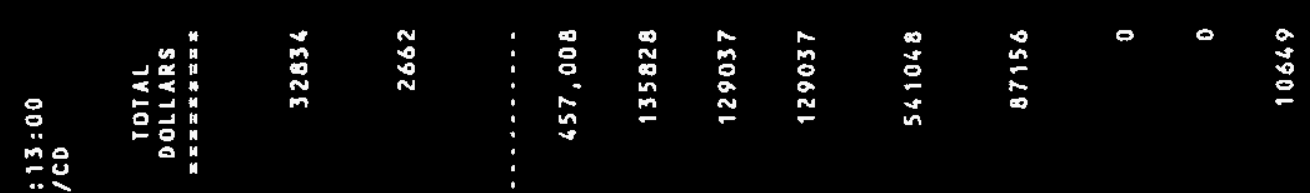

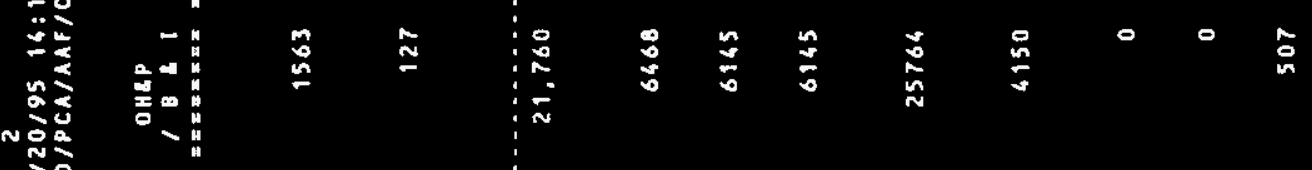

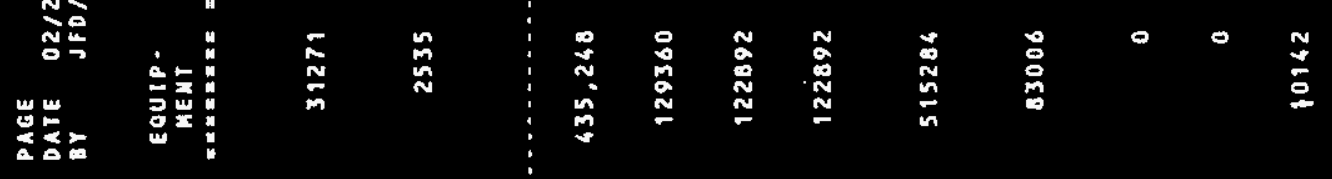
筆 羁

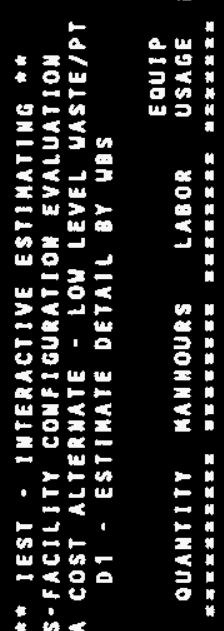

笨 稫

ఏ ఏ

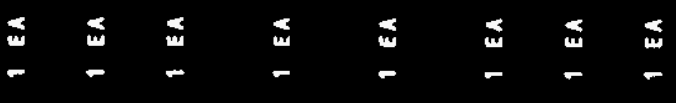

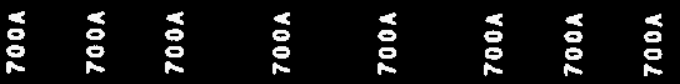

盖

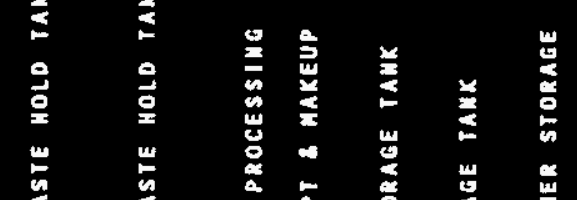

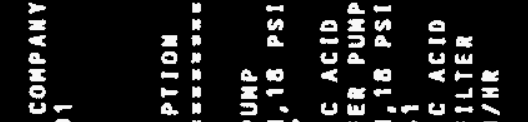

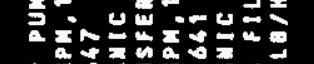

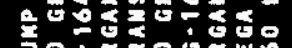

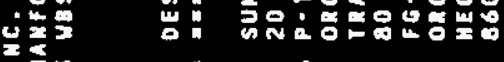

ڤั

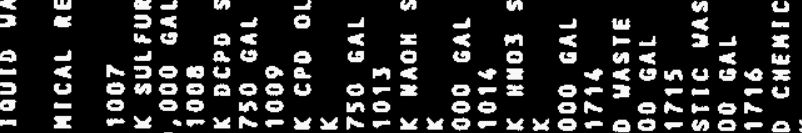

때ำ

僬翡

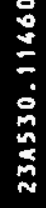

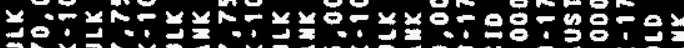

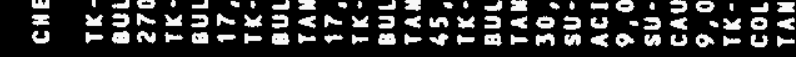

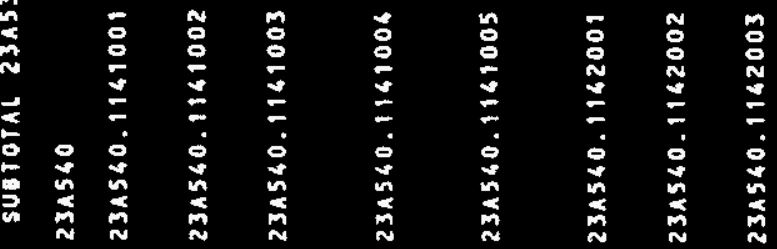




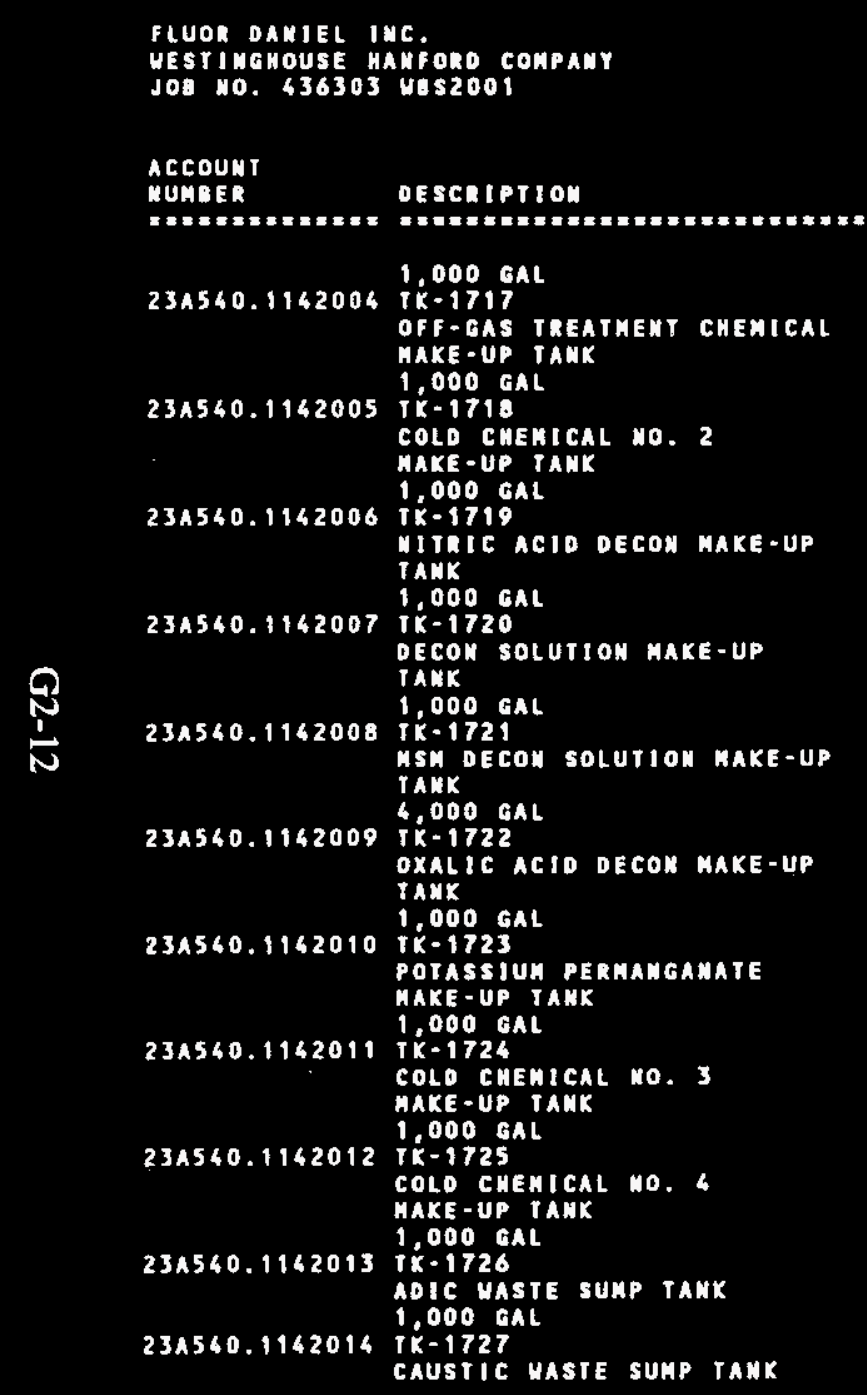

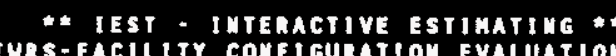
DELTA COST ALTERMTE o1. Estimate detall BY WBS

PAGE $02 / 20 / 95 \quad 14: 13: 01$ BY JFD/PCA/AAF/CD

COST EQUiP SUR- EQUIP- OKEP TOTAL CODE OUANTTY MANHOUR LABOR USAGE MATERIAL cOMTRACT MERT,

\begin{tabular}{|c|c|c|c|c|c|c|c|c|c|c|}
\hline $700 \mathrm{~A}$ & 1 & EA & 0 & 0 & J & 0 & 0 & 10142 & 507 & 10649 \\
\hline $700 A$ & 1 & EA & 0 & 0 & 0 & 0 & 0 & 12677 & 634 & 13311 \\
\hline $700 A$ & 1 & EA & 0 & 0 & 0 & 0 & 0 & 10142 & 507 & 10649 \\
\hline $700 A$ & 1 & EA & 0 & 0 & 0 & 0 & 0 & 12677 & 636 & 13311 \\
\hline TOOA & 1 & EA & 0 & 0 & 0 & 0 & 0 & 23664 & 1184 & 24848 \\
\hline $700 A$ & 1 & EA & 0 & 0 & 0 & 0 & 0 & 12677 & 634 & 13311 \\
\hline $700 A$ & 1 & EA & 0 & 0 & 0 & 0 & 0 & 10142 & 507 & 10649 \\
\hline $700 A$ & 1 & EA & 0 & 0 & 0 & 0 & 0 & 10142 & 507 & 10649 \\
\hline $700 A$ & 1 & EA & 0 & 0 & 0 & 0 & 0 & 12677 & 634 & 13311 \\
\hline $700 A$ & 1 & EA & 0 & D & 0 . & 0 & 0 & 10142 & 507 & 10649 \\
\hline $700 A$ & 1 & $E A$ & 0 & 0 & 0 & 0 & 0 & 10142 & 507 & 10649 \\
\hline
\end{tabular}




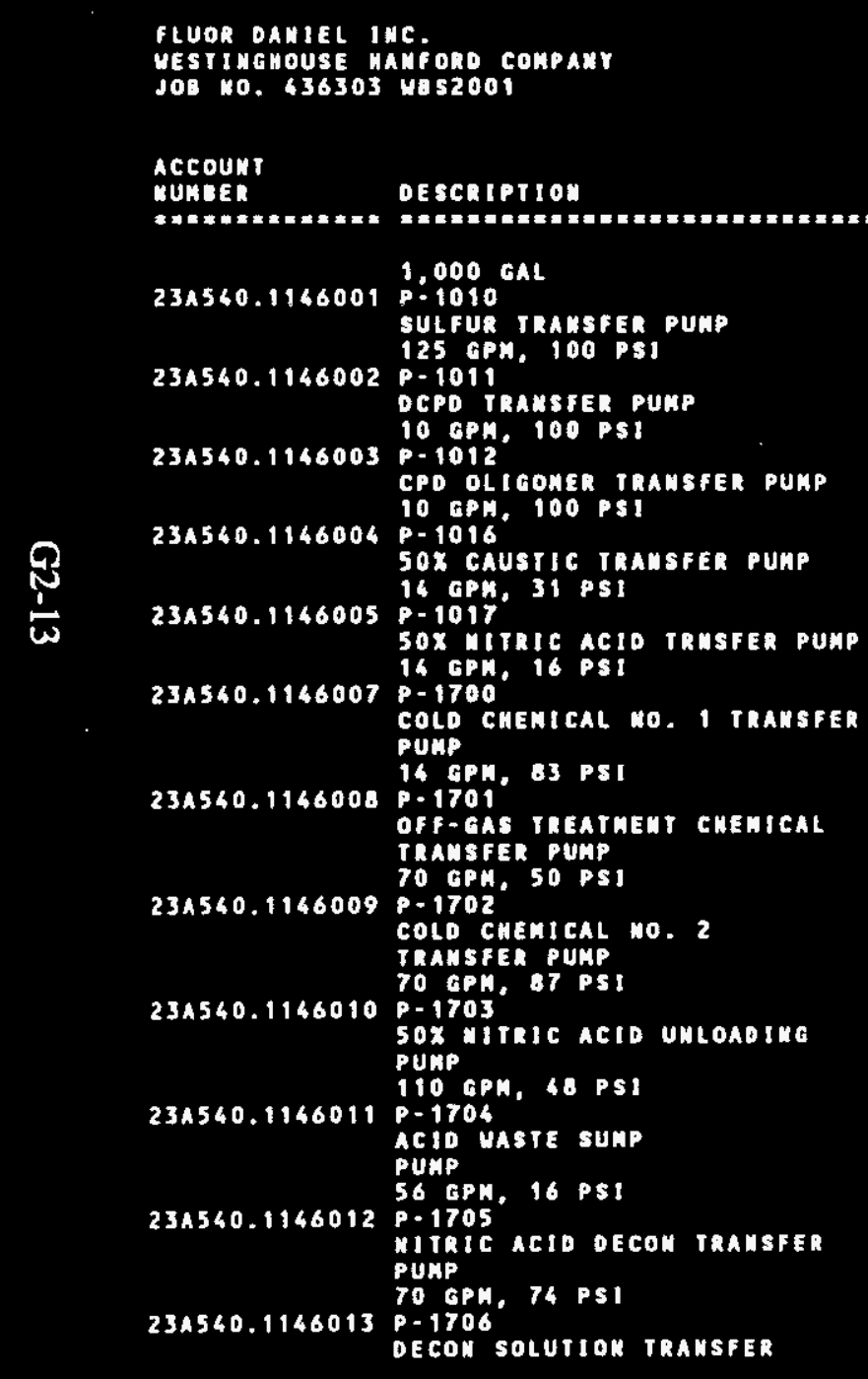
"* IEST - IMTERACTIVE ESTIHATIMG "* JURS-FACILITY COMFiguRATIOU EVALUATION DELTA COST ALTERATE - LOU LEVEL WASTE/PT D1 - ESTIRATE DETAIL gY uBS

PAgE

DATE $02 / 20 / 95 \quad 16: 13: 03$

COST EOUIP SUL- EQUIP- OHEP TOTAL

CODE GUANTITY MANMOURS LABOR USAGE MATERIAL COMTAACt MEMT, $B$ I DOLLARS

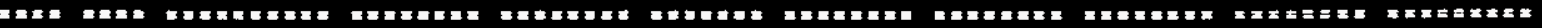
put The

$\operatorname{ros}$

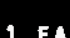

$700 A$

$1 E A$

0
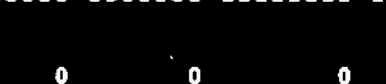

$700 A$

$1 E A$

0

0

0

7004

$1 \in A$

0

$700 \mathrm{~A}$

1 EA

0

$700 A$

1 EA

0

$700 A$

o

$700 A$

1 EA

0

$200 \mathrm{x}$

$1 E A$

0

ton

EA

$700 A$

1 EA

o

1 EA

0

$700 A$

1 EA

7001

1 EA

0
0

0

0

0

0

0

0

$\circ$

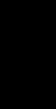

0

(

$\begin{array}{llll}5390 & 270 & 5660 & \\ 2156 & 108 & 2264 & \\ 2156 & 108 & 2264 & \\ 8452 & 423 & 8875 & 3099 \\ 6761 & 338 & 709 & 0 \\ 11832 & 592 & 12424 & 0 \\ 6761 & 338 & 7099 & 0\end{array}$




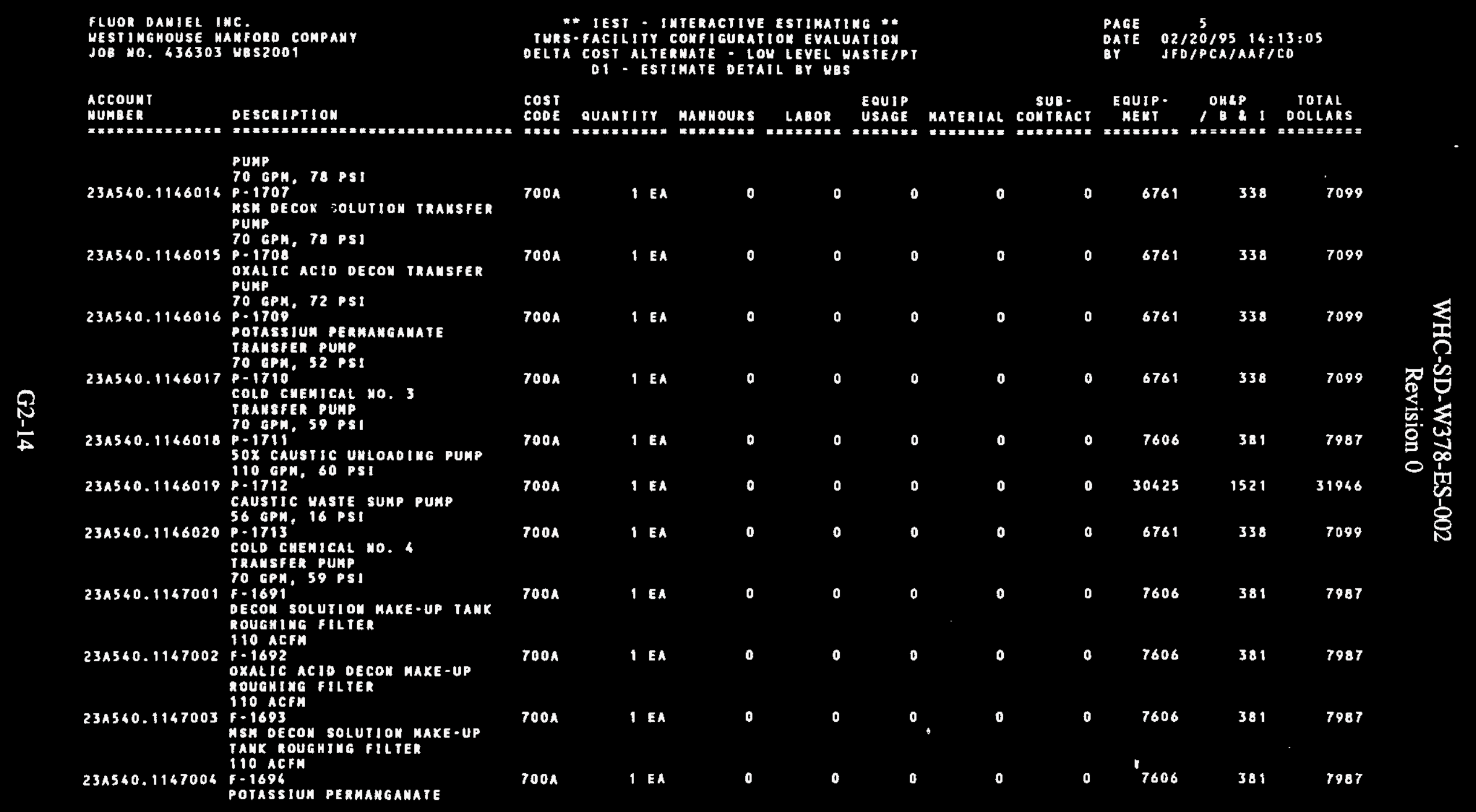


$\frac{1}{30}$

踣:

薄

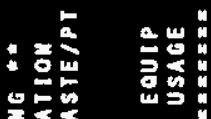

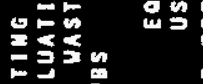

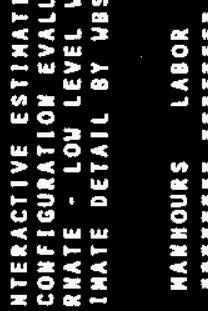

理要

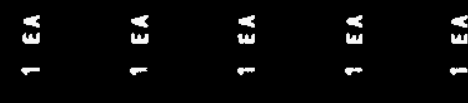

慗的

:

暂

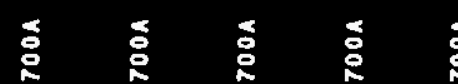

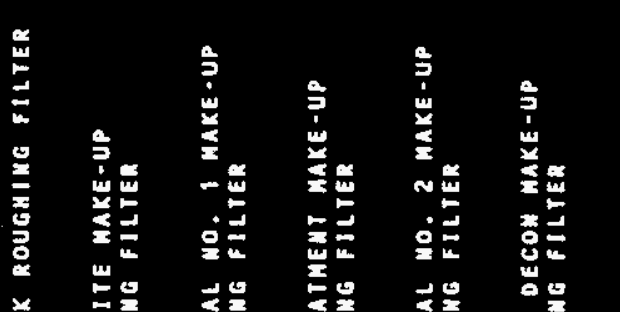

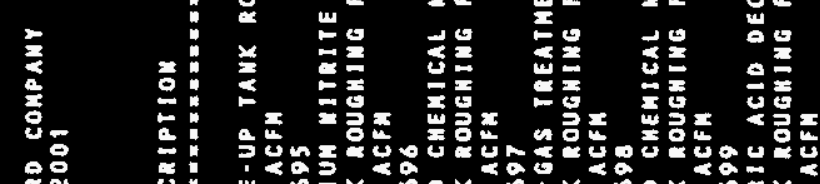

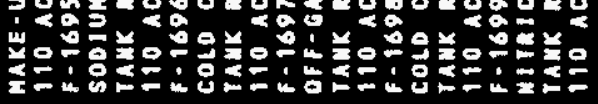




\section{WHC-SD-W378-ES-002 \\ Revision 0}

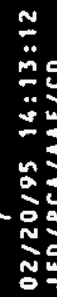

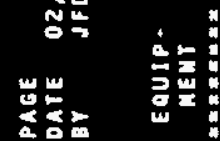

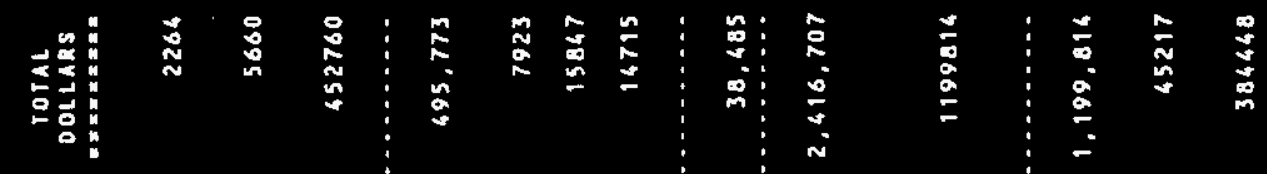

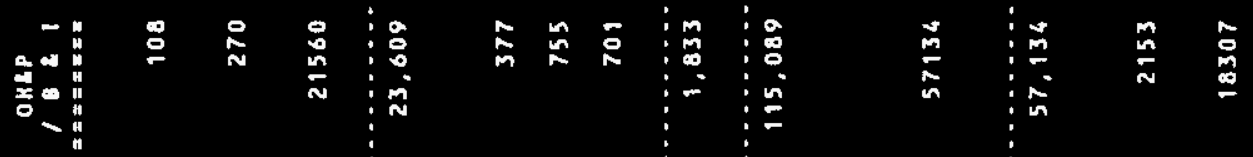

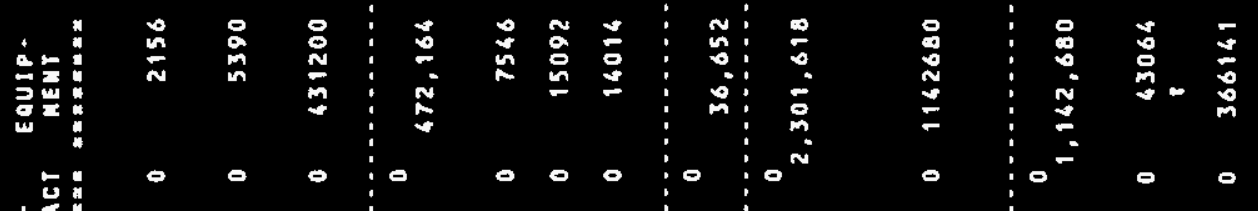

总

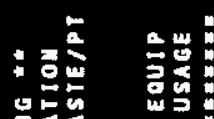

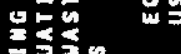

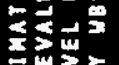

둔

등혀

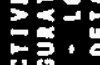

E.

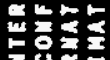
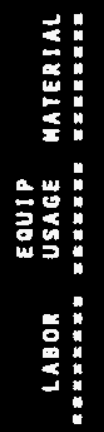

政

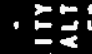

in

㩆的-

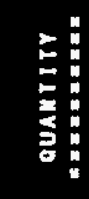

害哭

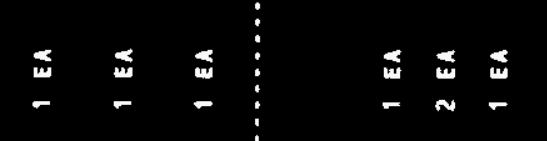

๖

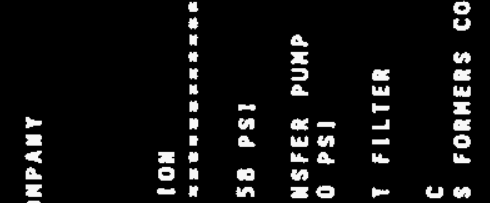

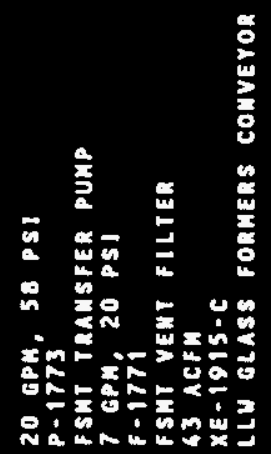

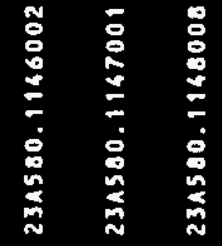

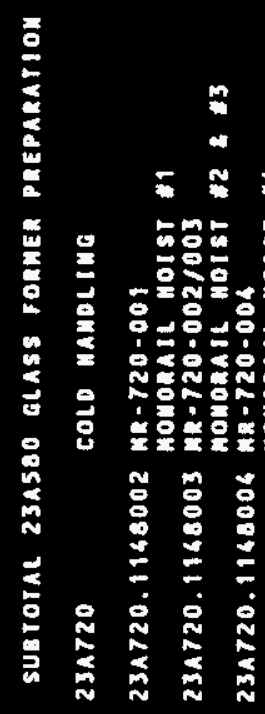

ఏ气 ఏ

ริ

$\vdots$

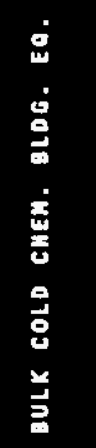

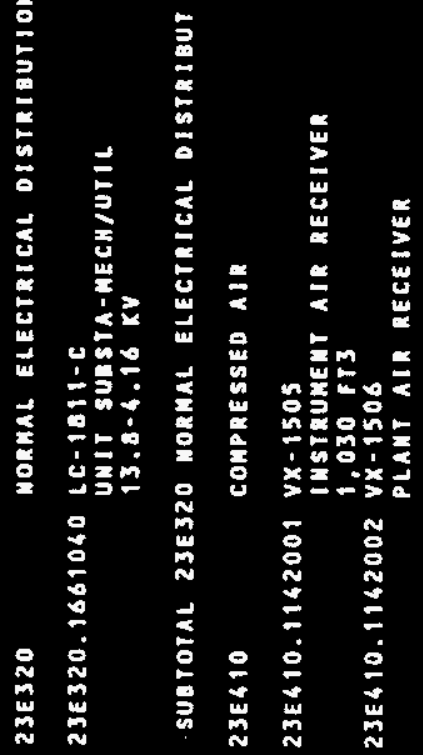




\section{WHC-SD-W378-ES-002 Revision 0}
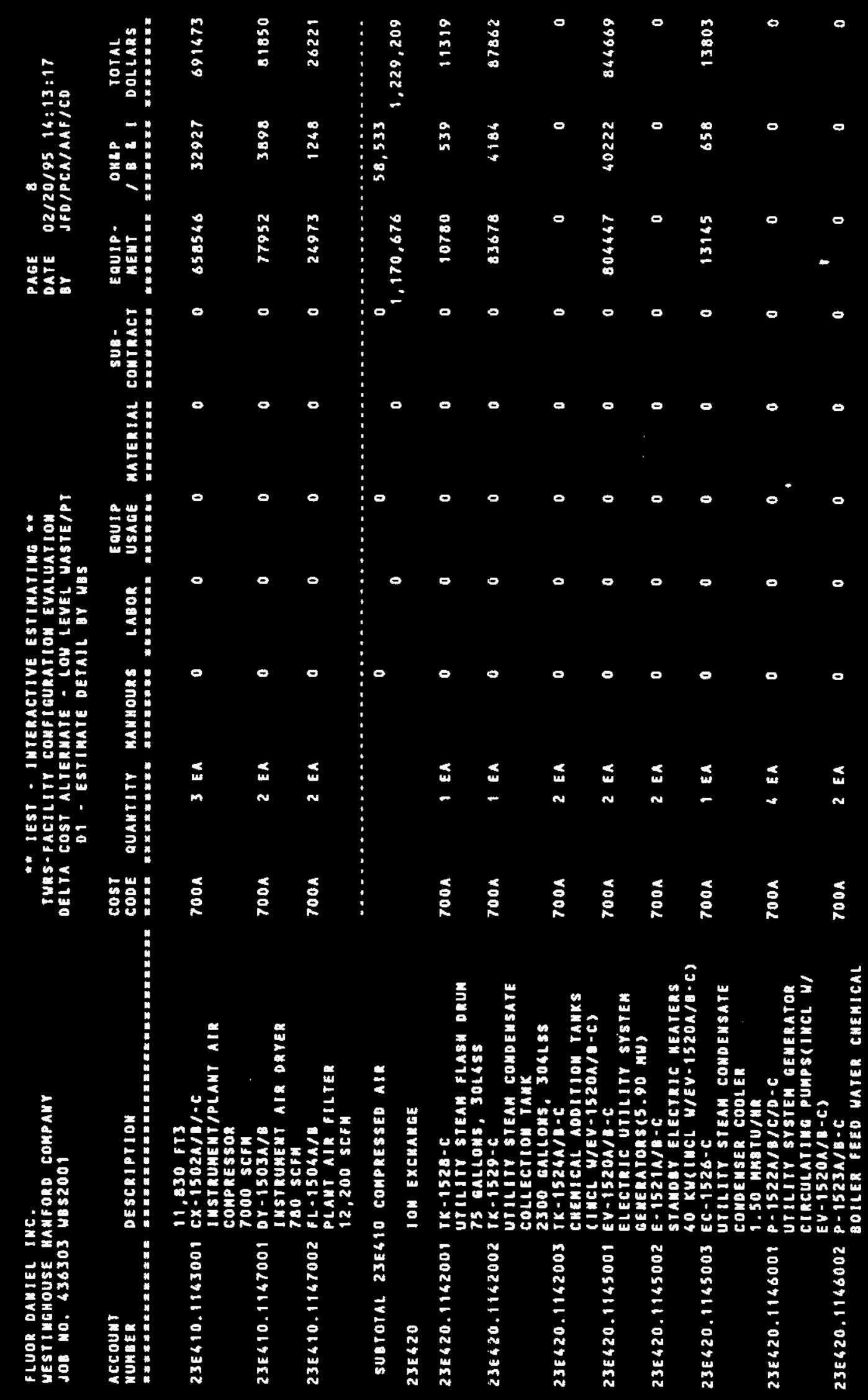


\section{WHC-SD-W378-ES-002 \\ Revision 0}

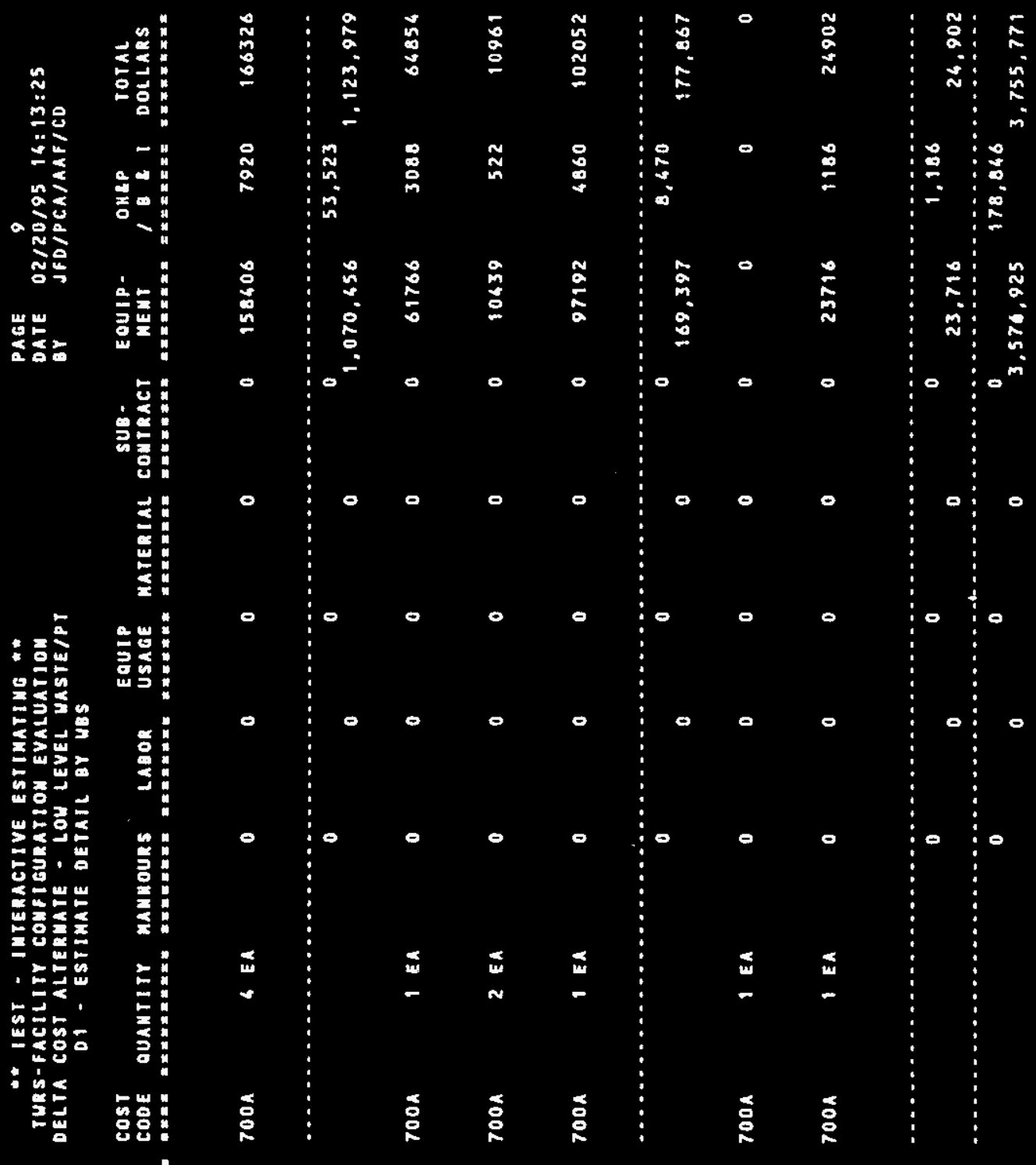

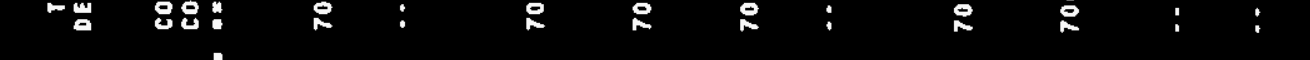

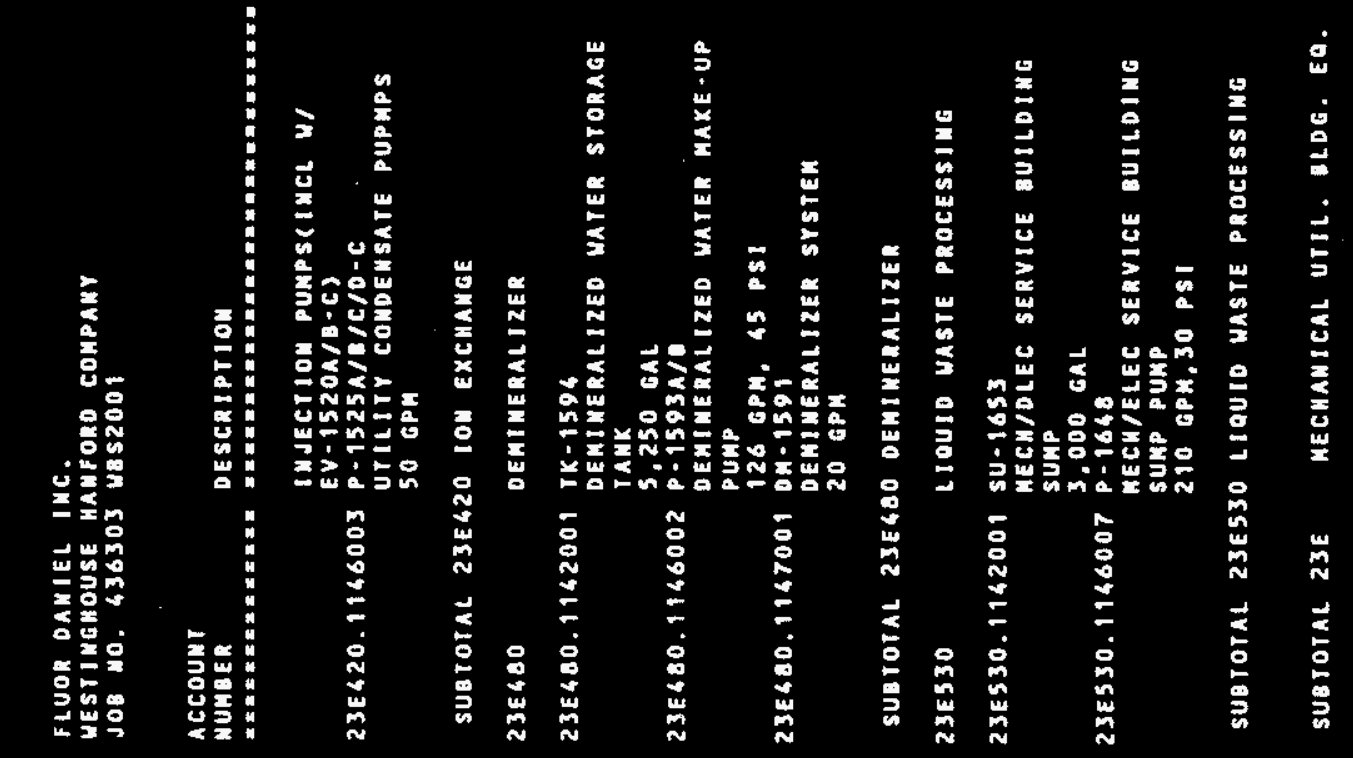




\section{WHC-SD-W378-ES-002 \\ Revision 0}

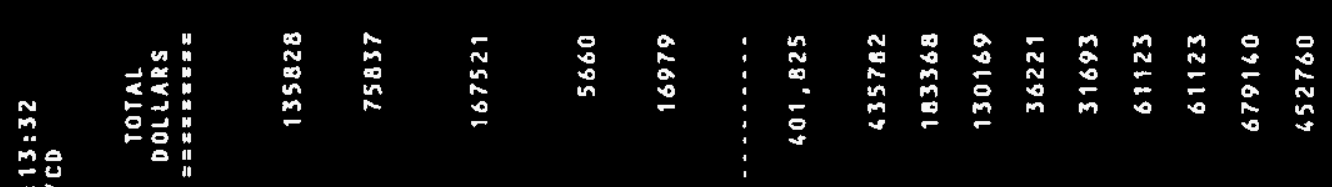

薄

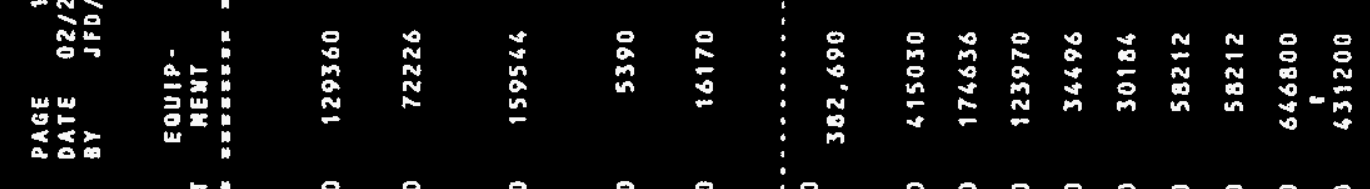
窟:

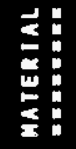

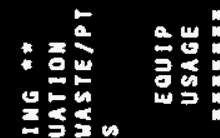

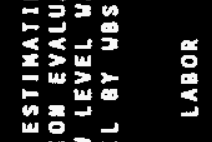

뜸훌

言.

政

능출

xim

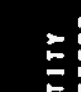

든

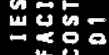

* a

点

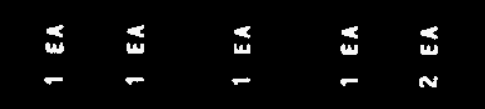

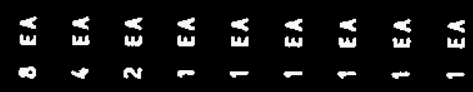

总

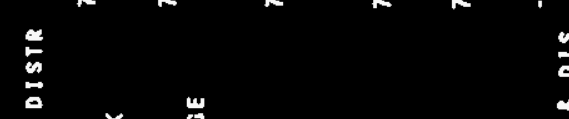

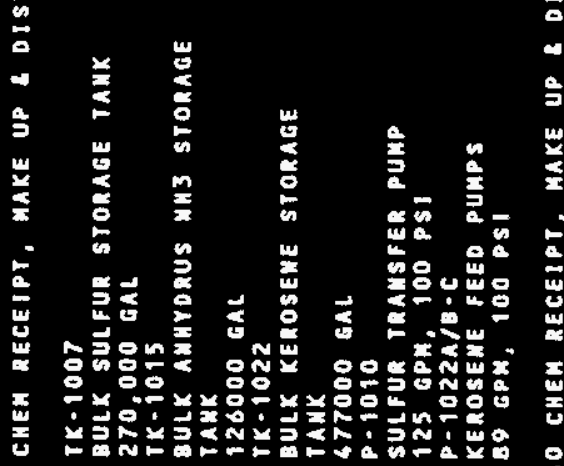


FLUOR DARIEL JWC.

YESTINGMOUSE HAMFORO COAPANY

JOB $\mathrm{No}$. 436303 Yas200

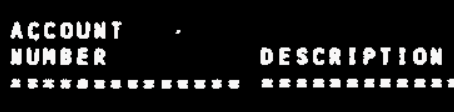

236580.1148007 XWLOABER

230580.1148008 CONYEYOR TO MIXER

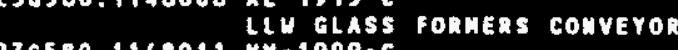

236580.1168011 MH-1909-C

LLW GATCH MIXER

SUBTOTAL 230580 FRIT RECEIPT \& MAKE UP

236590 (Deseription not evellable)

236590.1149001 As - 1025 OXYGE PLANT

subrotal 236590 (deseription not avellable)

$236 \times \times 0$

BULK MAHDLING AREA

$236 \times \times 0.1500001$ ALLOUAME FOR LAOOR ANB ouLK MAtERIALs Associated Uith the instalcation of $236 \times \times 0.1500002$ ALLOWAHCE BOR LABOR AND BULK MATERIALS ASSOCIATEO HITH THE IUSTALLATION OF

SUBTOTAL $236 \times \times 0$ BULK MAMOLIMG AREA

SUBTOTAL 236 BULK MAMDLIMG AREA EOUIP.

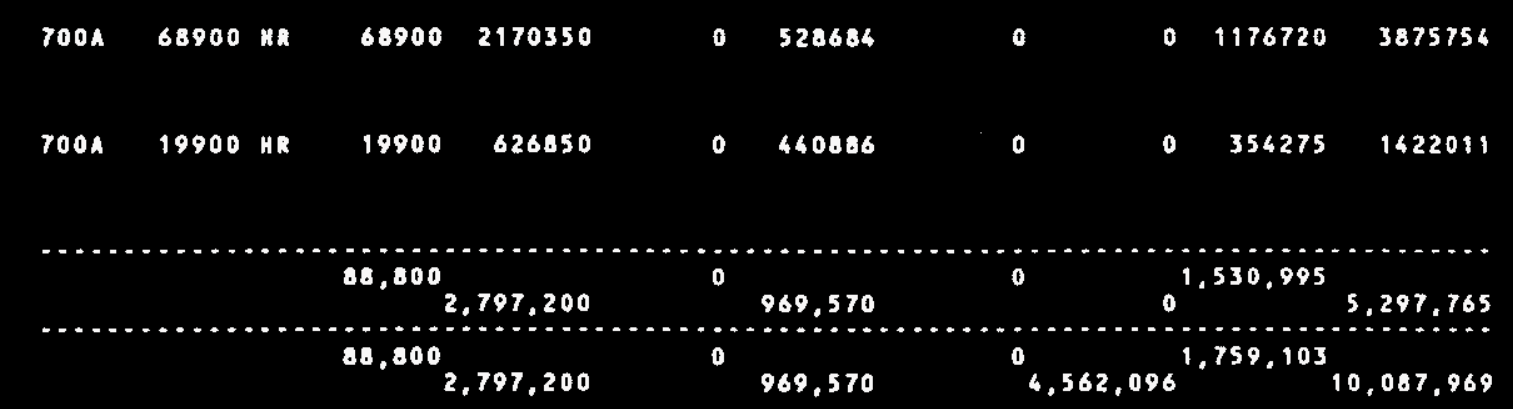

231320 MORMAL ELECTAICAL DISTRIBUTION

$23 L 320.1661035$ LC-1810-C UWI SUBSTA-COOLING TOUER
$13.8-4.16$ KY

$600 A$

1 EA

0

0

0

$\mathbf{0}$

o 1055362

$52768 \quad 1108130$

SUBTOTAL 231320 MORHAL ELECTRICAL DISTRIBU
TEST - IMTERACTIVE ESTIMATIME "* DELTA COST ALTERMTE. LOU LEVEL MASTEJPT

$\cos t$

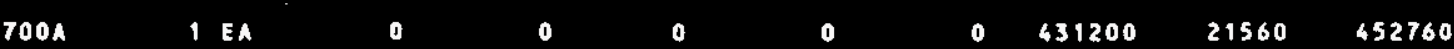

$\begin{array}{llllllllll}700 A & 1 \text { EA } & 0 & 0 & 0 & 0 & 0 & 431200 & 21560 & 452760\end{array}$

$\begin{array}{llllllllll}700 A & 1 \mathrm{EA} & 0 & 0 & 0 & 0 & 0 & 145530 & 7277 & 152807\end{array}$

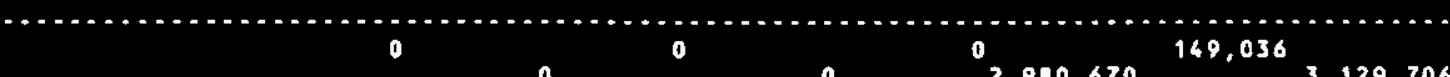

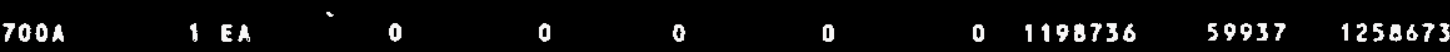

.............................

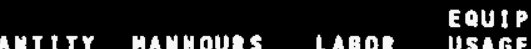

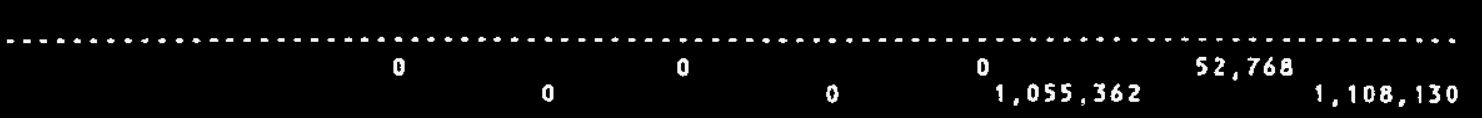




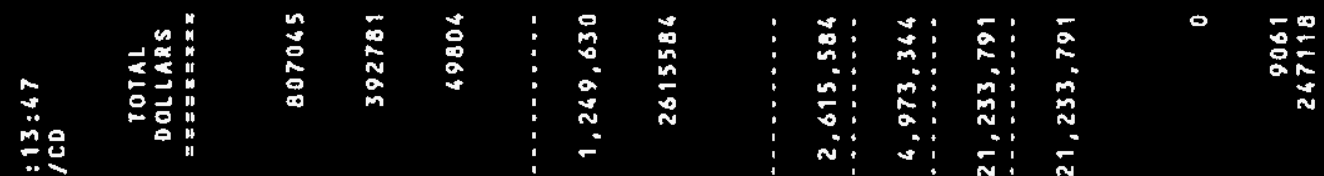

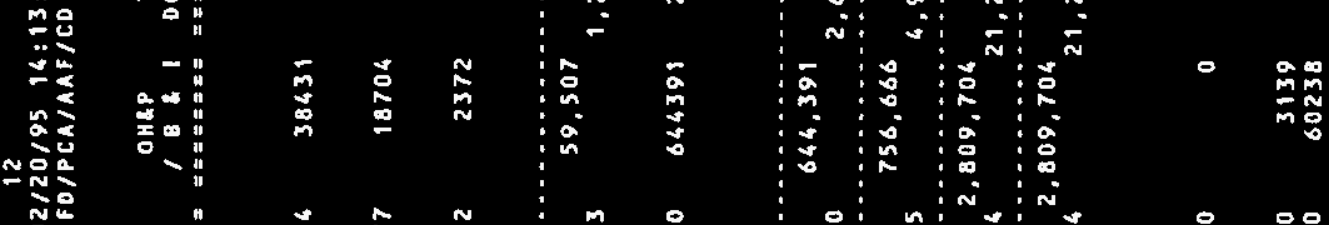

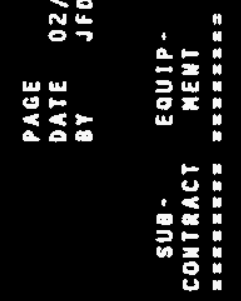

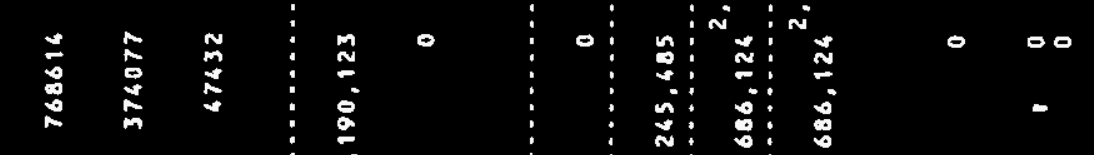

- o o $\vdots_{0}$ o $\vdots_{0} \vdots_{0}$

$0 \quad 00$

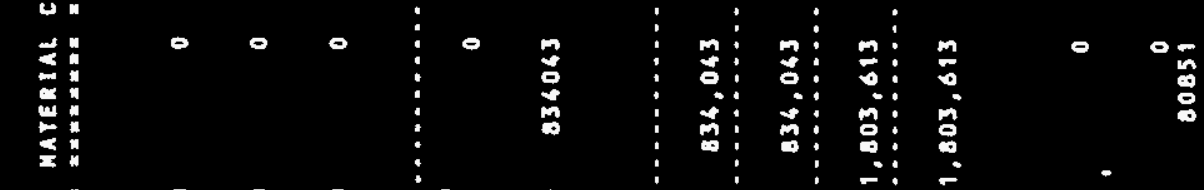

点

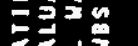

:

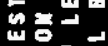

푸을

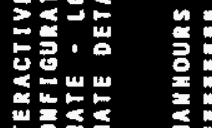

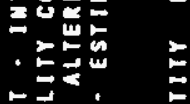

过

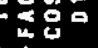

$\dot{s}$

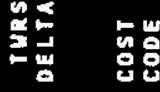

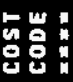

¿
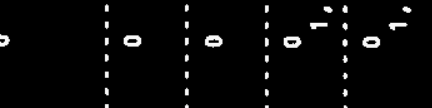

000

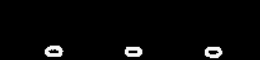

$\circ$

采

- Nลำ

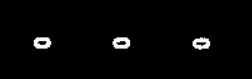

$\therefore-$

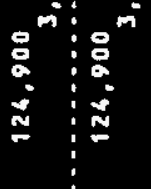

- $\because \frac{0}{m}$

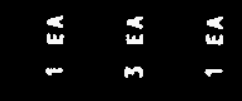

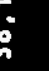

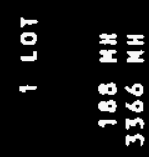

은 훙

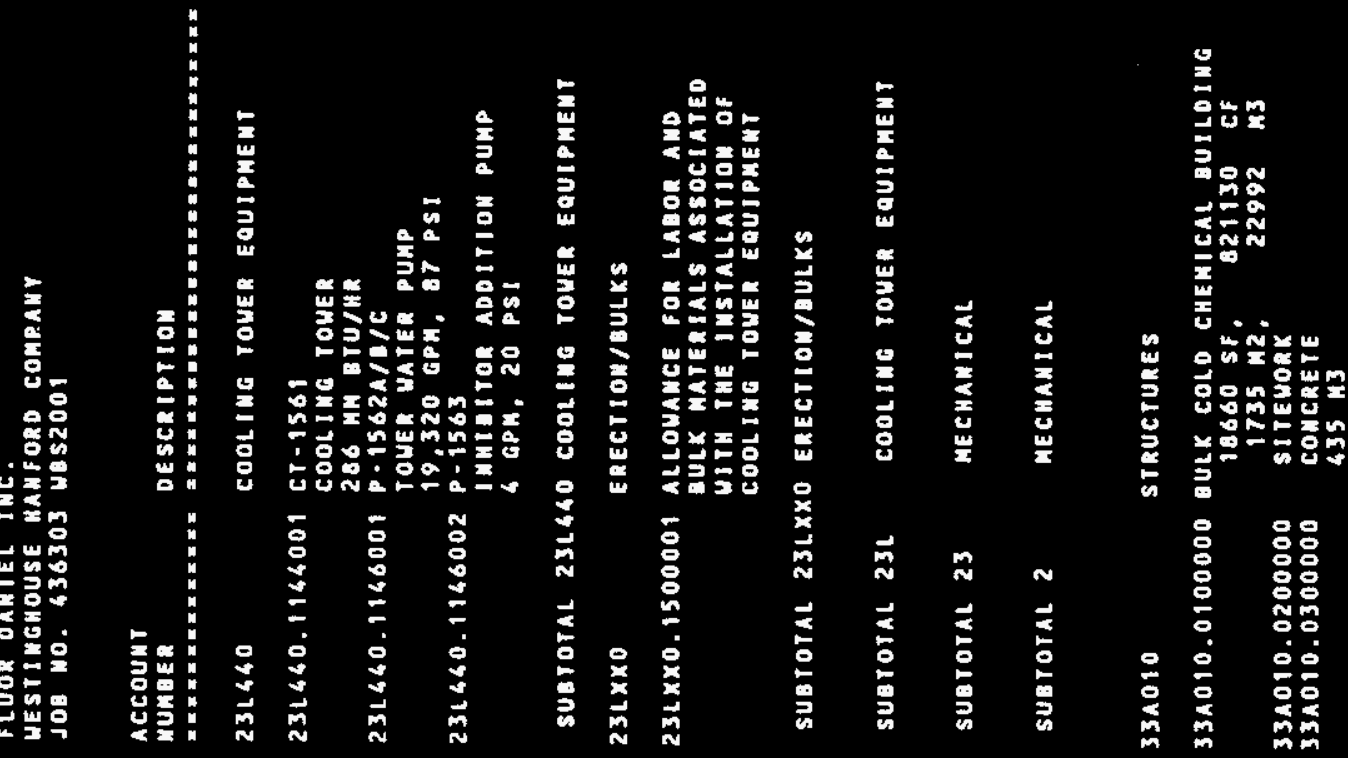




\section{WHC-SD-W378-ES-002}

Revision 0

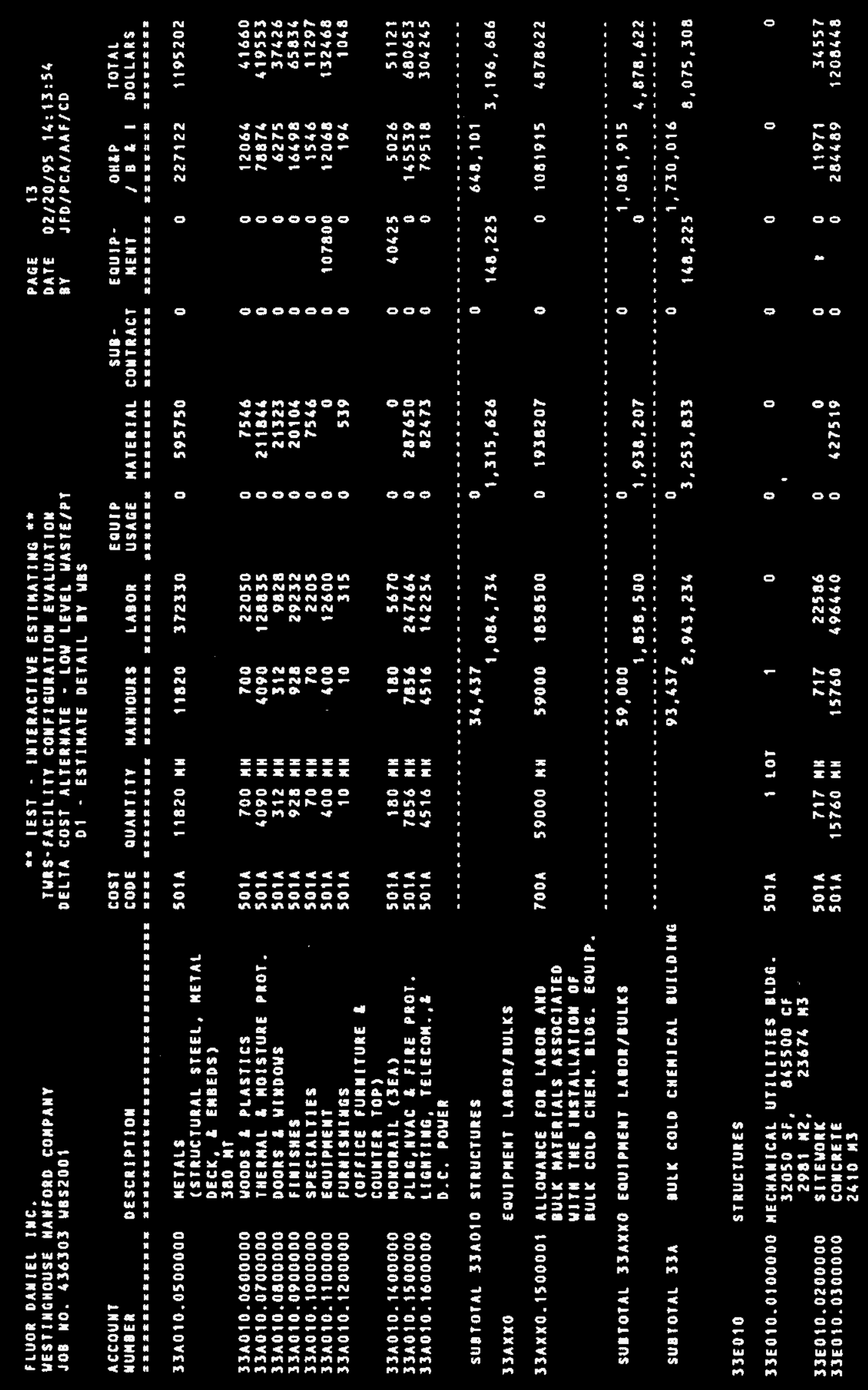

G2-22 


\section{*alls View/Frint Document Cover Sheet tow}

This document was retrieved from the Documentation and Records Manaqement (DRM) ISEARCH System. It is intended for Information only and may not be the most recent or updated version. Contact a Document Service Center (see Hanford Info for locations) if you need additional retrieval information.

Accession \#: D195067282

Document \#: SD-W378-ES-002

Title/Desc:

FACILITY DESIGN PHILOSOPHY TWRS PROCESS SUPPORT \& INFRASTRUCTURE DEFINITION [SEC 4 OF 4]

Pages: 85 
THIS DOCUMENT WAS TOO LARGE TO SCAN AS A SINGLE DOCUMENT. IT REQUIRED BREAKING INTO SMALLER SECTIONS.

DOCUMENT NUMBER: SD - 11378- \&S-002

SECTION: 4 OF 4

TITLE: facility Dusign Philomophy fante Wante Bomodiation dyptem Procese seppoort \& Infractrusture Definition

AUTHOR: Beach, Galleraith

RECIPIENT:

DATE: $12 / 11 / 95$

KEYWORDS:

REFERENCES: $8 D T-6 \mid 3161$ 


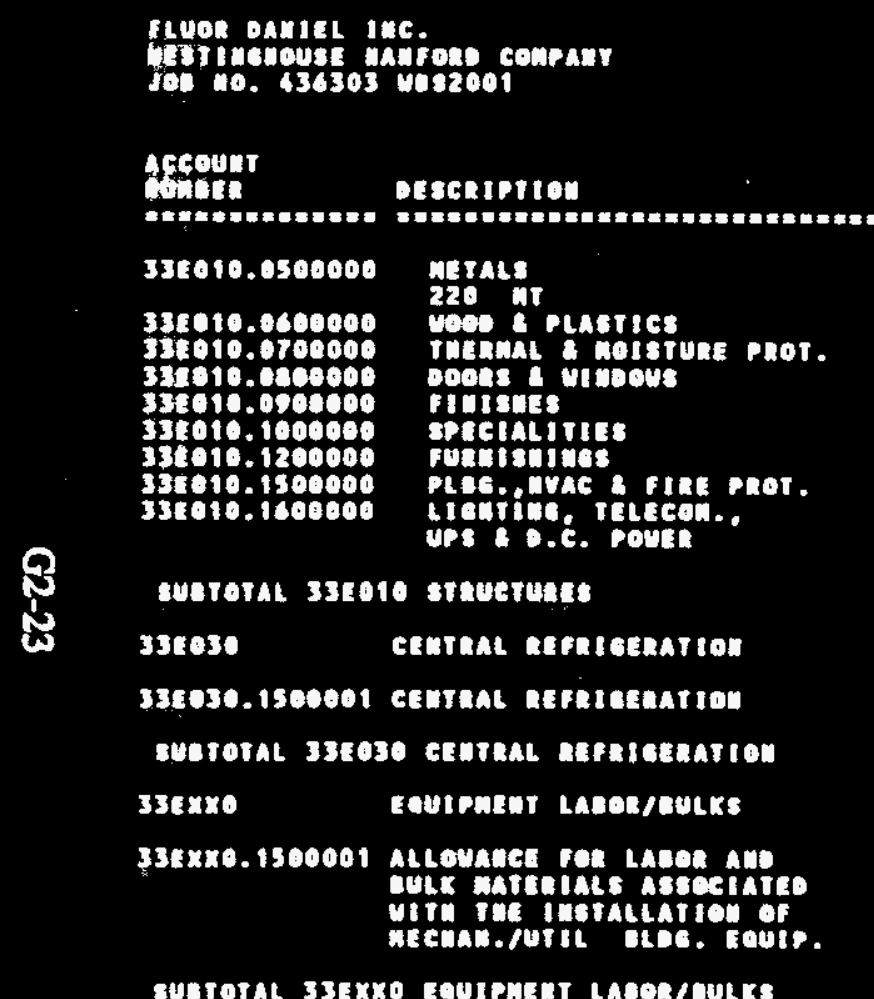

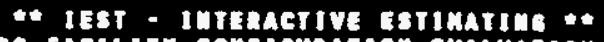

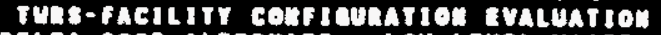

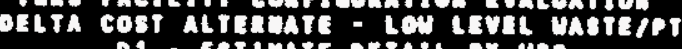 D1. Cotimate Detati or uns

cost ceul

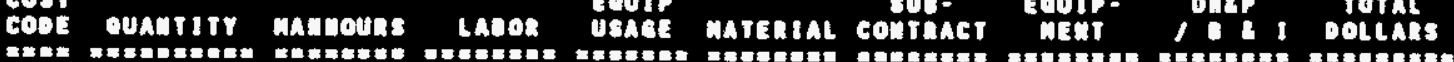

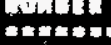

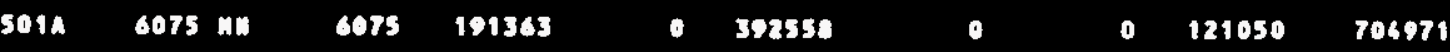

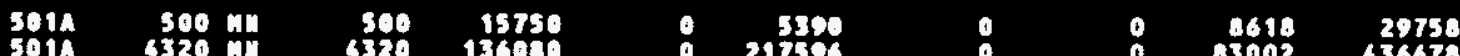

432 136090 a $2175 \%$ a 8300243667

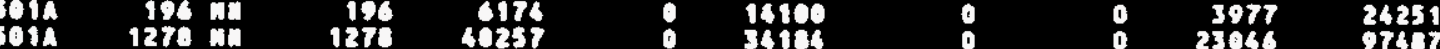

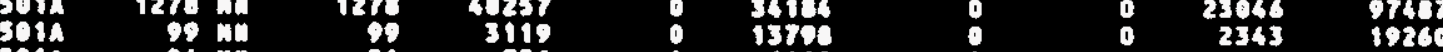

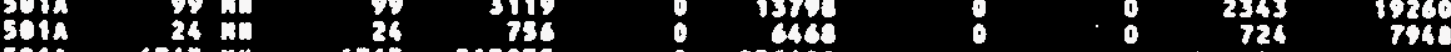

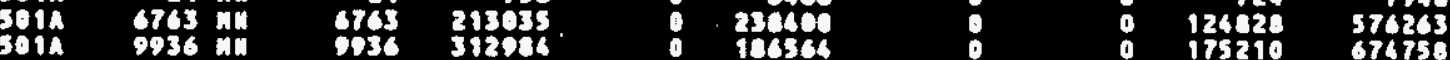

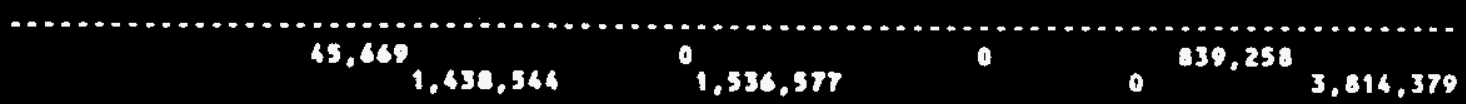

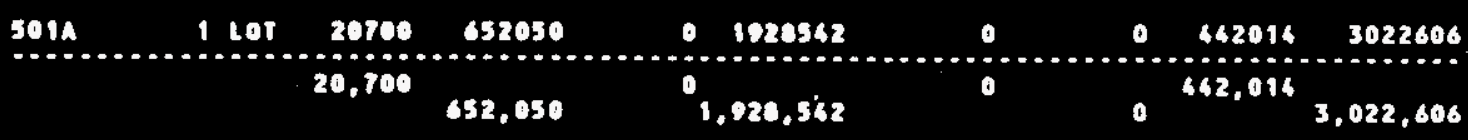

SUnToral 33Exxo EOUIPAERT LABOR/OULKS

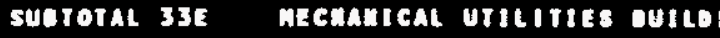

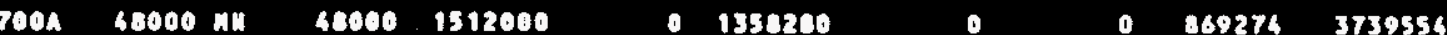

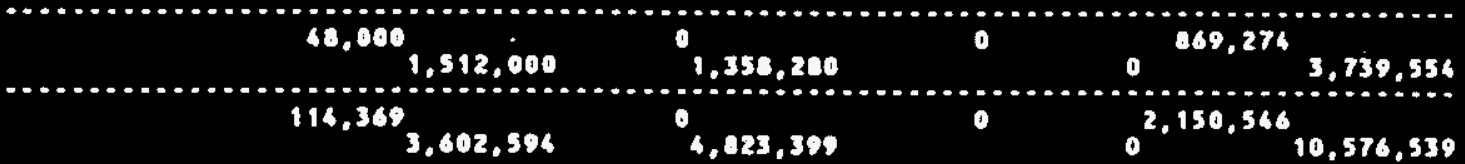

336010 stauctunes

33e010.0100000 oces tank ofer

1440 if

336010.0200000 sisgwank

336010.0300000 concint

conchere (cunte - 50 nn)

$\begin{array}{rrrrrr}501 A & 1 \text { LOT } & 1 & 0 & 0 & 0 \\ 5011 & 440 \text { ML } & 440 & 13860 & 0 & 0 \\ \operatorname{so1A} & 4170 . M 11 & 4170 & 131355 & 0 & 68777\end{array}$

$\begin{array}{rrrr}0 & 0 & 0 & 0 \\ 0 & 0 & 7346 & 21206 \\ 0 & 0 & 73057 & 273189\end{array}$


Ftuon DAMtel ING.

yest inanoust wanfons conpanr

Accoun

Descatption

suntoral 336010 stmuctunes

336011

DCen PA

336011.0100001 SULK GOLO CMEAICAL PAD 15400 of

330011.0200001 sirtuent

336011.0300001

336011.0200001 pingsts

sudTataL 336011 aces pAB

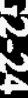

* IEst - Iutenaetive Estinatius *

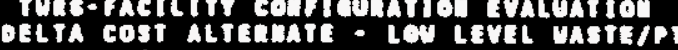
D1 - Estimate detail of uos
PAGE 02120/95 14:16:09

if JFAPEA/AAF/CD

cost at and

gouip

sus-

suts:

caup. Onep toral

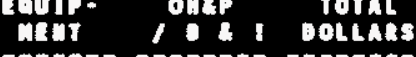

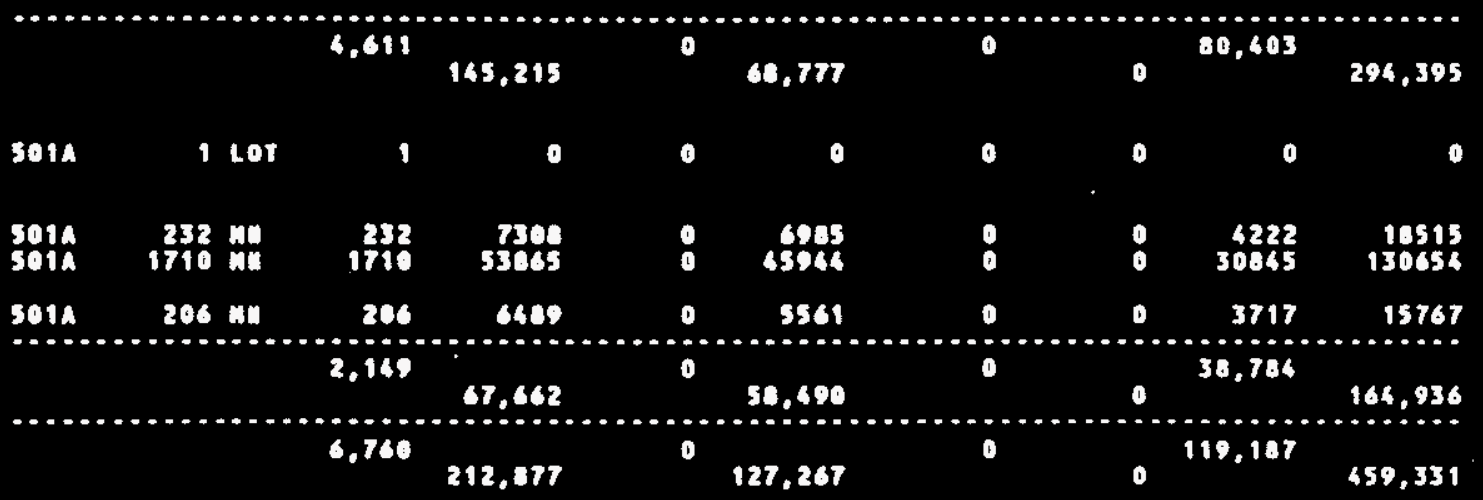

$33 n 010$ struetunes

$33 n 010.0100000$ ayatrigal mactiry

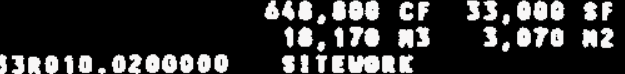
37010.0300000 conenterts 3 If 10.030000

33010.06909 mos plagries

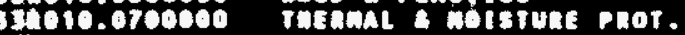

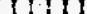

33910.190000

3ing10. 1200000

boens 2 viusers

civistes

geretaltries

curpater

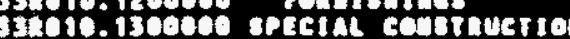

33noro. 1400009 converine sretans

$33 n 010.1500000^{1}$ PLes. yyac o fine ptor.

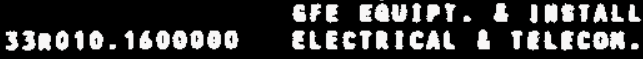

suntoral 33naso stauctunes

\begin{tabular}{|c|c|c|c|c|c|c|c|c|c|c|}
\hline $501 A$ & 1 & Lor & 1 & 0 & 0 & 0 & 0 & & 0 & 0 \\
\hline 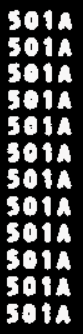 & $\begin{array}{r}700 \\
43700 \\
18100 \\
400 \\
2900 \\
1360 \\
5600 \\
400 \\
133300 \\
600 \\
18900 \\
500\end{array}$ & nun & 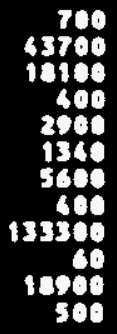 & $\begin{array}{r}22050 \\
137550 \\
579150 \\
12600 \\
71350 \\
42210 \\
176400 \\
12890 \\
4170950 \\
1090 \\
595350 \\
15750\end{array}$ & $\begin{array}{l}0 \\
0 \\
0 \\
0 \\
0 \\
0 \\
0 \\
0 \\
0 \\
0 \\
0 \\
0\end{array}$ & 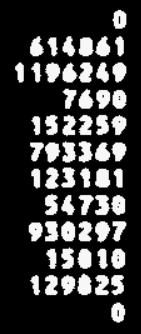 & $\begin{array}{l}0 \\
0 \\
0 \\
0 \\
0 \\
0 \\
0 \\
0 \\
0 \\
0\end{array}$ & $\begin{array}{r}8 \\
0 \\
0 \\
0 \\
0 \\
0\end{array}$ & $\begin{array}{rr}0 & 11657 \\
0 & 760314 \\
0 & 361992 \\
0 & 7063 \\
0 & 56029 \\
0 & 62040 \\
0 & 99651 \\
0 & 9415 \\
2 & 3552195 \\
0 & 1752 \\
0 & 322027 \\
0 & 0348\end{array}$ & $\begin{array}{r}33737 \\
2751725 \\
2120391 \\
27353 \\
290638 \\
697619 \\
399232 \\
76745 \\
34286164 \\
10652 \\
1047202 \\
26098\end{array}$ \\
\hline IA & 22000 & nu & 22000 & 603000 & 0 & 1164068 & 0 & & 424493 & 2261553 \\
\hline 114 & 10200 & nn & 10200 & 321300 & 0 & 191774 & 8 & 0 & 179878 & 092952 \\
\hline
\end{tabular}


Revision 0

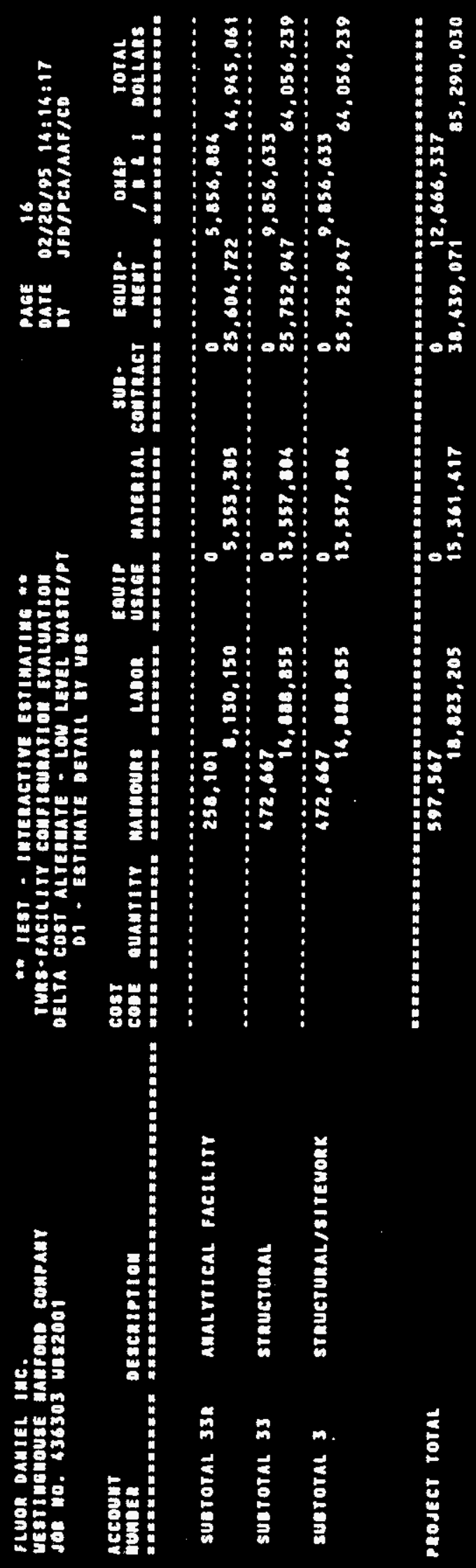

G2-25 


\section{Revision 0}

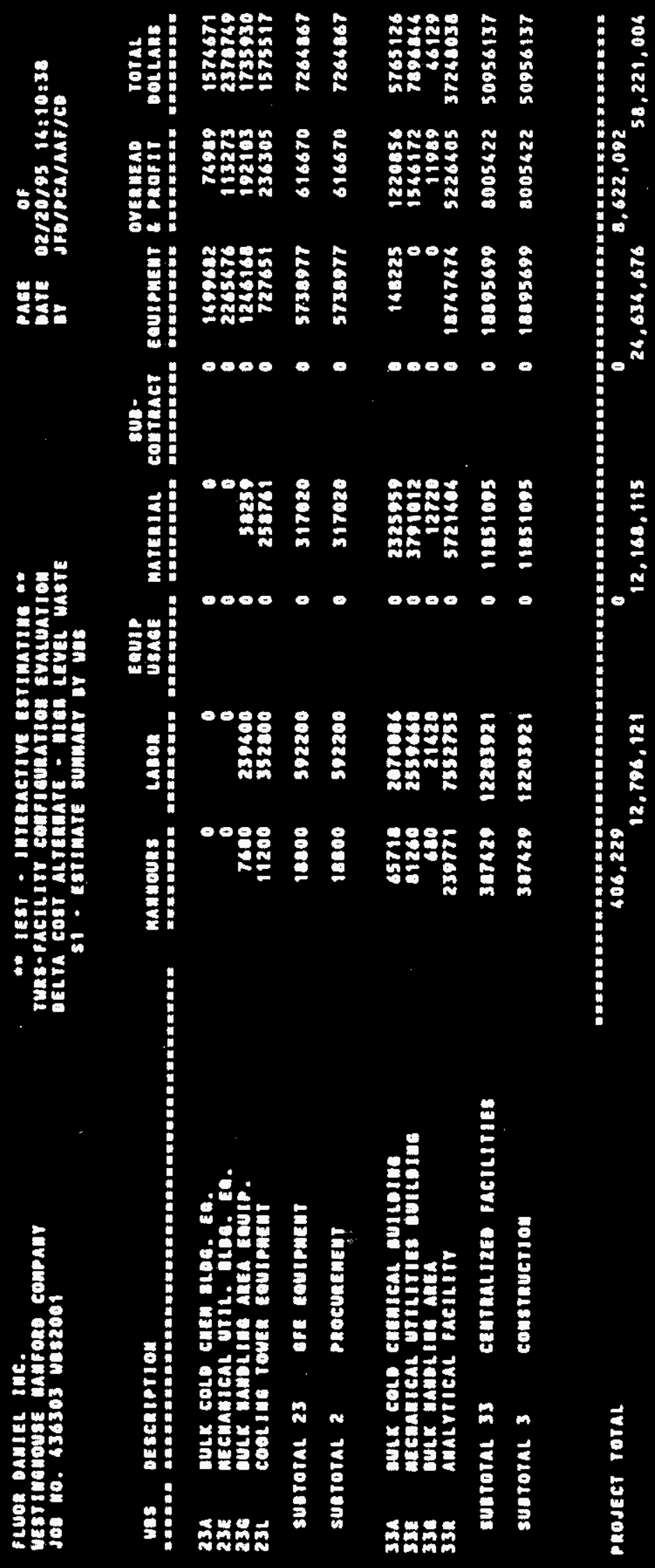




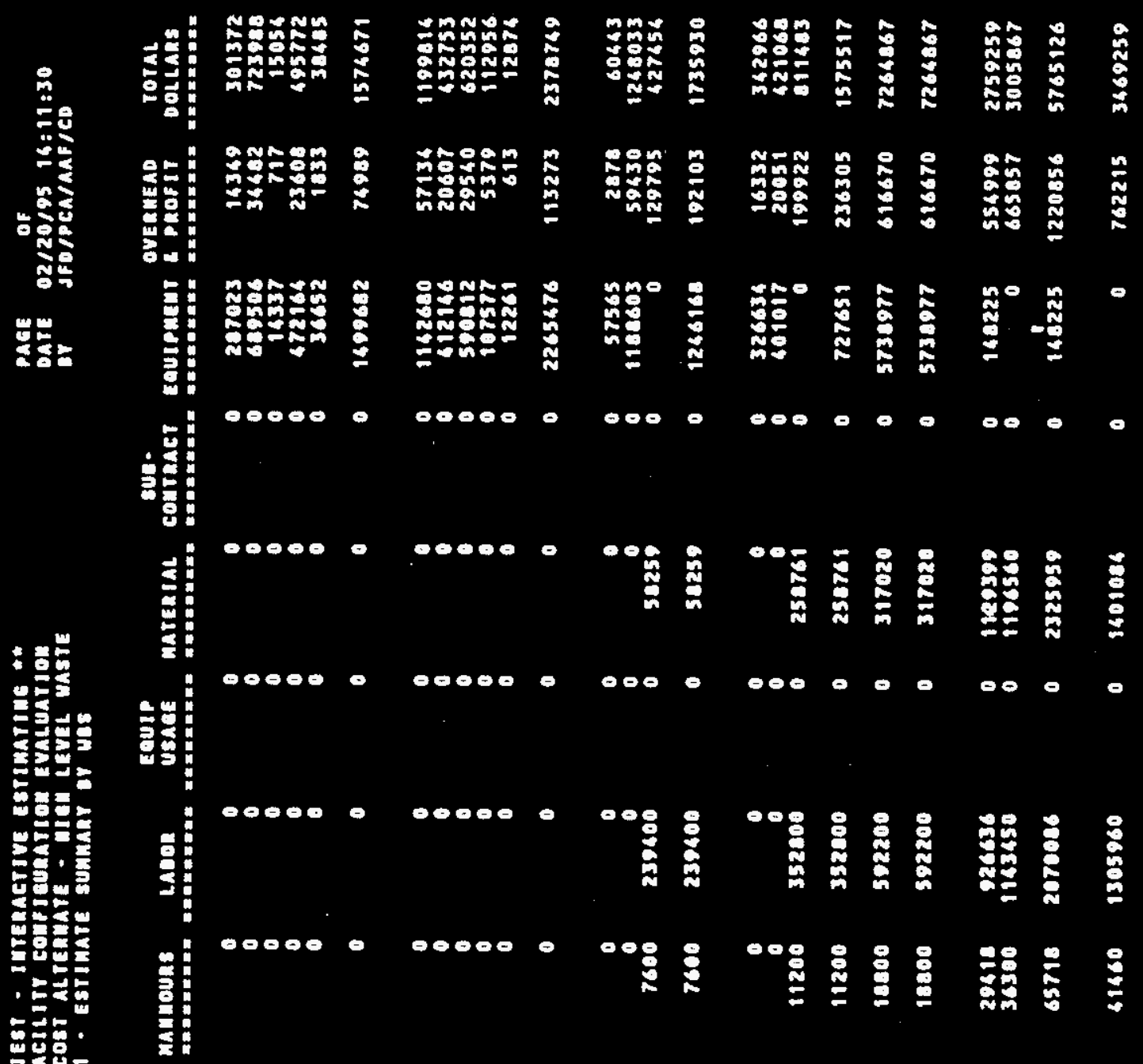




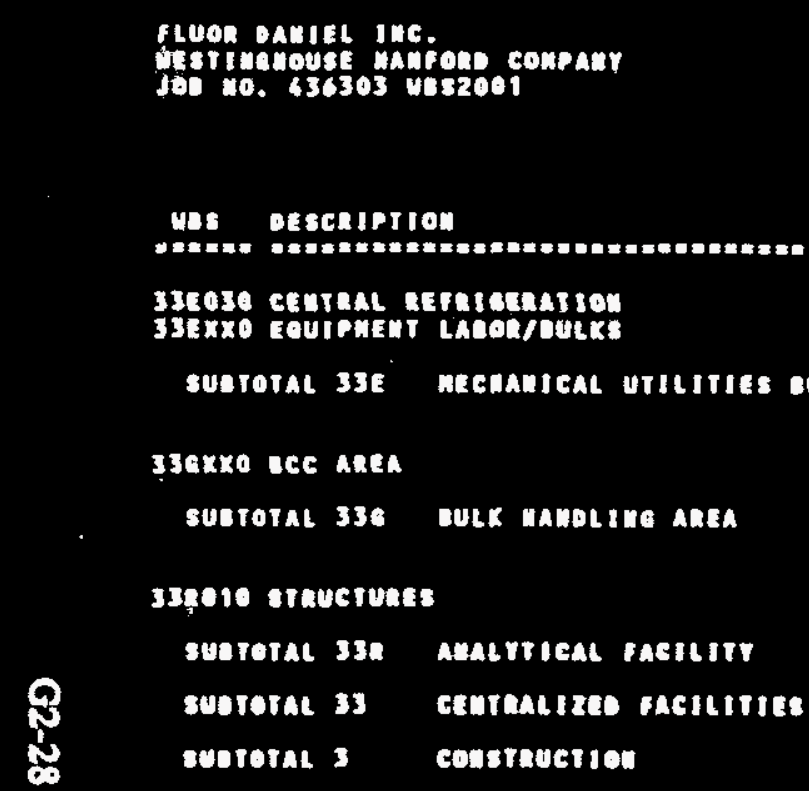

prodect total

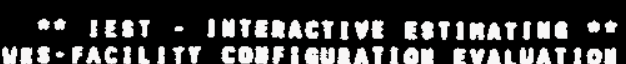

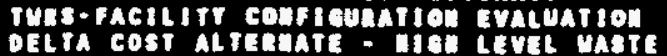

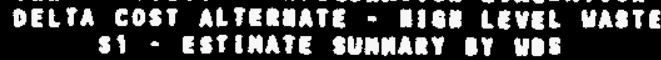

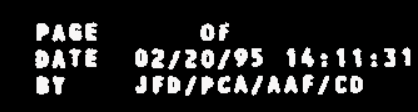

sus. wamowhs

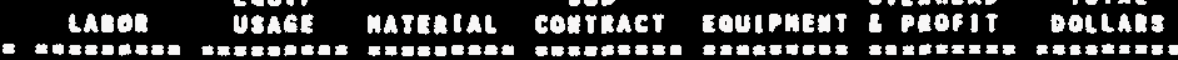

Eautp

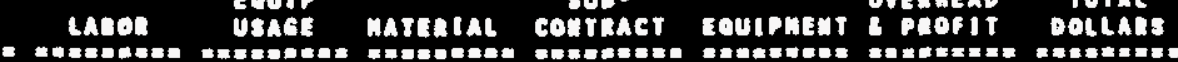

contract

ovenaEAd

rotal

$\begin{array}{llllllll}19000 & 595900 & 0 & 1774305 & 0 & 0 & 405924 & 2778512 \\ 20000 & 455200 & 0 & 615540 & 0 & 0 & 378033 & 1646773\end{array}$

$812602559660 \quad 03791012 \quad 0 \quad 1566172709646$

$\begin{array}{llllllll}600 & 21420 & 0 & 12720 & 0 & 0 & 11989 & 46129\end{array}$

$\begin{array}{lllllll}680 & 21620 & 0 & 12720 & 0 & 0 & 11989\end{array}$

230771 755275s $05721606 \quad 0$ 10747474 522640537248030

230771 75s27ss 0 s721604 18747474522640537240038

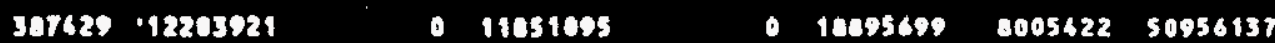

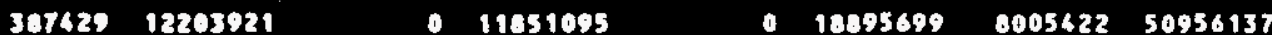




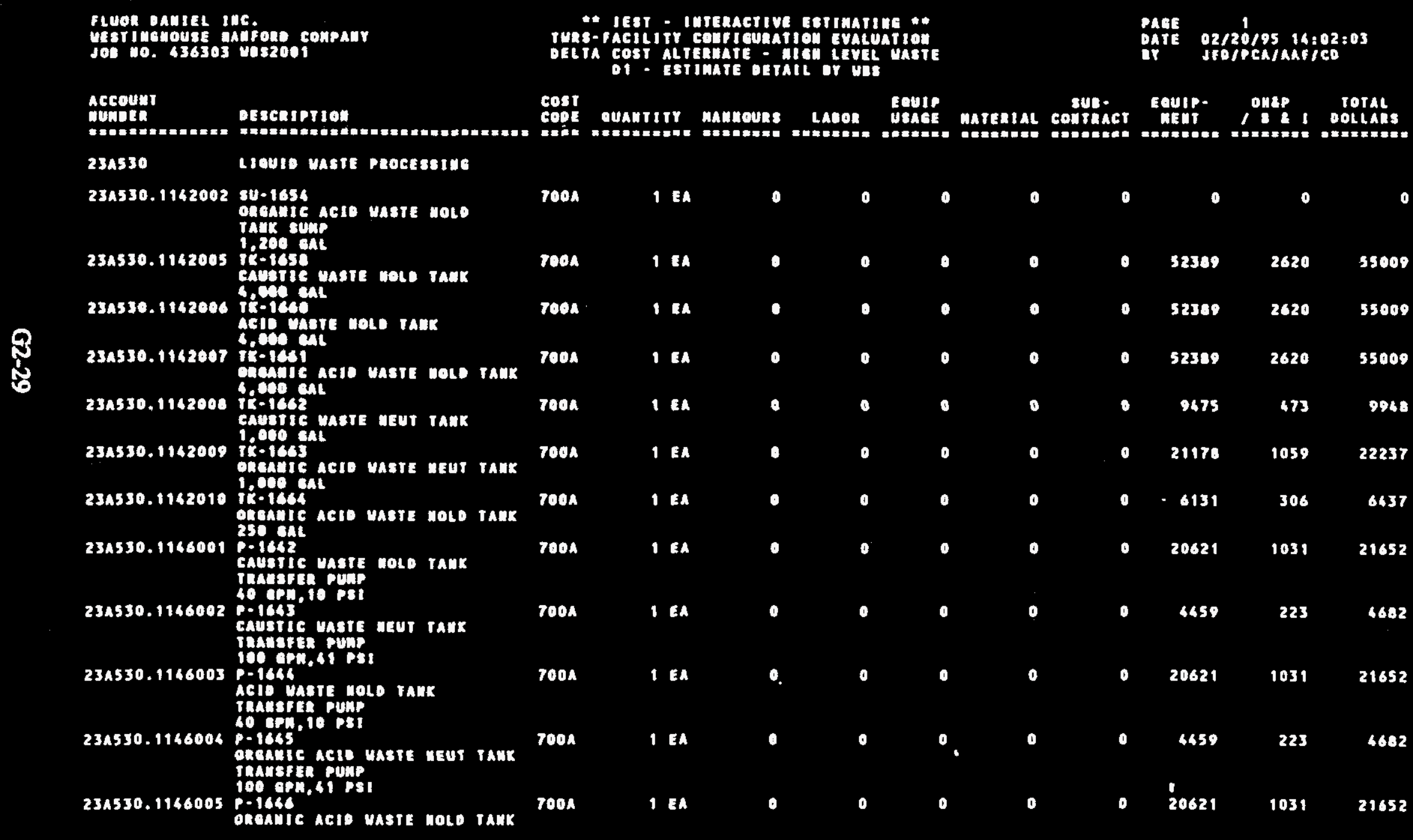


Revision 0

晜

舟 홍

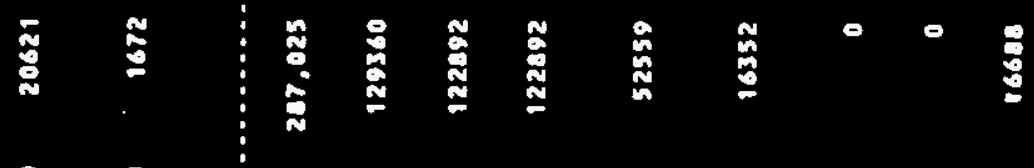

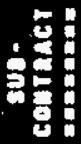

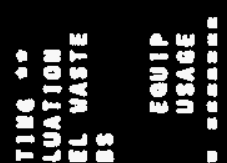

Eस⿱乛龰

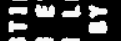

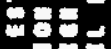

두롱

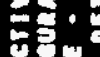

둘를 훌

은

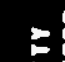

$\div$

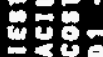

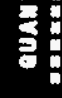

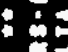

행

8

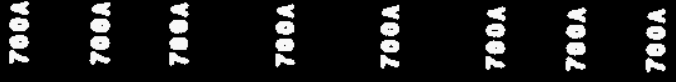

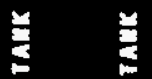

$\stackrel{9}{3}$

형

8
8
8
8
5
8
3
8
0

$\leqslant \pm \leqslant \leqslant \leqslant \leqslant \leqslant$

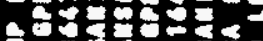

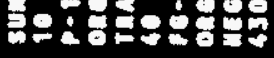

$\frac{8}{8}$

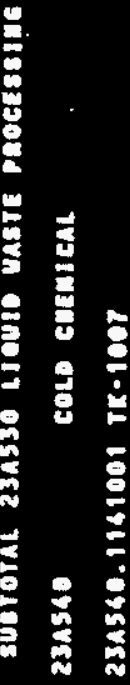

总

$\stackrel{3}{\mathrm{z}}$

흘 훟 혈 है

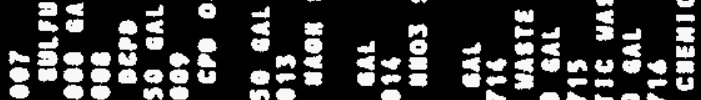

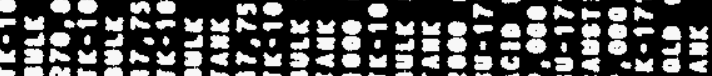

प्रुड

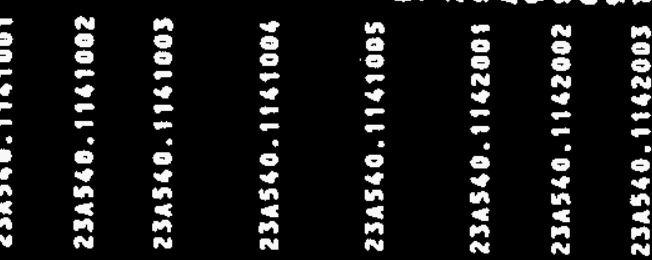




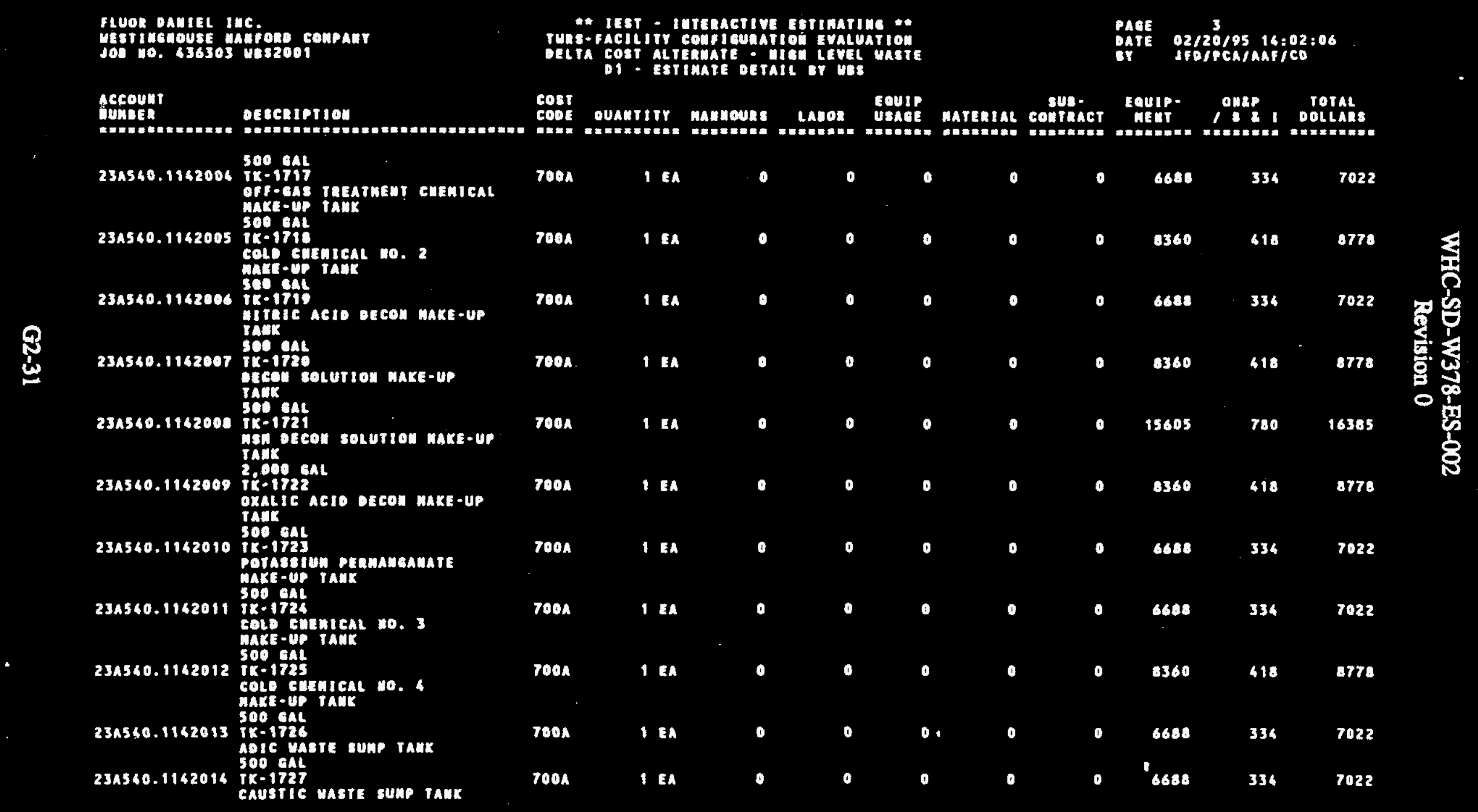




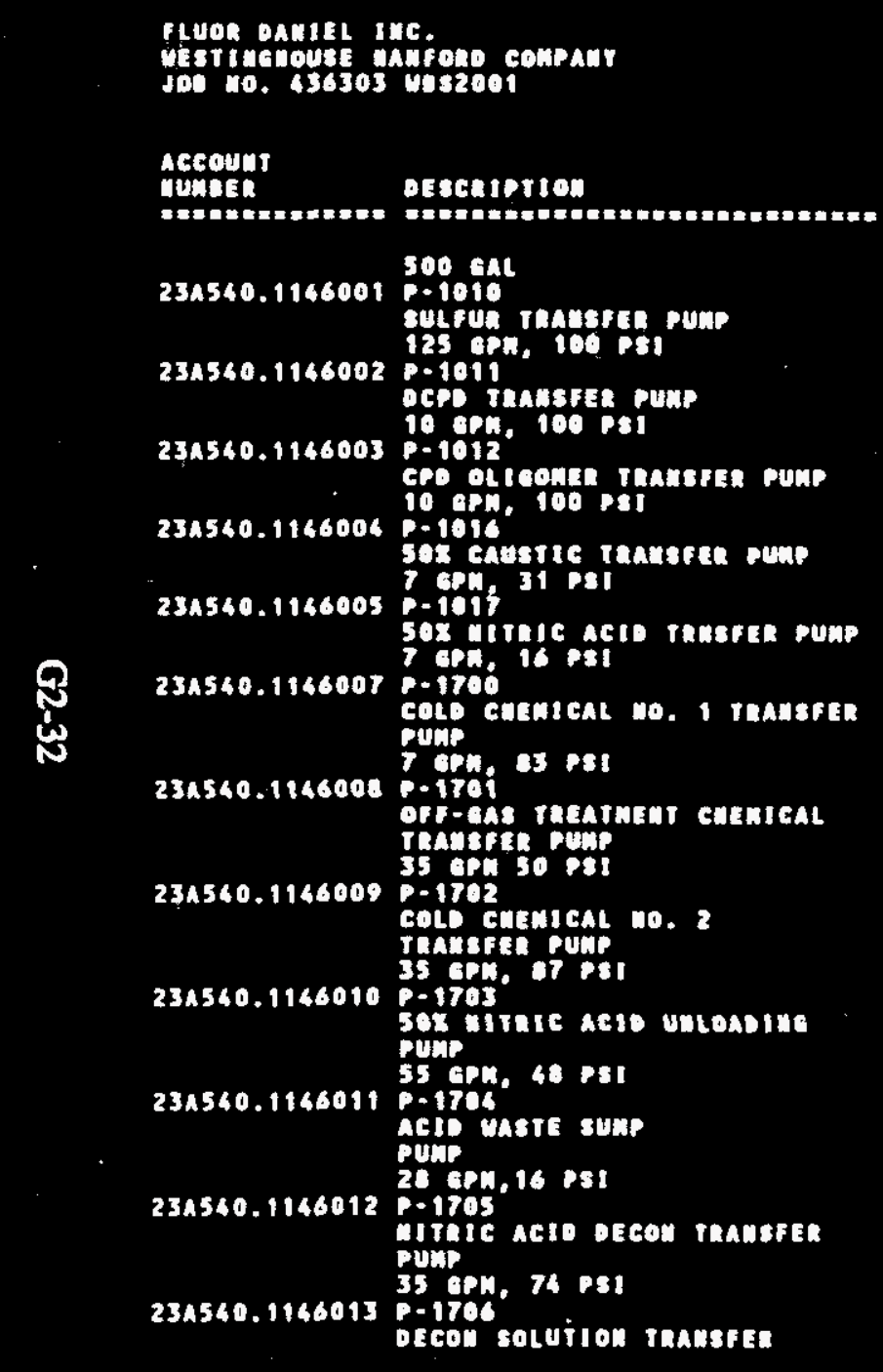

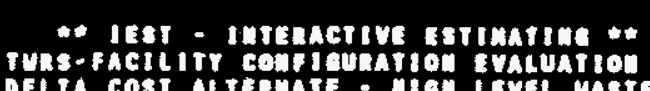

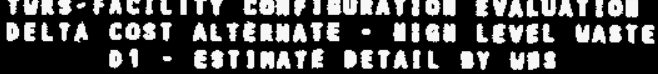

PAGE 02120/95 14:02:07

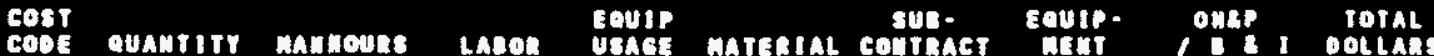

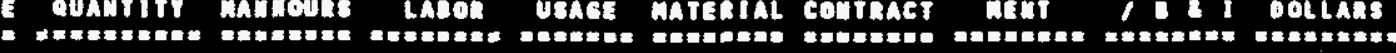

3005

$r 00$

I EA

$700 A$

en

roan

roos

,

0

0

reos

$1 \mathrm{ka}$

0

1 en

reon

1 EA

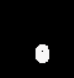

rosk

\& 8

7009

tea

7osa

$1 \mathrm{EA}$

a

1 EA

$a$

7094

$1 \mathrm{kA}$

7000

$1 \mathrm{EA}$

$700 x$

1 हn

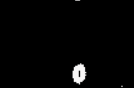

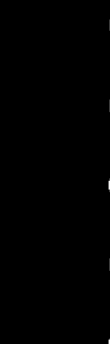

0

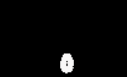

0

0
0
0

becon soluiton ramseft 


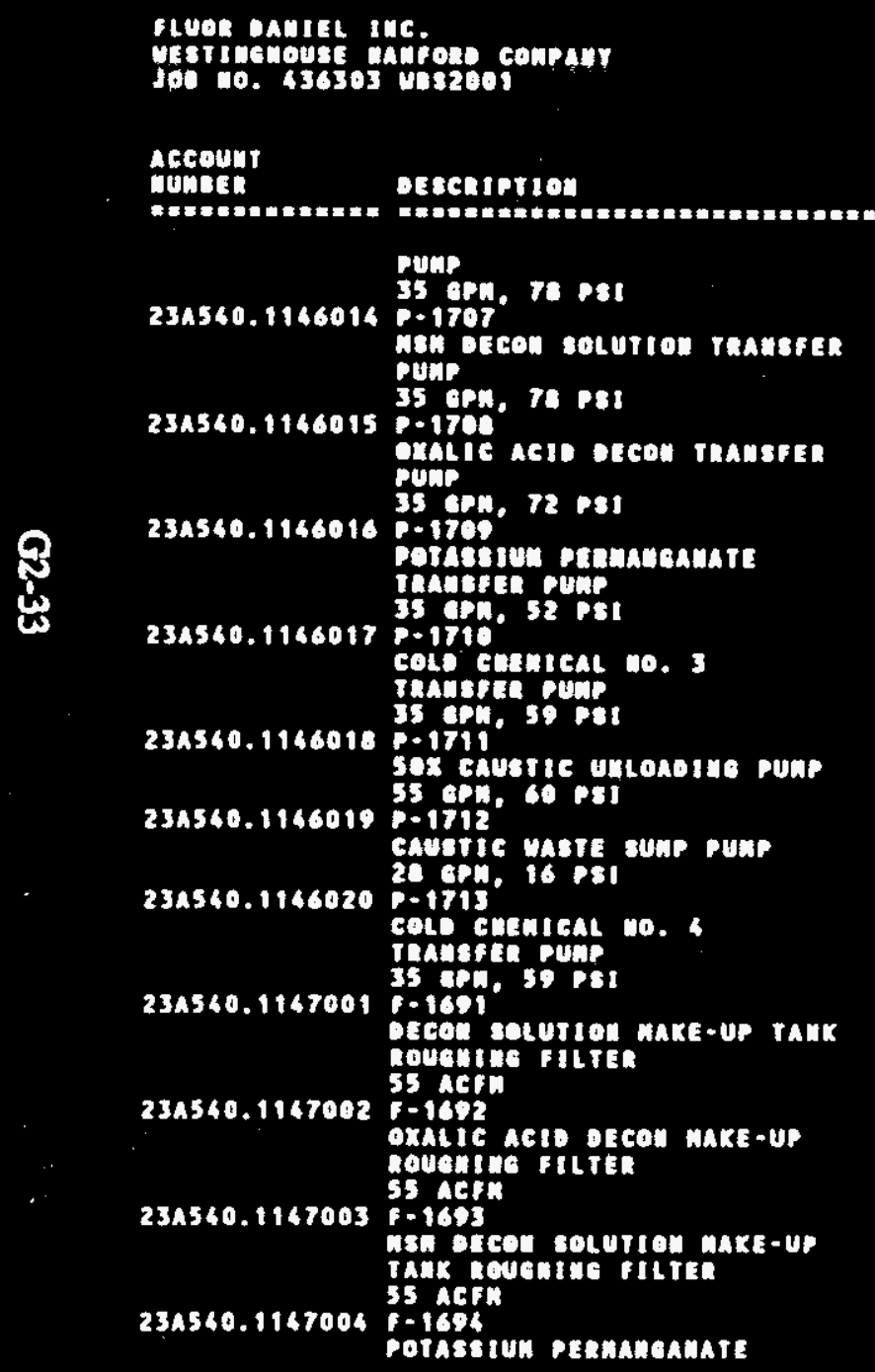
"* IEst : Intennetsve Estimative **

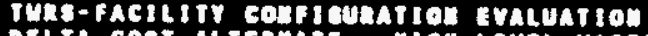

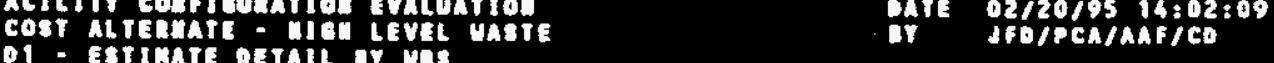

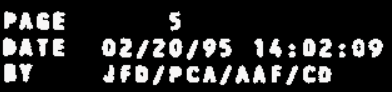

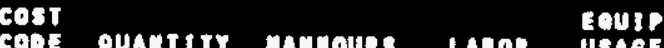

gus -

un- engur-

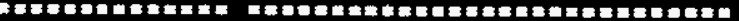

Pret

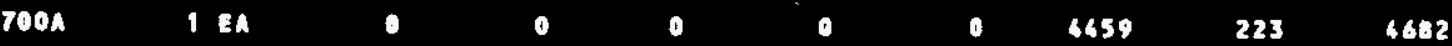

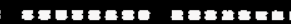

NEIt

\& 1 bollans

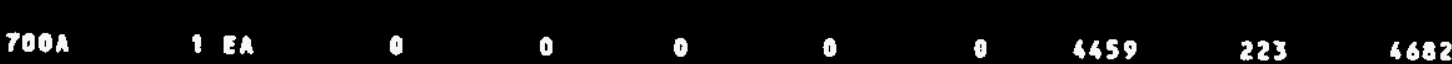

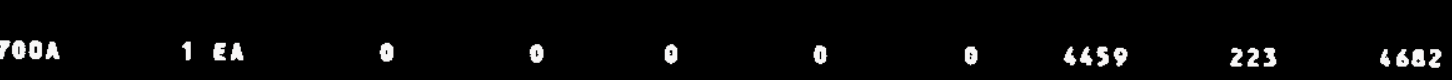

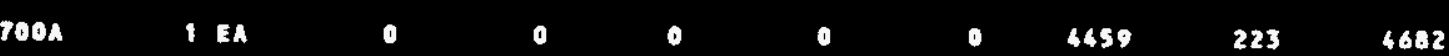

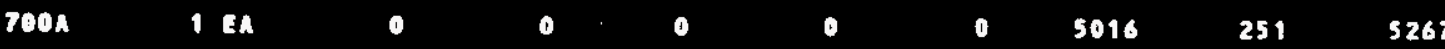

$\begin{array}{rlllllllll}7004 & 1 E A & 0 & 0 & 0 & 0 & 0 & 20064 & 1004 & 21068\end{array}$

700 .

EA

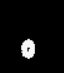

700

1 EA

0

$4659 \quad 223 \quad 4682$

$700 a$

$1 \mathrm{EA}$

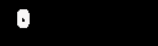

roon

I EN

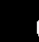

700A

$1 \mathrm{EA}$

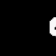

roon

$1 E A$

0 


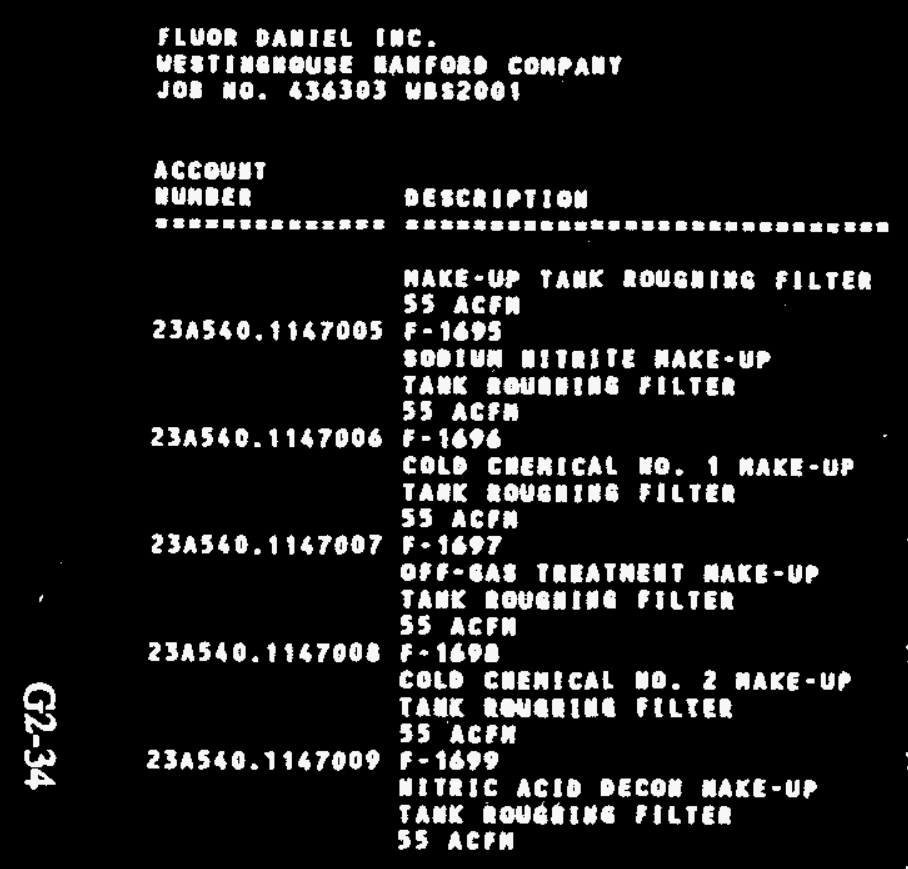

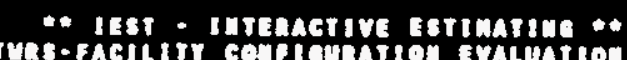

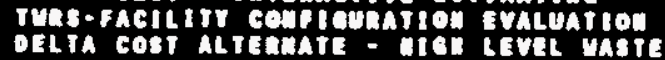
PAGE
DATE $02 / 20 / 95$ 16:02:16
OY JPB PCA/AAF/CD

o1 - Estimate oerail or wo

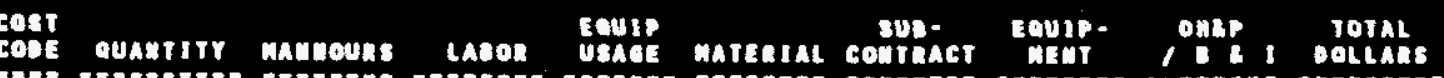

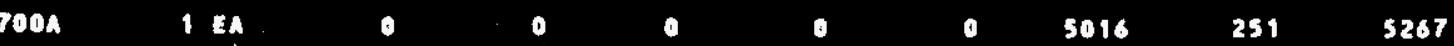

raga IEA $\quad 0 \quad 0 \quad 0 \quad 0 \quad 5016 \quad 251 \quad 5267$

$\begin{array}{rllllllll}7004 & 0 & 0 & 0 & 0 & 0 & 5016 & 251 & 5267\end{array}$

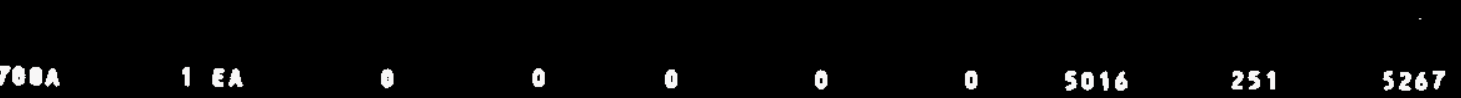

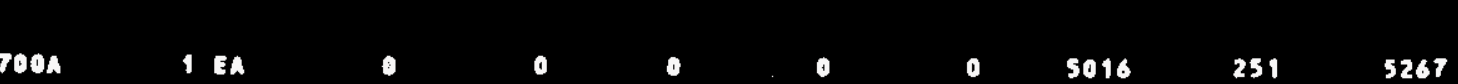

suntotal $23 A 560$ CoLD CuEnICAL

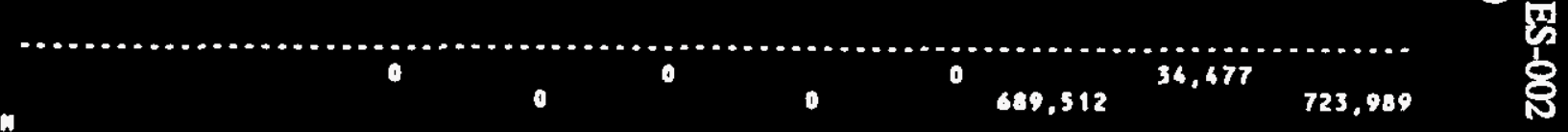

23Asso duLK colo carnical vent ststen

234550.1143001 no-17614ä

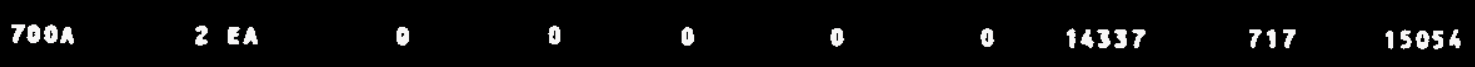

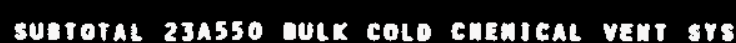

23asao

colb casmical

$234580.114200154 \cdot 1774$

Rot? stuner sun

$23 A 500.1142002$ ik-17\%s

TR-177s

234580.1146001 : $: 1772$

p:1772
fsut sample punt

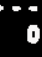

0

0

roos

700 a

roon
1 EA

1 EA

1 EA

-

0

0

cont samp pup 


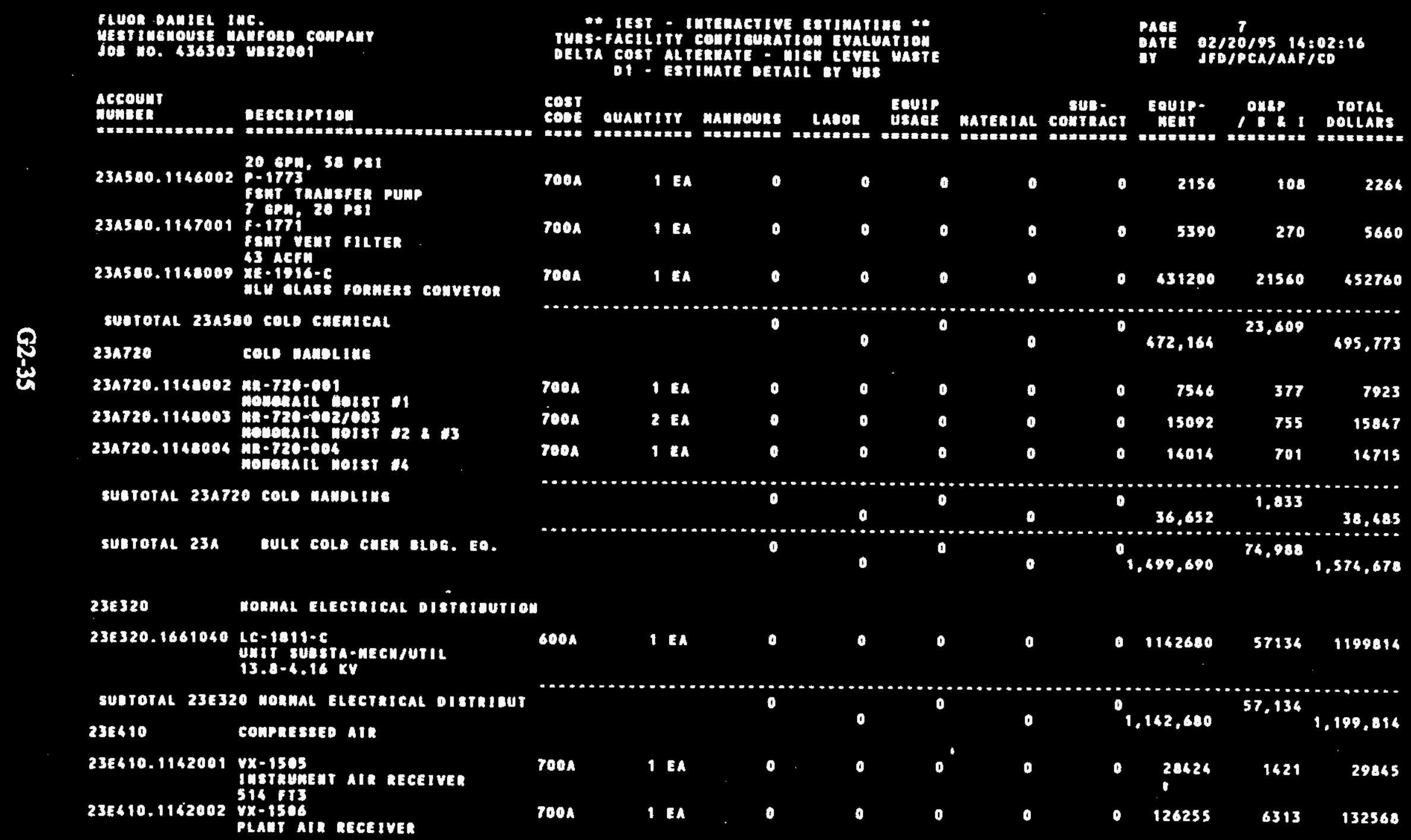




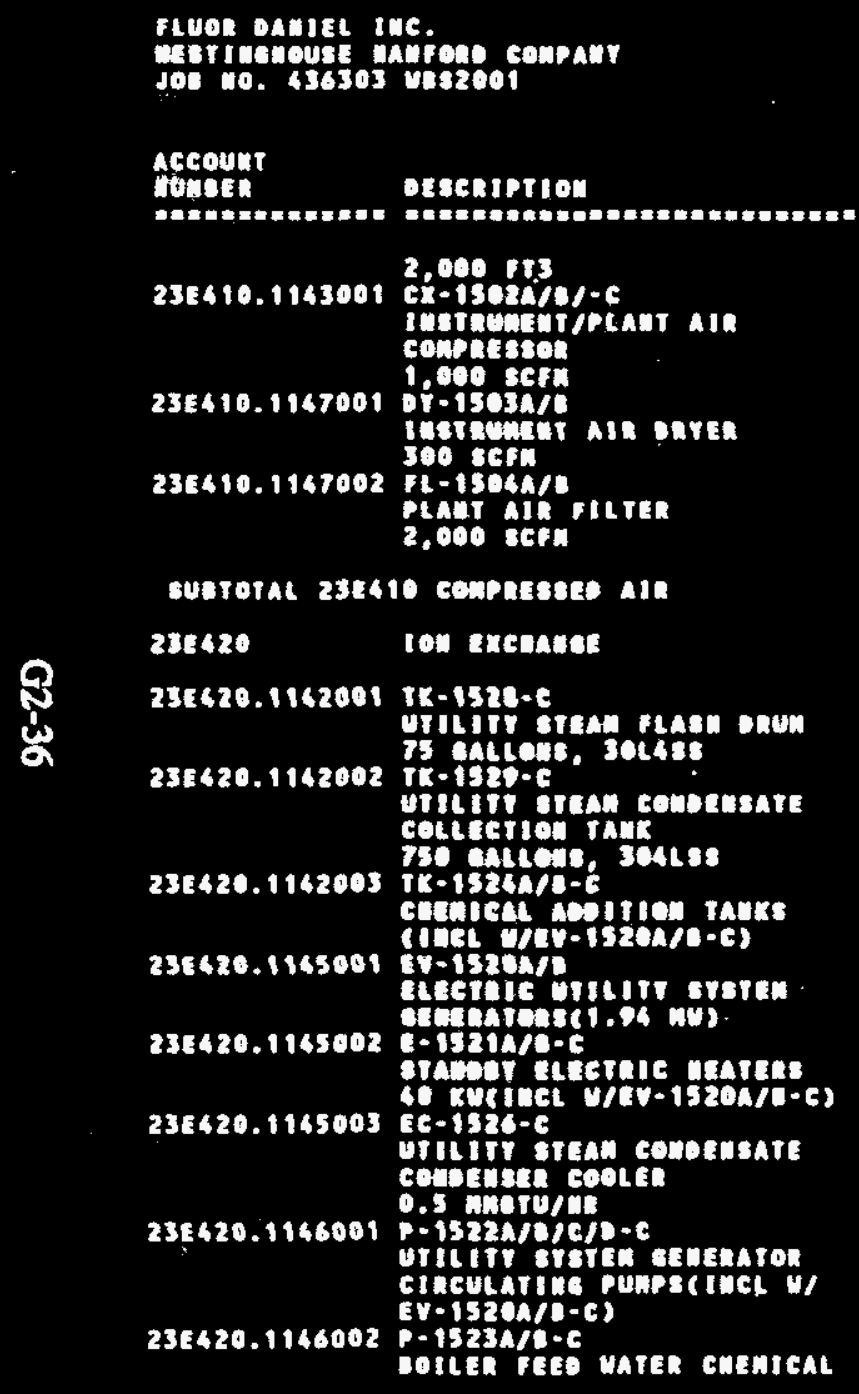

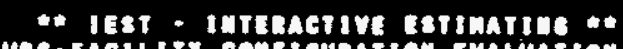
Tuas-Factitir confeunation EVALutio
Detra cost alsentare - wien trvet uaste
D1 - Estiante opratl of use

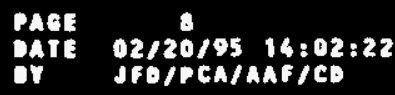

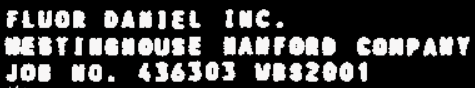

Quantity mannouns lapos usace matental courtact

cours sus-

Eouip. ont? тотAL anchosh

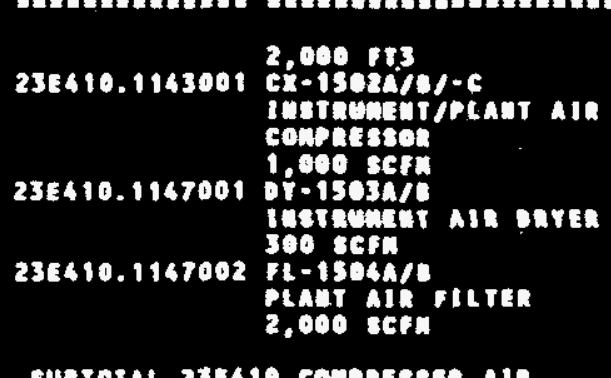

$\begin{array}{cccccccccc}\text { roOA } & 3 E A & 0 & 0 & 0 & 0 & 0 & 205165 & 10258 & 215423 \\ 700 A & 2 E A & 0 & 0 & 0 & 0 & 0 & 43436 & 2192 & 46028 \\ 700 A & 2 E A & 0 & 0 & 0 & 0 & 0 & 4667 & 424 & 4891\end{array}$

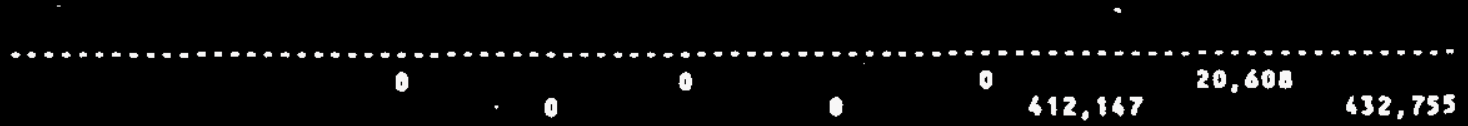

\begin{tabular}{|c|c|c|c|c|c|c|c|c|c|}
\hline $708 \mathrm{~A}$ & I Eh & 0 & 8 & 8 & $\theta$ & 0 & 18700 & 539 & 11319 \\
\hline 7000 & $1 \mathrm{EA}$ & 0 & 0 & 0 & 0 & 0 & 83670 & 4184 & 87862 \\
\hline jes & $2 \mathrm{EA}$ & 0 & 0 & 0 & 0 & 0 & 0 & 0 & 0 \\
\hline
\end{tabular}

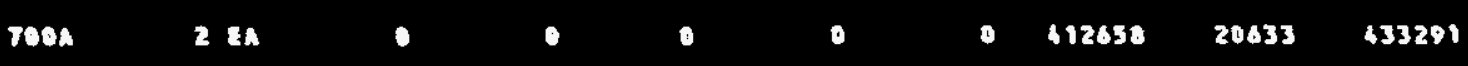

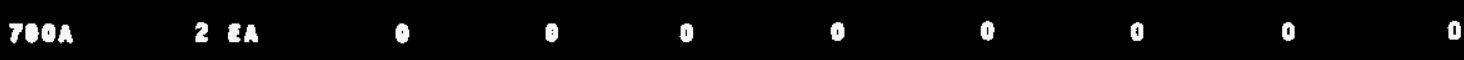

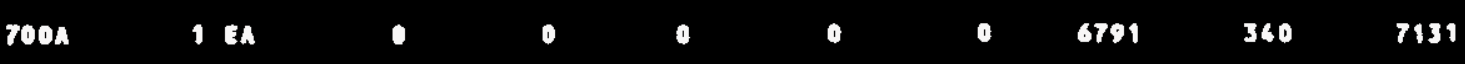

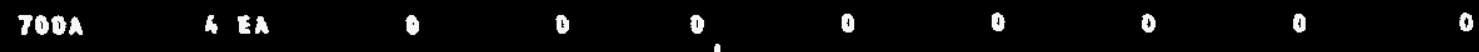

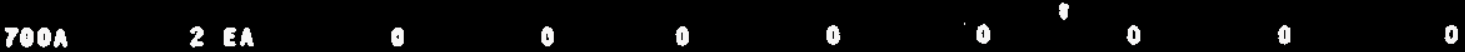




\section{WHC-SD-W378-ES-002}

Rovision 0

葛

浅

舟

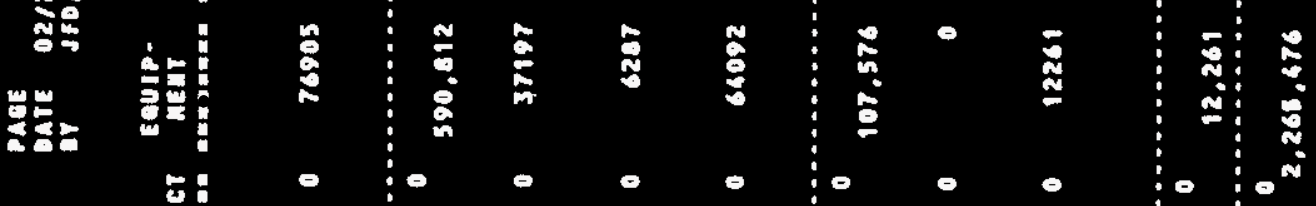

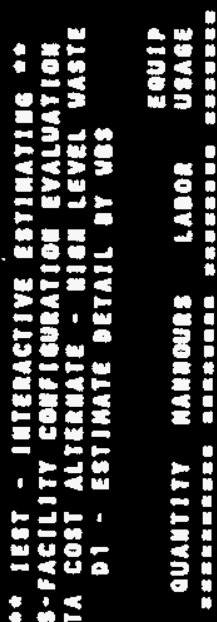

通

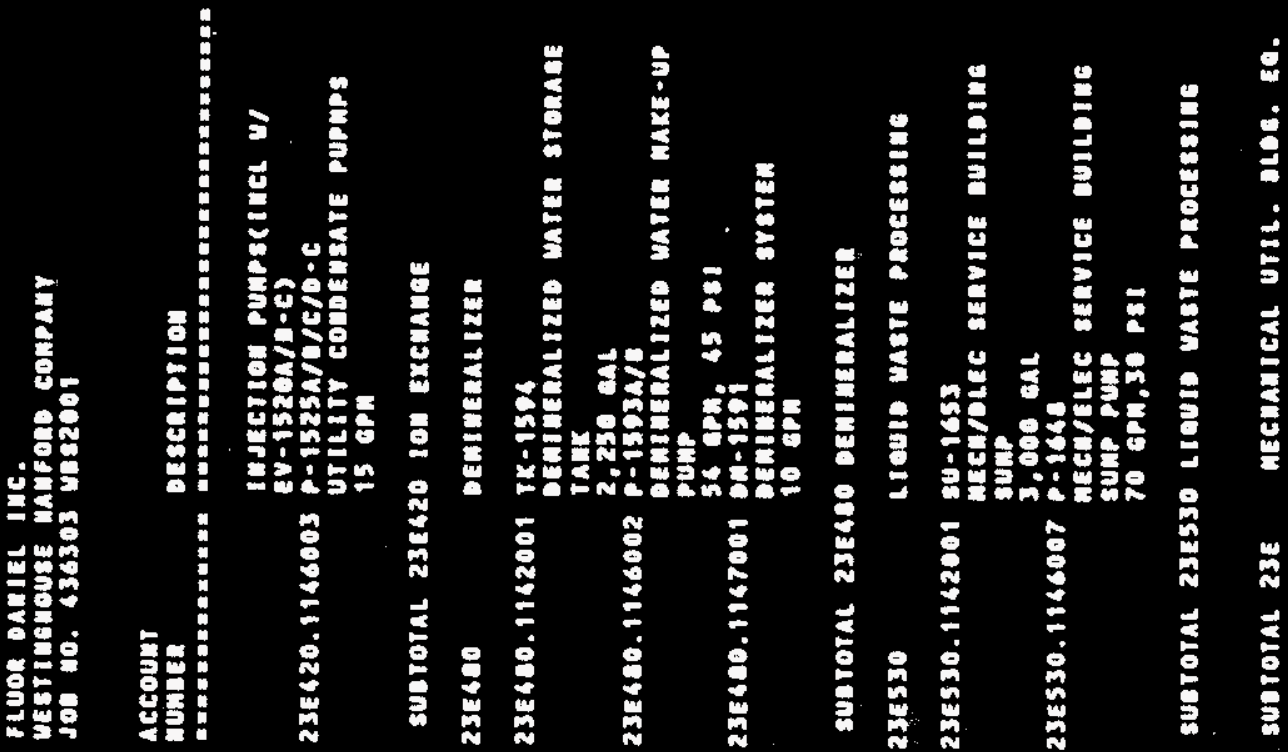




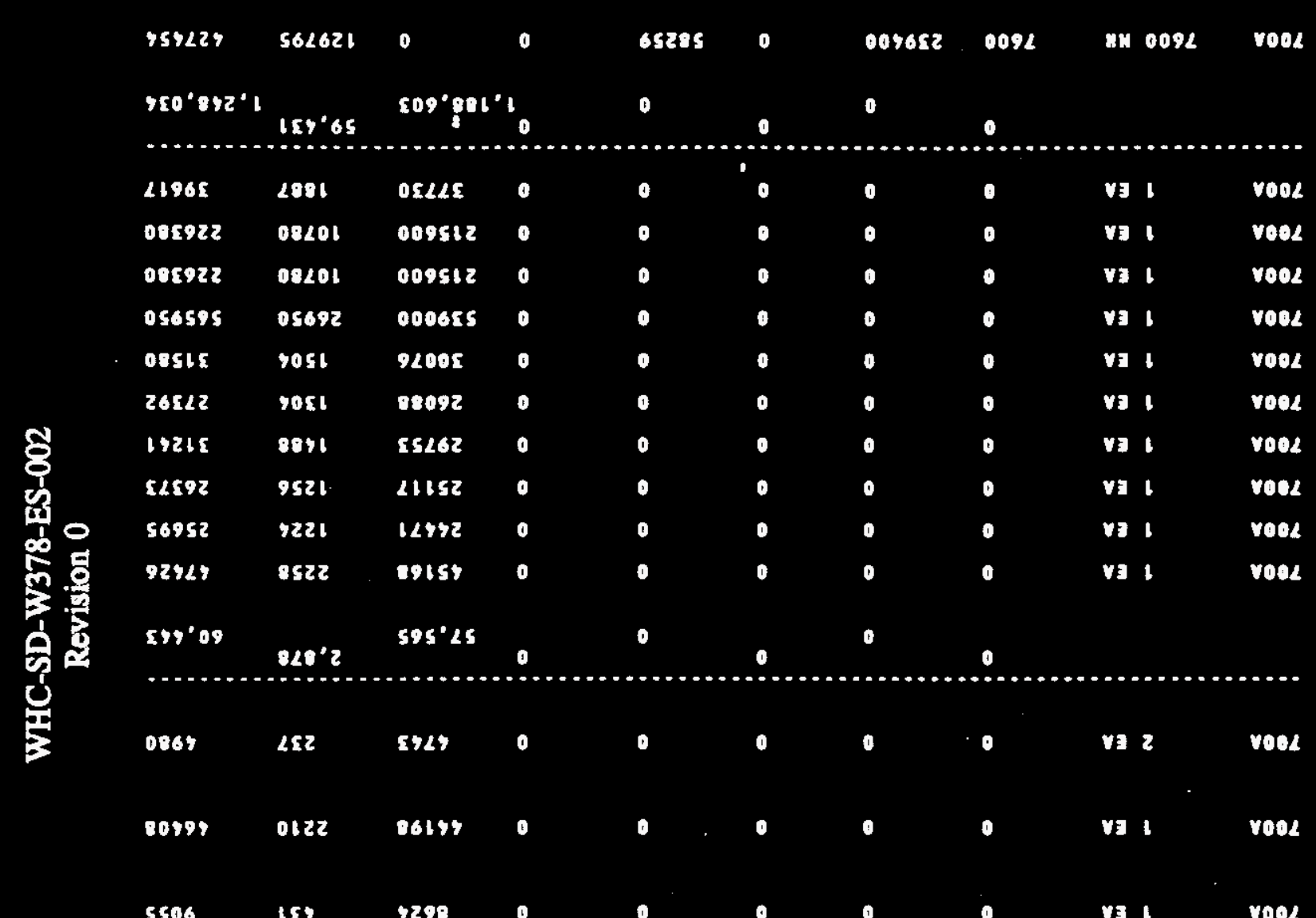

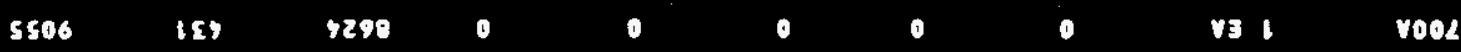

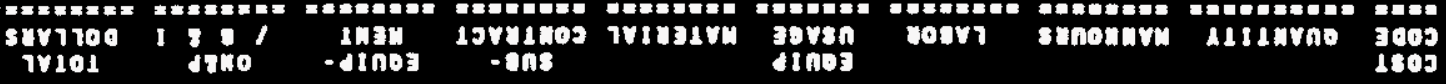

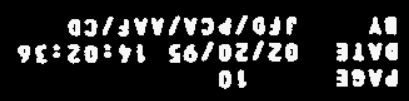

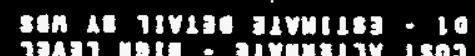

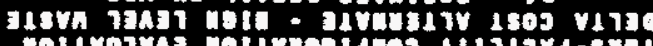

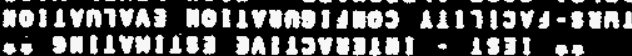

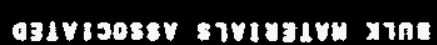

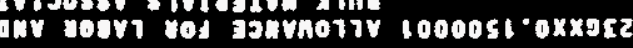

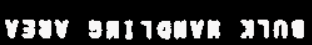

oxxerz Tvasusus a

amic natve nit

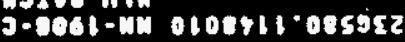

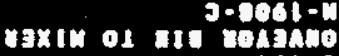

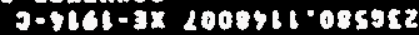

vacreitu xany

2-5061-3x 20004t1-08sect Irte enve

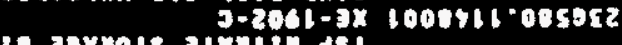
nots arvarit ds 1

sure soriois oen

surs gavions $3-2041-1$

$3 \cdot 9001 \cdot-8$

010 jovuass gagrt

nte zavreis 3 -soct.

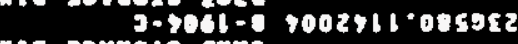
j-best-8 coozsat cosecz

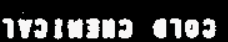

essers

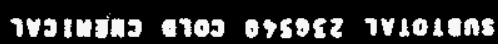
tod opt "udes it

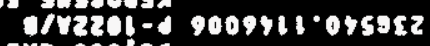
ive ecotos

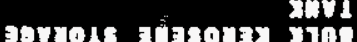

$2201-312001961 \cdot 055952$ ivo ozes

3avuods gan snowetuny yin

stet-112 9001461-045952

Tพอง

oysert

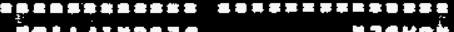

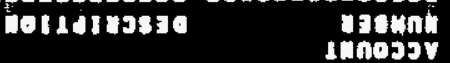

bogzen cosgry on ger invanos duasuvi gsnonont 1 isn 


\section{Revision 0}

\$

然

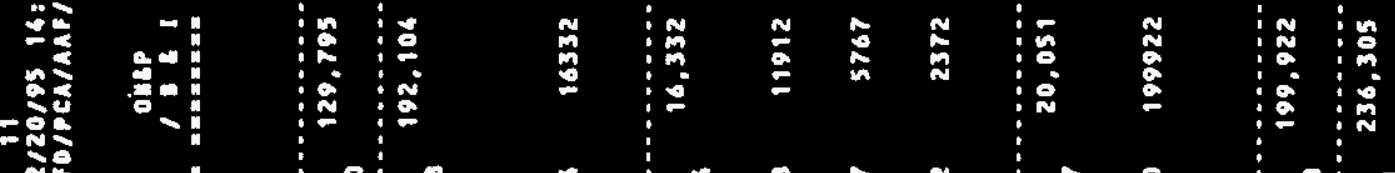

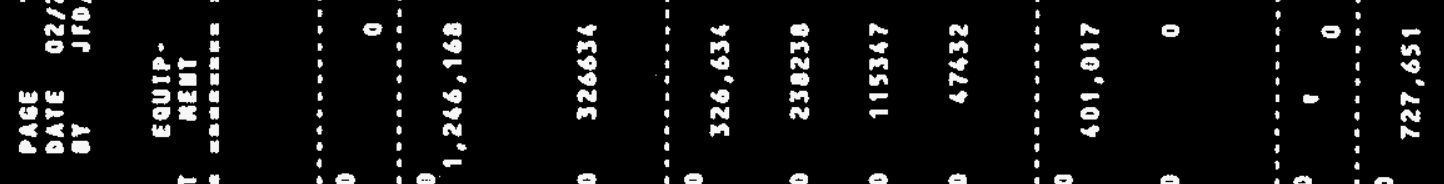

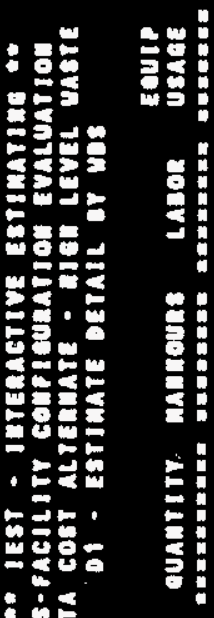

해용

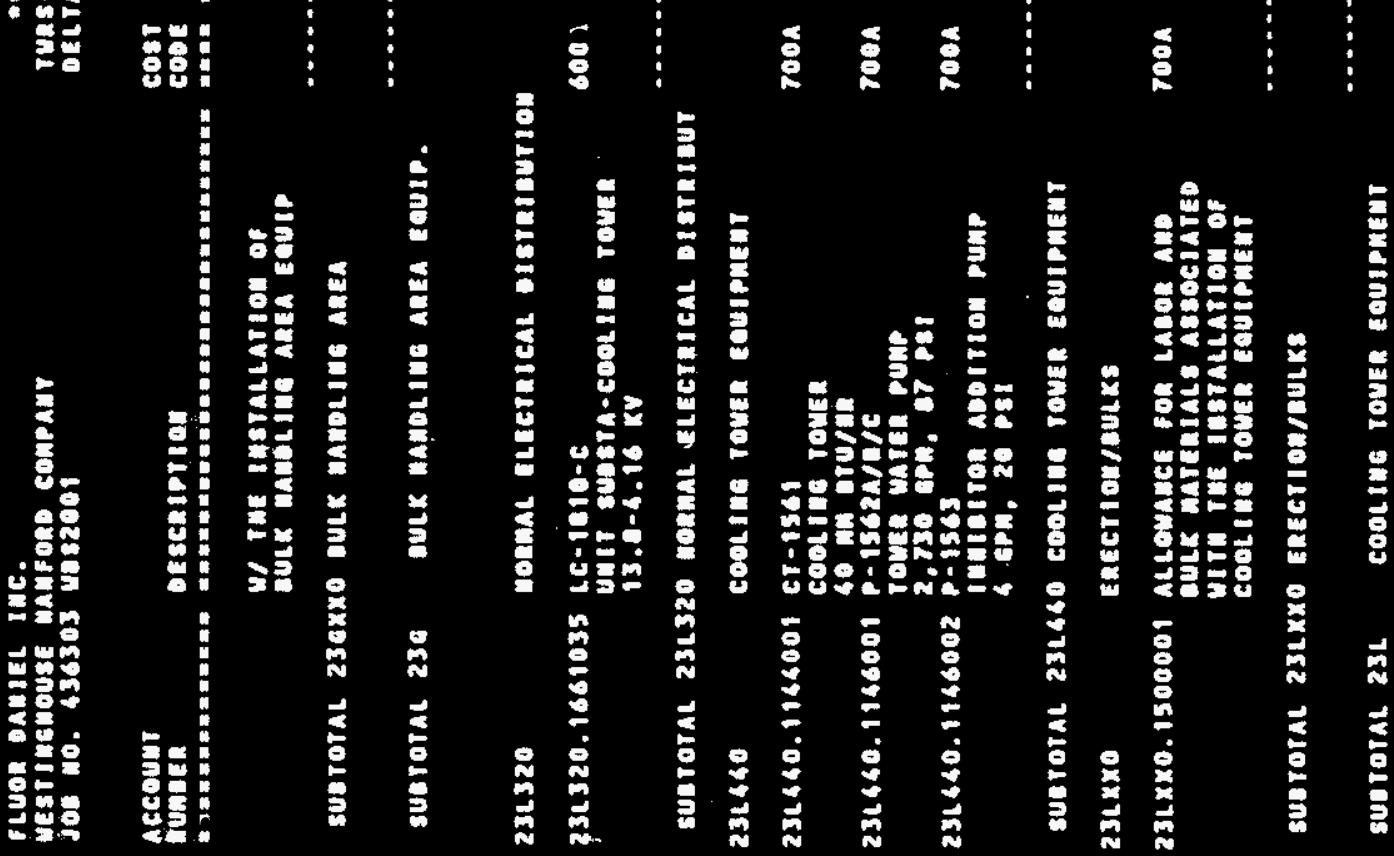




\section{WHC-SD-W378-ES-002 \\ Revision 0}

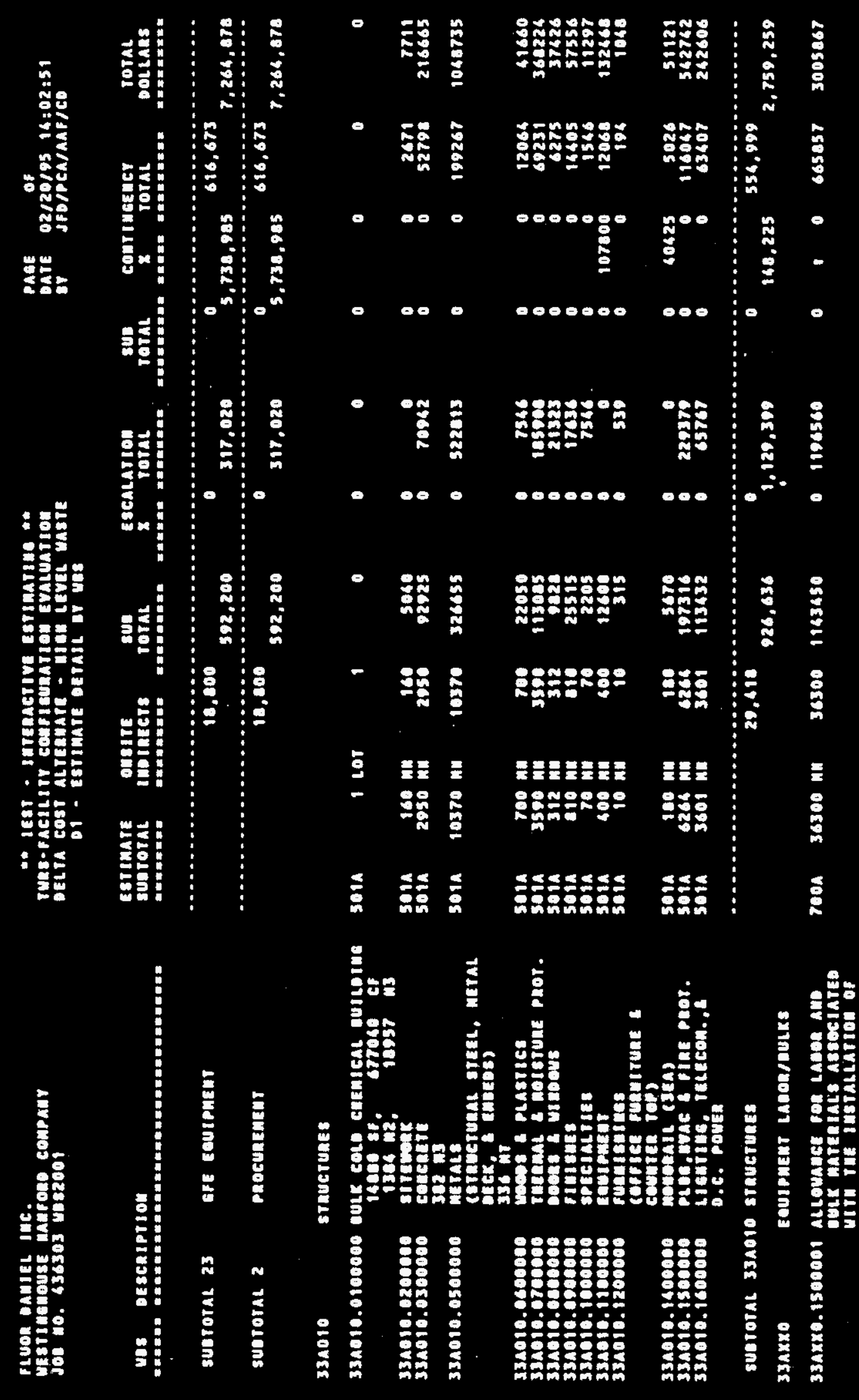


WHC-SD-W378-ES-002

Revision 0
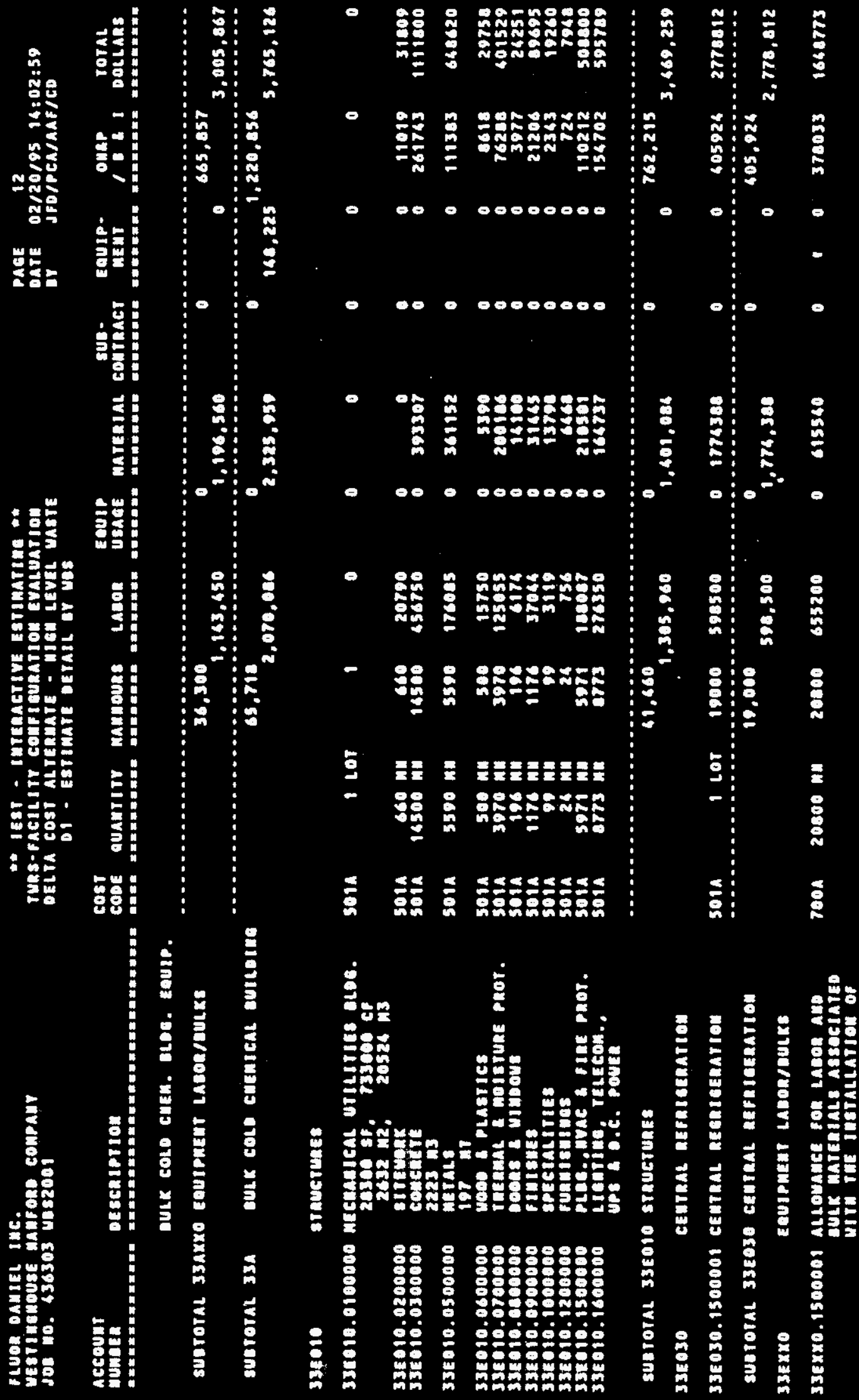

G2-41 


\section{WHC-SD-W378-ES-002 \\ Revision 0}

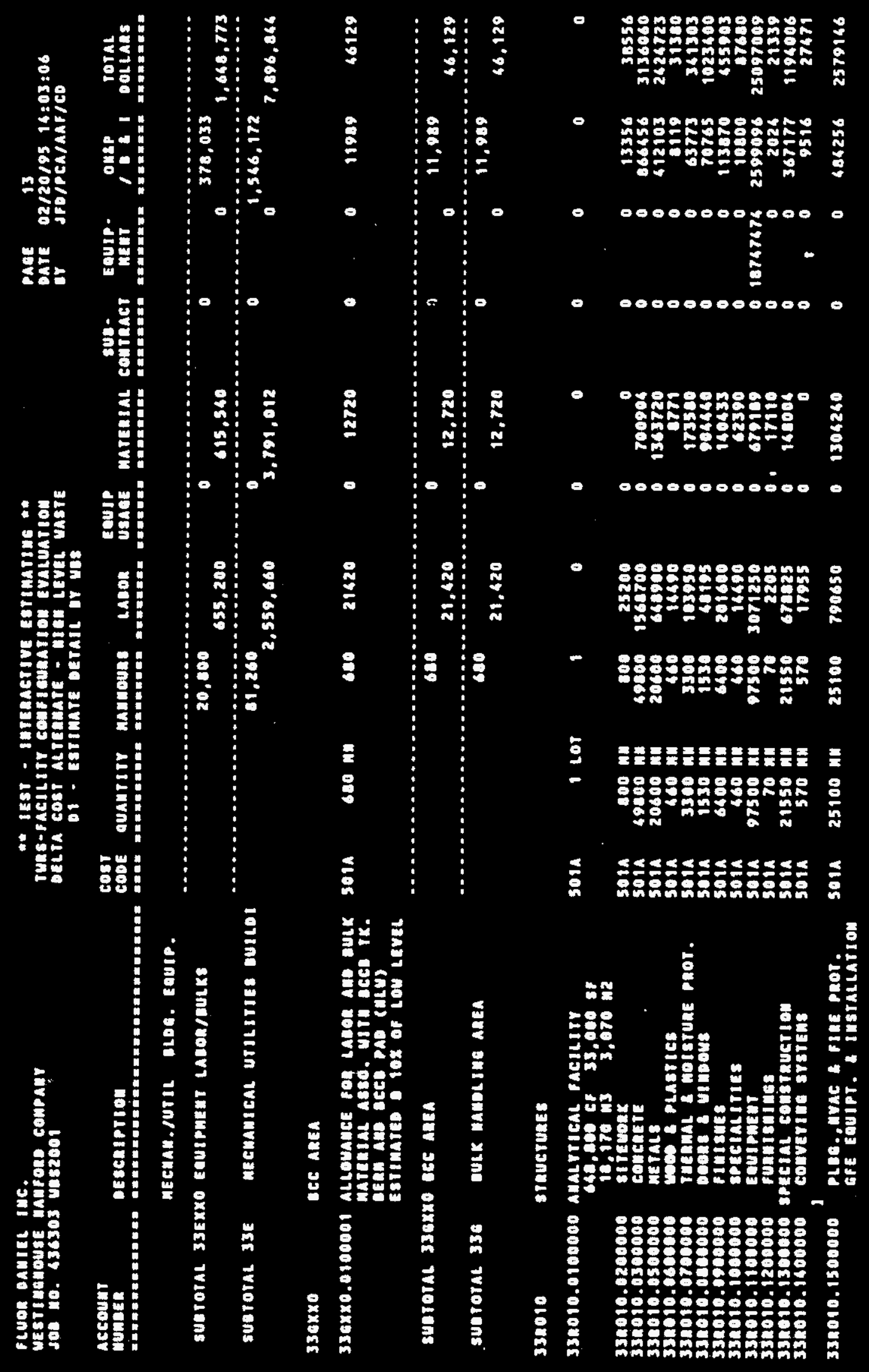




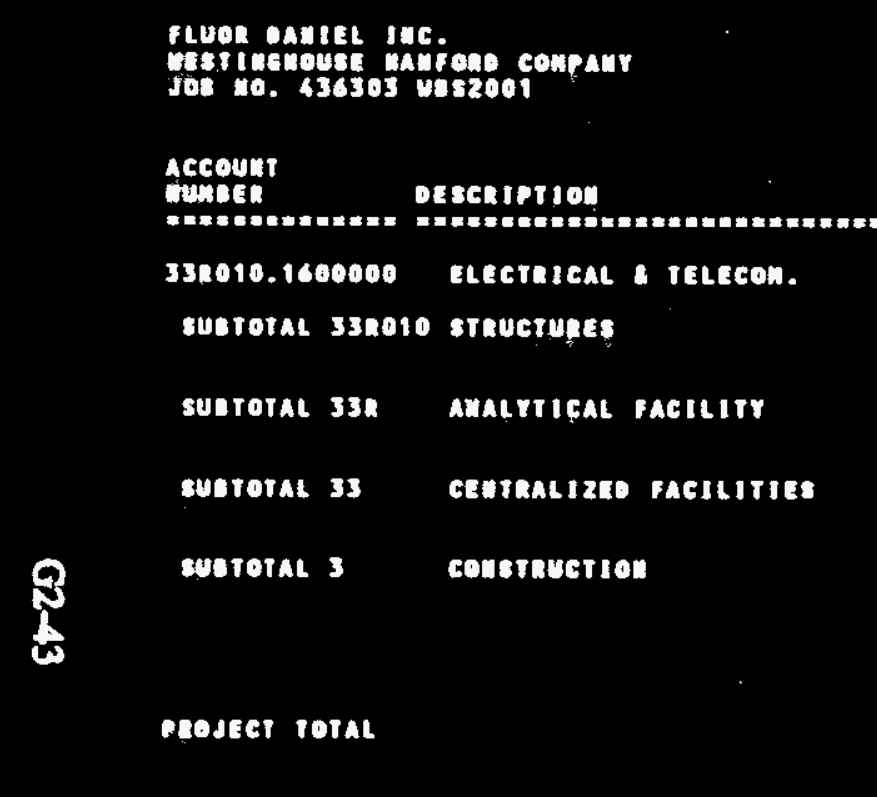
* IEst - Iurenactive estimatiag -

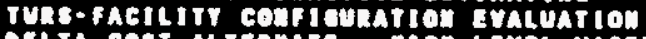

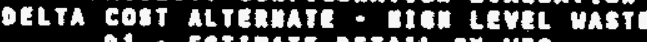

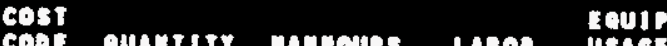

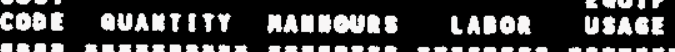

marketal conthict

PAge $16,0516: 03: 13$

of IFDPeAlaAfico

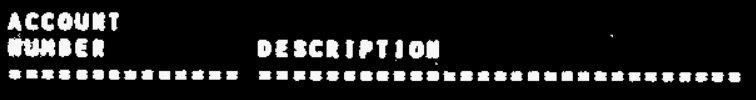

33010.1600000 ELEetalcal a telecon.

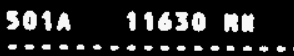

- 210423 $239,771,0.352,755$ s,

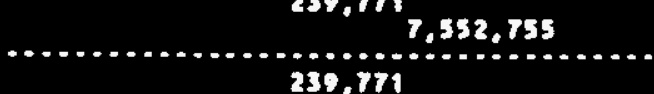

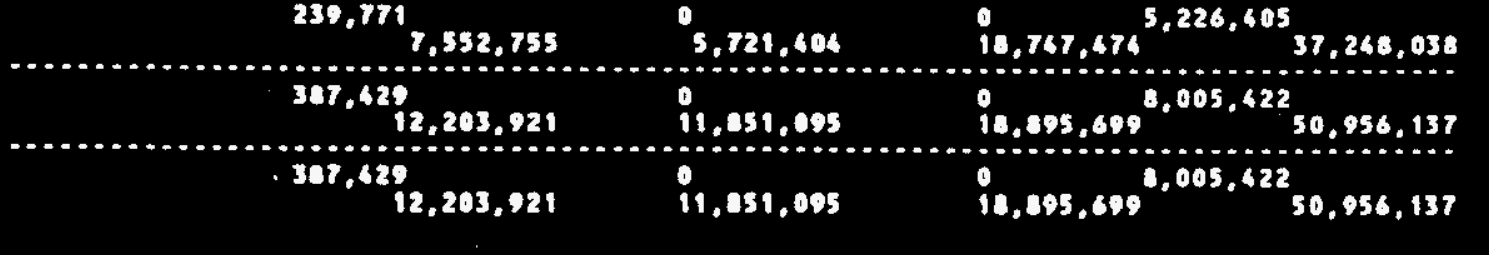


Ftuon paWJEL IUC.

mancone cenpatry

tos mo. 636304 uss 7001
** test - InTERaetrye Estinarine "* ALTERMATIVE MELTE ororens AssesenEut at STIRRE MELTE CUT UP GELL - CASE F DOE_ROI - prodect cost summar cost
cose Deschiption

501 custernes

700 spetal EQUip/PRocess ststens

Prodect total
Tercalate:

Total cost

$2,677,221$

$2,169,507$

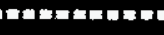

$4,026,008$

$x$

contruacus

rotal

$\mathbf{0}$

0

-
PAGE OF

ATE 02/20/95 16:26:38

or AFo/PCA/AAF

.

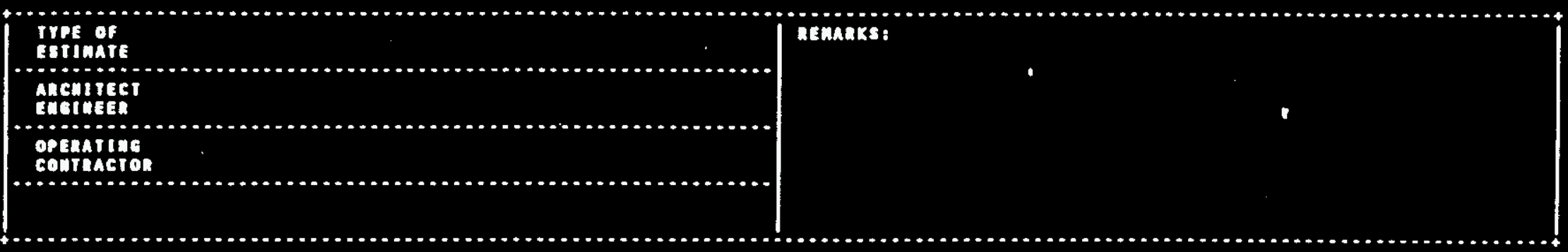


Fluan DAMIEL IUC. UEST I MGHOUSE HAMfong conpaur Jos 10.436304 uns 7001

\section{Account} description

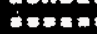

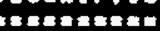

221710 REMOTE MAMLLi DO EQUIPAENT

221710.1300001 cutup celt surEL yimoous 221710.140000 All Fant cutup cell nen's

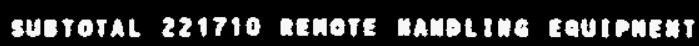
221850 MELTER CUt UP CELl EAUTAEA

271050.1160105 abrastre sal

2210se. I149125 ane say oreten

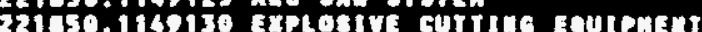
221050.1169135 EleGt20 necthatcal manio.

ULATod

14iks sinteren

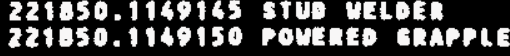

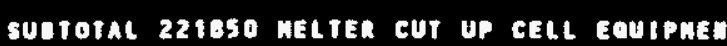

suntoral 221 In-cell EQUipaEmt

SURTOTAL 22 GF PROGUREMEAT

sustoral 2 procunenent

312010 Structunes

312010.0300001 CUTUP GEL CONGRTE CuTuP CELL conchete

312010.0300002 CUTUP CELL CoN
ELEVATEO SLAL
221950.1149101 me ewayleat saY

22159.1169110 LARGE gitca

22105.1169120 plasma Tonen steren

3LAR ON ERADE

\begin{tabular}{|c|c|c|c|c|c|c|c|c|c|c|}
\hline $\begin{array}{l}790 \\
700 \\
700 \\
709 \\
700 \\
700\end{array}$ & 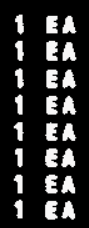 & $\begin{array}{l}8 \\
0 \\
0 \\
0 \\
8 \\
0 \\
0\end{array}$ & $\begin{array}{l}0 \\
0 \\
0 \\
0 \\
0 \\
0 \\
0 \\
0 \\
0\end{array}$ & $\begin{array}{l}0 \\
0 \\
0 \\
0 \\
0 \\
0 \\
0\end{array}$ & $\begin{array}{l}0 \\
0 \\
0 \\
0 \\
0 \\
0 \\
0\end{array}$ & $\begin{array}{l}0 \\
0 \\
0 \\
0 \\
0 \\
0\end{array}$ & $\begin{array}{r}1078 \\
1978 \\
99176 \\
5390 \\
43120 \\
209500 \\
10780 \\
005500\end{array}$ & $\begin{array}{r}54 \\
56 \\
4959 \\
270 \\
2156 \\
13675 \\
539 \\
40425\end{array}$ & $\begin{array}{r}1132 \\
1132 \\
106135 \\
5660 \\
45276 \\
282975 \\
11319 \\
068925\end{array}$ & 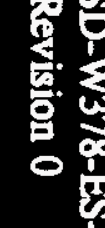 \\
\hline $\begin{array}{l}700 \\
700 \\
700\end{array}$ & $\begin{array}{l}1 E A \\
1 E A \\
1 E A\end{array}$ & $\begin{array}{l}0 \\
8 \\
0\end{array}$ & $\begin{array}{l}0 \\
0 \\
0\end{array}$ & $\begin{array}{l}0 \\
0 \\
0\end{array}$ & $\begin{array}{l}0 \\
0 \\
0\end{array}$ & $\begin{array}{l}0 \\
0 \\
0\end{array}$ & $\begin{array}{l}53900 \\
53900 \\
53900\end{array}$ & $\begin{array}{l}2695 \\
2695 \\
2695\end{array}$ & $\begin{array}{l}56595 \\
56595 \\
56595\end{array}$ & \\
\hline
\end{tabular}

"* IEst - Intenactive Estimative *

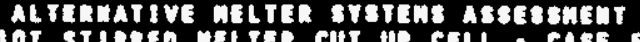

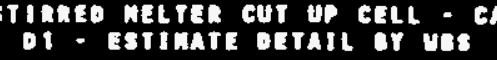

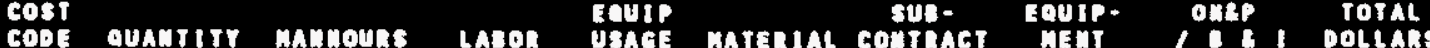

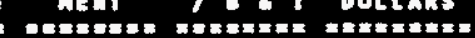

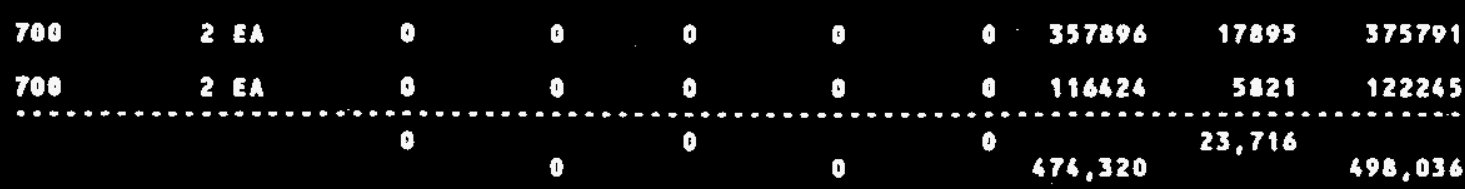

PAgE $02,20 / 95 \quad 16: 28: 25$ Iforpcainat

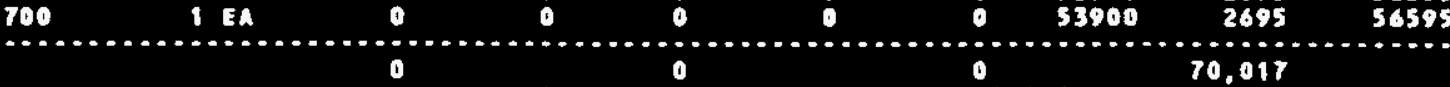
$1,670,33$

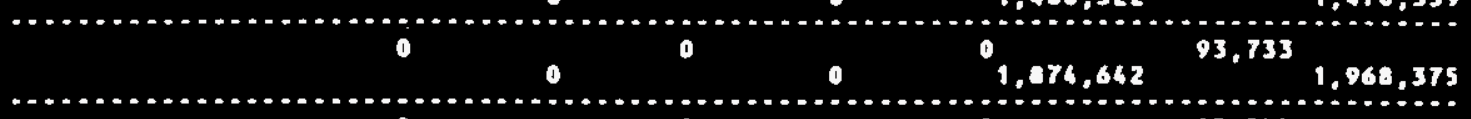

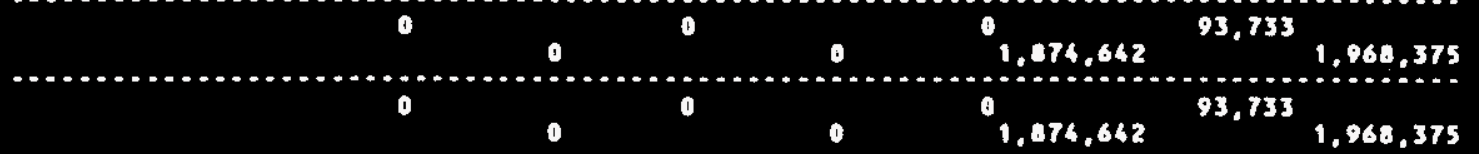

$\begin{array}{rrrrrrrrrrr}501 \mathrm{~A} & 416 \mathrm{CY} & 2696 & 79624 & 0 & 56504 & 0 & 0 & 44696 & 179624 \\ 501 \mathrm{~A} & 416 \mathrm{cY} & 4992 & 157248 & 0 & 63231 & 0 & 0 & 86503 & 306982\end{array}$


FLUOR BAMIEL IUC. gererimenouse maufons compaur Jos no. 436304 use roos

\section{Account}

Consen Description

312010.0300003 GUTUP GEL conchete

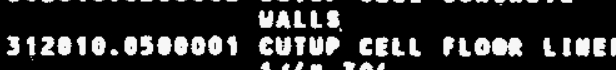
$1 / 40304$ 312010.0300002 curup cth

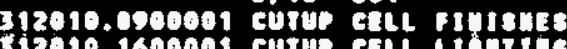
suatotal 312010 struictuns: 312710 Renote nanos ine coutphent

312710.1300091 Install curup GRL sutele 12710.1400001 vinoous and fanars

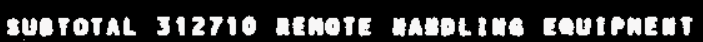
312050 aetith cut up geurpatat 312450.1149100 tastale MFLtER CUT UP EOuiphent

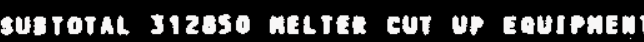

suototal 312 Vithification nuilotms

suntoral 31 process factitir

suntoral 3 consteuction

PROJECT TOTAL

" IEst - Intenactive Eetematsug ** altenuarive netren orstens assegenter tor stinheb net TER GUT UP CELL - CASE DI. Estimate of TAR or vis

PAGE 022005 16:28:27

or dfospcesait

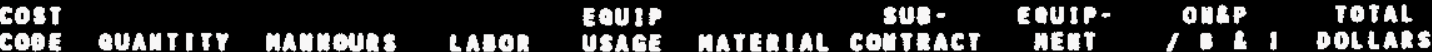

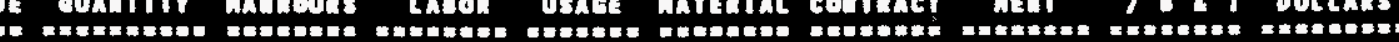

\begin{tabular}{|c|c|c|c|c|c|c|c|c|c|}
\hline 5014 & $1416 \mathrm{Cr}$ & 21210 & 608115 & 0 & 205751 & 0 & 0 & 367438 & 1302304 \\
\hline $501 \mathrm{~A}$ & $1500 \mathrm{sF}$ & 3975 & 125213 & 0 & 20703 & 0 & 0 & 67802 & 221798 \\
\hline $501 \alpha$ & 5290 sf & 11180 & 352170 & 0 & 74867 & 0 & 0 & 190397 & 617514 \\
\hline $\begin{array}{l}5014 \\
\text { soin }\end{array}$ & $\begin{array}{l}3255 \text { sf } \\
1500 \text { \&f }\end{array}$ & $\begin{array}{l}352 \\
428\end{array}$ & $\begin{array}{l}11008 \\
13482\end{array}$ & 0 & $\begin{array}{l}3334 \\
5330\end{array}$ & 8 & 0 & $\begin{array}{l}6143 \\
7422\end{array}$ & $\begin{array}{l}22565 \\
26434\end{array}$ \\
\hline
\end{tabular}

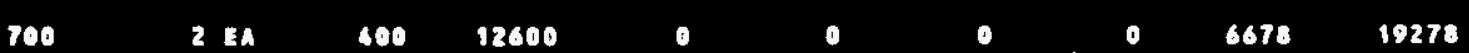

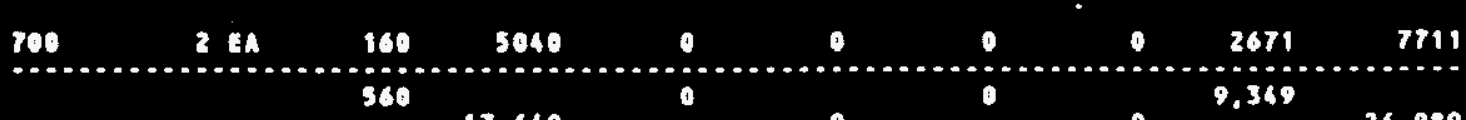

$17,640 \quad 0 \quad 0 \quad 0 \quad 9,369 \quad 26,989$

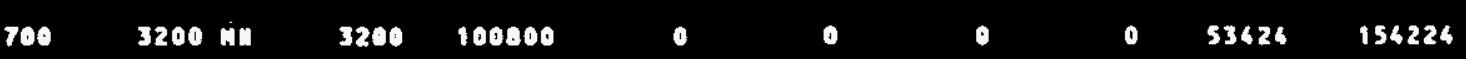

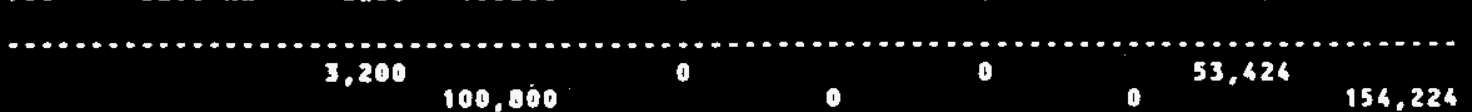

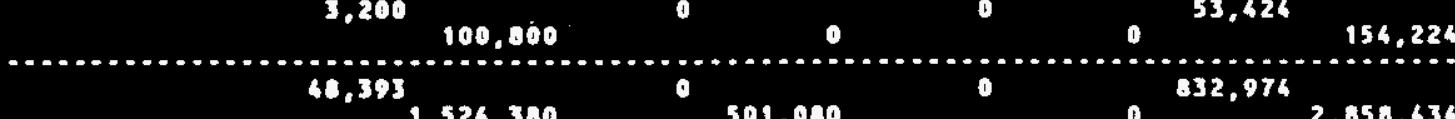
$0 ., 2,858,434$

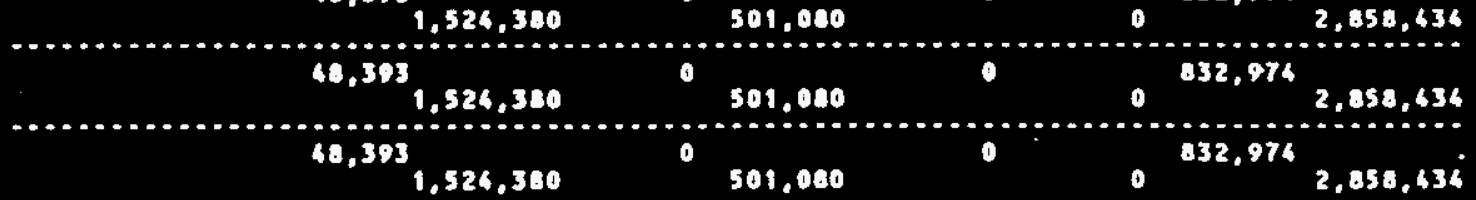

$501,090 \quad 0,926,707$

$1,074,642926,707 \quad 4,026,809$ 

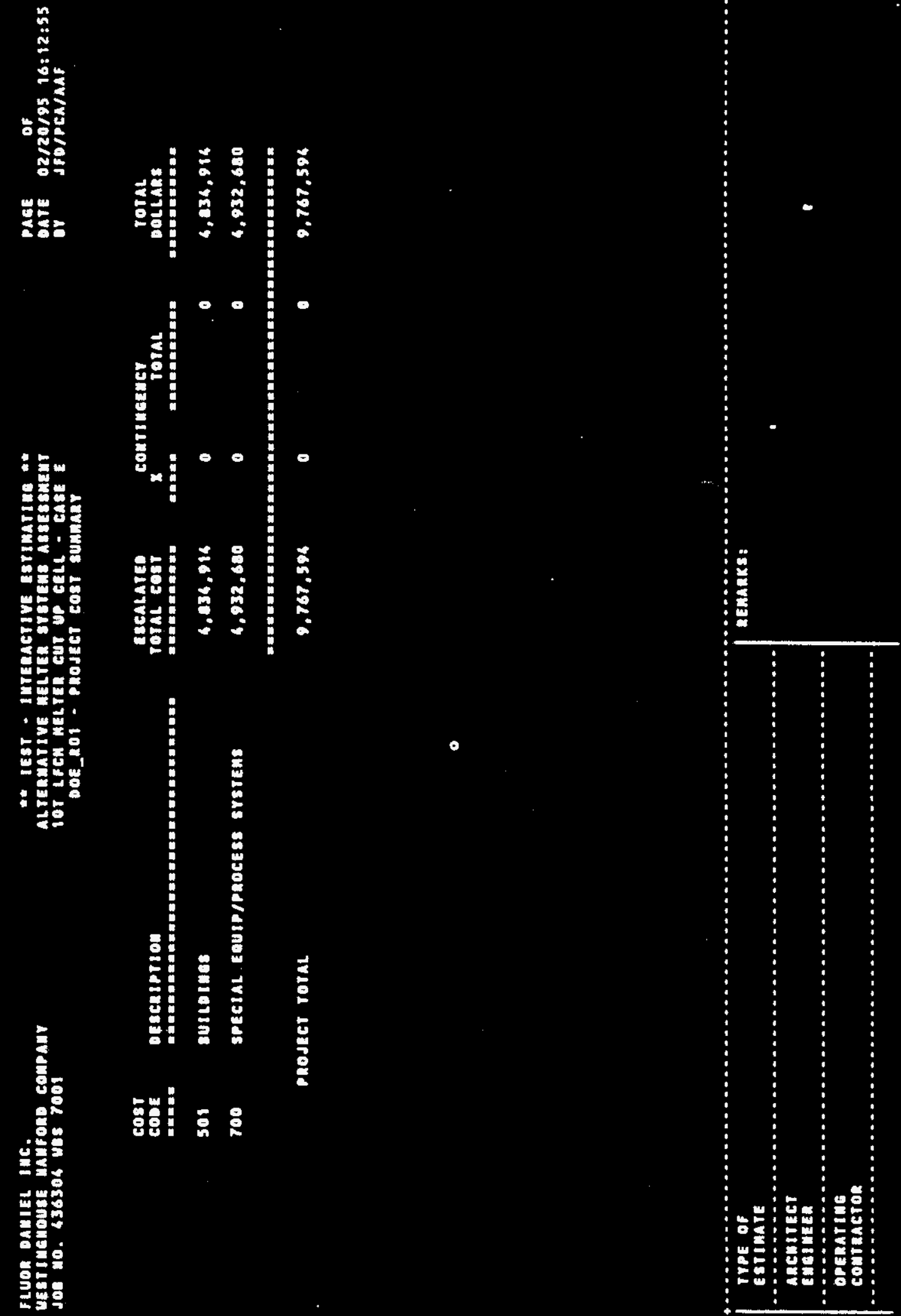
FLuon DANIEL Ine.

conpaur

Account

nutisen

Deschiption

agnote naybl the courpazer

221710

221710.1300001 cutup eEL suikl wabous 221710.1400001 Ans firant

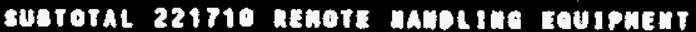

221850

MELTER CUI UP CELL ROUPAENT

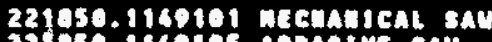

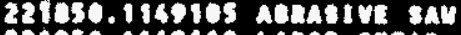

221650.1149110 canes gne

221850.116911 PIof guter

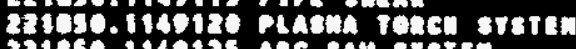

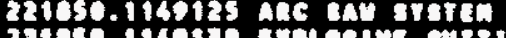

A 2ise.

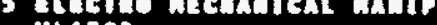

221090.1140140 intor.

221050.116019 stes ution

221050.1169150 pownes canple

suntoral 221050 MEtTER CUT UP CELL EAUIPUE

SUSTOTAL 221 IN-CELL EQUIPMEAT

suntotal 22 GF procunenent

sustoral 2 Pnocunenent

312010 StRuctukes

312010.0300001 CUTUP CELL COMCRETE

312010.0300002 curup ceLt congRete
* IEst - inzenactive certuartmo **

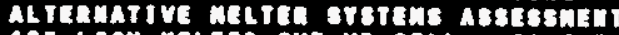

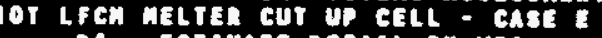
Di. Estimate defail or vas

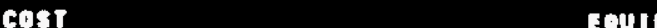

sus- Eoutp. onep toral

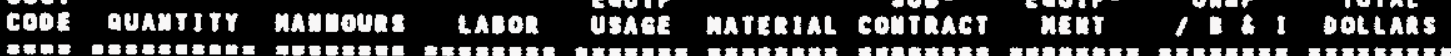

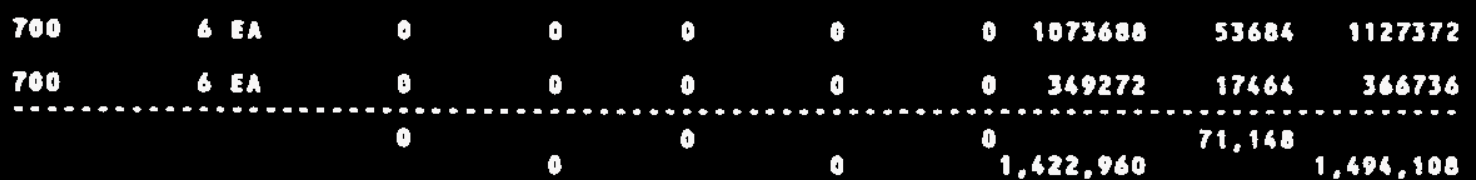

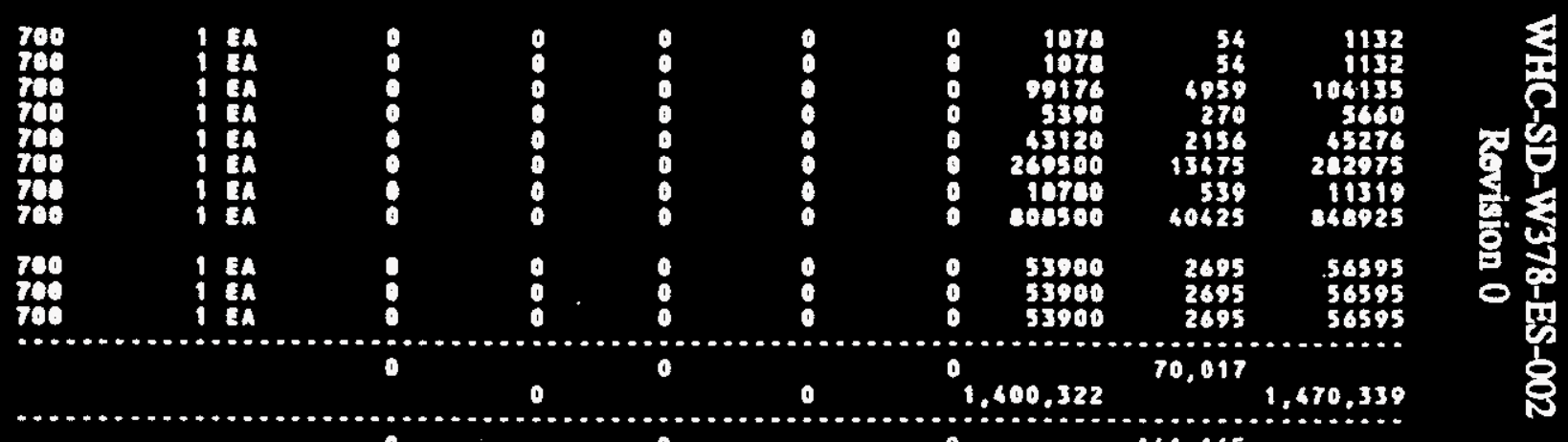

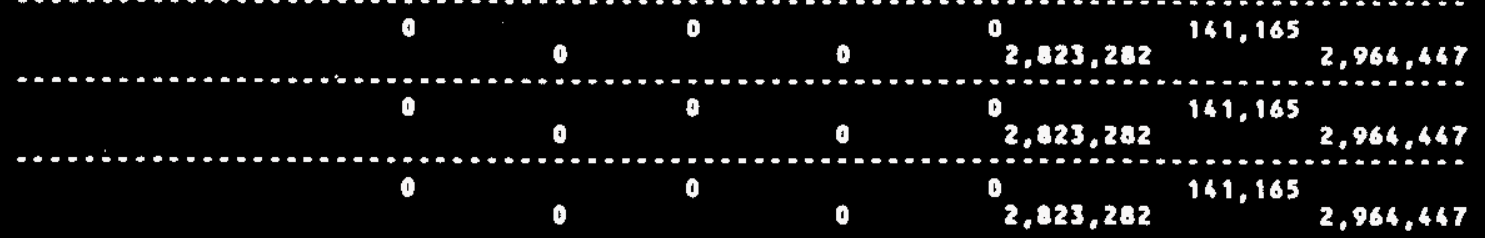

$\begin{array}{rrrrrrrrrrr}501 A & 801 \mathrm{CY} & 4806 & 151389 & 0^{\circ} & 108790 & 0 & 0 & 85676 & 345863 \\ 5014 & 801 \mathrm{CY} & 9612 & 302778 & 0 & 121750 & 0 & 0 & 166559 & 591087\end{array}$




\section{WHC-SD-W378-ES-002 \\ Revision 0}
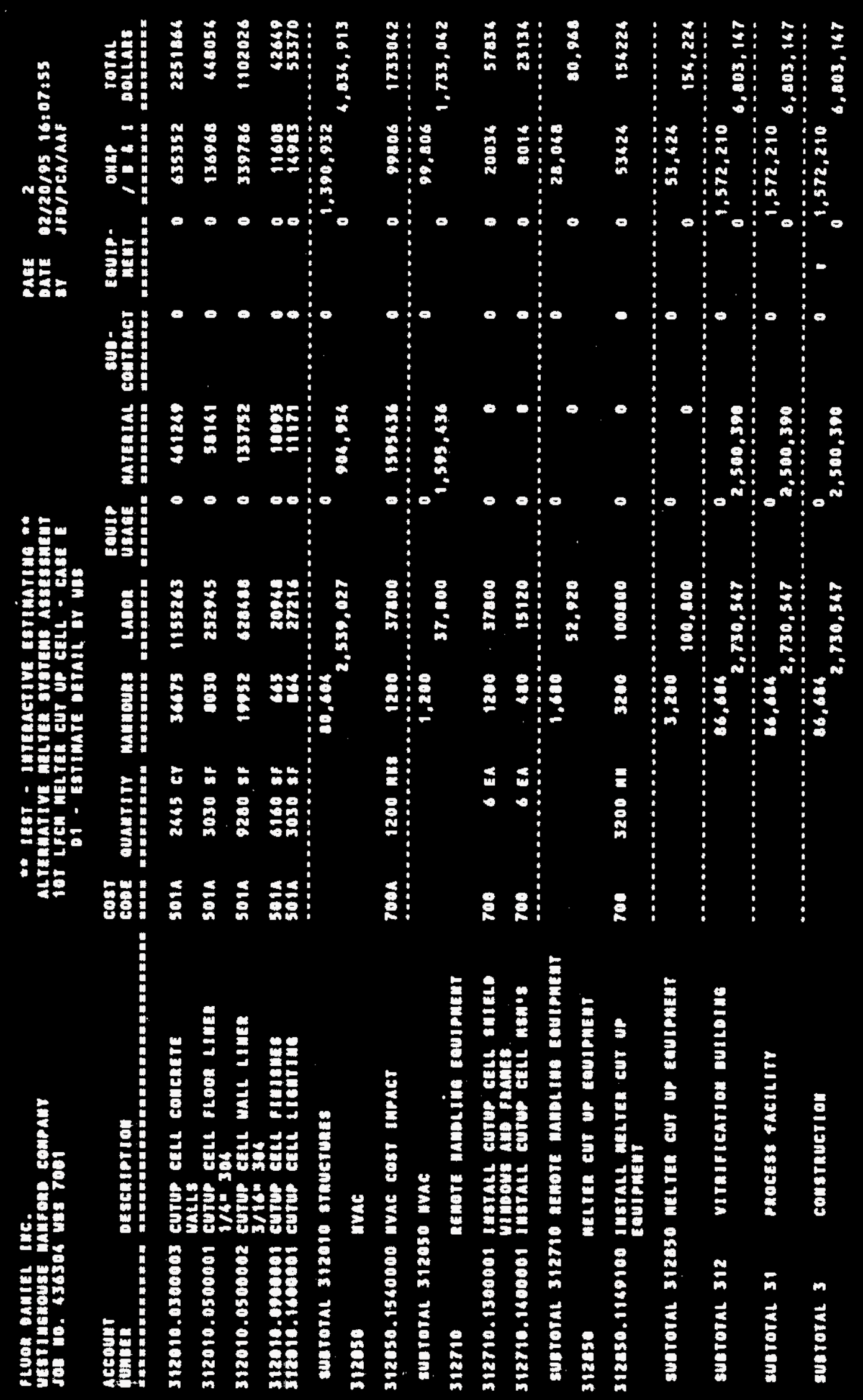
WHC-SD-W378-ES-002

Revision 0

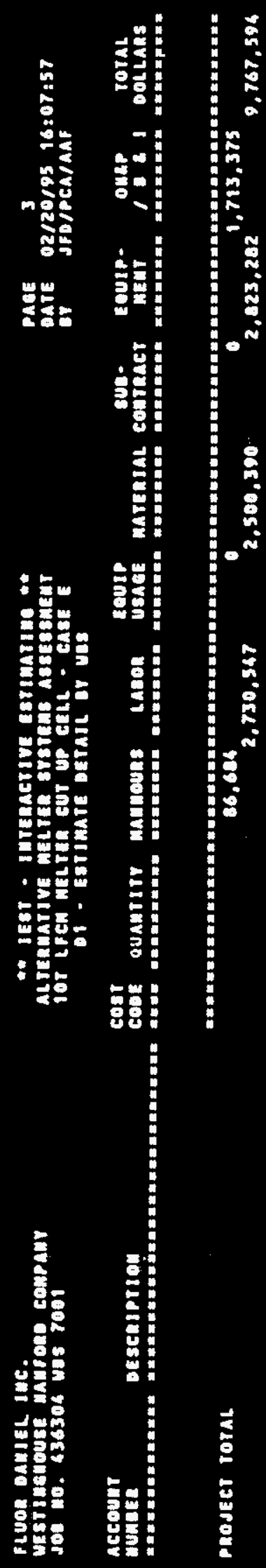

G2-50 


\section{WHC-SD-W378-ES-002 \\ Revision 0}

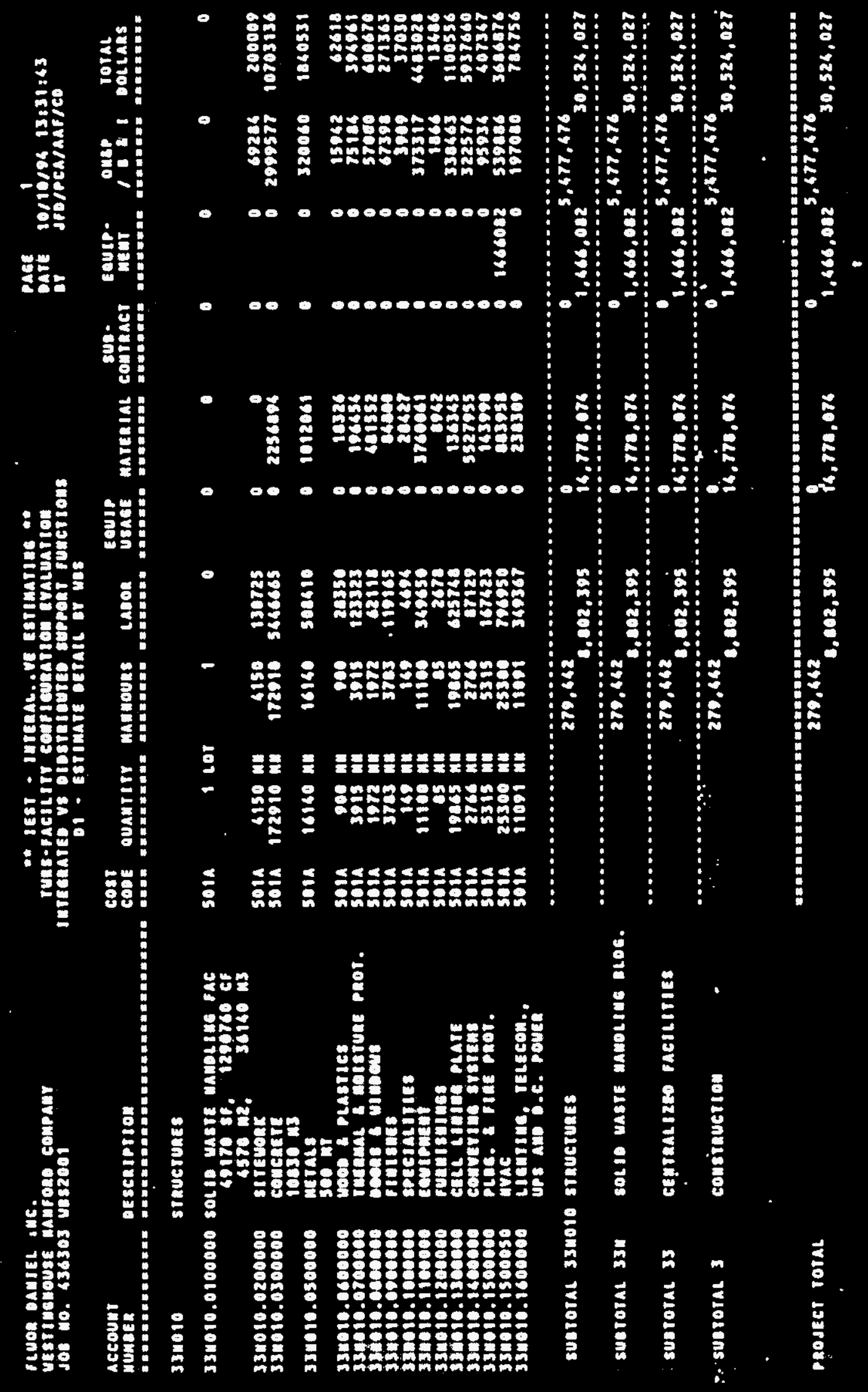

G2.51 


\section{WHC-SD-W378-ES-002}

Rovision 0

This page intentionally left blank. 
WHC-SD-W378-ES-002

Rovision 0

APPENDIX G3

FCS FACILITY COST COMPARISON

G3-1 
WHC-SD-W378-ES-002

Revision 0

This page intentionally left blank. 


\begin{tabular}{|c|c|c|c|c|c|c|c|c|c|c|c|}
\hline $9 z c^{c} 9 g$ & $05681^{-}$ & 9LE'Lr & $89981-$ & $\varepsilon L^{\prime} \varepsilon z$ & $\mathbf{0}$ & $\varepsilon 80^{\circ} 8 \varepsilon$ & $0 L E^{2} 6$ & ON & $\begin{array}{c}\cos \theta \\
\infty x\end{array}$ & $\begin{array}{l}(\operatorname{tas}) \\
\infty \mathbf{x}\end{array}$ & spa resqpins \\
\hline $16 t^{\prime} 86-$ & 62088 & $80 Z^{\circ} 0 L^{-}$ & $859^{\circ} \angle z^{-}$ & css'zt & 0 & $05 s^{2} 20$ & 0 & oN & $\underset{\infty x}{\operatorname{cas} x)}$ & $\begin{array}{l}\text { (coldisul } \\
\text { ON }\end{array}$ & 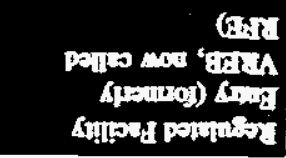 \\
\hline ostos- & Etost- & $\cos 6 \theta$ & Ist'st' & SSt $6 \varepsilon^{-}$ & 951 '6E & $\mathbf{0}$ & 0 & $\boldsymbol{\omega x}$ & oN & $\underset{\infty \mathrm{A}}{(\mathrm{av} / \mathrm{m})}$ & monstory ariolos \\
\hline Ixces & $026^{\prime} 81^{-}$ & toc'Lt & t69'81- & $\angle 5962-$ & 29988 & 0 & 0 & $\boldsymbol{\omega x}_{\mathbf{X}}$ & oN & 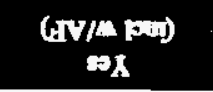 & 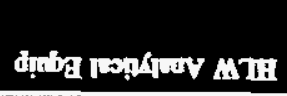 \\
\hline $085^{6} 6 L 1$ & istis & $96 z^{c} 82 I$ & $\angle I S^{\circ} O S$ & 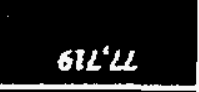 & 0 & 0 & $6 L L^{\circ} U$ & & $\begin{array}{l}\text { (bat: Nm } \\
\text { (Bwie) on }\end{array}$ & $\begin{array}{l}(\infty) \\
\infty x\end{array}$ & 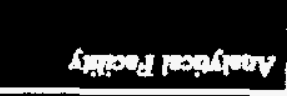 \\
\hline tw'ct & $0 i \theta^{\prime} \varepsilon$ & 1096 & $20 L^{\prime} \varepsilon$ & 6I8's & 0 & 0 & 6I8's & on & on & $\underset{\infty x}{\cos }$ & 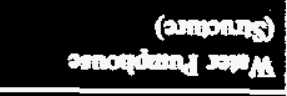 \\
\hline wret & $\angle \mathcal{L L} E$ & $\angle I V^{\prime} 6$ & OKL'E & $20 L^{\prime} \mathrm{s}$ & 0 & qLE'6 & ENo'st & oN & $\frac{600}{\infty x}$ & $\tan _{\infty x}$ & $\sin$ \\
\hline 6ro'sz & $\sin ^{2} \alpha$ & $I L x^{\prime} L I$ & $0.0 \% 2$ & IEs:0I & 0 & 0 & IEs'oI & oN & (cos) on & 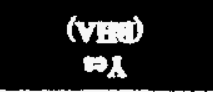 & 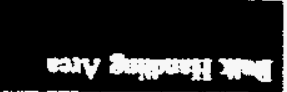 \\
\hline LSL'S & sto't & $2 \mathrm{tr} t$ & $069^{\prime} t$ & $26 t^{2} z$ & 0 & IEะ' 6 & $\varepsilon \boldsymbol{E x}^{\circ} \mathrm{II}$ & oN & $(\infty \infty)$ & $(0 \infty x)$ & 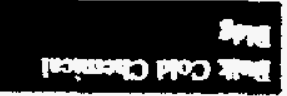 \\
\hline ito $\mathrm{L}-$ & $800^{\prime} z-$ & $800 \%$ & $\varepsilon \epsilon^{\circ} \mathrm{T}^{-}$ & S50'E- & 0 & $520^{\circ} \varepsilon$ & 0 & oN & $\underset{\infty x}{(\$ \infty 0)}$ & oN & aromo now \\
\hline $\sin t$ & $8 E I^{\prime} t$ & mior & $S L 0^{\circ} \mathrm{b}$ & $69 \pi^{\prime} 9$ & 0 & 0 & $69 \tau^{\prime} 9$ & ON & $\begin{array}{c}(800 / \mathrm{s} \text { pous) } \\
\text { oN }\end{array}$ & $\underset{\infty x}{(0 \infty x)}$ & 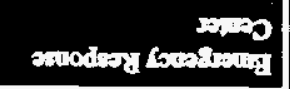 \\
\hline $1 L^{*} L$ & $0 z z^{2} z$ & Iss's & $\angle S I^{\prime} z$ & $\operatorname{\omega ec}^{\prime} \varepsilon$ & $\mathbf{0}$ & $819 \%$ & $2866^{\circ} 6$ & oN & $\begin{array}{l}(1980) \\
\infty \mathbf{X}\end{array}$ & $\begin{array}{l}(980) \\
\infty \mathbf{X}\end{array}$ & uoding worgendo \\
\hline LSL'S & 5691 & $z 1 I^{2}$ & $029^{\prime} I$ & $265^{\circ} z$ & 0 & IEE'6 & $\varepsilon z 8^{\circ} 11$ & ON & $\begin{array}{l}(\operatorname{tgc} 0) \\
\infty \mathbf{X}\end{array}$ & 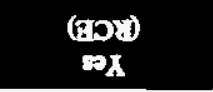 & 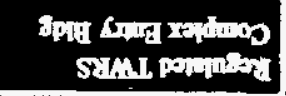 \\
\hline 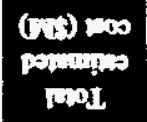 & 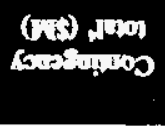 & Thongus & 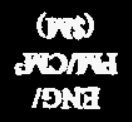 & 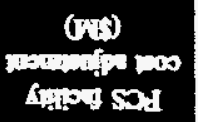 & 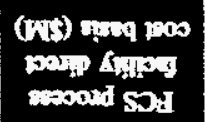 & 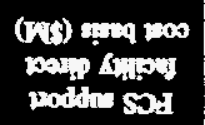 & $\begin{array}{l}\text { (WH) syseq } \\
\text { woo poutp } \\
\text { pasing }\end{array}$ & 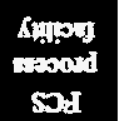 & wathed sod & 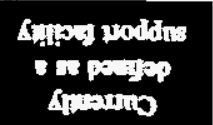 & 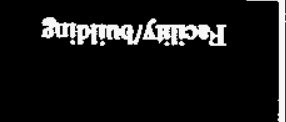 \\
\hline
\end{tabular}




\section{WHC-SD-W378-ES-002}

Revision 0

Table H1-11A. Analytical Laboratory Equipment Requirements

Separations Function.

(Low Cs DF Mode of Operation)

\begin{tabular}{|l|c|l|}
\hline \multicolumn{1}{|c|}{ Equipment/Instrumentation } & Space & \multicolumn{1}{|c|}{ Utilities/Service Required } \\
\hline Equipment Storage & $2^{\prime} \times 8^{\prime}$ & \\
\hline Inductively Coupled Plasma (ICP) & $3^{\prime} \times 8^{\prime}$ & Liquid argon \\
\hline ICP Hood & $3^{\prime} \times 4^{\prime}$ & Waste jet,hot water drain, water \\
\hline ICP Computer Terminal & $3^{\prime} \times 3^{\prime}$ & Power \\
\hline Bench with deionized water system & $3^{\prime} \times 4^{\prime}$ & Sanitary water \\
\hline Dionex hood & $3^{\prime} \times 4^{\prime}$ & Hot water drain \\
\hline Dionex bench and cabinets & $3^{\prime} \times 4^{\prime}$ & Air \\
\hline $\begin{array}{l}\text { Actinide and other radiochemical } \\
\text { separations hood }\end{array}$ & $3^{\prime} \times 4^{\prime}$ & Hot waste drain \\
\hline Solids, visual, microwave, filtration, & $3^{\prime} \times 4^{\prime}$ & Hot waste drain \\
\hline other hood & & \\
\hline Autotitration bench/cabinet & $3^{\prime} \times 4^{\prime}$ & Drain \\
\hline pH meter and bench & $3^{\prime} \times 4^{\prime}$ & Power \\
\hline Balance w/marble table & $3^{\prime} \times 4^{\prime}$ & Power \\
\hline Organic storage & $3^{\prime} \times 4^{\prime}$ & \\
\hline Utility/General purpose bench/cabinet & $3^{\prime} \times 6^{\prime}$ & Deionized water \\
\hline Centrifuge & $2^{\prime} \times 2^{\prime}$ & \\
\hline Microwave & $2^{\prime} \times 2^{\prime}$ & Power \\
\hline Furnace & $2^{\prime} \times 2^{\prime}$ & Power \\
\hline Fluorometer & $3^{\prime} \times 4^{\prime}$ & Power \\
\hline Shielded radiation detector & $3^{\prime} \times 3^{\prime}$ & Power \\
\hline Spectrometer & $3^{\prime} \times 3^{\prime}$ & Power \\
\hline Gas Chromatograph & $3^{\prime} \times 4^{\prime}$ & Power, carrier gas \\
\hline & & \\
\hline
\end{tabular}




\section{WHC-SD-W378-ES-002}

Revision 0

Table H1-12A. Additional Analytical Equipment

Consideration Separations Function.

(Low Cs DF Mode of Operation)

- Space must be allocated and/or supporting services should be planned.

- Sample and material transfer (handling) carts

- Approved containers for laboratory waste

- Pneumatic lift for handling (lead) sample pigs (containers)

- $\quad$ Area Radiation Monitors (ARMs); wall mounted 2'x2'x2'

- Record Air Samplers (RAS); wall mounted 1'x1'x1'

- Continuous Air Monitors (CAMs); floor mounted 2' $\times 4^{\prime} \times 5$ '

- Hand and Foot Monitor (HFM); floor mounted 2' $x 4$ ' $x 6$ '

- General Laboratory HVAC. Sufficient space between hoods, benches and desks for HEPA filter exchange.

- Central sink with process water, deionized water, hot water supply, and appropriate drainage system.

- Safety shower and eyewash station.

- $\quad$ Trouble alarms at selected working places.

- $\quad$ Main double door access.

- Space for computer terminals and communal work stations. 
WHC-SD-W378-ES-002

Revision 0

Table H1-13A. Analytical Facility

Estimated Space Requirements.

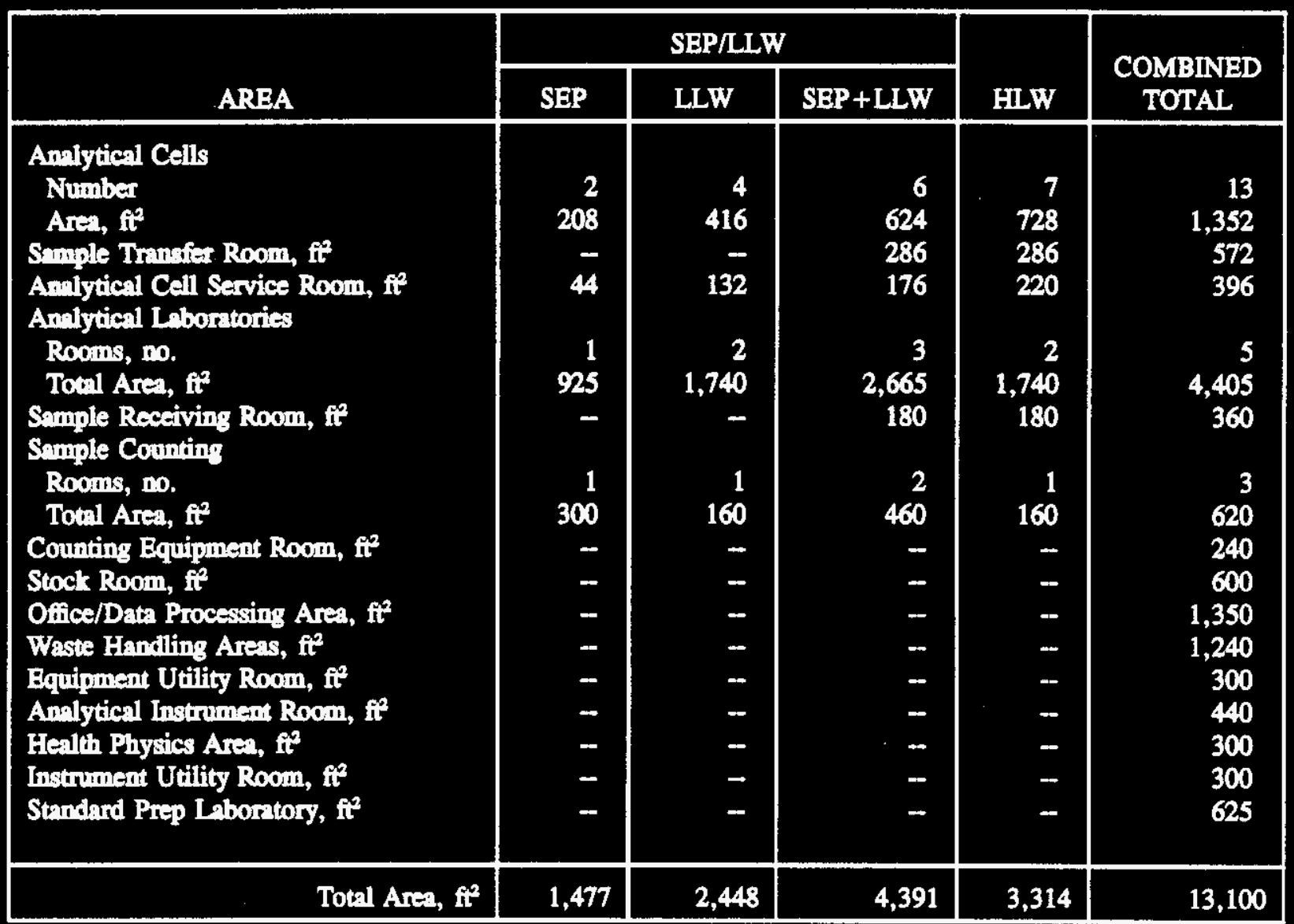




\section{Revision 0}

Table H1-1B. Process Gas, Liquid and Solid Sampling Frequeacy Low-Level Waste Function.

\begin{tabular}{|c|c|c|c|c|}
\hline Sample Location & $\begin{array}{l}\text { Geb Sample } \\
\text { Prequeas }\end{array}$ & $\begin{array}{l}\text { Sampley } \\
\text { Day }\end{array}$ & $\begin{array}{l}\text { Sample } \\
\text { Putpose }\end{array}$ & Anslyea Required \\
\hline $\begin{array}{l}\text { 1. LLW Empontor Feed Tant } \\
(\mathrm{IL}-400)\end{array}$ & $\begin{array}{c}\text { Once every } 8 \\
\text { hos }\end{array}$ & 3 & PC & SpG, TNS, TDS \\
\hline 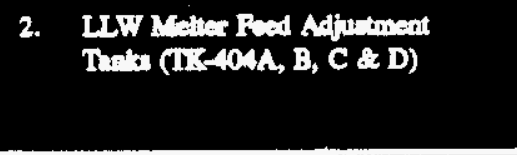 & $\begin{array}{l}\text { Once every } \\
18 \text { hrithank }\end{array}$ & 5.3 & $\begin{array}{l}\text { PC } \\
\text { (portibly } \\
\text { WFQ } \\
\text { also) }\end{array}$ & $\begin{array}{l}\text { SpG, TSS, TDS } \\
\text { Elementhi Compodition) From ICP-MS } \\
\text { Radionelides }\end{array}$ \\
\hline $\begin{array}{l}\text { 3. LLW Mater Fead Tunte (IS-406A, } \\
\text { B, C \& D) }\end{array}$ & $\begin{array}{l}\text { Not requited } \\
\text { on routine } \\
\text { beris }\end{array}$ & - & & \\
\hline $\begin{array}{l}\text { 4. LWW Cullet Cotch Tank (TK-416A } \\
\text { \& B) }\end{array}$ & $\begin{array}{l}\text { Not roguined } \\
\text { on routine } \\
\text { batis }\end{array}$ & - & & \\
\hline $\begin{array}{l}\text { 5. LLW Queach Water Recycle Tunts } \\
\text { (IS-421A \& B) }\end{array}$ & $\begin{array}{l}\text { Not required } \\
\text { on routine } \\
\text { bacis }\end{array}$ & - & & On-line $\mathrm{pH}$ anelyais and TDS \\
\hline $\begin{array}{l}\text { 6. ULW Cullet Day Lag Storage (B- } \\
427 \text { A \& B) }\end{array}$ & $\begin{array}{c}\text { Once every } 2 \\
\text { hra/bin }\end{array}$ & 24 & $\begin{array}{l}\text { PC \& } \\
\text { WFQ }\end{array}$ & $\begin{array}{l}\text { Blemental Composition \}From ICP-MS } \\
\text { Radionuclides } \\
\text { PCT? } \\
\text { Fretion of Fine Particulnted } \\
\text { Present? } \\
\text { Crytullinity/Densiby - Intrequent }\end{array}$ \\
\hline $\begin{array}{l}\text { 7. LWW Filter Cuteh Turts (1L-426 A } \\
\text { (B) }\end{array}$ & $\begin{array}{l}\text { Once every } \\
24 \text { mithant }\end{array}$ & 2 & PC & TSS, TDS \\
\hline $\begin{array}{l}\text { 8. LLW Condenate Catch Tunks } \\
\text { (TK-429 A \& B) }\end{array}$ & $\begin{array}{l}\text { Once a } \\
\text { weak/tonk }\end{array}$ & - & PC & $\begin{array}{l}\text { Elemental Composition\}From ICP-MS } \\
\text { Radionuclides }\end{array}$ \\
\hline 9. Fine Wan Cateh Thak (kK-455) & Infreanint & - & PC & \\
\hline 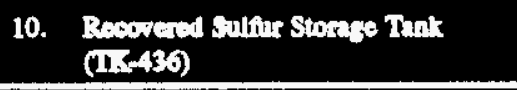 & Not recinited & - & & \\
\hline $\begin{array}{l}\text { 11. ILW Roside Culld Cotch Tanks } \\
\text { (IL-SosA \& B) }\end{array}$ & 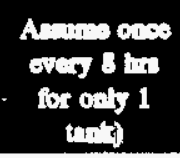 & 3 & PC & $\begin{array}{l}\text { Elemental Composition) From ICP-MS } \\
\text { Redicanelides }\end{array}$ \\
\hline $\begin{array}{l}\text { 12. LIW Menl Fitter Wush Cutah Tant } \\
(\text { IL-626) }\end{array}$ & & - & & \\
\hline 13. LLW Serub Fitter Tuk (IK-611) & 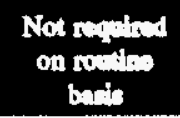 & - & & \\
\hline $\begin{array}{l}\text { 14. LLW Serub Solution Tanka (KK-614 } \\
\text { A \& B) }\end{array}$ & $\begin{array}{l}\text { Onee every } \\
24 \text { hretont }\end{array}$ & 2 & $\mathbf{P C}$ & 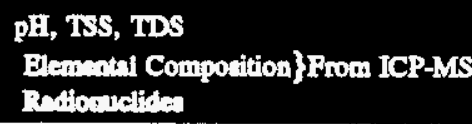 \\
\hline
\end{tabular}


Table H1-1B. Process Gas, Liquid and Solid Sampling Frequency Low-Level Waste Function.

(continued)

\begin{tabular}{|c|c|c|c|c|}
\hline Sample Location & $\begin{array}{l}\text { Grab Sample } \\
\text { Frequeisy }\end{array}$ & $\begin{array}{l}\text { Semples/ } \\
\text { Day }\end{array}$ & $\begin{array}{l}\text { Sumple } \\
\text { Purpose }\end{array}$ & Analyses Required \\
\hline $\begin{array}{l}\text { 15. LLW Procen Condenate Regrele } \\
\text { Tunks (ILA0 A, B \& C) }\end{array}$ & $\begin{array}{l}\text { Once eviag } \\
20 \text { hes for } \\
\text { each of } 2 \\
\text { tank only }\end{array}$ & 2.4 & PC & $\begin{array}{l}\text { pH } \\
\text { Elemental Composition \} From ICP-MS } \\
\text { Radiomulides }\end{array}$ \\
\hline 16. pR Adjutmot That (1:-803) & $\begin{array}{c}\text { Not } \\
\text { appliables }\end{array}$ & - & $\mathbf{P C}$ & pII (on-line analyaio) \\
\hline $\begin{array}{l}\text { 17. Proces Condenate from Condener } \\
\text { (EC-140) }\end{array}$ & $\begin{array}{l}\text { Not } \\
\text { appliabss }\end{array}$ & - & PD & Contimuous on-line anslyain for activity \\
\hline $\begin{array}{l}\text { 20. Gas Outla trom LLW Separtor } \\
(S-616 A \text { \& B) }\end{array}$ & $\begin{array}{l}\text { Once evey } \\
24 \\
\text { hedecinatos }\end{array}$ & 2 & $\mathbf{P D}$ & Particulntea Rudiosuclidea (ICP-MS) \\
\hline $\begin{array}{l}\text { 21. Gas Ortict fom LLW Mint } \\
\text { Eliminator (DB-618A \& B) }\end{array}$ & $\begin{array}{l}\text { Once every } \\
24 \text { britsin }\end{array}$ & 2 & PD & Particulates Radionuclidea (CCP-MS) \\
\hline $\begin{array}{l}\text { 22. Gas Outle from MOG Motal BiRA } \\
\text { Filter (FM-625A2, B2 \& C2) }\end{array}$ & $\begin{array}{l}\text { Once every } \\
24 \text { hrs for } \\
\text { each of } 2 \\
\text { train only }\end{array}$ & 2 & PD & Particulntes Radionuclides (CP-MS) \\
\hline 23. VOG Syaten Eilter Inict Stream & $\begin{array}{l}\text { Once erety } \\
24 \mathrm{hr}\end{array}$ & 1 & PD & Particulates Radionnclides (CP-MS) \\
\hline 24. VoO Syuten Dixcharge Stream & $\begin{array}{l}\text { Once cresy } \\
24 \mathrm{hrs}\end{array}$ & 1 & $\mathbf{P D}$ & Puticulaten Rudionuclides (ICP-MS) \\
\hline 25. CVOG Sytem Discharge Stream & $\begin{array}{l}\text { Once every } \\
24 \text { hrs }\end{array}$ & 1 & PD & Particulates Radionuclides (ICP-MS) \\
\hline 26. CVOG Syctem Discharge Stream & $\begin{array}{c}\text { Once every } \\
24 \text { hes }\end{array}$ & 1 & PD & Particulates Radionuclides (ICP-MS) \\
\hline TOTAL & & 51.7 & & Pariculntes Radionelidea (CP-MS) \\
\hline
\end{tabular}

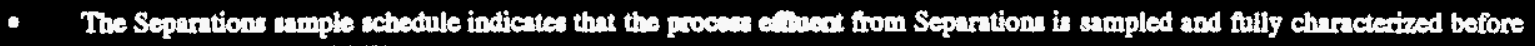
being sert as foed to LIW.

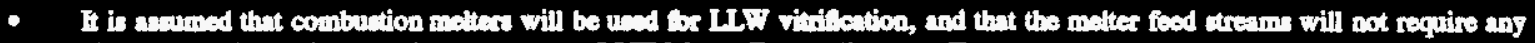

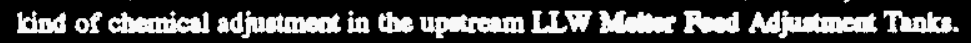

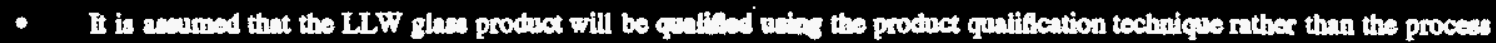
qualincation technique.

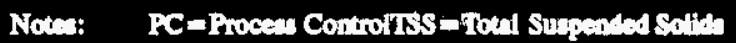

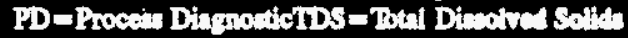

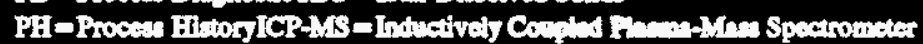

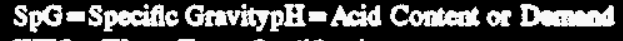

WPQ - Wate Form Quallication 
WHC-SD-W378-ES-002

Revision 0

Table H1-2B. Location of Analyses

Low-Level Waste Function.

ANALYUTCAL CELL

(Undiluted samples)

pH

SpG

Solids-work: TSD, TDS, TSS

Elements and Radionuclides:

ICP-MS closely coupled to the

Analytical Cells allowing

processing of undiluted or slightly

diluted $(1: 10)$ samples

Anions: Sample preparation

Dilution

Particulates

PCT (Product Consintency Test)

Crystallinity/Donsity
ANALYTTCAL LABORATORY

(Diluted/low level and cold samples)

OTR (Over-the-Top Reading)

$\mathrm{pH}$

SpG

Solids-work: TSD, TDS, TSS

Anions: HPLC, Dionex

Elements:

ICP-MS

ICP-AES

AAS

Spectrophotometer

Fluorometer

Radionuclide Separations

(prior to radionuclide analyses):

Extractions

Precipitations

HPLC

Ion Exchange

Radionuclide Analysis:

IPC-MS

Total Alpha

AEA

Total Beta

GEA

Beta Sci

Titrations

Gas Chromatography

Particulates 


\begin{tabular}{|c|c|c|c|c|c|c|c|c|c|c|c|c|c|c|c|c|c|}
\hline & 089 & $0 \%$ & $z$ & $z$ & $\tau$ & $z$ & 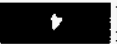 & 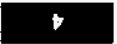 & + & 87 & 8 & $\mathfrak{\varepsilon}$ & 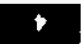 & $k$ & TIR & 6 & STrLal \\
\hline & $\alpha$ & or & $I$ & I & $\mathrm{T}$ & $\mathbf{t}$ & $z$ & $\tau$ & 2 & & & & & & & & onguping \\
\hline & & & & & & & & & & & & & & & & & \\
\hline & & & & & & & & & & & & & & & & & ming \\
\hline & & & & & & & & & & & & & & & & & \\
\hline 8 & 6925 & Lot & I & I & $\mathbf{t}$ & $\mathbf{t}$ & $\tau$ & $\tau$ & $\tau$ & $\forall 2$ & 2 & $\varepsilon$ & & $n$ & E.5 & & $m=-4$ \\
\hline 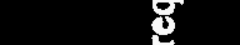 & & & & & & & & & & & & & & & & & \\
\hline & & & & & & & & & & & & & & & & & \\
\hline$\theta$ & & & & & & & & & & & & & & Enbay. & & & 15 \\
\hline & & & & & & & & & & & & & & & & & \\
\hline & & & & & & & & & & & & & & - & & & 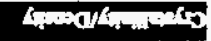 \\
\hline $\boldsymbol{E}$ & & & & & & & & & & & & & & & & & 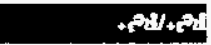 \\
\hline 3 & & & & & & & & & & & & & & & & & \\
\hline 8 & & & & & & & & & & & & & & & & & mapo mapos \\
\hline 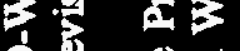 & & & & & & & & & & & & & & & & & mandace \\
\hline 웅 总客 & & & & & & & & & & & & & & & & & 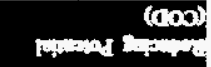 \\
\hline$<\frac{5}{6}$ & r.98 & $\varepsilon \pi$ & & & & & & & & & 2 & & $\tau$ & & $\boldsymbol{E s}$ & $\varepsilon$ & 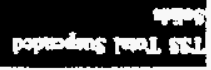 \\
\hline${ }^{\circ}$ & $\tau$ & $\varepsilon \pi$ & & & & & & & & & 2 & & 2 & & es & $\varepsilon$ & 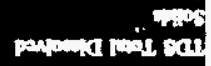 \\
\hline 1 & & & & & & & & & & & & & & & & & \\
\hline 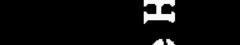 & & & & & & & & & & & & & & & & & $(\infty+\infty)$ and \\
\hline$\frac{y}{7}$ & & & & & & & & & & & & & & & & & \\
\hline$\Leftrightarrow$ & res & E8 & & & & & & & & & & & & & ES & $\varepsilon$ & as \\
\hline & $8 \boldsymbol{E x}$ & $m$ & & & & & & & & $n z$ & $\tau$ & & & & & & $\bar{F}$ \\
\hline & Pans & $\lim _{\lim 20}$ & 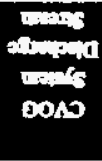 & 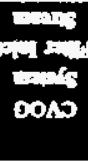 & $\operatorname{mim}_{\substack{\min \\
\min }}$ & Dos & 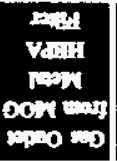 & 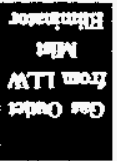 & 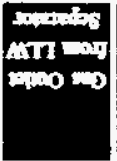 & 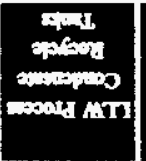 & 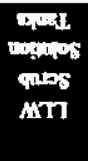 & 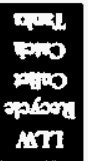 & $\prod_{\substack{\infty \\
m \rightarrow 1}}$ & $\begin{array}{c}\infty \\
x \rightarrow 1 \\
x \rightarrow 1 \\
x \rightarrow 1\end{array}$ & 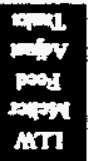 & $\frac{1}{m 11}$ & \\
\hline
\end{tabular}


Rovision 0

Table H1-4B. Time Per Week for Analytical Cell Sample Analyses Low-Level Waste Function.

\begin{tabular}{|l|c|c|c|}
\hline Type of Analysis & $\begin{array}{c}\text { Number of } \\
\text { Determinations } \\
\text { per Week }\end{array}$ & $\begin{array}{c}\text { Time/Analysis } \\
\text { (Hours) }\end{array}$ & $\begin{array}{c}\text { Total Analysis } \\
\text { Time } \\
\text { (Hours/Week) }\end{array}$ \\
\hline pH & 30.8 & 0.5 & 15.4 \\
\hline SpG & 58.1 & 0.5 & 29.0 \\
\hline TSD (dried) & & 1.0 & \\
\hline TDS & 86.1 & 1.12 & 96.4 \\
\hline TSS & 86.1 & 1.12 & 96.4 \\
\hline COD & & 0.5 & \\
\hline OH Equivalent & & 0.5 & \\
\hline TOC/Total Carbon & & 1.0 & \\
\hline Fe' + Fe & & 2.0 & \\
\hline Crystallinity/Density & & 2.0 & \\
\hline PCT & & 2.0 & \\
\hline Particulates & 70 & 0.5 & 35 \\
\hline Elements and Radionuclides & & 0.3 & \\
\hline TOTALS & 331.1 & & 272.2 \\
\hline
\end{tabular}


WHC-SD-W378-ES-002

Revision 0

Table H1-5B. Analytical Cell Time Required for Sample Preparation Analytical Laboratory Analysis Low-Level Waste Function.

\begin{tabular}{|l|c|c|c|}
\hline \multicolumn{1}{|c|}{ Type of Analysis } & $\begin{array}{c}\text { Number of } \\
\text { Analyses Per } \\
\text { Week }\end{array}$ & $\begin{array}{c}\text { Analytical Cell } \\
\text { Preparation Time } \\
\text { (Hours) }\end{array}$ & $\begin{array}{c}\text { Total Preparation } \\
\text { Time } \\
\text { (Hours/Week) }\end{array}$ \\
\hline $\begin{array}{l}\text { Elements and } \\
\text { Radionuclides }\end{array}$ & 326.9 & 0.3 & 98.1 \\
\hline Anions & & 1.5 & \\
\hline $\begin{array}{l}\text { Total Organic } \\
\text { Carbon/Total Carbon }\end{array}$ & & 1.0 & \\
\hline Mixing (Homogenize) & & & \\
\hline Splits & & & \\
\hline Dissolutions & & & \\
\hline Dilutions & & & \\
\hline Separations & & & 98.1 \\
\hline \multicolumn{1}{|c|}{ TOTALS } & 326.9 & & \\
\hline
\end{tabular}




\section{WHC-SD-W378-ES-002}

Revision 0

Table H1-6B. Analytical Cell Sample Analysis

and Preparation Time Low-Level Waste Function.

$\begin{array}{lcc} & \text { Factor } & \text { Hours Per Week } \\ \text { Analysis Time } & \text { Table Value } & 272.2 \\ \text { Add time for reruns } & 5 \% & 13.6 \\ \text { Add time for standards } & 10 \% & 27.2 \\ & \text { Subtotal } & 313.0 \\ \text { Sample Preparation Time } & & \\ \text { Add time for reruns } & \text { Table Value } & 98.1 \\ \text { Add time for standards } & 5 \% & 4.9 \\ \text { Add time for sample load-out } & 10 \% & 9.8 \\ & 5 \text { min./sample } & 112.8 \\ \text { Total Analysis and Preparation Time } & \text { Subtotal } & \\ \text { Credit for Parallel Tests } & & 425.8 \\ & & 38.3 \\ & \text { Less 9\% } & \\ & & \end{array}$


Table H1-7B. Analytical Cell Availability.

\begin{tabular}{|l|c|c|}
\cline { 2 - 3 } \multicolumn{1}{c|}{} & Factor & Hours/Week \\
\hline Hours available per week per cell & $7 \times 24$ & 168.0 \\
\hline Worlforce available (percent) & 70 & 117.6 \\
\hline Manipulators available (percent) & 93 & 109.4 \\
\hline Not devoted to cleamup (percent) & 94 & 102.8 \\
\hline Equipment available (percent) & 90 & 92.5 \\
\hline
\end{tabular}

Note: $92.5 / 168(100)=55$ percent availability

\begin{tabular}{|l|c|c|}
\hline & Factor & Hours/Week \\
\hline Hours available per week per cell & $7 \times 24$ & 168 \\
\hline Workforce available (percent) & 100 & 168 \\
\hline Manipulator available (percent) & 93 & 156.2 \\
\hline Not devoted to cleanup (percent) & 94 & 146.9 \\
\hline Equipment available (percent) & 90 & 132.2 \\
\hline
\end{tabular}

Note: $132.2 / 168(100)=79$ percent availability 


\begin{tabular}{|c|c|c|c|c|c|c|c|c|}
\hline Case & $\begin{array}{c}\text { Anlysis } \\
\text { Per } \\
\text { Week }\end{array}$ & $\begin{array}{l}\text { Andysis } \\
\text { Time } \\
\text { Required } \\
\text { (H) }\end{array}$ & $\begin{array}{l}\text { Analytical } \\
\text { Cell Prep } \\
\text { Time } \\
\text { (H) }\end{array}$ & $\begin{array}{l}\text { Total } \\
\text { Arnalytical } \\
\text { Cell Analysis } \\
\text { Time } \\
\text { (H) }\end{array}$ & $\begin{array}{l}\text { Total } \\
\text { Anslytical } \\
\text { Cells Prep } \\
\text { Time } \\
\text { (H) }\end{array}$ & $\begin{array}{c}\text { Total } \\
\text { Amblytical } \\
\text { Cells Time } \\
\text { Required } \\
\text { (H) }\end{array}$ & $\begin{array}{l}\text { Amalytical } \\
\text { Cell } \\
\text { Availability } \\
\text { (H) }\end{array}$ & $\begin{array}{c}\text { Number of } \\
\text { Analytical } \\
\text { Cells } \\
\text { Required }\end{array}$ \\
\hline LLU (Base Cose) & 65.0 & 272.2 & 98.1 & 313.0 & 112.8 & 387.5 & 92.5 & 4.2 \\
\hline $\begin{array}{l}\text { Asous } 100 \text { paremt } \\
\text { Merpower }\end{array}$ & 658.0 & 272.2 & 98.1 & 313.0 & 112.8 & 387.5 & 132.2 & 2.9 \\
\hline 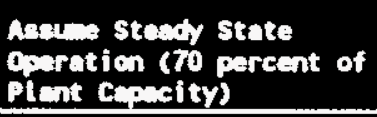 & 460.6 & 190.5 & 68.7 & 219.1 & 79.0 & 271.3 & 92.5 & 2.9 \\
\hline $\begin{array}{l}\text { Asecon } 100 \text { parcent } \\
\text { Manpower and } 70 \text { percent } \\
\text { IOE }\end{array}$ & 460.6 & 190.5 & 68.7 & 219.1 & 79.0 & 271.3 & 132.2 & 2.1 \\
\hline
\end{tabular}




\section{Revision 0}

Table H1-9B. Simplified Time and Motion Study -

Analytical Laboratory Low-Level Waste Function.

\begin{tabular}{|c|c|c|c|c|}
\hline Type of Amalysea & $\begin{array}{l}\text { Samplea from } \\
\text { Analytical Couls } \\
\text { Per Weal }\end{array}$ & $\begin{array}{l}\text { Proceses Gas Samples, Other } \\
\text { Waste/Wastevater and } \\
\text { Eavinommental Samples }\end{array}$ & Hourza/Arnalysis & $\begin{array}{l}\text { Total Hours } \\
\text { Per Week }\end{array}$ \\
\hline OTR & & 110 & 0.1 & 11.0 \\
\hline$\overline{\mathrm{pH}}$ & & 60 & 0.25 & 15 \\
\hline SpG & & 80 & 0.25 & 20 \\
\hline $\begin{array}{l}\text { Visual: } \\
\text { Color } \\
\text { Percent Settled } \\
\text { Solids } \\
\text { Percent } \\
\text { Centrifuged } \\
\text { Solid }\end{array}$ & & $\begin{array}{l}40 \\
40\end{array}$ & $\begin{array}{l}0.1 \\
1.0\end{array}$ & $\begin{array}{c}4 \\
40\end{array}$ \\
\hline TSD (Dried) & & 60 & 1.0 & 60 \\
\hline TSC (Calcined) & & & 1.25 & \\
\hline TDS & & & 1.12 & \\
\hline TSS & & & 1.12 & \\
\hline TOC/Total Carbon & & & 2.0 & \\
\hline \multicolumn{5}{|l|}{ Control Elements } \\
\hline $\begin{array}{l}\text { Elements and } \\
\text { Redionuclides }\end{array}$ & & 40 & 0.1 & 4.0 \\
\hline \multicolumn{5}{|l|}{ Isotopes } \\
\hline Particulates & 70 & & 0.5 & 35 \\
\hline Anions & & 60 & 0.5 & 30 \\
\hline GEA & & 110 & 0.5 & 55 \\
\hline Total Alpha & & 140 & 0.5 & 70 \\
\hline AEA & & & 0.5 & \\
\hline Total Beta & & 140 & 0.5 & 70 \\
\hline Beta Sci & & & 0.5 & \\
\hline Soluble Cs-137 & & & 0.5 & \\
\hline Soluble Sr-90 & & & 0.5 & \\
\hline $\mathbf{G C}$ & & 20 & 1.0 & 20 \\
\hline Titrations & & 72 & 0.5 & 36 \\
\hline \multicolumn{3}{|c|}{$\begin{array}{l}\text { SUBTOTAL } \\
\text { Add time for reruns ( } 5 \text { percent) } \\
\text { Add time for standards (10 percent) }\end{array}$} & & $\begin{array}{l}470 \\
23.5 \\
47.0\end{array}$ \\
\hline TOTAL & 70 & 972 & & 540.5 \\
\hline
\end{tabular}


WHC-SD-W378-ES-002

Revision 0

Table H1-10B. Equipment Requirements/Assessment

Low-Level Waste Function.

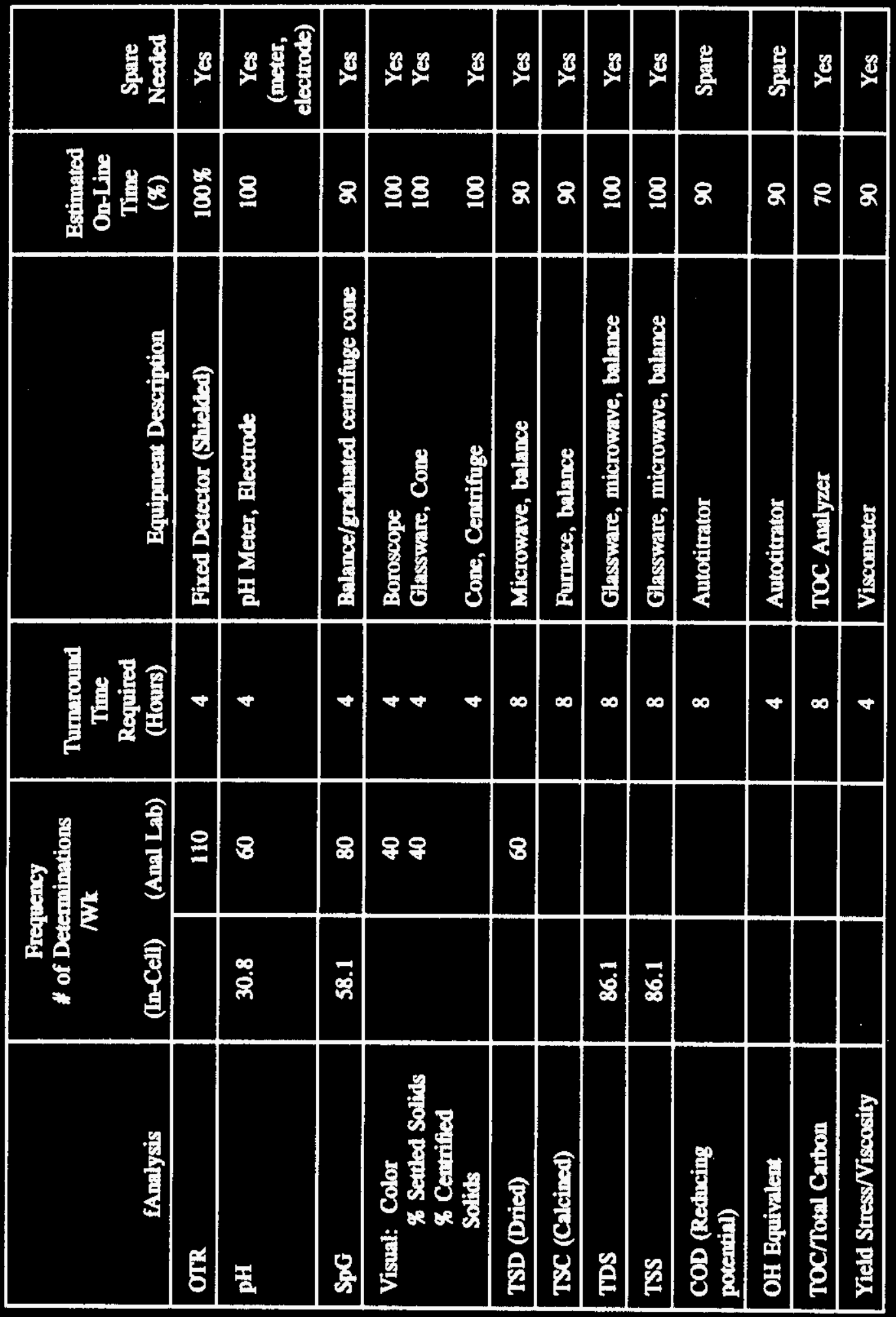


Revision 0

Table H1-10B. Equipment Requirements/Assessment Low-Level Waste Function.

(continued)

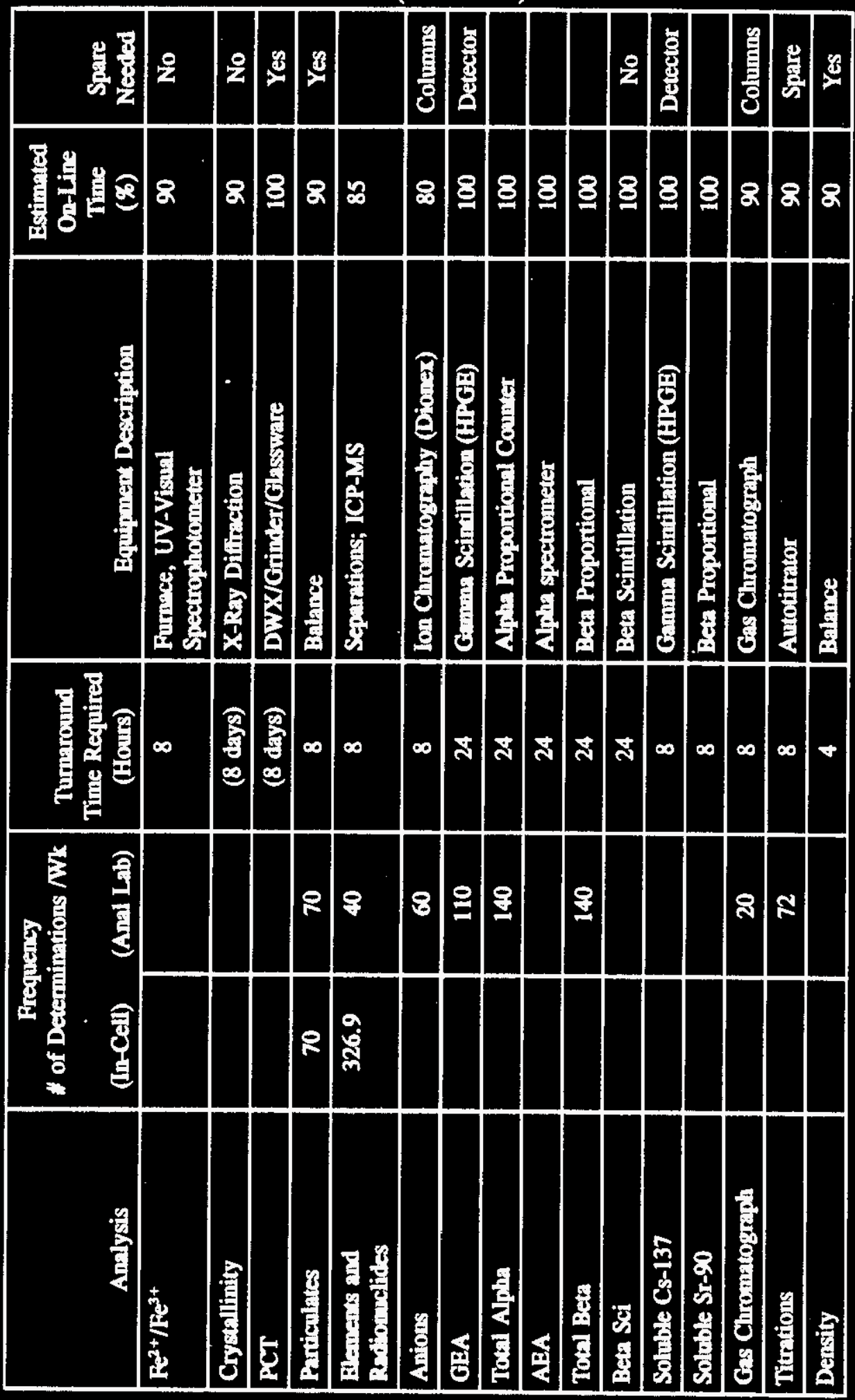




\section{Revision 0}

Table H1-11B. Analytical Laboratory/Instrument Room Equipment Requirements Low-Level Waste Function.

\begin{tabular}{|c|c|c|c|}
\hline Equipment/Instrumentation & $\begin{array}{l}\text { Number } \\
\text { Required }\end{array}$ & Space & Utilities/Service Required \\
\hline Shielded Radiation Detector & 2 & $3^{\prime} \times 3^{\prime}$ & power \\
\hline pH Meter and Bench & 2 & $3^{\prime} \times 4^{\prime}$ & power \\
\hline Balance w/marble table & 1 & $3^{\prime} \times 4^{\prime}$ & power \\
\hline Centrifuge & 1 & $2^{\prime} \times 2^{\prime}$ & power \\
\hline Microwave & 1 & $2^{\prime} \times 2^{\prime}$ & power \\
\hline Furnace & 1 & $3^{\prime} \times 3^{\prime}$ & power \\
\hline Balance & 2 & $2^{\prime} \times 2^{\prime}$ & power \\
\hline $\begin{array}{l}\text { Inductively Coupled Plasma (ICP) } \\
\text { Spectrometer }\end{array}$ & 2 & $3^{\prime} \times 8^{\prime}$ & liquid argon \\
\hline ICP Computer Terminal & 2 & $3^{\prime} \times 3^{\prime}$ & power \\
\hline Bench with deionized water & 2 & $3^{\prime} \times 4^{\prime}$ & Sanitary water \\
\hline Dionex bench and cabinets & 1 & $3^{\prime} \times 4^{\prime}$ & air \\
\hline Atomic Absorption (AA, flame) & 1 & $3^{\prime} \times 4^{\prime}$ & $\begin{array}{l}\text { nitrous oxide, acetylene, hot } \\
\text { waste drain }\end{array}$ \\
\hline AA Computer terminal & 1 & $3^{\prime} \times 3^{\prime}$ & power \\
\hline Fluorometer & 1 & $3^{\prime} \times 4^{\prime}$ & power \\
\hline Spectrophotometer, IR & 1 & $3^{\prime} \times 4^{\prime}$ & power \\
\hline Spectrophotometer, UV and Visible & 1 & $3^{\prime} \times 4^{\prime}$ & power \\
\hline Gas Chromatograph & 1 & $3^{\prime} \times 4^{\prime}$ & power, carrier gas \\
\hline Equipment Storage & 2 & $2^{\prime} \times 8^{\prime}$ & \\
\hline Organic Storage & 2 & $3^{\prime} \times 4^{\prime}$ & \\
\hline Utility/general purpose bench/cabinets & 5 & $3^{\prime} \times 6^{\prime}$ & de-ionized water \\
\hline Auto-titration bench/cabinet & 2 & $3^{\prime} \times 4^{\prime}$ & drains \\
\hline
\end{tabular}


WHC-SD-W378-ES-002

Revision 0

Table H1-12B. Additional Analytical Equipment Consideration Low-Level Waste Function.

- Space must be allocated and/or supporting services planned for the following items:

- Sample and material transfer (handling) carts

- Approved containers for laboratory waste

- Pneumatic lift for handling (lead) sample pigs (containers)

- Area Radiation Monitors (ARMs); wall mounted 2'x2'x2'

- Record Air Samplers (RASs); wall mounted 1'x1'x1'

- Continuous Air Monitors (CAMs); floor mounted 2' $\times 4$ ' $\times 5$ '

- Hand and Foot Monitors (HFMs); floor mounted 2'x4'x6'

- General Laboratory HVAC. Sufficient space between hoods, benches and desks for HEPA filter exchange.

- Central sinks with process water, deionized water, hot water supply, and appropriate drainage system.

- Safety shower and eyewash stations.

- Trouble alarms at selected working places.

- Main double door access.

- Space for computer terminals and communal work stations. 
Revision 0

Table H1-13B. Analytical Facility Estimated Space Requirements.

\begin{tabular}{|c|c|c|c|c|c|}
\hline \multirow[t]{2}{*}{ AREA } & \multicolumn{3}{|c|}{ SEP/LLW } & \multirow[t]{2}{*}{ HLW } & \multirow{2}{*}{$\begin{array}{l}\text { COMBINED } \\
\text { TOTAL }\end{array}$} \\
\hline & SEP & LLW & SEP+LLW & & \\
\hline Analytical Cells & & & & & \\
\hline Number & 2 & 4 & 6 & 7 & 13 \\
\hline Area, $\mathrm{ft}^{2}$ & 208 & 416 & 624 & 728 & 1,352 \\
\hline Sample Transfer Room, $\mathrm{ft}^{2}$ & - & - & 286 & 286 & 572 \\
\hline $\begin{array}{l}\text { Analytical Cell Service Room, } \mathrm{ft}^{2} \\
\text { Analytical Laboratories }\end{array}$ & 44 & 132 & 176 & 220 & 396 \\
\hline Rooms, no. & 1 & & 3 & 2 & 5 \\
\hline Total Area, $\mathrm{ft}^{2}$ & 925 & 1,740 & 2,665 & 1,740 & 4,405 \\
\hline Sample Receiving Room, $\mathrm{ft}^{2}$ & - & - & 180 & 180 & 360 \\
\hline Rooms, no. & 1 & 1 & 2 & 1 & 3 \\
\hline Total Area, $\mathrm{ft}^{2}$ & 300 & 160 & 460 & 160 & 620 \\
\hline Counting Equipment Room, $\mathrm{ft}^{2}$ & - & - & - & - & 240 \\
\hline Stock Room, $\mathrm{ft}^{2}$ & - & - & - & - & 600 \\
\hline Office/Data Processing Area, $\mathrm{ft}^{2}$ & -- & - & - & - & 1,350 \\
\hline Waste Handling Areas, $\mathrm{ft}^{2}$ & - & - & - & - & 1,240 \\
\hline Equipment Utility Room, $\mathrm{ft}^{2}$ & - & - & - & - & 300 \\
\hline Analytical Instrument Room, $\mathrm{ft}^{2}$ & - & - & - & - & 440 \\
\hline Health Physics Area, $\mathrm{ft}^{2}$ & - & - & - & - & 300 \\
\hline Instrument Utility Room, $\mathrm{ft}^{2}$ & - & - & - & - & 300 \\
\hline Standard Prep Laboratory, $\mathrm{ft}^{2}$ & 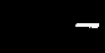 & - & - & - & 625 \\
\hline Total Area, $\mathrm{ft}^{2}$ & 1,477 & 2,448 & 4,391 & 3,314 & 13,100 \\
\hline
\end{tabular}


WHC-SD-W378-ES-002

Revision 0

Table H1-14B. Hood Requirements for Analytical Facility Rooms Low-Level Waste Function.

\begin{tabular}{|c|c|c|}
\hline General Function & $\begin{array}{l}\text { Analysis per } \\
\text { Week }\end{array}$ & $\begin{array}{c}\text { Hood } \\
\text { Requirements }\end{array}$ \\
\hline \multicolumn{3}{|l|}{ Analytical Laboratory } \\
\hline OTR, pH, Spg, Visual, Other & 330 & 2 \\
\hline Microwave, Filtration & 60 & 1 \\
\hline Autoditrator & 72 & 1 \\
\hline Actinide Separations & N/A & \\
\hline TOC/Total Carbon & N/A & \\
\hline Cold Cremical & N/A & \\
\hline Gas Chromentouraph & 20 & 1 \\
\hline Extroction & $\overline{\mathrm{N} / \mathrm{A}}$ & \\
\hline Fuorometer & N/A & \\
\hline R Spectrophotometer & N/A & \\
\hline I-129 Separation & N/A & \\
\hline Beta Separation \#1 & N/A & \\
\hline Beta Separation " 2 & N/A & 1 \\
\hline AT Flone Hood & N/A & \\
\hline Spare & N/A & 1 \\
\hline \multirow{2}{*}{ Ion Chromatography (Dionex) } & N/A & 1 \\
\hline & Subtotal & 8 \\
\hline \multicolumn{3}{|l|}{ Instrument Room } \\
\hline AA Hood & N/A & 1 \\
\hline ICP Hoods & N/A & 2 \\
\hline Ehuent/Separation Hood & N/A & 1 \\
\hline \multirow[t]{2}{*}{ Wraste and Utility Hood } & N/A & 1 \\
\hline & Subtotal & 5 \\
\hline \multicolumn{3}{|l|}{ Sample Receiving Room } \\
\hline Sample Storage Hood & $\mathbf{N} / \mathbf{A}$ & 1 \\
\hline Sample Preparation Hood & N/A & 1 \\
\hline Sample Preparation Hood & N/A & \\
\hline Decontamination Hood & N/A & 1 \\
\hline \multirow[t]{2}{*}{ Waste Collection Hood } & N/A & 1 \\
\hline & Subtotal & 4 \\
\hline \multicolumn{3}{|l|}{ Analytical Cells Service Room } \\
\hline Decontamination and Cell Service Hoods & N/A & 1 \\
\hline Total Foods & & 18 \\
\hline
\end{tabular}


WHC-SD-W378-ES-002.

Revision 0

This page intentionally left blank. 
WHC-SD-W378-ES-002

Revision 0

\title{
APPENDIX $\mathrm{H} 2$
}

\author{
HIGH-LEVEL WASTE \\ ANALYTICAL FUNCTION STUDY
}


WHC-SD-W378-ES-002

Revision 0

This page intentionally left blank.

H2-2 


\section{WHC-SD-W378-ES-002}

Revision 0

CONTENTS

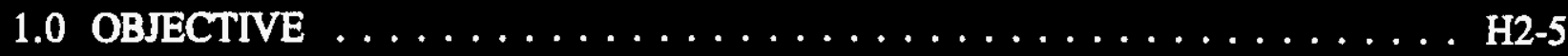

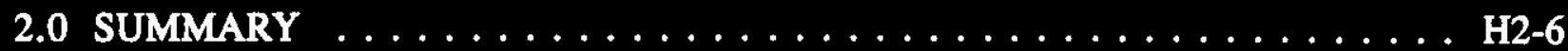

3.0 TECHNICAL FINDINGS AND CONCLUSIONS $\ldots \ldots \ldots \ldots \ldots \ldots$ H2-6

4.0 INITIAL ESTIMATES OF ANALYTICAL REQUIREMENTS $\ldots \ldots \ldots \ldots$ H2-7

5.0 DISCUSSION OF ALTERNATIVES . . . . . . . . . . . . . . . H2-9

5.1 ASSUMPTIONS AND UNCERTAINTIES . . . . . . . . . . H2-9

5.2 SUMMARY OBSERVATIONS $\ldots \ldots \ldots \ldots \ldots \ldots \ldots \ldots \ldots \ldots$ H2-12

6.0 REFERENCES . . . . . . . . . . . . . . . . . . . H2-13

\section{LIST OF TABLES}

H2-1. Process Gas Liquid and Process Solid Sampling Frequency High-Level Waste Function . . . . . . . . . . . . . . . . . . H2-14

H2-1. Process Gas Liquid and Process Solid Sampling Frequency High-Level Waste

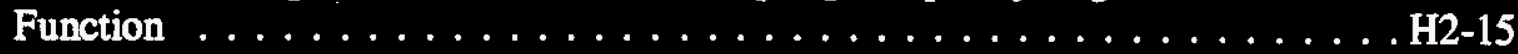

H2-2. Location of Analyses $\ldots \ldots \ldots \ldots \ldots \ldots \ldots \ldots \ldots \ldots \ldots \ldots \ldots \ldots$ H2-16

H2-3. Average Process Sampling Frequency High-Level Waste Function. . . . . . . H2-17

H2-4. Time Per Week for Analytical Cell Sample Analyses High-Level Waste Function. . . . . . . . . . . . . . . . . . . H2-18

H2-5. Analytical Cell Time Required for Sample Preparation for Analytical Laboratory Analysis High-Lavel Waste Function . . . . . . . . . H2-19

H2-6. Analytical Cell Sample Analysis and Preparation Time High-Level Waste Function. . . . . . . . . . . . . . . . . . . . . H2-20

H2-7. Analytical Cell Availability. . . . . . . . . . . . . . . H2-21

H2-8. Simplified Time and Motion Stidy of Analytical Cell Requirements HighLevel Waste Function. 


\section{WHC-SD-W378-ES-002 \\ Revision 0 \\ LIST OF TABLES (continued)}

H2-10. Equipment Requirements/Assessment High-Level Waste Function. . . . . . . H2-24

H2-10. Equipment Requirements/Assessment High-Level Waste Function. . . . . . . H2-25

H2-11. Hood Requirements for Analytical Facility High-Level Waste Function . . . H2-26

H2-12. Analytical Laboratory/Instrument Room Equipment Requirements High-Level Waste Function. . . . . . . . . . . . . . . . . . . H2-27

H2-13. Additional Analytical Equipment Consideration High-Level Waste Function. . H2-28

H2-14. Analytical Facility Estimated Space Requirements. . . . . . . . . . . . . H2-29 


\author{
WHC-SD-W378-ES-002 \\ Revision 0 \\ APPENDIX H2 \\ HIGH-LEVEL WASTE \\ ANALYTICAL FUNCTION STUDY
}

\title{
1.0 ONJCTIV
}

This appendix presents a simplified time and motion study of the analytical capabilities associated with the High-Lovel Waste (HLW) function. The analytical requirements, which are developed in this apsendix, are used to develop the requirements for analytical cells, analytical laboratories, and other associated rooms. For the purpose of this appendix, the following definitions are used:

Anslytical Cells. This term refers to the areas where undiluted, high radiological activity samples are remotely handled. Sample preparation, dilution, and limited sample analysis occurs in analytical cells.

Analytical Laboratories. This term refers to the areas where diluted and/or low radiological activity samples are analyzed. Amalyzers within the laboratories are located in hoods to contain radioactivity.

Other Associated Rocms. This term refers to the miscellaneous support areas that are outside of the analytical cells and analytical laboratories. These rooms include service rooms, receiving rooms, counting rooms, equipment and stock rooms, waste handling areas, and analytical instrument rooms.

This appendix identifies the critical sample analyes required to support the process, such as process control and waste form qualification. Supplemental analyses, such as offgas and environmental samples, are also addreaced. Limited on-line sample analyses assumed to occur within the process facility are identified and are not developed further here. Potential analytical needs associated with incoming wase softy isues, such as criticality, have not been considered here.

This appendix has substantially profited frem the design of the Hanford Waste Vitrification Plant (HWVP) analytical function. As such, it incorporates lessons learned at the Defense Waste Process Facilities (DWPF). 


\section{WHC-SD-W378-ES-002}

Revision 0

\subsection{SUMMARY}

This appendix develops the technical requirements for the HLW function. The initial step is to establish a sample schedule to support process control and waste form qualification. The schedule also includes offgas and environmental samples.

A simplified time and motion study is then performed to develop the requirements for the analytical cells and analytical laboratories. Major equipment and instrumentation items are identitied and major phnt utilities and service interfaces are established. Initial analytical cell layouts are developed to support Anslytical Facility (AF) layouts. Analytical laboratory space requirements are based on space requirements for individual equipment and instruments.

The requirements are developed for the HLW function in this appendix. Appendix H1 develops separate requirements for the Separations and low-level waste (LLW) functions. This approach highlights the requirements attributable to each function and the potential areas of consolidation. Some consolidation is expected even though the appendixes do not evaluate the impact of consolidation. The AF layouts are based on the assumption that a 20 percent reduction in the analytical laboratories can be achieved by combining the Separations, LLW, and HLW analytical functions. Additional study is required to validate this assumption.

\subsection{TICENICAL FIDINGS AND CONCLUSIONS}

The simplified time and motion study for the analytical cells indicates that seven analytical cells are required for the HLW function. The time and motion study is based on 70 percent staff availability, 100 percent Total Operating Efficiency (TOE) in the process facility, and process qualification to confirm product quality. The stafing availability is based on operator breaks, meetings, scheduled training, etc. The analytical requirements do not rely on slack time caused by operating inoficiencies in the process facility. Further eraluation of the bases may indicate that more or less analytical cells are required.

The simplified time and motion study also indicates that two analytical laboratories are required to support the HLW analytical function. The study includes an assessment of the equipment requirements, the space requirements for each piece of equipment, and the resulting total analytical laboratory space requirements. Redundant spare equipment and instruments are included in the analytical laboratory requirements. Further evaluation should confirm the redundancy requirements and also the analytical laboratory space requirements. 


\section{Revision 0}

Process qualification, rather than product qualification, is the assumed method of HLW waste form qualification. Process qualification requires sampling and analyzing the melter feed and comparing the results to reference compositions. Feed characterization, melter feed envelop determination, equipment qualification, and process parameter control are also required for process qualification.

\subsection{NIIIAL DSTIMATISS OF ANALYICAL RJQURBMIDNTS}

The results of this appendix are presented in a series of tables discussed as follows:

- Samples which require processing through the analytical cells and analytical laboratory are identified in Table H2-1. Sample frequency (occasions), sample purpose and analysis required are also given in Table H2-1. Initial estimates of process gas samples and other waste/wastewater and environmental samples are also included. These values could change greatly depending on future requirements for additional sample analyses.

- Table H2-2 defines the analyses that are performed in an analytical cell and those that are analyzed in an analytical laboratory.

- The daily analytical requirements for analyses performed in an analytical cell are identified in Table H2-3. The requirements for each type of analysis are totalled, and the total analytical demand is also indicated.

- Table H2-4 summarizes the time requirements for analyses performed in the analytical cells. Total analysis requirements from Table H2-3 are multiplied by the time required for each analysis and the total time is indicated.

- Table H2-5 defines the analyses that occur in the analytical laboratories, but that require the sample preparation time in the analytical cells. The total analytical cell sample preparation time required is indicated.

- Table H2-6 provides the total analytical cell time requirements. The requirements include the analyses performed in the analytical cells and the sample preparation time for those performed in the analytical laboratories. Additional requirements for sample reruns and standards and estimated sample load-out times as well as credit for parallel testing are also included.

- Analytical cell availability is calculated in Table H2-7. The availability is based on an assumed staff availability of 70 percent, manipulator downtime, 


\section{WHC-SD-W378-ES-002}

\section{Revision 0}

cleanup time and equipment availability. Analytical cell availability at 100 percent stafing availability is also indicated.

- In Table H2-8 the number of analytical cells is determined by dividing the total time required by the available time per analytical cell. The base case evaluation is based on 70 percent staff availability and 100 percent process facility TOE. Table H2-8 also provides a sensitivity analysis of staff availability and TOE.

- Table H2-9 provides estimates of the time requirements for analyses performed in the analytical laboratory.

- Table H2-10 provides initial estimates of sample turnaround time requirements and equipment reliability. This table will assist in developing duplicate and spare equipment needs.

- Table H2-11 estimates the number of hoods required to support the Sample Analysis function for HLW. The estimated 18 hoods are located in several areas.

- Table H2-12 provides approximate space requirements and plant utility interfaces required to support the analytical laboratory equipment.

- Table H2-13 lists additional equipment requirements for safe and efficient operation of the AF. These items do not directly impact the initial AF layouts or cost, however, they must be considered so that space can be allocated and supporting services can be planned.

- Table H2-14 presents the estimated space requirements for the various working areas of the Analytical facility. The space requirements of the Separations function, which are provided in Appendix H1, are given in the column headed "SEP." The space requirements for the Separations and LLW, also from Appendix H1, are summed and are given in the column headed "SEP+LLW." The HLW space requirements are indicated, and the requirements for the three functions are summed. These cells, rooms, and laboratories are included in the layout of a combined Separations/LLW/HLW AF. Note that the facility AF layout is based on the assumption that a 20 percent reduction in the analytical laboratories can be achieved by combining the Separations, LLW, and HLW analytical functions. 


\subsection{DISCUSSION OF ALTMRNATIVES}

\subsection{ASSUMPTIONS AND UNCERTANTIIJS}

This section identifies the assumptions made for this appendix. A brief discussion of each is given to illustrate the importance and uncertainties of each assumption.

- The sample schedule is based on the process flow diagrams (PFDs) for the combined Separations/LLW facility and the detached HLW facility from the Facility Configuration Study (Boomer et al. 1994). The PFDs are used to identify sample locations, frequencies of sample collection, and the types of analyses required. The sample schedule is designed to support process diagnosis, control and history and waste form qualification. Emphasis is placed on the use of on-line analyzers and Inductively Coupled Plasma-Mass Spectrometer (ICP-MS) analysis to reduce the load on analytical cells and laboratories. Laser ablation is assumed to prepare ICP-MS samples, where appropriate. In addition, no process time and motion analysis has been performed on the process itself. Any changes in the number of sample locations and particularly in the frequencies of sampling and type of analyses could impact the analytical cell and laboratory needs.

- Product glass waste form qualification is based on process qualification, rather than product qualification. Process qualification requires sampling and analyzing the melter feed and comparing the results to reference compositions that were previously identified. Feed characterization, melter feed envelop determination, equipment qualification, and process parameter control are also required for process qualification. Changes to the waste form qualification method impacts the number of analytical cells required.

- This appendix assumes that the AF receives samples around the clock, rather than simultaneously. The analytical cell requirements include no allowances for concurrent analysis and/or sample preparation of all of the samples.

- Analytical cell operations are to be fully supported by the analytical laboratory. Although no complete time and motion study in the analytical laboratory is available, it is assumed this laboratory is self sufficient and that adequate laboratory capacity is available so as not to limit analytical cell throughput.

- The number of analytical hot cells and associated facilities is based on the liquid and slurry samples. The layouts for the analytical laboratory and other contact areas are based on both the samples from the bot cells and additional contact-handled samples. The contact-handled samples include process gas 


\section{Revision 0}

samples and environmental samples. Layouts for the Bulk Cold Chemical Building include space for cold chemical testing.

- AF waste handling (both liquid and solid) is extremely important. Personnel, equipment, and facilities must be provided to sort, combine, absorb, package, and stage waste for transfer to a treatment, storage, or disposal facility. Space must be provided for load-out from the analytical cells and other laboratory and counting room areas.

- Analytical facilities outside the TWRS complex are assumed to be not available. As a result, enough overlap and redundancy must be built into the laboratory design so that analytical results are available to support plant operations. It is also assumed that the AF is not required to support other Hanford Site operations.

- Table H2-1 identifies the samples that must be processed through the analytical cells. Any additional samples not included in Table H2-1 would increase analytical cell requirements. Samples which may be borderline for analytical cell processing due to radioactivity are included in Table H2-1 to be conservative.

- Properties are assumed to be inferred from the ICP-MS analysis, thereby reducing the number of samples and analyses required. In particular, the rates of disintegration and emitted energies of radionuclides may be inferred from the measured isotopic composition.

- Analytical cell analysis requirements are identified in Table H2-2. Determination of the sample solids content and rheology and sample preparation (including dissolutions and separations) are assumed to be performed in the analytical cells. Elemental and anion analyses as well as radionuclide counting are assumed to be performed in the analytical laboratory, rather than analytical cell.

- Analyses and sample preparation time requirements are.as idontified in Table H2-4 and Table H2-5. Some are estimates but most are based on Hanford Site and other analytical laboratory experience.

- Staffing availability is assumed to be 70 percent for the base case. This figure is derived from Hanford Site experience of chemical technologist availability of 5.5 hours per 8 hour shift. This operator availability is based on operator breaks, meetings, scheduled training, etc. A sensitivity study examines the 100 percent staff availability case (Table H2-8). 


\section{WHC-SD-W378-ES-002 \\ Revision 0}

- Manipulator availability is assumed to be 93 percent, which is the same as the Hanford Site experience with the CRL Model F MSM. Although manipulator availability could be improved with the System $\mathbf{5 0}$ manipulator, that is expected to be used in the AF, the availability is not now known. When a manipulator fails, a replacement is assumed to be ready for installation. The AF layouts include a manipulator repair/replacement system to support manipulator failure and recycle.

- A 6 percent downtime is assumed for dedicated cell cleanup. This is based on experience where 30 minutes per eight hour shift is used for cleaning. Maintaining a "clean-cell" policy has been found to be extremely effective in maintaining continuity of operations.

- A 10 percent downtime is assumed for equipment failure. For equipment or procedures requiring newly developed equipment this assumption may need to be increased.

- Additional time for standards (10 percent) and reruns (5 percent) is assumed. Additional quality control related analyses (blanks, duplicates, spikes) may be necessary due to equipment requirements and/or environmental protocols.

- Sample load-outs into rabbit containers from the analytical cells is assumed to require five minutes each. This assumes that multiple load-out techniques are possible.

- The size of the analytical laboratory is based on the space requirements for individual equipment and instruments. The analytical laboratory requirements benefit from detailed layouts that was developed during HWVP. However, additional study is required to validate this assumption.

- The requirements are developed separately for the Separations and LLW function in Appendix H2 and then summed. This appendix develops the requirements for the HLW function. Some consolidntion is expected even though the appendixes do not evaluate the impact of consolidation. The facility AF layouts are based on the assumption that a 20 percent reduction in the analytical laboratories can be achieved by combining the Separations, LLW, and HLW analytical functions. Additional study is required to validate this assumption. 
WHC-SD-W378-ES-002

Revision 0

\subsection{SUMMARY OBSERVATIONS}

Some specific observations on the number of analytical cells required and the needs of the analytical laboratory are presented below.

Tables H2-1 through H2-3 indicate that a wide variety of analytical analyses are required.

The baseline analytical cell availability is determined to be 55 percent (Table H2-7). This includes 7 percent downtime for manipulators, 6 percent downtime dedicated to cell clean-up and 10 percent downtime for equipment failures. The major variable is the 70 percent work force availability factor, at 100 percent work force availability, the cell availability increases to 79 percent. By addressing this staffing issue, the analytical cell requirements could be reduced (Table H2-8).

Table H2-8 indicates that seven analytical cells are sufficient for the HLW function.

Tables H2-9 through H2-11 provide initial estimates of the number of samples, approximate size/space and plant utility interfaces required to support the Analytical Laboratory equipment for the HLW function. Equipment requirements will need to be revised as additional (or new) measurement methods are identified and developed. Analyses and analytical methods, and therefore equipment, will also be a function of the required detection levels and turnaround times.

Table H2-12 lists some additional items which need to be considered since these contribute to the safe and efficient operation of the analytical facility. An additional item of importance to be considered is the waste handling operations for both solids and liquids. Facilities and personnel need to be provided to sort, combine, absorb, package, and stage wastes from the analytical cells, the analytical laboratories, and counting rooms for transfer to a treatment, storage, or disposal facility.

The design with respect to waste handling, particularly solids and organic liquid handling, is discussed only to a level that shows allocation of space and interfaces between waste handling and other AF activities. There are many details to waste handling that have yet to be investigated, which may have significant impacts on the layout of laboratory operating areas. An additional effort will be needed to determine further details of design to fully accommodate the waste handling tasks, e.g., special handling of hazardous and radioactive mixed wastes. 


\section{WHC-SD-W378-ES-002 \\ Revision 0}

\subsection{ROMMPDNCES}

Boomer, K.D., J. M. Colby, T. W. Crawford, J. S. Garfield, J. D. Galbraith, C. E. Golberg, C. E. Leach, D. E. Mitchell, F. D. Nankani, E. J. Slaathaug, L. M. Swanson, T. L. Waldo, Cm. M. Winkler, June 1994, Tank Waste Remediation System Facility Configuration Evaluation, WHC-SD-WM-ES-295, Rev. 0, Westinghouse Hanford Company, Richland, Washington. 
WHC-SD-W378-ES-002

Revision 0

Table H2-1. Process Gas Liquid and Process Solid

Sampling Frequency High-Level Waste Function.

\begin{tabular}{|c|c|c|c|c|c|}
\hline & Somple Point & $\begin{array}{l}\text { Gab Saguple } \\
\text { Froquaney }\end{array}$ & $\begin{array}{l}\text { Sampled } \\
\text { Day }\end{array}$ & $\begin{array}{l}\text { Sample } \\
\text { Purpose }\end{array}$ & Analysea Required \\
\hline 1. & $\begin{array}{l}\text { Receipusample Tants } \\
(\mathrm{TE}-300 \mathrm{~A}, \mathrm{~B}, \mathrm{C}, \mathrm{D}, \mathrm{E} \\
\text { and } \mathrm{F})\end{array}$ & $\begin{array}{l}\text { Ones every } 10 \\
\text { dayshink }\end{array}$ & $\begin{array}{l}2 \text { (wort } \\
\text { casedos) }\end{array}$ & PC & $\begin{array}{l}\text { SpG, Total Solids } \\
\text { pH } \\
\text { Blemontal Composition \} From ICP-MS } \\
\text { Radioneltides } \\
\text { OA Ba? } \\
\text { Anion? } \\
\text { TOC? } \\
\text { Reducing Potertinl? }\end{array}$ \\
\hline 2. & 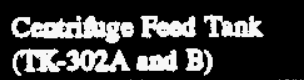 & $\begin{array}{l}\text { Not requirad on } \\
\text { rowing buis }\end{array}$ & - & $\mathbf{P C}$ & \\
\hline 3. & 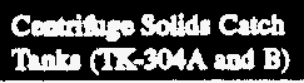 & $\begin{array}{l}\text { Oase evey } 17 \text { he } \\
\text { (for only I that) }\end{array}$ & 1.4 & $\mathbf{P C}$ & SpG, TDS, TSS \\
\hline 4. & $\begin{array}{l}\text { Cantrite Catch Tonks } \\
(1 \mathrm{~B}-307 \mathrm{~A} \text { and } \mathrm{B})\end{array}$ & $\begin{array}{l}\text { Oase ererg } 8 \text { hre } \\
\text { (for only } 1 \text { tant) }\end{array}$ & 3 & PC & TSS \\
\hline s. & $\begin{array}{l}\text { FLW Evapontor Feed } \\
\text { Tant (IK-309) }\end{array}$ & Once every 8 hro & 3 & PD & $\begin{array}{l}\text { TSS, TDS } \\
\text { pH }\end{array}$ \\
\hline 6. & $\begin{array}{l}\text { Procis Coadrante } \\
\text { fon Condeanex } \\
\text { (BC-312) }\end{array}$ & Not applicable & - & $\mathbf{P C}$ & Contisuous on-line analyais for activity \\
\hline 7. & $\begin{array}{l}\text { EIWW Emaporator Catch } \\
\text { That (KK-313) }\end{array}$ & Once every 17 he & 1.4 & PC & $\begin{array}{l}\text { TNS, TDS } \\
\text { pH }\end{array}$ \\
\hline 8. & $\begin{array}{l}\text { BIW Melter Feed } \\
\text { Adjutment Punls } \\
\text { (TK-315A and B) }\end{array}$ & $\begin{array}{l}2 \text { times every } 34 \\
\text { hrs/tank }\end{array}$ & 3 & $\begin{array}{l}\mathrm{PC} \& \\
\mathrm{WFQ}\end{array}$ & $\begin{array}{l}\text { SpG, TSS, TDS } \\
\text { pH } \\
\text { Elemental Composition \} From ICP-MS } \\
\text { Redionuclides } \\
\text { OH Eq? } \\
\text { Anions? } \\
\text { TOC? } \\
\text { Retheing Potertint? } \mathrm{Fe}^{++} \mathrm{Fe}^{+++?}\end{array}$ \\
\hline 9. & $\begin{array}{l}\text { EIW Mether Fond } \\
\text { Tan's (L-317A and B) }\end{array}$ & 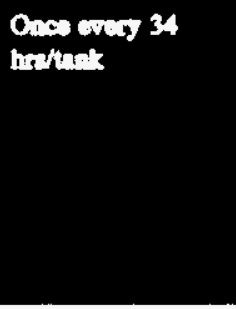 & 1.5 & PA & 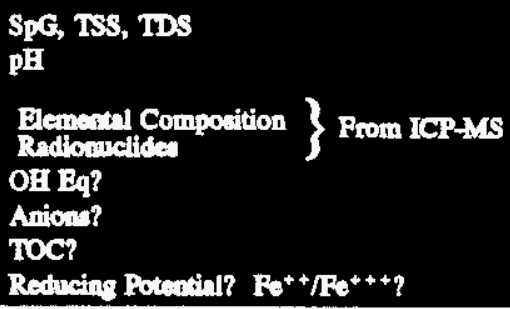 \\
\hline 10. & $\begin{array}{l}\text { Molten Glas Pour from } \\
\text { Moltees (Anume } 2 \\
\text { Moleen) }\end{array}$ & Intrequent & - & PA & $\begin{array}{l}\text { Elemental Compoition \} From ICP-MS } \\
\text { Radiondided } \\
\text { Cogtallinity } \\
\text { Bet+/Fet++ } \\
\text { PCT }\end{array}$ \\
\hline
\end{tabular}


WHC-SD-W378-ES-002

Revision 0

Table H2-2. Location of Analyses.

\begin{tabular}{|c|c|}
\hline $\begin{array}{l}\text { ANALYTCAL CELL } \\
\text { (Undiluted samples) }\end{array}$ & $\begin{array}{l}\text { ANALYTICAL LABORATORY } \\
\text { (Diluted/low level and cold samples) }\end{array}$ \\
\hline $\begin{array}{l}\mathrm{pH} \\
\mathrm{SpG}\end{array}$ & $\begin{array}{l}\text { OTR (Over-the-Top Reading) } \\
\text { pH } \\
\text { SpG }\end{array}$ \\
\hline Solids-work: TSD, TDS, TSS & Solids-work: TSD, TDS, TSS \\
\hline $\begin{array}{l}\text { Reducing Potential (COD) } \\
\text { OH Equivalent } \\
\mathrm{Fe}^{2+} / \mathrm{Fe}^{3+}\end{array}$ & $\begin{array}{l}\text { TOC/Total Carbon } \\
\text { Anions: HPLC, Dionex }\end{array}$ \\
\hline \multirow[t]{2}{*}{$\begin{array}{l}\text { Elements and Radionuclides: ICP-MS } \\
\text { closely coupled to the Analytical Cells } \\
\text { allowing processing of undiluted or slightly } \\
\text { diluted }(1: 10) \text { samples }\end{array}$} & $\begin{array}{l}\text { Elements: } \\
\text { ICP-MS } \\
\text { ICP-AES } \\
\text { AAS } \\
\text { Spectrophotometer } \\
\text { Fluorometer } \\
\end{array}$ \\
\hline & $\begin{array}{l}\text { Radionuclide Separations (prior to } \\
\text { radionuclide analyses): } \\
\text { Extractions } \\
\text { Precipitations } \\
\text { HPLC } \\
\text { Ion Exchange }\end{array}$ \\
\hline $\begin{array}{l}\text { Anions: Sample preparation } \\
\text { Dilution }\end{array}$ & $\begin{array}{l}\text { Radionuclide Analysis: } \\
\text { ICP-MS } \\
\text { Total Alpha } \\
\text { AEA } \\
\text { Total Beta } \\
\text { GEA } \\
\text { Beta Sci }\end{array}$ \\
\hline $\begin{array}{l}\text { Particulates } \\
\text { PCT (Product Consistoncy Test) } \\
\text { Crystllinity/Density }\end{array}$ & $\begin{array}{l}\text { Titrations } \\
\text { Gas Chromatography } \\
\text { Particulates }\end{array}$ \\
\hline
\end{tabular}




\begin{tabular}{|c|c|c|c|c|c|c|c|c|c|c|c|c|c|c|c|c|c|c|c|}
\hline & $t \varepsilon+L$ & $\tau .901$ & $\tau$ & $\tau$ & $\tau$ & $z$ & $\tau$ & $z$ & $\tau$ & 86 & $b$ & SI & $O E$ & $2 t$ & 6 & $\varepsilon$ & $2 \cdot 6$ & 81 & STVJal \\
\hline & & & & & & & & & & & & & & & & & & & \\
\hline & $\varepsilon: 8 I I$ & 691 & I & $\mathbf{I}$ & I & I & I & I & I & $\nabla z$ & I & 5.1 & $\varepsilon$ & & & & & $\tau$ & 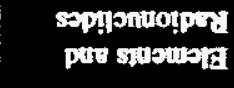 \\
\hline & S5t & S'9 & & & & & & & & & & S'I & $\varepsilon$ & & & & & 2 & sogoguty \\
\hline & $6 t$ & $\boldsymbol{L}$ & $\mathbf{I}$ & $I$ & I & I & I & I & 1 & & & & & & & & & & sesunaturd \\
\hline g & & & & & & & & & & & & & & & & & & & 104 \\
\hline$\vec{g}$ & & & & & & & & & & & & & & & & & & & \\
\hline 皇 & & & & & & & & & & & & & & & & & & & 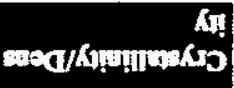 \\
\hline 8.8 & STE & $5 \%$ & & & & & & & & & & S'I I & $\varepsilon$ & & & & & & $+r^{3}: 4 /+5_{3}^{4}$ \\
\hline 8 & & & & & & & & & & & & & & & & & & & \\
\hline$\frac{8}{8} 8$ & 556 & $5 \cdot 9$ & & & & & & & & & & SII & $\varepsilon$ & & & & & $\tau$ & $\begin{array}{r}\text { noquas } \\
\text { mos/304 }\end{array}$ \\
\hline d 4 & s.st & 59 & & & & & & & & & & 51 & $\varepsilon$ & & & & & $z$ & 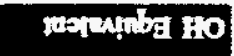 \\
\hline $\begin{array}{ll}7 \\
0\end{array}$ & SSt & 59 & & & & & & & & & & SII & $\varepsilon$ & & & & & $z$ & 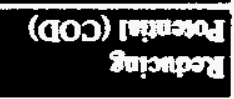 \\
\hline 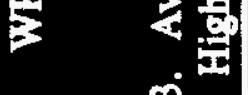 & IbII & $\varepsilon: 91$ & & & & & & & & & $\mathbf{I}$ & $5+1$ & $\varepsilon$ & $b t$ & $\varepsilon$ & $\boldsymbol{\varepsilon}$ & $\forall I$ & $\tau$ & 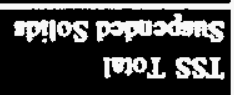 \\
\hline 2 & $\mathrm{I} \cdot \varepsilon 6$ & $\varepsilon \cdot \varepsilon I$ & & & & & & & & & $\boldsymbol{l}$ & 51 & $\varepsilon$ & 1 & $\varepsilon$ & & +1 & $\tau$ & 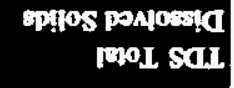 \\
\hline$\frac{4}{8}$ & & & & & & & & & & & & & & & & & & & \\
\hline & & & & & & & & & & & & & & & & & & & (POIP) GSL, \\
\hline & & & & & & & & & & & & & & & & & & & \\
\hline & E'SS & $6 \%$ & & & & & & & & & & S.I & $\bar{\varepsilon}$ & & & & $\forall t$ & 2 & ods \\
\hline & I'00I & $\varepsilon+1$ & & & & & & & & 12 & $\mathbf{I}$ & S.I & $\varepsilon$ & 81 & $\varepsilon$ & & & 2 & $\overline{\mathrm{H}^{\mathrm{d}}}$ \\
\hline & $\lim _{i=1}$ & $\min _{\operatorname{man}}$ & $\sum_{\sin }$ & $=$ & $\min _{\sin }$ & $m_{\infty}$ & $\lim _{\infty}$ & $x_{\infty}$ & $\underset{m}{m}$ & $\prod_{\min }$ & $\min ^{5 x}$ & $\min _{n \rightarrow 18}$ & $\underset{m i n}{m}$ & mis & $\min _{\min }$ & $=$ & $=$ & $\sum_{i=1}^{x}$ & \\
\hline
\end{tabular}


WHC-SD-W378-ES-002

Revision 0

Table H2-4. Time Per Week for Analytical Cell Sample Analyses High-Level Waste Function.

\begin{tabular}{|l|c|c|c|}
\hline \multicolumn{1}{|c|}{ Type of Analysis } & $\begin{array}{c}\text { Number of } \\
\text { Determinations } \\
\text { per Week }\end{array}$ & $\begin{array}{c}\text { Time/Analysis } \\
\text { (Hours) }\end{array}$ & $\begin{array}{c}\text { Total Analysis } \\
\text { Time } \\
\text { (Hours/Week) }\end{array}$ \\
\hline pH & 100.1 & 0.5 & 50.0 \\
\hline SpG & 55.3 & 0.5 & 27.6 \\
\hline TSD (dried) & 93.1 & 1.0 & \\
\hline TDS & 114.1 & 1.12 & 104.3 \\
\hline TSS & 45.5 & 1.12 & 127.8 \\
\hline COD & 45.5 & 0.5 & 22.8 \\
\hline OH Equivalent & & 0.5 & 22.8 \\
\hline TOC/Total Carbon & 31.5 & 2.0 & 63.0 \\
\hline Fe ${ }^{2+} / F^{3+}$ & & 2.0 & \\
\hline Crystallinity/Density & & 2.0 & \\
\hline PCT & 49 & 0.5 & 24.5 \\
\hline Particulates & 534.1 & & 442.8 \\
\hline \multicolumn{1}{|c|}{ TOTALS } & & & \\
\hline
\end{tabular}




\section{WHC-SD-W378-ES-002 \\ Revision 0}

Table H2-5. Analytical Cell Time Required for Sample Preparation for Analytical Laboratory Analysis High-Level Waste Function.

\begin{tabular}{|l|c|c|c|}
\hline \multicolumn{1}{|c|}{ Type of Analysis } & $\begin{array}{c}\text { Number of } \\
\text { Analyses } \\
\text { Per Week }\end{array}$ & $\begin{array}{c}\text { Analytical Cell } \\
\text { Preparation Time } \\
\text { (Hours) }\end{array}$ & $\begin{array}{c}\text { Total Preparation } \\
\text { Time (Hours/Week }\end{array}$ \\
\hline Elements and Padionuclides & 118.3 & 0.3 & 35.5 \\
\hline Anions & 45.5 & 1.5 & 68.2 \\
\hline $\begin{array}{l}\text { Total Organic } \\
\text { Carbon/Total Carbon }\end{array}$ & 45.5 & 1.0 & 45.5 \\
\hline Mixing (Homogenize) & & & \\
\hline Splits & & & \\
\hline Dissolutions & & & \\
\hline Dilutions & & & \\
\hline Separations & & & 149.2 \\
\hline \multicolumn{1}{|c|}{ TOTALS } & 209.3 & & \\
\hline
\end{tabular}


Table H2-6. Analytical Cell Sample Analysis and Preparation Time High-Level Waste Function.

Analysis Time

Add time for reruns

Add time for standards

Sample Preparation Time

Add time for reruns

Add time for standards

Add time for sample loadout

Total Analysis and Preparation Time

Credit for Parallel Tests
Factor

Table Value

$5 \%$

$10 \%$

Subtotal

Table Value

$5 \%$

$10 \%$

$5 \mathrm{~min}$./sample

Subtotal

Less 9\%
Hours Per Week

442.8

22.1

44.3

509.2

149.2

7.5

14.9

7.6

179.2

688.4

62.0

626.4

TOTAL 
Table H2-7. Analytical Cell Availability.

Hours available per week per cell

Workforce available (percent)

Manipulators available (percent)

Not devoted to cleanup (percent)

Equipment available (percent)
Factor

$7 \times 24$

70

93

94

90
Bours/Week

168.0

117.6

109.4

102.8

92.5

Note: $92.5 / 168(100)=55$ percent availability

Hours available per week per cell

Workforce available (percent)

Manipulator available (percent)

Not devoted to cleanup (percent)

Equipment available (percent)
Factor

$7 \times 24$

100

93

94

90
Hours/Week

168 168

156.2

146.9

132.2

Note: $132.2 / 168(100)=79$ percent availability 
WHC-SD-W378-ES-002

Revision 0

Table H2-8. Simplified Time and Motion Study of Analytical Cell Requirements High-Level Waste Function.

\begin{tabular}{|c|c|c|c|c|c|c|}
\hline 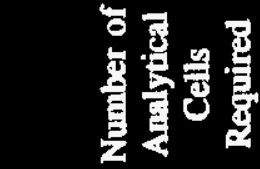 & $\stackrel{\infty}{0}$ & $F$ & $F$ & 7 & $\stackrel{\infty}{i}$ & $\stackrel{m}{m}$ \\
\hline 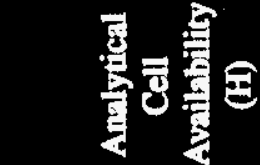 & $\tilde{z}$ & జี & $\stackrel{n}{8}$ & $\tilde{\delta}$ & జี่ & ָู่ \\
\hline 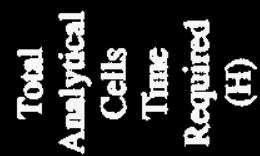 & ఫ্రి & ఫ్ర & 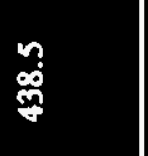 & 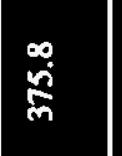 & $\begin{array}{l}\stackrel{\infty}{0} \\
\stackrel{n}{m}\end{array}$ & $\begin{array}{l}n \\
\infty \\
\dddot{q}\end{array}$ \\
\hline 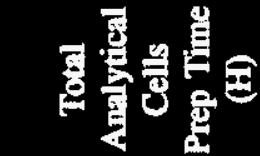 & $\begin{array}{l}N \\
\stackrel{5}{\Xi}\end{array}$ & $\stackrel{2}{\sigma}$ & $\underset{d}{\grave{d}}$ & $\frac{n}{s}$ & $\frac{n}{5}$ & $\stackrel{\dot{s}}{\mathrm{~d}}$ \\
\hline 要量量焉 & ๙ั้ & $\frac{2}{8}$ & 宊 & 号 & 号 & 芦 \\
\hline 㿣量 & $\frac{a}{g}$ & ra & 苛 & $\stackrel{n}{\infty}$ & $\stackrel{n}{\infty}$ & $\underset{8}{8}$ \\
\hline 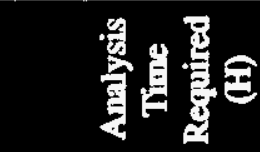 & 文 & 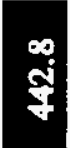 & $\stackrel{\circ}{\stackrel{0}{m}}$ & 형 & 淧 & ஜ \\
\hline$\frac{8}{8}$ & $\frac{\pi}{n}$ & $\vec{n}$ & ళ్రై & 웅 & 㝵 & ఫ্ঠ \\
\hline 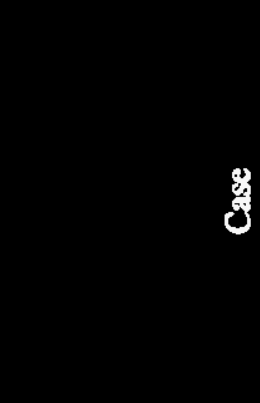 & 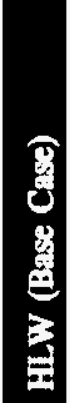 & 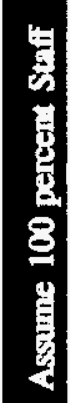 & 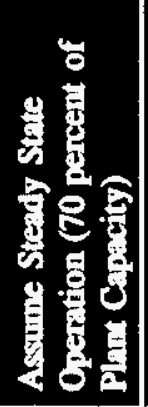 & 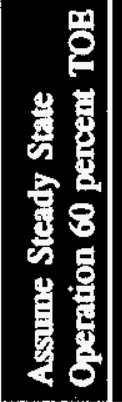 & 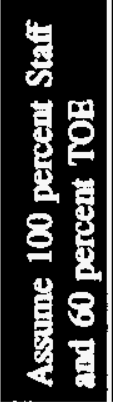 & 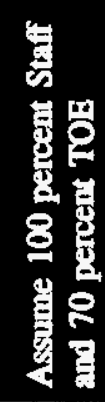 \\
\hline
\end{tabular}




\section{WHC-SD-W378-ES-002}

Revision 0

Table H2-9. Time and Motion Study - Analytical Laboratory

High-Level Waste Function

\begin{tabular}{|c|c|c|c|c|}
\hline Type of Anlyees & $\begin{array}{c}\text { Samples from } \\
\text { Analytical } \\
\text { Cells Per } \\
\text { Woak } \\
\end{array}$ & $\begin{array}{c}\text { Process Gas } \\
\text { Samples, Other } \\
\text { Waste/Wastewater } \\
\text { and Environmental } \\
\text { Samples } \\
\end{array}$ & Hours/Analysis & $\begin{array}{c}\text { Total } \\
\text { Hours Per } \\
\text { Week }\end{array}$ \\
\hline OTR & & 89 & 0.1 & 8.9 \\
\hline pH & & 60 & 0.25 & 15 \\
\hline Spg & & 80 & 0.25 & 20 \\
\hline $\begin{array}{l}\text { Visual: } \\
\text { Color } \\
\text { Percent Settled Solids } \\
\text { Percent Centrifuged Solid }\end{array}$ & & $\begin{array}{l}40 \\
40\end{array}$ & $\begin{array}{l}0.1 \\
1.0\end{array}$ & $\begin{array}{r}4.0 \\
40.0\end{array}$ \\
\hline TSD (Dried) & & 60 & 1.0 & 60 \\
\hline TSC (Calcined) & & & 1.25 & \\
\hline TDS & & & 1.12 & \\
\hline TSS & & & 1.12 & \\
\hline TOC/Total Carbon & 45.5 & & 0.5 & 22.8 \\
\hline Elements & & 40 & 0.1 & 4.0 \\
\hline Particulates & 49 & & 0.5 & 24.5 \\
\hline Anions & 45.5 & 60 & 0.5 & 52.8 \\
\hline GEA & & 40 & 0.5 & 20 \\
\hline Total Alpha & & 140 & 0.5 & 70 \\
\hline AEA & & & 0.5 & \\
\hline Total Beta & & 140 & 0.5 & 70 \\
\hline Bata Sci & & & 0.5 & \\
\hline Soluble ${ }^{137} \mathrm{Cs}$ & & & 0.5 & \\
\hline Soluble ${ }^{90} \mathrm{Sr}$ & & & 0.5 & \\
\hline GC & & 20 & 1.0 & 20 \\
\hline Titrations & & 72 & 0.5 & 36 \\
\hline $\begin{array}{l}\text { SUBTOTAL } \\
\text { Add time for reruns ( } 5 \\
\text { Add time for standards } \\
\text { percent) }\end{array}$ & $\begin{array}{l}\text { ercent) } \\
10\end{array}$ & & & $\begin{array}{l}468.0 \\
23.4 \\
46.8\end{array}$ \\
\hline TOTAL & 140 & 881 & & 538.2 \\
\hline
\end{tabular}




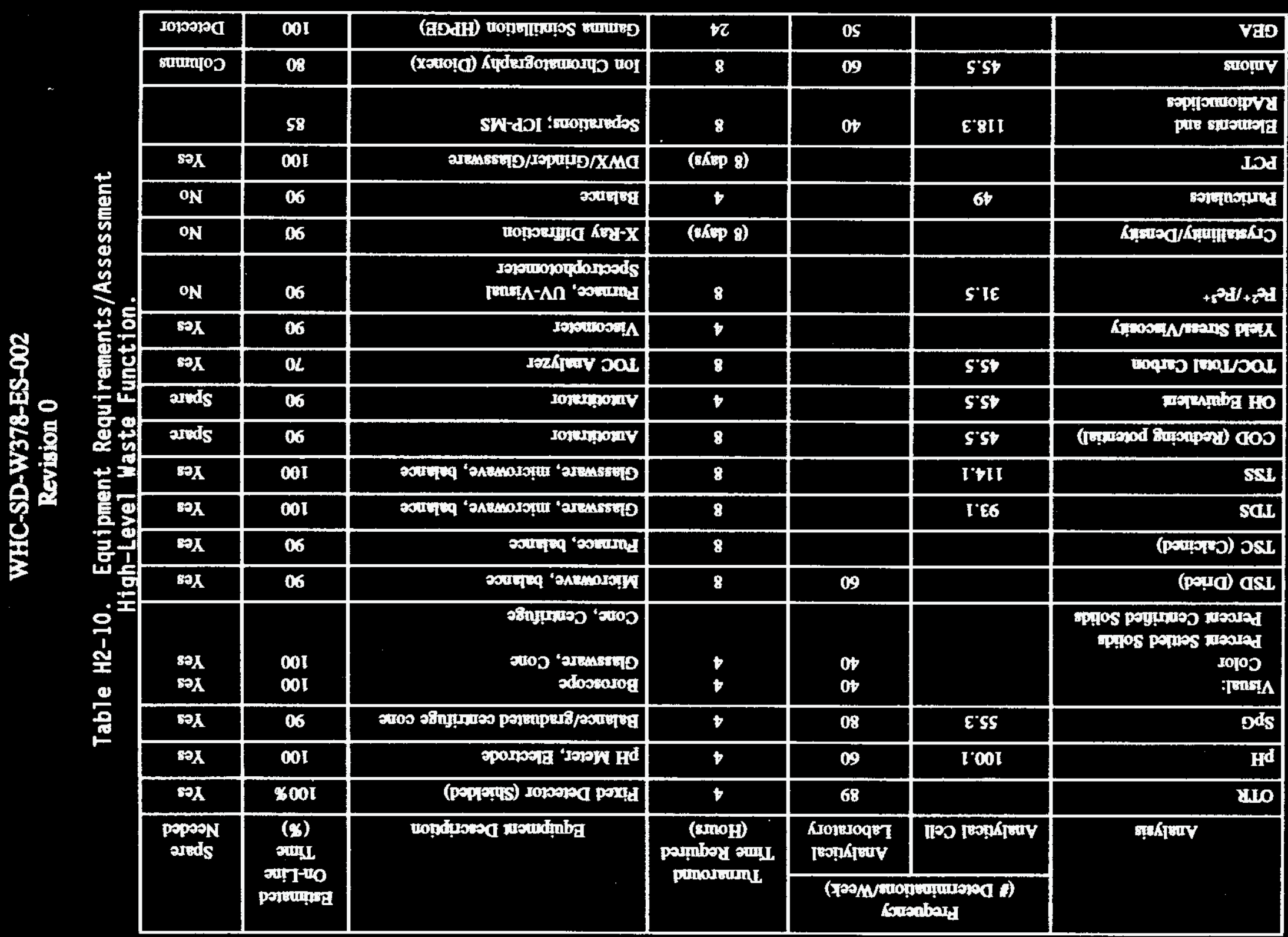




\section{WHC-SD-W378-ES-002 \\ Revision 0}

Table H2-10. Equipment Requirements/Assessment

High-Level Waste Function. (continued)

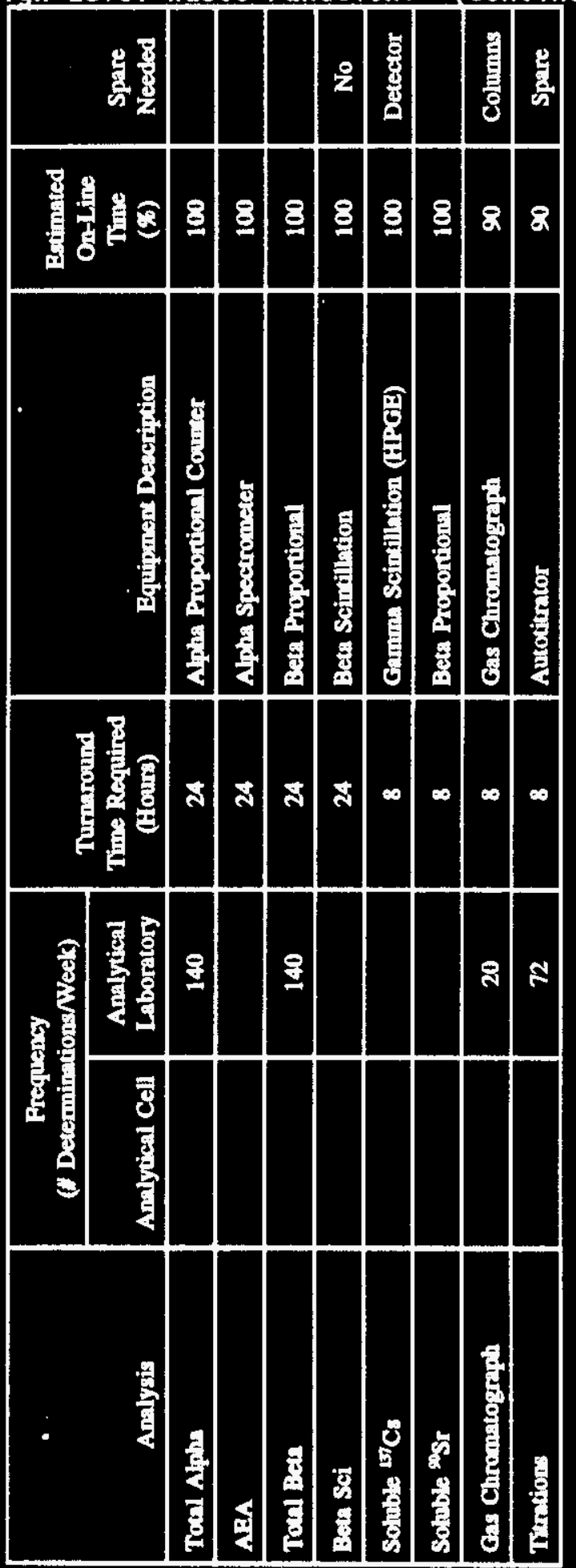


WHC-SD-W378-ES-002

Revision 0

Table H2-11. Hood Requirements for Analytical Facility High-Level Waste Function

\begin{tabular}{|c|c|c|}
\hline General Function & $\begin{array}{l}\text { Analys is } \\
\text { per Week }\end{array}$ & $\begin{array}{c}\text { Hood } \\
\text { Requirements }\end{array}$ \\
\hline \multicolumn{3}{|l|}{ Analytical Laboratory } \\
\hline OTR, PH, SpG, Visual, Other & 309 & 2 \\
\hline Microwave, Filtration & 60 & 1 \\
\hline Autotitrator & 72 & 1 \\
\hline \multicolumn{3}{|l|}{ Actinide Separations } \\
\hline Toc/Total Carbon & 74 & 1 \\
\hline \multicolumn{3}{|l|}{ Cold Chemical } \\
\hline Gas Chronatograph & 20 & 1 \\
\hline \multicolumn{3}{|l|}{ Extraction } \\
\hline \multicolumn{3}{|l|}{ Fluorometer } \\
\hline \multicolumn{3}{|l|}{ IR Spectrophotometer } \\
\hline \multicolumn{3}{|l|}{$1-129$ Separation } \\
\hline \multicolumn{3}{|l|}{ Beta Separation \#1 } \\
\hline Bata Separation \#2 & & 1 \\
\hline \multicolumn{3}{|l|}{ AT Flane Hood } \\
\hline \multicolumn{3}{|l|}{ Spare } \\
\hline Ion Chromatography (Dionex) & & 1 \\
\hline Subtotal & & 8 \\
\hline \multicolumn{3}{|l|}{ Instrument Room } \\
\hline Atomic Absorption & & 1 \\
\hline Eluent/Separation & & 1 \\
\hline ICP & & 2 \\
\hline Wash and Utility & N/A & 1 \\
\hline Subtotal & & 5 \\
\hline \multicolumn{3}{|l|}{ Semple Receiving Room } \\
\hline Senple Preparation & $N / A$ & 1 \\
\hline Senple Preparation & N/A & 1 \\
\hline Senple Storage & $N / A$ & \\
\hline Decontamination & $\mathrm{N} / \mathrm{A}$ & 1 \\
\hline Waste Collection & N/A & 1 \\
\hline Subtotal & & 4 \\
\hline \multicolumn{3}{|l|}{ Analytical Cells Service Room } \\
\hline Decontamination and Cell Service & $N / A$ & 1 \\
\hline Total Hoods & & 18 \\
\hline
\end{tabular}


WHC-SD-W378-ES-002

Revision 0

Table H2-12. Analytical Laboratory/Instrument Room Equipment Requirements High-Level Waste Function.

\begin{tabular}{|c|c|c|c|}
\hline Equipment/Instrumentation & $\begin{array}{c}\text { Number } \\
\text { Required }\end{array}$ & Space & $\begin{array}{l}\text { Utilities/Service } \\
\text { Reguired }\end{array}$ \\
\hline Shielded Radiation Detector & 2 & $3^{\prime} \times 3^{\prime}$ & power \\
\hline pH Mater & 2 & $2^{\prime} \times 2^{\prime}$ & power \\
\hline Balance & 2 & $2^{\prime} \times 2^{\prime}$ & power \\
\hline Centrifuge & 1 & $2^{\prime} \times 2^{\prime}$ & power \\
\hline Microwave & 1 & $2^{\prime} \times 2^{\prime}$ & power \\
\hline Furnace & 1 & $3^{\prime} \times 3^{\prime}$ & power \\
\hline Balance w/Marble Table & 1 & $3^{\prime} \times 4^{\prime}$ & power \\
\hline Autotitrator & 1 & $2^{\prime} \times 2^{\prime}$ & power \\
\hline TOC Analyzer & 1 & $3^{\prime} \times 4^{\prime}$ & power \\
\hline $\begin{array}{l}\text { Inductively Coupled Plasma (ICP) } \\
\text { Spectrometer (ICP-AES and } \\
\text { ICP-MS) }\end{array}$ & 2 & $3^{\prime} \times 8^{\prime}$ & power, liquid argon \\
\hline ICP computer terminal & 2 & $3^{\prime} \times 3^{\prime}$ & power \\
\hline Ion Chromatograph (Dionex) & 1 & $3^{\prime} \times 4^{\prime}$ & power, sanitary water \\
\hline Atomic Absorption (AA, Flame) & 1 & $3^{\prime} \times 4^{\prime}$ & $\begin{array}{l}\text { nitrous oxide, } \\
\text { acetylene, hot waste } \\
\text { drain }\end{array}$ \\
\hline AA Computer Terminal & 1 & $3^{\prime} \times 3^{\prime}$ & power \\
\hline Gas Chromatograph & 1 & $3^{\prime} \times 4^{\prime}$ & power, carrier gas \\
\hline Fluoroneter & 1 & $3^{1} \times 4^{\prime}$ & power \\
\hline IR Spectroneter & 1 & $3^{\prime} \times 4^{\prime}$ & power \\
\hline UV-Visible Spectroneter & 1 & $3^{\prime} \times 3^{\prime}$ & power \\
\hline$X$-Ray Diffraction Spectrometer & 1 & $3^{\prime} \times 4^{\prime}$ & power \\
\hline Equipment Storage Units & 2 & $3^{\prime} \times 8^{\prime}$ & \\
\hline Organic Chemical Storage Units & 2 & $3^{\prime} \times 4^{\prime}$ & Ventilation \\
\hline $\begin{array}{l}\text { Utility/General Purpose } \\
\text { Bench/Cabinets, etc. }\end{array}$ & 4 & & $\begin{array}{l}\text { de-ionized water, hot } \\
\text { water, sanitary } \\
\text { water, drains }\end{array}$ \\
\hline
\end{tabular}




\section{WHC-SD-W378-ES-002}

Revision 0

Table H2-13. Additional Analytical Equipment Consideration High-Level Waste Function.

- Space must be allocated and/or supporting services should be planned.

- Sample and material transfer (handling) carts

- Approved containers for laboratory waste

- Pneumatic lift for handling (lead) sample pigs (containers)

- Area Radiation Monitors (ARMs); wall mounted $2^{\prime} \times 2^{\prime} \times 2^{\prime}$

- Record Air Samplers (RAS); wall mounted 1'xl'xl'

- Contfnuous Air Monitors (CAMs); floor mounted $2^{\prime} \times 4^{\prime} \times 5^{\prime}$

- Hand and Foot Monitor (HFM); floor mounted $2^{\prime} \times 4^{\prime} \times 6^{\prime}$

- General Laboratory HVAC. Sufficient space between hoods, benches and desks for HEPA filter exchange.

- Central sink with process water, deionized water, hot water supply, and appropriate drainage system.

- Safety shower and eyewash station.

- Trouble alarms at selected working places.

- Main double door access.

- Space for computer terminals and communal work stations. 
Table H2-14. Analytical Facility Estimated Space Requirements.

\begin{tabular}{|c|c|c|c|c|c|}
\hline \multirow[t]{2}{*}{ AREA } & \multicolumn{3}{|c|}{ SEP/LLW } & \multirow[t]{2}{*}{ HLW } & \multirow{2}{*}{$\begin{array}{l}\text { COMBINED } \\
\text { TOTAL }\end{array}$} \\
\hline & SEP & LLW & $S E P+L L W$ & & \\
\hline 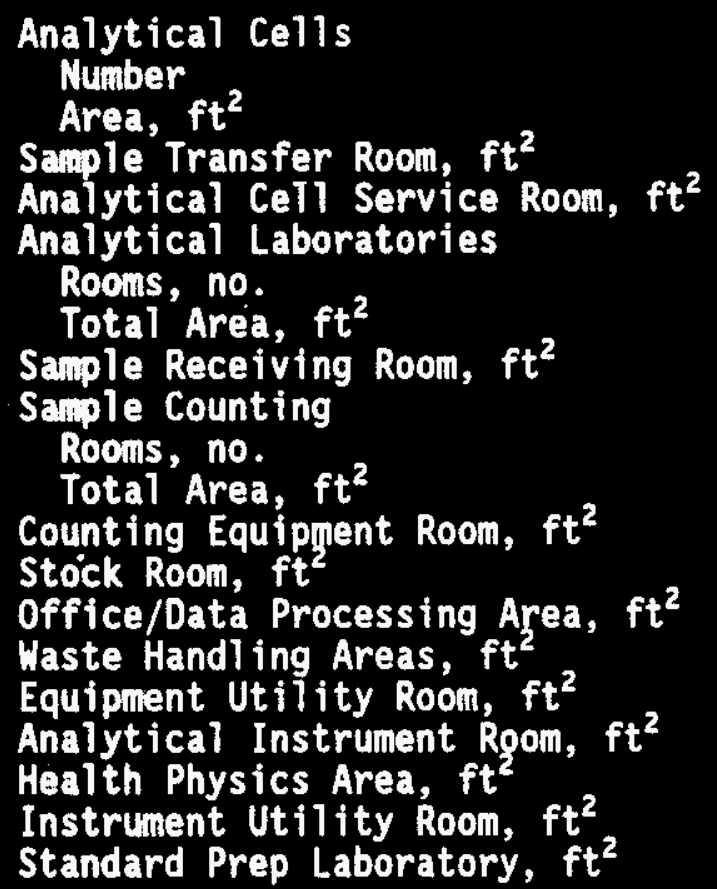 & $\begin{array}{r}208 \\
44 \\
1 \\
925 \\
-- \\
1 \\
300 \\
-- \\
-- \\
-- \\
-- \\
-- \\
-- \\
-- \\
--\end{array}$ & $\begin{array}{r}4 \\
416 \\
132 \\
2 \\
1,740 \\
-- \\
1 \\
160 \\
-- \\
-- \\
-- \\
-- \\
-- \\
-- \\
-- \\
--\end{array}$ & $\begin{array}{r}6 \\
624 \\
286 \\
176 \\
3 \\
2,665 \\
180 \\
2 \\
460 \\
-- \\
-- \\
-- \\
-- \\
-- \\
-- \\
-- \\
-- \\
--\end{array}$ & $\begin{array}{r}7 \\
728 \\
286 \\
220 \\
2 \\
1,740 \\
180 \\
1 \\
160 \\
-- \\
-- \\
-- \\
-- \\
-- \\
-- \\
-- \\
--\end{array}$ & $\begin{array}{r}13 \\
1,352 \\
572 \\
396 \\
5 \\
5 \\
4,405 \\
360 \\
3 \\
620 \\
240 \\
600 \\
1,350 \\
1,240 \\
300 \\
440 \\
300 \\
300 \\
625\end{array}$ \\
\hline Total Area, $\mathrm{ft}^{2}$ & 1,477 & 2,448 & 4,391 & 3,314 & 13,100 \\
\hline
\end{tabular}


Revision 0

This page intentionally left blank. 